\title{
Regionaler Sprachgebrauch in Fachkontexten
}

\author{
Lexikologische und textuelle Untersuchungen \\ zu Gestaltung und Dynamik fachsprachlicher Kompetenz \\ in zweisprachigen Regionen der europäischen Romania
}

\author{
Habilitationsschrift \\ Westfälische Wilhelms-Universität Münster \\ Fachbereich 11: Philologie
}

\section{Ulrich Hoinkes}

Januar 1999

Zeitpunkt der Online-Veröffentlichung: Oktober 2018 
DOI: 10.21941/HoInKesRegioSprGebrFachKontext 


\section{Inhaltsverzeichnis}

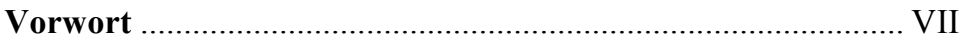

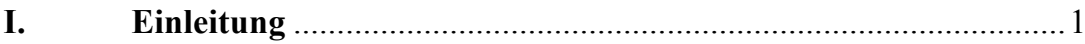

1. Kurzpräsentation der gesamten Untersuchung ................................. 1

2. Theoretische Erläuterung des Untersuchungsschwerpunkts .............5

II. Theoretischer Teil: Situierung des Themas in den Kontext sprachwissenschaftlicher Theoriebildung ................................ 16

1. Die Interpretation der Sprachkompetenz im Rahmen einer Theorie des Sprechens.............................................................. 16

1.1. Der sprachtheoretische Grundansatz Eugenio Coserius...................16

1.2. Die Unterscheidung sprachlicher Wissensebenen.........................26

1.2.1. Das allgemein-sprachliche Wissen............................................26

1.2.2. Das einzelsprachliche Wissen .................................................... 31

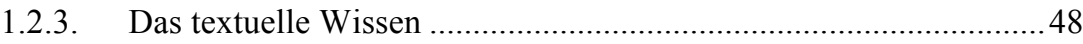

2. Aspekte der sprachwissenschaftlichen Beschreibung des regionalen Sprachgebrauchs in Fachkontexten ........................57

2.1. Das soziolinguistische Verständnis der Sprachvariation.................57

2.2. Das Problem der Formalisierung einzelsprachlicher Varietäten .....67

2.3. Die Konzeption des 'Sprachgebrauchs in Fachkontexten' .............. 77

2.4. 'Alltagssprache', 'Gemeinsprache' und 'regionaler Sprach-

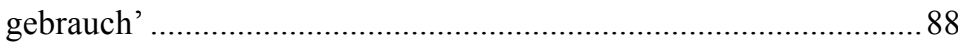

2.5. Sprachkontakt und sprachliche Standardisierung .......................... 101

2.6. Standard und Normen: zur theoretischen Konzeption einer empirischen Beschreibung der Sprachkompetenz 
III. Empirischer Teil: Exemplarische Untersuchungen zum regionalen Sprachgebrauch in Fachkontexten mit Bezug auf zwei Bereiche der wirtschaftlichen Nutzung von Baumbeständen in zwei diglossischen Regionen der europäischen Romania

1. Grundsätzliche Darstellung des gesamten Untersuchungs-

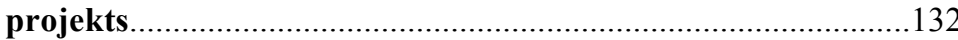

1.1. Allgemeine Zielsetzung ........................................................ 132

1.2. Die Auswahl der geographischen Untersuchungsgebiete und regionaltypischen Sachbereiche

1.3. Hinweise zur Gestaltung, Durchführung und Auswertung der Untersuchung

2. Die sprachlichen Untersuchungen zum Sachbereich 'Wald und Waldbau' im Béarn (Gaskogne, Frankreich) ......... 146

2.1. Das Untersuchungsgebiet ....................................................... 146

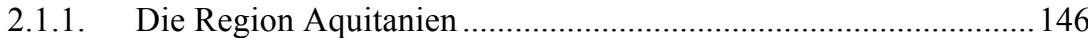

2.1.2. Das Land Béarn ....................................................................... 149

2.1.3. Der Gebrauch des Gaskognischen im Béarn ............................... 155

2.1.4. Der Wald im Béarn............................................................... 162

2.2. Der bearnesische Wortschatz im Sachbereich 'Wald und Nutzung des Waldes'

2.2.1. Lexikographische Bestandsaufnahme und kommunikativer Wert

2.2.2. Empirische Überprüfung der Kenntnis und Verfügbarkeit des bearnesischen Wortschatzes im Kommunikationssektor 'Wald und Nutzung des Waldes'

2.2.2.1 Die Bezeichnungen für 'Wald, Holz, Waldarbeit und Waldarbeiter'.

2.2.2.2 Der lexikalische Bereich 'Brennholzproduktion' 190

2.2.2.3 Der lexikalische Bereich 'Wertholzproduktion' 195

2.2.2.4. Der lexikalische Bereich 'Botanik und Nomenklatur des Baums' 
2.3. Beispiele bearnesischer Diskurse im Sachbereich 'Wald und Nutzung des Waldes'

2.3.1. Der bearnesische Sprachgebrauch in Fachkontexten des Waldes

2.3.2. Die Dokumentation der bearnesischen Sprachaufnahmen auf dem beiliegenden Tonträger (Audio-CD) 218

2.3.3. Transkription einer Auswahl fachbezogener Diskurse auf Bearnesisch 224

2.4. Fachbezogene Kommunikation auf Französisch im Sachbereich 'Waldbau im Béarn' 252

2.4.1. Zielsetzung, methodisches Vorgehen und Probandenauswahl......252

2.4.2. Das standardisierte Interview zum Thema 'Waldbau im Béarn' ..257

2.4.3. Die Befragung zum Thema Gestion de la forêt et sylviculture en Béarn-Detailauswertung von vier Gesprächen

2.4.4. Zusammenfassende Analyse der französischen Textcorpora: kommunikatives Verhalten, fachsprachliche Kompetenz, Konzeptualisierung und Diskursgestaltung 353

2.4.4.1. Kommunikatives Verhalten 353

2.4.4.2. Fachsprachliche Kompetenz. 361

2.4.4.3. Exkurs: Entwicklungstendenzen des Waldbaus im Béarn 368

2.4.4.4. Fachliche Konzeptualisierung und Diskurs 370

2.5. Fachbezogene Kommunikation auf Bearnesisch im Sachbereich 'Waldbau im Béarn'

2.5.1. Zielsetzung, methodisches Vorgehen und Probandenauswahl.......382

2.5.2. Die Befragung zum Thema Los ahars deu bòsc e la silvicultura dens lo Biarn-Detailauswertung eines Gesprächs. 388

2.5.3. Analyse des bearnesischen Textcorpus: Normative Gestaltungsebenen des fachkontextuellen Sprechens........................405

3. Die sprachlichen Untersuchungen zum Sachbereich ' $\mathrm{Zi}$ trusfruchtanbau' in der Comunitat Valenciana (Spanien) ..... 418

3.1. Das Untersuchungsgebiet ........................................................ 418

3.1.1. Die Comunitat Valenciana ............................................................. 418

3.1.2. Die Region Valencia (L'Horta) ................................................. 423

3.1.3. Der Gebrauch des Valenzianischen in der Region Valencia......... 427

3.1.4. Die citricultura in der Horta de València 
3.2. Fachbezogene Kommunikation auf Katalanisch und Kastilisch im Sachbereich 'Zitrusfruchtanbau in der Horta de València'

3.2.1. Zielsetzung, methodisches Vorgehen und Probandenauswahl...... 440

3.2.2. Das standardisierte Interview zum Thema 'Zitrusfruchtanbau in der Horta de València' und seine Auswertung.

3.3. Die Befragung zum Thema 'Zitrusfruchtanbau in der Horta de València' - Teiltranskription von zwei Gesprächen (kastilisch / katalanisch) 448

3.4. Hinweise zur Ebene des Sprachbewusstseins und zum Gebrauchsumfang des Valenzianischen 462

3.5. Vergleichende Analyse der katalanischen und kastilischen Textcorpora: Spezifika des fachkontextuellen Sprechens in seiner Abhängigkeit von Sprache, Sprecher und Sachbezug

IV. Schlussbetrachtung 488

V. Literaturverzeichnis

1. Auswahlbibliographie zum Thema der Arbeit

2. Auswahlbibliographie zum Fachgebiet 'Waldbau' (im Béarn / in Frankreich)

3. Auswahlbibliographie zum Fachgebiet 'Zitrusfruchtanbau' (in der Comunitat Valenciana)

Annex 515

Questionnaire: Gestion de la forêt et sylviculture en Béarn. 515

Qüestionari: Citricultura valenciana. 


\section{Vorwort}

Die hier vorgelegten Untersuchungen haben eine lange Genese. Sie sind das Produkt einer Zusammenführung verschiedener Interessensschwerpunkte, die sich im Laufe meines Studiums und meiner anschließenden Lehr- und Wanderjahre herausgebildet haben. Auf diesem Weg bin ich einigen für meinen fachlichen Werdegang besonders wichtigen Personen zu Dank verpflichtet.

An erster Stelle möchte ich Herrn Professor Dr. Horst Geckeler, Münster, nennen, der mich schon früh unter seine Fittiche nahm und der mir im Laufe der Jahre viel wissenschaftliche Freiheit gelassen hat. Die Tatsache, dass diese Arbeit auf der Sprachtheorie Eugenio Coserius aufbaut, ist auch auf die Wirkung dieser Freiheit zurückzuführen.

Mein Interesse für die okzitanische und katalanische Sprache hat noch in Münsteraner Tagen Professor Dr. Georg Kremnitz geweckt. Diese Arbeit macht deutlich, wie viel ich ihm zu verdanken habe.

Das konkrete Thema meiner Untersuchungen wäre nicht ohne den beratenden Einfluss der Professoren Dr. Sigurd Wichter, Göttingen, und Dr. Thomas Stehl, Potsdam, zustande gekommen. Auch ihnen möchte ich an dieser Stelle danken.

Bei der empirischen Arbeit in Frankreich und Spanien habe ich viele freundliche und hilfsbereite Menschen kennengelernt. Mein besonderer Dank gilt den Probanden, die viel Geduld aufgebracht haben.

Für Hilfen bei der Transkription der gaskognischen und katalanischen Texte danke ich Herrn Joseph Bourguinat und Frau Marisol Bellonch i Orenes.

Für Hilfeleistungen verschiedener Art habe ich vielen am Romanischen Seminar Münster zu danken. Stellvertretend nenne ich Frau Birgit Langer, Frau Hanne Riehm und Frau Sandra Sánchez Münninghoff.

Ohne die Unterstützung meiner Familie hätte ich diese Arbeit wohl niemals fertig bekommen. Daher möchte ich an dieser Stelle auch meiner Frau Monika Hoinkes zutiefst danken.

Ich widme diese Arbeit dem Andenken an meinen Vater und an meinen Bruder, die sich mit mir über die Fertigstellung dieser Habilitationsschrift gefreut hätten.

Münster, im Januar 1999 


\section{I. $\quad$ Einleitung}

\section{Kurzpräsentation der gesamten Untersuchung}

Die Arbeit ist ein Beitrag zu der Erforschung gesprochener Sprache in Bezug auf bestimmte Textformen und kommunikative Inhalte unter gleichzeitiger Berücksichtigung ausgewählter Sprachkontaktsituationen.

Es fällt auf, dass die gesprochene Sprache bislang zwar eingehend unter den Gesichtspunkten ihrer formalen Strukturiertheit (Lexikon, Morphologie, Syntax) untersucht worden ist, der Sprachinhalt und die textuelle Gestaltungsebene aber stark vernachlässigt wurden. Insbesondere liegen noch keine größeren Untersuchungen $\mathrm{zu}$ den normativen Bedingungen und der kommunikativen Funktion gesprochener Sprache in enger definierten Bereichen (thematischen Sektoren) des alltäglichen gesellschaftlichen Lebens vor. Entsprechende systematisch ermittelte Textcorpora stehen ebenfalls nicht zur Verfügung. ${ }^{1}$

Im Mittelpunkt des allgemeiner definierten Untersuchungsinteresses steht die Analyse der Sprachkompetenz in ihrer Bezugnahme auf verschiedene Wissensdimensionen und gesellschaftliche Normen. Als sprachtheoretische Grundlage erfolgt dabei zunächst eine umfassende Auseinandersetzung mit der Theorie des Sprechens von Eugenio Coseriu. Diese Theorie öffnet den Blick für eine sehr umfassende Analyse der faktisch-referentiellen, der kognitiven, der sozialen und der individuellen Bedingungen des Sprechens in einer historischen Sprache. Auf der Ebene der empirisch beobachtbaren gesellschaftlichen Kommunikation sind diese Bedingungen des Sprechens als Normen interpretierbar. In der konkreten Untersuchung werden Sachnormen, Regionalnormen, biographische Normen und einzelsprachliche Normen unterschieden und in ihrer Relevanz als Bedingungen des Sprechens an Beispielen erklärt. Die Komplexität der analytischen Ausrichtung leitet sich dabei nicht primär aus einer theoretischen Zielsetzung ab, sondern verfolgt den Anspruch der Erklärung des Funktionierens sozialer Kommunikation.

Der Untersuchungsgegenstand basiert auf der empirischen Alltagserfahrung, dass ein Großteil der Kommunikation im beruflichen Umfeld, in der Familie, im Freundeskreis und bei Freizeitbeschäftigungen thematisch differenzierbar ist und nach Fächern oder Fachgebieten gruppiert werden kann. Dies gilt z.B. für Gespräche über Krankheit mit einem Arzt, über Speisezubereitung in der Familie, über Politik unter Freunden oder über die neuesten Sportergebnisse

Bei dieser Aussage sowie weiteren Hinweisen zum Forschungsstand im weiteren Verlauf ist der Entstehungszeitraum der Arbeit Ende der 1990er Jahre zu berücksichtigen. 
am Arbeitsplatz. All diese Formen sektoriellen themengebundenen Sprechens stellen kommunikative Fachkontexte dar, die für das gesellschaftliche $\mathrm{Zu}$ sammenleben von großer Wichtigkeit sind. Die zentrale These der Arbeit lautet nun, dass bestimmte Fachkontexte in bestimmten Regionen eine besondere oder sogar exponierte Stellung einnehmen und daher in alltäglichen fachinternen wie auch fachexternen Kommunikationen häufig vorkommen und zu einem wesentlichen Faktor in der Gestaltung und Dynamik regionalen Sprachgebrauchs werden.

Die enge Verbindung von Region und Sachbereich (bzw. Fachgebiet) lässt sich häufig auf die geographischen und wirtschaftlichen Gegebenheiten zurückführen. Zum einen entstehen aus diesen Bedingungen Prädominanzen des primären Wirtschaftsektors (Land-, Forst- und Seewirtschaft), zum anderen begründen sich, oft in der Folge dieser Prädominanzen, Traditionen im handwerklichen Bereich, spezielle Prägungen des Freizeitsektors (Jagd, Tiersportarten, etc.) oder auch Eigenheiten der regionalen Küche. Das in der Region entwickelte Identitätsbewusstsein in seiner stabilisierenden und abgrenzenden Funktion sowie seine Außendarstellung, die oft eine politische und - über den Tourismus - wiederum wirtschaftliche Dimension einnimmt, konsolidiert sich dabei im Rückgriff auf regionale Normen, die von diesen sozio-ökonomischen Verhältnissen ausgehen. Diese Normen sind Sachnormen, Wissensnormen, Verhaltensnormen und Normen der Erwartungshaltung, die allesamt direkte Auswirkungen auf den regionalen Sprachgebrauch haben, ihn entscheidend prägen und in ihm nachgewiesen werden können.

Im Rahmen der Untersuchung findet 'regionale Sprache' daher eine andere als die in der Sprachwissenschaft ansonsten übliche Definition. Die klassischen dialektologischen und sprachgeographischen Fragestellungen werden ebenso wenig verfolgt wie das inzwischen gut dokumentierte Phänomen sprachlicher Interferenzen in Sprachkontaktgebieten, auf die sich die Untersuchung grundsätzlich bezieht. Stattdessen soll versucht werden, unter Konzentration auf lexikologische und diskursanalytische Aspekte ein Bild von der Prägung und Funktionalität des regionalen Sprachgebrauchs zu entwickeln. Dabei konzentriert sich die Analyse exemplarisch zum einen auf zwei zweisprachige Regionen der westlichen europäischen Romania, zum anderen auf zwei für diese Regionen typische Sachbereiche des primären Wirtschaftsektors, die den theoretischen Voraussetzungen der Untersuchung in einer jeweils besonderen (und damit auch interessant zu vergleichenden) Weise entsprechen.

Die Arbeit widmet sich in einem galloromanischen Teil dem regionalen Sprachgebrauch in Fachkontexten, die den Wald und die Nutzung des Waldes im Béarn, einer historischen Region innerhalb der administrativen Région d'Aquitaine Frankreichs, betreffen. In einem zweiten Teil führt die Untersuchung nach Spanien in die Comunitat Valenciana, genauer die Horta de Va- 
lència, die wirtschaftlich entscheidend durch den Orangenanbau geprägt ist. Die jeweiligen Produktionsbereiche, Waldbau (sylviculture) im Béarn und Orangenanbau (citricultura) in der Comunitat Valenciana, werden auf einer breiten empirischen Basis und in einer reichen Sprachdokumentation auf ihre kommunikative Ausgestaltung hin untersucht. Dabei stehen entsprechend dem bereits skizzierten Untersuchungsinteresse lexikologische (terminologische) und textuelle Analysen im Vordergrund. Der empirische Ansatz ist durch die ausschließliche Betrachtung des spontanen mündlichen Sprachgebrauchs charakterisiert.

Ein wesentlicher Teil der Arbeit besteht aus der Eruierung, Dokumentation, Transkription und Auswertung entsprechender Textcorpora, die auf insgesamt fünf Feldforschungsreisen in Südwestfrankreich und Ostspanien zusammengetragen wurden. Die empirische Grundlage der Arbeit bilden somit interdisziplinäre Feldforschungen, in denen - mit dem jeweiligen Rückhalt durch regionale Fachinstitutionen - inhaltlich strukturierte Probandenbefragungen $\mathrm{zu}$ lexikalischem (terminologischem) Wissen und fachlichen Themen durchgeführt und aufgezeichnet wurden. Die Befragungen fanden in den jeweiligen Sprachen statt und gestalteten sich in allen Fällen als ungezwungene Gespräche spontanen Charakters, in denen die Probanden bereitwillig und ausführlich Auskunft über ein ihnen mehr oder weniger vertrautes Fachgebiet gaben. In den so ermittelten Beispielen fachkontextuell determinierten Sprechens konzentriert sich die Analyse in beiden Untersuchungsgebieten parallel auf die zwei Sprachen, die dort heute jeweils aktiv gesprochen werden, das heißt in Frankreich auf das Französische und das Bearnesische, einen Dialekt des Gaskognischen, und in Spanien auf Kastilisch und Valenzianisch, einer Varietät des Katalanischen. Beide Sprachkontaktgebiete, die soziolinguistisch gut erforscht sind, stellen Diglossiesituationen dar, in denen die regionale Sprache regressiv ist und im Falle des Bearnesischen sogar mittelfristig vom Aussterben bedroht wird. Die Diglossieforschung und die Sprachkontaktlinguistik haben auf das Konfliktpotential dieser regionalsprachlichen Regression hingewiesen. Demgegenüber gibt es jedoch nur wenige nicht sprachsoziologisch bzw. nicht auf ein metalinguistisches Eruierungsverfahren ausgerichtete Untersuchungen zu dem faktisch verifizierbaren Kommunikationswert der dominierten Regionalsprachen. Die vorliegende Arbeit will in diese Lücke hineinstoßen.

Die vorgelegten empirischen Untersuchungen dokumentieren anschaulich, dass das Bearnesische als eine der letzten 'Bastionen' des untergehenden Okzitanisch und das Valenzianische als Regionalsprache mit stark eingeschränkten sozialen Sprachfunktionen die aktuellen kommunikativen Ansprüche fachkontextueller Gesprächssituationen in differenzierter Weise erfüllen und auf die modernen Veränderungen des Sachbereichs eigenständig reagieren. Dieses 
Ergebnis ist keineswegs selbstverständlich, da - wie die für die Untersuchung ausgewählten Wirtschaftssektoren zeigen - beide Regionalsprachen keinen (oder fast keinen) Anteil am offiziellen Sprachgebrauch in den jeweiligen Fachgebieten haben, d.h. auf fachinstitutioneller Ebene (so auch in der Ausund Weiterbildung) und im schriftlichen Bereich keine Verwendung finden.

Die naheliegende Vermutung, dass die Regionalsprachen aufgrund dieses eingeschränkten Gebrauchsumfangs in den untersuchten fachkontextuellen Situationen nur im Schatten der dominanten Sprachen stehen bzw. von ihnen langsam 'aufgesogen' werden - eine Vorstellung, die sich aus den Ergebnissen mancher interferenzbezogenen Untersuchungen ableiten lässt - wird durch die vorgelegte Arbeit nicht bestätigt. Die präzise Konzentration auf regional relevante Sachgebiete macht vielmehr deutlich, welch hohen kommunikativen Wert die Regionalsprache sich in jedem Fall erhält, solange sie noch gebraucht wird. ${ }^{2}$ Die Untersuchung versucht dies in Gegenüberstellungen der ermittelten Sprachkompetenzen in den dominanten und dominierten Sprachen zu verdeutlichen. Dabei wird, um den Aspekt der Vergleichbarkeit zu wahren, ausschließlich auf den mündlichen Sprachgebrauch, das lexikalisch-semantische Wissen der Sprecher und die Gestaltungsebene des Textes (Diskurses) Bezug genommen. Ein erstaunliches Ergebnis ist in diesem Zusammenhang, dass Sprachkompetenz und Sprachdynamik des fachbezogenen Sprechens nicht in der einseitigen Abhängigkeit von der überregional gebräuchlichen Sprache stehen, sondern dass gerade unter dem Gesichtspunkt des regionalen Sprachgebrauchs, der ja auch für die dominanten Sprachen in den jeweiligen mündlichen Fachkontexten charakteristisch ist, wesentliche Prägungen (normative Wirkungen) von der regressiven Regionalsprache ausgehen.

Die vorliegende Arbeit ist von der Deutschen Forschungsgemeinschaft gefördert worden. Sie versteht sich als Grundlegung eines umfangreicheren, auf weitere Forschungen ausgerichteten Projekts, dessen Entwicklung ich parallel zu meiner eigenen Arbeit initiiert habe. Im Rahmen dieses Projekts sind bereits zwei wissenschaftliche Arbeiten verfasst worden, drei weitere, darunter eine Dissertation, sind in Vorbereitung. Ferner besteht eine Kooperation mit dem Zentrum für Mehrsprachigkeit an der Katholischen Universität Brüssel. Die Schwerpunkte der weiteren Forschungsarbeit sollen in den Bereichen Sprachkompetenz (Sprachwissen), Sprachnormen, gesprochene Sprache (auf textanalytischer Basis), mündlicher Fachsprachengebrauch, Sprachkontakte, (europäische) Sprachpolitik und Sprachökologie liegen.

2 Die Arbeit beabsichtigt keine Korrektur soziolinguistischer Forschungsergebnisse. Sie macht gleichwohl darauf aufmerksam, dass sprachliche Regression oder sogar Sprachtod mit der konsequenten Aufrechterhaltung (Stabilität) kommunikativen Reichtums und hoher einzelsprachlicher Kompetenz (bei muttersprachlichen Sprechern) einhergeht: Regionalsprachen verlieren soziale Funktionen, aber - bis zuletzt - nicht ihre kommunikative Potentialität. 


\section{Theoretische Erläuterung des Untersuchungsschwer- punkts}

Der modernen Sprachwissenschaft geht es darum, den sehr komplexen Gegebenheiten sprachlicher Strukturiertheit und der gesellschaftlichen Realität von Sprache in einer immer differenzierteren Theoriebildung gerecht zu werden. Verfolgt man die Weiterentwicklungen einiger einflussreicher linguistischer Erklärungsmodelle, so fällt auf, dass sie, ausgehend von den grundsätzlichen Zielsetzungen, darum bemüht sind, auch die dem Grundansatz nicht unbedingt genuinen, gleichwohl aber relevanten Aspekte sprachlicher Wirklichkeit in den erweiterten Blick und zugleich auch methodisch in den Griff zu bekommen. Dies führt oft zu der Bereitschaft der Vertreter eines bestimmten sprachwissenschaftlichen Erklärungsmodells, ursprünglich enge Problemorientierungen oder auch Spezialisierungen linguistischer Forschung zu einer umfassenderen Beschreibung und Analyse sprachlicher Wirklichkeit auszubauen. ${ }^{3}$ Im Zuge dieser Tendenz werden notwendigerweise dogmatische Positionen in Frage gestellt, einseitige Perspektiven erweitert, methodische Verflechtungen vorgenommen und somit letztlich die starren Grenzen der traditionellen Theoriebildung überwunden.

Andererseits gelingt es vielfach nicht, alte Feindbilder abzubauen und Anleihen bei konkurrierenden oder alternativen Theorien und Methoden als solche zu erkennen oder gar zu akzeptieren. Das Rad wird daher in der Sprachwissenschaft immer wieder neu erfunden und darüber hinaus oft nur als für einen einzigen Wagen passend dargestellt. Dabei ergibt sich die Gefahr einer Überschätzung des gewählten theoretischen Ansatzes, der gelegentlich etwas als neu hinstellt, was längst schon herausgefunden worden ist, oder der grundsätzliche Wahrheiten linguistischer Analyse nur in Bezug auf die vertretene Theorie zur Geltung kommen lässt und auf diese Weise einseitig perspektiviert.

Für eine neue, umfassend angelegte sprachwissenschaftliche Untersuchung, wie sie in dieser Arbeit präsentiert werden soll, stellt sich so von vornherein ein methodologisches Problem, insofern weder versucht wird, einen vorhandenen theoretisch-methodischen Ansatz auszubauen, noch eine völlig eigenständige Theorie und Methodik zu kreieren. Berücksichtigt man die oben erwähnte

\footnotetext{
${ }^{3}$ Ich sehe auch die Erweiterungen, Präzisierungen und Vervollständigungen der Sprachtheorie Eugenio Coserius im Laufe vieler Jahre als einen solchen Prozess an. Die in analytischer Hinsicht umfassende und offene Theorie des Sprechens, die Coseriu in seinen späteren Veröffentlichungen immer klarer als sprachtheoretische Gesamtkonzeption darstellt, ist in diesem Sinne ein wichtiger Erklärungsansatz für meine Untersuchung (vgl. Kap. II).
} 
Komplexität sprachlicher Wirklichkeit, so bleibt nur übrig, Verbindungen zu einer Reihe vorhandener linguistischer Analysemodelle und Beschreibungsverfahren zu suchen und dabei sich der nicht immer leichten Aufgabe zu stellen, unerwartete - weil in den jeweiligen Theorien nicht angelegte - Bezugnahmen zu rechtfertigen bzw. vermeintliche Inkompatibilitäten als sinnvolle Ergänzungen umzudeuten. Wer diesen Weg gehen will, hat die Chance, seine errungene theoretisch-methodische Freiheit wissenschaftlich zu legitimieren, aber er muss anfänglich den Untersuchungsgegenstand in besonderer Weise begründen. Ich möchte dies im Folgenden versuchen.

Es gibt bekanntermaßen Untersuchungsschwerpunkte der modernen Sprachwissenschaft, die aus besonderen Forschungsinteressen heraus entstanden sind und die in der Regel aktualitätsbezogene Fragestellungen zur sprachlichen Realität in den heutigen Sprachgemeinschaften reflektieren. Zu diesen aktuellen Untersuchungsschwerpunkten gehören die Eigenheiten der gesprochenen Sprache, die Existenz und Realisation von Fachsprachen, der Gebrauch regionaler Sprachen und Sprachformen, das Phänomen sprachlicher Normierung und Standardisierung und das vielfältig in Erscheinung tretende Faktum gesellschaftlicher Mehrsprachigkeit sowie des mit ihr verbundenen Sprachkontakts. $\mathrm{Zu}$ all diesen Bereichen existieren differenzierte linguistische Theorien und Modelle sowie eine Vielzahl z.T. sehr ausführlicher Einzeluntersuchungen. Allerdings zeigt sich in der Zusammenschau der genannten Analysebereiche das zunächst verblüffende Fehlen eines Untersuchungsgegenstands, dessen Verankerung in der gesellschaftlichen Realität unmittelbar einsichtig ist, dessen Untersuchung wohl aber gerade aus Gründen der scheinbaren Inkompatibilität bestimmter Fragestellungen und Ansätze der Sprachwissenschaft bislang ausgeblieben ist. Ich nenne diesen Untersuchungsgegenstand 'Regionaler Sprachgebrauch in Fachkontexten' oder auch 'Kommunikation in regionalspezifischen Sachbereichen'.

Das primäre Interesse dieses Untersuchungsgegenstands ist auf einen wichtigen Ausschnitt gesellschaftlicher Kommunikation bzw. Kommunikationsfähigkeit ausgerichtet. Überall ist zu beobachten, dass in bestimmten Regionen bestimmte Sachbereiche an sozialer Bedeutung gewonnen haben, da sie im Sinne einer beruflichen Erwerbstätigkeit oder Freizeitbeschäftigung für viele Menschen der Region eine wichtige Rolle spielen. Solche Sachbereiche sind zumeist ohne Schwierigkeit im Rahmen einer fachlichen Struktur präzisierbar, die auch außerhalb der Region Relevanz besitzt. Das spezifisch Fachliche nimmt jedoch in diesen Fällen innerhalb der Region eine besondere soziale Gestalt an und verdient es auch, genau unter diesem Aspekt untersucht zu werden. Die Menschen der Region sind mit dem Fach und seinen sozialen Kontexten konfrontiert, und genau dieses Phänomen wird durch eine ausführliche gesellschaftliche Kommunikation im Sachbereich reflektiert, deren Um- 
stände und Bedingungen es aus sprachwissenschaftlicher Sicht zu ermitteln gilt.

Präzisieren wir zunächst, um welche möglichen Fachkontexte es gehen kann. Hier drängt sich als erstes der primäre Wirtschaftsektor auf, der sehr oft für eine Region typische Berufszweige aufweist. Es ließen sich z.B. Fischfang in Küstenregionen, Viehzucht im Gebirge oder Weinbau in klimatisch und geographisch geeigneten Gebieten nennen. Es handelt sich dabei jeweils um Erwerbszweige, die das wirtschaftliche Leben der Region prägen und mit denen innerhalb sowie auch außerhalb der jeweiligen Berufsgruppen eine Vielzahl von Redeanlässen verbunden ist. Neben dem primären ist auch der sekundäre Wirtschaftssektor ein typisches Untersuchungsfeld. Gerade im Handwerk, aber auch im industriellen Fabrikationsbereich gibt es viele Beispiele für regionaltypische Produktionen, die z.T. sogar zu Aushängeschildern für ganze Regionen werden. Die Schweizer Uhren sind hier sicherlich ein extremes (und inzwischen schon fast veraltetes) Beispiel, aber man wird auch ohne Schwierigkeiten sogleich an eine Reihe geographisch begrenzterer regionaltypischer Handwerks- und Industriezweige denken können. Oft stehen diese als Weiterverarbeitung land-, see- und forstwirtschaftlicher Produkte in direkter Abhängigkeit vom primären Wirtschaftsektor der Region.

Man ist erstaunt zu beobachten, in welch ausdrücklicher Form sich auch heute in einer globalisierten Welt einzelne Regionen über ihre vorrangigen ökonomischen Produktionsverhältnisse definieren. Zur Stabilisierung dieses Identifikationsfaktors trägt natürlich zum einen die Erwerbsabhängigkeit größerer Bevölkerungsanteile von dem jeweiligen Sektor bei. Zum anderen fördert aber auch die institutionelle Außendarstellung der Region im Rahmen wirtschaftlicher Marktkonkurrenz und selbst die Tourismusbranche eine solche Identifikation mit bestimmten Produktionssparten. Zudem kann unterstellt werden, dass über diese materiell zweckgebundenen Identifikationsmechanismen hinausgehend auch die persönliche Betroffenheit vieler einzelner sowie der Hang, regionale Lebensverhältnisse als gemeinschaftliche Existenzgrundlage zu begreifen, für die Identifikation mit einem regionaltypischen Sachbereich - und insbesondere auch seiner regionaltypischen Ausprägungausschlaggebend ist.

Mehr noch: Regionales Leben rekurriert über die wirtschaftlichen Verhältnisse hinaus auf Besonderheiten des Freizeitsektors und den Bereich volkstümlicher Traditionen. Hier lassen sich für jede Region typische Aktivitäten und Festivitäten benennen, deren Kultivierung in der Regel ebenfalls eine eindeutig fachliche Dimension bekommt und dementsprechend $\mathrm{zu}$ einer Kommunikation in Fachkontexten führt. Beispielhaft können für diesen Bereich etwa Formen der Jagd, der Vereinsbildung oder regionaltypische Volksfeste genannt werden. Auch der in allen Regionen identitätsstiftende Aspekt 
des Kulinarischen in Form der regionalen Küche gehört hierher. Dabei gibt es meistens im Sinne einer ganzheitlichen regionalen Identifikation eindeutige Verbindungen des Freizeit- und kulinarischen Sektors zu den wirtschaftlichen und landschaftlichen Gegebenheiten der Region.

An diese Feststellungen schließt sich nun in sprachwissenschaftlicher Hinsicht die Frage an, ob es in der Tat gerechtfertigt ist, den regionaltypischen Sachbereichen auch eine besondere Form der Kommunikation zuzuordnen. Man könnte zunächst der Auffassung sein, dass es sich nur in frequentativer Hinsicht um eine exponierte Stellung des Sprechens in den jeweiligen Fachkontexten handelt, da die entsprechenden Redeanlässe recht häufig und für das Leben der Region typisch sind. Wieso aber sollte man in Burgund anders über den Weinbau sprechen als in der Gegend von Bordeaux? Und was unterscheidet in sprachlicher Hinsicht die Schafzucht auf Sardinien von derjenigen in den Pyrenäen? Die Antwort hierauf muss in einer differenzierten Form gegeben werden. Wenn es um die vornehmlich terminologisch orientierte reine Fachsprache geht, so wie sie meist in schriftlicher Form auch in Lehrbüchern und Literatur für berufliche Bildung zu finden ist, wird es schwer fallen, sofort auf Eigentümlichkeiten des regionalen Sprachgebrauchs zu stoßen. Gerade im Zeitalter der zunehmenden Technisierung, des Wissenstransfers und des überregionalen Warentransports spielen regionale Besonderheiten des Fachsprachengebrauchs nicht mehr die zentrale Rolle von einst. Durch allgemeine Optimierungsverfahren gleichen sich die Produktionsbedingungen an, und die regionalen Besonderheiten des jeweiligen Produktionszweigs gehen verloren. Dementsprechend gibt es auch einen Rückgang im sektoriellen Gebrauch regionaler Sprachformen. Aber erübrigt sich damit der Untersuchungsgegenstand als solcher?

Gerade das veränderte Erkenntnisinteresse der modernen Sprachwissenschaft weist den Weg zu einer interessanten Sichtweise und Behandlung des hier thematisierten Untersuchungsgegenstands. Der analytische Blick auf den 'regionalen Sprachgebrauch in Fachkontexten' wird nämlich durch die Hervorhebung der gesprochenen Sprache und der Kommunikationsbedingungen, unter denen sie gebraucht wird, entscheidend geprägt. Maßgeblich ist hier zum einen die Verwendung einer 'Sprache der Nähe', so wie sie Koch/Oesterreicher definiert haben und wie sie nicht nur in der Familie oder unter Freunden in der gemeinschaftlich erlebten Freizeitgestaltung, sondern auch unter gut bekannten Berufskollegen bzw. im vertrauten Berufsumfeld prädominant und typisch ist. Zum anderen ist aber im fachlichen Bereich, um den es hier ja geht, die Relevanz einer distanzsprachlich orientierten, formalistischen Redeweise nicht von der Hand zu weisen. Dies gilt - zumindest insoweit ausbildungs - und berufsstrukturbedingte Hierarchien eine Rolle spieleninsbesondere für fachliche Erklärungen und Instruktionen, die häufig in einer 
terminologisch geprägten Sprechweise realisiert werden. Die traditionelle Untersuchung von Fachsprachen mit vorrangigem Bezug auf Terminologien und schriftliche Texte vermittelt bisweilen sogar den Eindruck, dass eine gewisse Affinität zwischen fachlichen Kontexten und einem formellen, auf kommunikativer Distanz basierenden Sprachgebrauch besteht.

Die vorliegende Untersuchung ist darum bemüht, eine grundsätzlich andere Optik einzunehmen. Dabei geht es im Prinzip darum, fachliche Kontexte aus sprachlicher Sicht nicht nur als Redeanlässe zu begreifen, bei denen es aus pragmatischen Gründen zu der konzentrierten Darstellung fachlicher Inhalte kommt, sondern - viel weiter gefasst - als Redeanlässe, die die Betroffenheit und das Eingebundensein der Kommunikationspartner in den fachlichen Sektor bzw. den Sachbereich dokumentieren. Dort wo der persönliche Bezug und die Einbindung vieler Menschen in einen Sachbereich unterstellt werden kann, und sei dies auch nur mittelbar, kommt es ganz unweigerlich zu einer Vielzahl von fachkontextuellen Gesprächssituationen, deren Motivation sehr unterschiedlich und vielfältig ist. Besonders hervorzuheben ist der Aspekt des implizierten Selbstverständnisses und der sachbezogenen Identifikation, die viele Kommunikationen im Sachbereich prägen und die dazu beitragen, dass das jeweilige Sprechen einen Charakter annimmt, der sich zum Teil weit von den typischen Merkmalen rein fachsprachlicher Diskurse entfernt. Kurzum ist der hier vertretenen Auffassung zufolge gesprochene Fachsprache ein Begriff, der mehr impliziert als nur die spezifisch mediale Verwirklichung von Fachsprache im engeren Sinne. Es geht letztlich um die Erfassung einer kommunikativen Situation, die zugleich mit dem Fachwissen des Sprechenden wesentliche Dimensionen seiner existentiellen sowie normativen Prägung durch den Sachgegenstand offenbart. Den sprachlichen Implikationen dieser Prägung gilt dabei die besondere Aufmerksamkeit der Untersuchung.

Die Tendenz der modernen Fachsprachenlinguistik, neben der fachsprachlichen Kompetenz der ausgewiesenen Experten auch die der durch das Fach nur mittelbar Betroffenen und die der fachfremden Laien einzubeziehen, bietet gute theoretische Ansätze für die Analyse des hier in den Vordergrund gestellten Aspekts mündlichen Fachsprachengebrauchs. Dabei gilt es zu berücksichtigen, dass das inzwischen viel beachtete Spannungsfeld des unterschiedlichen Sprachgebrauchs von Experten und Laien in Bezug auf die vorliegende Untersuchung nicht einfach durch die Dimension der Vertikalität von Wissensstrukturen aufgelöst werden kann. Zwar gehe ich in diesem Zusammenhang weitgehend mit der von Sigurd Wichter überzeugend dargelegten semantischen Konzeption der 'Lexikologie der Vertikalität' einig, die eine jeweils spezifische inhaltlich strukturelle Ausdeutung des kommunikativen Gebrauchs von Fachwörtern der semantischen Verifikation eines gradierbaren sprachlich ausgedrückten Fachwissens vorzieht. Ich stelle jedoch gleichzeitig fest, dass es in 
Bezug auf den regionalen Sprachgebrauch in Fachkontexten nicht immer möglich ist, eine klare Unterscheidung zwischen experten- und laienhaftem Sprachgebrauch zu treffen. Dies betrifft zum einen das zum Ausdruck gebrachte Wissen selbst - denn die Kommunikation in regionalspezifischen Sachbereichen wird häufig mit einem recht hohen $\mathrm{Ma} ß$ an Fachwissen von den interessierten Laien und mit einem erstaunlich defizitären $\mathrm{Ma} ß$ an spezifischer fachsprachlicher Präzision von den Experten vollzogen. Zum anderen ist zu berücksichtigen, dass die alltäglichen Gespräche in Fachkontexten über die Manifestation von Wissenstrukturen hinaus auch die persönliche Betroffenheit des Einzelnen durch den Sachbereich sowie den Einfluss der normativen Wirklichkeit in der Region reflektieren.

Unter semantischem Gesichtspunkt kann diese mehrfache Prägung des regionalen Sprachgebrauchs in Fachkontexten nur in der kommunikativen Verwendung umfassenderer Begriffsstrukturen dargestellt und analysiert werden. Damit entfernt sich der analytische Ansatz unweigerlich von einer lexikalischen Semantik im engeren Sinn hin zu der Beobachtung sprachkognitiv erklärbarer semantischer Muster, für deren Darstellung aus dem Repertoire etablierter semantischer Erklärungsansätze mir der der Schema-Theorie am geeignetsten erscheint. Die vorliegende Untersuchung wird dennoch keine Applikation der Schema-Theorie vornehmen, da auch dieses Modell der lexikalischen Semantik sich als nicht geeignet erweist, die relevanten Aspekte des hier gegebenen Untersuchungsgegenstands vollständig zu erfassen. Das was den Sprachgebrauch in regionalspezifischen Fachkontexten prägt, lässt sich eben nicht nur lexikalisch-semantisch bestimmen, sondern hat auch wesentliche sprachsoziale und sprachnormative Dimensionen, die nicht aus dem Blick zu verlieren sind.

Im Rahmen des von mir vertretenen theoretischen Ansatzes lege ich ein besonderes Gewicht auf den Aspekt der Sprachstandardisierung. Dabei ist zu betonen, dass ich sprachliche Standardisierung nicht im Sinne einer Ausbildung von Standardsprachen, so wie es dem konventionellen Verständnis in der Sprachwissenschaft entspräche, verstehe. Ich schlage vielmehr ein neues Konzept sprachlicher Standardisierung vor, das sich auf die Erkenntnisse der Varietätenlinguistik gründet und dynamische Prozesse der Sprachveränderung zu berücksichtigen versucht. Im Rahmen dieser Standardisierungstheorie spielt die Herausbildung regionaler Standards eine besondere Rolle. Damit trifft sich, vom untersuchten Faktum her, mein analytischer Ansatz mit der Hervorhebung desselben Phänomens vonseiten einer Reihe moderner Sprachwissenschaftler, die allerdings jeweils eine Interpretation aus dem Blickwinkel ihrer eigenen Theoriebildung vorschlagen. Im Gegensatz zu der gängigen Auffassung über regionalen Sprachgebrauch interpretiere ich regionale Sprachformen nicht als Abweichung von einem überregionalen Standard, sondern unter vorrangigem 
Bezug auf ihre Prägung durch Sprachverhaltensnormen der Region. Allein dadurch kann nämlich auf die relevante Abhängigkeit regionaler Sprachformen von den spezifischen natürlichen, wirtschaftlichen und sozialen Gegebenheiten der Region aufmerksam gemacht werden. Dabei betrachte ich diese Perspektive auch als Beitrag zu einer modern verstandenen Ökolinguistik.

Besondere Beachtung verdient nun die Situation in zweisprachigen Gebieten, deren regionale Begrenztheit meistens schon durch die geographische Sprachausdehnung gegeben ist, in der Regel aber durch die dialektale Ausprägung der sogenannten Regionalsprache noch weiter eingeschränkt wird. Man muss sich hier zunächst die Frage stellen, inwieweit die Sprachregion mit der Region im sozialen, wirtschaftlichen und politischen Sinne koinzidiert bzw. ob eine Region in dem genannten Sinne auch mehrere Sprachregionen umfassen kann. Betrachten wir das Problem einmal aus der Perspektive des als regional empfundenen Sprachgebrauchs. In der Regel ist festzustellen, dass trotz der üblichen, häufig auf die fehlende Anerkennung einer expliziten Sprachnorm zurückzuführenden Bereitschaft der Sprecher, dialektale Sprachvarietäten noch auf lokaler Ebene zu differenzieren, doch ein gemeinschaftliches Sprachbewusstsein entsteht. Dabei wird die verwendete Sprache als 'regional' im Sinne einer Deckungsgleichheit mit der historischen oder politischen Region, in der sie gesprochen wird, interpretiert. Diese Interpretation findet ihren Niederschlag häufig auch in der entsprechenden Bezeichnung der Sprache.

Für meine Untersuchungszwecke habe ich zwei Regionen innerhalb des okzitanischen und katalanischen Sprachgebietes gewählt: den Béarn in Frankreich und die Comunitat Valenciana in Spanien. In beiden Fällen konnte ich feststellen, dass im Bewusstsein der einheimischen Bevölkerung und insbesondere der Sprecher der Regionalsprache unter dem entsprechenden geographischen Bezug auch eine sprachliche Homogenität der Region anerkannt wurde. Ich bin allerdings der Meinung, dass dieses Bewusstsein der Sprecher, Bearnesisch bzw. Valenzianisch zu sprechen, in der Abhängigkeit einer Akzeptanz der historisch bestimmten bzw. aktuellen administrativen und politischen Grenzen steht und keine genauere Kenntnis dialektaler Zusammenhänge impliziert. In diesem Sinne fällt auf, dass nur sehr wenige Sprecher das Bearnesische als einen gaskognischen bzw. okzitanischen Dialekt und das Valenzianische als eine Form des Katalanischen bestimmen. Im ersten Fall ist hierfür die fehlende sprachhistorische Kompetenz, im zweiten Fall das dominante (sprach)politische Bewusstsein ausschlaggebend. Andererseits ist ebenso auffällig, dass die unter den Sprechern verbreitete Kenntnis mundartlicher Differenzierungen innerhalb des Béarn bzw. der Comunitat Valenciana nicht dazu führt, die Homogenität der regionalen Sprache in Frage zu stellen. Signifikanter ist in diesem Zusammenhang die vielen Sprechern bekannte Situierung von Teilregionen, in denen man die Regionalsprache kaum noch oder gar nicht 
mehr spricht. Insgesamt gesehen lässt sich aus diesen Beobachtungen der interessante Schluss ziehen, dass ein nicht sprachlich bestimmter Regionenbegriff auch der gebräuchlichen Regionalsprachform begrifflich zugeordnet wird und nicht umgekehrt. Der Soziolinguist wird anerkennen müssen, dass seitens der Sprecher das sozio-politische Regionalbewusstsein auf die Sprache und nicht das dialektale Sprachbewusstsein auf die Region übertragen wird.

Sowohl der Béarn als auch die Comunitat Valenciana sind Sprachkontaktgebiete, deren soziolinguistische Untersuchung, insbesondere auf der theoretischen Grundlage der Diglossieforschung, weit vorangeschritten ist. Mit den katalanischen und okzitanischen Soziolinguisten gehe ich darin einig, dass die Diglossie in Südfrankreich und Nordostspanien bis in die jüngere Vergangenheit hinein ein erhebliches Sprachkonfliktpotential bereitgestellt hat und dass es gerade die sozialen Sprachkonflikte waren, die zu der Dynamik und Veränderung der Sprachverhältnisse in den entsprechenden Gebieten beigetragen haben. In Bezug auf die aktuelle Situation beurteile ich die Sprachverhältnisse jedoch vorsichtiger als Sprachkonkurrenz und bisweilen sogar als eine Form relativ friedlicher Sprachkoexistenz. Die Gründe hierfür werden an späterer Stelle noch dargelegt werden. In diesem Zusammenhang sei aber bereits darauf hingewiesen, dass entscheidende wirtschaftliche, technologische, soziale und politische Entwicklungen in Europa, die bis auf die regionale Ebene durchschlagen, nicht ohne Auswirkungen auf das Sprachverhalten und Sprachbewusstsein zweisprachiger Regionen in Europa geblieben sind. Das diglossische Sprachkonfliktmodell muss sich diesen neuen Gegebenheiten anpassen und dabei auch die Erkenntnisse der modernen sprachpolitischen Forschung in eine veränderte Interpretation einbeziehen.

Überall in Europa ist der Rückgang und teilweise Untergang von Regionalsprachen zu verzeichnen. Auch das Bearnesische und Valenzianische müssen in diesem Sinne als regressive Sprachen betrachtet werden, da ihr normaler Gebrauch-wenn auch in sehr unterschiedlicher Intensität-im Kontakt mit der dominanten Staatssprache bedroht ist. Allerdings ist bekannt, dass Dialekte und Regionalsprachen unterschiedlich schnell aus ihren verschiedenen Verwendungsbereichen verdrängt werden. Die soziale Funktion der Regionalsprache beschränkt sich im Verlauf dieses Prozesses immer stärker auf nähesprachliche Kommunikationssituationen, wie sie insbesondere in der Familie, unter Freunden und guten Bekannten sowie bei Freizeitaktivitäten, aber eben auch im vertrauten Berufsalltag, und hier ganz besonders dem des Landwirts oder Handwerkers, typisch sind. Der Sektor regionaltypischer Berufe ist sogar eine bevorzugte Domäne des Erhalts regionaler Sprache, da in ihm Traditionen gepflegt werden und sich der Sprachgebrauch nicht so stark nach den Maßstäben sozialen Prestiges ausrichtet. Andererseits stehen die Phänomene des immer schnelleren Strukturwandels und der voranschreitenden Technisierung 
dem beständigen Gebrauch der Regionalsprache im jeweiligen Sachbereich oft entgegen. Diese ambivalente Situation macht es besonders interessant, den Gebrauch der Regionalsprache in regionaltypischen Fachkontexten genauer zu untersuchen. Letztlich geht es dabei um die Frage, welche kommunikative Funktion die Regionalsprache im Sachbereich hat und ob sie gegebenenfalls im Zuge des Rückgangs der Regionalsprache durch die überregionale Standardsprache adäquat ersetzt werden kann.

In der neueren Kontaktlinguistik hat der Rückgang von Dialekten und Regionalsprachen zugunsten dominanter Standardsprachen bereits einige Beachtung gefunden. Dabei sind unterschiedliche Mechanismen der Sprachveränderung und Sprachdynamik herausgestellt worden. Thomas Stehl hat zu Beginn der 90er Jahre hierzu ein theoretisches Modell entworfen, das an strukturalistische Prinzipien der Sprachbeschreibung anknüpft und das Phänomen sprachlicher Interferenz in den Mittelpunkt des sprachdynamischen Prozesses stellt. Damit folgt Stehl einer weit verbreiteten Sicht des Verhältnisses von Dialekt und Standardsprache, die von einer gewissen Form der Assimilation des Dialekts an die Standardsprache ausgeht und die letztendliche Aufgabe des Dialektgebrauchs in normativer Hinsicht als eine Form der generationsspezifischen Korrumpierung des ursprünglich reinen Dialekts ansieht. Stehl weist nach, dass dies im metasprachlichen Bewusstsein der Sprachteilhaber eine Entwicklung darstellt, die, obwohl sie aus einer synchronischen Sprachvariation entsteht, von den Sprechergenerationen Schritt für Schritt als irreversibler Prozess nachvollzogen und akzeptiert wird. Stehls Argumentation setzt aber voraus, dass der schrittweise, durch immer stärkere Interferierung geprägte Abbau des Dialekts bzw. der Regionalsprache in der Sprachgemeinschaft unterstellt werden kann. Ich bin jedoch der Meinung, dass diese Interpretation sprachlicher Veränderung für meinen Untersuchungsgegenstand nicht uneingeschränkt zutrifft.

Wenn in einem beruflichen Sektor bzw. in fachlichen Kontexten die Regionalsprache noch Verwendung findet, so geschieht dies auf Seiten der Sprecher in der Regel sehr bewusst und mit einer guten sprachlichen Kompetenz. Steht diese Kompetenz dem Sprecher nicht zur Verfügung, so benutzt er in einer (mikro-)diglossisch interpretierbaren Sprachkontaktsituation ohne weiteres die dominante Standardsprache, deren kommunikative Funktion im Sachbereich zumindest als reine Fachsprache außer Frage steht. Es zeigt sich im Alltag ganz konkret, dass die zweisprachigen Sprecher wie selbstverständlich zwischen der regionalen Sprache und der Standardsprache je nach Einschätzung der fachlichen Kommunikationssituation wechseln und ihnen dabei nur wenige Interferenzen im Sinne ungewollter Normverstöße unterlaufen. ${ }^{4}$ Meinem Ein-

${ }^{4}$ Das je nach individuellem Sprachverhalten mehr oder weniger häufige Code-Switching ist in 
druck nach - und ich stütze mich hierbei auf persönliche Erfahrungen ebenso wie auf die Ermittlung und Auswertung umfangreichen empirischen Materials - schwindet die Regionalsprache aus einem Sachbereich auf den einzelnen Sprecher bezogen eher von heute auf morgen und - aufs Ganze gesehen durch die quantitative Abnahme von Sprechern, nicht aber durch die immer stärkere Infiltrierung des überregionalen Standards in die Regionalsprache. Diese These ist nicht mit der Verkennung eines hohen Lehnwortaufkommens durch kontaktsprachliche Vermittlung und auch eines gewissen Maßes an Interferenzerscheinungen in der Regionalsprache zu verwechseln. Vielmehr weist sie darauf hin, dass die typischen kontaktlinguistischen Phänomene und hierzu gehört auch das verbreitete Code-Switching - nicht als Ausdruck eines allgemeinen sprachlichen Kompetenzverlustes zu werten sind. Es macht nämlich Sinn, den Ablösungsprozess Regionalsprache - Standardsprache in Bezug auf die gesamte Sprachgemeinschaft anders zu interpretieren, und zwar, wie ich vorschlagen möchte, unter dem Aspekt des Erhalts und der Transformierung von Diskurstraditionen, die für eine Region prägend sind. Wenn diese Diskurstraditionen, die es noch näher zu bestimmen gilt, vom einzelnen Sprecher nicht mehr in der Regionalsprache realisiert werden können, so wechselt er aufgrund des normativen Drucks vollständig zu der ihm näher liegenden Standardsprache und vollzieht damit eine Entwicklung mit, die in vielen zweisprachigen Regionen, aber längst nicht in allen, auf Dauer die sprachlichen Verhältnisse in Richtung Einsprachigkeit prägt.

Um diese These zu untermauern, gilt es nachzuweisen, dass der regionale Sprachgebrauch in Fachkontexten durch Normen bestimmt wird. Diese Normen prägen das von mir so genannte 'sektorielle Sprechen' in einer Interdependenz von Fachlichkeit, regionaler Faktizität und persönlicher Betroffenheit als Ganzes. Der einzelne Sprecher bringt diese Normierung sowohl durch seine fachsprachliche Kompetenz als auch durch sein kommunikatives Verhalten in Fachkontexten, d.h. insbesondere durch die Art seiner Diskursgestaltung, zum Ausdruck. In theoretischer Hinsicht kann man zum Zweck dieser Analyse an grundsätzliche Erkenntnisse der Sprachnormentheorie anknüpfen und versuchen zu ergründen, inwieweit sich die Ausbildung regionaler Identität exemplarisch an einem Sachbereich darstellen lässt, dessen Relevanz für die Region unmittelbar gegeben ist und dessen fachsprachliche und kommunikative Besetzung in einer Weise erfolgt, die als regionalspezifisch qualifiziert werden kann und sich darüber hinaus auch in der Form eines regionalen Sprachge-

diesem Zusammenhang ebenfalls nicht nur unter dem Gesichtspunkt sprachlicher Interferenz zu beurteilen. Der beständige Wechsel zur dominanten Sprache ist kein unbedingtes Anzeichen mangelnder Sprachkompetenz, sondern kann auch ein Indikator für den sozialen Funktionsverlust der Regionalsprache sein, dem sich der Muttersprachler in bestimmten Kommunikationssituationen zu widersetzen versucht. 
brauchs manifestiert. Unter Bezug auf die in einer Serie von Interviews von verschiedenen Probanden geäußerten fachlichen Inhalte sollen in der hier vorgelegten Untersuchung insbesondere semantische und textuelle Strukturen ermittelt werden, die belegen können, dass bestimmte Formen des sektoriellen Sprechens in der Region dadurch charakterisiert werden, dass sie sich an regionalen und anderen Normen ausrichten. Auf diese Weise wird ein regionaler Sprachgebrauch in Fachkontexten erkennbar, der als normativ identifiziert, beschrieben und sogar klassifiziert werden kann. Dabei ist zu klären, bis zu welchem Grad Fachwissen und fachsprachliche Kompetenz eine Rolle spielen und inwieweit der Gebrauch von Regionalsprache oder Standardsprache im kommunikativen Verhalten ausschlaggebend ist. 


\section{Theoretischer Teil:}

\section{Situierung des Themas in den Kontext sprach- wissenschaftlicher Theoriebildung}

\section{Die Interpretation der Sprachkompetenz im Rahmen einer Theorie des Sprechens}

\subsection{Der sprachtheoretische Grundansatz Eugenio Coserius}

Die sprachtheoretische Einbettung der vorliegenden Untersuchung kann nur durch ein sehr umfassendes Interpretationsmodell geleistet werden, das schon vom Prinzip her über die Betrachtung der Einzelsprache hinausgeht. Ein solches Modell hat Eugenio Coseriu in einer Reihe von Publikationen seit den 1950er Jahren entwickelt. Es findet seine ausführlichste und reifste Darstellung in der Veröffentlichung der Vorlesungsnachschrift mit dem Titel Sprachkompetenz von 1988. Coseriu geht es bei der Entwicklung seines sprachtheoretischen Modells um den analytischen Aufbau einer 'Theorie des Sprechens', die von dem Phänomen des Sprechens als der einzig realen und damit auch grundlegenden Manifestation menschlicher Sprache ausgeht. Dabei bekennt er sich zu einer aristotelisch und humboldtianisch geprägten Auffassung der Sprache:

Doch der Gegenstand der Sprachwissenschaft (als 'Wissenschaft aller Sprache') kann nur die Sprache in jeder Hinsicht sein. Diese kommt konkret nur als Tätigkeit, d.h. als Sprechen vor (und Humboldts Satz, nach dem die Sprache kein ह̌pyov, sondern

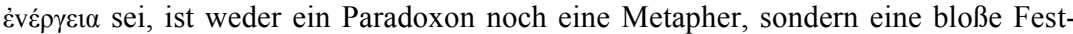
stellung). Ja mehr noch, nur weil sie als Tätigkeit erscheint, kann sie auch als 'Produkt' untersucht werden. Denn eine Tätigkeit vermag, um damit eine Unterscheidung des Aristoteles in Erinnerung zu bringen, betrachtet zu werden: $a$. als solche,

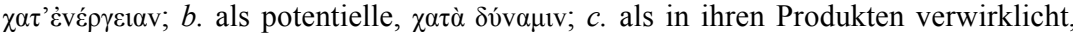
$\chi \alpha \tau$ ' $̌$ $\rho \gamma o v$. Dabei handelt es sich eindeutig nicht um drei jeweils unterschiedene Wirklichkeiten, sondern um drei Seiten, besser noch um drei Betrachtungsweisen ein und derselben Wirklichkeit.

(Coseriu 1975, 256)

Die Konzentration der Sprachwissenschaft auf das Sprechen stellt nach Coseriu eine 'radikale Änderung des Gesichtspunkts' (Coseriu 1988a, 57) dar. So 
stellt er fest, dass die großen und einflussreichen Sprachtheorien von De Saussure und Chomsky nicht über eine Betrachtung der Einzelsprache hinausreichen und daher wesentliche Momente der sprachlichen Wirklichkeit nicht in den Blick bekommen. Die moderne Linguistik interpretiert seiner Meinung nach das Sprechen fast ausschließlich als Realisierung der Einzelsprache und damit nur in einer sehr eingeschränkten Weise. Der Grund hierfür liegt offensichtlich in der guten oder doch zumindest relativ guten Strukturierbarkeit des so definierten Untersuchungsobjekts. Es ist jedoch Coserius Überzeugung - und er ist hier von seinen Schülern bislang wenig rezipiert worden -, dass die moderne Sprachwissenschaft versuchen muss, über diese Beschränkung bzw., wie er selbst programmatisch formuliert, 'über den Strukturalismus hinaus' zu gelangen:

Über den Strukturalismus hinaus bedeutet daher folgerichtig und in Übereinstimmung mit unserer These, dass man die Grammatik nicht zum Modell für die Sprachwissenschaft schlechthin wählen darf, sondern dass man über die phonologische und grammatische Beschreibung-im spezifischen Sinne dieser Ausdrücke - und über die strukturelle Semantik (Lexikologie) hinausgehen muss.

Man muss all das untersuchen und der Sprachwissenschaft wieder zugänglich machen, was man notwendigerweise ausklammert, sobald man eine strukturelle Untersuchung in Angriff nimmt. [...]

Wir wissen gegenwärtig genug über die Strukturen, oppositiven Funktionen und die Homogenität der Sprachen, aber wir wissen sehr wenig darüber, was ein Sprecher tatsächlich tut.

(Coseriu in Energeia und Ergon I, 1988, 107)

'Was ein Sprecher tatsächlich tut', und diese Formulierung trifft in ihrer Schlichtheit in der Tat das Wesentliche, ist eine Frage, mit der man sich auf der Basis einer Theorie des Sprechens durchaus den konkret zu beschreibenden Phänomenen der sprachlichen Wirklichkeit annähern kann. Im Rahmen der hier vorgelegten Untersuchung identifiziere ich mich daher genau mit dieser Fragestellung und versuche, sie auf den unterschiedlichen Ebenen der Sprachbetrachtung, die Coseriu unterscheidet, genauer zu bestimmen. Dieses methodische Vorgehen im Rückgriff auf Coserius Sprachtheorie bietet sich aus meiner Sicht für den gegebenen Untersuchungsgegenstand, den regionalen Sprachgebrauch in Fachkontexten, in besonderer Weise an. Ich wage es daher, die Theorie des Meisters, soweit ich dies überblicken kann, erstmalig in ihrer Gesamtheit auf einen konkreten Untersuchungsgegenstand anzuwenden. ${ }^{5}$

5 Meiner Kenntnis nach hat bislang nur Thomas Stehl in seiner Habilitationsschrift den ausdrücklichen Versuch unternommen, Coserius Theorie des Sprechens insgesamt zur methodologischen Grundlage einer umfangreichen empirischen Untersuchung zu machen. Allerdings bezieht sich Stehl in seiner Ausdeutung des Modells von Coseriu wiederum nur auf die Ebene der Einzelsprache (und hier ganz im Sinne der traditionellen Rezeption auf die Betrachtung funktioneller Sprachen), weshalb ich auch in seiner sehr profunden Arbeit noch keine 
Coseriu unterscheidet grundsätzlich drei Ebenen der Sprachbetrachtung: die universelle, die historische und die individuelle. Auf allen drei Ebenen manifestiert sich die Sprache im Wesentlichen als Sprechen und damit, nach Coserius Interpretation, als eine kreative Tätigkeit, die in ihrer Aktualisierung etwas Überliefertes weiterträgt und gleichzeitig etwas Neues schafft. Wir haben es hier mit einem kulturellen Sprachbegriff zu tun, der gerade das Traditionsstiftende, das Traditionserhaltende und das Traditionsverändernde der Sprache als historischer Sprechtätigkeit betont. Aber der analytische Blick auf die Sprache als kulturelles Phänomen und als Tätigkeit ist prinzipiell weiter gefasst. Er schließt neben der historischen Ebene, auf der sich die Einzelsprachen ausbilden, auch eine universelle und eine individuelle Betrachtungsebene ein.

Auf der universellen Ebene geht es um die Erkenntnis des Sprechens als allgemein-menschliches Phänomen. Wilhelm von Humboldt, auf den Coseriu immer wieder rekurriert, betont den Zusammenhang des Sprechens als der den Menschen bestimmenden geistigen Tätigkeit mit einer durch die einzelne Sprache gegebenen 'Weltansicht':

Der Mensch lebt auch hauptsächlich mit den Gegenständen, so wie sie ihm die Sprache zuführt, und da Empfinden und Handeln in ihm von seinen Vorstellungen abhängt, sogar ausschließlich so. Durch denselben Act, vermöge welches der Mensch die Sprache aus sich heraus spinnt, spinnt er sich in dieselbe ein, und jede Sprache zieht um die Nation, welcher sie angehört, einen Kreis, aus dem es nur insofern hinauszugehen möglich ist, als man zugleich in den Kreis einer andren Sprache hinübertritt.

(Humboldt 1972, III, 224 f.)

Diese Hervorhebung der Anverwandlung der Welt mittels Sprache betrifft sicherlich in erster Linie die universelle und nicht die historische Ebene des Sprechens. ${ }^{6}$

Coseriu selbst entfernt sich jedoch bei der Ausdeutung dieser Betrachtungsebene von der idealistischen Interpretation und betont stattdessen den kognitiven Charakter und die faktische Gebundenheit des Sprechens.

Das Sprechen im allgemeinen, die Tätigkeit des Sprechens ganz allgemein betrachtet, gehorcht in jeder Einzelsprache einer eigenen Technik, einer Technik, die z.B. den stillschweigenden Bezug auf eine ganze Reihe von allgemeingültigen Denkprinzipien umfasst, den Bezug auf die vom Menschen erkannte Welt, den Gebrauch nichtsprachlicher, nicht-grammatischer, d.h. nicht zu einer bestimmten Sprache gehöriger

Umsetzung von Coserius gesamtem sprachtheoretischen Ansatz erkennen kann.

6 Leo Weisgerber hat aus dieser Vorstellung Humboldts den Gedanken der 'sprachlichen Zwischenwelt' entwickelt, die das Ergebnis einer sprachtheoretischen Reflexion ist, mit der er versucht, Humboldts universell begründete Sprachauffassung auf ihre Implikationen im Bereich der einzelsprachlichen Betrachtung hin zu überprüfen. Es erscheint mir dabei wichtig, die anthropologische Dimension von Humboldts Ansatz nicht mit dem Aspekt seiner semantischen Interpretierbarkeit zu verwechseln. 
Techniken, also eine ganze Reihe anderer Ausdruckssysteme. Dies alles gehört zum Sprechen im Allgemeinen und müsste Gegenstand einer Linguistik des Sprechens im allgemeinen sein, die es zum gegenwärtigen Zeitpunkt noch nicht gibt.

(Coseriu in Energeia und Ergon I, 1988, 103)

Coserius 'Linguistik des Sprechens im allgemeinen' ist auf das Denken und die Sachen konzentriert, verliert aber nicht die Sprache als Tätigkeit aus den Augen. Die Determinationen des als übereinzelsprachlich definierten Sprechens sind durch Faktoren der außersprachlichen Realität gegeben, die wesentlich zu der Gestaltung der sprachlichen Kommunikation beitragen. Coseriu sagt selbst nicht explizit, wie Sprache als allgemeines Sprechen unter dem Aspekt der Tätigkeit genauer zu bestimmen ist. ${ }^{7}$ In einer interpretatorischen Erweiterung seiner Theorie möchte ich hierfür daher die Verwendung des Begriffs 'sprachliche Interaktion' in seiner allgemeinsten Bedeutung vorschlagen. In diesem Terminus scheint mir der Aspekt der Universalität und derjenige des Tätigseins miteinander vereinbar zu sein. Außerdem findet hier sowohl der kommunikative ${ }^{8}$ als auch der normative Charakter des Sprechens im Allgemeinen einen passenden terminologischen Bezug.

Neben der historischen und der universellen Ebene des Sprechens weist Coseriu noch auf die Existenz einer individuellen Ebene hin. Hiermit meint er die Betrachtung des Sprechens als konkreten und zufälligen Akt der Sprachverwendung des Einzelnen, d.h. als einen Akt, der immer in eine Kommunikationssituation eingebunden ist und meiner Meinung nach unter dem Aspekt der Tätigkeit auch durchaus als Kommunikationsakt begriffen werden kann. ${ }^{9}$ Coseriu zieht in diesem Zusammenhang allerdings den Terminus 'Diskurs' vor, da es ihm so möglich ist, eine enge begriffliche Bezugnahme zum 'Text' als Produkt des individuellen Sprechens zu begründen. ${ }^{10}$ Seine Sichtweise einer Textlinguistik fasst er wie folgt zusammen:

Die andere Ebene der Sprache, die durch diese Konzentration auf den Bereich der Einzelsprachen ausgeklammert wird, ist die Ebene des Textes, die ebenfalls ihren eigenen Techniken unterliegt. Zum einen ist ein Text nicht notwendigerweise in ein und derselben Sprache verfasst, sondern sehr oft gerade in mehreren Sprachen. Zum anderen verfügt diese Ebene auch über eigene Traditionen, die im Prinzip von den Traditionen der Einzelsprache unabhängig sind. (So gibt es z.B. die Tradition des

${ }^{7}$ Die von ihm benutzte Formulierung 'Sprechen im Allgemeinen' hat in der Tat keinen Erklärungscharakter.

${ }^{8}$ Coseriu betont auch die Existenz der non-verbalen Umstände des Sprechens im Allgemeinen.

9 Vgl. in diesem Zusammenhang die grundlegende Besprechung von kommunikativen Zeichenmodellen (Bühler, Jakobson) in Coserius Textlinguistik (1994, 71-92)

10 „Zur Bezeichnung dieser individuellen Tätigkeit in einer bestimmten Situation schlage ich nach dem französischen discours - den Terminus 'Diskurs' vor. Im Deutschen sagt man für diese Ebene auch 'Text'; dabei muß man aber daran denken, dass es hier zuerst um die Tätigkeit selbst geht und nicht um ihr Produkt.“ (Coseriu, 1988a, 71) 
'Sonetts' oder des 'Märchens', und zwar unabhängig vom Spanischen, vom Französischen usw.) Es geht hier um den Gegenstand einer anderen Disziplin, nämlich der Linguistik des Diskurses, der Texte, also der Disziplin, die gegenwärtig als Textlinguistik bezeichnet wird und im Begriff ist, Form anzunehmen.

(Coseriu in Energeia und Ergon I, 1988, 103 f.)

Coseriu betont in seinen Schriften und Vorträgen immer wieder den eigenständigen disziplinären Status der einzelnen von ihm differenzierten Betrachtungsebenen. Es verwundert daher kaum, dass seine Schüler bislang nicht den Versuch unternommen haben, mehr als eine Ebene auf ein und denselben Untersuchungsgegenstand im Rahmen einer einzigen Untersuchung anzuwenden. Gleichwohl scheint sich genau dieses analytische Verfahren im Rahmen einer Themenstellung mit klarem Bezug auf einen Ausschnitt aus der kommunikativen Realität anzubieten. Im Grunde verdeckt die strikte Trennung in Disziplinen sogar den von Coseriu selbst hervorgehobenen, sehr wichtigen Aspekt des analytischen Ineinandergreifens der einzelnen abstraktiven Betrachtungen. Erst in seiner Veröffentlichung 'Sprachkompetenz', der zuletzt erschienenen Ganzschrift, macht Coseriu auf dieses Phänomen ausführlich aufmerksam.

Nachdem ich nun die drei unterscheidbaren Betrachtungsebenen des Sprechens kurz dargestellt und darauf hingewiesen habe, dass in jedem Fall das Sprechen als Tätigkeit in den Mittelpunkt gerückt wird, ist es notwendig, die von Coseriu hervorgehobenen verschiedenen Aspekte dieser Tätigkeit zu behandeln. Coseriu interpretiert das Sprechen als reine Tätigkeit im Sinne Hum-

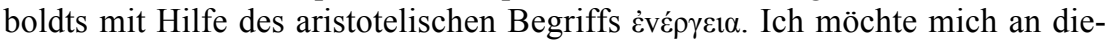
ser Stelle nicht auf die lange Diskussion der humboldtianischen Interpretation in der modernen Sprachwissenschaft einlassen. Aber es lässt sich doch feststellen, dass es in jedem Fall um einen philosophisch sehr differenzierten Tätigkeitsbegriff geht, der nur in seiner dichotomischen Verbindung zum Gegenbegriff des ह̌pyov, des auf die Tätigkeit bezogenen Produkts, zu verstehen ist. Ich

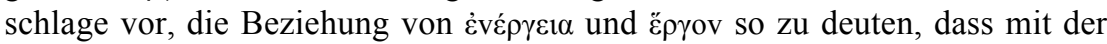

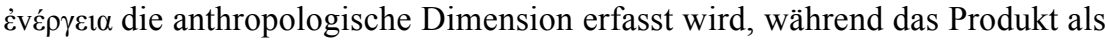
beständiges Korrelat der Tätigkeit, also das ह̌ prov, die Tätigkeit in ihrer sozialen Relevanz zum Ausdruck bringt. ${ }^{11}$ Konkret bin ich der Auffassung, dass es nur dann Sinn macht, das है $\rho \gamma o v$ sprachtheoretisch hervorzuheben, wenn man seine Realität als eine in der Sprachgemeinschaft verankerte (und nicht bloß als eine Erscheinung in der Welt) betrachtet. Als Konsequenz einer solchen Deutung kann das Sprechen auf den unterschiedlichen Betrachtungsebenen

${ }^{11}$ Selbst auf die Gefahr hin, mit dieser Deutung über Humboldt (oder Aristoteles) hinauszugehen, möchte ich in Bezug auf eine aktuell formulierte Sprachtheorie wie diejenige Coserius an dieser Interpretation festhalten. Coseriu selbst gibt aus meiner Sicht keine zufriedenstellende Erklärung des ह̌prov. 
einerseits als Sprechen eines Sprechers (des Subjekts) beurteilt werden: universell gesehen als elokutionelle Interpretation der Welt, historisch gesehen als Gebrauch der Einzelsprache (Performanz) und individuell gesehen als Diskurs; andererseits kann im Sinne der Verwirklichung eines Produkts das Sprechen dann aber auch als sozial relevantes Phänomen gemeint sein, wodurch der normative Aspekt der Tätigkeit in den Vordergrund gerückt würde, und zwar universell gesehen als sprachliche Interaktion, historisch gesehen als einzelsprachliche Verständigung und individuell gesehen als Serie von kommunikativen Redeakten.

Mir ist bewusst, dass diese Interpretation über Coserius eigene Erklärungen hinausgeht. Sie verfolgt aber den Zweck, das Produkt des Sprechens in einen sinnvollen Bezug zur Tätigkeit selbst zu bringen. Genau dies gelingt nämlich Coseriu m.E. in seinen theoretischen Ausführungen nicht. Beschäftigt man sich eingehender mit seiner Sprachtheorie und stellt sich die Frage, welchen Erklärungswert die auf den einzelnen Ebenen differenzierten 'Produkte' haben, so fällt eine Antwort zunächst schwer. Coseriu nennt als Produkte die 'Totalität der Äußerungen', die 'abstrakte Einzelsprache' (er setzt diesen Ausdruck in Klammern) und den 'Text'. Jedoch ist es nicht leicht, diese drei heterogen definierten Produkte auf die jeweilige Tätigkeit des Sprechens, also das 'Sprechen im Allgemeinen', die 'konkrete Einzelsprache' und den 'Diskurs' zu beziehen. Es erscheint mir in diesem Sinne nachvollziehbarer, die 'Totalität der Äußerungen' als das Produkt der sprachlichen Interaktion, die 'abstrakte Einzelsprache' als Produkt der einzelsprachlichen Verständigung (in Form von Regeln und Normen) und den Text als Produkt einer Serie von Redeakten zu erklären. Diese Interpretation hat meiner Meinung nach auch den Vorteil, zu erläutern, inwieweit Coserius Theorie des Sprechens an (gesellschaftlich relevanten) Normen orientiert ist und einen kommunikativen Sprachbegriff voraussetzt.

Aus diesen Darlegungen folgt, dass ich es für wichtig und nutzbringend hal-

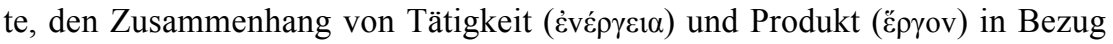
auf die soziale Determiniertheit des Sprechens zu verdeutlichen. Um dabei Coserius Theorie nicht ungewollt zu unterminieren, schlage ich zu diesem Zweck eine doppelte Ausdeutung des Sprechens als Tätigkeit vor, die zum einen 'Tätigkeit des einzelnen Sprechers' (in Anlehnung an Humboldt und im Sinne der Interpretation Coserius), zum anderen 'Tätigkeit als Kommunikation' (in einer normativen Betrachtungsweise) beinhaltet. Das 'Produkt' sehe ich dabei vorrangig als ein soziales Faktum an und begründe seinen essentiellen Zusammenhang mit der Tätigkeit aus dem interaktiven Aspekt des Sprechens. Damit ergibt sich meiner Überzeugung nach auch die Möglichkeit einer sinnvollen Einordnung des sprachlichen Wissens, das Coseriu ergänzend zu ह̌ $\rho \gamma o v$

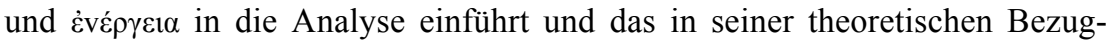




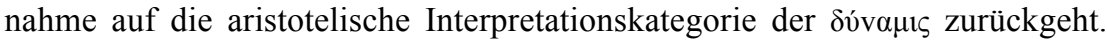
Ich möchte versuchen, diesen Wissensbegriff, der für meine Untersuchung eine erhebliche Rolle spielt, im Folgenden ein wenig näher zu erläutern.

In dem bekannten Schema zu seiner Theorie des Sprechens setzt Coseriu das Wissen zwischen Tätigkeit und Produkt (vgl. Coseriu 1988a, 75; 1988b, 254).

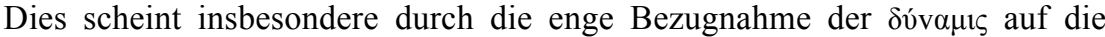

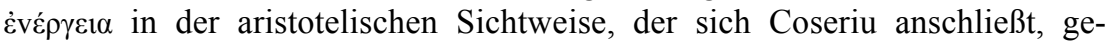
rechtfertigt zu sein ${ }^{12}$. Ich kritisiere hieran jedoch, dass Tätigkeit und Produkt auf diese Weise zu stark getrennt werden und der Eindruck entstehen könnte, das Wissen vermittle zwischen beiden ${ }^{13}$. Der Status des Wissens ist aber ein

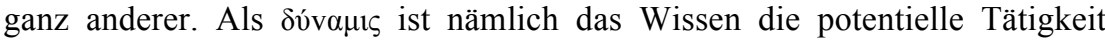
selbst und damit die unmittelbare Voraussetzung des Sprechens. Andererseits ist das Wissen in seiner Intersubjektivität - und nur als Intersubjektives kann es in der Sprachgemeinschaft Gestalt annehmen - die unmittelbare Folge des Produkts, d.h. eine Folge aus der Verwirklichung des Sprechens. Die enge Verbindung von Tätigkeit und Produkt bleibt aber in jedem Fall durch die Dimension des Wissens unberührt. Erläutern wir kurz diese Interpretation.

Coseriu selbst betrachtet das sprachliche Wissen in seiner Eigenschaft als $\delta$ $v \alpha \mu ı \varsigma$ als eine potentielle Tätigkeit des Sprechens. Damit wird das Wissen realiter nicht nur zur Voraussetzung der Tätigkeit, sondern darüber hinaus zu einer Form des technischen Wissens, d.h. zu einer Kompetenz, die der Tätigkeit in jedem Fall zugrunde liegt. Der letztlich sehr komplizierte Zusammenhang von Tätigkeit und Wissen darf dabei jedoch nicht außer Acht gelassen werden. Hierzu bemerkt Coseriu:

Diese Tätigkeit erschöpft sich nicht in der mechanischen Realisierung oder Anwen-

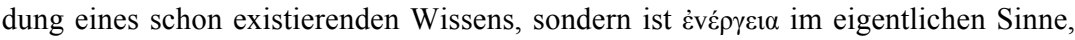
d.h. eine kreative Tätigkeit, die sich eines vorhandenen Wissens bedient, um etwas Neues zu sagen, und die neues sprachliches Wissen schaffen kann.

(Coseriu 1988a, 71)

Als technisches Wissen repräsentiert die sprachliche Kompetenz in jedem Fall eine offene, veränderbare Technik, deren Wandlungsfähigkeit ein Garant für den funktionellen Nutzen der Sprache in der Gesellschaft ist. Andererseits garantiert nur der Aspekt des Wissens die Möglichkeit einer geordneten Darstellung der Prinzipien, Strukturen und Normen des Sprechens. Dies ist wohl

${ }^{12}$ Vgl. hierzu Di Cesare 1988.

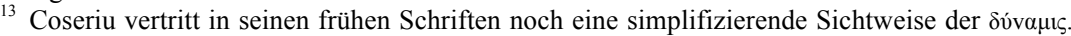
Zwar betont er bereits ihre nachgeordnete Stellung gegenüber der Tätigkeit des Sprechens

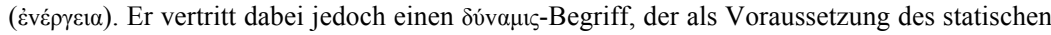

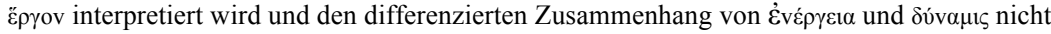
zu erkennen gibt. Vgl. hierzu Coseriu in Energeia und Ergon I, 1988, 4f. 
auch der Grund dafür, dass sich Coseriu bei seiner Darlegung der 'Grundzüge der Theorie des Sprechens' auf die Sprachkompetenz konzentriert.

In ihrem sehr profunden Beitrag zu Coserius Festschrift Energeia und Ergon diskutiert Donatella Di Cesare die Definition und gegenseitige Bezugnahme

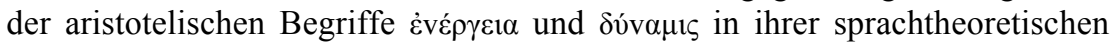
Relevanz. ${ }^{14}$ Dabei begründet sie ausführlich die aristotelische These der Priori-

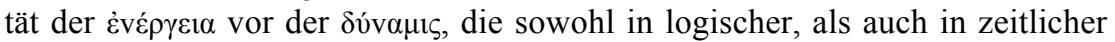
und auf das Wesen bezogener Hinsicht gilt (vgl. S. 36f.) Auf die Sprache übertragen lässt sich diese These dahingehend formulieren, dass die Potentialität

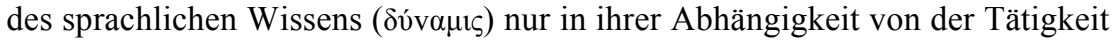
des Sprechens als der tatsächlichen Manifestation von Sprache begriffen werden kann. Wie aber sollte diese Manifestation von Sprache zu einem Wissen für die Sprecher werden, wenn nicht über die Vermittlung des Produktiven, d.h. der faktischen Verwirklichung des Sprechens. Diese faktische Verwirklichung des Sprechens lässt sich nun unterschiedlich deuten: als primär reflexiver Akt im Sinne einer Formalisierung der erfahrenen Welt, so wie es der Sprachauffassung Humboldts entspricht ${ }^{15}$, oder als primär kommunikativer Akt im Sinne einer Form sozialer Interaktion, deren Ergebnis die 'Produkte' der sprachlichen Äußerungen (auf universeller Ebene), der durch Regeln und Normen bestimmten Einzelsprachen (auf historischer Ebene) und der als Texte

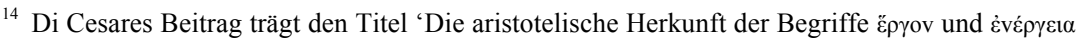
in Wilhelm von Humboldts Sprachphilosophie'. De facto behandelt aber der Beitrag im We-

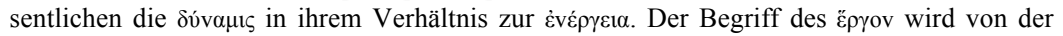
Autorin, die sich selbst darüber nicht im Klaren zu sein scheint (vgl. S. 42, Anm. 62), in keiner Weise näher definiert. Sie fasst ihn, in Übereinstimmung mit der gängigen Rezeption des Humboldtschen Satzes, die Sprache sei 'kein Werk, sondern eine Tätigkeit', nur als negativ zu bestimmenden Terminus auf, dessen primäre Funktion es zu sein scheint, auf die inadäquate Möglichkeit einer statischen (d.h. nicht dynamischen) Sprachauffassung hinzuweisen: „Wenn die Sprache ein ह̋ $\rho \gamma o v$ wäre, [...] wenn der Vorgang der sprachlichen Erzeugung sich in seinem äußeren Werk vollendet hätte, so wie der Vorgang des Bauens sich in einem erbauten Haus vollendet, dann wäre die sprachliche Erzeugung nicht weiter fortzusetzen. Das Individuum würde die Sprache als ihm fremdes Erzeugnis erleiden, und würde deshalb nur das schon Geformte annehmen" (S. 41). Die Produkte des Sprechens, die Coseriu in seiner theoretischen Differenzierung nennt, die 'Totalität der Äußerungen', die abstrakte Einzelsprache und der Text, sind aber m.E. keine 'fremden Erzeugnisse, die das Individuum erleidet' und die es in seiner sprachlichen Kreativität blockieren, sondern die essentiell wichtigen und einzig faktischen gesellschaftlichen Voraussetzungen seiner Befähigung zum Sprechen überhaupt. Andererseits kann auch aus der aristotelischen Argumentation heraus, die Di Cesare überzeugend darlegt, nicht sinnvollerweise behauptet werden, dass das negativ definierte

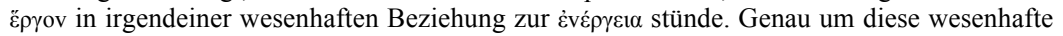
dichotomische Beziehung geht es aber in der aristotelischen Philosophie.

15 Vgl. Humboldt 1972, III, 13: „Das Wesen der Sprache besteht darin, die Materie der Erscheinungswelt in die Form der Gedanken zu gießen; ihr ganzes Streben ist formal, und da die Wörter die Stelle der Gegenstände vertreten, so muss auch ihnen, als Materie, eine Form entgegenstehen, welcher sie unterworfen werden." Siehe auch: Di Cesare 1988, 39. 
realisierten Diskurse (auf individueller Ebene) sind. Allein ein solches Verständnis des ह̋ $\rho \gamma o v$ als soziales Produkt und sein Bezug auf eine normativ aus-

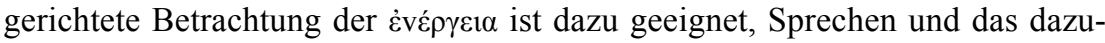
gehörige Wissen in eine sinnvolle Verbindung miteinander zu bringen. Denn die Sprache manifestiert sich als Sprechen immer in einer gesellschaftlich relevanten Form, und sie kann ohne einen Bezug zu ihrer gesellschaftlichen Realität auch nicht als strukturiertes oder normiertes Wissen beschrieben werden. Alle Ebenen der Sprachbetrachtung setzen in diesem Sinne nicht nur die Anerkennung der reflexiven, sondern auch die der kommunikativen Funktion von Sprache voraus.

Das folgende Schema fasst meine erweiterte Interpretation des Ansatzes von Coseriu zusammen. Es soll darauf hinweisen, dass das Verständnis von Sprache als Kommunikation (Interaktion) auch für Coserius Theorie des Sprechens konstitutiv ist. Die Betonung dieses Aspekts ist als theoretischer Hintergrund für die Schwerpunktsetzung meiner Untersuchung von besonderem Interesse. Es wird sich nämlich zeigen, dass das nach Schichten spezifizierbare Wissen der Sprecher sehr stark an Normen gebunden ist, die sich im Sprechen selbst manifestieren. Das normativ geprägte Sprechen führt in diesem Sinne zu einer sprachlichen Produktion, von der eine dynamische Rückwirkung auf das Wissen der Sprecher, d.h. ihre Sprachkompetenz, ausgeht. Diese Dynamik des Sprachgebrauchs ist aber aus der statischen Konzeption des ह̌pyov nicht abzuleiten, sondern hängt wesentlich von der engen Beziehung zwischen der interaktiven Tätigkeit des Sprechens und der sozialen Realisation von Texten ab. ${ }^{16}$

${ }^{16}$ Ich hebe hier den 'Text' als Produkt des Sprechens hervor, weil er in empirischer Hinsicht die einzig verifizierbare Form der Produktivität des Sprechens ist. 

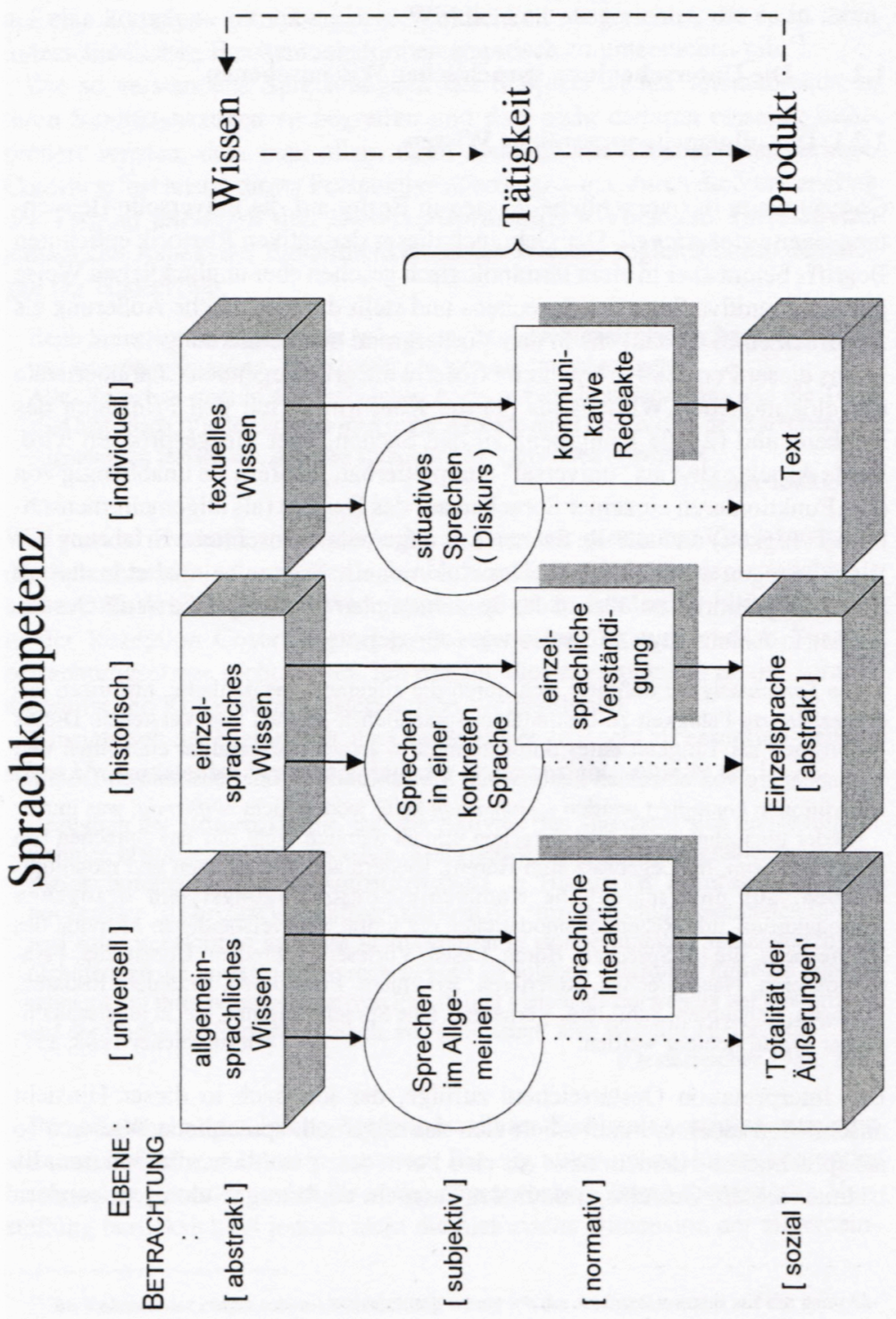


\subsection{Die Unterscheidung sprachlicher Wissensebenen}

\subsubsection{Das allgemein-sprachliche Wissen}

Coseriu nennt das sprachliche Wissen in Bezug auf die universelle Betrachtungsebene elokutionell. Der Gebrauch dieses der antiken Rhetorik entlehnten Begriffs betont aber in einer terminologisch gesehen eher unglücklichen Weise nur die kognitive Seite des Sprechens und stellt die sprachliche Äußerung als Ausdruck eines Gedankens in den Vordergrund der Betrachtung.

Aus dieser Perspektive beschreibt Coseriu die grundlegenden Charakteristika des elokutionellen Wissens als (1) die Konformität mit den Prinzipien des Denkens und (2) die Kongruenz zu den Sachen, über die gesprochen wird. Beide Aspekte sind als , universal' interpretierbar, insofern sie unabhängig von dem Funktionieren einzelner Sprachen auf das Denken (als allgemeinmenschliche Fähigkeit) und auf die Sachen (als allgemein-menschliche Erfahrung der Welt) bezogen werden können. Das elokutionelle Wissen beinhaltet in diesem Sinne ein potentielles Wissen der Sprechtätigkeit überhaupt, die Wulf Oesterreicher in Anlehnung an Coseriu wie folgt definiert:

Die Sprechtätigkeit definiert sich durch die allgemein menschliche, historisch unspezifizierte Fähigkeit zu bestimmtem sprachlichen Meinen und Verstehen. Dieses Sprechen als Tätigkeit eines Subjekts muss in seiner Universalität einheitlich und unabhängig von einzelnen historischen Sprachtechniken oder bestimmten Diskurstraditionen konzipiert werden - einheitlich heißt jedoch nicht einförmig, was immer wieder übersehen wird. Das Sprechen umfasst nämlich nicht nur das Sprechen (im engeren Sinn, im Gegensatz zum Hören), sondern alle dialogischen und monologischen, auf unterschiedliche Kommunikationsbedingungstypen bezogenen Produktions- und Rezeptionsmodalitäten der umfassend verstandenen Aktivität des Sprechens, die im Sprechen, Hören, Lesen, Vorlesen, Schreiben, Übersetzen, Paraphrasieren, Nachsprechen, Referieren, Benennen, Prädizieren, Erzählen, Erklären, Fragen, Behaupten, Schildern, Verneinen, eine Sprache erlernen, etc. in unterschiedlicher Weise sichtbar werden.

(Oesterreicher 1988, 357)

Der Interpretation Oesterreichers zufolge, der ich mich in dieser Hinsicht anschließen möchte, manifestiert sich das allgemein-sprachliche Wissen also als sprachliches Handeln bzw. als eine Form der sprachlichen Interaktion. Es ist unter diesem Gesichtspunkt in der Tat nicht einförmig strukturiert, sondern auf eine komplexe kommunikative Wirklichkeit ausgerichtet, die es in ihren unterschiedlichen Erscheinungsformen empirisch zu untersuchen gilt. ${ }^{17}$

${ }^{17}$ Im Rahmen der empirischen Untersuchung werde ich die Aufmerksamkeit auf die sprachlichen 'Produktionsmodalitäten' des Benennens und Erklärens konzentrieren. 
Die so verstandene Sprechtätigkeit des Subjekts ist nur intersubjektiv in ihren Realitätsbezügen zu begreifen und darf nicht dadurch einseitig interpretiert werden, dass man allein ihren einheitlichen Charakter hervorhebt. Coseriu selbst leistet dieser Perspektive allerdings - u.a. durch die Verwendung der Termini universell und übereinzelsprachlich - Vorschub. Er relativiert jedoch den Aspekt der Einheitlichkeit dieses Wissens sogleich durch denjenigen der Historizität:

Beim Sprechen im allgemeinen geht es um das Übereinzelsprachliche, d.h. um das, was zu jedem Sprechen - gleichgültig in welcher Sprache - gehört.

Alles Sprechen steht in der Geschichte. Nicht nur die Einzelsprachen und die Texte sind historisch. Vielleicht kann man sogar Aspekte einer Geschichte des Sprechens im allgemeinen feststellen, d.h. des sprachlichen Verhaltens überhaupt.

(Coseriu 1988a, 76)

Will man es vermeiden, zwischen den beiden hier genannten Charakteristika des Sprechens im Allgemeinen - der Universalität (Übereinzelsprachlichkeit) und der Historizität - einen Widerspruch sehen zu müssen, so hilft einem die in der Rezeption Coserius gängige Interpretation der universellen Sprachbetrachtungsebene nicht weiter. Ich möchte dies exemplarisch an der sprachtheoretischen Konzeption Oesterreichers verdeutlichen.

Hinsichtlich der Historizität, die Oesterreicher zu Recht als essentiellgenerisches Universale des Sprechens in jeder Form ansieht, schreibt er:

Bezüglich der Historizität gilt, dass die Aktivität des Sprechens sich notwendig im Rahmen historischer Einzelsprachen, historisch-sozietätischer Intersubjektivität und soziokultureller Wirklichkeit vollziehen muss [...]: 'Historizität' meint also gerade die notwendige Historizität und Differenziertheit der einzelsprachlich gestalteten Inhalte und Ausdrucksformen und ihre Manifestation in sinnbestimmten Sprachvollzügen, nicht jedoch die Struktur der Sprechtätigkeit als solcher. Allerdings führt die Sprechtätigkeit mit ihrer reflexiv-kreativen Flexibilität gleichsam notwendig zur Historizität auf der Ebene der Sprachtechniken, sie 'produziert' also förmlich Historizität.

(Oesterreicher 1988, 366)

Die allgemein-sprachliche Schicht ist dieser Sichtweise zufolge eine rein wissenschaftliche Abstraktionsebene. Ein als autonom zu interpretierender historischer Charakter wird ihr völlig abgesprochen. Diese theoretische Vorstellung berücksichtigt jedoch nicht die historische Dimension der allgemeinsprachlichen Schicht, die Coseriu postuliert und die ihn dazu führt, das entsprechende Wissen als ein konkretes (und bisweilen in kommunikativen Situationen bekundetes) Wissen der Sprecher selbst zu identifizieren. Wir können nämlich davon ausgehen, dass ein Sprecher ohne sprachwissenschaftliche Kenntnisse nichts von der Universalität der von ihm geäußerten oder rezipier- 
ten Redeakte weiß. Er wird sich beispielsweise kaum darüber Gedanken machen und schon gar nicht darauf reagieren, welche Form der Referentialisierung einen Diskurs auszeichnet, welche kommunikativen Produktionsmodalitäten den Diskurs veranlasst haben und auf welcher Kongruenz basierend dieser die sprachliche Ordnung eines Weltausschnitts impliziert. All dies sind universale Fragestellungen, die selbst unter Linguisten nur wenig Beachtung finden und die analytische Signifikanz der universellen Betrachtungsebene erheblich einschränken. Wenn Coseriu dennoch eine Linguistik des Sprechens auf dieser Ebene ansiedeln will, so geht es ihm daher nicht allein um den Aspekt des Übereinzelsprachlichen im Sinne eines methodischen Ansatzes der Universalienforschung zur Beschreibung der Sprachwirklichkeit. Neben den universalistischen Interpretationen richtet sich seine Aufmerksamkeit nämlich auf eine Struktur des Sprechens, die dadurch als übereinzelsprachlich (bzw. voreinzelsprachlich) zu qualifizieren ist, dass sie sich weder an den Strukturen einer Einzelsprache noch an denen des Textes ausrichtet.

Mit dieser Vorstellung geht Coseriu weit über den Ansatz einer universalistischen Sprachbetrachtung hinaus. Ihm geht es darum, an der Sprache bzw. am Sprechen all das zu erkennen und zu untersuchen, was zwar genuin sprachlich ist, aber weder durch das Besondere der Einzelsprache noch durch die Besonderheit des Textes in der Einzelsprache determiniert wird. Auch dieser analytische Bereich des Sprechens im Allgemeinen kann aber nur im konkreten Vollzug des Sprechens beobachtet und beschrieben werden. Das Wissen von dieser Sprechtätigkeit wird nur im Sprechen selbst manifest. Wendet man die Kon-

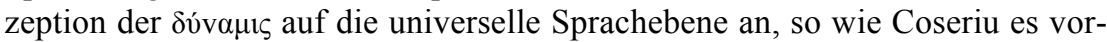
schlägt, dann gibt es keine andere Möglichkeit, als das Universelle im Sprechen des Subjekts bzw. in der konkreten Form seiner sprachlichen Interaktion zu suchen. Methodisch gesehen liegt das Universelle dann in der Frage, welche kognitiven Strukturen, die der Sprecher zum Ausdruck bringt, mit welchen sprachexternen Realitäten seiner Erfahrungswelt so in Verbindung gebracht werden, dass daraus der interindividuelle Gebrauch von Sprache (und damit auch die Möglichkeit des sinnvollen Sprachgebrauchs) entsteht. Auf die Tatsache, dass es Muster und Normen dieser sprachkonstitutiven Verbindung gibt, weist Coseriu anhand einiger Beispiele konkret hin (vgl. Coseriu 1988a, 89 ff.). Er weist damit den Weg in ein weites Untersuchungsfeld der Linguistik (genauer: einer Linguistik des Sprechens), das eine empirische Methodik erfordert und noch kaum bearbeitet worden ist. Ich werde versuchen, im Rahmen meiner Untersuchung hier erste Schritte zu tun.

Die empirische Verifikation der allgemein-sprachlichen Schicht des Sprechens sieht Coseriu in der Existenz von Urteilen 'naiver' Sprecher gegeben:

Diese Urteile beziehen sich darauf, ob das Sprechen den üblichen normalen Erwartungen jeweils entspricht. Ein Sprechen, das auf dieser Ebene nichts Negatives oder 
Mangelhaftes aufweist, d.h. das den zu erwartenden Normen entspricht, wird als klar, kohärent, kongruent beurteilt: es erreicht den Nullwert der bloßen Entsprechung. Wir wählen als Fachausdruck für die Gesamtheit dieser Urteile, die sich auf das Sprechen in jeder Sprache beziehen, den Terminus 'kongruent'.

(Coseriu 1988a, 77)

Zur Illustration der Tatsache, dass man zwar einzelsprachlich korrekt sprechen, dabei aber durchaus gegen die Strukturen und Normen der allgemeinsprachlichen Schicht verstoßen kann, wählt Coseriu (1988a, 90) u.a. folgendes Beispiel:

Die fünf Erdteile sind vier: Europa, Asien und Afrika.

Das Beispiel zeigt sehr schön, dass in dieser sprachlichen Äußerung gleich von mehreren Kongruenzen abgewichen wird, und zwar sowohl in Bezug auf den kognitiven Gehalt der Aussage als auch hinsichtlich ihrer sachlichen Behauptung. Im Einzelnen:

(1) Unsere mathematisch-logische Interpretationsfähigkeit erlaubt keine Gleichung $5=4$.

(2) Eine Aufzählung von drei Dingen entspricht quantitativ weder der Zahl 5 noch der Zahl 4.

(3) Bei der Auflistung der fünf Erdteile, um die es in dieser Aussage geht, fehlen Amerika und Australien (Ozeanien).

Diese Inkongruenzen der sprachlichen Aussage wird ein Rezipient (Hörer, Leser) sofort erkennen und als Normverstöße werten. Seine Reaktion beruht auf einer Erwartungshaltung, mit der er im Normalfall eine Entsprechung zwischen sprachlicher Aussage und Wirklichkeit fordert. Dabei ist der Wirklichkeitsbegriff in keiner Weise sprachlich determiniert, sondern ausschließlich auf die Denkinhalte, Denkformen und Sachbezüge bezogen. Es ist Coserius Verdienst, mit der Forderung einer Linguistik des Sprechens darauf hingewiesen zu haben, dass diese Bezüge zur außersprachlichen Wirklichkeit beim Sprechen ebenfalls sprachlicher Natur sind, dabei aber prinzipiell unabhängig von den einzelsprachlichen Strukturen und der situativen Sprachverwendung interpretiert werden müssen.

Auf der allgemein-sprachlichen Ebene stellt sich der Gehalt des Sprechens in einer referentiellen Form dar. Dies entspricht der semiotischen Funktion von Sprache, denn Sprache bedeutet letztlich immer etwas, das sie selbst nicht ist. Der Inhalt des Sprechens im Allgemeinen ist für Coseriu dementsprechend auch nichts anderes als die 'Bezeichnung' in ihrer Unterscheidbarkeit von 'Bedeutung' und 'Sinn':

Die Bezeichnung, die auf der allgemein-sprachlichen Ebene anzusiedeln ist, ist die Beziehung zu außersprachlichen Gegenständen oder zur außersprachlichen 'Wirk- 
lichkeit', seien es nun die Sachverhalte selbst oder die entsprechenden Gedankeninhalte.

Die Bedeutung, die der einzelsprachlichen Ebene entspricht, ist der sprachlich gegebene Inhalt in einer Einzelsprache, d.h. die besondere Gestaltung der Bezeichnung in einer bestimmten Sprache.

Der Sinn, der auf der Ebene des Diskurses übermittelt wird, ist das mit dem Sagen 'Gemeinte', d.h. der besondere sprachliche Inhalt, der mittels der Bezeichnung und der Bedeutung ausgedrückt wird, der aber in einem individuellen Diskurs über beide hinausgeht und den Einstellungen, Absichten und Annahmen des Sprechers entspricht.

(Coseriu 1988a, 79)

In meiner Untersuchung zum regionalen Sprachgebrauch in Fachkontexten spielt die Inhaltsebene der Bezeichnung eine ganz besonders wichtige Rolle. In der Bezeichnung spiegelt sich nämlich der sprachliche Bezug auf die Sachverhalte wider, die durch das Fach und die mit ihm verbundene Lebensrealität in der Region gegeben sind. Darüber hinaus ergeben sich aus der Einbindung der Sprecher in die fachlichen Kontexte gedankliche Referenzen in Form von Reflexionen über das Fach und seine Bedeutung für das regionale Leben bzw. auch für das Leben des Einzelnen, der durch das Fach mehr oder minder betroffen ist. Der sprachliche Umgang mit den fachlichen Inhalten verweist schließlich auf die reflexive Durchdringung des Fachs selbst und damit auf das Verhältnis von adäquater Sachkenntnis und einer auf die Lebensumstände bezogenen Interpretation. Auf diese Weise gestaltet sich die Inhaltsebene der Bezeichnung gerade im Rahmen meiner Untersuchung als ein komplexer Interpretationsbereich, dessen analytische Durchdringung Aufschluss darüber zu geben vermag, welche Funktion das in einen fachlichen Sektor eingebundene Sprechen für das gesellschaftliche Zusammenleben in der Region bekommt und wie dieses auf den Sprachgebrauch zurückwirkt. Damit wären wir aber wieder bei dem historischen Moment des Sprechens im Allgemeinen angelangt, auf das Coseriu so großen Wert legt.

Die universellen Aspekte der Interpretation der allgemein-sprachlichen Schicht ergeben sich in meiner Untersuchung aus der Beurteilung des engen Zusammenhangs von sprachlicher Produktion (bzw. Kommunikation), Sachbereichsbindung (kontextuelle Determination) und fachlichem Wissen (Sachadäquatheit). Ich werde an späterer Stelle noch genauer darauf eingehen, dass dieser Zusammenhang im Wesentlichen über soziale Normen hergestellt wird. Der theoretische Ansatz ist dabei in unserem Fall die Eruierung und Analyse essentieller Aspekte des sprachlich manifestierten Fachwissens. Dabei erscheint es mir methodisch von großer Wichtigkeit, diese Aspekte, die ich in den Kapiteln 2.3. und 2.4. differenziert darlegen werde, aus der Betrachtung der empirisch ermittelten Diskurse abzuleiten. Denn nur ein methodisches Vorgehen, das von der Tätigkeit des Sprechens selbst ausgeht, kann zu adäquaten Erkenntnissen darüber führen, 'was ein Sprecher wirklich tut'. Der 
tatsächliche Zusammenhang von Regionalität und Fachlichkeit lässt sich daher in Bezug auf das sektorielle Sprechen in einer Region m.E. nur aus der Analyse beispielhafter Diskurse ermitteln.

Es ist für meinen Zweck also besonders wichtig, eine Methodik zu entwickeln, die die Prinzipien einer Theorie des Sprechens im Allgemeinen, so wie Coseriu sie propagiert, auf den Untersuchungsgegenstand anwendet. Die Schwierigkeit dieses methodischen Vorgehens liegt jedoch darin, dass eine solche Theorie des Sprechens noch gar nicht existiert, sondern bislang nur von Coseriu in ihrer Zielsetzung näher bestimmt und exemplifiziert worden ist. Ich halte mich daher in methodischer Hinsicht im Rahmen dieser Untersuchung zunächst an Coserius eigenen Ratschlag:

Solange wir eine Linguistik des Sprechens im allgemeinen noch nicht haben, müssen wir stets bedacht sein, bei der Betrachtung der Sprachen uns zu fragen, ob eine bestimmte Norm tatsächlich Norm dieser Sprache ist, ob sie wirklich die Gestaltung des Denkens und der außersprachlichen Wirklichkeit durch diese Sprache betrifft, oder ob sie zu der allgemein-sprachlichen Kompetenz gehört, und für jedes Sprechen in jeder Sprache grundsätzlich gelten könnte, wenn sie nicht in dieser oder jener Sprache durch die einzelsprachliche Tradition aufgehoben ist. (Coseriu 1988a, 128)

Die Normen, die mich am regionalen Sprachgebrauch in Fachkontexten in der Hauptsache interessieren, sind - theoretisch gesehen - tatsächlich weitgehend unabhängig von der einzelsprachlichen Konstitution des Sprechens, ja sie werden sogar von mir jeweils vergleichend in Bezug auf die beiden verschiedenen historischen Sprachen, die in der Region gebräuchlich sind, untersucht. Andererseits sind das zu ermittelnde allgemein-sprachliche Wissen und seine Verwirklichung im konkreten Sprechen stets mit der Kompetenz in einer (oder zwei) historischen Sprachen aufs Engste verbunden und lassen sich auch nur auf der Ebene individueller Textproduktionen in den Einzelsprachen eruieren. Ich sehe es daher als notwendig und unverzichtbar an, auch die anderen beiden Schichten des Sprechens nach Coseriu, die idiomatische und die textuelle, in meine Untersuchung mit einzubeziehen.

\subsubsection{Das einzelsprachliche Wissen}

Viele Missverständnisse, die mit dem Postulat eines funktionalen Strukturalismus in der Sprachwissenschaft in Verbindung stehen, könnten vermieden werden, wenn die Gesamtstruktur des einzelsprachlichen Wissens nicht, wie es oft den Anschein hat, von den Kritikern und bisweilen auch von den Strukturalisten selbst aus den Augen verloren würde. Die schon von Beginn an erfolgte Argumentation Coserius, derzufolge der sprachwissenschaftliche Strukturalismus viele Bereiche sprachlicher Realität methodisch ausgrenzen 
muss, um zu seinem eigentlichen Untersuchungsobjekt, der funktionellen Sprache, zu gelangen, hat in diesem Sinne nicht nur segensreich gewirkt. In einer simplifizierenden Rezeption dieses methodologischen Ansatzes ist häufig übersehen worden, in welch komplexe Struktur des einzelsprachlichen Wissens die funktionelle Sprache auf einer niedrigeren Abstraktionsebene grundsätzlich eingebunden ist. ${ }^{18}$ Coserius Funktionalismus grenzt nur das aus der Betrachtung des Sprechens einer Einzelsprache aus, von dem feststeht, dass es eigentlich, d.h. unter Verzicht auf die methodische Abstraktion, dazugehört. Ich möchte daher einmal den umgekehrten Weg gehen und aufzeigen, was alles die Schicht des einzelsprachlichen Sprechens konstituiert. Zu diesem Zweck greife ich auf ein älteres Schaubild zurück, in dem Coseriu die Sprache als 'realen Gegenstand' insgesamt analysiert. Es findet sich ursprünglich in dem 1972 erschienenen Aufsatz 'Sobre el desarrollo de la lingüística', wird hier aber in der 1988 publizierten deutschen Fassung wiedergegeben:
A) Biologische Ebene: Sprachvermögen (Fähigkeit zu sprechen)
B) Kulturelle Ebene: Sprachkenntnis (Wissen, wie man spricht)
a) elokutionelles Wissen
b) idiomatisches Wissen

1. außersprachliches idiomatisches Wissen

2. 'textgebundenes' idiomatisches Wissen

3. 'Sprache' im strengen Sinne
aa) Dialekte
bb) Sprachniveaus
cc) Sprachstile

c) expressives Wissen

(Coseriu in Energeia und Ergon I, 378)

Auf die Tatsache, dass Coserius Sprachbegriff kulturell ist, habe ich bereits hingewiesen. Erst auf der kulturellen Ebene kann die Fähigkeit zu sprechen als (tradierbares) Wissen interpretiert werden. $\mathrm{Zu}$ der Sprachkompetenz in ihrer Gesamtheit gehört aber auch die physiologisch und psychisch bedingte Befähigung zum Sprechen, die Coseriu der biologischen Ebene zuweist. ${ }^{19}$ Die Un-

${ }^{18}$ Es ist daher falsch, den Vorwurf zu erheben, Coseriu klammere viele Aspekte der sprachlichen Realität aus der strukturalistischen Betrachtung aus, weil sie nicht für das Sprechen einer Einzelsprache konstitutiv seien. Seine methodischen Abstraktionen sind vielmehr eine Folge der uneingeschränkten Anerkennung der einzelsprachlichen Komplexität und stellen den Versuch dar, die sprachwissenschaftliche Analyse auf einen genau bestimmten Untersuchungsgegenstand, den der funktionellen Strukturen einer Einzelsprache, einzuschränken. Aus dem Blickwinkel der sprachtheoretischen Grundüberzeugungen Coserius kann dies aber nur ein bescheidener Anfang auf dem Weg zu einer umfassenden Analyse menschlichen Sprechens sein.

${ }^{19}$ Vgl. hierzu Coseriu 1988a, 68 f. Der biologische Aspekt des Sprechens wird in Coserius Theorie nicht weiter verfolgt. Eine grundlegende Darstellung zu diesem Gebiet ist die informative Dissertation von Beate Marquardt mit dem Titel Die Sprache des Menschen und ihre 
terscheidung von elokutionellem, idiomatischem und expressivem Wissen ist demgegenüber eine Binnendifferenzierung des kulturellen Wissens, das in jedem Fall historisch ist, d.h. in Traditionen steht und einer sozialen Realität entspricht. Die universellen Aspekte des elokutionellen Wissens, die Formalisierbarkeit des idiomatischen Wissens und die Situationsgebundenheit des expressiven Wissens ändern nichts an dieser Historizität, die ein wesentliches Charakteristikum aller drei Wissensformen ist.

Insgesamt vertritt Coseriu damit eine Vorstellung von der Sprachkompetenz, die diese nur in einem sehr geringen Maß als formalisierbar kennzeichnet. In der Tat existiert die Formalisierungsstufe, die Coseriu im Rahmen seines sprachwissenschaftlichen Funktionalismus als strukturell bestimmt, nicht auf den Ebenen des elokutionellen und des expressiven Wissens. Aber auch auf der Ebene des idiomatischen Wissens kann zunächst einmal nicht von der Existenz oder Wirksamkeit struktureller Funktionen ausgegangen werden. Weder das außersprachliche idiomatische Wissen noch das 'textgebundene' idiomatische Wissen, auf deren Charakter ich im Folgenden noch kurz eingehen werde, sind in diesem Sinne strukturell beschreibbar. Nicht einmal die 'Sprache' im strengen Sinne, wie Coseriu sich ausdrückt, ist ausschließlich strukturell nach den Prinzipien des sprachwissenschaftlichen Funktionalismus (weshalb Coseriu hier wohl auch nicht von 'funktionellem idiomatischen Wissen' spricht). Um auf die Ebene des einzelsprachlichen Wissens bis zu einer strukturellen Beschreibung vorzudringen, muss nämlich zunächst das Phänomen innersprachlicher Heterogenität (Coseriu spricht von Sprachvarietät) und die Normativität des historischen Sprechens methodisch überwunden werden. Funktionelle Strukturen sind nur durch Abstraktion von der Architektur der Einzelsprache zu ermitteln und sie sind auch dann noch in der sozialen Realität einer umfassenderen einzelsprachlichen Norm aufgehoben. ${ }^{20}$

Es lässt sich m.E. nur aus den gegebenen rezeptionsgeschichtlichen bzw. historiographischen Zusammenhängen heraus erklären, dass Coserius Sprachbegriff oft einseitig als strukturalistisch bzw. funktionalistisch interpretiert worden ist. ${ }^{21}$ Hingegen ist meines Wissens noch nicht der eigentlich naheliegende Versuch unternommen worden, Coserius gesamte Sprachkonzeption als

biologischen Voraussetzungen (Tübingen: Narr 1984).

${ }^{20}$ Vgl. hierzu den Zusammenhang von System und Norm, z.B. in Coseriu 1988a, $298 \mathrm{f}$.

${ }^{21}$ Ich gebe zur Illustration dieser schwierigen Rezeption Coserius hier zwei Zitate aus den einleitenden Beiträgen zu Coserius Festschrift Energeia und Ergon wieder, zunächst von Jörn Albrecht, dann von Hans Helmut Christmann: „Nur wirklich gut informierte Beobachter der Szene, wie z.B. Kurt Baldinger und Hans Helmut Christmann, haben frühzeitig gesehen, daß Coseriu zwar ein guter Kenner, aber keineswegs ein vorbehaltloser Anhänger des Strukturalismus ist [...]“ (XXXVIII). „Im Licht eines humboldtianischen Strukturalismus, wie wir Coserius Lehre nennen können, erscheint Sprechen als freie kreative Tätigkeit und erscheint die Einzelsprache als offenes System bzw. als offene Technik“ (XIII). 
Ausdruck einer normativen Sprachbetrachtung aufzufassen. ${ }^{22}$ Ich bin der festen Überzeugung, dass Coseriu den Normbegriff als wesentliches Element in sein analytisches Grundverständnis der sprachlichen Realität integriert und auf alle Ebenen der Sprachbetrachtung anwendet. Insbesondere lässt sich zeigen, dass ein normatives Sprachverständnis auch für alle Aspekte des einzelsprachlichen Wissens konstitutiv ist. Ich gehe sogar noch weiter und möchte behaupten, dass die sprachlichen Normen als Ausdruck der sprachlichen Realität bzw. als Manifestation des Sprechens in jeder Form und in Bezug auf jede Abstraktion in Coserius Konzeption der einzige empirische Ansatzpunkt der Sprachbeschreibung sein können. Damit baue ich keinen Widerspruch zu der analytischen Vorstellung auf, dass das Funktionieren einer Einzelsprache durch Strukturen geprägt ist, die es innerhalb der normativen (d.h. sozialen) Realität des Sprechens zu erkennen und darzustellen bzw. zu beschreiben gilt. Ich möchte vielmehr darauf hinweisen, dass eine sprachwissenschaftliche Untersuchung, in der es um andere analytische Dimensionen als die sprachlicher Strukturiertheit geht, notwendigerweise zunächst von einer funktionalistischen Sprachbetrachtung zu lassen hat und ihr Erkenntnisinteresse auf die Existenz der Normierung des Sprechens auf allen Ebenen konzentrieren muss. Die Homogenität des Sprachbegriffs, die nicht mit der Vorstellung einer Homogenität der Sprache selbst zu verwechseln ist, erfordert es, die Suche nach sprachlichen Normen in den Vordergrund zu stellen und dabei die Formalisierungsmöglichkeiten der Sprachbeschreibung nicht aus den Augen zu verlieren. Ich möchte versuchen, zu dieser spezifischen Sichtweise im Folgenden einige Präzisierungen zu geben. Dazu wende ich mich den unterschiedlichen Aspekten des idiomatischen Wissens im Sinne des weiter oben wiedergegebenen Schemas zu und versuche, diese in den Kontext des besonderen Untersuchungsgegenstands dieser Arbeit zu stellen.

Das außersprachliche idiomatische Wissen charakterisiert Coseriu als „die traditionelle allgemeine Kenntnis der 'Sachen', die auch die traditionellen Vorstellungen von und Einstellungen gegenüber diesen Sachen einschließt"

${ }^{22}$ Einen ersten Ansatz zu dieser Sichtweise kann man dem Beitrag von Luis Fernando Lara (1983) zum Normbegriff in Coserius Sprachtheorie entnehmen. Lara weist darauf hin, dass dem Aspekt der Norm nicht nur in Coserius linguistischem Modell eine zentrale Bedeutung zukommt, sondern auch aus der Perspektive seiner Sprachtheorie. Der sprachtheoretische (d.h. nicht strukturalistische) Normbegriff aber ist grundsätzlich nicht formalistisch zu bestimmen, da er an der Tätigkeit des sprechenden Subjekts und nicht an der Beschreibung des abstrakten linguistischen Modells ansetzt: „Par conséquent, il est permis de conclure que la norme est la même tant du point de vue descriptif que sur le plan de ce qui vient à l'esprit de l'individu; la différence réside non pas dans l'objet d'étude mais bien dans le genre d'analyse qu'il est possible d'en faire: l'analyse descriptive se fait 'en étendu' tandis que l'analyse psychologique s'effectue 'en profondeur': [...] “ (Lara 1983, 168 f.). Ich werde auf diese Zusammenhänge in Kapitel 2.6 noch näher eingehen. 
(Coseriu in Energeia und Ergon I, 378). Die Relevanz dieses Wissensbereichs für eine Untersuchung des regionalen Sprachgebrauchs in Fachkontexten ist grundsätzlich einsichtig und wird im Laufe meiner Darlegungen noch verschiedentlich zur Sprache kommen. In diesem Zusammenhang soll aber die Frage aufgeworfen werden, ob es sich tatsächlich um einen Bereich des einzelsprachlichen Wissens handelt oder ob dieses Wissen nicht im Sinne der Ausführungen des vorangegangenen Kapitels als elokutionelles Wissen zu charakterisieren ist. Hierzu ist zunächst zu bemerken, dass Coseriu die Zuordnung dieses Wissensbereichs zur Einzelsprache in späteren Publikationen nicht mehr so explizit wie in dem Schema von 1972 vornimmt. Allerdings bedeutet das nicht, dass er von dieser Zuordnung prinzipiell Abstand nimmt. Es handelt sich nämlich mehr um eine interpretatorische Verlagerung innerhalb der analytischen Gesamtkonzeption, die mit einem veränderten Verständnis der universellen Sprachbetrachtungsebene zusammenhängt. Das was Coseriu in seiner 1988 erschienenen Schrift Sprachkompetenz zum allgemein-sprachlichen Wissen an Erläuterungen und Beispielen gibt, zeigt sehr deutlich, in welch enger Verbindung dieser Wissensbereich zum Bereich des einzelsprachlichen Wissens steht.

Auf der Ebene des allgemein-sprachlichen Wissens wird das Sprechen mit der Kenntnis der Prinzipien des Denkens und der allgemeinen Kenntnis der Sachen in Zusammenhang gebracht. Die Sprecher setzen dabei in der Regel jeweils das in der Sprachgemeinschaft Normale als gegeben voraus. Der Aspekt der außersprachlichen Normalität gewinnt aber auch in einem direkten Bezug auf die Interpretation einzelsprachlicher Strukturen an Bedeutung. Beispielhaft lässt sich hier der Bereich der Wortbildung anführen, in dem es immer wieder um die referentielle Präzisierung der Inhalte von Wortbildungsprodukten geht, so dass die Grenze zwischen Bedeutung und Bezeichnung oft schwierig nachzuvollziehen ist. Coseriu führt in diesem Zusammenhang einige illustrative Beispiele an. So bedeutet z.B. Wecker auf der Ebene des Sprachsystems nur 'einer der weckt'. Dass die Bedeutung dieses Wortes in der Regel als 'spezielle Uhr mit einstellbarer Alarmfunktion' interpretiert wird und nicht etwa als 'Mensch, der einen anderen aufweckt', hängt mit dem normalen außersprachlichen Bezug des Wortinhalts zusammen. Andererseits ist das Wort 'Wecker' auch nur in der üblichen Bedeutung und in keiner anderen lexikalisiert, also einzelsprachlich fixiert. Ebenso ist z.B. der 'Notenständer' im deutschen Sprachgebrauch eindeutig eine Haltevorrichtung für Musikpartituren und nicht, wie es dem Sprachsystem nach auch möglich wäre, eine präsentative Ablage für Schulzeugnisse. Die normale Erfahrung der Welt lehrt uns nämlich, dass Notenständer sinnvoll und nützlich sind, Vorrichtungen zum Aufstellen von Schulzeugnissen hingegen nicht. 
Aber nicht nur Ableitungen und Komposita, die wir als feste Elemente des Wortschatzes einer Sprache betrachten können, hängen in ihrer lexikalisierten Bedeutung von Aspekten des allgemein-sprachlichen Wissens ab. Auch die Lesarten von Lexemen, die dem primären Wortschatz einer Sprache zuzurechnen sind, stehen in der Abhängigkeit des allgemein-sprachlichen Wissens. So muss z.B. bei einer Übersetzung des deutschen Wortes 'Band' ins Spanische je nach Kontext entschieden werden, ob 'cuerda', 'cinta', 'lazo', 'tomo' oder noch etwas anderes gemeint ist. Es ist jedoch falsch, anzunehmen, dass jeweils der Kontext selbst über die Bedeutung des Wortes entscheide. Ausschlaggebend für die Möglichkeiten des Sprachgebrauchs in einem jeden Kontext ist nämlich, dass die Einzelsprache neben der systemhaften Bedeutungsfunktion von 'Band' eine Reihe üblicher Bedeutungspräzisierungen (Lesarten) bereithält, die in der Rede aktualisiert werden können. Diese üblichen Bedeutungspräzisierungen sind einzelsprachlich normativ und als solche aus dem allgemein-sprachlichen Wissen, genauer, aus der allgemeinen Kenntnis der Sachen abgeleitet.

Die Grenze zwischen allgemein-sprachlicher und einzelsprachlicher Kompetenz ist in Bezug auf Beispiele der Art, wie sie hier gegeben worden sind, sehr schwer zu ziehen, so dass wir leichter von einem Ineinandergreifen beider Kompetenzebenen ausgehen können. Dies liegt daran, dass die Beispiele im Bereich des normalen Sprechens liegen. Das Ineinandergreifen der Wissensebenen kommt gerade im Bereich des Normativen zustande, d.h. die Norm des Sprechens im Allgemeinen lässt sich oft nicht genau von der Norm der Einzelsprache trennen. ${ }^{23}$ Coseriu macht auf diesen Aspekt allerdings selbst nicht aufmerksam. Ihm geht es nämlich hauptsächlich darum, die theoretische Autonomie der jeweiligen Wissensebenen vor Augen zu führen. Dies kann aber nur durch die Wahl 'verrückter' Beispiele gelingen, in denen eine Norm, entweder die des einzelsprachlichen Wissens oder die des allgemein-sprachlichen Wissens, durchbrochen wird. So finden sich bei Coseriu Beispielsätze wie 'Dieser Baum singt schöne Weihnachtslieder' oder 'Ich habe mein Klavier gekocht' (vgl. Coseriu 1988a, 113 f.), die belegen sollen, dass eine sprachliche Aussage zwar nach den Regeln der Einzelsprache korrekt sein kann, aber dennoch das allgemein-sprachliche Wissen des Sprechers brüskiert. Der Fall eines einseitigen Normverstoßes auf einzelsprachlicher Ebene wäre hingegen z.B. der Satz 'Jeden Tag geht die Sonne hoch.'

${ }^{23}$ Ich beziehe mich mit dieser Aussage auf die Möglichkeit einer konkreten Analyse sprachlicher Wirklichkeit, wie sie im Rahmen der Untersuchung geschehen soll. Davon unberührt bleibt die grundsätzliche Interdependenz der Normebenen im Sinne ihrer theoretischen Unterscheidung. Ebenfalls nicht kritisiert werden soll die berechtigte Unterscheidung von Norm und System aus strukturalistischer Sicht. 
Für den Zweck meiner Untersuchung erweist es sich als notwendig, die Übergänge und unscharfen Grenzziehungen von einzelsprachlichem Wissen und allgemein-sprachlichem Wissen in Bezug auf die Wirklichkeit des Sprechens hervorzuheben. In den Exempla sprachlicher Darstellung zu einem Sachbereich, um die es mir geht, gewinnen notwendigerweise die regionalspezifischen Normen des Sachbereichs als Sozialnormen auch Einfluss auf den Sprachgebrauch. Sie tun dies aber in einer engen Verbindung mit den Normen der jeweils verwendeten Einzelsprache, die als fachsprachlich, regionalsprachlich bzw. dialektal und auch sprechergruppenspezifisch bestimmbar sind. Es ist daher unabdingbar, die Architektur der benutzten Einzelsprache zu berücksichtigen und der Frage nachzugehen, in welcher varietätenspezifischen Sprechweise die jeweilige Darstellung des Sachbereichs erfolgt. Damit aber kommen wir zu dem Bereich der Sprache im engeren Sinne.

Bevor ich diese Wissensbezüge auf die funktionellen Strukturen der Einzelsprache genauer zu erläutern versuche, möchte ich jedoch noch kurz auf den anderen prinzipiell nicht strukturierbaren Ausschnitt aus dem einzelsprachlichen Wissen eingehen, den Coseriu 'textgebundenes' idiomatisches Wissen nennt. Hierbei handelt es sich um die 'Kenntnis von Texten, die innerhalb einer Sprachgemeinschaft in fester Form überliefert werden, wie z.B. Sprichwörter, Denksprüche, Redewendungen, usw.' (Coseriu in Energeia und Ergon I, 378). Der Bereich dieses Wissens fällt mit dem zusammen, was Coseriu an anderer Stelle als wiederholte Rede kennzeichnet, d.h. als eine rein repetitive Form der Anwendung einer historischen Sprache, die sich von der kreativen Form der Anwendung einer freien Sprachtechnik grundsätzlich unterscheidet. Als unterschiedliche Modi des Sprechens definieren sich die wiederholte Rede und die freie Technik unabhängig von den Einzelsprachen. In ihrer Verwirklichung sind sie aber jeweils an eine historische Sprache gebunden und gehören damit auch zum einzelsprachlichen Wissen. Als 'textgebundenes', aber nicht formalisierbares Wissen ist die wiederholte Rede immer nur interindividuell zu begreifen, und zwar in konkretem Bezug auf eine bestimmte Sprachgemeinschaft. Sie ist damit auch Ausdruck der sozialen Normierung einer historischen Sprache.

In meiner empirischen Untersuchung wird das 'textgebundene' einzelsprachliche Wissen, zu dem auch allgemein bekannte Zitate (z.B. 'Grau, teurer Freund, ist alle Theorie, und grün des Lebens goldner Baum. ${ }^{24}$ ) und etablierte Vergleichsformeln (z.B. 'zittern wie Espenlaub') gehören, kaum eine Rolle

${ }^{24}$ Vgl. zu diesem Zitat aus Goethes Faust Coserius Interpretation auf der Ebene der allgemeinsprachlichen Kompetenz (Coseriu 1988a, 123 f.) sowie auf der Ebene des Textes (Coseriu 1994, 123f.). Es zeigt sich, dass repetitives Sprechen einer Einzelsprache in Bezug auf das elokutionelle und das expressive Wissen durchaus sehr anspruchsvoll und feinsinnig sein kann. 
spielen. Dennoch muss betont werden, dass es sich hier um Normen des Sprechens in einer Sprachgemeinschaft handelt, die diese Normen in der Regel pflegt und mehr oder weniger intensiv nutzt. Unter Berücksichtigung dieses Phänomens ist auch die Frage interessant, ob bestimmte Sachbereiche, die für die Lebensrealität in einer Sprachgemeinschaft von Bedeutung sind, materielle bzw. auch ideelle Grundlagen für ein repetitives Sprechen geben. Wenn wir z.B. an den Wald denken, so fallen einem Redewendungen wie 'den Wald vor lauter Bäumen nicht sehen', 'die Bäume in den Himmel wachsen lassen' oder 'die Axt im Haus ersetzt nicht den Zimmermann' ein, die von der grundsätzlichen Wichtigkeit des Waldes für das gesellschaftliche Leben zeugen. Interessanter noch ist in unserem Zusammenhang die Feststellung, dass im bearnesischen Sprachraum eine ganze Reihe solcher sprichwörtlicher Wendungen existieren, die sich auf die Lebensrealität des Waldes beziehen. So zitiert z.B. Gerhard Rohlfs (1977) die folgenden proverbes:

Lou càssou ne cat pas d'ou permé còp. (Le chêne ne tombe pas au premier coup.)

Ad arbe quèut tou lou mounde que hè estères. (À l'arbre tombé tout le monde ramasse [fait] des éclats.)

Und in dem Dictionnaire bilingue des expressions gasconnes von André Hourcade (1990) finden sich Redewendungen wie:

amors de darrèr las segas (amours de derrière les ronces ' amours cachés, illicites)

shens nat bronc (sans aucun nœud [du bois] ' de caractère égal, sans difficulté)

Wir können also davon ausgehen, dass ein regionalspezifischer Sachbereich auch das 'textgebundene' Wissen in Bezug auf den regionalen Gebrauch einer Einzelsprache in besonderer Weise prägt. Allerdings zeigt sich die Prägung in der autochthonen Regionalsprache bzw. dem regionalen Dialekt wohl sehr viel deutlicher als in dem regional gebräuchlichen Standard der Hochsprache.

Kommen wir nun zu dem Bereich einzelsprachlicher Strukturiertheit im engeren, d.h. funktionellen Sinn. Das Sprecherwissen, das sich auf diesen Bereich bezieht, ist schon von jeher in der Sprachwissenschaft beachtet worden und hat das allgemein verbreitete Begriffsverständnis von Sprachkompetenz entscheidend geprägt (vgl. Coseriu 1988a, 73 f.). Coseriu leitet die 'Kompetenz' des Sprechers jedoch von einem energetischen Sprachbegriff ab und unterstellt ihr daher auch auf der einzelsprachlichen Ebene zunächst noch keine feste Strukturierung. Der Sprecher muss dieser Sichtweise zufolge beim Sprechen in erster Linie mit der komplexen Realität einer historischen Sprachtechnik umgehen können, deren Wesensmerkmal Heterogenität und nicht 
Homogenität ist. Das bedeutet, dass jede Art der Strukturierung der Einzelsprache für den Sprecher primär tätigkeitsbestimmt, d.h. sprachverwendungsorientiert ist. Der Sprecher leitet also die Kriterien für die Differenzierung und Auswahl sprachlicher Strukturen aus der kommunikativen Realität ab, in der er steht, und konstituiert sein Wissen auf der Grundlage dieser Erfahrung.

Die so verstandene Sprachkompetenz der Sprecher einer Sprachgemeinschaft lässt sich - zumindest ansatzweise - empirisch aus dem Sprachbewusstsein der Sprecher ermitteln (vgl. Schlieben-Lange 1988, 458). Allerdings liegt damit noch keine Beschreibung des eigentlichen Sprecherverhaltens vor, d.h. es ist noch nicht erklärt, 'was ein Sprecher wirklich tut', wenn er sich einzelsprachlicher Strukturen bedient. Meiner Überzeugung nach liegt das methodische Grundproblem hier in der adäquaten Perspektivierung des Erkenntnisinteresses. Wenn nämlich das Wissen des Sprechers als potentielle Tätigkeit des Sprechens erfasst werden soll, so muss das 'Produkt' des Sprechens, sein unmittelbares Resultat zum empirischen Ausgangspunkt gemacht werden, also-auf den verschiedenen Ebenen des Sprechens - die getanen Äußerungen in übereinzelsprachlicher Interpretation, die angewendeten Regeln der Einzelsprache (in Form von lexikalischen, grammatischen und syntaktischen Strukturen) sowie die Gestaltung des Diskurses als kommunikativer Texteinheit. Was nun die angewendeten Regeln der Einzelsprache betrifft, so sind diese Regeln formal als Variationsmechanismen zu begreifen. Ich bezweifele jedoch mit Brigitte Schlieben-Lange und Harald Weydt, dass Variationsgrammatiken einen geeigneten methodischen Ansatz in der sprachwissenschaftlichen Beschreibung darstellen ${ }^{25}$, und plädiere in dieser Hinsicht für ein weniger komplexes, weil 'realistischeres' Verfahren (bzw. Annäherungsverfahren) der sprachwissenschaftlichen Beschreibung. Zur Erläuterung dieser Position müssen wir genauer auf den Begriff der Sprachvarietät eingehen.

Coseriu versteht unter Sprachvarietät nicht in erster Linie eine funktionell bestimmte Abgrenzung des Sprachsystems, sondern ein grundlegendes Merkmal der historischen Sprache, das als Betrachtungsdimension geeignet ist, diese in ihrer Gesamtheit zu erfassen und darüber hinaus die strukturellen Verbindungen der historischen Sprachen untereinander in Zeit und Raum zu begründen. Die Varietät historischer Sprachen wird dabei durch den Aspekt der Homogenität in der Weise ergänzt, dass sich gerade durch die Delimitierung dieser beiden Dimensionen ein strukturelles Profil der historischen Einzelsprache ergibt. Coseriu nennt dieses Strukturprofil die Architektur der Einzelsprache und bestimmt sie als eine 'äußere Strukturierung', die 'die Gestaltung der Verhältnisse zwischen verschiedenen Sprachsystemen in einer Gemeinschaft betrifft' (vgl. Coseriu, 1988a, 148).

${ }^{25}$ Vgl. Weydt/Schlieben-Lange 1981 sowie meine Anmerkung zu diesem Beitrag in Kapitel 2.2 . 
Interessanterweise hat Coserius Interpretation der Varietätenstruktur einer Einzelsprache in der Sprachwissenschaft eine weitaus größere Akzeptanz gefunden als seine Theorie der funktionellen Sprache. Dies ist erstaunlich, da man die einzelsprachliche Architektur adäquat eben nur in ihrer Abhängigkeit von einer differenzierten funktionellen Struktur der Sprache begründen kann. Sie ergibt sich bekannterweise aus einer rein synchronischen Optik durch die Aufgliederung in drei Variationsdimensionen, die Coseriu wie folgt bestimmt:

1. diatopische Verschiedenheit (Verschiedenheit im Raum)

2. diastratische Verschiedenheit (Verschiedenheit in den sozial-kulturellen Schichten der Sprachgemeinschaft)

3. diaphasische Verschiedenheit (stilistische Verschiedenheit je nach den Typen von Situationen des Sprechens)

Die drei Typen der Verschiedenheit sind einander keineswegs parallel, sondern erscheinen jeweils untereinander kombiniert und haben verschiedene Grenzen.

(Coseriu 1988a, 141)

Die Sprachwissenschaft hat sich bislang zu wenig um den Aspekt der Kombinatorik von diatopischer, diastratischer und diaphasischer Variation gekümmert. Stattdessen ist es in funktionalistischen Einzeluntersuchungen üblich, nur einer der drei unterscheidbaren Variationsdimensionen nachzugehen und dementsprechend ausschließlich die Differenzierung in Mundarten und Dialekte, die in Sprachniveaus oder die in Sprachstile zu analysieren. Dieses analytische Vorgehen wird durch das gängige disziplinäre Verständnis der Sprachwissenschaft gestützt, demzufolge man entweder Dialektologie oder Soziolinguistik oder Sprachstilistik bzw. Fachsprachenlinguistik betreibt, die inhaltlichen Verbindungen dieser einzelnen Disziplinen untereinander jedoch höchstens peripher berücksichtigt. Zwar gibt es gerade in der jüngeren Sprachwissenschaft auch Ansätze zu einer 'innersprachwissenschaftlichen Interdisziplinarität', jedoch gelangen diese kaum aus den grundsätzlichen Betrachtungsweisen der einzelnen Disziplinen hinaus. Wenn Coseriu theoretisch die komplexe Kombinatorik verschiedener Sprachverschiedenheiten mit jeweils verschiedenen Grenzen evoziert, so ist es methodologisch eben ein sehr weiter und kaum gangbarer Weg, dieser einzelsprachlichen Wirklichkeit auf der Grundlage einer funktionalistischen Sprachbetrachtung näher zu kommen oder gar gerecht zu werden.

Auf der Suche nach einer alternativen methodologischen Konzeption, die es erlaubt, die Sprachvarietät insgesamt auf ein einheitliches analytisches Prinzip zurückzuführen, haben Peter Koch und Wulf Oesterreicher an die These der Hierarchisierbarkeit der Sprachvariationsdimensionen angeknüpft:

Bisherige Untersuchungen zu den drei diasystematischen Varietäten haben immer wieder gezeigt, dass die diatopischen, diastratischen und diaphasischen Unterschiede innerhalb einer Einzelsprache nicht zusammenhanglos nebeneinander stehen. Dabei 
ist die Einsicht wichtig, dass zwischen Dimensionen der Sprachvarietät gerichtete Beziehungen derart bestehen, dass Diatopisches als Diastratisches und Diastratisches als Diaphasisches funktionieren kann (nicht aber umgekehrt).

(Koch/Oesterreicher 1990, 14)

Im Rahmen ihrer bekannten Konzeption von Mündlichkeit und Schriftlichkeit stellen die beiden Autoren nun die These auf, die von Coseriu erkannte Varietätenkette 'Mundart/Dialekt' zu 'Sprachniveau' zu 'Sprachstil' ließe sich durch den Übergang 'Sprachstil zu Nähesprache' erweitern, da es Funktionselemente der Sprache gebe, die nicht diatopisch, diastratisch oder diaphasisch bestimmt sind, gleichwohl aber Merkmale nur der gesprochenen Sprache in einer konzeptionellen Sicht darstellen. Diese Interpretation erscheint mir allerdings kritikabel, da es in meinen Augen eine methodische Inkonsequenz darstellt, die gesprochene Sprache als konzeptionelle 'Nähesprache' und die geschriebene Sprache als konzeptionelle 'Distanzsprache' in einen direkten Strukturzusammenhang mit den funktionellen Sprachen im Sinne Coserius zu stellen. Die Variationsdimension 'gesprochen/geschrieben', für die ich den Terminus 'diamedial' verwende, bezieht sich nämlich nur insofern auf die Architektur einer Sprache, als dass sie eine Binnendifferenzierung der Sprache als Diasystem darstellt, sich also potentiell gleichermaßen als Verschiedenheit diatopischer, diastratischer und diaphasischer Realisationsformen der Sprache manifestiert.

Demgegenüber betont Oesterreicher zu Recht, dass neben der diasystematischen Variation noch eine weitere Variationsdimension der Einzelsprache besteht:

Es gibt in der Tat eine ganze Reihe von Fakten im morphosyntaktischen, lexikalischsemantischen und textuell-pragmatischen Bereich der Einzelsprachen, die von den genannten drei Dimensionen der Varietät nicht oder nur teilweise erfasst werden, die also in keiner dieser Dimensionen 'aufgehen'. Hierbei handelt es sich nun aber gerade um einzelsprachliche Manifestationen, die vom durch bestimmte Kommunikationshaltungen und Redekonstellationen definierten Nähe- bzw. Distanzsprechen determiniert sind. Es gibt also einzelsprachlich eine Dimension der Varietät, die noch vor den drei beschriebenen Variationstypen liegt. Diese kontinual dimensionierte Varietät hat notwendig, nämlich als einzelsprachliche Ausprägung der Sprache der Nähe und der Distanz, zwei Pole. Ich nenne diese einzelsprachlichen Varietätenpole Nähesprache und Distanzsprache.

(Oesterreicher 1988, 374)

Die Unterscheidung von Nähesprache und Distanzsprache ist ein Aspekt, den Oesterreicher den von Coseriu unterschiedenen Betrachtungsweisen der Sprachvarietät, der diachronischen und der synchronischen, hinzufügt und zu dessen Charakterisierung ich den Begriff 'panchronisch' vorschlagen möchte. Oesterreicher leitet diesen Aspekt der Sprachvarietät aus einer universalistischen Betrachtung der Sprechtätigkeit ab und weist ihm daher einen prinzi- 
piellen, aber keinen historischen Status zu. Das Fazit seiner diesbezüglichen Überlegungen bringt er in folgender Weise auf den Punkt:

1. Der Unterschied zwischen Nähesprechen und Distanzsprechen meint die Sprechleistungen im Rahmen des universell verstandenen Kontinuums der skizzierten Kommunikationshaltungen und Versprachlichungsstrategien. [...]

2. Dem Nähesprechen und Distanzsprechen können logischerweise keine konkreten, spezifischen sprachlichen Fakten zugeordnet werden. Dies ist erst auf der Ebene der Einzelsprache und des Diskurses möglich.

(Oesterreicher 1988, 372)

Im Rahmen meiner Untersuchungen zum regionalen Sprachgebrauch in Fachkontexten spielt die konzeptionelle Unterscheidung von Nähesprechen und Distanzsprechen eine wesentliche Rolle. Es wird zu zeigen sein, dass sich eine ganze Reihe sprachlicher Fakten und Gestaltungsverfahren der ermittelten Diskurse speziell aus der nähesprachlichen Kommunikationshaltung erklären lassen und dabei auch den Grad sowie die Art und Weise der Verwendung fachsprachlicher Elemente mitbestimmen und prägen. Die von mir angestrebte Interpretation der sprachlichen Realität basiert jedoch auf der grundsätzlichen Unterscheidung nähesprachlich motivierter Sprachfakten und der Verifikation eines mündlichen Fachsprachengebrauchs. Insbesondere werden wir, von der Theorie Oesterreichers abweichend, keine fundierende Funktion des Nähe/Distanz-Kontinuums im Hinblick auf den Gebrauch funktioneller Sprachen zu erkennen versuchen. Die diesbezügliche von Oesterreicher erhobene Forderung halte ich für gerechtfertigt, ziehe aus ihr aber ein gänzlich anderes Fazit:

$\mathrm{Zu}$ fordern ist daher eine Konzeption, die nicht nur den einzelsprachlichen Varietätenraum hinsichtlich der Analyse und Beschreibung der Fakten vollständig abdeckt; darüber hinaus müssen in einer akzeptablen Konzeptualisierung des internen Aspekts des Universale 'Historizität' auch die Anschlußflächen für universelltätigkeitsbezogene und aktuell-diskursbezogene Aspekte von Variation sichtbar werden. Soviel zu den sprachtheoretisch-begrifflichen Unannehmlichkeiten der dreidimensionalen Varietätenkonzeption.

(Oesterreicher 1988, 374)

Ohne hier zu sehr in die theoretischen Details gehen zu wollen, erscheint es mir doch angebracht darauf hinzuweisen, dass das von Oesterreicher und auch Koch vertretene sprachtheoretische Modell mit seinem vorrangigen Bezug auf die Konzeption einer durch Nähe und Distanz polarisierten Sprechtätigkeit Gefahr läuft, die Solidität und Kohärenz des Gesamtaufbaus von Coserius Theorie des Sprechens zu unterminieren. Dies liegt wohl kaum in der Absicht der genannten Sprachwissenschaftler, erscheint aber als Folge der Anerkennung ihrer universalistischen Sprachbetrachtung naheliegend. Ich verfolge daher in dieser Untersuchung das Ziel, einerseits die Validität der Nähe/Distanz-Konzeption für die Erfassung sprachlicher Wirklichkeit herauszustellen, andererseits aber zu zeigen, dass Coserius eigene Interpretation der 
Sprechtätigkeit bzw. des Sprechens im Allgemeinen zumindest für meine Untersuchungszwecke geeigneter ist, die universelle Ebene des Sprechens in ihrer Verbindung zum Gebrauch der Einzelsprache und zu den Gestaltungsformen der individuellen Diskurse zu erklären. Mit anderen Worten: Ich halte die Nähe/Distanz-Konzeption von Oesterreicher und Koch für ein überzeugendes Interpretationsmodell, ihre versuchte Integration in Coserius Sprachtheorie jedoch für problematisch.

Die Zusammenhänge einzelsprachlicher Varietät lassen sich insgesamt besser auf einer empirischen als auf einer universalistischen Betrachtungsebene erkennen und beschreiben. Thomas Stehls ausführliche Untersuchung zu Sprachkontakt und Sprachdynamik auf der Grundlage der von ihm entwickelten Variationslinguistik ist ein gutes Beispiel dafür (vgl. Stehl 1990). Stehl weist nach, dass im Sprecherbewusstsein Gradata vorhanden sind, die zur Markierung funktioneller Sprachstufen zwischen Dialekt und Hochsprache geeignet sind. Die Auswahl und Verwendung eines Gradatums in einer kommunikativen Situation ist dabei von den kommunikativen Umständen selbst abhängig, d.h. von Thema, Ort sowie der Einschätzung der Gesprächspartner und ihrer Sprachkompetenz. Stehl zeigt in seinen empirischen Untersuchungen deutlich auf, dass das Wissen der Sprecher die maßgebliche Steuerungsinstanz für die Verwendung funktioneller Sprachen ist bzw. anders ausgedrückt, dass die Sprachkompetenz zum Leitfaden sprachlichen Handelns auf der Ebene der Einzelsprache wird. ${ }^{26}$

Es ist ein wesentliches Anliegen der Sprachwissenschaft, die Voraussetzungen, Kriterien und Mechanismen zu beschreiben, die einen Sprecher dazu befähigen, mit dem Faktum einzelsprachlicher Varietät kommunikativ angemessen umzugehen. Stehl hat sich dieser Aufgabe im Hinblick auf das bekannte Phänomen des Sprachkontakts zwischen regressiver Sprache (Dialekt, Minderheitensprache) und dominanter Sprache (Standard) gestellt und vertritt dabei die These, dass es synchron betrachtet keine kontinuierlichen, sondern sprunghafte Übergangsformen in der Verwendung der Kontaktsprachen gibt. Eben diese Übergangsformen nennt er 'Gradata' und weist ihnen den Status funktioneller Sprachen zu. Stehl gibt auf diese Weise einen interessanten Einblick in die Komplexität funktioneller Strukturgrenzen, zwischen denen sich zweisprachige Sprecher bewegen und mühelos zurechtfinden. Dabei führt ihn die funktionalistische Sichtweise des Problems zu der Schlussfolgerung, die Sprecher seien-je nach Alter und Kompetenz-dazu in der Lage, aus einem

${ }^{26}$ In der ihm eigenen Methodologie unterscheidet Stehl, um den Umgang der Sprecher mit sprachlicher Variation analytisch differenziert zu beschreiben, zwischen den Aspekten der Kompetenz, der Pragmatik und der Linguistik der Variation. Explikativen Wert für die Auswahl und Verwendung funktioneller Spracheinheiten hat dabei allein die Kompetenz (vgl. Stehl 1991, 80f.). 
Spektrum von bis zu fünf Gradata das passende für eine kommunikative Situation auszuwählen. ${ }^{27}$ In Bezug auf den einzelnen Sprecher erscheint diese Sichtweise allerdings allzu formalistisch. Tatsächlich wird ein Sprecher im konkreten Kontakt von Dialekt und Standard zunächst einmal nur zwischen diesen beiden Sprachformen bzw. Sprachen selektieren und dann seinen Sprachgebrauch auf der Basis einer normativen Fokussierung gestalten, deren Erklärung und Beschreibung meiner Meinung nach am besten aus einer standardologischen Perspektive erfolgt. Die standardologische Perspektive bietet dabei den Vorteil, die Normabhängigkeit des Sprachverhaltens zu dokumentieren und aufzuzeigen, auf welcher sprachstrukturellen Grundlage sich der Sprecher befindet und wie er diese Strukturbasis im Hinblick auf die ihm zur Verfügung stehende Sprachvarietät kommunikativ nutzt und erweitert. Die von mir vorgeschlagene Optik der Analyse ist also eine andere als die Stehls, indem sie stärker von der im Kommunikationsakt ermittelten Kompetenz des einzelnen Sprechers ausgeht und sein Sprachverhalten weniger aus der konstatierbaren Vielfalt sprachlicher Strukturformen heraus zu begründen versucht. In diesem Sinne strebe ich auch eine engere Anbindung an Coserius sprachtheoretische Vorstellungen an.

Hinsichtlich der Beschreibung einer einzelsprachlichen Kompetenz erweist sich Coserius Theorie des Sprechens als ein radikaler Neuansatz der linguistischen Deskription, der in der Sprachwissenschaft als solcher bislang kaum Beachtung gefunden hat und noch nicht zur Grundlage konkreter Untersuchungen gemacht worden ist. Ich möchte mit dieser Arbeit einen bescheidenen Anfang wagen, um diese Lücke zu füllen, da mir Coserius innovativer Interpretationsvorschlag gerade für meinen Untersuchungszweck besonders geeignet erscheint. Das Neue dieses Ansatzes ist in erster Linie methodologisch begründet. Coseriu stellt diesbezüglich die programmatische Frage:

Genügt die Beschreibung funktioneller Sprachen aber, um das sprachliche Wissen eines Sprechers auf der historischen, d.h. der einzelsprachlichen Ebene zu beschreiben? Kann man so diesem Wissen gerecht werden?

(Coseriu 1988a, 153)

Coserius Antwort ist ein 'Nein'. Zwar erkennt er theoretisch die Möglichkeit an, aus der kompletten Beschreibung aller einem Sprecher zur Verfügung stehenden funktionellen Sprachen seinen jeweiligen Anteil am Sprachwissen abzuleiten. Allerdings stellt dieses Vorgehen den Linguisten vor die praktisch unlösbare Aufgabe, die Architektur einer Sprache zunächst unter rein funktionalistischen Gesichtspunkten und unabhängig von der Sprachkompetenz der Sprecher vollständig zu beschreiben. Coserius Fazit ist eindeutig:

${ }^{27}$ Da Stehl die Kompetenzverteilung in der 'Kontaktzone' generationsspezifisch interpretiert, verfügt der einzelne Sprecher aktiv jeweils nur über zwei oder drei der Gradata zwischen reinem Dialekt und reiner Standardsprache (vgl. Stehl 1991, 124). 
Ein solches Vorgehen würde jedoch zunächst einmal zu riesigen empirischen Schwierigkeiten führen, weil die Beschreibung tatsächlich aller funktionellen Sprachen in einer komplexen historischen Sprache wohl kaum zu leisten ist. Doch selbst wenn dies gelänge, so würde es uns doch nicht näher an das Ziel bringen, gerade das zu beschreiben, was ein Sprecher weiß.

(Coseriu 1988a, 154)

Die Sprachkompetenz eines Sprechers auf der einzelsprachlichen Ebene darzustellen ist ein Ziel, das eine grundsätzlich andere Methodologie erfordert. Coserius diesbezügliche Hinweise lassen sich wie folgt systematisieren und mit meinem Untersuchungsanliegen in Zusammenhang bringen:

1. Bezug auf den Sprecher: Die Ermittlung von einzelsprachlicher Kompetenz kann grundsätzlich jeweils nur in Bezug auf einen konkreten Sprecher erfolgen. Die empirische Beschreibungsgrundlage ist damit in jedem Fall individuell, d.h. personenbezogen und nicht ohne weiteres generalisierbar. Repräsentative Aspekte einer solchen Beschreibung lassen sich nur durch die Einbeziehung normativer Bestimmungen des Sprecherwissens (Individualnormen, Sozialnormen, Regionalnormen) ermitteln. Empirisch können diese aus dem Vergleich von Sprecherkompetenzen abgeleitet werden. Coseriu selbst spricht von dem Ziel, die Sprachkompetenz eines normalen Sprechers zu beschreiben, macht aber keine weiteren Angaben zu den Kriterien dieser Normalität. Ich bin der Meinung, dass diese Normalität in Bezug auf die Sprachregion und die Sprechergruppe, aber auch je nach Maßgabe typisierbarer Sprechsituationen variiert. Dabei gilt es zu berücksichtigen, dass diese normativ wirkenden Determinanten nicht mit der diatopischen, diastratischen und diaphasischen Differenzierung der Einzelsprache zu verwechseln sind. So wird sich z.B. an den Untersuchungsergebnissen konkret zeigen lassen, dass normative Fakten der Sprachregion Auswirkungen auf die diaphasische Sprachkompetenz der Sprecher in dieser Region haben.

2. Bezug auf die Sprache: Coserius Auffassung zufolge ist die Sprachkompetenz des einzelnen Sprechers jeweils auf die Verwendung einer 'Hauptmundart' bzw. einer zentralen funktionellen Sprache bezogen:

Der normale Sprecher spricht zwar an erster Stelle eine bestimmte funktionelle Sprache. Wie wir gesehen haben, besitzt er aber mehr oder weniger ausgeprägte Kenntnisse diatopischer Varietäten seiner historischen Sprache und darüber hinaus gewisse, wenn auch vage Kenntnisse anderer historischer Sprachen. Das gleiche gilt natürlich auch für die diastratische und diaphasische Dimension der sprachlichen Varietät.

(Coseriu 1988a, 152)

Die Zugrundelegung einer 'Hauptmundart' des Sprechers ist ein methodologisch interessanter Vorschlag, den Coseriu jedoch nicht weiter erläutert. Ich schlage daher vor, diese 'Hauptmundart' des Sprechers als Standard zu charakterisieren. Diesen Vorschlag rechtfertige ich damit, dass die 'Hauptmun- 
dart' des Sprechers, aber auch das ihn charakterisierende Sprachniveau und der von ihm bevorzugte Sprachstil innerhalb der Sprechergruppe, in der er sich hauptsächlich bewegt, als normal einzustufen ist, d.h. von mehreren (oder sogar den meisten) Sprechern einer Sprachgemeinschaft im Alltag verwendet wird. Zudem ist es möglich, das Konzept des Standards auch dann anzuwenden, wenn ein Sprecher je nach kommunikativem Anlass bewusst zu einer funktionellen Sprache mit diasystematischer Bestimmung wechselt, d.h. wenn er in einer kommunikativen Situation nicht-alltäglichen Charakters z.B. einen Dialekt oder eine Fachsprache als Standardform wählt. In allen Fällen ist zu konstatieren - und damit folge ich wieder Coseriu -, dass die Sprachkompetenz des Sprechers über die Verwendung der gewählten Standardsprachform hinausgeht, also beim Sprechen immer auch Abweichungen von dem zugrunde liegenden bzw. gewählten Standard feststellbar sind. Diese diatopischen, diastratischen und diaphasischen Abweichungen vom verwendeten Standard sind als Integration anderer funktioneller Sprachen und z.T. auch als Verwendung von Elementen aus anderen historischen Sprachen zu beschreiben. Diese Interpretation lässt es jedoch nicht mehr sinnvoll erscheinen, das Sprachwissen eines Sprechers aus der diskreten Beschreibung funktioneller Sprachen abzuleiten. Coseriu verdeutlicht den Unterschied in folgendem Schaubild: ${ }^{28}$

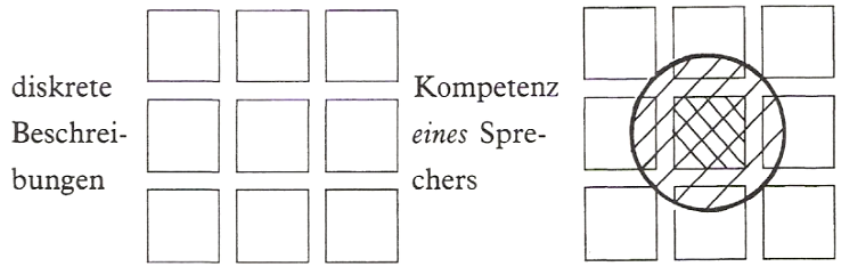

${ }^{28}$ „Die historische Sprache funktioniert in der Rede nicht nur durch ihre strukturelle Homogenität, sondern auch durch ihre Varietät. Der Sprecher trifft nämlich seine Wahl nicht nur innerhalb der Paradigmata einer funktionellen Sprache, sondern auch innerhalb der Architektur der historischen Sprache, und zwar nicht nur vor Beginn eines Textes, sondern auch in ein und demselben Text oder sogar mitten im Satz. Freilich kann man auch Mundarten, Sprachniveaus oder Sprachstile synchronisch beschreiben, jedoch nicht als Bestandteile eines einzigen Sprachbesitzes, sondern jeweils als selbständige, voneinander getrennte Systeme. Auch können natürlich die entsprechenden Einzelfakten strukturell bestimmt werden, jedoch nicht in der Hinsicht, wie sie am Funktionieren der Sprache in der Rede beteiligt sind. Denn in der streng strukturellen Sprachbeschreibung verschwindet gerade das, was ihr Funktionieren in Texten charakterisiert: Eine Form ist, zum Beispiel, nicht 'mundartlich' in der Mundart, zu der sie gehört, so wie ein 'Archaismus' als solcher nicht in einem älteren Sprachsystem auftritt.“ Coseriu in Energeia und Ergon I, 1988, 142. 
3. Bezug auf das Wissen: Der Gebrauch der funktionellen Sprachen (Mundarten, Sprachniveaus, Sprachstile), durch die der Sprecher seine Standardsprachform ergänzt bzw. modifiziert, geht auf ein partielles Sprachwissen hinsichtlich dieser funktionellen Sprachen zurück. Einfacher ausgedrückt ergänzt der Sprecher die von ihm verwendete Standard-Varietät durch sprachliche Elemente, die aus bestimmten Mundarten, Sprachniveaus oder Sprachstilen stammen, ohne dabei jeweils eine umfassende oder gar vollständige Kenntnis dieser funktionellen Varietäten zu haben. Er gebraucht sie nur zusätzlich zum Standard entsprechend der jeweiligen kommunikativen Erfordernisse. Das Sprachwissen, auf das er dabei rekurrieren kann, ist häufig inkorrekt, d.h. nur annähernd oder nachahmend in Bezug auf die Normen der betreffenden Varietät. Dies lässt sich im Rahmen der Untersuchung sehr schön an dem Gebrauch von Fachsprachen zeigen, deren partielle Verwendung in einer Region aufgrund vorhandener Normen typisch ist, die jedoch von den allermeisten Sprechern nicht adäquat beherrscht werden. Häufig ist die Kenntnis solcher über den Standard hinausgehenden Sprachvarietäten auch weitaus stärker passiv als aktiv, d.h. die Sprecher verstehen mehr, als sie selbst zum Ausdruck bringen würden.

Resümierend lässt sich also festhalten, dass der von einem Sprecher verwendete Standard in der Regel vollständig, korrekt und aktiv beherrscht wird, in der alltäglichen Kommunikation jedoch Erweiterungen oder Veränderungen durch die Einbeziehung eines partiellen, inkorrekten und teilweise auch nur passiven Sprachwissens hinsichtlich kommunikativ relevanter Sprachvarietäten erfährt. Solche Abweichungen vom Standard als funktionell beschreibbarer Standard-Varietät betrachte ich nicht als Verstöße gegen die Normen dieses Standards, sondern als normative Anpassungen des Standards, die sich aus den faktischen Gegebenheiten der Sprachregion, aus den sozialen Verhältnissen, in die der Sprecher integriert ist, und aus seinen biographisch begründeten Erfahrungen herleiten lassen. Meiner Überzeugung nach steht das partielle Wissen des Sprechers zu diatopischen, diastratischen und diaphasischen Varietäten der von ihm verwendeten Sprache dementsprechend nicht isoliert da, sondern ist abhängig von einer zentralen Sprachkompetenz, die Coseriu als 'Hauptmundart' und ich als 'Standard' charakterisiert habe.

Die Angemessenheit dieser methodologischen Grundsätze für meine eigene Untersuchung zum regionalen Sprachgebrauch in Fachkontexten wird sich im Laufe der weiteren theoretischen Überlegungen, ganz besonders aber in der empirischen Analyse selbst, zeigen. Dabei betrete ich Neuland und bin mir der besonderen methodischen Schwierigkeiten meines Vorhabens bewusst:

Als Tatsache ist also festzuhalten, dass wir bis heute über keine geeignete Methode verfügen, um die Varietät der idiomatischen sprachlichen Kompetenz eines Sprechers zu beschreiben und um den Status anzugeben, der den Elementen aus den Varietäten 
in der Kompetenz tatsächlich zukommt. Man kann allenfalls Vorschläge machen, wie man dies tun könnte. Zunächst müsste man aber wissen, was ein mittlerer, mehr oder weniger typischer Sprecher einer historischen Sprache von den übrigen Mundarten [ich ergänze: Sprachniveaus und Sprachstilen], die er nicht spricht, normalerweise kennt und unter welchen Umständen er diese Kenntnis aktivieren kann, und sei es nur als Nachahmung in der geschilderten Weise.

(Coseriu 1988a, 157f.)

\subsubsection{Das textuelle Wissen}

Coserius sprachtheoretischer Ansatz wäre keine vollständige Theorie des Sprechens, wenn er nicht auch das Sprecherwissen auf der Ebene der Textproduktion mit einbeziehen würde. Letztlich ist die Ebene des Textes sogar diejenige, auf die jede umfassende linguistische Betrachtung hinauslaufen muss, da erst der Text alle Dimensionen sprachlicher Semantizität zum Ausdruck bringt. Coseriu spricht von der Textlinguistik als einer 'Linguistik des Sinns' und erklärt den 'Sinn' damit zur semantischen Kategorie des Textes. Er weist darauf hin, dass der Sinn Teil einer semiotischen Einheit ist, die er 'Textzeichen' nennt und in folgender Weise charakterisiert:

Bezeichnung und Bedeutung, d.h. das, was die sprachlichen Zeichen benennen und das, was sie durch eine Einzelsprache allein bedeuten, bilden-zusammengenommenim Text den Ausdruck für eine Inhaltseinheit höherer, komplexerer Art, eben für den Sinn. Analog zur Saussureschen Unterscheidung zwischen signifiant und signifié, die für das sprachliche Zeichen gilt, wollen wir beim $\mathrm{T}$ e $\mathrm{x} \mathrm{t} \mathrm{z}$ e i $\mathrm{c} \mathrm{h}$ e $\mathrm{n}$ ebenfalls zwischen signifiant und signifié unterscheiden. Bedeutung und Bezeichnung konstituieren zusammen das signifiant, der Sinn hingegen das signifié der Textzeichen:

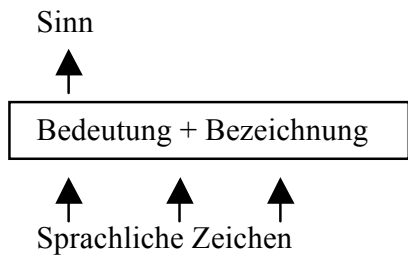

(Coseriu 1994, 65)

Eine Analogie zu de Saussures Semiotik begründen zu wollen ist in diesem Zusammenhang sicherlich nicht unproblematisch. Wir können aber Coseriu in jedem Fall in der Argumentation folgen, dass der Sinn einen Sprachinhalt auf der Ebene des Textes konstituiert und dass der Ausdruck dieses Inhalts mittels der einzelsprachlichen Bedeutung in einer konkreten referentiellen Funktion geschieht. Anders ausgedrückt setzt die Konstitution des Sinns eine Aktualisierung von Sprache im Vorgang des Sprechens voraus und diese Aktualisie- 
rung ergibt sich eben gerade bei der Produktion von gesprochenen oder geschriebenen Texten. Wenn Coseriu nun betont, Bezeichnung und Bedeutung bildeten zusammengenommen die formale Seite des Sinns als Inhaltseinheit höherer und komplexerer Art, so scheint mir Coseriu dennoch mit dem signifiant/signifié-Modell keine Progression oder Komplexitätssteigerung im semantischen Gehalt der Äußerung andeuten zu wollen. ${ }^{29}$ Ich möchte daher alternativ eine andere Interpretation vorschlagen.

Will man die linguistische Betrachtung auf das Sprechen in einer bestimmten Situation und unter besonderen Umständen konzentrieren - und genau das ist das Anliegen der Textlinguistik -, gleichzeitig aber von strukturalistischen Betrachtungsprinzipien ausgehen, die nicht mit denen der Sprechakttheorie übereinstimmen, so ist es sinnvoll, die Inhaltsseite des sprachlichen Zeichens, also die Bedeutung im Sinne Coserius, zum theoretischen Ausgangspunkt der semantischen Analyse zu machen. Wir befinden uns jedoch im Rahmen einer solchen einzelsprachlichen Bedeutungsanalyse - für die z.B. die Wortfeldtheorie eine geeignete methodische Basis abgibt - auf der abstrakten Betrachtungsebene sprachlicher Strukturierung und können noch keine Aussagen über die Verwendung der Bedeutungseinheiten (Zeichen) beim konkreten Sprechen machen. Aus der Gesamtkonzeption der Theorie des Sprechens, die Coseriu entworfen hat, ergibt sich nun, dass der Übergang von der abstrakten Bestimmung der Bedeutung hin zu einer Beschreibung ihrer pragmatischen Funktion auf der Ebene des Textes nur über die Vermittlung der universellen Betrachtungsebene vollzogen werden kann, auf der die Bedeutung zur Bezeichnung wird.

Die Bezeichnung kann nicht unabhängig von der Bedeutung eruiert und beschrieben werden. Sie ergibt sich aus dem Akt der Referentialisierung des sprachlichen Zeichens, für das die Bedeutung - als abstrakte Form des sprachlichen Inhalts - konstitutiv ist. Die Analyse dieses Referentialisierungsaktes kann sich jedoch in einer dreifachen Orientierung vollziehen. Zum einen ist es möglich, die Referentialisierung auf die einzelsprachliche Ebene zu beziehen und dadurch den engen Zusammenhang von Bedeutung und Bezeichnung in einer strukturellen Interpretation des sprachlichen Inhalts herauszustellen. ${ }^{30}$ Zum anderen ist es möglich, die Referentialisierung als einen formalen Akt des Sprechens im Allgemeinen zu betrachten. Diese universalistische Optik erfordert es, neben der Referentialisierung als allgemeiner Technik des Sprechens auch noch die allgemeinen Techniken der Alterisierung und Finalisierung mit einzubeziehen, um ein vollständiges Bild von der Produktion sprachlicher

${ }^{29}$ Diese Vorstellung könnte z.B. aus dem zitierten Schema abgeleitet werden.

${ }^{30}$ Auf diesen Zusammenhang bin ich bereits in den vorangegangenen Kapiteln ausführlicher eingegangen. 
Äußerungen zu erlangen. ${ }^{31}$ Brigitte Schlieben-Lange begründet in ihrer Publikation Traditionen des Sprechens in einer überzeugenden Weise, dass es Sinn macht, das Sprechen in einer grundsätzlichen Abhängigkeit von diesen drei universalen Techniken zu interpretieren (vgl. Schlieben-Lange 1983, 13-25). Dabei sorgt die Referentialisierung für die Bezugnahme auf die außersprachliche Welt, die Alterisierung für das Zustandekommen von Kommunikation und die Finalisierung für die Manifestation des Sprechens als zielgerichtetes Handeln. Schlieben-Langes Fazit lautet:

Referentialisierung, Finalisierung und Alterisierung von beidem - alle drei durch die Umfelder des Sprechens ermöglicht ${ }^{32}$ - sind also die fundamentalen Verfahren des Sprechens. Zu ihnen kommt noch die Möglichkeit der Selbstthematisierung, der Reflexivierung.

(Schlieben-Lange 1983, 25)

Die auf der universalistischen Ebene erlangte Einsicht, dass der Akt der Referentialisierung zumindest noch den der Alterisierung, gegebenenfalls auch den der Finalisierung mit einschließt, lässt den theoretischen Übergang von der Bezeichnung zum Sinn im konkreten Sprechakt, also von der denotativen zur pragmatischen Funktion des Sprechens, transparent werden. Hier eröffnet sich die dritte Optik, in der die Referentialisierung auf die textuelle Ebene bezogen werden kann. Dabei wird auch der enge Zusammenhang von universeller und individueller Schicht des Sprechens deutlich.

Wenn also in einer semantischen Ausleuchtung der drei unterscheidbaren Ebenen des Sprechens die Bezeichnung auf der Grundlage der Bedeutung bestimmt wird und der Sinn als 'textuelle Bedeutung' (als signifié, wie Coseriu sagt) auf die Bezeichnung zurückzuführen ist, so zeigt sich, dass der Sinn in der Tat alle sprachlichen Bedeutungsdimensionen in sich vereint. Er tut dies jedoch nur in Bezug auf einen individuellen, situativen Sprechakt, der an sich eine kontingente Form des Sprechens darstellt und für sich allein nicht als empirische Grundlage allgemeinerer Aussagen über das Sprechen taugt. Letztlich führt die Theorie des Sprechens scheinbar zu dem methodologischen Problem, die ganze Komplexität sprachlicher Bedeutung beim Sprechen erst auf der individuellen Betrachtungsebene ansiedeln zu können, ohne dass für diese Ebene eine Formalisierung der linguistischen Deskription im Sinne des Strukturalismus geschaffen werden könnte.

Die Feststellung dieses methodologischen Problems entspringt allerdings meiner Überzeugung nach einem falschen Verständnis von Coserius gesamter Theorie des Sprechens. Coseriu schlägt nämlich vor, das Sprechen in einem

${ }^{31}$ In diesem Sinne habe ich auch in Kapitel 1.1 vorgeschlagen, die Sprechtätigkeit im Allgemeinen mit dem Terminus 'sprachliche Interaktion' zu belegen.

${ }^{32}$ Die 'Theorie der sprachlichen Umfelder' geht auf Coseriu zurück; vgl. Coseriu 1975 und auch Kapitel 2.5. dieser Arbeit. 
umfassenden Sinn zu analysieren und differenziert gerade aus diesem Grund zwischen den einzelnen Betrachtungsebenen. Dabei geht er, wie wir bereits erörtert haben, vom Sprechen als Tätigkeit aus. Diese Tätigkeit des Sprechens ist in einer methodisch undifferenzierten Sichtweise immer konkret, individuell und aktuell, entspräche also in dieser Attribuierung der parole im Sinne de Saussures. Coserius Theorie des Sprechens ist aber keine Verfeinerung des Ansatzes von De Saussure, sondern der methodologische Vorschlag einer Differenzierung von drei Betrachtungsebenen, die alle drei Abstraktionen (und zwar jeweils von den beiden anderen Betrachtungsebenen) darstellen. Unter semantischem Aspekt ist also die Bedeutung eine Abstraktion von Bezeichnung und Sinn, die Bezeichnung eine Abstraktion von Bedeutung und Sinn und der Sinn eine Abstraktion von Bedeutung und Bezeichnung. ${ }^{33}$ Andererseits können nur Bedeutung, Bezeichnung und Sinn gemeinsam die Semantizität von Texten erklären.

Die Hierarchisierung von Bedeutung, Bezeichnung und Sinn in der gegebenen Reihenfolge entspricht einer theoretischen Induktion, die darauf hinweist, dass abstrakte Sprachfunktionen die Basis für den Akt der Referentialisierung bilden und dass die Referentialisierung ihrerseits als wesentlicher Aspekt sprachlicher Interaktion zu der konstitutiven Grundlage eines sprachlichen Sinns wird. Dabei ergibt sich eine Form der Progression, die nicht etwa einer semantischen Komplexitätssteigerung entspricht, ${ }^{34}$ sondern die die semantische Bestimmung durch die Einbeziehung nicht-sprachstruktureller Faktoren komplexer werden lässt. Die Bezeichnung ist also nicht komplexer als die Bedeutung, sondern die Bestimmung des sprachlichen Inhalts muss auf der denotativen Ebene zusätzlich die konkreten, aber allgemeinen Bedingungen und Umstände des Sprechens berücksichtigen. ${ }^{35}$ Ebenso ist der Sinn nicht komplexer als die Bezeichnung, sondern die Bestimmung des sprachlichen Inhalts muss auf der pragmatischen Ebene zusätzlich die situativen und individuell gegebenen kommunikativen Bedingungen und Umstände des Sprechens berücksichtigen.

Coseriu vermeidet es, die situativen und individuellen Bedingungen und Umstände des Sprechens im Rahmen einer Sprachpragmatik zu beschreiben,

${ }^{33}$ Nur so lässt sich z.B. Coserius Aussage verstehen, Bedeutung und Bezeichnung bildeten zusammen das signifiant des Textzeichens. Ohne die Annahme der entsprechenden Abstraktion erscheint es unsinnig, die sprachinhaltlich orientierten Begriffe 'Bedeutung' und 'Bezeichnung' als formale Ausdrucksseite eines Zeichens auf der Textebene zu werten.

${ }^{34}$ Denn der konkrete Sinn einer sprachlichen Äußerung muss nicht komplexer sein als die in ihr enthaltenen semantischen und denotativen Funktionen.

${ }^{35}$ Coseriu weist auf den besonderen Charakter dieser Bedingungen und Umstände in einer systematischen Analyse der allgemeinen Technik des Sprechens hin. Dabei entwirft er eine Theorie der sprachlichen Determinierung (zu der er auch das Phänomen der Aktualisierung rechnet) und eine Theorie der 'Umfelder des Sprechens'; vgl. Coseriu 1975. 
da er sich nicht von den Voraussetzungen der bekannten Sprechakttheorie leiten lässt. Stattdessen siedelt er die entsprechende Betrachtung auf der von ihm differenzierten Ebene des Textes an. Im Rahmen der Theorie des Sprechens konstituiert sich diese textuelle Ebene, für die die Produktion gesprochener Diskurse ebenso charakteristisch ist wie die geschriebener Texte, in der Form eines spezifischen Sprecherwissens, das Coseriu 'Textkompetenz' oder auch expressives Wissen nennt.

Das 'expressive' oder, wie ich neutraler formulieren möchte, textuelle Wissen, steht zunächst einmal in der Abhängigkeit der jeweils konkret gegebenen Kommunikationsbedingungen. In allgemeiner Hinsicht lassen sich vier determinierende Faktoren des Diskurses unterscheiden, nämlich Sprecher, Adressat, Gegenstand und Situation. Der Einfluss dieser vier Faktoren auf die Gestaltung des Diskurses ist dabei nicht unmittelbar gegeben, sondern wird über soziale Normen ermittelt. Coseriu weist explizit darauf hin, dass alle vier allgemeinen Determinationen des Sprechens auf der textuellen Ebene normativ geregelt sind:

(1) Der Sprecher

Es ist immer ein Sprecher da, der den Normen des Diskurses folgt und in dessen Sprechen diese Normen festzustellen sind.

(2) Der Adressat

Es gibt immer einen Adressaten des Sprechens. Auch ein geschriebener Text ist an eine andere Person oder an eine Kategorie von Personen gerichtet, und auch er bietet Möglichkeiten, sich an diesen Adressaten zu wenden, indem man ihn z.B. lieber Leser nennt. Es gibt Normen darüber, wie man mit bestimmten Kategorien von Personen spricht, z.B. mit Kindern, mit Frauen oder mit älteren Menschen.

(3) Der Gegenstand

Das Sprechen hat einen Gegenstand, nämlich das, worüber man spricht. Es gibt Normen, wie man über bestimmte Sachen spricht, z.B. über Gegenstände der Wissenschaft, Gegenstände des alltäglichen Lebens oder erfundene Gegenstände.

(4) Die Situation

Man spricht jeweils in einer besonderen Situation bzw. unter bestimmten Umständen, d.h. in einer besonderen Relation zum Adressaten und zum Gegenstand. Es gibt Normen, die den besonderen Situationstyp betreffen. So ist es beispielsweise etwas völlig anderes, über ein bestimmtes sprachwissenschaftliches Problem eine Vorlesung zu halten oder einen volkstümlichen Vortrag, oder über das gleiche mit einem Freund oder in der Familie zu sprechen.

Die Normen, die die allgemeinen Determinationen des Sprechens betreffen, werden nur selten explizit als solche formuliert. Sie werden aber vorausgesetzt, wenn das expressive sprachliche Wissen bewertet wird.

(Coseriu 1988a, 160)

Die Normen der Textkonstitution werden in Coserius Publikation Sprachkompetenz ausführlich behandelt und mit Beispielen belegt (vgl. Coseriu 1988a, 161ff.). Coseriu geht darauf ein, wie man mit Kindern und wie man 
über Sachen spricht. Er stellt die Frage nach den Normen von Textgattungen und beschreibt den normalen Aufbau einer Nachricht. Er wendet sich den formalen Normen des Sonetts und der Textart 'Syllogismus' als rhetorischer Figur zu. Schließlich behandelt er ausführlich den Bereich der Grußformeln in verschiedenen Sprachen. Es zeigt sich an diesen Beispielen der normativen Gestaltung von Texten, dass die betreffenden Normen nicht einzelsprachlich, sondern sozial und damit kulturell fixiert sind. Die Textkompetenz ist also ein kulturelles Wissen par excellence, das von Formen, Ausdrucksweisen und Darstellungsarten gesellschaftlichen Zusammenlebens geprägt ist und dabei nur mittelbar in der Abhängigkeit von Sprachstrukturen steht.

Das so verstandene textuelle Wissen ist von dem einzelsprachlichen Wissen in Bezug auf die Textstrukturierung zu unterscheiden. So gibt es Normen, die auf der Ebene des Textes wirksam werden, aber einzelsprachlich gebunden sind. Sie gehen auf das Verständnis des Textes als oberhalb des Satzes liegender 'Struktureinheit der Einzelsprache' zurück, nicht aber auf das Verständnis des Textes als Produkt individuellen Sprechens. Solche den Text betreffenden Normen der Einzelsprache ermittelt Coseriu gleichermaßen in der Syntax, der Grammatik und der Lexik. Als lexikalisches Beispiel führt er das deutsche Verb meckern an:

Es ist dies ein Verb, das (in seiner 'übertragenen' Bedeutung) auf eine bestimmte Textfunktion fixiert ist, nämlich die Funktion 'Ablehnung der unbegründeten Kritik eines anderen' oder 'Feststellung, dass die Kritik eines anderen unbegründet ist'. Der, der meckert, ist also immer der andere: [...] Das Verb meckern ist einerseits ein Element des deutschen Wortschatzes, andererseits ist es aber etwas, was einer besonderen Textfunktion entspricht. Für diese Textfunktion können in anderen Sprachen vergleichbare Ausdrücke zur Verfügung stehen; sie können aber auch im Wortschatz völlig fehlen. Das Französische hat hier kein eigenes Wort, sondern die syntaktische Konstruktion trouver à redire oder avoir à redire; redire allein ist in dieser Bedeutung nicht möglich.

(Coseriu 1988a, 169; vgl. auch ders. 1994, 42)

Das Beispiel lässt die von Coseriu hervorgehobenen drei Ebenen der Semantizität gut erkennen. Meckern hat im Deutschen die Bedeutung 'unfreundlich Kritik üben', es wird beim Sprechen auf den Angesprochenen oder eine dritte Person bezogen. Erst auf der Interpretationsebene des Textes zeigt sich jedoch, dass diese Referentialisierung-einer geltenden Norm entsprechend - grundsätzlich den Sprecher selbst ausklammert und dadurch den Sinn einer 'Ablehnung der geäußerten Kritik' bzw. ihrer Bewertung als 'ungerechtfertigt' bekommt. Die soziale Stabilisierung dieser nur textuell verifizierbaren Norm könnte zu der Lexikalisierung des entsprechenden Sprachinhalts führen, d.h. $\mathrm{zu}$ der Integration der normalen Konnotation in die einzelsprachliche Bedeu- 
tung des Wortes. Diese Lexikalisierung lässt sich den deutschen Wörterbüchern zur Zeit aber noch nicht entnehmen.

Trotz ihrer teilweise recht engen Verbindung zur einzelsprachlichen Strukturierung weisen die Normen, die für die Konstitution von Texten als Textgattungen, Textsorten oder individuelle Diskurse verantwortlich sind, in der Regel eindeutig über die einzelsprachliche Interpretation des Textes hinaus. Coseriu zeigt sogar auf, dass es Normen gibt, die spezifische Texttraditionen begründen und dabei in besonderen Fällen die Geltung einzelsprachlicher Strukturen aufheben können. Im Wesentlichen geht es ihm aber um den Hinweis darauf, dass die textkonstituierenden Normen in ihrer Mehrzahl über- bzw. außereinzelsprachlich zu definieren sind. Dabei gibt es eine große Spannbreite von der formalen Fixierung insbesondere kürzerer Textarten - z.B. der metrisch festgelegten Form eines Sonetts ganz gleich in welcher Sprache - bis hin zu der Feststellung situationspezifischer Sprechweisen, die zwar typisch für die Deutschen, Franzosen oder Spanier sein können, es aber nicht für das Deutsche, Französische oder Spanische sind.

Der Bewertungsmaßstab für die Einhaltung von Normen der Textkonstitution beim Sprechen ist derjenige der Angemessenheit. Insbesondere kann ein Diskurs in Bezug auf die allgemeinen Determinationen des Sprechens als 'unangemessen' gelten. Dies ist der Fall, wenn eine Sache 'inadäquat' dargestellt wird, jemand etwas 'Unpassendes' zu einem anderen sagt oder eine Äußerung in einer gegebenen Situation 'unangebracht' erscheint. ${ }^{36}$ Diese Bewertungen sind als Reaktionen auf die Abweichung von einer gegebenen Norm des Sprechens zu interpretieren. Sie finden aufseiten der naiven Sprecher statt, wenn die Abweichung über ein gewisses Toleranzmaß hinausgeht. Für die linguistische Beschreibung ist es allerdings sehr schwer, solche Normen und das Maß ihrer Toleranz zu spezifizieren. Sie werden zwar in der Textkompetenz des einzelnen Sprechers sozial erlernt und intuitiv erfasst, jedoch kaum je verbalisiert. Die Deskription des textuellen Wissens stellt daher ein besonderes methodisches Problem dar.

Für Coseriu besteht eine Aufgabe der Textlinguistik darin, „die Normen festzustellen, die das expressive Wissen gestalten und die der Bewertung als 'angemessen' oder als 'nicht angemessen' zugrundeliegen“" (Coseriu 1988a, 183). Darüber hinaus setzt er der Textlinguistik das Ziel, den Sinn als die textspezifische Inhaltsebene zu erkennen und die sprachlichen Ausdrucksformen dieses Sinns interpretativ zu bestimmen. Coseriu schlägt für diese zweite Zielsetzung, also für die 'Linguistik des Sinns' eine komplexe Methodik vor, die als eine Form der linguistischen Analyse auf dem Verfahren der Kommutation aufbaut, in ihrer stilistischen Ausrichtung aber eine differenzierte Applikation

${ }^{36}$ Vgl. zu dieser Terminologie: Coseriu 1988a, 180. 
der Prinzipien des Textverstehens in hermeneutischer Tradition darstellt. Der Entwurf dieser Textlinguistik à la Coseriu ist den entsprechenden Ausführungen seiner gleichnamigen Publikation (Coseriu 1994) im Detail zu entnehmen. Allerdings spielt diese 'Linguistik des Sinns' für meinen Untersuchungszweck keine wesentliche Rolle und soll daher hier nicht weiter erörtert werden. Ich möchte stattdessen dieses Kapitel mit einer Reflexion darüber abschließen, inwieweit die Normenbestimmtheit der textuellen Wissensebene für die Zielsetzung der hier vorliegenden Untersuchung zum Sprachgebrauch in Fachkontexten relevant ist.

Die Einbeziehung der textuellen Wissensebene in meine Untersuchung ist schon deshalb notwendig, weil Gespräche in der Form standardisierter Interviews und damit Diskurse der gesprochenen Sprache als empirische Datenbasis gewählt wurden. Es ist sinnvoll, sich Rechenschaft darüber abzulegen, inwieweit diese Diskurse situativ (Ort und Zeit), durch die gegebenen Umstände (Befragungsanlass, Grad der 'Zwanglosigkeit', etc.) und durch die vorhandenen Gesprächspartner (Interviewer und Befragter, ggf. weitere Anwesende) geprägt werden. Von noch entscheidenderer Bedeutung aber ist die Themenspezifizierung des Interviews als Gegenstand des Gesprächs (Grad der thematischen Einengung, Einschätzung des Fachniveaus, etc.). Es steht außer Frage, dass die in der Untersuchung zugrunde gelegten Interviews authentische Diskurse darstellen. Welcher Art diese Authentizität jedoch ist, muss gerade in Bezug auf die determinierenden Faktoren des Sprechens geklärt werden. Dabei ergibt sich notwendigerweise die Einsicht, dass die typischen Gesprächsanlässe fachkontextuellen Sprechens in der Region nicht systematisch erfasst werden konnten, da dies außerhalb der empirischen Möglichkeiten der Untersuchung lag. Andererseits zeigt sich, dass die ermittelten Diskurse, u.a. durch ihre feste thematische Strukturierung und ihre Vergleichbarkeit, aber auch durch die Auswahl der Probanden, in besonderer Weise für den Untersuchungszweck geeignet sind. Diese Eignung lässt sich eben auf die Konstanz und Variation der Determinationen des Sprechens zurückführen.

Die konkreten Auswertungen der Interviews und ihre jeweiligen Vergleiche werden die entscheidende Rolle vor Augen führen, die die regional geltenden sozialen Normen, zu denen auch die normativ vermittelte Faktizität des Untersuchungsgegenstands selbst zu rechnen ist, für die Gestaltung der Diskurse haben. Diese Normen werden vorrangig auf der Ebene der allgemein-sprachlichen Kompetenz, d.h. auf der Ebene des sprachlichen Wissens, das Bezüge zu der Bezeichnung des Gegenständlichen (in unserem Fall des Fachlichen) herstellt, zu ermitteln sein. Ebenso wie diese Normen jedoch dabei beständig auf einzelsprachliche Strukturen rekurrieren, so stehen sie auch in einem engen Zusammenhang mit den Normen der Gestaltung von Texten. Die ermittelten Diskurse gehören nämlich vorrangig zu bestimmten Modalitäten des Spre- 
chens (antworten, benennen, beschreiben, etc.) bzw. zu spezifischen Textarten, wie z.B. der Sacherklärung oder der Gegenstandsbestimmung (Definition). Es gehört zu den Zielsetzungen der empirischen Untersuchung, diese textuellen Determinationen und Normabhängigkeiten angemessen $\mathrm{zu}$ berücksichtigen, um Fehlinterpretationen zu vermeiden. 


\section{Aspekte der sprachwissenschaftlichen Beschreibung des regionalen Sprachgebrauchs in Fachkontexten}

\subsection{Das soziolinguistische Verständnis der Sprachvariation}

Es entspricht einer Tradition sprachwissenschaftlicher Analyse, die Vielgestaltigkeit der Erscheinungsformen einer historischen Sprache auf ihr Funktionieren als gesellschaftliches Kommunikationsmedium zurückzuführen. Ich betrachte dies als den soziolinguistischen Aspekt der Sprachvariation oder, vom Faktum selbst her, als die soziale Variabilität der Sprache. Dieser Sichtweise entspricht ein kommunikatives Sprachverständnis, das auf das Phänomen sprachlicher Interaktion ausgerichtet ist. Die entscheidenden Faktoren dieser sprachlichen Interaktion sind zum einen die beteiligten Gesprächspartner, zum anderen die kommunikative Situation selbst. Die konkrete Ausgestaltung der sozialen Variabilität einer Sprache im Kommunikationsakt hängt von einer Reihe durch diese beiden Faktoren jeweils gegebener Voraussetzungen $a b$.

In seinem Buch Varieties of Contemporary French gibt Malcolm Offord $(1990,56)$ folgendes Schaubild von der Struktur der sozialen Varietät von Sprache:

\section{The structure of a variety}

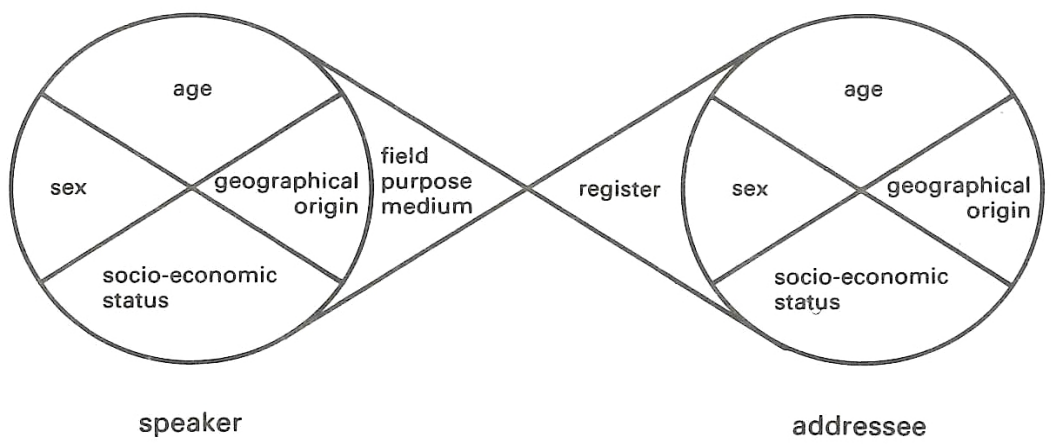

Sowohl auf der Seite des Sprechers als auch auf der des Adressaten unterscheidet Offord vier Aspekte der biographischen Voraussetzung des Kommunikanten, die selbst nicht sprachlich sind, wohl aber direkten Einfluss auf den Sprachgebrauch nehmen. Es sind dies im Einzelnen das Alter, das Geschlecht, 
der sozio-ökonomische Status und die geographische Herkunft. Nach der herkömmlichen Interpretation sind mit den beiden zuletzt genannten Aspekten vor allem das Bildungsniveau des Sprechers bzw. Hörers und der Grad seiner Bindung an eine Region gemeint, also die Aspekte der diastratischen und diatopischen Determination. Neben diesen biographischen Voraussetzungen, die Einfluss auf das Sprechen nehmen, gibt es nun weitere Faktoren, die der Versprachlichung des Kommunikationsaktes direkt zuzurechnen sind und die Offord aus diesem Grund auch als interactional factors bezeichnet. Es handelt sich dabei auf der einen Seite um die thematische Ausrichtung der Kommunikation (Offord betrachtet diese als auf ein Themengebiet fokussiert, geht also von der sujet-Gebundenheit der Mitteilung aus) und das kommunikative Anliegen (denn es gibt immer einen Zweck der Mitteilung, auch wenn dieser bisweilen nicht pragmatisch $\mathrm{zu}$ bestimmen, sondern nur psychologisch $\mathrm{zu}$ ergründen ist). Auf der anderen Seite variiert das Sprechen in einer Kommunikationssituation auch hinsichtlich der Wahl des Mediums (gemeint ist in erster Linie der Unterschied zwischen geschriebener und gesprochener Sprache) sowie derjenigen eines bestimmten Registers, durch das insbesondere der Formalitätsgrad des Sprachgebrauchs bestimmt wird.

In Anlehnung an die von Offord vorgenommene Differenzierung schlage ich vor, in Bezug auf eine gegebene Kommunikationssituation die folgenden Aspekte der sozialen Variabilität von Sprache zu unterscheiden:

1) Biographische Voraussetzungen der Kommunikanten

2) Referentielle und pragmatische Charakteristika des Kommunikationsgegenstands

3) Situative Auswahl der Modalität und Form des Sprechens

Die unter Punkt 1) genannten biographischen Voraussetzungen erfassen bereits alle wesentlichen gesellschaftlichen Determinationen der sprachlichen Variation. Sie charakterisieren den Sprecher durch seine sozio-ökonomische Position als zugehörig zu einer Schicht, zu einer bzw. mehreren Gruppen und zu einer Ethnie (vgl. Berruto 1980, 56-124). Sie weisen ihn darüber hinaus als weiblich oder männlich und als Repräsentanten einer bestimmten Altersgruppe aus. Hinzu kommt die Integration in einen geographischen Lebensraum, die-je nach Intensität-weit mehr als nur die Annahme einer mundartlichen Sprachform impliziert. Der Sprecher wird nämlich immer durch die alltägliche Erfahrung seiner unmittelbaren Lebensrealität geprägt.

Die unter den Punkten 2) und 3) subsumierten Faktoren lassen sich demgegenüber als situative Determinanten der sprachlichen Variation kennzeichnen. Gaetano Berruto macht in seinem Buch La variabilità sociale della lingua darauf aufmerksam, dass der kanadische Sprachwissenschaftler Michael Gre- 
gory hierzu schon in den 60er Jahren einen fundamentalen Erklärungsansatz geliefert hat: ${ }^{37}$

Gregory, a cui ci rifaremo specificamente qui, distingue anzitutto due grandi classi di 'categorie' della diversificazione in una lingua: la variazione 'dialettale' ('il riflesso linguistico di caratteristiche dell'utente nelle situazioni linguistiche, ragionevolmente permanenti') e quella 'diatipica' ('il riflesso linguistico di caratteristiche ricorrenti dell'uso que l'utente fa della lingua in situazione'). La prima, come sappiamo, si manifesta principalmente (a parte il caso dell'idioletto) nelle categorie 'temporale', 'geografico', 'sociale' e 'standard' (il criterio che contrassegna lo standard è qui il grado di intelligibilità).

La variazione diatipica - ed è qui che la tipologia delle dimensioni si fa più interessante - si manifesta secondo tre parametri, che interagendo fra loro determinano questa o quella varietà nell'impiego situazionale concreto. I tre parametri, o dimensioni (che Gregory chiama 'categorie contestuali', in quanto agganciano la realizzazione linguistica con i suoi tratti specifici al contesto dato delle categorie della situazione) sono: il field of discourse ('campo di discorso'), il tenor of discourse ('tenore di discorso'), il mode of discourse ('modo di discorso'). Essi corrispondono rispettivamente alle 'categorie situazionali' (extralinguistiche) 'ruolo intenzionale dell'utente', 'relazione col destinatario' (che può essere vista dai due punti di vista 'personale' e 'funzionale'), 'relazione col mezzo'.

(Berruto 1980, 36f.)

Gregorys Vorstellung von der 'diatypischen Variation' der Sprache impliziert die Tatsache, dass sich der Sprecher in einer kommunikativen Situation mit drei Parametern auseinandersetzt und auf diese in einer jeweils bestimmten Weise reagiert: den Kommunikationsgegenstand, den Gesprächspartner und das sprachliche Medium selbst. Dabei vermittelt der Sprecher zwischen den außersprachlichen Gegebenheiten der Kommunikationssituation und der ihm möglichen sprachlichen Variation in einer Weise, die bezüglich des Kommunikationsgegenstandes das 'Feld' (field), bezüglich des Gesprächspartners den 'Tenor' (tenor) und bezüglich des sprachlichen Mediums den 'Modus' (mode) konstituieren. Das 'Feld' steht auf diese Weise in der Abhängigkeit der kommunikativen Intention und des Bezugs auf die reale oder eine vorgestellte Welt. Der 'Tenor' umfasst sowohl die persönliche - sozial verankerte und emotiv geprägte - Beziehung zum kommunikativen Du als auch die funktionale kommunikative Ausrichtung auf das Gegenüber, die z.B. ein Auffordern, Überreden, Benachrichtigen, Erklären, Drohen oder Schmeicheln sein kann. Der 'Modus' schließlich meint das Sprechen - als Übertragung von Lauten oder in der Form der Schrift - in seiner Expressivität und Gestaltung in Abhängigkeit von den objektiv und subjektiv gegebenen sprachlichen Mög-

${ }^{37}$ Vgl. Gregory in Spencer (Hg.) 1964 und Gregory/Caroll 1978. Gregorys Theorie der 'diatypical variation' ist vor allem im englischen Sprachraum stark rezipiert worden. Auch Malcolm Offord (1990) steht in dieser Tradition. 
lichkeiten. Nach Gregory ergeben field, tenor und mode zusammen die 'textuelle Varietät' des register, das somit eine spezifische, mehrdimensional begründete situative Form der Sprachverwendung darstellt. ${ }^{38}$ Häufig wird das Register in einer typischen Kommunikationssituation aber auch nur durch einen der drei Faktoren - field, tenor oder mode - dominiert bzw. maßgeblich geprägt, so dass die beiden anderen Faktoren nur noch sekundär zum Aufbau des Registers beitragen. Im Falle der hier vorgelegten Untersuchung beziehe ich mich beispielsweise ausschließlich auf situative Varietäten des Sprechens, die im Sinne Gregorys 'feldbestimmt' sind, da es mir um das Sprechen in einem bestimmten Fachkontext geht. Gegenüber dieser beherrschenden Determination durch das 'Feld' erweist sich die Einflussnahme von 'Tenor' und 'Modus' auf das Sprechen als zweitrangig. Gewisse Konstanten des 'Tenors' waren in persönlicher Hinsicht ein durch die fachliche Interessenbekundung motiviertes freundschaftlich zwangloses Zugehen auf den Interviewer und in funktionaler Hinsicht die kommunikativen Handlungen des Benennens, Erklärens und Beschreibens. Der 'Modus' war in der Regel durch eine nur wenig formelle und teilweise recht affektive Ausdrucksweise gekennzeichnet. Insgesamt entsprachen fast alle Register der geführten Interviews in diesem Sinne ein und demselben Typus 'textueller Varietät'.

Kommen wir nun noch einmal auf die drei Aspekte der sozialen Variabilität von Sprache zurück, die weiter oben unterschieden worden sind, um auf einige Besonderheiten dieser Sichtweise aufmerksam zu machen.

Die biographischen 'Gegebenheiten' stellen personenbezogene Fakten dar, die das Sprechen in der Kommunikationssituation definieren und die die Gesprächspartner zum Teil gar nicht, zum Teil nur sehr schwer und keinesfalls

${ }^{38}$ Dieser komplexe register-Begriff der anglosächsischen Tradition, der u.a. von dem bekannten englischen Sprachtheoretiker M.A.K. Halliday (1978) noch weiter differenziert und ausgearbeitet wurde, muss von der Definition des Sprachregisters als Funktionalstil in Anlehnung an die Prager Schule deutlich unterschieden werden (vgl. Berruto 1980, 39ff. u. 49 ff.). Er ist insbesondere auch nicht mit der diaphasischen Dimension bzw. einer Abstufung nach Formalitätsgraden des Sprechens zu verwechseln. Offords Definition des register ist in diesem Sinne sehr unklar gehalten (vgl. Offord 1990, 53ff.). Vgl. zur weiteren Klärung Berruto 1980, 46: „I funzionalisti britannici tendono a usare la categoria di registro come termine generale per designare ogni tipo di varietà situazionale (o varietà 'diatipica'), e ad accentuarne, in genere, la caratterizzazione in termini semantici. Tipica a questo proposito è la concezione hallidayana: per Halliday, un registro è 'ciò che si sta dicendo (in una data occasione), determinato da ciò che si sta facendo (la natura dell'attività sociale in cui si è impegnati), ed esprimente la diversità del processo sociale (la divisione sociale del lavoro)', per cui, 'in linea di principio i registri sono modi [ways] di dire cosi diferenti, e tendono a differire per la semantica (e quindi per la lexicogrammar [lessico + grammatica] e talvolta per la fonologia, in quanto realizzi quest'ultima)'; la loro manifestazione specifica sono le 'varietà occupazionali (tecniche, semi-tecniche)', i 'casi estremi' sono le 'lingue ristrette' o le 'lingue per scoppi speciali'; e, infine, sono controllati, come variabili principali, da campo ('tipo di azione sociale'), tenore ('relazioni di ruolo') e modo ('organizzazione semiologica').“ 
kurzfristig in der Situation verändern oder beeinflussen können. In gewisser Hinsicht handelt es sich bei Alter, Geschlecht, sozio-ökonomischem Status (Bildungsniveau, Beruf, etc.) und geographischer Herkunft daher um Konstanten, die der Sprecher als Kommunikant selbst mit einbringt und auf die er beim Kommunikationspartner reagiert. Ein Hauptaspekt der sprachlichen Variation des Kommunikationsaktes liegt demnach in der Konstellation der Gesprächspartner begründet. Diese Konstellation kann in Bezug auf die einzelnen Faktoren homogener oder heterogener Natur sein. In jedem Fall aber ist die Einschätzung des Adressaten eine wichtige Bedingung sprachlichen Handelns. Die biographischen Voraussetzungen des Kommunikanten haben daher nicht nur Konsequenzen für seinen eigenen Sprachgebrauch, sondern auch für den des Gesprächspartners. Das diesbezügliche Sprachverhalten steht in der Abhängigkeit sozialer Normen, die erst allmählich durch die besonderen Forschungsinteressen der Soziolinguistik aufgedeckt werden. Mein eigener Beitrag zu dieser Erweiterung sprachsoziologischer Erkenntnisse soll sich auf die Dimension der geographischen Herkunft des Sprechers konzentrieren, d.h. genauer auf seine Bestimmtheit durch die (normativ vermittelte) Realität der Region, in der er lebt.

Die Tatsache, dass auch der Kommunikationsinhalt eine zentrale Rolle bei der Ausgestaltung sprachlicher Variation spielt, wird sowohl in der soziolinguistischen als auch in der strukturalistischen Sprachwissenschaft häufig übersehen. Das, worüber man spricht, und das, was man mit seiner Mitteilung bezweckt, macht aber gerade die Vielfalt und Vielgestaltigkeit von Kommunikationssituationen aus. Es ist eben in der Regel nicht zufällig, was jemand einem anderen mitteilt, und der Sprecher schätzt auch meist genau ab, in welcher Form er mit dem anderen spricht, um etwas Bestimmtes zu erreichen. Die Berücksichtigung der Person des Gesprächspartners und die Wahl einer für die Situation geeigneten Sprachform ist in diesem Sinn von dem mitzuteilenden Inhalt abhängig und nicht umgekehrt. In gewisser Hinsicht wird das Sprechen daher in erster Linie durch seinen Gegenstand bestimmt.

Der prioritäre Zusammenhang von Kommunikationsgegenstand und sprachlicher Variation ist erst im Rahmen der Fachsprachenlinguistik und einiger ihr verwandter Ansätze so richtig entdeckt und in das analytische Blickfeld gerückt worden. Dabei lässt sich in einer absoluten Sichtweise der Dinge behaupten, dass alles Sprechen in der Welt fachlich gebunden ist, jedenfalls insofern es darstellender Natur ist. ${ }^{39}$ Die Möglichkeit der Differenzierung des gesamten Weltwissens in Fächer wird uns bei der Behandlung der Fachsprache im engeren Sinne noch beschäftigen. Es handelt sich bei diesem Versuch einer

${ }^{39}$ Vgl. zu dieser Präzisierung Karl Bühlers Organon-Modell (Unterscheidung der Funktionen Ausdruck, Appell und Darstellung des sprachlichen Zeichens) sowie die Hervorhebung der Darstellungsfunktion der Sprache in Bühlers Sprachtheorie. 
horizontalen Gliederung des Fachsprachlichen um einen enzyklopädischen Ansatz, der insbesondere im Rahmen der Lexikologie bereits sprachwissenschaftliche Tradition besitzt. Offord verweist in diesem Zusammenhang auf den 1852 erschienenen Thesaurus des englischen Lexikographen Roget sowie auf das 100 Jahre später erschienene Begriffssystem als Grundlage für die Lexikographie von Rudolf Hallig und Walther von Wartburg (Berlin 1952), das eine Grobunterteilung in die Bereiche (1) das Universum, (2) der Mensch und (3) der Mensch und das Universum vornimmt (Hallig/Wartburg 1952, XIVf.).

Die Variation des Kommunikationsgegenstands ist aber nicht potentieller Natur, sondern ein Charakteristikum des konkreten Diskurses bzw. Gesprächs in seinem Verlauf. Nach Offord stellt sich dies im Alltag so dar:

In other words, for conversation to occur a field of discourse has to be selected from the infinite variety of topics available to the average speaker. A conversation does not necessarily, does not even usually, consist of a single topic: a number of fields may be involved. In the course of a day, the average speaker will undoubtedly converse on a very large number of topics, some trivial, some highly significant, some charged with emotion, others purely factual, some accessible to everyone, some exclusive because of their technical character.

(Offord 1990, 52)

Wenn man mit Offord die thematische Variation eines Gesprächs als interactional factor der Kommuniktionssituation betrachtet, dann macht es Sinn, das 'Feld' (field) als bestimmendes Moment der Interaktion in Abhängigkeit von der Finalität der Kommunikationshandlung (purpose) zu interpretieren. Letztlich gibt es immer nur eine Abhängigkeit des Kommunikationsgegenstands vom Kommunikationszweck und nicht umgekehrt. Offord weist nun darauf hin, dass der Kommunikationszweck durch die soziale Position des Sprechers, d.h. die Rolle, die er in der Gesellschaft spielt, entscheidend geprägt wird. Diese Prägung kann beruflicher Art sein, aber auch anderen sozialen Funktionen des Kommunikanten entsprechen. Die gesellschaftliche Einbindung in Sachbereiche korrespondiert in dieser Hinsicht, je nach Intensität, mit einem mehr oder weniger frequenten Aufkommen von Gesprächsanlässen zu bestimmten 'Feldern'. Auf meine Untersuchungsgebiete übertragen hieße das: Wer von Wäldern umgeben in einer ruralen Gemeinschaft lebt und mehrere Hektar Wald sein Eigen nennt, wird relativ oft Anlass zum Reden über den Wald haben. Und wer in die Produktion von Orangen eingebunden ist, eigene Felder besitzt oder am Handel mit Zitrusfrüchten beteiligt ist, dessen Gesprächsthema wird häufig und besonders im beruflichen Sektor der Orangenanbau sein.

Über diese speziellen gesellschaftlichen Prägungen des Lebens hinaus und, wie ich meine, oft mit ihnen verbunden, gibt es auch eine allgemeine Determination von Kommunikationsanlässen durch die Integration des Sprechers 
in ein individuelles soziales Umfeld bzw. durch seinen Wunsch nach dieser sozialen Integration. Offord beschreibt sie so:

At a deep psychological level speech is engaged in to avoid loneliness, to form a bond with other human beings, to avoid the anguish of mental and emotional isolation. It is vital for self-awareness, which derives from the warmth and consolation which contact with other human beings provides; it is through conversation that a person is able to share her or his life with another. More precisely people indulge in conversation to express their needs, thoughts, desires, hopes and plans: in other words to project their own inner feelings. In addition they indulge in conversation to enter into two-way communication by enquiring, encouraging, criticizing and discovering information from another person or persons.

(Offord 1990, 51)

Es erscheint mir wichtig, auf die enge Verflechtung der äußeren Zwecken dienenden und der persönlich motivierten Gestaltung sprachlicher Interaktionsanlässe hinzuweisen, so wie sie für das soziale Leben im Alltag (d.h. auch im beruflichen Alltag) typisch sind. Die situationelle Betrachtung von Kommunikationen und der mit ihnen verbundenen sozialen Variation von Sprache muss letztlich immer aus einer pragmatischen Perspektive erfolgen, die auch psychologische Aspekte mit berücksichtigt. Dies gilt für die thematische Gestaltung der Diskurse ebenso wie auch hinsichtlich der Auswahl der Modalität und Form des Sprechens.

Es ist nicht zufällig, ob sich ein Sprecher der gesprochenen oder der geschriebenen Sprache bedient. Neben sachlichen Faktoren, die für diese Wahl ausschlaggebend sind (so u.a. die räumliche Distanz der Kommunikationspartner), geht es dabei vor allem um die Verwendung einer konzeptionell mündlichen oder konzeptionell schriftlichen Sprache. Peter Koch und Wulf Oesterreicher haben diese Differenzierung sehr schön als Sprache der Nähe und Sprache der Distanz beschrieben (vgl. Koch/Oesterreicher 1985). Sie beziehen sich mit dieser Beschreibung, ähnlich wie Offord, auf die psychologische Dimension sprachlicher Interaktion. ${ }^{40}$ Als die typischen Kommunikationsbedingungen der Sprache der Nähe nennen sie Privatheit, Vertrautheit,

${ }^{40}$ Es ist zu vermuten, dass in der anglosächsischen Tradition (vgl. Fußnote 38) die Unterscheidung von Sprache der Nähe und Sprache der Distanz weitgehend dem Gesichtspunkt der Konzeption des 'Registers' sprachlicher Handlungen zugeordnet würde. Das Argument wäre hier, dass der Sprecher - einem psychisch fundierten Grundanliegen sprachlicher Kommunikation folgend - sich stets soweit auf die Sprache der Nähe einlässt, wie er dies in Bezug auf den Gesprächspartner, den Kommunikationsgegenstand und die Umstände der Kommunikation für sozial vertretbar hält. Die Sprache der Distanz wäre demnach eine sozial oktroyierte Sprachform, die einer Überlagerung persönlich motivierter Kommunikation durch äußere, sachbedingte Kommunikationszwecke entspräche. Koch/Oesterreicher haben meines Wissens diesen funktionalistisch orientierten Interpretationsansatz ihrer Theorie selbst nicht angedacht. Er würde aber z.B. eine Erklärung für die intuitiv gegebene positivere Konnotierung der Sprache der Nähe gegenüber der Sprache der Distanz darstellen. 
Emotionalität, Situations- und Handlungseinbindung, physische Nähe, Dialogizität, Spontaneität usw. Demgegenüber charakterisieren sie die Sprache der Distanz als eine Sprache der Öffentlichkeit, der Fremdheit, ohne Situationsund Handlungseinbindung, meist gekennzeichnet durch physische Distanz, Monologizität und Reflektiertheit. ${ }^{41}$ Diese Charakterisierungen verstehen sie als theoretische Polarisierungen des Sprachgebrauchs, der sich konkret immer an einem bestimmten Punkt zwischen diesen idealtypischen Sprechweisen befindet und von Kommunikationssituation zu Kommunikationssituation hinsichtlich dieser Situierung variiert. Der Übergang von der Sprache der Nähe zur Sprache der Distanz ist in diesem Sinne nicht graduell, sondern kontinuierlich durch die Vielzahl der realen Kommunikationssituationen besetzt. Allerdings lassen sich auf dieser Kontinuitätsskala textsortenspezifische Abstufungen erkennen.

In einem engen Zusammenhang mit der Wahl der von Koch und Oesterreicher hervorgehobenen Modalität des Sprechens steht auch der jeweils gewählte Grad an Formalisierung. Auf die Tatsache, dass es dem einzelnen Sprecher möglich ist, diesen Formalitätsgrad selbst zu bestimmen, ist im Rahmen der sog. Registeranalysen einzelner Sprachen immer wieder hingewiesen worden. Diese Bestimmungsmöglichkeit ist einerseits eine Folge der Situationsgebundenheit des Sprechens, insofern nämlich die Wahl des Registers von den kommunikativen Umständen abhängt. Anderseits trägt der Sprecher durch die Registerwahl auch aktiv zu der situationellen Differenzierung des Sprechens bei, indem er der Kommunikationssituation einen stilistischen Wert verleiht. Über die Menge und Art der einem Sprecher in einer Sprache zur Verfügung stehenden Register bzw. Stilebenen lässt sich nur in Bezug auf diese Sprache selbst etwas aussagen. Das Französische verfügt hier z.B. über einen besonders ausgeprägten, wenn auch keineswegs klar gegliederten Variationsbereich (z.B. hinsichtlich der Unterscheidung von français parlé, français familier, français populaire und français vulgaire), während das Spanische nur wenige Differenzierungsmöglichkeiten dieser Art bietet. Insgesamt ist die Verbindung der Formalitätsregister bzw. des Sprachstils mit anderen Dimensionen der Sprachvarietät, vor allem der sozio-kulturellen (z.B. im Falle des argot) und der dialektalen (wie-besonders ausgeprägt-im Italienischen) so eng, dass es schwerfällt, die stilistische Variation isoliert zu betrachten. Ich werde auf diesen Aspekt an späterer Stelle noch zurückkommen und zeigen, dass eine sprachliche Standardvarietät die Funktion übernimmt, als kommunikativ wirksamer Referenz des normalen Sprechens den wesentlichen Bezugspunkt für das stilistische Abweichungsverhalten zu konstituieren.

${ }^{41}$ Vgl. das Schema in Koch/Oesterreicher 1990, 12, ähnlich auch in dieselb. 1985, 23. 
Nachdem ich nun eine Reihe von Einsichten in die soziale Variabilität der Sprache aufgezeigt habe, möchte ich abschließend ihre Relevanz für die Analyse unseres Untersuchungsgegenstandes hervorheben.

Der regionale Sprachgebrauch in Fachkontexten stellt sich unter soziolinguistischem Gesichtspunkt als eine Form des situationsspezifischen Sprechens dar, die vorrangig durch ihre thematische Gebundenheit gekennzeichnet ist. Der thematische Rahmen wird dabei durch das jeweilige Fach in seiner sozialen Wirklichkeit, d.h. - genauer - durch einen gesellschaftlich relevanten Sachbereich konstituiert, dem oft wichtige Berufs- und Freizeitsektoren in der Region entsprechen. Die regionale Determination des Sprechens ist in diesem Sinne ein kommunikativer Reflex, der sowohl durch die in der Sprachgemeinschaft geltenden Normen des Sachbereichs, als auch durch die individuelle Apperzeption seiner regionalen Realität ausgelöst wird. Dieser komplexe Vorgang bezieht sich wiederum sekundär auf die Beziehungsstrukturen der Gesprächspartner untereinander, indem diese z.B. Kriterien wie 'Vertrautheit', 'Sachkenntnis', 'Integration', 'Betroffenheit', 'Engagement' und 'Affektivität' zur Grundlage einer nahen kommunikativen Beziehung werden lassen, die negative Bestimmtheit dieser Kriterien aber eine kommunikative Distanz hervorruft. Die Gestaltungsform des Diskurses zeigt darüber hinaus an, welche Einschätzung der Kommunikationssituation der Sprecher jeweils vornimmt. Die typischen 'Versprachlichungsstrategien' der konzeptionellen Mündlichkeit werden dabei zu Indikatoren einer vertrauten Gesprächsführung, bei der sich der Sprecher - in unserem Fall der Interviewte - trotz der fachlichen Themenfixierung des Gesprächs bisweilen weit von der typischen Formalität fachsprachlicher Diskurse entfernt und oft auch die Darstellung persönlicher Erfahrungen mit einbringt. Dabei muss jedoch unterschieden werden, ob dieses Sprechverhalten auf die sachliche bzw. theoretische Unkenntnis des Gegenstands oder auf die individuelle Einschätzung der Kommunikationsbedingungen zurückzuführen ist. Koch/Oesterreicher (1990, 10f.) betonen, dass insgesamt vier verschiedene Arten von Kontexten für die Ausgestaltung des Nähe- oder Distanzsprechens ausschlaggebend sind. Im Einzelnen:

- der situative Kontext (Personen, Gegenstände, Sachverhalte)

- der Wissenskontext (einerseits individuell in Bezug auf den Gesprächspartner, andererseits allgemein, d.h. soziokulturelles und universales Wissen betreffend)

- $\quad$ sprachlich-kommunikative Kontexte ('Ko-Text')

- nichtsprachliche bzw. parasprachliche kommunikative Kontexte (Intonation, Gestik, Mimik) 
Offensichtlich tragen der situative Kontext, der individuelle Wissenskontext und die kommunikativen Kontexte im Sinne dieser Auflistung zu der variablen Gestaltung des Sprechens in einer Kommunikationssituation bei und müssen daher auch im Rahmen der Auswertung unserer fachbezogenen Interviews berücksichtigt werden. Allerdings bin ich der Überzeugung, dass der 'allgemeine Wissenskontext', den Koch/Oesterreicher in diesem Zusammenhang ebenfalls nennen und zu dem sie einerseits 'kulturelle Tatsachen, Werte, usw.', andererseits 'logische Relationen, physikalische und biologische Gesetzmäßigkeiten usw.' rechnen, keinen Faktor der 'diasituativen' Varietät des Sprechens darstellt und daher auf einer ganz anderen Analyseebene angesiedelt werden muss. Meine Untersuchung wird sich vorrangig mit den Auswirkungen des 'allgemeinen Wissenskontextes' im Sinne der Einflussnahme eines regional determinierten soziokulturellen Wissens auf das Sprechen beschäftigen. Dabei möchte ich gerade zeigen, dass die Determination des Sprechens durch diesen 'allgemeinen Wissenskontext' prinzipiell autonom ist und nicht einfach unter die Differenzierung von Nähe- und Distanzsprechen subsumiert werden darf. Diese von mir vertretene Sichtweise knüpft an Coserius Theorie des Sprechens an. Sie ist in diesem Sinne weder eine Abwertung der situativen Parameter des Sprechens (die auf der textuellen Wissensebene zu untersuchen sind) noch leugnet sie die Affinität des durch das allgemein-sprachliche Wissen geprägten Sprechens - in unserem Fall des Sprechens in Fachkontexten - zu einer bestimmten Form der nähe- oder distanzsprachlichen Kommunikation. Die konkreteren Zusammenhänge werden sich dabei in der empirischen Analyse zeigen. 


\subsection{Das Problem der Formalisierung einzelsprachlicher Varietäten}

Wie wir gesehen haben, legt die soziolinguistische Analyse der Sprachvariation ihren Schwerpunkt auf das Sprechen in einer Kommunikationssituation und berücksichtigt systematisch alle Faktoren, die für die sprachliche Interaktion bestimmend sind. Diese Betrachtungsweise wird häufig mit dem Phänomen einzelsprachlicher Varietät verwechselt oder durcheinandergebracht. Um die Konfusion zu vermeiden, ist es zweckmäßig, zwischen dem Untersuchungsgegenstand des situativen Sprechens und dem der 'Architektur' der Einzelsprache zu unterscheiden. Die Erforschung der sozialen Variabilität der Sprache führt zu einer 'diasituativen' ${ }^{42}$ Interpretation des Sprechens. Demgegenüber differenziert das Phänomen der einzelsprachlichen Varietät eine gegebene historische Sprache nach verschiedenen Variationsdimensionen. Unter ihnen können bei einer synchronischen Betrachtung die 'diatopische', die 'diastratische' und die 'diaphasische' heute als allgemein anerkannt gelten. Ihre begriffliche Einführung geht auf die Romanisten Leiv Flydal ('diatopisch' und 'diastratisch', 1951) und Eugenio Coseriu ('diaphasisch', 1958, in Ergänzung) zurück (vgl. Coseriu in Energeia und Ergon I, 50).

Die trichotomische Terminologie von Diatopik, Diastratik und Diaphasik ist als ein geschlossenes Analysekonzept zu verstehen und wird auch in diesem Sinne von Coseriu konsequent verteidigt. Die weit verbreitete Anerkennung der Begrifflichkeit hat jedoch inzwischen zu einer großen Spannbreite des Verständnisses der einzelnen Begriffe und zu der leider oft mangelnden Präzision im Umgang mit diesen Termini geführt. Ausdruck dieser linguistischen 'Vulgarisierung' der Termini ist die Tatsache, dass oft ohne eine differenzierte sprachtheoretische Begründung Modifikationen an dem Analysemodell vorgenommen werden, so etwa durch die Reinterpretation von 'diaphasisch' als 'diasituativ' oder die Hinzufügung des Begriffs 'diamedial' (bzw. in italienischer Tradition 'diamesisch') zum Zwecke der Unterscheidung 'gesprochen/geschrieben'. Darüber hinaus werden oft besondere Erscheinungsformen einzelsprachlicher Varietät aus diesem Schema herausgelöst, so dass viele Linguisten z.B. Standardsprachformen nicht zur diatopischen Variation, bestimmte Gruppensprachen nicht zur diastratischen Variation oder die Fachsprachen nicht zur diaphasischen Dimension rechnen. Der exhaustive Anspruch des trichotomischen Analysemodells in Bezug auf das Phänomen einzelsprachlicher Varietät wird meist außer Acht gelassen. Auf diese Weise

${ }^{42}$ Ich schlage vor, durch diesen Terminus an die anglosächsische Konzeption der diatypical variation im Deutschen anzuknüpfen. Vgl. hierzu Nabrings, 1981, 140, die jedoch unter diesem Variationstyp Klassifizierungen subsumiert, die ich der diaphasischen Variation zuordnen würde. 
gehen jedoch wesentliche Gesichtspunkte der sprachwissenschaftlichen Interpretation verloren.

Die strukturalistische Auseinandersetzung mit der einzelsprachlichen Varietät folgt einer funktionellen Sprachauffassung, die sich von der Vorstellung der systemgebundenen Variation des Sprechens leiten lässt. Diese Vorstellung darf allerdings nicht - so wie es oft fälschlich kritisiert wurde - mit dem Postulat der Homogenität des Sprechens in der Kommunikationssituation verwechselt werden. Die strukturalistische Interpretation der einzelsprachlichen Varietät besagt vielmehr, dass es möglich ist, abstrakte Strukturmuster einer historischen Sprache zu bestimmen, durch die diese in der Vielfalt ihrer Manifestationsformen beschrieben und charakterisiert wird. Diese abstrakten Strukturmuster der Sprache werden von Coseriu funktionelle Sprachen genannt. Die Soziolinguistik-sofern sie einer strukturellen Interpretation der Sprache offen gegenüber steht-bezeichnet sie meist als Teil- oder Subsysteme der Sprache. Als neutraler Terminus bietet sich wiederum Varietät, diesmal in einer pluralisierbaren Bedeutung an. Es gibt demnach mehrere einzelsprachliche Varietäten die sich grob als Erscheinungs- oder Realisationsformen einer historischen Sprache definieren lassen und in theoretischer Hinsicht eine Konsequenz aus dem allgemeinen Phänomen einzelsprachlicher Varietät (als grundlegender Qualität der Einzelsprache) darstellen. Die sprachwissenschaftliche Untersuchung dieser einzelsprachlichen Varietäten, die sog. Varietäten-linguistik, gilt allgemein als eine Domäne der Soziolinguistik. So schreibt z.B. Gaetano Berruto unter dem Stichwort 'Varietät' im HSK-Band zur Soziolinguistik:

In der Soziolinguistik operiert man allgemein mit dem Terminus Varietät, um die Grundeinheit der Forschung auf der Ebene des sprachlichen Systems zu bezeichnen. $[\ldots]$

Eine sprachliche Varietät dadurch aus, daß gewisse Realisierungsformen des Sprachsystems in vorhersehbarer Weise mit gewissen sozialen und funktionalen Merkmalen kookkurrieren. Wenn eine Menge von gewissen kongruierenden Werten bestimmter sprachlicher Variablen (d.h. Realisierungen gewisser Formen, die in der betreffenden Sprache variieren) zusammen mit einer gewissen Menge von Merkmalen auftreten, die Sprecher und/oder Gebrauchssituationen kennzeichnen, dann können wir von einer sprachlichen Varietät sprechen.

(Berruto, 1996, 189)

Berruto hebt in seiner Definition der sprachlichen Varietät den wichtigen $\mathrm{Zu}$ sammenhang von sprachstruktureller und soziolinguistischer Bestimmung des Begriffs hervor. Dabei löst er jedoch die Sprachstruktur in eine 'Menge von Werten sprachlicher Variablen' (= Formen mit mehr als einer Realisierung) auf. Diese Sichtweise entspricht dem Ansatz der sog. Variationsgrammatik, deren methodisches Ziel in der empirischen Beschreibung einzelsprachlicher Variation liegt. In der modernen Sprachwissenschaft ist dieser Ansatz aller- 
dings nicht unumstritten geblieben. Ich möchte daher im Folgenden kurz auf einige wesentliche Kritikpunkte eingehen.

Harald Weydt und Brigitte Schlieben-Lange haben sich in einem FestschriftBeitrag mit dem Titel ,Wie realistisch sind Variationsgrammatiken?‘ (1981) programmatisch mit dem Thema auseinandergesetzt. Ihre Kritik gerät dabei zu einer grundsätzlichen Verteidigung des strukturalistischen Ansatzes gegenüber einigen soziolinguistisch fundierten Erklärungsmodellen amerikanischer Provenienz aus den 70er Jahren sowie auch gegenüber dem variationslinguistischen Modell von Wolfgang Klein (1974). Die Einwände der beiden Autoren richten sich dabei gegen eine Reihe theoretischer Schwächen dieser Methoden, die in der jüngeren Entwicklung der amerikanischen Soziolinguistik größtenteils erkannt und kompensiert worden sind. Die in sprachtheoretischer Hinsicht fundamentale Argumentation von Schlieben-Lange und Weydt macht ihren Beitrag jedoch zu einem interessanten Ansatzpunkt der Diskussion einzelsprachlicher Varietäten. Ich möchte daher zu einigen von den Autoren vorgebrachten Argumenten Stellung beziehen.

Die Autoren betonen die Unangemessenheit einer Methodik, die versucht, ein formalistisches Beschreibungsmodell systematisch auf die sprachliche Wirklichkeit zu übertragen. Ihrer Ansicht nach läuft eine solche Methodik Gefahr, das tatsächliche Sprachverhalten der Sprecher nicht hinreichend zu berücksichtigen, da dieses in einer anderen Weise als durch systematische Variationsregeln der Sprachverwendung bestimmt sei. Die Kommentierung des bekannten 'Tassen'-Experiments von William Labov macht deutlich, worum es bei dieser Kritik geht:

Labov untersucht, wie seine englischen Informanten verschiedene Gefäße benennen. Er schließt, unter Einfluß von Black (...), daß die Begriffe cup u.ä. vage seien. Uns erscheint eine Erklärung wie die von M. Faust (...) richtiger, der bemerkt, es handle sich nicht darum, daß etwa der Begriff cup im Englischen unklar oder vage sei, sondern vielmehr darum, daß man die Gegenstände variieren kann, so daß es in einzelnen Fällen schwierig ist, sie unter die - völlig klaren - Begriffe zu subsumieren. (Weydt/Schlieben-Lange 1981, 128)

Das Problem liegt in der Unterscheidung von 'Substanz' und 'Form' in der linguistischen Analyse. Schlieben-Lange und Weydt betonen, dass die Betrachtung der substantiellen Ebene des Sprechens nicht das Faktum der einzelsprachlichen Formalisierung erfasst, die für die Sprachkompetenz der Sprecher ausschlaggebend ist. Dabei wird jedoch nicht ganz klar, wo der wesentliche Unterschied zwischen Substanz und Form in Bezug auf die Sprache zu suchen ist. Es drängt sich die Vermutung auf, dass die Autoren mit der Form des Sprechens ausschließlich die funktionalistische Betrachtungsebene des europäischen Strukturalismus meinen und dabei anderen Ansätzen einen Formalisierungsanspruch vollständig absprechen. Dies aber käme einer sehr weitreichen- 
den Verabsolutierung des eigenen Ansatzes gleich. Es ist in diesem Zusammenhang zu berücksichtigen, dass Coseriu, auf den sich die beiden Autoren berufen, das Prinzip der Substanz als ein konstitutives Element der 'positivistischen Ideologie in der Sprachwissenschaft' ansieht und wie folgt beschreibt:

Das Prinzip der Substanz bedeutet, daß jeder Tatbestand als das betrachtet wird, was er 'ist', also als 'Substanz', und, wenn es sich um einen materiellen Sachverhalt handelt, sogar als das, was er für die physische Erfahrung 'ist', und nicht im Hinblick auf das, was er 'bewirkt' bzw. wozu er 'dient', d.h. nicht vom Gesichtspunkt seiner Funktion oder seines Zweckes aus. ${ }^{43}$

(Coseriu 1988b, 31)

Aus Coserius eigener Argumentation lässt sich nicht ohne weiteres ableiten, dass es sich bei der nicht-strukturalistischen Sprachwissenschaft grundsätzlich um Analysemethoden handelt, die das Prinzip sprachlicher Formalisierung missachten. Seine Argumentationsführung ist hier in der Tat wesentlich differenzierter. Die Berücksichtigung des angedeuteten methodologischen Hintergrunds führt daher zu einem klareren Verständnis der von Schlieben-Lange und Weydt vorgebrachten Kritik. Den Autoren geht es nämlich letztlich um nichts anderes als um die Verteidigung eines funktionalistischen Sprachverständnisses gegenüber den empirisch orientierten Ansätzen der (amerikanischen) Soziolinguistik, deren Sprachbegriff nicht mit den Vorstellungen des europäischen Strukturalismus korrespondiert.

Betrachten wir die von Schlieben-Lange und Weydt vertretenen Thesen unter diesem Aspekt etwas genauer: Die Autoren behaupten zunächst einmal, dass Variationsgrammatiken an der Realität des Sprechens in dem Sinne vorbeigehen, dass sie nicht die tatsächliche Sprachkompetenz des Sprechers zum Maßstab ihrer Betrachtung machen. Dieses Argument ist schwerwiegend, sofern nachgewiesen werden kann, dass die Formalisierung des Sprecherwissens nicht mit der Anwendung kontinuierlich strukturierter Variationsregeln erfasst werden kann. Die mangelnde Fortune der Variationsgrammatiken in der jüngeren und jüngsten Sprachwissenschaft gibt den Autoren hier offensichtlich Recht. Darüber hinaus ist jedoch die Frage zu stellen, ob eine geeignete Formalisierung des Sprecherwissens in der Tat von dem Prinzip der funktionalistischen Sprachbetrachtung im Sinne des europäischen Strukturalismus abhängt. Schlieben-Lange und Weydt sind dieser festen Überzeugung und verbinden sie mit der Forderung nach der Beachtung des Sprachsystems in der sprachwissenschaftlichen Deskription:

${ }^{43}$ Coseriu stellt dem Substanzprinzip in der Sprachwissenschaft, das er als überholt ansieht, das 'Funktionsprinzip' des modernen sprachwissenschaftlichen Verständnisses gegenüber. Insgesamt setzt er sich mit einer Reihe von kontradiktorischen Prinzipien auseinander, um die Abgrenzung zwischen Positivismus und Antipositivismus in der Sprachwissenschaft aus historiographischer Perspektive zu erklären (vgl. Coseriu 1988, 9-91). 
Eine funktionelle Beschreibung eines Sprachsystems zu geben, heißt nichts als das Netz der relevanten, distinktiven Funktionen, die dem jeweiligen Sprechen zugrundeliegen, zu identifizieren und zu beschreiben.

(Weydt/Schlieben-Lange 1981, 132)

Die Autoren fordern daher, 'System' oder 'funktionelle Sprache' so aufzufassen, ,daß sie das jeweils realisierte System von Möglichkeiten an einem beliebigen Punkt des jeweiligen Sprechens darstellt" (S. 136) und verschreiben sich somit der Vorstellung, die Sprachkompetenz des Sprechers sei maßgeblich durch die Kenntnis verschiedener funktioneller Sprachen innerhalb einer historischen Sprache bestimmt. ${ }^{44}$ Coserius Theorie stellt aber auch diese Sichtweise in ein differenzierteres Licht. In seiner Publikation Sprachkompetenz gelangt er sogar dazu, die diskrete Beschreibung funktioneller Sprachen als Methodik zur Ermittlung der Kompetenz eines Sprechers vollständig abzulehnen. Die entsprechenden Hinweise haben in der Rezeption Coserius bislang zu wenig Beachtung gefunden:

Wenn wir mehrere Beschreibungen (zu ergänzen: funktioneller Sprachen) machen, haben wir auf jeden Fall ein Nebeneinander von getrennten oder, wie man sagt, diskreten Beschreibungen. Im sprachlichen Wissen sind dagegen die Kenntnisse, die ein Sprecher auch von anderen Mundarten hat, nicht getrennt. Sie sind in seine Kompetenz integriert und bestehen als Parallelmöglichkeiten zu seiner 'Hauptmundart'. Beim Sprecher besteht gerade nicht ein Nebeneinander, sondern eher ein Übereinander.

Die Elemente, die man bei jeder Beschreibung einer funktionellen Sprache erfaßt, sind in diese Sprache integriert, d.h. sie hängen grundsätzlich mit allen übrigen Elementen dieser Sprache zusammen. Was aber der Sprecher einer funktionellen Sprache von anderen funktionellen Sprachen weiß, hängt nur lose mit den übrigen Elementen des jeweils anderen Sprachsystems zusammen, die diesem Sprecher vielleicht gar nicht bekannt sind. (Coseriu 1988a, 154, Hervorhebungen vom Verf.)

Das Zitat unterhöhlt die Argumentation, die Schlieben-Lange und Weydt zur Verteidigung des strukturalistischen Ansatzes hervorgebracht haben: Aus demselben Grunde nämlich, aus dem Variationsgrammatiken - wie die Autoren hervorheben - nicht 'realistisch' sind, ist auch die Beschreibung diskreter funktioneller Sprachen kein geeignetes Mittel, die Sprachkompetenz des Sprechers, so wie sie für sein sprachliches Handeln verantwortlich ist, deskriptiv zu erfassen. Coseriu nimmt hier nicht etwa eine nachträgliche Korrektur seines

${ }^{44}$ Diese Vorstellung hat sprachkonzeptionell und methodisch gesehen weitreichende Konsequenzen. Sie hat z.B. Thomas Stehl dazu veranlasst, die von ihm empirisch im Bewusstsein der Sprecher ermittelten 'Gradata' (Übergangsformen) zwischen Dialekt und Hochsprache als 'funktionelle Sprachen' im Sinne Coserius zu interpretieren. Die konkrete Anregung zu dieser Interpretation findet sich in dem Aufsatz von Weydt und Schlieben-Lange $(1981,135)$. 
eigenen Ansatzes vor, sondern er stellt die Betrachtung der Einzelsprache (und ihre Beherrschung) in Relation $\mathrm{zu}$ einem komplexen Begriff sprachlicher Kompetenz, der mehrere Betrachtungsebenen zu berücksichtigen hat, wenn er darstellen will, 'was ein Sprecher wirklich tut'. Auch Schlieben-Lange und Weydt werden im Übrigen auf diesen problematischen Aspekt aufmerksam:

In Hinsicht auf den Sprecher stellt sich die interessante Frage, wie die sprachliche Variation für ihn gegeben ist. Hier müßten Unterschiede zwischen verschiedenen Graden der Kompetenz (aktiv-passiv-Identifizierung über Signalmerkmale), der Status von Leit- und Modellvarietäten und die Regeln, die die Übersetzung und Zuordnung zwischen den verschiedenen Varietäten leiten, untersucht werden.

(Weydt/Schlieben-Lange 1981, 139)

Im Rahmen meines eigenen theoretischen Ansatzes greife ich den Gedanken der 'Leit- und Modellvarietäten' bzw., wie es bei Coseriu heißt, der 'Hauptmundart' des Sprechers auf und interpretiere ihn als die normative Setzung einer Standard-Varietät in der Sprachkompetenz des Sprechers. Anders ausgedrückt bin ich der Überzeugung, dass ein Sprecher mit einer Einzelsprache immer nur dann kommunikativ umgehen kann, wenn er sein Sprechen auf der Basis des Gebrauchs einer Standard-Varietät gestaltet. ${ }^{45}$ Der Aspekt der Sprachvariation macht es aber erforderlich, diese Standard-Varietät als flexiblen Standard zu konzipieren, der grundsätzlich für die Integration von Elementen aus anderen Varietäten offen ist. Eine genauere Darstellung dieser Konzeption und ihrer theoretischen Implikationen werde ich in Kapitel $2.4 \mathrm{zu}$ geben versuchen. An dieser Stelle erscheint es mir hingegen wichtig, darauf hinzuweisen, welcher Stellenwert der Formalisierung einzelsprachlicher Varietäten in dieser theoretischen Konzeption zukommt.

Die formale Abgrenzung einzelsprachlicher Varietäten macht sowohl für den Strukturalisten als auch für den Soziolinguisten Sinn. Dabei hängt die Interpretation der Varietät als sprachlicher Erscheinungsform selbstverständlich von dem gewählten Ansatz ab. Der methodische Zweck der Abgrenzung ist jedoch in jedem Fall derselbe, da es sich stets um einen Beschreibungsansatz der sprachlichen Wirklichkeit handelt, zu dem der Sprecher und das Sprachverhalten des Sprechers in Bezug zu setzen sind. Ich halte es in diesem Sinne für methodisch wenig sinnvoll, nach einer Beschreibung einzelsprachlicher Varietäten zu suchen, die in der Lage ist, die Sprachkompetenz des Sprechers direkt abzubilden. Der Zugriff der Sprachkompetenz (des Sprecherwissens) auf das Phänomen einzelsprachlicher Variation ist nämlich in jedem Fall so kompli-

${ }^{45}$ Diese Standard-Varietät kann in bestimmten Gesprächssituationen z.B. auch ein dialektaler Standard, ein gruppenspezifischer Standard oder ein fachsprachlicher Standard sein. In den meisten Fällen wird es sich jedoch um den gängigen Standard der gesprochenen Umgangssprache handeln. 
ziert, dass er weder durch eine Variationsgrammatik noch durch die Beschreibung verschiedener funktioneller Sprachen befriedigend dargestellt werden kann. Andererseits kann das Sprachverhalten eines Sprechers und insbesondere sein Gebrauch der Einzelsprache kaum ohne die Unterscheidung von Sprachvarietäten beschrieben werden. Die Frage, ob diese Sprachvarietäten im Bewusstsein der Sprecher als diskret anerkannt werden oder nicht ist dieser Beschreibung nachgeordnet. Sie kann Begründungen für das Sprachverhalten liefern, aber dieses nicht erklären.

Unter diesem Gesichtspunkt ist auch das vieldiskutierte Thema der kontinuierlichen Übergänge zwischen den Sprachvarietäten eher müßig. Es hängt nämlich in erster Linie von der Optik des einzelnen Sprachwissenschaftlers (und nicht von der des Sprechers) ab, ob die Übergänge als scharf oder unscharf empfunden werden. ${ }^{46}$ Die von Schlieben-Lange und Weydt vermutete Tatsache, dass die Sprecher entlang dieser Übergänge „Kristallisationspunkte für einheitliche Techniken des Sprechens finden“ (S. 140) ist ein interessanter Gedanke, der insbesondere durch Thomas Stehl bestätigt worden ist. ${ }^{47}$ Er gibt einen Hinweis darauf, wie sich die Sprecher in der Komplexität der sprachlichen Variation, die durch Situationen des Sprachkontakts noch erheblich gesteigert wird, zurechtfinden. Ich verfolge im Rahmen meines theoretischen Ansatzes eine ganz ähnliche Konzeption, die sich jedoch auf eine Theorie sprachlicher Standardisierung beruft. Diese Theorie geht von der sprachgeschichtlich orientierten These aus, dass der Ausbildung einzelsprachlicher Varietäten ein antagonistisches Prinzip in der Konzentration auf sprachliche Standards gegenübersteht.

Es ist nun an der Zeit, deutlich zu sagen, auf welche Konzeption einzelsprachlicher Variation ich mich in dieser Arbeit berufe. Die Antwort auf diese Frage hängt entscheidend mit der Ausrichtung meines Untersuchungsinteresses zusammen. Die strukturalistische Differenzierung in diatopische, diastratische und diaphasische Varietäten stellt für meine empirische Untersuchung keinen geeigneten Ansatzpunkt dar, da sie sich auf einer abstrakten linguistischen Ebene dem Phänomen einzelsprachlicher 'Architektur' zuwendet und die Systemhaftigkeit der formalen Unterscheidungen auf der Basis eines funktionalistischen Sprachbegriffs zu erkennen sucht. Es handelt sich in diesem Sinne nicht um einen methodischen Ansatz, der auf dem kommunikativen Sprach-

${ }^{46}$ Das Zusammenspiel von Quantität und Qualität spielt hier eine wesentliche Rolle. So ist z.B. die simple Unterscheidung von Hochsprache und Dialekt ein sprachwissenschaftliches Analysemodell, das unweigerlich von den 'naiven Sprechern' bestätigt werden wird. Wenn hingegen in dem analytischen Modell zusätzlich zwei, drei oder vier Übergangsvarietäten unterschieden werden, so stellt die Abgleichung mit dem Sprachbewusstsein der Sprecher den Linguisten schon vor eine kompliziertere Aufgabe.

${ }^{47}$ Vgl. Stehl 1991. Vor Stehl hat bereits R. Muhr (1981, vgl. 46, 136) ebenfalls auf dieses Phänomen in einer empirischen Untersuchung aufmerksam gemacht. 
verständnis basiert, das ich in der Sprachtheorie Coserius als konstitutiv ansehe. Der Grund für dieses Missverhältnis von sprachtheoretischer Basis und sprachdeskriptiver Methodik ist aber einfach zu erklären. Er hängt mit der Fixierung des Varietätenmodells von Coseriu zusammen, das die Sprachvarietät ausschließlich auf der Ebene der Einzelsprache analysiert. Die meiner Untersuchung zugrunde liegende Methodik ist jedoch weiter gefasst und berücksichtigt die Sprachkompetenz auf allen drei unterscheidbaren Ebenen des Sprechens. Das gemeinsame Maß dieser Analyse ist somit nicht mehr die funktionelle Sprache, sondern das Sprachwissen des einzelnen Sprechers, der seinen individuellen Weg im Umgang mit der einzelsprachlichen Variation findet.

Die Soziolinguistik greift den Aspekt der Sprachvariation meistens im Rahmen der Analyse des situativen Sprachverhaltens auf, dessen relevante Faktoren im vorangegangenen Kapitel behandelt worden sind. Zum Teil konzentriert sie sich jedoch auch auf die Realisation einzelsprachlicher Varietäten innerhalb der gesamten Sprachgemeinschaft. Insbesondere in der Italianistik gibt es einen solchen Untersuchungsschwerpunkt, der aus der Beschäftigung mit dem Phänomen des Sprachkontakts von Dialekt und Hochsprache erwachsen ist. Die Erläuterung regional bestimmter Sprachvariation ist dabei häufig nur die Basis für kompliziertere Interpretationen unter den Aspekten einer sozialen und stilistischen Differenzierung. Gaetano Berruto hat in dieser sprachwissenschaftlichen Tradition des Italienischen ein komplexes Varietätenstrukturmodell entwickelt, das den Blick für die Zusammenhänge von sprachstruktureller und sprachfunktionaler Interpretation bewahrt. Berruto erklärt die Differenzierung des zeitgenössischen Italienisch in einem Modell, das auf drei verschiedenen Achsen der Sprachvariation (diastratico, diafasico, diamesico ${ }^{48}$ das komplizierte Ineinandergreifen von Übergängen und Polarisierungen des Sprachverhaltens auf der sozialen Ebene verdeutlicht (vgl. Berruto 1987, 21). Die strukturelle Identifizierbarkeit der einzelnen Varietäten wird von Berruto in ein Konzept sprachvariationeller Kontinuität integriert, das die Existenz sog. 'Verdichtungen' (addensamenti, vgl. Berruto 1987, 29 f.) zu seiner Interpretationsgrundlage macht. Dieses Konzept ist jedoch im Grunde nichts weiter als die Applikation eines Beschreibungsmodells, dessen Bezug auf das Sprachverhalten des einzelnen Sprechers nicht deutlich wird. ${ }^{49}$

Als methodische Grundlage meiner Untersuchungen zum regionalen Sprachgebrauch in Fachkontexten ziehe ich daher ein Konzept sprachlicher

${ }^{48}$ Die regionale Variation des Italienischen wird in dieses Modell nicht integriert, da sie als Grundkonstante der Existenzformen des gesprochenen Italienischen angesehen wird.

49 In Berruto (1980) und Berruto (1987) lassen sich in dieser Hinsicht keine konzeptionellen Gemeinsamkeiten in der Behandlung des Themas der Sprachvariation erkennen. Dies ist trotz des thematischen Unterschieds der beiden Monographien ein bedauerliches Manko. 
Varietäten vor, das diese auf der Ebene der Einzelsprache differenziert, dabei jedoch den Bezug zum Sprecherverhalten nicht außer Acht lässt. Nur ein solches Konzept ist geeignet, die Begriffe 'Regionalsprache' und 'Fachsprache' in einer Weise zu interpretieren, die ihre strukturelle Analyse ermöglicht, sie aber zugleich in kein festes System formal abgegrenzter Varietäten zwingt. Wolfdietrich Hartung hat in den 80er Jahren diese Sichtweise zusammen mit einer Arbeitsgruppe (unter Mitwirkung von Helmut Schönfeld) entwickelt. Es handelt sich dabei um einen Beitrag der empirischen Forschung zur Sprachvariation in der ehemaligen DDR, der eine umfassende Analyse der gesellschaftlich relevanten Faktoren des variierenden Sprechens der Einzelsprache gibt. Methodischer Ansatzpunkt ist die Feststellung der sprachlichen Heterogenität in einer Weise, die als Spannungsfeld von Kontinuität und Diskontinuität beschrieben werden kann. Die Einzelsprache wird in diesem Spannungsfeld zunächst als eine 'Variantenmenge' charakterisiert, was der Zugrundelegung eines substantiellen Sprachbegriffs im Sinne Coserius entspricht. Die auf diesem Sprachbegriff aufbauende Definition der Varietät ist jedoch eine eindeutig funktionell orientierte Interpretation der Sprachwirklichkeit:

Die Sprachen, die sich aus regional, situativ oder sozial verteilten Variantenmengen konstituieren, unterscheiden sich kaum in jeder Hinsicht. Im allgemeinen weisen sie eine große Zahl von Übereinstimmungen auf, nicht nur in Einzelmerkmalen, sondern in weiten Bereichen der einzelnen sprachlichen Ebenen. Dies ist der sprachliche Reflex des Kontinuums auf der Textebene. Es handelt sich hier im strengen Sinne also gar nicht um eigentliche oder selbständige Sprachen, eher um bestimmte Ausprägungen einer übergeordneten oder zugrundeliegenden Sprache, um Varianten oder Bestandteile einer solchen Sprache, die durch einen Kern gemeinsamer Merkmale zusammengehalten werden. Terminologisch wird dieses Eingeordnetsein unterschiedlich gefaßt, man spricht von Subsprachen, Subsystemen, Varietäten, Sprachformen oder - für eine spezielle Teilmenge - auch von Existenzformen einer Sprache. (Für die Gesamtheit solcher Untergliederungen werden wir im folgenden vornehmlich die relativ neutrale und verbreitete Bezeichnung Varietät verwenden. Wir meinen damit systemhafte und im Sprecherbewußtsein verankerte Manifestationen einer 'abstrakten Sprache', nicht notwendigerweise Modifikationen oder Varianten einer 'konkreten Sprache'. In diesem Sinne ist die deutsche Literatursprache ebenso eine Varietät 'des Deutschen', wie es beliebige deutsche Dialekte oder - mit gewissen zusätzlichen Bestimmungen - Umgangssprachen sind).

(Kommunikation und Sprachvariation 1981, 75 f.)

Hartungs Sichtweise sprachlicher Varietät ist mit der zu Beginn des Kapitels wiedergegebenen Definition Berrutos durchaus kompatibel. Sie weist auf die zentrale Bedeutung hin, die der Aspekt der Sprachverwendung für die Bestimmung sprachlicher Varietät hat. Kirsten Nabrings ordnet den entsprechenden Untersuchungsschwerpunkt dem sog. 'funktionalistischen Ansatz' in der 
Variationsforschung $\mathrm{zu}$, der ihrer Meinung nach der vielversprechendste ist und den sie programmatisch wie folgt charakterisiert:

Die Heterogenität der Sprache erscheint in diesem Ansatz als unmittelbarer Ausfluß der unterschiedlichen lebensweltlichen Zusammenhänge, in denen Sprache gebraucht wird, so daß die Verflochtenheit von Sprache und Sozialstruktur, d.h. die engen Beziehungen zwischen den verschiedenen in einer Gesellschaft möglichen Interaktionsformen und unterschiedlichen sprachlichen Varietäten, den Ausgangspunkt der Überlegungen bilden. Nicht die variable Ausformung gleicher Schemata, letztlich also immer gleicher kommunikativer Absichten, steht hier im Mittelpunkt, sondern die Untersuchung der für unterschiedliche kommunikative Absichten verwendeten typischen Sprachformen.

(Nabrings 1981, 15 f.)

Dieser Ansatz erlaubt es, die Varietäten der Einzelsprache als 'geschlossene Gebilde' zu betrachten, die unterschiedliche Formen des Sprachgebrauchs darstellen. ${ }^{50}$ Allerdings ist der auch in der Soziolinguistik immer wieder hervorgehobene Aspekt des Systemhaften hier in der Tat zweitrangig. Er verweist allein auf die Tatsache, dass es charakteristische sprachliche Merkmale dieser Formen des Sprachgebrauchs gibt, ohne dass ihre Identifizierung mit einem funktionalistischen Anspruch in der sprachstrukturellen Beschreibung einhergehen könnte. In diesem Sinne folge ich Nabrings auch nicht, wenn sie im abschließenden Teil ihres Buches über Sprachliche Varietäten diese als 'Realisationsmuster des Sprachsystems' auf der strukturalistischen Beschreibungsebene wiederzufinden glaubt und sie mit der von Coseriu definierten Normebene identifiziert. Nabrings bringt hier genau die methodischen Verfahren durcheinander, die ich sauber zu trennen versuche. Die Verwechslung ist umso riskanter, als der Einfluss von Normen auf die Konstitution sprachlicher Varietäten außer Frage steht. Es handelt sich aber um eine andere Art von Normierung als diejenige, die Coseriu als Beschreibungsebene zwischen Sprachsystem und Rede ansiedelt. Ich werde in den folgenden Kapiteln noch weitere Erklärungen hierzu geben.

50 „Demgegenüber bezeichne ich mit dem Begriff 'sprachliche Varietät' die verschiedenen in sich mehr oder weniger geschlossenen, konventionellen und sozial verbindlichen Typen der Sprachverwendung innerhalb einer Sprachgemeinschaft.“ (Nabrings 1981, 17). 


\subsection{Die Konzeption des 'Sprachgebrauchs in Fachkontexten'}

Das Thema meiner Untersuchung weist einen Bezug zur Fachsprachenlinguistik auf. Aus den bisherigen Ausführungen ergibt sich, dass der gewählte Ansatz varietätenlinguistisch ist und auf einem kommunikativen Verständnis der Sprache basiert. Auf dieser theoretischen Grundlage muss nun geklärt werden, ob der Untersuchungsgegenstand eine Fachsprache ist und in welcher Form der thematische Fachbezug des Sprechens die Sprachkompetenz des Sprechers determiniert.

Ein elementares methodisches Problem der Fachsprachenlinguistik besteht in der Definition des Begriffs 'Fach', auf den sie sich notwendigerweise bezieht. Der Pluralismus fachsprachenlinguistischer Konzeptionen hat hier eher zur Verwirrung als zur Klarheit beigetragen. Allerdings zeichnet sich ab, dass das 'Fach' als differenzierbare Einheit enzyklopädischen Wissens konzeptionell gegenüber der qualifizierenden Vorstellung von 'Fachlichkeit' bevorzugt wird. 'Fächer' sind quantifizierbare Mengeneinheiten von Weltwissen, deren Kohäsion in einer abgrenzbaren Form der Referentialisierung zu suchen ist. Die soziale Wirklichkeit der Fächer spielt dabei eine entscheidende Rolle. So kann man sich z.B. durchaus vorstellen, dass die Theologie in einer atheistischen Gesellschaft kein Fach konstituiert. Es gibt jedoch nicht nur eine ideologische Gebundenheit der Existenz von Fächern ${ }^{51}$, sondern auch ihre faktische, d.h. in der materiellen Realität verankerte Konstitution. Fächer beziehen sich auf die Erfahrung unserer Umwelt, ganz gleich, ob diese natürlich oder artifiziell geschaffen ist.

Die Fachsprachenlinguistik macht nur selten auf den Aspekt der sozialen Relativität des Fachs aufmerksam. Der zweite Teil meiner empirischen Untersuchung wird sich mit der citricultura beschäftigen. Dieser Sachbereich hat in der Comunitat Valenciana eindeutig den Status eines Fachs oder doch zumindest den eines fachlichen Sektors. Das Verständnis des 'Zitrusfruchtanbaus' ist aber in Deutschland ein ganz anderes, denn es gibt keine deutschen Orangen-, Mandarinen- oder Zitronenhaine, keine deutschen Fachinstitutionen (nicht einmal einen Verein von Orangenliebhabern...), keine Artikel über die Marktkonkurrenz marokkanischer Orangen in deutschen Zeitungen und auch keine deutschsprachige Literatur über das Pfropfen und Beschneiden von Zitrusbäumen. Kann man da, so möchte ich fragen, als (Fachsprachen-)Linguistik den Zitrusfruchtanbau in eine horizontale Gliederung aller möglichen Fächer

${ }^{51}$ Die Rhetorik ist beispielsweise eine solche Art von Fach. Sie hat je nach Zeit und Ort der Menschheitsgeschichte einen sehr unterschiedlichen sozialen Status eingenommen. Bis heute ist sie dabei ein den Experten vorbehaltenes Fach geblieben, das zur gesellschaftlichen Machtausübung instrumentalisiert wird. 
integrieren, ohne sich gleichzeitig über die gesellschaftliche Relevanz oder Irrelevanz dieses Sachbereichs Rechenschaft abzulegen? Das angedeutete Problem ist grundsätzlicher Art: Ich plädiere dafür, die Fachsprachenlinguistik stärker auf die existentiellen Lebensbedingungen der Sprachgemeinschaft auszurichten bzw. ihr Interesse sogar zu 'regionalisieren' und nicht ausschließlich (oder nahezu ausschließlich) eine linguistische Beschreibung von Fächern vorzunehmen, die - z.B. aufgrund ihres wissenschaftlichen oder technologischen Status - an die Vorstellung eines (potentiellen) pan-gesellschaftlichen Sachbezugs gebunden sind. ${ }^{52}$ Die Sprache der Medizin, der Jurisprudenz, der Chemie und Technolekte im engeren Sinne sind sicherlich interessante Themen, aber nicht die einzigen, die die Fachsprachenlinguistik zu bieten hat.

Kommen wir noch einmal auf die Definition des Fachs zurück. Es gehört zur opinio communis, dass Fächer mit Wissen und Arbeit zu tun haben (vgl. Möhn/Pelka 1984, 30). Sie prägen sich daher in Bereichen der wissenschaftlichen und beruflichen Tätigkeit aus. Die Lebensbezüge von Fächern greifen jedoch über diese Bereiche hinaus. Die meisten Arbeiten, die der Einzelne außerhalb seines Berufs verrichtet, sind in bestimmte Fächer integriert. Dies gilt ebenso für handwerkliche Tätigkeiten am eigenen Haus wie für die Steuererklärung, das tägliche Kochen oder die Do-it-yourself-Reparatur am Auto. Selbst im Freizeitbereich verlässt uns das Fachliche nicht, egal, ob wir segeln, jagen oder fotografieren, ganz zu schweigen von der neu entdeckten Computer-Begeisterung vieler Zeitgenossen. Die Fachsprachenlinguistik ist dabei, all diese Themenschwerpunkte zu entdecken und zu beschreiben. Ich schließe mich somit dem Fazit von Terglane-Fuhrer an:

Zusammenfassend läßt sich sagen, daß in den Versuchen den Begriff 'Fach' zu bestimmen, die Aspekte 'Arbeitskontexte' und 'Berufe' sowie die Aufgliederung des Wissens in verschiedene Wissenschaften auf dem Hintergrund einer arbeitsteilig organisierten Gesellschaft konstitutiv sind.

Hinzu treten sollte der gesamte Freizeitbereich - das 'Hobby'. Hierbei handelt es sich um Tätigkeiten, die in der Regel nicht auf den Erwerb ausgerichtet sind, die sich aber in einigen Teilen professionalisieren und so auch Fächer darstellen.

(Terglane-Fuhrer 1996, 10)

Im Hinblick auf die fachlichen Gebiete meiner eigenen Untersuchung ist die Trennung von Beruf und Freizeit nicht leicht zu ziehen. Der Waldbau ist im Béarn kein beruflicher Sektor, aber er wird - meist von Landwirten - oft mit professionellen technischen Möglichkeiten betrieben. Die Nutzung des Waldes ist dabei durchaus auf Erwerb ausgerichtet, wird aber privat bewerkstelligt und

${ }^{52}$ Unkonventionelle Bezüge fachsprachlichen Interesses entwickeln sich z.B. unter den Schülern von Sigurd Wichter. Vgl. in dieser Hinsicht Schräder 1991, Terglane-Fuhrer 1994, Kissenbeck 1997. 
stellt nicht das berufliche Tätigkeitsfeld des privaten Waldbesitzers dar. Eine ähnliche Situation ergibt sich heute mehr und mehr in der citricultura der Comunitat Valenciana. Der Anbau von Orangen und Mandarinen ist für viele nur noch eine Teilzeitbeschäftigung oder sogar eine Arbeit, der sie erst nach Feierabend nachgehen. Der Beruf dieser Besitzer von 'Minilatifundien' ist meistens im tertiären Sektor angesiedelt: Man arbeitet in Valencia und kümmert sich nach Dienstschluss um seinen Orangenhain. Das beschriebene Phänomen ist in vielen Teilen Europas ein wesentliches Merkmal der (agrar-)wirtschaftlichen Struktur. Die Fachsprachenlinguistik sollte solche sozialen Wirklichkeiten in den Blick bekommen.

Angesichts der faktischen Gegebenheiten in meinen Untersuchungsgebieten gehe ich methodisch von dem Begriff des 'Fachkontextes' aus und meine damit verschiedene Formen des lebenspraktischen Bezugs fachgebundener Tätigkeiten im Alltag. Die Fachkontexte lassen sich häufig in dem beschriebenen Sinne als 'Arbeitskontexte' zwischen Beruf und Freizeit lokalisieren, sie gehören bisweilen jedoch auch eindeutig in die Bereiche des tatsächlich ausgeübten Berufs oder der reinen Freizeitgestaltung hinein. Die Übergänge sind hier fließend, so wie es der Realität des gesellschaftlichen Lebens entspricht. Unter 'Fachkontext' verstehe ich also den sozialen Handlungsbereich der Sprecher. Dieser Handlungsbereich ist nun auf seine Voraussetzungen und auf seine Folgen hin zu untersuchen. Wenden wir uns zunächst den Voraussetzungen zu.

Hinsichtlich der faktischen und kommunikativen Realität von Fachkontexten unterscheide ich zwischen einer biographischen und einer sachorientierten Optik. Die Biographie beinhaltet sowohl die Einflussnahme der fachlichen Ausbildung als auch die der fachbezogenen Lebenspraxis des Individuums. In extremer Form gibt es eine fachliche Ausbildung ohne lebenspraktische Bezüge (insbesondere in der Wissenschaft) und eine lebenspraktische Bezugnahme ohne Ausbildung, die z.B. im Sektor des Waldbaus im Béarn sogar die Regel ist. Die Sachdetermination der Fachkontexte ist ebenfalls in zweifacher Hinsicht gegeben: Sie kann zum einen institutioneller Natur sein, zum anderen aus der sozialen Einbindung in das Lebensumfeld resultieren. Die institutionelle Verankerung des Sachgebiets spielt in meiner Untersuchung eine wesentliche Rolle. Das Vorhandensein und der Wirkungsgrad von Fachinstitutionen sind in einem Sachbereich von regionaler Bedeutung in besonderem Maße konstitutiv. Daneben gibt es jedoch das Faktum der Integration des Fachs in die alltägliche Lebensrealität, für das ich mich in meiner Untersuchung vorrangig interessiere. Diese Integration vollzieht sich über Normen, die eine Form der Apperzeption des Sachlichen darstellen. Die Implikationen und Gestaltungsformen dieser normativen Bestimmtheit werde ich in Kapitel 2.6 noch eingehender darstellen. 
Welche Auswirkungen haben nun die Fachkontexte als gegebener sozialer Handlungsbereich auf die Kompetenz des Sprechers? Ihre Konsequenz liegt in der Produktion eines Wissens, das zunächst sprachenunabhängig als fachliche Kompetenz angesehen werden kann. Man darf dabei keinesfalls übersehen, dass die fachliche Kompetenz nicht nur aus einer Ausbildungssituation und / oder einem fachinstitutionellen Betätigungsfeld resultiert, sondern oft sogar in prädominanter Form eine Folge der praktischen und normativen Erfahrung des Lebensumfelds darstellt. Die Fachkompetenz ist daher prinzipiell in ein theoretisches und ein normatives Wissen untergliedert, wobei die Zusammenhänge beider Wissensebenen oft so eng sind, dass sie kaum getrennt werden können. Einfach ausgedrückt handelt es sich um den Zusammenhang von Sachkenntnis und Erfahrung, der gerade auf Fachgebieten mit regionaler Bedeutung ein Konstitutivum der sich sozial entwickelnden Fachkompetenz darstellt.

Im methodischen Aufbau meiner Untersuchung schließt sich die weitere Frage an, welches Maß an Fachkompetenz in dem Untersuchungsgebiet, das ich als 'Region' qualifiziere, festgestellt werden kann. Man wird dabei von vornherein vermuten, dass die eruierbare Fachkompetenz in der Region in Bezug auf einen Sachbereich, der diese Region in besonderem Maße betrifft, relativ hoch ist. Diese Vermutung konnte in zwei wissenschaftlichen Arbeiten innerhalb meines Forschungsprojekts bestätigt werden (Riehm 1997, Sánchez Münninghoff 1998). Es handelt sich dabei um ein zu erwartendes Ergebnis, das jedoch durch die Form seiner analytischen Darstellung in den beiden Arbeiten nicht nur das Maß, sondern auch die Qualität der verifizierbaren Fachkompetenz zu erkennen gibt. Genau hier liegt der interessante Aspekt. Der Anteil theoretischer Wissensstrukturen steht nämlich in regionalspezifischen Sachbereichen sehr deutlich in der Abhängigkeit normativen Wissens und wird durch dieses Erfahrungswissen beeinflusst und geprägt. Diese Beobachtung gilt selbst für Personen, die eine fachspezifische Ausbildung genossen haben und in Fachinstitutionen arbeiten.

Die normative Prägung der Fachkompetenz ist eine wesentliche Voraussetzung fachbezogener Kommunikation in der Region. Niemand wird an der sozialen Lebensrealität des Fachs Anteil haben, wenn er sich nur auf ein theoretisches Wissen ohne praktische Bezüge berufen kann. Und ebenso wird niemand aus der sozialen Lebensrealität des Fachs ausgeschlossen, weil er sich nur auf praktische Erfahrung und nicht auf eine entsprechende Ausbildung berufen kann. In meinen speziellen Untersuchungsbereichen habe ich beobachten können, dass die Fachinstitutionen sogar primär nach erfahrungsorientiertem Wissen Ausschau halten, da nur Personen mit diesen Wissensdimensionen überhaupt zu einem Engagement im Fach bereit sind. Es ist ein von der Öffentlichkeit zu wenig beachtetes Faktum, dass wirtschaftlich profitables Engagement, von dem unser Wohlstand abhängt, zu einem Großteil an 
persönlichen Erfahrungen ansetzt, d.h. von der biographischen Prägung und normativen Eingebundenheit der handelnden Personen, abhängt. Dies gilt ganz besonders für fachliche Bereiche, die im Verhältnis zu ihrer sozio-ökonomischen Relevanz nicht genügend berufliche Arbeitsplätze zur Verfügung stellen können. Meine Untersuchung berührt hier virulente Fragen der wirtschaftlichen Konstitution moderner Industriegesellschaften, die jedoch im Rahmen einer linguistischen Untersuchung nicht weiter verfolgt werden können.

Aus sprachwissenschaftlicher Perspektive erhebt sich nun die Frage, welche Signifikanz das Sachwissen und die normative Erfahrung des Sachbereichs für den Sprecher, also für den Sprachgebrauch in Fachkontexten haben. Im Grunde geht es dabei um die Klärung des Verhältnisses von Fachkompetenz und Sprachkompetenz, das ein bekanntes Grundproblem der Fachsprachenlinguistik ist. Ich bin der Meinung, dass das Sprechen in Fachkontexten, so wie ich es definiert habe, nicht notwendigerweise den Gebrauch einer Fachsprache impliziert, wenn man darunter die formal abgrenzbare Varietät einer Einzelsprache bzw. ein gesamtsprachliches Subsystem versteht. Damit ist nicht gesagt, dass es die Fachsprache des entsprechenden Sachgebiets überhaupt nicht gebe. Sie ist im Einzelfall nach den methodischen Prinzipien linguistischer Forschung, vor allem aber als terminologische Ausprägung der Einzelsprache recht genau $\mathrm{zu}$ beschreiben. Allerdings wird diese formalisierte Varietät der Fachsprache eben nicht in der alltäglichen fachbezogenen Kommunikation zur Normalform des Sprechens gemacht. Diese Beobachtung gilt vielfach sogar für den beruflichen Sektor und für Fachgespräche auf institutioneller Ebene. In der kommunikativen Gestaltung nicht-professioneller Arbeitskontexte und des Freizeitbereichs ist der Einsatz einer Fachsprache aber in der Regel überhaupt nicht mehr bestimmend.

Die Fachsprachenlinguistik hat Überlegungen angestellt, wie sie mit der Tatsache einer 'Fachkommunikation' unter Verzicht auf 'Fachsprache' methodisch umgehen soll. Ihre Reaktion, die sich teilweise in einer Neuorientierung und in einem Wandel der Disziplin ausdrückt, impliziert drei Sichtweisen des Problems:

1)Die Fachsprache wird nicht mehr ausschließlich unter rein formalen Gesichtpunkten analysiert, sondern als Ausprägung einer kommunikativen Wirklichkeit gedeutet.

2)Der Fachbezug der Kommunikation wird so weit gefasst, dass unter ihn auch Gesprächssituationen fallen, die als 'fachextern' bezeichnet werden können, da sie weder in beruflichen noch in institutionellen Zusammenhängen stehen. ${ }^{53}$

${ }^{53}$ Vgl. hingegen die traditionelle Sichtweise in Munsberg 1994, 39: „Unter 'Fachkommunikation' ist all das zu verstehen, was an kommunikativem Handeln in einer gegebenen Institution 
3)Die Analyse der Fachkommunikation bezieht den Aspekt der Gesprächsbeteiligung von Nicht-Fachleuten mit ein, interessiert sich also verstärkt für die Integration der sog. 'Laien' in das fachliche Umfeld. ${ }^{54}$

Ich möchte im Folgenden versuchen, die drei genannten Aspekte einer modernen Fachsprachenlinguistik aus der Perspektive meines Untersuchungsinteresses heraus zu erläutern.

Innerhalb der verschiedenen Richtungen der Fachsprachenlinguistik schließe ich mich prinzipiell der Tradition einer funktionalen bzw. funktionalstilistischen Interpretation von Fachsprache an. Die Anfänge und Grundlagen dieser Sichtweise finden sich bei Bohuslav Havránek (1932), Eduard Beneš (1971) und Heinz Ischreyt (1965). Die Funktionalstilistik interpretiert die Fachsprachen als themengebundene Sprachen, d.h. als Sprachformen die nicht durch ihren Kommunikationsgruppenbezug, sondern durch ihre Sachbezogenheit definiert werden. Dabei wird die Auffassung vertreten, Fachsprachen seien spezifische bzw. eingeschränkte Formen des Sprachgebrauchs, woraus ein hierarchisches Verhältnis von Fachsprache und übergeordneter Gemeinsprache abgeleitet werden kann. Die so verstandene Fachsprachenlinguistik konzentriert sich auf besondere Texttypen bzw. auf spezielle Kommunikationskontexte, die grundsätzlich durch ihren Sachbezug charakterisiert werden. ${ }^{55}$ Elemente einer funktionalen Fachsprachenkonzeption finden sich z.B. in der Definition von 'Fachsprache' bei Möhn / Pelka (1984, 26):

Wir verstehen unter Fachsprache heute die Variante der Gesamtsprache, die der Erkenntnis und begrifflichen Bestimmung fachspezifischer Gegenstände sowie der Verständigung über sie dient und damit den spezifischen kommunikativen Bedürfnissen im Fach allgemein Rechnung trägt. Fachsprache ist primär an Fachleute gebunden, doch können an ihr auch fachlich Interessierte teilhaben. Entsprechend der Vielzahl der Fächer, die man mehr oder weniger exakt unterscheiden kann, ist die Variante 'Fachsprache' in zahlreichen mehr oder weniger exakt abgrenzbaren Erscheinungsformen realisiert, die als Fachsprachen bezeichnet sind. Je nach fachlich bestimmter Situation werden sie schriftlich oder mündlich gebraucht, sowohl innerhalb der Fächer (fachintern) als auch zwischen den Fächern (interfachlich).

Möhn/Pelka ergänzen im Anschluss an diese Definition:

Der dritte Teil 'fachextern' des inzwischen breit akzeptierten Tripels 'fachinterninterfachlich-fachextern' spielt bei der Definition der Variante 'Fachsprache' keine Rolle. Er wird erst dann aktuell, wenn es um die Beziehungen und Übergänge zwi-

auftritt und dem Fortgang des institutionellen Prozesses dient.“

${ }^{54}$ Vgl. z.B. Dressler / Wodak (Hgg.) 1989.

${ }_{55}$ Im Rahmen dieses Ansatzes kommt es z.T. zu einer leichtfertigen Übertragung von Stildifferenzierungen auf ein funktionales Konzept sprachlicher Variation. Sofern eine solche Übertragung die Verlagerung der Optik von der Ebene des Sprechens auf die der Beschreibung des Sprachsystems impliziert, möchte ich mich von dieser Sichtweise distanzieren. 
schen den Varianten 'Fachsprache' und 'Gemeinsprache' geht, also um Phänomene und Probleme der fächerüberschreitenden Kommunikation.

Möhns und Pelkas Definition der Fachsprache ist 'sprachverwendungsorientiert'. Doch werden auch die Aspekte des referentiellen Bezugs der Sprache (ihre Themengebundenheit) und der Sprachstruktur (Systembezogenheit) ${ }^{56}$ nicht außer Acht gelassen. Das Problem dieses definitorischen Ansatzes liegt aber darin, dass die Gesichtspunkte der kommunikativen Sprachverwendung und des strukturellen Sprachsystems zu heterogen sind, um im Rahmen eines theoretischen Definitionsansatzes als kompatibel gelten zu können. Die Charakterisierung der Fachsprache als 'Subsystem' entspricht nämlich nicht mehr dem umfassenden Konzept ihrer kommunikativen Funktion auf der Basis der thematischen Sachbezogenheit. Es ist wichtig anzuerkennen, dass in einer Sprachgemeinschaft viele kommunikative Anlässe zu den verschiedenen Themen eines Fachs bestehen, die mit Hilfe einer nur marginalen Verwendung der Fachsprache realisiert werden oder die stattfinden, ohne dass die Sprachteilhaber überhaupt die Fachsprache beherrschen. Ich plädiere dafür, auch diese Formen der sehr frequenten 'fachlichen' Kommunikation, die in der Fachsprachenlinguistik üblicherweise als 'fachexterne' Kommunikation qualifiziert wird, ${ }^{57}$ in die Untersuchung mit einzubeziehen. Um dabei in keinen Konflikt

56 „Sprachsystembezogen kann Fachsprache als ein Subsystem dargestellt werden, das durch eine spezifische Auswahl und Nutzung sprachlicher Mittel in morphologischer, lexikalischer, syntaktischer und textlicher Hinsicht charakterisiert ist.“ (Möhn/Pelka 1984, 26)

${ }^{57}$ Der Begriff 'fachexterne Kommunikation' ist nicht unbedingt glücklich, da er impliziert, dass eine Konversation über fachliche Themen nicht mehr zu dem Bereich des Fachlichen gerechnet wird, weil eine oder mehrere der beteiligten Personen nicht als Fachleute ausgewiesen sind. Auf diese Weise werden das Kriterium des Sachbezugs und das des Sprechergruppenbezugs aber in einer definitorisch unvorteilhaften Weise miteinander vermengt.

Für Klarheit sorgt hier die definitorische Unterscheidung von Sigurd Wichter (1994, 10). Wichter definiert das 'Fach' unter Bezug auf die Sprechergruppe: „Ein Fach umfaßt personal gesehen die Gruppe der Experten. Die Gruppe der informierten Laien bildet das Fachumfeld. Personen ohne Informationen über das Fach, die absoluten Laien, ergeben das Fachaußenfeld." Demgegenüber erläutert Wichter den kommunikativen Aspekt des Fachsprachengebrauchs wie folgt: „Kommunikationen finden in einem vertikalitätsbezogenen Kontext statt. Sie können in einem Fachkontext oder in einem fachfreien Kontext stehen. Ein Teil der Wörter kann usuell nur im Fachkontext verwendet werden, ein weiterer Teil sowohl im Fachkontext als auch im fachfreien Kontext, und für einen dritten Teil ist die Kontextzuordnung irrelevant (z.B. Artikel, Pronomen, etc.).“

Wichters Ansatz ist methodisch gesehen grundsätzlich verschieden von dem, der meiner Untersuchung zugrunde liegt. Allerdings stellt Wichters Methodik auch die Alternative eines anderen Untersuchungsinteresses dar. Die 'Lexikologie der Vertikalität', um die es Wichter geht, basiert auf einem Semantik-Modell, das die Wissensungleichverteilung in der Gesellschaft darzulegen versucht. Die Bezüge auf die Sprache finden bei Wichter mit Hilfe der Erklärungen der Schema-Theorie statt, integrieren sich also in eine kognitive Semantik. Die Berührungspunkte zu meinem eigenen Ansatz sind durch die Interpretation sprachlich verankerter Konzeptualisierungen gegeben. 
zu der Definition von Fachsprache als funktioneller Varietät zu gelangen, ziehe ich es vor, allgemeiner die Begriffe 'Kommunikation in Fachkontexten' bzw. 'sektoriell gebundenes' oder 'domänenspezifisches' Sprechen zu verwenden.

Ein Definitionsversuch, der meiner Vorstellung von 'Fachsprache' als 'Kommunikation in Fachkontexten' sehr nahe kommt, ist von Lothar Hoffmann $(1985,53)$ gegeben worden:

Fachsprache, das ist die Gesamtheit aller sprachlichen Mittel, die in einem fachlich begrenzbaren Kommunikationsbereich verwendet werden, um die Verständigung zwischen den in diesem Bereich tätigen Menschen zu gewährleisten.

Hoffmann, der ebenfalls an die Prinzipien einer funktionalen Sprachbetrachtung anknüpft, hebt in dieser Definition den Mitteilungsinhalt als Hauptkriterium hervor. Die Fachsprache ist nach ihm primär durch die Themenwahl und den Sachgebietsbezug des Sprechens bestimmt. Diese Sichtweise bettet Hoffmann in eine Lehre von den Subsprachen ein, die im Grunde eine varietätenlinguistische Auseinandersetzung mit der Problematik darstellt. Nach Hoffmann ist die Gemeinsprache (bzw. Gesamtsprache), in der sich die Fachsprachen konkretisieren, durch das Kriterium der allgemeinen Verfügbarkeit der sprachlichen Mittel bestimmt. Fachsprachen konstituieren sich hingegen in diesem komplexen System der Gemeinsprache als Teilsprachen (Subsysteme), zu denen sie vermittels ihrer konkreten kommunikativen Verwendung werden. In einer globalisierenden Sicht deckt somit die Gesamtheit der Fachsprachen (als 'Konkreta') den Bereich der Gesamt- oder Gemeinsprache als 'Abstraktum' ab. Damit vertritt Hoffmann eine varietätenlinguistische Konzeption, die mit derjenigen Hartungs, die ich am Ende des vorangegangenen Kapitels 2.2. zitiert habe, konform geht. Es muss jedoch auf einige kritikable Aspekte dieser Konzeption aufmerksam gemacht werden.

Hoffmanns Modell macht die Unzulänglichkeit des funktionalstilistischen Ansatzes bei der Übertragung auf ein funktionales Varietätenkonzept deutlich. Der hauptsächliche Kritikpunkt ist dabei die Definition der Gemeinsprache, mit der Hoffmann selbst nicht so recht klarzukommen scheint. Hoffmann geht grundsätzlich von der Annahme aus, dass sich die Gemeinsprache in einer statistischen Annäherung als „Durchschnitt des Sprachbesitzes aller Individuen" (S. 48) ermitteln lässt, wendet jedoch sogleich ein, dass auf diese Weise nur „Inventare von Elementen und Konstruktionen“ (S. 49) eruiert werden könnten, aber nicht das grammatische System der Sprache, das diese Elemente und Konstruktionen zu Formen der sprachlichen Äußerung werden lässt. In der Gegenüberstellung von Fachsprache als konkreter Verwendungsweise der Sprache und abstrakter Gemeinsprache als vermittelnder Ebene der gemeinsamen Sprachteilhabe gerät der Begriff der Gemeinsprache damit in die Nähe des Sprachsystems, was Hoffmann selbst erkennt, jedoch im Rahmen seiner 
Theoriebildung als unliebsame Konsequenz ablehnt. Als mögliche Alternativbetrachtung schlägt Hoffmann daher vor, die Gemeinsprache (in ihrer Definition als statistischer Durchschnitt) ebenso wie die Fachsprachen oder besondere Literatursprachen als Teilsystem unter die Gesamtsprache (bzw. Nationalsprache) zu subsumieren. Doch auch diese Interpretationsweise lehnt Hoffmann sogleich wieder ab, denn er stellt fest, dass im Gegensatz zur Fachsprache die Gemeinsprache nur sehr schwer empirisch zu beschreiben ist:

Während sich das Inventar einer Fachsprache dank der Begrenzung ihres Wirkungsbereiches leichter vollständig erfassen läßt, bleibt das der Gemeinsprache schwer greifbar, weil nicht eindeutig feststeht, in welchen kommunikativen Bereichen oder Situationen davon Gebrauch gemacht wird. Wir sehen also, daß die Gemeinsprache als Subsprache schwer zu fassen ist.

(Hoffmann 1985, 52)

Hoffmann bietet letztlich keine Lösung an, es sei denn die, auf den Terminus 'Gemeinsprache' ganz zu verzichten. Ich halte diese ehrliche Zugabe einer theoretisch-methodischen Unzulänglichkeit im konkreten Fall für aufschlussreich und sogar fruchtbar. ${ }^{58}$ Die Fachsprachenlinguistik hat es allerdings versäumt, auf der Basis des Hoffmannschen Varietätenkonzepts nach Lösungen für das beschriebene Dilemma zu suchen. Damit ist der funktionale Ansatz in der Fachsprachenlinguistik in eine Sackgasse geraten, die bedauerlich ist, da das Grundkonzept der kommunikativen Fachsprachendefinition aus meiner Sicht nach wie vor ein vielversprechendes Modell darstellt. Ich werde daher versuchen, in den folgenden Kapiteln zumindest ansatzweise Lösungsstrategien für die Weiterentwicklung dieses Konzepts im Rahmen meiner Theorie der sprachlichen Standardisierung aufzuzeigen. Zuvor jedoch möchte ich noch kurz darauf eingehen, welche alternativen Sichtweisen der Fachsprache es in der jüngeren linguistischen Forschung gibt.

Besondere Beachtung hat die pragmatische Fachsprachentheorie von Walter von Hahn (vgl. von Hahn 1983) gefunden. Von Hahn gibt eine handlungstheoretische Erklärung der Sprache, beruft sich also auf die enge Bindung von Sprechen und Handeln, die er in Bezug auf die Fachsprachen als deren instrumentellen Plancharakter bestimmt. Die Beschreibung der Fachsprache ist in seiner Theorie rollen- und funktionsorientiert. Dabei spielt der Begriff des 'Fachs' wieder eine zentrale Rolle, wird aber eher im Sinne von 'Fachlichkeit' interpretiert: ${ }^{59}$

Fächer sind Arbeitskontexte, in denen Gruppen von fachlichen zweckrationalen Handlungen vollzogen werden. Fachsprachen sind demnach sprachliche Handlungen

${ }^{58}$ Vielleicht bräuchten wir in den Geisteswissenschaften nach dem Vorbild der Naturwissenschaften mehr Wissenschaftler, die bereit sind, die Grenzen eines Forschungsstands zu akzeptieren und auf noch ungelöste Problyeme klar und deutlich hinzuweisen.

${ }^{59}$ Die Konzeption des 'zweckrationalen Handelns' übernimmt von Hahn von Jürgen Habermas. 
dieses Typs sowie sprachliche Äußerungen, die konstitutiv oder z.B. kommentierend mit solchen Handlungen in Verbindung stehen (...).

(von Hahn 1983, 65)

Dieser pragmatische Ansatz geht mit den Prinzipien meiner eigenen Untersuchung nicht konform. Von Hahn sieht die Sprachteilhaber in fachsprachliche Handlungen allein durch ihre Funktion, nicht aber durch ihre individuelle, sozial definierte Person eingebunden. Sein Hauptaugenmerk ist auf die Wichtigkeit sog. 'Problemlösungsstrategien' im Sprech-Handlungs-Komplex des Fachsprachengebrauchs gerichtet. Diese Problemlösungsstrategien sind nach ihm als kontext- und personenunabhängige instrumentelle Methoden zu verstehen, die in fachlichen Texten repräsentiert werden. Die Vorstellung aber geht vollständig an dem von mir vertretenen Erkenntnisinteresse vorbei. Für unangemessen halte ich insbesondere die Unterstellung einer nicht-sozialen Absicht des mit dem Fachsprachengebrauch verbundenen Handelns. Zudem lässt sich von Hahns Ansatz nicht auf die Betrachtung fachexterner Kommunikation ausweiten (vgl. von Hahn 1983, 67 f.).

Eine alternative Problemstellung bietet hingegen der Ansatz von Sigurd Wichter (vgl. Wichter 1994, 1995), der bewusst über die Betrachtung der Fachkommunikation im engeren Sinne hinausgeht und auch das 'Fachumfeld', die interessierten Laien, mit berücksichtigt. Damit trifft Wichters analytischer Blick auf eine Realität des Fachsprachengebrauchs, die auch für meine Untersuchung relevant ist. Die Unterscheidung von Experten und Laien wird von Wichter im Rahmen einer 'Lexikologie der Vertikalität' vorgenommen, wodurch der Autor seinen eigenen Ansatz als der lexikalischen Semantik zugehörig charakterisiert und ihn von der Betrachtung der Diskursebene abkoppelt. Diese Abstraktion des fachsprachenlinguistischen Interesses ist im Rahmen einer kohärenten lexikologischen Methodik vorgegeben, sie versperrt aber in unserem Fall den Blick für die kommunikative Gestaltung des Fachs in der Gesamtheit ihrer sprachlichen Dimensionen, die auf verschiedenen Sprachbeschreibungsebenen angesiedelt sind. Im Gegensatz zu Wichter mache ich nicht den Fachterminus, sondern den (mündlichen) Text bzw. Diskurs zu der empirischen Basis der Untersuchung. ${ }^{60}$ Zudem erscheint es mir auch nicht möglich, die Entsprechung von Wort und Begriff, die Wichter de facto zur methodischen Voraussetzung seiner Untersuchung macht, auf meinen Untersuchungsgegenstand des Sprachgebrauchs in Fachkontexten konsequent anzuwenden. Es wird sich zeigen, dass die Sprecher immer wieder auf Begriffskonzepte rekurrieren, ohne die dafür passende Terminologie überhaupt zu verwenden. Nicht die semantische Annäherung oder Alternativbesetzung eines Fachterminus ist in diesem Fall ausschlaggebend, sondern die Darstellung fachlicher

${ }^{60}$ Wichters empirische Methode beruht hingegen auf der Eruierung lexikalischen Wissens der Sprecher mittels Fragebögen. 
Gegenstände mit den Mitteln der standardbasierten Gemeinsprache. Für dieses Phänomen hat die Fachsprachenlinguistik aber bis heute noch kein überzeugendes Erklärungsmodell gefunden. 


\section{4. 'Alltagssprache', 'Gemeinsprache' und 'regionaler Sprach- gebrauch'}

Man könnte einwenden, dass die Erscheinungsform der Sprache, die ich als 'regionalen Sprachgebrauch in Fachkontexten' zu definieren versuche, wohl eher mit einer Konzeption wie derjenigen der 'Alltagssprache' von Hugo Steger übereinstimmt als mit dem üblichen Begriff der Fachsprache. Ich möchte auf diesen möglichen Einwand kurz eingehen.

Auch Stegers Modell ist varietätenlinguistisch fundiert. Allerdings setzt sich Steger in einer ablehnenden Weise mit den gängigen terminologischen Unterscheidungen der Varietätenlinguistik auseinander und erkennt im Prinzip nur die in ihnen wirksamen Gliederungsdimensionen als berechtigt an.

Lässt man sich auf Stegers unkonventionelle Methodologie ein, so muss konzidiert werden, dass sie zu einer Reihe vernachlässigter oder unbeachtet gebliebener Gesichtspunkte in der bisherigen Varietätenlinguistik führt. Stegers Blickwinkel deckt sich dabei zum Teil mit dem in der vorliegenden Untersuchung angeregten Erkenntnisinteresse, weswegen einige diesbezügliche Erklärungen angebracht erscheinen. Kommen wir zunächst auf den Begriff der 'Alltagssprache', den Steger vorschlägt und in medialer und semantischer Hinsicht ausleuchtet.

Die 'Alltagssprache' wird definitorisch zu einer Reihe bekannter varietätenlinguistischer Differenzierungen in Bezug gesetzt. Demnach ist 'Alltagssprache' eine Verwendungsweise der Einzelsprache (vgl. Steger 1991, 58-63):

1) die sich als 'natürliche Sprache' gegenüber den 'Fachsprachen' und 'Kunstsprachen' absetzt, ${ }^{61}$

2) die sich im Sinne ihrer sozialen Reichweite mit dem Begriff der regionalen Umgangssprache mehr oder weniger deckt,

3) die eine gesprochene Form der Sprache darstellt,

4) die (in funktional-stilistischer Hinsicht) 'alltäglich-lebenspraktischen Zwecken' der Kommunikation dient und

5) die durch einen niedrigen Formalitätsgrad gekennzeichnet ist.

Steger sieht nun den funktional-stilistischen Aspekt als den definitorischen Kern der 'Alltagssprache' an. Die 'Alltagssprache' stellt demnach in erster Linie ein sprachliches Inhaltssystem (und kein Ausdruckssystem) dar, das durch seine kommunikative Zielsetzung im Alltag bestimmt wird, d.h., das durch die semantische Funktion, alltägliche Erfahrungen der Sprachteilhaber in

${ }^{61}$ Wieso es in Stegers Optik zu dieser überraschenden Opposition kommt, werde ich im Weiteren noch verdeutlichen. 
ihrer Normbedingtheit auszudrücken, definiert ist. Letztlich unklar bleibt jedoch, wieso diese Inhaltsfunktion von vornherein in einer diametralen Opposition zu der Inhaltsstruktur fachsprachlicher Begrifflichkeit stehen soll (vgl. Punkt 1). Steger veranschaulicht diese postulierte Opposition von 'Alltagssemantik' und 'Fachsprachensemantik' an einer Reihe von Beispielen, die jedoch weder auf einer empirischen Untersuchung beruhen, noch aus einem anderen Grund eine zu verallgemeinernde Beweiskraft haben. An einem konkreten Beispiel, das zudem noch sehr gut in meine eigene Untersuchung passt, lässt sich am schnellsten die Problematik dieses Ansatzes erkennen. Steger folgert aus der von ihm beschriebenen 'Alltagssemantik' insgesamt sieben Prinzipien, ${ }^{62}$ von denen ich hier nur das 'Prinzip der naiven Theoriebildung' herausgreifen möchte. Es besagt:

daß die Herausbildung sprachlicher Begriffe und ihre Lexikalisierung in einem Prozeß der Theoriebildung aus empirisch wahrgenommenen oder 'theoretisch erdachten' Weltdaten erfolgt.

(Steger 1991, 102)

\section{U.a. gibt Steger das Beispiel des Begriffs 'Wald':}

Die alltäglich Sprache versieht, nach der Meinung der Lexikographen, den Ausdruck Wald mit der Teilbedeutung 'größere, mit Bäumen dicht bewachsene Fläche' und setzt damit auch andere Begriffe wie 'Baum', 'Fläche' ohne weiteres schon voraus oder faßt Gehölz teilweise als einen 'kleinen inmitten von Feld- oder Wiesenfluren gelegenen Bestand aus niedrigen Bäumen'.

Die bisher hervorgehobenen Prinzipien werden dabei erst besser sichtbar, wenn man solche Angaben zur ganzheitlichen Bedeutung ergänzt, die dem Waldbegriff auch bewertende und beziehungsdefinierende Teilbedeutungen zuordnet [sic!]: gefährlich, dunkel, kühl, schattig, schön, deutsch, die hinterm Wald (Hinterwäldler) usw., wodurch lebenssichernde und/oder ideologisch gestützte Elemente sichtbar werden (u.U. mit Verschränkungen, die aus literatursprachlichen Deutungen bezogen sind). Die Relevanzfokussierung fällt dabei - jenseits von fachlichen Bezügen, etwa für Förster und Waldbauern - ganz unterschiedlich z.B. auch für Stadt- und Landbewohner, Naturschützer aus.

(Steger 1991, 103)

${ }^{62}$ Diese sieben Prinzipien der 'Alltagssemantik' dienen dazu, ihren besonderen Charakter gegenüber der 'Fachsprachensemantik' aufzuzeigen. Ich zitiere im Folgenden die Benennungen der einzelnen Prinzipien, da ihre Formulierung bereits einen Erklärungswert besitzt: (1) Prinzip der umfassenden Versprachlichung der menschlichen Primärsphären [gemeint ist die Erfassung der gesamten Lebenswirklichkeit im Gegensatz zu der Konzentration auf spezifische fachliche Aspekte], (2) Prinzip der ganzheitlich-komplexen Versprachlichung [gemeint ist der einfache begriffliche Bezug auf eine komplexe Situation im gegebenen Erfahrungsbereich im Gegensatz zu den differenzierteren konzeptuellen Zugriffen der Fachsprache], (3) Prinzip der lebenspraktischen Relevanz, (4) Prinzip des ausreichenden Genauigkeitsgrades, (5) Prinzip der syntaktischen Genauigkeitsregulierung, (6) Ökonomieprinzip [gemeint ist: weniger Begriffe als in der Fachsprache], (7) Prinzip der naiven Theoriebildung [wird zitiert] (vgl. Steger 1991, 55). 
Stegers Argumentation ist m.E. nicht überzeugend. Zunächst einmal wird nicht klar, was das Zitat der Duden-Definitionen von 'Wald' und 'Gehölz' veranschaulichen soll. Will Steger sagen, dass 'Baum' und 'Fläche' nicht zu der begrifflichen Konzeption des Waldes in der Gruppe der Nicht-Fachleute gehören? Mir erschiene dies unzutreffend. Oder will er sagen, dass die Begriffsdefinition des Experten komplexer ist. Das erschiene trivial. Will er des Weiteren sagen, dass 'Gehölz', so wie es der Duden definiert, sich nicht in den begrifflichen Konzeptionen von Laien und Experten wiederfindet? Ich wüsste nicht, warum. Steger ergänzt nun, dass die semantischen Implikationen des Waldes im Alltag noch komplexer seien. Doch gilt dies allenfalls mit Einschränkungen: Wenn ich in einer typischen Alltagskonversation meinem Freund vorschlage, einen Waldspaziergang mit ihm zu machen, denke ich vielleicht (im Hochsommer) an kühl und schattig, aber bestimmt nicht an deutsch und Bangesichts der Beschaffenheit kultivierter Waldspazierwegeauch nicht an gefährlich und dunkel. Ja mehr noch: Als Naturschützer (der Gesinnung nach jedenfalls) beanspruche ich durchaus einen fachlichen Zugang zu meinem Interessengebiet, ebenso wie der Förster seinen Wald ganz einfach mal als schön empfinden kann. Wo liegen also die Grenzen von Alltags- und Fachsprachensemantik?

Doch verfolgen wir die Argumentation Stegers noch ein wenig weiter. Der Autor zitiert im Anschluss an die wiedergegebene Textstelle eine längere fachwissenschaftliche Reflexion, in der u.a. die verschiedenen Wuchsformen von Bäumen, Sträuchern und Halbsträuchern differenziert werden und die eine Klassifikation der vegetativen Gegebenheiten in 'Wälder', 'Lockergehölze' und 'Gras- und Zwergstrauchvegetation' vornimmt. Sein Kommentar ist:

Die botanische und forstwissenschaftliche Interpretation von Bäumen und Sträuchern zeigt somit mehr, andere und rationalere Kriterien [...].

(Steger 1991, 104)

Die Tatsache, dass im Alltag mit keiner wissenschaftlichen Klassifikation operiert wird (oft nicht einmal von den Fachleuten selbst), ist aber nicht weiter erstaunlich. Das von Steger gegebene Beispiel lässt sich sogar noch ad absurdum führen, wenn man es auf die Ergebnisse meiner empirischen Untersuchung im Béarn bezieht. Die Unterscheidung in 'Wälder', 'Lockergehölze' und 'Gras- und Zwergstrauchvegetation' ist dort nämlich jedermann bekannt, wenn auch nicht in der entsprechenden Fachterminologie, so doch in der gängigen Begrifflichkeit von bois, sous-bois und ronces et fougères. Der Grund für diese Tatsache liegt einfach darin, dass auch wissenschaftliche Klassifikationen oft an der erfahrbaren Wirklichkeit ansetzen und damit durchaus konzeptionelle Bezüge zur Lebenspraxis aufweisen.

Was Steger zeigen will, ist auch in der Fachsprachenlinguistik erkannt worden und führt hier zu der Ausarbeitung differenzierter Vertikalitätskonzepte 
des fachsprachlichen Wissens. Die Unterscheidung eines Experten- und eines Laienniveaus innerhalb der Fachsprachenlinguistik erscheint mir in diesem Sinne methodisch sinnvoller als die Konfrontation einer Alltags- und einer Fachsprachensemantik, die die letztere zu der Semantik einer 'nicht natürlichen Sprache' degradiert. Es ist darüber hinaus nicht gut, die Wissensungleichverteilung in der Gesellschaft durch die Abgrenzung zweier semantischer Systeme methodisch zu fundamentieren, obwohl gerade die Übergangsbereiche von fachsprachlich und gemeinsprachlich organisiertem Wissen eine interpretative Herausforderung an die Fachsprachenlinguistik darstellen.

Die methodologischen Implikationen von Stegers Ansatz sind jedoch noch wesentlich weitreichender. Steger verbindet nämlich seinen Hinweis auf die 'Alltagssprache' mit einer grundsätzlichen Kritik an der varietätenlinguistischen Betrachtung der Einzelsprache. Das folgende Exzerpt seiner Ausführungen soll dies verdeutlichen:

Der bewußt wahrgenommene Gegenstandsbereich 'Einzelsprache', z.B. also 'Deutsche Sprache', hat heute einen in der bisherigen Geschichte der gesamten Sprachwissenschaft nie erreichten Umfang angenommen. [...] Die begrifflich gefaßten Ausschnitte wie die hierfür verwendeten Termini sind verwirrend vielfältig und in ihrer gegenseitigen Abgrenzung unklar. [...] So stellt sich gegenwärtig fast alles dar als eine Vielzahl von einzelnen 'Sprachvarietäten', die nur in manchen Bereichen Zusammenhänge mit 'benachbarten' 'Sprachvarietäten' zeigen, [...]

So ist ein systematischer (und evtl. hierarchischer) Zusammenhang unter den verschiedenen als Sprachvarietäten, Erscheinungsformen, Existenzformen, Substandards, Teilsprachen, Sondersprachen, Teilsysteme, Stile bezeichneten Ausschnitten und 'Binnengliederungen' des Deutschen heute nicht erkennbar. [...] Die Bestimmung des 'Ganzen' und sein Verhältnis zu seinen 'Teilen' ist offenbar im Laufe der Entwicklung unklar geworden.

(Steger 1988, 292)

Steger kritisiert, dass die Sprachvarietäten heterogene 'Interpretationen einer komplexen kommunikativen Wirklichkeit' (S. 293) seien, die er selbst auf eine methodisch homogene Weise zu analysieren versucht. Dabei unterscheidet er zwischen zwei Variationsdimensionen der Einzelsprache, nämlich ihrer 'funktional-zweckhaften Leistung' und ihrer 'sozialen Reichweite'. Er trennt damit aber ganz offensichtlich die kommunikative Funktion der Sprache (in inhaltlicher Betrachtung) von ihrer sozialen Wirklichkeit ('sozialräumlicher' Bezug und Sprechergruppenbezug) ab, was an sich problematisch erscheint. Die Erscheinungsformen bzw. Existenzformen der Einzelsprache bindet Steger, da er dies selbst erkennt, wieder an eine 'Verkoppelung' beider Dimensionen, die jedoch auch nur zur Bestimmung von 'Teilsystemen als theoretische Konstrukte' führt (S. 309). Solche Konstrukte sind in seiner Interpretation dann wiederum sehr spezifisch, so dass sie in Termini wie dialektale Alltagssprache, regionale Alltagssprache, Standardalltagssprache, dialektale Grup- 
pen(alltags)sprache, dialektale Familien(alltags)sprache, regionale Studenten(alltags)sprache, Standard-Frauensprache oder dialektale Literatursprache umgesetzt werden (vgl. S. 313 f.). Der von Steger angestrebte Erfolg einer begrifflichen Klarheit muss hier stark in Zweifel gezogen werden. Zudem bleibt das eigentliche Problem der Varietätenlinguistik, nämlich der Zusammenhang von Varietät und Gesamtsprache, nach wie vor ungelöst:

Wenn auch in den Existenzformen die tatsächlichen (virtuellen) sprachlichen Systeme einer Sprachbevölkerung gefaßt werden, so erscheint doch die Vorstellung einer Gesamtsprache, z.B. der deutschen Sprache, als Gesamtheit aller Erscheinungsformen (Existenzformen) als gerechtfertigt. Sie ist in linguistischer Hinsicht allerdings ein rein theoretisches Konstrukt (ein 'Supersystem', in dem alle Existenzformen abstrahierend zusammengefaßt werden [...]).

(Steger 1988, 315)

Meiner Meinung nach macht es keinen großen Unterschied, ob man die Varietät als abstraktes 'Subsystem' oder die Gesamtsprache als abstraktes 'Supersystem' betrachtet. Das eigentliche Problem liegt in der mangelnden Konkretisierung der Analyse des Sprachgebrauchs, der eben nur als Sprachkompetenz des einzelnen Sprechers eruierbar ist. Ich schlage daher vor, in der Varietätenlinguistik einen ganz anderen, nämlich empirischen Weg zu gehen, ohne dabei jedoch auf die theoretischen Errungenschaften der Varietätenanalyse zu verzichten. Auf diesem Weg gibt es aber bislang nur wenige Hilfen aus dem Bereich der schon geleisteten Forschung.

Wo soll die Empirie in der Varietätenlinguistik ansetzen? Eine einfache Antwort hierauf ist: beim Sprecher. Allerdings liegen die Dinge nicht so klar, wie es scheint. Wenn nämlich der Sprecher befragt werden soll, so muss zunächst grundsätzlich entschieden werden, ob dies auf einer metalinguistischen oder einer primärsprachlichen Ebene erfolgen soll. Varietätenlinguistisch ausgerichtete Konzeptionen, seien sie nun soziolinguistisch oder strukturalistisch orientiert, haben bislang die metalinguistische Befragungsebene bevorzugt. Pragmatisch orientierte Konzeptionen hingegen gehen in der Regel von der konkreten Kommunikationssituation aus und untersuchen das Sprecherverhalten im Hinblick auf ihre variablen Parameter (Sprecher, Thema, Kontext, etc.), ohne dabei eine systematische Erklärung kommunikativer Funktionsweisen der Einzelsprache anzustreben. Ist es also erforderlich, wenn untersucht werden soll, 'was ein Sprecher wirklich tut', auf den Begriff der Einzelsprache vollständig zu verzichten und ihn gegebenenfalls durch die grundsätzliche Vorstellung einer 'Alltagssprache' als einzig 'natürlicher', aber eben nicht formalisierbarer Form des Sprachgebrauchs zu ersetzen? Ist die Einzelsprache als 'Gemeinsprache', als 'Gesamtsprache' als 'Nationalsprache' oder auch als 'Minderheitensprache' zu theoretisch, um als Ansatzpunkt zu einer empirischen Fragestellung in der Varietätenlinguistik zu taugen? 
Ich meine, die Varietätenlinguistik sollte auf den Begriff der 'Gemeinsprache' als Komplement zur 'Varietät' nicht verzichten. Dabei hängt es von der begrifflichen Konzeption ab, ob die Gemeinsprache als solche terminologisiert wird oder sich in Bezeichnungen wie 'historische Sprache', 'Gesamtsprache', 'Nationalsprache', 'Minderheitensprache' usw. wiederfindet. Entscheidend ist der Aspekt des inneren Zusammenhalts der einzelsprachlichen Ausprägungen, der bei 'Nationalsprachen' und manchen 'Minderheitensprache' deutlich im Sprecherbewusstsein reflektiert wird. Doch kann das Sprecherbewusstsein allein nicht der verbindliche Maßstab für eine varietätenlinguistische Betrachtung sein. Um hier nicht missverstanden zu werden, möchte ich betonen, dass ich keinesfalls an der Ebene dieses Sprecherbewusstseins vorbei argumentieren möchte. Die Dinge sind aber auch hier viel zu kompliziert, als dass sie metalinguistisch durch die Sprecher entschieden werden könnten. Die Ebene des Sprachbewusstseins ist nämlich ein Spiegel oft konfliktärer Verhältnisse der Sprachverwendung, deren Komplexität insbesondere in Situationen des Sprachkontakts bzw. des Kontakts von Sprachvarietäten immens zunimmt. Sprecher können in solchen konfliktären Verhältnissen nicht zu 'objektiven Linguisten' gemacht werden, will man nicht die gesicherten Erkenntnisse der Kontaktlinguistik, insbesondere der Diglossieforschung und der Ausbaukomparatistik, einfach unbeachtet lassen. Es mag in diesem Sinne an ein 'Prinzip' der sprachtheoretischen Konzeption Coserius erinnert werden, dem ich mich voll und ganz anschließe:

Die Sprache funktioniert für und durch die Sprecher und nicht für und durch die Linguisten, und der Linguist muß folglich von diesem Funktionieren der Sprache für und durch die Sprecher ausgehen, auch wenn er später andere Gründe für das Verhalten der Sprecher finden kann als die, die die Sprecher selbst identifizieren oder zu identifizieren glauben. Denn bei dieser Identifizierung sind die Sprecher nicht mehr bloß Sprecher. Wenn sie ausdrücklich sagen, warum sie so oder so sprechen, d.h. wenn sie Gründe angeben, dann sind sie schon Linguisten. Als Linguisten können sie sich auch irren, weil sie normalerweise als naive Sprecher schlechte Linguisten sind. Aber in ihrem naiven Verhalten als Sprecher, gerade ohne reflexive Begründung, sind jeweils sie und nicht die Linguisten die maßgebenden.

(Coseriu 1988a, 83)

Was für die Beschreibung strukturalistischer Sprachfunktionen gilt, gilt auch für die Beschreibung von Sprachfunktionen aus soziolinguistischer Sicht: Die 'Einstellung der Sprecher' ist ein für den Soziolinguisten entscheidendes Kriterium, aber als Basis seiner Interpretationen und nicht als empirische Verifikation einer sprachwissenschaftlichen Konzeption. Im Falle der von mir untersuchten Sprachgebiete beispielsweise, wird man erklären müssen, warum die Sprecher sich mit den Bezeichnungen biarnés und valencià problemlos identifizieren, die Begrifflichkeiten von occitan und català in Bezug auf die von ihnen verwendete Sprache jedoch nur zum Teil anerkennen und oft explizit 
ablehnen. Ebenso sollte die linguistische Bewertung der Sprachkompetenz eines Sprechers nicht von seiner eigenen Meinung abhängen, ob er die entsprechende Sprache 'gut' oder 'schlecht' spreche (allein das Bewertungsschema ist hier kein linguistisches). Mehr noch: Sprecher, die glauben, eine Standardsprachform zu verwenden, sind sich häufig der regionalen Gebundenheit ihres Sprachgebrauchs nicht genügend bewusst. Und die Verwendung einer Fachsprache wird von vielen Sprechern aus linguistischer Sicht nicht korrekt eingeschätzt. Wir müssen also ermitteln, was ein Sprecher wirklich tut und über seine Sprache (von sich aus) sagt, wenn wir eine empirische Grundlage für die Behandlung varietätenlinguistischer Fragen aufbauen wollen. Dabei ist es wichtig, zu erkennen, dass der 'naive Sprecher' nicht zwischen einer sprachstrukturellen und einer sprachsoziologischen Dimension seines Sprechens unterscheidet. In diesem Sinne kann auch der Linguist sprachstrukturelle Phänomene des Sprechens zur Grundlage einer soziolinguistischen Erklärung machen und Einstellungen der Sprecher zu ihrer Sprache als ein Kriterium in die Analyse der Sprachstruktur hineinbringen. ${ }^{63}$

Doch kommen wir auf den Aspekt der Gemeinsprache zurück. Die Gemeinsprache ist ein linguistischer Bezugsrahmen, der in der Realität des Sprechens verankert ist. Jeder Sprecher, der eine konkrete Sprache spricht, geht-um in der Diktion Stegers zu bleiben - von einer gewissen 'sozialen Reichweite' dieser Sprache aus, d.h. er ist sich sicher, von einer mehr oder weniger großen Sprechergruppe in einem mehr oder weniger großen geographischen Raum verstanden zu werden. Diese Annahme ist für den Sprecher nicht nur theoretischer Natur, sondern eine Grundkonstante seiner Erfahrung des Sprechens. Ich bezeichne dies als die Erfahrung des 'Gemeinsprachlichen'. Diese Erfahrung des 'Gemeinsprachlichen' lässt sich bei der Verwendung einer Standardsprache ebenso machen wie bei der Verwendung eines Dialekts oder einer Fachsprache. Genau genommen, macht der Sprecher die Erfahrung des 'Gemeinsprachlichen' immer und ausschließlich bei der Verwendung einer Sprachvarietät, denn ein Sprechen, das nicht auf die konkrete Verwendungsweise einer historischen Sprache zurückgreift, ist nicht möglich. Es ergibt sich also von vornherein ein Spannungsverhältnis von konkretem Sprachgebrauch und 'gemeinsprachlicher Erfahrung', das nicht etwa einen Konfliktstoff bein-

${ }^{63}$ Der zuletzt genannte Aspekt ist hochbrisant im Sinne der oft nicht unproblematischen Annäherung von sprachstruktureller und sprachsoziologischer Forschung. Dies lässt sich exemplarisch an der Entwicklung der Forschungsorientierung von Žarko Muljačić aufzeigen. Während sich Muljačić dem Untersuchungsfeld einer typologischen Klassifikation der romanischen Sprachen zunächst auf einer rein strukturellen Ebene annäherte, ist er inzwischen durch seine individuelle Assimilation des theoretischen Ansatzes von Heinz Kloss zu einer relativistischen Erklärungstheorie gelangt, die politische und soziale Machtverhältnisse in der Konfrontation von Sprachen zum Erklärungsrahmen einer varietätenlinguistischen Typologie macht. 
haltet, sondern die Basis für eine Dynamik des Sprechens darstellt, die zu der dauernden Veränderung sprachlicher Verhältnisse führt.

Die 'gemeinsprachliche Erfahrung' der Sprecher muss in die varietätenlinguistische Konzeption mit einbezogen werden. Die Sprecher können sich bewusst auf den Gebrauch einer Varietät der Einzelsprache konzentrieren. Diese Konzentration hängt vom sozialen Kontext ab. So wird auf dem Amt ein bürokratischer Sprechstil bevorzugt, im Theater eine literarische Sprache gepflegt, in bestimmten sozialen Gruppen ein Jargon verwendet, im Heimatort der Dialekt gesprochen oder am Arbeitsplatz eine Fachsprache benutzt. Im Alltag jedoch ist die Basis der Kommunikation in der Regel keine spezifische funktionelle Sprachvarietät. Der 'Alltag' reicht in diesem Sinne auch weit in die berufliche oder andere fachspezifische Sphären (z.B. des Freizeitsektors) hinein. Die Erfahrung des 'Gemeinsprachlichen' ist in diesen Gesprächssituationen jedoch nicht größer, sondern nur anders orientiert: Der Alltag ist der 'Normalfall' des Sprechens, aber dieses Sprechen kann sich ebenfalls nur auf der Basis einer konkreten Form des Sprechens vollziehen. Diese Form des Sprechens bezeichne ich als 'Standard-Varietät'. Auf diese Weise wird die Erfahrung des 'Gemeinsprachlichen' im Alltag in eine varitätenlinguistische Interpretation hineingebracht, die es erlaubt, die 'Gemeinsprache' konkret zu betrachten. Allerdings darf diese Optik nicht so weit gehen, ihr den Charakter eines formalisierbaren 'Subsystems' zuzuschreiben. Denn 'gemeinsprachlich' ist die Standard-Varietät im Alltag nur, weil sie eine prinzipiell offene Varietät darstellt, also sich nicht so einfach abgrenzen lässt wie eine Fachsprache oder ein Dialekt.

Die Erfahrung des 'Gemeinsprachlichen', die der Sprecher bei der Verwendung einer flexiblen Standard-Varietät macht, ist in der Varietätenlinguistik bereits erkannt worden und hat dort zu der Prägung einer eigenen Begrifflichkeit geführt. In der Germanistik wird das Phänomen meist mit dem Terminus 'Umgangssprache' beschrieben. ${ }^{64}$ Innerhalb der Romanistik hat sich bislang vor allem die Italianistik dem Problem zugewandt und hierfür Begriffe wie italiano dell'uso medio (Sabatini 1985) oder neo-standard (vgl. Berruto 1987, 23 f.) geprägt. Es ist hier nicht der Ort, den deskriptiven Details dieser begrifflichen Konzeptionen im Einzelnen nachzugehen. Jedoch soll hervorgehoben werden, dass es sich um die Anerkennung des grundsätzlichen Phänomens sprachlicher Standardisierung handelt, das zu den typischen Formen des Sprachgebrauchs in den modernen Industriegesellschaften führt. In der Tat

${ }^{64}$ Die Charakterisierung der 'Umgangssprache' führt dabei je nach methodischem Interesse zu der Hervorhebung unterschiedlicher Definitionsmerkmale. Im Allgemeinen wird festgestellt, dass die 'Umgangsprache' regional differiert, mehrere soziale Gruppen (bzw. Schichten) umfasst, stilistisch auf einem intermediären (Ausgleichs-)Niveau anzusiedeln ist und als 'Sprache des Alltags' keiner thematischen Bindung unterliegt. 
werden die varietätenspezifischen Unterschiede in der Verwendung einer Einzelsprache immer stärker zurückgedrängt und durch die großflächigere Verwendung standardisierter Sprachformen ersetzt. Italien ist hierfür ein signifikantes Beispiel, jedoch findet sich das Phänomen überall in Europa. ${ }^{65}$

Die Sprecher verbinden heute mit der Erfahrung des 'Gemeinsprachlichen' zunehmend die Normalität eines Standard-Gebrauchs der Einzelsprache, der verschiedenen kommunikativen Zwecken dient, ohne dass sogleich auf eine grundsätzlich andere funktionelle Sprachebene, d.h. zu einer anderen Sprachvarietät, gewechselt werden muss. Die Umgangssprache oder der 'NeoStandard' sind aber grundsätzlich offen für diatopische, diastratische und diaphasische Besonderheiten des Sprachgebrauchs. Die Sprachkompetenz der Sprecher ist für die Verwendungsmöglichkeiten eines flexiblen Standards im Alltag stärker sensibilisiert als für die funktionale Trennung verschiedener Varietäten. Hierfür gibt es gesellschaftliche Gründe. Zum einen machen die globalisierenden Tendenzen der modernen Informationsgesellschaft und die im Rahmen überregional verflochtener Wirtschaftsstrukturen oft unabdingbare Mobilität des Einzelnen die Existenz ausgeprägter Mundarten und Dialekte immer unrealistischer. Zum anderen lässt die Komplexität der arbeitsteiligen Gesellschaft, in der der Einzelne immer stärker mit immer mehr fachlichen Bereichen in Berührung kommt, die Erlangung des Expertenniveaus in einem oder wenigen Fächern und die Unkenntnis über viele andere Fächer heute ebenfalls nicht mehr realistisch erscheinen. Die soziale Abgrenzung des einzelnen Sprechers erfolgt daher noch am ehesten über eine Gruppensprache bzw. eine Form des Substandards. Aber selbst diese Tendenz wird zum Teil durch die gesamtgesellschaftliche Diffusion gruppenspezifischen Sprachverhaltens reduziert. ${ }^{66}$

Das beschriebene Phänomen sprachlicher Standardisierung ist ein Schlüssel zu der Erklärung dynamischer Prozesse, die sich in Sprachkontaktsituationen ergeben und oft zu der Verlagerung der Sprachtraditionen vom Dialekt zur Hochsprache bzw. von der Regionalsprache zum Standard führen. Ich werde dies im folgenden Kapitel im Rahmen eines eigenen Erklärungsansatzes zur

${ }^{65}$ Eine Erklärung liefert der amerikanische Sprachwissenschaftler John Gumperz (vgl. Gumperz 1972). Seine These, die besagt, dass die Unterschiede zwischen sprachlichen Varietäten mit einer komplexeren Strukturierung und Höherentwicklung der Gesellschaftsformen abnehmen, wird in Nabrings 1981, 22 ff., dargestellt und kommentiert. Dabei hebt die Autorin die Tatsache hervor, dass mit dem sprachgeschichtlichen 'Ausgleich von Varietäten', insbesondere der Zurückdrängung dialektaler Eigenheiten, die Durchsetzung einer Standardsprache einhergeht, die für eine erneute interne Differenzierung offen sein muss, da sie eine große Vielfalt kommunikativer Funktionen übernimmt, die immer weniger von den klar abgegrenzten Varietäten der Einzelsprache ausgefüllt werden (können).

${ }^{66}$ Ältere nehmen Elemente der Jugendsprache an; Argot-Wörter werden umgangsprachlich, Strukturen einer Sondersprache (Sport, Werbung, Journalismus, etc.) finden sich im allgemeinen Sprachgebrauch wieder... 
sprachlichen Standardisierung zu verdeutlichen versuchen. Dabei werden sich weitere methodische Klärungen ergeben. Zuvor jedoch möchte ich noch auf den Aspekt des 'regionalen Sprachgebrauchs' eingehen, dessen Verständnis für den Untersuchungsansatz in dieser Arbeit wesentlich ist und dessen Konzeption sich aus den bisherigen Darlegungen ergibt.

Es wird immer wieder die These aufgestellt, die 'landschaftliche Färbung' der Umgangssprache bzw. die Regionalisierung der Gemeinsprache (vor allem mittels der Aufnahme diatopischer Elemente in die Aussprache und in die Lexik) sei im modernen Sprachverhalten ein Substitut für den schwindenden Gebrauch von Dialekten und Regionalsprachformen. Mir scheint hier eine grundsätzliche Fehlinterpretation vorzuliegen. Betrachtet man die romanistischen Forschungen zum français régional, zum español regional und zum italiano regionale (colto medio) ${ }^{67}$ genauer, so zeigt sich, dass diese Varietäten durch eine überschaubare Zahl von lexikalischen und phonetischen Eigenheiten beschrieben werden, deren Begründung meist in der Einflussnahme regressiver oder untergegangener Kontaktsprachen zu suchen ist. Es handelt sich also gewissermaßen um die formale Analyse von Adstrat- und Substrateinwirkungen, deren Prinzip aus der Geschichte der romanischen Sprachen hinlänglich bekannt ist. Allerdings gibt es keine sprachgeschichtlichen Darstellungen, die davon ausgehen, dass entsprechende Sub- oder Adstratwirkungen des Keltischen oder Baskischen in den romanischen Sprachen die verloren gegangene kommunikative Funktionalität dieser Sprachen widerspiegelten oder gar repräsentierten. Genauso unsinnig erscheint aber die Vorstellung, dass die partielle regionale Prägung materieller Sprachstrukturen eine Funktionsäquivalenz zu weniger gebräuchlichen oder nicht mehr gebräuchlichen Dialekten und Regionalsprachen sein könnte. Dennoch ist diese Sichtweise in der Romanistik implizit verbreitet, jedenfalls insofern, als dass weder der Strukturalismus noch die Kontaktlinguistik bislang auf dieses methodische Defizit aufmerksam geworden sind. Wir werden an späterer Stelle noch darauf eingehen, dass Thomas Stehl einer der wenigen Sprachwissenschaftler ist, die das Problem erkannt und thematisiert haben.

Unter 'regionalem Sprachgebrauch' verstehe ich ganz einfach den Sprachgebrauch in einer 'Region'. Dieser Sprachgebrauch kann (aber er muss nicht qua definitione) diatopisch markiert sein. Er ist jedoch in erster Linie ein Sprachgebrauch, der auf einer Standard-Varietät beruht ${ }^{68}$ und eine kommunikative Funktionsvielfalt im alltäglichen Leben der Region abdeckt. Der 'regionale Sprachgebrauch' ist durch die typische Offenheit und Flexibilität der 'Gemeinsprache' gekennzeichnet. Er taugt für die soziale Identifikation in der

${ }^{67}$ Berruto verwendet den Ausdruck italiano regionale colto medio synonym zu italiano neostandard, (vgl. Berruto 1987, 23).

${ }^{68}$ Dies kann auch die Standard-Varietät einer Regionalsprache sein. 
Region mittels der Sprache ebenso wie für die kommunikative Bewältigung von Fachkontexten, die für die Region von besonderer Relevanz sind. Es ist ein Sprachgebrauch, dem niemand 'entgeht', der in der Region lebt und dort kein Fremder bleiben will. Es ist sogar ein Sprachgebrauch, der in Sprachkontaktgebieten mehr als eine historische Sprache zu seiner Kommunikationsgrundlage machen kann (aber nicht muss). In einer Diglossiesituation ist der 'regionale Sprachgebrauch' der dominanten Sprache tendenziell ein Substitut für den Gebrauch der dominierten Sprache (deren regionale Bindung ein Konstitutivum ist), vor allem wenn diese dominierte Sprache wenig oder kaum noch gebraucht wird. Der 'regionale Sprachgebrauch' ist also keine materielle Ausprägung einer Standardsprache, sondern eine kommunikative Existenzform der Sprache oder der Sprachen in einer 'Region'. Bleibt noch zu klären, was unter 'Region' und 'regionaler Determination' zu verstehen ist.

Die 'Region' ist meinem Verständnis nach in erster Linie nicht sprachlich bestimmt, sondern eine Form von Abgrenzung innerhalb der zusammenwachsenden Gesellschaft, die auf ihren tradierten Mustern der Identitätsfindung beharrt. Die Existenz von Regionen ist in diesem Sinn eng mit dem Aufbau und Erhalt vielschichtiger gesellschaftlicher Normen verbunden. Unter ihnen spielt die sprachliche Norm eine ganz wesentliche Rolle. Während sich 'diatopisch' auf die entsprechende Dimension einer strukturellen Gliederung der Einzelsprache (im Sinne der 'Architektur' dieser Sprache) bezieht, meint 'regional' das Vorhandensein einer gebietsbezogenen Normierung sprachlichen Verhaltens, die im extremen Fall mit der geographischen Begrenzung der entsprechenden Sprache oder Sprachform einhergehen kann, jedoch auf jeden Fall einer bewusstseinsmäßigen Eingrenzung des von den Sprechern als einheitlich empfundenen Sprachgebiets entspricht. Anders ausgedrückt ist 'regionale Sprache' die sprachliche Ausdrucksform in einer Region, wobei sich die Region aufgrund historischer und sozio-kultureller, aber auch politischer und ökonomischer Faktoren als eine solche definiert. Letztlich verstehe ich also unter dem regionalen Sprachgebrauch nicht mehr und nicht weniger als das durch regionale Bedingungen erklärbare Sprachverhalten einer geographisch abgrenzbaren Sprachgemeinschaft.

Unter soziolinguistischem Aspekt hat die so verstandene 'regionale Sprache' eine gesellschaftliche Identifikationsfunktion, die sie sowohl als eigenständige Regionalsprache als auch in der Form einer standardbasierten Regionalsprachform ausüben kann. Damit ist in Bezug auf die in Europa allenthalben beobachtbaren Phänomene von Sprachwandel und Sprachwechsel ein Kontinuum gegeben, das insbesondere durch die kommunikativen Bezüge regionaler Sprache, aber auch durch die regional ausgebildeten Diskurstraditionen (Texttypen) garantiert wird. Hieraus leitet sich die Verpflichtung ab, die Veränderung sprachlichen Verhaltens in einer Region verstärkt unter dem Blickwinkel von 
Kontinuität und Wandel der sozio-kulturellen Bedingungen der Sprechergemeinschaft zu erklären. Dies wiederum erfordert die Anwendung spezieller Beschreibungsverfahren.

Der einzig mögliche empirische Ansatz zu der Beschreibung der Sprachkompetenz, die mit dem 'regionalen Sprachgebrauch' verbunden ist, liegt in einem Rekurs auf den einzelnen Sprecher, insofern er als Repräsentant einer typischen Sprachkompetenz in der Region anzusehen ist. Diese Sprachkompetenz lässt sich aber nur aus Gesprächen, also längeren Diskursen entnehmen. Die interpretative Auswertung dieser Diskurse kann dabei mehrere Aspekte des Sprachverhaltens auf den einzelnen Ebenen des Sprechens (Bezeichnung, Bedeutung, Sinn) hervorheben. Unter varietätenlinguistischem Aspekt ist das Sprachverhalten des Sprechers dabei von verschiedenen Normen abhängig. Wir können sie grob in Individualnormen und Regionalnormen differenzieren. Im Hinblick auf die Individualnormen schreibt z.B. Helmut Schönfeld:

Von wesentlicher Bedeutung für die Art und Weise der Sprachvariation ist die Person des Sprechers mit ihren individuellen Merkmalen. [...] Das konkrete sprachliche Verhalten hängt ab von den verfügbaren sprachlichen Differenzierungen, den sprachlichkommunikativen Fähigkeiten und Fertigkeiten, von seinen sprachlichen Erfahrungen und Gewohnheiten, vom Wissen über die sprachlichen Differenzierungen und deren angemessene Verwendung, von Normenwissen und Normenbewußtsein sowie von der Einstellung zu den sprachlichen Differenzierungen. [...] Dabei ist das sprachliche Verhalten in die Gesamtheit der Verhaltensweisen des Individuums verwebt.

(Schönfeld 1985, 221)

Einen Hinweis auf die Qualität der Regionalnormen findet man in Coserius 'Theorie der Umfelder' (Coseriu 1975, 276 ff.). Es würde zu weit führen, auf diese Theorie hier detailliert einzugehen. ${ }^{69}$ Ich beschränke mich daher auf einige kurze Bemerkungen und ein Zitat. Die 'Umfelder' sind für Coseriu die 'Umstände des Sprechens', die bei jedem Sprechen vorhanden sind und die jedes Gespräch orientieren. Diese 'Umfelder' können sehr spezifisch sein (die 'Situation' als das Raum-Zeitliche des Sprechens) oder auch sehr weit gefasst (Coseriu spricht von 'Redeuniversien', zu denen er u.a. die 'Erfahrungswelt' rechnet). Eine intermediäre Stufe dieser 'Umfelder' nun ist die 'Region'. Der Begriff ist bei Coseriu in diesem Zusammenhang nicht geographisch bestimmt,

${ }^{69}$ Das Kapitel „In welchen Traditionen stehen wir, wenn wir sprechen?“ in Schlieben-Lange 1983, 13-29, erklärt die aufgeworfene Frage im Wesentlichen auf der Basis von Coserius Theorie der Umfelder. Allerdings verlegt sich die Autorin mehr auf die ausführliche Zitierung als auf eine Kommentierung dieser Theorie. Eine detailliertere Auseinandersetzung mit dem wichtigen, schon 1955 auf Spanisch verfassten sprachtheoretischen Beitrag Coserius „Determinación y entorno. Dos problemas de una lingüística del hablar“ steht m.W. bis heute noch aus. 
aber er impliziert eine Normierung die in einer geographischen Region, so wie ich sie verstehe, zum Tragen kommt:

Region nennen wir den Raum, innerhalb dessen ein Zeichen in bestimmten Bedeutungssystemen funktioniert. Dieser Raum wird auf der einen Seite durch die Sprachtradition und auf der anderen Seite durch die Erfahrungen mit den bezeichneten Wirklichkeiten eingegrenzt. Dabei sind drei Typen der 'Region' unterscheidbar: Zo$n e$, Bereich und Umgebung. Die Zone ist hier die 'Region', in der ein Zeichen gewöhnlich bekannt ist und verwendet wird; ihre Grenzen beruhen auf der Sprachtradition und fallen zumeist mit anderen, ebenfalls sprachlichen Grenzen zusammen. Der Bereich ist die 'Region', in der das Objekt als ein Element des Lebensbezirks der Sprecher oder eines organischen Gebietes der Erfahrung bzw. der Bildung bekannt ist, wobei dessen Grenzen nicht von der Sprache bestimmt werden. So etwa ist der Raum, innerhalb dessen der Gegenstand 'Haus' bekannt wird, ein 'Bereich'. Und die Umgebung endlich ist eine sozial oder kulturell bestimmte 'Region': die Familie, die Schule, die Berufsgemeinschaften, die Kasten usw., insofern sie ihnen eigene Sprechweisen besitzen, sind solche 'Umgebungen'. Eine 'Umgebung' kann nun besondere Zeichen für 'Gegenstände' mit einem weiteren Bereich haben; aber auch spezifische 'Gegenstände'; oder kann schließlich besondere Zeichen für ebensolche Gegenstände kennen. D.h., sie kann als 'Zone', als 'Bereich' oder als 'Zone' und 'Bereich' zugleich funktionieren.

(Coseriu 1975, 278 f.)

Coseriu bringt hier das sprachliche Ausdruckssystem ('Zone' als Zeichen), die außersprachliche Referenz ('Bereich' als Objekt) und die kulturell bestimmte Sprechergemeinschaft ('Umgebung') in einen normativen Bezug zur Sprachkompetenz des Sprechers. Diese Sprachkompetenz wird faktisch durch alle drei Arten von 'Umfeldern' in jedem Sprechakt normativ bestimmt. Die normative Reichweite dieser Bestimmung qualifiziert Coseriu nicht ohne Grund als 'Region'. Es handelt sich nämlich um einen identifikationsstiftenden Regionenbegriff. Auch die von mir vertretene Konzeption von 'regional' knüpft an diesen Aspekt an. Sie bezieht sich nicht in jedem Fall auf eine geographisch exakt bestimmbare Extension, ermöglicht es aber, den Sprachgebrauch faktisch sowie auch im Bewusstsein der Sprecher als 'regional bestimmt' zu erklären. 


\subsection{Sprachkontakt und sprachliche Standardisierung}

Das Thema des 'regionalen Sprachgebrauchs in Fachkontexten' lässt sich prinzipiell auch in Bezug auf monolinguale Gemeinschaften behandeln. Allerdings ist die analytische Einbeziehung gesellschaftlicher Mehrsprachigkeit mehr als nur eine methodische Komplikation. Gerade im Hinblick auf Situationen des Sprachkontakts zeigt sich nämlich die Fruchtbarkeit des varietätenlinguistischen Ansatzes in Zusammenhang mit dem Verfahren des Sprachvergleichs. Auch trifft man hier auf eine reiche Forschungstradition.

Die Sprachkontaktforschung ist bis auf wenige Ausnahmen in prädominanter Weise soziolinguistisch geprägt. Dies ergibt sich aus der Präferenz für Fragestellungen, die sich vor allem der Beschreibung sozialer Sprachfunktionen zuwenden. Dabei steht der Kontakt von zwei oder mehr Einzelsprachen heute im Vordergrund der Betrachtung. Das Interesse für den Status von Dialekten und Mundarten ist demgegenüber rückläufig, was sicherlich mit dem schwindenden Gebrauch dieser Form diatopischer Varietäten in den Sprachgemeinschaften der europäischen Industrienationen zu tun hat. ${ }^{70}$ Die aktuellen Sprachkontaktsituationen, um die es der (europäischen) Kontaktlinguistik hauptsächlich geht, sind in der Regel durch das Aufeinandertreffen und die Konvivenz verschiedener Ethnien begründet. Ausschlaggebende Faktoren sind die Multikulturalität in den großen Städten, die wirtschaftlich (und auch politisch) bedingte Migration und Mobilität sowie der gesellschaftlich-politische Strukturwandel, der einen Reflex in der Sprachpolitik findet. Der Prozess der europäischen Einigung bringt hier vieles 'durcheinander', das die Kontaktlinguistik noch weiter aufarbeiten wird.

Der orientierende Begriff der Sprachkontaktlinguistik ist der des 'Konflikts' (vgl. Rindler Schjerve 1999). Die Auffassung, es gebe keinen Sprachkontakt ohne Sprachkonflikt, wurde in den 80er Jahren von Peter Hans Nelde zu einer Art Axiom dieser Forschungsrichtung gemacht (vgl. Nelde 1988 ff.). Doch ist $\mathrm{zu}$ bedenken, dass es keine theoretisch-methodische Klammer einer Sprachkonfliktforschung innerhalb der Kontaktlinguistik gibt. Der konzeptionelle Rahmen, in dem Sprachkonflikte aufgespürt und analysiert werden, ist sogar aufgrund verschiedener Forschungstraditionen heute nicht nur vielfältig, sondern zunehmend uneinheitlich. Wie jede blühende Disziplin, wird die Sprach-

${ }^{70}$ Hervorzuheben sind jedoch - wie im Falle der deutschsprachigen Schweiz oder Luxemburgs - einige Ausnahmen von Sprachgemeinschaften, in denen es eine Form der stabilen Zweisprachigkeit von Dialekt und Hochsprache gibt. Einen Sonderfall bildet Italien. Der immer stärkere Rückgang der italienischen 'Basilekte' (d.h. primärer Dialekte, deren Zuordnung zur historischen Sprache 'Italienisch' problematisch ist) bildet ein Hauptinteressengebiet der italienischen Soziolinguistik, das jedoch von dem Problembereich 'Minderheitensprachen in Italien' methodisch kaum zu trennen ist. 
kontaktforschung immer mehr auch mit internen Konflikten zurechtkommen müssen, jedenfalls soweit diese mit den unterschiedlichen Sichtweisen einzelner Forscher verbunden sind. In dem erforderlichen Methodenpluralismus bleibt aber die Frage nach dem einzelnen Sprecher und seinem beobachtbaren Sprachverhalten, d.h. sein Umgang mit ein, zwei oder mehr Sprachen in einer Sprachengemeinschaft und seine zum Ausdruck gebrachte Einstellung zu den verschiedenen Sprachen, ein zentraler Ausgangspunkt der Theoriebildung. Die Verpflichtung zu einer empirisch-deskriptiven Konzentration auf sozial existente Formen des Sprachgebrauchs und ihrer Bewertung erscheint dabei oft langwierig und mühevoll gegenüber den schnelleren Formen der sprachpolitischen Beteiligung auf der Grundlage allgemeiner Theorien und statistischer Umfragen.

Es darf in diesem Zusammenhang nicht außer Acht gelassen werden, dass die Kontaktlinguistik in Europa auf der Basis varietätenlinguistischer Modelle entstanden ist, deren analytisches Interesse auf die konkrete Verwendung einzelner Sprachformen ausgerichtet ist. Dies gilt sowohl für die Diglossieforschung $^{71}$ als auch für die sog. 'Ausbaukomparatistik'. ${ }^{72}$ Beide Forschungsrichtungen sind jedoch aus der Perspektive eines vermeintlich schnellen Wandels der Disziplin 'Kontaktlinguistik' heute scheinbar schon in die Jahre gekommen und befinden sich in einer immer stärkeren Konkurrenz zu jüngeren, meist aus der amerikanischen Soziolinguistik stammenden Analyseansätzen. Dabei stellt sich aber die Frage, ob alles 'Alte' wirklich schon überholt ist und alles 'Neue' tatsächlich so anders, wie es auf den ersten Blick erscheint. Diese Frage ist differenziert zu beantworten. Wenn beispielsweise in einem selbst auferlegten Modernisierungszwang der Disziplin heute alles aus der Perspektive der 'Ökolinguistik' betrachtet werden sollte, so wäre dies sicherlich eine unangebrachte Form der Methodenhysterie. Wenn hingegen Vorschläge zur Modifikation und Erweiterung bestehender Modelle unterbreitet werden, so gehört dies zur Normalität wissenschaftlichen Fortschritts.

Kommen wir unter diesem Gesichtspunkt auf den varietätenlinguistischen Interpretationsansatz zurück. Meiner Meinung nach lassen sich auf der Basis der methodischen Grundlagen der Diglossieforschung und der Ausbaukomparatistik konstitutive Elemente einer Theorie sprachlicher Standardisierung finden, die eine angemessene Erklärung für die dynamischen Prozesse in Sprachkontaktsituationen liefert. Ich habe versucht, diese Theorie der Stan-

${ }^{71}$ Die Grundkonzeption der 'Diglossie' ist bekannterweise in den USA entstanden (Ferguson, Fishman). Sie hat aber sehr nachhaltig zu der theoretischen Fundierung der europäischen Minderheitensprachenforschung geführt (Katalanistik, Okzitanistik, etc.).

${ }^{72}$ Begründer dieser Forschungsrichtung ist der Germanist Heinz Kloss. Seine Schüler Harald Haarmann und Žarko Muljačić haben zu der Verbreitung und Konsolidierung dieses theoretischen Ansatzes maßgeblich beigetragen (vgl. Haarmann / Muljačić 1996) 
dardisierung in einigen Beiträgen zu entwickeln, zu begründen und darzustellen (vgl. Hoinkes 1995, 1995a, 1997). ${ }^{73}$ Im Zusammenhang der hier gegebenen Argumentationslinie, die auf die Analyse des diglossischen Sprachgebrauchs in Fachkontexten abzielt, werde ich die wesentlichen Elemente dieser Theorie resümieren und einige weitere Aspekte zu ihrer Begründung anführen. Dazu erscheint es mir angebracht, an eine varietätenlinguistische Sichtweise von Georg Kremnitz anzuknüpfen, der als ein maßgeblicher Vertreter der Diglossieforschung in Europa angesehen werden kann (vgl. u.a. Kremnitz 1987 u. 1996). In einem Beitrag mit dem Titel 'Sprache und Gesellschaft in den Katalanischen Ländern' beruft sich Kremnitz auf einen kommunikativen Sprachbegriff, der den Kommunikationsakt vor dem Hintergrund einer gemeinsamen Teilhabe an subjektiven Erfahrungswelten interpretiert. Einem solchen Sprachbegriff schließe ich mich grundsätzlich an, sofern impliziert ist, dass die 'subjektive Erfahrungswelt' eine Erfahrungswelt des Subjekts ist, in der die Normen des intersubjektiven Lebensbereichs (der 'Region') vom einzelnen Sprecher persönlich anverwandelt werden. Die normative Grundlage dieser Lebenswelt als sozialer, wirtschaftlicher und politischer Realität ist ein Garant für die Gemeinsamkeit der Erfahrung, sofern diese außerhalb der rein anthropologischen Dimensionen liegt. Kremnitz interpretiert nun auf der Basis eines solchen Sprachbegriffs die Einzelsprache als Varietätenstruktur:

Was man also gewöhnlich als eine Einzelsprache bezeichnet, ist ein komplexes Geflecht sprachlicher Varietäten, denen von den Sprechern ganz unterschiedliche Bewertungen gegeben werden. Neben den gemeinsamen grammatischen Grundstrukturen (auch hier können die Unterschiede innerhalb einer einzigen 'Sprache' erstaunlich groß sein) spielt das kollektive Bewußtsein der Sprecher, daß alle diese Varietäten zusammen die Gesamtheit der Kommunikation in der betreffenden Gesellschaft sicherstellen, eine ausschlaggebende Rolle. Jede historische Sprache ist räumlich, sozial, stilistisch und nicht zuletzt historisch differenziert. Das kann so weit gehen, daß gewisse Varietäten einer einzigen Sprache gegenseitig für die Sprecher kaum noch verständlich sind.

Nun wird natürlich den einzelnen Varietäten von den Sprechern ein ganz unterschiedliches Prestige zugemessen; während z.B. der Sprachform der führenden Schicht in der Hauptstadt gewöhnlich Vorbildcharakter beigelegt wird, gelten die Dorfmundarten als zurückgeblieben und 'hinterwäldlerisch', die Sprechweisen von Angehörigen der Unterschichten als ungebildet. Das hat zur Folge, daß in sozial hierarchisierten Gesellschaften, wie wir sie kennen, die Sprecher sich zumindest bei formellen Anlässen darum bemühen, solche Sprachformen zu verwenden, denen ein hohes Prestige zukommt, um damit auch das Ansehen ihrer eigenen Person zu heben. Umgekehrt werden Sprecher, die sich, aus welchen Gründen auch immer, dieser

${ }^{73}$ Anmerkung: Dieses Kapitel übernimmt einige Textpassagen (Exzerpte) aus Hoinkes 1995a und Hoinkes 1997, die in den methodischen Erklärungsrahmen dieser Arbeit eingepasst werden. 
Formen nicht bedienen, oft abqualifiziert. Das sprachliche Verhalten kann somit vielfach zur sozialen Selektion dienen.

(Kremnitz 1995, 98)

Die zitierte Sichtweise geht von einigen Voraussetzungen aus, die für den varietätenlinguistischen Erklärungsrahmen bestimmend sind. Im Einzelnen:

1) Das konkrete Sprechen einer Einzelsprache vollzieht sich immer in einer bestimmten Varietät.

2) Die Differenzierung der Varietät innerhalb einer Variationsdimension (räumlich, sozial, stilistisch, historisch) ist den Sprechern bewusst und bestimmt die Auswahl in einer gegebenen Situation.

3) Die Einzelsprache existiert als Gesamtheit nur in der Vorstellung der Sprecher. Diese Vorstellung beruht auf dem Aspekt der 'kompletten kommunikativen Funktionalität' der Sprache.

4) Die kommunikative Funktionsdifferenzierung der Sprache ist für den einzelnen Sprecher als Verhaltensmuster zwischen dem Erleiden und dem Selbstbestimmen sozialer Abgrenzung angesiedelt.

5) Der Umgang mit den varietätenspezifischen Funktionen der Sprache ist für die Sprecher ein Konfliktfeld des Lebens in der Sprachgemeinschaft.

Der skizzierte Argumentationsgang lässt sich nun auch auf eine Situation gesellschaftlicher Mehrsprachigkeit übertragen. Wichtig ist dabei die Voraussetzung des varietätenspezifischen Umgangs mit den einzelnen Sprachen. Für eine diglossische Situation schlage ich folgende Modifikationen vor:

1) Das konkrete Sprechen in einer der beiden Einzelsprachen vollzieht sich immer in einer bestimmten Varietät.

2) Die Differenzierung der Varietät innerhalb einer Variationsdimension (räumlich, sozial, stilistisch, historisch) ist den Sprechern bewusst. Die Variationsdimensionen greifen jedoch in einer diglossischen Situation über die Einzelsprache hinaus. Dabei ergeben sich tendenziell Oppositionen zwischen den Markierungen der Varietät der H-Sprache (geringe räumliche Einschränkung, großes soziales Prestige, hohe stilistische Wertung, Modernität) und der Varietät der L-Sprache (jeweils gegensätzlich).

3) Der 'komplette Kommunikationsraum' wird in der Vorstellung der Sprecher anteilig durch beide Sprachen ausgefüllt. Dadurch werden aber beiden Sprachen auch nur gewisse Funktionsweisen zuerkannt (abstraktives Bewertungsverfahren).

4) Das Erleiden und Selbstbestimmen sozialer Abgrenzung wird mit der Funktionsdifferenzierung der Sprachen und nicht mit derjenigen ihrer Varietäten in Verbindung gebracht. (Ich schlage vor, dieses Phänomen terminologisch als 'Makrodiglossie' zu fassen.) 
5) Der Umgang mit den varietätenspezifischen Funktionen der Sprachen ist für die Sprecher ein Konfliktfeld des Lebens in zwei Sprachgemeinschaften. ${ }^{74}$ Dadurch ergeben sich zusätzliche Konflikte und Spannungen, die in bestimmten Fällen bis zu Identitätsproblemen und Akkulturationsschwierigkeiten führen können.

Die Lösung diglossischer Konfliktsituationen ist in der Forschung immer wieder als eine Form der Durchsetzung dominanter Standardsprachen beschrieben worden. Auch die Entwicklung der romanischen Standardsprachen ist in den meisten Fällen als ein Prozess beschreibbar, den man zumindest in einer fortgeschrittenen Phase als das Durchleben einer solchen diglossischen Konfliktsituation charakterisieren kann. Die großen romanischen Nationalsprachen (z.B. Französisch, Spanisch, Italienisch) sind aus historischer Perspektive von Standardisierungsprozessen in Kontaktsituationen genauso betroffen wie die Sprachen ethnischer Minderheiten (z.B. Katalanisch, Okzitanisch, Galegisch) und die noch um Normierung bzw. Anerkennung ringenden Sprachformen kleiner Sprachgemeinschaften (z.B. Aragonesisch, Piemontesisch, Wallonisch). Die Romanistik hat in den letzten Jahren viel zu der Klärung dieser sprachgeschichtlichen und sprachgegenwartsbezogenen Realitäten beigetragen (vgl. exemplarisch: Schmitt 1988, Dahmen [et al.] (Hgg.) 1991).

Auf den Einzelfall bezogen zeigt die Forschung jeweils, dass es notwendig ist, von einer varietätenspezifischen Betrachtung der in Kontakt stehenden romanischen Sprachen und Dialekte auszugehen. Schon für die Erklärung der frühesten Ausbildung romanischer Sprachräume gilt dies in Bezug auf das schriftsprachliche und offiziell gebräuchliche Latein des Mittelalters, gegen das sich die gesprochenen Volkssprachen durchzusetzen hatten. Auch die Verschriftlichung der romanischen Volkssprachen selbst vollzog sich unter jeweiligem Rekurs auf bestimmte Varietäten, die sich gerade durch den Prozess der Standardisierung noch veränderten und deutlicher gegenüber anderen Varietäten derselben Sprachen abgrenzten.

Aus varietätenlinguistischer Sicht ist der Prozess der Standardisierung im Wesentlichen durch die Mechanismen der Selektion und Abgrenzung von Sprachformen zu beschreiben. Dies gilt insbesondere in diglossischen Situationen sowohl für die intralinguale als auch für die interlinguale Perspektive. Die Konstitution einer Sprachnorm ergibt sich häufig als Folge einer Binnendiglossie, in der die prestigeträchtigste Varietät einer historischen Sprache zum schriftsprachlichen Standard avanciert. Die Außendiglossie, in der sich diese Sprache möglicherweise befindet, stützt sich dann ebenfalls auf gesellschaftliche Selektionsmechanismen sprachlicher Varietäten. Dabei kann es

${ }^{74}$ Weniger konfliktbeladen ist die Konzeption des Lebens in einer Sprachengemeinschaft, wie sie in manchen stabilen Diglossiesituationen realisiert zu sein scheint. 
sogar zu der Durchsetzung von mehreren high-oder low-varieties, also im Prinzip zu einer Polyglossie kommen. ${ }^{75}$

Dem Sprachvergleich kommt im Rahmen des varietätenlinguistisch fundierten Standardisierungskonzepts eine bedeutsame methodische Funktion zu. Seine Aufgabe ist es, den Abstand gesellschaftlich relevanter Sprachformen untereinander darzustellen und diesbezügliche Veränderungen im Verlauf der Sprachentwicklung zu beschreiben. Sinn und Zweck einer solchen Abstandmessung ist aber nicht die Festlegung von Sprachformen als Abstandsprachen, wie sie ursprünglich von Heinz Kloss angeregt wurde. Hans Goebl (1989, 282 f.) hat in einer grundsätzlichen Kritik darauf hingewiesen, dass die von Kloss vorgeschlagene Methodik der quantitativen Abstandmessung keine Grundlagen für die taxometrische Fixierung einer formalen Minimaldistanz zwischen Abstandsprachen bietet. Die Messung des sprachlichen Abstands, so wie Kloss sie verstanden hat, erliegt somit leicht der Gefahr, zu einem methodischen Selbstzweck zu werden und nur scheinbar objektive Bedingungen für die Identifikation von eigenständigen Sprachen aufzuzeigen. Nicht zuletzt aus diesem Grund erscheint es sinnvoll, die mit der Abstandmessung verbundene Problematik der Sprache / Dialekt-Differenzierung zugunsten einer varietätenbezogenen Betrachtung von Sprachen aufzugeben.

In einer differenzierten standardologischen Untersuchung dient der Sprachvergleich dazu, das gesamte Abstandgefüge der in einer Sprachgemeinschaft gebräuchlichen Sprachvarietäten aus formaler Perspektive zu verdeutlichen. In Ergänzung hierzu ist es notwendig, die Funktion dieses sprachstrukturell charakterisierbaren Abstandgefüges als eindeutig sozial determiniert auszuweisen und $\mathrm{zu}$ seiner kompletten Beschreibung auf soziolinguistische Statusbestimmungen und die typologischen Erkenntnisse der Ausbaukomparatistik zurückzugreifen. Dieses methodische Vorgehen macht es notwendig, die Theorie des sprachlichen Standards auf ein Standardisierungskonzept zu gründen, das über die Analyse und Klassifikation von schriftsprachlichen Ausbaustufen hinausgeht. Hier ist es angebracht, den Ansatz von Kloss zu erweitern. Die Forschung kann aber in diesem Bereich bereits an einen guten Wissensstand der statusbezogenen funktionalen Typologie von Sprachsystemen und Sprachteilsystemen anknüpfen. Ulrich Ammon gehört zu den Soziolinguisten, die auf

${ }^{75}$ Wie die Sprachverhältnisse in Italien sehr deutlich zeigen, können die varietätenspezifischen Ausprägungen des sozialen Sprachverhaltens zu der unklaren Abgrenzung einer historischen Sprache führen. In diesem Sinne halten einige Forscher an der theoretischen Vorstellung eines Kontinuums zwischen den gebräuchlichen Sprachformen sozial wenig ausgebauter Dialekte und der ausgebauten Standardhochsprache des Italienischen fest. Die Verhältnisse gestalten sich noch komplizierter, berücksichtigt man die kommunikative Eigenfunktion gewisser Substandards, die ihrerseits zu einer Beeinflussung der Standardhochsprache, zumindest im sprechsprachlichen Bereich, führen. 
diesem Gebiet besonders wichtige Systematisierungen und Ergebnisse vorgelegt haben (vgl. Ammon 1987).

Die Herausbildung von Standardsprachen kann als ein sprachgeschichtlicher Vorgang gewertet werden, in dessen Verlauf es zu dem umfassenden Ausbau (im Sinne von Kloss) eines sozial prestigeträchtigen Dialekts zu einer funktionsreichen Kultursprache kommt. Eine solche Kultursprache ist per definitionem kein homogenes Gebilde, sondern ein durch vielfältige kommunikative Bedürfnisse geprägter sprachlicher Varietätenraum. Die diatopische, diastratische, diaphasische und diamediale Differenzierung der ausgebildeten Kultursprache ist das Ergebnis eines sehr komplexen Vorgangs, der durch die Erweiterung kommunikativer Funktionalität in Verbindung mit der Bewahrung von Diskurstraditionen begründet wird. Dabei spielen jedoch nicht nur lektale Abgrenzungen, sondern auch innersprachliche Angleichungsprozesse eine wichtige Rolle.

Die Emanzipation einer historischen Sprachform zu einer Kultursprache ist nämlich in entscheidender Weise von einer vereinheitlichenden Sprachentwicklung abhängig, die in der soziolinguistischen Forschung häufig als Durchsetzung der sog. Standard-Varietät dieser Sprache interpretiert wird und die Aspekte der Kodifizierung und der Normalisierung umfasst. Unter dieser Perspektive allein lässt sich aber kaum die komplexe Gesamtheit der beobachtbaren Standardisierungsphänomene erklären. Diese führen nämlich einerseits zu der Ausbildung unterschiedlicher varietätenbezogener Standards innerhalb einer historischen Sprache, so z.B. neben dem gemeinsprachlich referentiellen Standard zu der Existenz von Substandards, regionalen Standards oder fachsprachlichen Standards. Andererseits tragen sie - ohne die referentielle Norm der Standard-Varietät de facto als Norm der Umgangssprache zu realisieren auch zu einer Homogenisierung des Sprachverhaltens bei, indem sie von der Standard-Varietät abweichende Sprachformen (Varianten) bis zu einem gewissen Grad in den tatsächlich benutzten Standard der Gemeinsprache mit einbeziehen.

Ich schlage daher ein Konzept vor, das sich von den theoretischen Prämissen der bekannten standardologischen Ansätze - z.B. desjenigen von Harald Haarmann in der Tradition von Heinz Kloss (vgl. Haarmann 1988) - abhebt und auf synchroner Ebene deutlicher zwischen den Bereichen von Sprachpflege und Sprachplanung einerseits und der strukturell ausgerichteten Beschreibung komplexer sprachlicher Standardentwicklungen zu differenzieren versucht. Der konkrete Definitionsansatz ergibt sich dabei aus der Betrachtung einzelsprachlicher Varietät im Sinne Coserius (vgl. Coseriu 1988a, 139-145) und geht konkret von der Vorstellung aus, dass die Standardisierung als Entwicklungsform einer historischen Sprache gekennzeichnet ist, die entgegengesetzt bzw. antagonistisch zu der Ausbildung einer sprachlichen Varietäten- 
struktur verläuft. Die Entwicklung eines Standards wird in diesem theoretischen Sinn als Ausgleichsmechanismus zwischen Varietäten bzw. als Varietätenbevorzugung betrachtet, nicht aber als Schaffung einer völlig neuen Varietät. Das ihr zugrunde liegende Verfahren ist das der Variantenselektion.

In struktureller Hinsicht liegt die Funktion der Standardisierung in der Reduktion diatopischer, diastratischer und diaphasischer Variation auf der Ebene der Gemeinsprache, wobei jeder einzelne Bereich auch isoliert angesprochen sein kann. Allerdings erfolgt eine solche Reduktion einzelsprachlicher Variation nicht willkürlich und orientierungslos, sondern ist stets auf einen als richtungsweisend oder gar bindend empfundenen Sprachgebrauch ausgerichtet, den Jörn Albrecht als die Existenz einer 'kanonischen Form' der jeweiligen Sprache interpretiert (vgl. Albrecht (1986/1990, 46). In dieser Interpretation offenbart sich sowohl die Diskrepanz zwischen der bloßen Anerkennung und dem tatsächlichen Gebrauch dieser 'kanonischen Form' als auch die Spannbreite von ihrem impliziten gesellschaftlichen Zustandekommen bis hin zu der expliziten institutionellen Setzung der zugrunde liegenden Norm.

Im Rahmen einer standardologischen Untersuchung, die von den Prinzipien der Varietätenlinguistik ausgeht, erscheint es sinnvoll, die 'kanonische Form' einer Sprache und ihre komplexen Zusammenhänge mit den in der Sprachgemeinschaft bestehenden Normen als die Ausbildung einer eigenen StandardVarietät zu betrachten. Diese Sichtweise hat zum einen den Vorteil, dass zwischen 'architektonisch' mehrdimensionaler Standardsprache (bei Coseriu: Gemeinsprache) und spezifischer funktioneller Standard-Varietät (bei Coseriu: Standardsprache) unterschieden wird, wobei die Standard-Varietät strukturell eindeutig beschrieben werden kann. Zum anderen wird die Standard-Varietät als exemplarische Form einer Sprache (vgl. Coseriu 1988a, 143) anhand soziolinguistischer Parameter definiert und von anderen Standards derselben historischen Sprache - so z.B. Substandards - unterscheidbar. Wesentlich ist jedoch, dass die Ausbildung eines sprachlichen Standards nicht mit der einer Sprachnorm verwechselt werden darf, da der Standard nur im Spannungsfeld eines vorhandenen Varietätengefüges bestimmt werden kann. Der beschreibbare Standard ist in diesem Sinne immer das (vorläufige) Produkt einer (historischen) Standardisierung, die sich auf der Ebene der varietätenspezifischen Ausdifferenzierung der Gemeinsprache vollzieht.

Jeder als historische Sprache etablierte sprachliche Varietätenraum verfügt somit notwendigerweise zumindest über eine Standard-Varietät (im Falle polyzentrischer Sprachen können dies auch mehrere sein), ohne die es nicht möglich ist, die historische Sprache als Einheit zu beschreiben. Zusätzlich prägen sich Standards auch auf extensionell begrenzten Beschreibungsebenen der einzelnen Sprachen aus, so z.B. in der Form regionaler Standards oder sozial markierter Substandards. 
Es ist nun interessant, sich auf die Frage zu konzentrieren, nach welchen Prinzipien und Gesetzmäßigkeiten die sprachliche Standardisierung erfolgt, insoweit sie als Reduktion sprachlicher Variation aufgefasst werden kann. Damit wird ein Konzept verfolgt, das sich von dem Hauptinteresse bisheriger standardologischer Untersuchungen abhebt, indem es nicht die sprachgeschichtliche Ausbildung und Begründung einer Standard-Varietät in der Sprachgemeinschaft $\mathrm{zu}$ seinem Untersuchungsschwerpunkt macht, sondern diese Standard-Varietät bereits als gesellschaftlich gegeben (wenn auch stets veränderbar) voraussetzt. Das Hauptaugenmerk ist darauf gerichtet, welche Position die Standard-Varietät im Verhältnis zu den übrigen Varietäten der betreffenden historischen Sprache sowie denjenigen mit ihr in Kontakt stehenden Sprachen einnimmt. Darüber hinaus muss danach gefragt werden, nach welchen Prinzipien sich die empirisch verifizierbare Standard-Varietät im dynamischen Gefüge des für die Sprachgemeinschaft relevanten Varietätenraums verändert.

Es ist zu vermuten, dass gerade in Situationen des Sprachkontakts die Konfrontation der als Standard beziehungsweise Nicht-Standard qualifizierten Varietäten aufeinander treffender Sprachen einen komplexen Sprachentwicklungsprozess in Gang setzt, der auf synchroner Betrachtungsebene als Variabilität sprachlicher Standards empirisch erfassbar und strukturell beschreibbar gemacht werden kann. Gerade in Bezug auf den Kontakt strukturell distanzierter Sprachformen erweist sich das varietätenlinguistische Konzept als besonders vorteilhaftes Erklärungsmodell durch seine Fähigkeit, Sprachentwicklungstendenzen nicht nur eindimensional als konvergenten Wandel hin $\mathrm{zu}$ einer Standard-Varietät $\mathrm{zu}$ interpretieren, sondern sie als eine vielfältige Orientierung an sprachlichen Standards zu charakterisieren. Die innere Dynamik dieser Sprachentwicklungsprozesse wird dabei durch das Gegeneinanderstehen der dem gesellschaftlichen Sprachgebrauch zugrunde liegenden Normen motiviert. Der Druck der präskriptiven Norm einer dominierenden Standardsprache in diglossischen Situationen ist dabei nur ein Faktor - wenn auch ein sehr wesentlicher - des mehrschichtigen sprachlichen Normenkonflikts.

Die Entwicklung eines standardologischen Konzepts auf varietätenlinguistischer Basis erscheint mir am besten dazu geeignet, Vergleichsmomente von Sprachentwicklungsprozessen ausfindig zu machen, deren Motivation in der konfliktären gesellschaftlichen Koexistenz von Abstandsprachen (bzw. voneinander strukturell distanzierter Varietäten) mit unterschiedlichem Status (d.h. Ausbaugrad) liegt und deren Zielrichtung nicht einfach durch die fortschreitende Aufgabe der sozial benachteiligten Sprachformen zugunsten einer prestigeträchtigen Standard-Varietät erklärt werden kann. Diese simplifizierende Vorstellung, die z.T. in der soziolinguistischen Betrachtung bestimmend 
ist, wäre nur zu rechtfertigen, wenn das kommunikative Verhalten einer Sprachgemeinschaft allein auf die Überregionalität, das hohe soziale Ansehen und die eindeutige Kodifikation einer etablierten und von allen Mitgliedern der Sprachgemeinschaft beherrschten Standardsprache ausgerichtet wäre. Dagegen sprechen jedoch eine Reihe sprachsoziologisch bekannter Faktoren wie die gemeinschaftliche Wahrung von Sprechtraditionen, die soziale Identitätsfindung in Regionalsprachformen, durch Sprachwechsel ausgelöste Entfremdungsprozesse, Identifikation mit Gruppensprachen, Einbindung von Substandard-Registern in das individuelle Sprachverhalten oder die notwendige Aneignung fachsprachlicher Kompetenz.

Insgesamt gesehen erscheint es vielversprechend, das Phänomen sprachlicher Standardisierung, so wie es in den europäischen Industrienationen als grobe Tendenz zu Vereinheitlichung und Reduktion, d.h. als Konzentration auf den Gebrauch der standardsprachlichen Varietäten der großen anerkannten Nationalsprachen offensichtlich wird, in einer sprachwissenschaftlich genauen varietätenspezifischen Analyse nach demselben Prinzip zu analysieren, d.h. unter dem Gesichtspunkt der Verminderung sprachlicher Variation. Ein vorrangiges Ziel der Untersuchung sollte es dabei sein zu zeigen, dass die Ausrichtung auf einen oder mehrere sprachliche Standards im Sprachverhalten einer Sprachgemeinschaft eine Reaktion auf normentheoretisch begründbare Sprachkonfliktsituationen darstellt, deren Überwindung nur durch die Aufrechterhaltung einer internen Variabilität des gewählten Standards gewährleistet wird.

Unter standardologischem Aspekt ergibt sich nun die Sichtweise, dass in einer als diglossisch interpretierbaren Sprachkontaktsituation die Sprecher der als low-variety klassifizierten Sprache nicht einfach nach Maßgabe funktionaler Erfordernisse zu der in diatopischer, diastratischer und diaphasischer Hinsicht neutralen Standardnorm der high-variety wechseln, sondern dass der von ihnen je nach Situation vollzogene Sprachwechsel eine interne Variabilität und Flexibilität des verwendeten Standards erfordert. ${ }^{76}$ Aus sprachgeschichtlicher Perspektive lässt sich die regionale Ausformung eines solchen

${ }^{76}$ Vgl. Tanzmeister 1995, 222: „Der sprachlichen Vereinheitlichung, Uniformierung sind menschliche Grenzen gesetzt. Die Schwierigkeit jeder Standardisierung besteht ja darin, soviel Differenz, regionale kleinräumige Autonomie wie möglich bei gleichzeitiger Wahrung überregionaler und sozialer Kommunikationsfähigkeit zu akzeptieren. [...] Entscheidend ist, daß in bereits standardisierten Sprachen eine stärkere Tendenz zum liberalen Normenpluralismus festzustellen ist, daß also die Bereitschaft zur Akzeptanz und Toleranz noch nicht kodifizierter Varietäten und Varianten steigt, was zu der Schlüsselfrage führt, wieviel Variation eine Standardvarietät verträgt, die ja per definitionem deren praktische Exklusion darstellt. Die Idealvorstellung der Identität von schriftlicher und mündlicher Standardvarietät ist - wie uns die gesprochene-Sprache-Forschung gezeigt hat - nicht haltbar und daher zu relativieren." 
Standards durchaus - im Sinne der durch Eugenio Coseriu vorgenommenen Begriffsbestimmung - als tertiärer Dialekt einer historischen Sprache definieren. Wir ziehen es jedoch vor, im Zusammenhang einer standardologischen Untersuchung lieber die von Thomas Stehl eingeführte terminologische Unterscheidung von exogenem und endogenem Standard zu übernehmen.

Unter 'exogenem Standard' versteht Stehl die ,zumeist schriftsprachlich gestützte Norm der exemplarischen Form des Standards“" (Stehl 1991, 15f.), die von den Sprechern als eine nicht heimische Ausprägung des Standards empfunden wird, der sie sich allein aufgrund ihres Prestiges anzunähern bemüht sind, ohne sie meist wirklich zu verwenden. Der exogene Standard bleibt somit unter pragmatischem Aspekt eine referentielle Sprachform mit virtuellem Status, sein kommunikativer Wert im Alltag ist gering oder sogar gar nicht vorhanden. Demgegenüber stellt der 'endogene Standard' die Realisierung der als Referenz dienenden Norm in einer gegebenen Sprachgemeinschaft dar. Er ist der empirisch nachvollziehbare Gebrauch der Standardsprache in einem bestimmten Sprachgebiet durch Angehörige einer bestimmten Sprechergruppe in einer besonderen Sprechsituation, wobei die von den Sprechern verwendete Sprachform durchaus als 'kanonische Form' der historischen Sprache (im Sinne J. Albrechts, s.o.) interpretiert werden kann und somit bewusst auf die Einschränkung diatopischer, diastratischer und diaphasischer Variation ausgerichtet ist.

Der entscheidende Unterschied zwischen exogenem und endogenem Standard besteht nun darin, dass der exogene Standard diese Standardnorm als Soll-Norm interpretiert, so dass man über ihre präskriptive Funktion zu einer eindeutigen Beschreibung der Standard-Varietät gelangt. Im Gegensatz dazu stellt der endogene Standard sozusagen die Ist-Norm dar und erweist sich in seiner funktionellen Deskription als weitaus weniger eindeutig. Nichtsdestoweniger ist aber auch der endogene Standard eine Beschreibungsform der Standard-Varietät, die sich de facto - wie auch im metasprachlichen Bewusstsein der Sprecher - deutlich von der Verwendung einer Nicht-Standard-Varietät (z.B. eines Dialekts) abgrenzt. In der Realisationsform des endogenen Standards stellt sich die Standardnorm jedoch weitaus toleranter und variantenreicher dar, als es die präskriptive Norm der Standard-Varietät (d.h. der exogene Standard) zunächst vermuten lässt. Das relativ hohe Maß an Variation innerhalb der Standard-Varietät wird dabei vor allem in der gesprochenen Sprache deutlich, die eine wesentlich größere Affinität zum endogenen Standard aufweist als die geschriebene.

Zwischen der Standard-Varietät und einer abgrenzbaren Nicht-StandardVarietät derselben historischen Sprache - sei es ein Dialekt, ein Soziolekt oder eine Fachsprache - kommt es in der Regel zu einer Kontaktsituation, die mit 
einem komplizierten Normenkonflikt einhergeht. Dieser Normenkonflikt gestaltet sich deshalb so kompliziert, weil auf der einen Seite die StandardVarietät in der Form des endogenen Standards ein hohes Maß an Offenheit, Toleranz und Variation aufweist und auf der anderen Seite die Nicht-StandardVarietät in Abhängigkeit von der Norm der Standard-Varietät steht. Der hieraus ableitbare Normenkonflikt ist von Fall zu Fall verschieden und wird durch Abgrenzungsmechanismen ebenso wie durch Interferenztechniken und Assimilationserscheinungen bestimmt. Auf längere Sicht wirkt dabei die integrative Kraft des endogenen Standards einer Aufrechterhaltung binnendiglossischer Situationen meistens entgegen. Aus diesem Grund werden Dialektismen, Substandardregisterformen, Elemente aus Gruppensprachen und auch Fachtermini, sofern sie von gemeinsprachlichem Interesse sind, häufig in die Standardsprache integriert, bevor sie zu einer dauerhaften Abgrenzung innersprachlicher Varietäten beitragen können. Damit einher geht in der Regel ein deutlicher Anpassungsdruck der Nicht-Standard-Varietäten an die Norm der StandardVarietät.

Der endogene Standard der H-Sprache hat in der Forschung bereits einige Beachtung gefunden. Die in der Germanistik gebräuchlichen Termini für diese Erscheinungsform sind 'Umgangssprache' und 'Alltagssprache', in der Romanistik finden sich Termini wie français régional und italiano regionale. Allerdings wird das Phänomen üblicherweise nicht unter dem standardologischen Gesichtspunkt betrachtet. Der Beitrag 'Mundart, Umgangssprache, Standard' im Handbuch der Kontaktlinguistik (Weisgerber 1996) gibt zu erkennen, dass stattdessen ein Zusammenhang zwischen diesen Begriffen gesehen wird, demzufolge die 'Umgangsprache' als eine Sprachform zwischen Mundart (Dialekt) und Standard zu interpretieren ist. Diese Sichtweise entspricht keiner standardologischen Konzeption, sondern der üblichen Vorstellung einer Kontaktsituation von Dialekt und Hochsprache. Bernhard Weisgerber schreibt explizit: ${ }^{77}$

Der Begriff Umgangsprache (oder Alltagssprache) läßt sich - wenn überhaupt - nur in Beziehung auf die beiden anderen Hauptvarietäten: Mundart und Standard definieren. Umgangssprache ist die Grauzone zwischen beiden, der Übergang zwischen Dialekt und Hochsprache, eine Mundart auf dem Weg zum Standard oder eine Standardsprache mit deutlichen dialektalen Zügen.

(Weisgerber 1996, 261)

Ein wenig später ergänzt Weisgerber den folgenden Gedankengang:

Dabei ist davon auszugehen, daß die Umgangssprache die verbreitetste Form des heutigen mündlichen Sprachgebrauchs, eben die Alltagssprache darstellt. Dies gilt zumindest in den Gebieten, in denen die Mundart nicht mehr voll verfügbar ist. Munske (1983, 1005) bezeichnet Umgangssprachen als 'Erscheinungen sprachlichen

${ }^{77}$ Die Hervorhebungen im Zitat mit dem Schriftattribut fett ergänze ich zur Verdeutlichung meiner eigenen Argumentation. 
Kontakts in einer Diglossie-Situation zwischen einer Standardsprache als H-Varietät und damit verwandten Dialekten als L-Varietäten' und interpretiert sie von ihrer Genese her als Lernersprachen, d.h. als noch unvollkommene Annäherungsversuche von Dialektsprechern an den Sprachstandard. Diese Betrachtungsweise übersieht jedoch die Tatsache, daß sich Umgangssprachen durchaus als eigenständige Systeme zwischen den anderen Varietäten etablieren, ebenso wie die häufigen Bemühungen von Standardsprechern, sich eine Umgangssprache anzueignen, um diese in entsprechenden Situationen normgerecht anwenden zu können.

(Weisgerber 1996, 262)

Weisgerbers Definitionsversuch der 'Umgangssprache' spiegelt zwei gängige Defizite des Begriffsverständnisses wider (deren eines vom Autor selbst hervorgehoben wird): Zum einen ist es m.E. konzeptionell nicht vertretbar, 'die verbreitetste Form des heutigen mündlichen Sprachgebrauchs' als eine 'Grauzone' zu definieren. Zum anderen widerspricht das Verständnis des Phänomens als 'unvollkommene Annäherungsversuche von Dialektsprechern an den Sprachstandard' der Tatsache, dass die Umgangssprache eine selbständige Sprachvarietät (Erscheinungsform der Sprache) konstituiert, der eine eigene Norm zugeordnet ist.

Die interpretative Optik einer varietätenlinguistisch fundierten Standardologie bietet hier in gewisser Hinsicht ein Gegenmodell zu der weithin etablierten Vorstellung, dass das Sprachverhalten der bilingualen Sprecher in diglossischen Situationen durch eine extensive Ausgestaltung von Interferenztechniken geprägt ist, die diese Sprecher in individuelle Sprachkonflikte stürzen, da sie weder in der Lage sind, die Zielnorm der von ihnen benutzten Sprachform zu erreichen - insbesondere wenn es sich um eine kodifizierte Standard-Varietät (wie z.B. den bon usage des Französischen) oder einen reinen Dialekt handelt -, noch die alternative Norm eines flexibleren Standards zu entwickeln. Letzteres erscheint insbesondere dann unmöglich, wenn alle gebräuchlichen, aber von den Zielnormen abweichenden Sprachformen nur als normativ nicht zu stabilisierende Übergangsstufen zwischen eben diesen als korrekt bzw. authentisch empfundenen Normen interpretiert werden.

Alternativ zu dieser Sichtweise schlage ich vor zu überprüfen, ob der nachweisbare Konflikt zwischen den in einer diglossischen Gemeinschaft verwendeten Sprachformen nicht auch im Sinne einer strukturell erfassbaren Konkurrenz der zugrunde liegenden Standardnormen gedeutet werden kann. Konkret gilt es dabei der Vermutung nachzugehen, dass die in der Sprachgemeinschaft gesprochenen Standards durch Offenheit und Variantenreichtum eine so weit gefasste integrative Kommunikationsfunktion annehmen, dass sie in der Lage sind, auf kommunikative Bedürfnisse, die durch den Rückgang dialektaler Sprachformen, die Aufrechterhaltung von Diskurstraditionen oder durch die Anbindung sozial relevanter Textsorten in einer der beiden Sprachen 
neu entstehen, flexibel zu reagieren, ohne das sprachnormative Bewusstsein der Sprecher beständig in Konflikt zu bringen.

Diese Vermutung kann nur dann eine empirische Bestätigung finden, wenn es gelingt, die strukturelle Variation von Standard-Varietäten im Sinne endogener Standards, also letztlich die Ausbildung von 'Umgangssprachen' oder 'Alltagssprachen' als Regionalsprachformen nachzuweisen. In der Vorstellung einer 'landschaftlichen Prägung' der Umgangssprache finden sich bereits Ansätze hierzu, die aber bislang über den Interpretationsrahmen sprachlicher Interferenzerscheinungen nicht hinausgelangt sind. Erst die Verbindung der gängigen Konzeptionen von 'Umgangssprache' oder 'Alltagssprache' mit der normativen Interpretation eines regionalen Sprachgebrauchs, so wie ich ihn im vorangegangenen Kapitel charakterisiert habe, ist geeignet, die 'verbreitetste mündliche Sprachform' in ihrer kommunikativen Funktionalität angemessen zu beschreiben. Dabei darf nicht übersehen werden, dass die normative Prägung der 'Umgangssprache' eine doppelte ist. Sie steht zum einen in der Abhängigkeit sprachexterner Normen, die ihr von Region zu Region einen spezifischen Charakter als Sprachgebrauchsform verleihen. Zum anderen aber basiert die 'Umgangssprache' auf einer Standard-Varietät, genau genommen: der Standard-Varietät der Einzelsprache (exogener Standard), durch die sie grundsätzlich an eine Reihe sprachlicher Normen gebunden ist. Die Tatsache, dass von den referentiellen Normen des exogenen Standards im Alltag abgewichen wird, ist aber nur zu einem Teil auf Interferenzerscheinungen zurückzuführen. Viel wesentlicher erscheint der Aspekt der kommunikativen Flexibilität, der die Umgangssprache in der Form des 'endogenen Standards' variabel gestaltet und für die Integration von Elementen aus Nicht-Standard-Varietäten offen hält. Genau diese offene Funktionalität der gesprochenen Standard-Varietät entspricht der im alltäglichen Sprechen verifizierbaren Sprachkompetenz der Sprecher.

Die hier vorgeschlagene Konzeption hat weitreichende Konsequenzen für die Interpretation instabiler diglossischer Situationen. Der Übergang vom Dialekt bzw. der Regionalsprache zum Standard ist nämlich in der beschriebenen Sichtweise mehr als nur der Wechsel zu einer anderen, d.h. der dominanten Sprache. Er ist gleichzeitig der Wechsel in ein neues einzelsprachliches Kommunikationsmuster, das durch die Orientierung an einer Standard-Varietät maßgeblich geprägt ist. Es wurde bisher nur wenig beachtet, dass Sprecher von Dialekten oder Minderheitensprachen, wenn sie zur dominanten Sprache wechseln, eine ihnen z.T. völlig neue Auseinandersetzung mit einzelsprachlichen Referenzformen durchleben. Die kommunikativen Muster des Sprachgebrauchs sind in der H-Sprache aufgrund der sprachnormativen Bindung einerseits (exogener Standard) und der sprachnormativen Freiheiten andererseits (endogener Standard) anders geartet als in der L-Sprache, insofern die L- 
Sprache überhaupt nur geringen normativen Bindungen und einer eingeschränkten kommunikativen Funktionalität unterliegt. Beide Aspekte aber sind für regressive Dialekte und Minderheitensprachen typisch.

Was passiert nun, wenn sich heute in unseren modernen Industriegesellschaften trotz aller Widrigkeiten sozial benachteiligte Sprachen (lesser used languages) als Kommunikationsmedien erhalten bzw. noch erhalten? Diese Frage führt in dem beschriebenen theoretischen Rahmen zu einer besonderen Erklärung. Es ist nämlich davon auszugehen, dass die Annahme der kommunikativen Verhaltensmuster und der Umgang mit den einzelsprachlichen Referenzformen der dominanten Sprache auf den Gebrauch der Regionalsprachen abfärben. Damit ist gemeint, dass die Unterscheidung von exogenem Standard und endogenem Standard auch für die Regionalsprachen zu einem Konstitutivum wird, wenn diese den kommunikativen Anforderungen im Vergleich mit der dominanten Sprache standhalten wollen. Hier müssen zwei Aspekte unterschieden werden.

Zum einen kommen Regionalsprachen heute, wenn sie weiterhin bestehen sollen, nicht um eine interne Auseinandersetzung mit ihrer normativen Fixierung herum. ${ }^{78}$ Dies ist selbstverständlich in erster Linie eine Auseinandersetzung der Sprecher mit diesen Normen, die in den meisten Fällen sehr konfliktbeladen ist. Es handelt sich dabei um das bekannte Problem der Kodifizierung von weniger gebräuchlichen Sprachen, das den Bereich der Sprachplanung berührt. Der mit diesen Sprachplanungsmaßnahmen verbundene Aufbau einer Referenznorm der jeweiligen Sprache ist im Einzelfall ein schwieriger Prozess. Das Beispiel des Valenzianischen zeigt, welche soziale und politische Sprengkraft in dieser Problematik stecken kann.

Zum anderen gibt es auch den Fall, dass sprachplanerische Bemühungen um weniger gebräuchliche Sprachen die Sprachgemeinschaft als Ganzes kaum erreichen. Offensichtlich sind die Minderheitensprachen und Dialekte in solchen Fällen akut vom Aussterben bedroht. Die Situation des Okzitanischen kann als ein solcher Fall angesehen werden. Die kommunikative Funktionalität der okzitanischen Dialekte-so auch des Bearnesischen-ist geographisch nicht

${ }^{78}$ Vgl. Tanzmeister 1995, 217: „Zu den grundsätzlich zu diskutierenden Fragen gehören, ob Sprachnormalisierung als Durchsetzung einer Varietät auf Kosten der anderen Varietäten verstanden werden soll, wie weit innersprachliche (also regionale oder soziale) Variation mitberücksichtigt oder eliminiert wird, ob die zu etablierende Leitnorm demokratisch fundiert oder an elitären, monozentrischen Normvorstellungen zu orientieren ist. [...] Die Normalisierungspolitik richtet sich sowohl gegen die dominante Sprache als auch gegen andere konkurrierende regionalsprachliche oder dialektale Varietäten. Zusätzlich hat sie die in Sprachkonfliktsituationen üblichen Vorurteile gegenüber der eigenen Varietät abzubauen. Außerdem stellt sich die Frage nach der Durchsetzung und Bewahrung der tradierten, etablierten präskriptiven, kodifizierten bzw. normativierten Norm oder der liberaleren Anpassung an den tatsächlichen modernisierten Sprachgebrauch unter Akzeptanz von Sprachvariation oder auch B zumindest teilweise B von regionalen Varietäten.“ 
mehr flächendeckend und sozial auf bestimmte Sprechergruppen eingeschränkt (insbesondere nur noch im oberen Teil der Alterspyramide zu finden). In einer solchen Situation erhält sich der Sprachgebrauch der Regionalsprache nur noch in gewissen 'Nischen', deren Existenz von den beteiligten Sprechern und von den thematisierten Sachbereichen abhängt. Die Sprachverhaltensweisen, die in solchen 'Nischen' der gesellschaftlichen Kommunikation zu beobachten sind, können sich jedoch nicht den beherrschenden Kommunikationsmustern des modernen Lebens entziehen. Wie aber schaffen es die Sprecher einer regressiven Regionalsprache, in besonderen Fällen domänenspezifischen Sprechens ihrer Sprache eine kommunikative Funktionalität zu verleihen, die zu derjenigen der dominanten Sprache äquivalent ist?

Die Frage ist m.E. falsch gestellt. Der domänenspezifische Erhalt einer regressiven Regionalsprache ist nämlich nur in Bereichen feststellbar, in denen diese Sprache traditionell eine kommunikative Funktion zu erfüllen hat. ${ }^{79}$ Diese Bereiche sind maßgeblich durch regionale Normen bestimmt, die auf den Sprachgebrauch einwirken und ihn zu einer Form des 'regionalen Sprachgebrauchs' in dem bereits erklärten Sinne machen. Auf diesen angestammten Kommunikationsgebieten bewegt sich der Sprecher einer Regionalsprache aber wie ein Fisch im Wasser. Es wäre beispielsweise verfehlt, unterstellen zu wollen, dass zwei Muttersprachler einer aussterbenden Regionalsprache über einen Sachbereich, der seit Generationen in dieser Sprache bewältigt worden ist, aufgrund der modernen Veränderungen dieses Sachbereichs mit einem Mal nicht mehr kommunizieren können. Mit dieser Feststellung aber ist eine wesentliche Aussage getroffen: Die kommunikative Funktionalität einer Regionalsprache, die auf der Basis der soliden Sprachkompetenz des Sprechers maßgeblich von Regionalnormen abhängt, ist grundsätzlich nicht mit der Regression des gesellschaftlichen Gebrauchsumfangs dieser Regionalsprache gleichzusetzen. Natürlich gibt es hier Zusammenhänge, die die kommunikative Reichweite betreffen. Diese ist jedoch in erster Linie ein soziales und politisches Problem der Standardisierung und Normalisierung der Sprache und betrifft keine prinzipiellen Defizite in der Sprachstruktur oder der Sprachkompetenz der Sprecher. Es fällt der sprachwissenschaftlichen Betrachtung bisweilen schwer, diese beiden Aspekte auseinanderzuhalten. ${ }^{80}$

${ }^{79}$ Vgl. Kremnitz 1997, 92: „Selbst die Sprecher, die gut okzitanisch sprechen, haben gewöhnlich eine sichere Kompetenz in den Domänen, die eine Beziehung zum Leben früherer Zeiten haben: Landwirtschaft, Handwerk usw. Sie ist in den Domänen des täglichen Lebens der Städter geringer und normalerweise in Belangen der modernen Welt der Technik und der Wissenschaft nahezu inexistent.“

${ }^{80} \mathrm{Um}$ nicht missverstanden zu werden: Ich rede nicht einer sprachpolitischen Haltung das Wort, die ganze Sprechergenerationen aufgrund ihrer mangelnden Sprachkompetenz unbeachtet ließe. Unter dem hier verfolgten Gesichtspunkt ist jedoch mit der Aufgabe der Regionalsprache als Primärsprache ein entscheidender Bruch in der Bewertung ihrer kommunikati- 
In den Bereichen, in denen sich die Regionalsprache kommunikativ (am längsten) erhält, haben sich Sprach- und Diskurstraditionen aufgebaut, die für das kommunikative Verhalten auch bei einem Wechsel in die dominante Sprache konstitutiv sind. Die Sprecher der dominierten Sprache beharren bis zuletzt auf diesen Sprach- und Diskurstraditionen, so dass sie im Falle eines unvermeidlichen Substitutionsprozesses in den Sprachgebrauch der dominanten Sprache übernommen werden. Dieses Prinzip von Sprachdynamik und Sprachwandel versuche ich, im empirischen Teil meiner Arbeit darzustellen. Die Kontinuität des Sprachgebrauchs ist unter diesem Gesichtspunkt durch die Einflussnahme sprachlicher und außersprachlicher Normen gegeben. Ihre Aufrechterhaltung ist jedoch grundsätzlich unabhängig von dem Phänomen einer von Generation zu Generation schwindenden Sprachkompetenz, deren Verifikation sich auf die allmähliche Auflösung der sprachstrukturellen Identität der regressiven Regionalsprache konzentriert. Thomas Stehl hat in seinen Arbeiten vor allem den zuletzt genannten Aspekt analysiert. Er weist jedoch auch explizit auf den Erhalt von Sprach- und Diskurstraditionen als konstitutives Phänomen in Sprachsubstitutionsprozessen hin:

Für zweisprachige Gemeinschaften, die ihre Minderheitensprachen zugunsten des tertiären Dialekts français régional oder italiano regionale aufgeben oder schon aufgegeben haben, gewinnt dieser Austauschprozeß der Diskurstraditionen besondere Bedeutung: allein an dem Umstand, wie jemand (in den Sprechtraditionen) über welche Inhalte (in den Texttraditionen) selbst im regionaltypischen Standard spricht, erkennen auch einsprachige Standardsprecher, ob und inwieweit er zur eigenen regionalen Sprachgemeinschaft gehört oder ob er einer anderen Region mit anderen sprachlichen Traditionen (selbst im Standard) zugerechnet werden muß. Im Verein mit den mehr oder weniger ausgeprägten, materialsprachlichen Charakteristiken und Standardabweichungen der français régionaux und italiani regionali erweisen sich die Diskurstraditionen somit als zentrale Dimension der Herstellung und der Abgrenzung von neuen regionalen Sprachgemeinschaften in neuen sprachlichen Grenzen, die ihre sprachliche Identität nicht zuletzt aus der Fortsetzung von Traditionen einer nicht mehr gesprochenen Minderheitensprache herleiten.

(Stehl 1994, 144)

Der von Stehl formulierten Sichtweise schließe ich mich voll und ganz an. Allerdings fehlt bislang eine geeignete sprachwissenschaftliche Methodik, um die postulierten Phänomene empirisch zu verdeutlichen. Ich hoffe, mit dem Vorschlag einer varietätenlinguistisch fundierten Theorie sprachlicher Standardisierung hier einen gangbaren Weg gefunden zu haben. Meine empirischen Untersuchungen verfolgen das Ziel, die Grundannahmen dieser Theorie $\mathrm{zu}$ belegen, indem sie sich eingehend mit der Art der regionalen Normierung des Sprachgebrauchs in Fachkontexten in Bezug auf die beiden Sprachen einer 
jeweiligen Diglossiesituation auseinandersetzen. Dabei werden neben lexikologischen Darstellungen textuelle Analysen im Vordergrund der Betrachtung stehen. Auf diesem ersten Versuch einer normativ bezogenen vergleichenden Sprachbetrachtung aufbauend wird man, so hoffe ich, in weiteren Untersuchungen eine verfeinerte Methodik ausarbeiten können.

Kommen wir zum Abschluss dieser Überlegungen noch einmal auf die varietätenlinguistische Basis des Erklärungsansatzes zurück. Die im ersten Teil des Kapitels gegebenen Erläuterungen zu der Interpretation diglossischer Verhältnisse führen im Lichte der Theorie sprachlicher Standardisierung zu einer veränderten Sicht, die die varietätenspezifische Funktionsdifferenzierung der beteiligten Sprachen genauer berücksichtigt. Im Einzelnen ergeben sich die folgenden Thesen:

1) Das konkrete Sprechen in einer der beiden Einzelsprachen vollzieht sich immer in einer bestimmten Varietät. Das kommunikative Verhalten der Sprecher im Alltag ist auf den Gebrauch einer Standard-Varietät ausgerichtet. Als 'Alltagssprache' bzw. 'Umgangssprache' ist die Funktionalität dieser Standard-Varietät vielfältig und weit gefasst. Sie steht unter dem Einfluss regionaler Normen der Sprachverwendung.

2) Die Standard-Varietäten zeichnen sich durch einen geringen Grad an Markierung innerhalb der einzelnen Variationsdimensionen aus. Sie sind gekennzeichnet durch eine mittlere räumliche Reichweite (regionale Prägung), nicht schichtenspezifisch (meist jedoch am Sprachgebrauch der Mittelschicht orientiert) und stilistisch variabel (umfassen mehrere Formalitätsgrade). Die (potentielle) kommunikative Funktionalität von $\mathrm{H}-$ Sprache und L-Sprache gleicht sich situationstypisch auf der Basis ihrer Standard-Varietäten an.

3) Der 'komplette Kommunikationsraum' wird durch die H-Sprache voll, durch die L-Sprache teilweise besetzt. Darüber hinaus bleibt in Diglossiesituationen bei den Sprechern das 'abstraktive Bewertungsverfahren' beherrschend, dem zufolge der einzelnen Sprache nur bestimmte Funktionsweisen zuerkannt werden. Das Sprachbewusstsein steuert hier das soziale Sprachverhalten. Dies kann zur Normalisierung der L-Sprache (zum Aufbau einer Sprachengemeinschaft) oder zu ihrer Substitution führen. ${ }^{81}$

${ }^{81}$ Entscheidend ist hier der Grad der diasystematischen Einengung des Sprachgebrauchs. Darüber hinaus spielt die schriftsprachliche Verwendung eine wichtige Rolle. Vgl. z.B. die folgenden Bemerkungen Harald Thuns zum heutigen Gebrauch des Bearnesischen: „Die meisten Sprecher aber schreiben das Bearnesische gar nicht, lesen es auch so gut wie nie, sondern benutzen es als Heimsprache oder im mündlichen Verkehr mit engeren Bekannten. Die Übergabe an die Kindergeneration ist gefährdet. Am besten behauptet es sich auf dem Lande, leidet aber dort am Bevölkerungsrückgang. Die moderne Literatur ist bescheiden und in der Regel eingeschränkt auf literarische Kleinformen und auf erheiternde Genera (diaphasische 
4) Das Erleiden und Selbstbestimmen sozialer Abgrenzung wird bis zu einem gewissen Grad mit der Funktionsdifferenzierung der Standard-Varietät (insbesondere derjenigen der H-Sprache) in Verbindung gebracht (durch eine 'Individualisierung' des Sprachverhaltens ${ }^{82}$ ). Darüber hinaus übernehmen Substandards und Gruppensprachen ähnliche Funktionen. Der Gebrauch der L-Sprache ist in dieser Situation nicht mehr notwendigerweise mit einer sozialen Stigmatisierung verbunden (situationsabhängige Neutralität).

5) Der Umgang mit den varietätenspezifischen Funktionen der Sprache ist für die Sprecher ein Konfliktfeld des Lebens in jeder der beiden Sprachgemeinschaften, sofern beide Sprachen über einen differenzierten Varietätenraum verfügen. (Ich schlage vor, dieses Phänomen terminologisch als 'Mikrodiglossie' zu fassen. ${ }^{83}$ ) Die typischen makrodiglossischen Funktionsweisen treten als Konfliktpotential nur dann in Erscheinung, wenn situationstypisch ein Ungleichgewicht der kommunikativen Funktionalität in Erscheinung tritt (meist im öffentlichen Leben). Dieses kommunikative Ungleichgewicht ist aber oft in den verbleibenden Domänen des Gebrauchs der L-Sprache qualitativ, d.h. in funktioneller Hinsicht, nicht zu verzeichnen.

Einengung). Übermittelt wird sie meistens mündlich, durch das Radio, Theatervorführungen, Gesangsveranstaltungen. Mangel an Masse und Substanz verhindert dauernde Gegenwart des Bearnesischen in den Hör-, Seh- und Druckmedien. Moderne Gebrauchsprosa, wie sie Heinz Kloss als wesentlich für den Ausbau eines Dialekts zur Sprache ansieht, fehlt. Ob heute überhaupt jemand ein Handbuch der Landwirtschaft oder die Beschreibung einer Maschine für das Handwerk lesen würde, wenn sie auf Bearnesisch statt auf Französisch geschrieben wären, darf man bezweifeln." (Thun 1995, 228)

${ }^{82}$ Vgl. zu diesem Aspekt: Eichinger 1999, 25.

${ }^{83}$ Es handelt sich bei diesem terminologischen Vorschlag um eine spezifische Interpretation der 'Mikrodiglossie', die auf die Konfrontation von individueller Sprachkompetenz und diglossischen Funktionsdifferenzierungen rekurriert. 


\subsection{Standard und Normen: zur theoretischen Konzeption einer empi- rischen Beschreibung der Sprachkompetenz}

Beginnen wir mit einem kurzen Resümee: Der varietätenlinguistische Ansatz führt, wie dargelegt wurde, auf der Basis einer sprachkontaktlinguistischen Interpretation zu der Theorie sprachlicher Standardisierung. Der Standard wird auf diese Weise zu der methodischen Grundlage einer sprachwissenschaftlichen Beschreibung der Sprachkompetenz des einzelnen Sprechers. Er ist das sich immer wieder verändernde Produkt einer nie abgeschlossenen Standardisierung und hat sich in einem komplizierten Prozess des interaktiven Sprachgebrauchs in der Sprachgemeinschaft herausgebildet. Der sprachliche Standard ist prinzipiell varietätenbezogen. Als referentieller Standard bezieht er sich auf die exemplarische Form einer historischen Sprache (im Sinne Coserius). Allerdings zeigt er sich im Alltag wesentlich variabler, als es der kodifizierten Referenznorm entspricht. Es macht daher Sinn, im Hinblick auf seine Beschreibung zwischen einem exogenen Standard (Soll-Norm) und einem endogenen Standard (Ist-Norm) zu differenzieren.

Der endogene Standard ist als eine Form des regionalen Sprachgebrauchs in der Forschung bislang fast ausschließlich unter materiellen Gesichtspunkten (phonetisch, lexikalisch, morpho-syntaktisch) untersucht worden: als 'landschaftliche Umgangssprache' bzw. français régional, italiano regionale usw. Die materielle Beschaffenheit des endogenen Standards stellt aber einen deskriptiven Aspekt dar, der die kommunikative Funktionalität dieser Varietät nicht zu erklären vermag. Daher ist es auch nicht möglich, auf der Grundlage eines materiellen Verständnisses des endogenen Standards die Sprachkompetenz von Sprechern angemessen zu beschreiben. Insbesondere basiert die Sprachkompetenz eines Sprechers funktional gesehen nicht auf Interferenzen (oder Transferenzen) aus einer Kontaktsprache. Diese Vorstellung widerspräche einer jeden soliden sprachtheoretischen Fundierung.

In methodologischer Hinsicht gehe ich von dem Sprachkompetenz-Modell Eugenio Coserius aus. Es ist auf den einzelnen Sprecher konzentriert und beschreibt seine sprachliche Kompetenz auf der Basis einer zugrunde liegenden Varietät ('Hauptmundart') als komplexe Einbeziehung von Elementen aus anderen Varietäten derselben oder auch einer anderen Sprache. Im Normalfall des Sprechens ist diese zugrunde liegende Varietät die Standard-Varietät einer historischen Sprache, für die sich der Sprecher auch in jeder Sprachkontaktsituation immer entscheiden muss. ${ }^{84}$ Diese Standard-Varietät konstituiert im Alltag das Zentrum des endogenen Standards, der so offen und flexibel konzi-

${ }^{84}$ Termini wie 'francitan' oder 'franglais', denen sicherlich ein gewisser Erklärungswert nicht abzusprechen ist, sind in sprachtheoretischen Argumentationen m.E. fehl am Platze. 
piert ist, dass sich in ihn auch Elemente aus anderen Varietäten integrieren. Im Falle von Sprachen, die einen klar differenzierten Varietätenraum für sich beanspruchen können (d.h. konkret bei relativ weit 'ausgebauten' Kultursprachen), wird man sowohl die Standard-Varietät als auch weitere Varietäten als Quellen für die komplexe Sprachkompetenz des einzelnen Sprechers exakt bestimmen können. So lässt sich, auf das Thema meiner Untersuchung bezogen, z.B. relativ klar bestimmen, welche lexikalischen Elemente zur französischen Fachsprache des Waldbaus und nicht mehr zur Standard-Varietät des Französischen gehören. Es zeigt sich aber bereits in einem lexikographisch orientierten Beschreibungsansatz, dass die Übergänge von Fach- und Gemeinsprache fließend sind und dass die Differenzierung in funktionelle Sprachen bei einer Deskription der im Alltag relevanten Sprachkompetenz nicht weiterhilft.

Noch schwieriger gestalten sich solche Differenzierungen im Hinblick auf Sprachen, deren Varietätenraum nicht klar gegliedert ist. Regionalsprachen verfügen in der Regel über ein differenziertes diatopisches System, aber schon die Festlegung einer kodifizierten Standard-Varietät ist häufig problematisch. Darüber hinaus lassen sich erst ab einem gewissen Ausbaugrad diastratische und diaphasische Besonderheiten des Sprachgebrauchs erkennen. Man muss in diesem Sinne unterscheiden, ob eine Regionalsprache diasystematisch eingeschränkt verwendet wird, weil sie sich in einer diglossischen Situation befindet, oder ob sie selbst dazu in der Lage ist, ein Spektrum diasystematischer Variation auszufüllen. Der letztere Fall hängt von einer fortgeschrittenen Normalisierung der Sprache ab. Wie aber kommen Sprecher von nicht oder nur wenig normalisierten Sprachen (lesser used languages) mit den kommunikativen Anforderungen des Alltags zurecht? Die übliche Antwort der Soziolinguistik hierauf ist, dass die kommunikativen Anforderungen selbst eingeschränkt werden, was durch den Rückgang von Gebrauchsdomänen der Sprache in der Regel auch nachweisbar ist.

Allerdings scheint die Realität gesellschaftlicher Kommunikation doch komplizierter zu sein. Der Blick auf die Sprachkompetenz des einzelnen Sprechers, so wie er in der Theorie des Sprechens von Coseriu hervorgehoben wird, macht nämlich zum einen deutlich, dass der Sprachgebrauch von Regionalsprachen in seiner kommunikativen Funktionalität prinzipiell dem der übergeordneten Standardsprachen entspricht (denn es gibt in dieser Hinsicht keine sprachtheoretische Sonderbetrachtung von Regionalsprachen). Zum anderen werden die Dinge aber in der Betrachtung kompliziert, weil zwar nach wie vor gilt, dass die Sprecher auf der Basis einer flexiblen Standard-Varietät kommunizieren, die deskriptive Unterscheidung in exogenen Standard und endogenen Standard aber erst in dem Moment greift, in dem die soziale Relevanz eines exogenen Standards der Regionalsprache überhaupt nachgewiesen werden 
kann. Das Modell der Teilhabe an verschiedenen funktionellen Sprachen kann also im Hinblick auf Regionalsprachen nur beschränkt verwendet werden und ist grundsätzlich durch die Konzeption eines flexiblen regionalen Standards zu ersetzen. Die varietätenspezifische Basis eines solchen regionalen Standards kann - im Falle der fehlenden Anerkennung einer referentiellen StandardVarietät - durch eine diatopische Varietät, z.B. einen Dialekt, gebildet werden (der wiederum den Charakter einer Referenznorm annehmen kann). In diesem Sinne interpretiere ich den Gebrauch der Regionalsprachen in meinen Untersuchungsgebieten auf der Basis eines bearnesischen und valenzianischen Standards, der jeweils auch dem Sprecherbewusstsein entspricht und zu Vorstellungen von einem guten oder schlechten Gebrauch der Regionalsprache führt.

Sprachplanung bedeutet demnach die Zusammenführung des exemplarischen Sprachgebrauchs bzw. der 'kanonischen Form' der Sprache (J. Albrecht) mit der Norm eines kodifizierten Standards, von dem dann in einem fortgeschrittenen Normalisierungsprozess selbstverständlich abgewichen werden darf und muss. Das Bearnesische ist von einem solchen Normalisierungsprozess überhaupt weit entfernt, das Valenzianische hingegen 'mitten drin', steckt aber nach wie vor in einer zutiefst problematischen Phase. Angesichts solcher Situationen lassen sich kaum sprachpolitisch neutrale Theorien zu Phänomenen des sozialen Sprachgebrauchs und des Sprachkontakts formulieren, es sei denn, sie ziehen sich auf die materielle Betrachtung von sprachlichen Interferenzerscheinungen zurück. Dies aber engt den sprachanalytischen Blickwinkel erheblich ein. Als Folge dieser Problematik ergibt sich eine nicht überwundene Trennung von sprachsoziologischem und sprachstrukturellem Erklärungsansatz, die m.E. methodologisch nicht sinnvoll ist.

Die Gefahr methodologischer Einseitigkeiten kann am besten durch die Verankerung in einem umfassend konzipierten sprachtheoretischen Grundansatz vermieden werden, in dem ein einheitlicher Sprachbegriff auf verschiedenen Deskriptionsebenen erklärt wird. Diese Deskriptionsebenen dürfen den Blick für anthropologische, soziologische, psychologische, kognitionspsychologische und strukturalistische Interpretationen nicht verstellen. Das gemeinsame $\mathrm{Ma}$ all dieser Erklärungen muss die Frage bleiben, 'was ein Sprecher wirklich tut' (Coseriu). Welchen Nutzen jedoch kann die empirische Beschreibung aus diesen methodologischen Bedingungen ziehen? Ich möchte diese Frage hier nicht definitiv beantworten; über eine Antwort sollte auch nicht voreilig entschieden werden. Allerdings weist meine vorläufige Antwort in eine Richtung, die den 'Normen' im Rahmen der Analyse von Sprachkompetenz und Sprachverwendung eine besondere Bedeutung zumisst. Damit stoße ich im doppelten Sinne auf ein Feld 'unübersehbarer' sprachtheoretischer und philosophischer Diskussionen, die in die Erklärungsansätze der genannten und weiterer Disziplinen hineinwirken. Ich werde mich im Folgenden darauf beschränken zu be- 
gründen, warum die Betrachtung von 'Normen' für den von mir vertretenen sprachanalytischen Ansatz wichtig ist und in welcher Form sie für meine empirische Untersuchung fruchtbar gemacht werden kann.

In Coserius sprachtheoretischen Darlegungen begegnet einem der Begriff der 'Norm' auf Schritt und Tritt. Interessanterweise ist dies in der Rezeption aber nur selektiv wahrgenommen worden (mit Ausnahme von L. F. Lara, auf den ich noch eingehen werde). Zwar gibt es kaum einen Sprachwissenschaftler, der nicht bereit wäre, Coserius besondere Verdienste um die Analyse der Sprachnorm zu würdigen, doch bezieht sich diese Anerkennung ausschließlich auf seinen klar definierten strukturalistischen Normbegriff, der die 'Norm' als vermittelnde Instanz zwischen System und Rede ansieht und dadurch den sozialen Aspekt auch auf der sprachwissenschaftlichen Betrachtungsebene der Einzelsprache ansiedelt. Wie aber sieht es auf der universellen und auf der individuellen Ebene des Sprechens aus? Im Verlauf meiner Interpretationen zu Coserius Theorie des Sprechens habe ich bereits mehrfach auf den explikativen Status der Norm hingewiesen. Allein die Dokumentation der Frequenz des Begriffs in Coserius Schrift 'Sprachkompetenz' würde deutlich machen, dass auf allen Ebenen mit der 'Norm' argumentiert wird. Exemplarisch möchte ich auf die 'universelle Betrachtungsebene' eingehen, die von der Coseriu-Rezeption m.E. oft falsch verstanden wird.

Ein für 'Coseriu-Anhänger' referentieller Beitrag zum Thema 'Norm' ist der von Peter Koch (1988). Auch Kochs Analyse bewegt sich prinzipiell auf der Basis des strukturalistisch eingeengten 'Norm'-Begriffs, den Coseriu zwar vertritt, aber eben nur auf der dazu passenden historischen Ebene der Einzelsprache. Koch argumentiert nun (in Anlehnung an Oesterreicher) so, als gäbe es keinen Normbegriff auf der universellen Ebene des Sprechens: ${ }^{85}$

Nachdem der Tätigkeit des Sprechens als solcher keine Historizität zugesprochen werden kann, wäre es sicherlich unglücklich, hier von '(sozialen) Normen' des Sprechens zu reden, denn der Norm-Begriff sollte für das historisch begrenzt Gültige, Konventionelle reserviert bleiben.

(Koch 1988, 338)

${ }^{85}$ Koch 1988, 328, unterscheidet insgesamt acht 'Sprach-Begriffe' (sprachtheoretisch angemessener erschiene es mir, von mehreren Dimensionen oder Aspekten eines Sprachbegriffs auszugehen). Nur drei 'Sprach-Begriffen' ordnet Koch jeweils einen 'Norm-Begriff' zu: dem deskriptiven, dem präskriptiven und dem systembezogenen. Ein Zusammenhang dieser drei Sprachbegriffe wird von ihm über die unterstellte Homogenität dieser 'dreigesichtigen' Normenkonzeption hergestellt, nicht umgekehrt. In der Vorstellung Kochs korrespondiert der deskriptive Norm-Begriff mit der Konstitution einzelsprachlicher Varietäten. Auf diese Weise werden Varietäten nicht als Sprachverwendungsweisen, sondern als 'funktionelle Sprachen' charakterisiert. Dem allgemeinen Sprach-Begriff wird keine Normebene zuerkannt. Damit legt sich Koch auf ein ausschließlich einzelsprachliches Verständnis der Norm fest. 
Ich habe bereits in Teil II.1 dargelegt, dass die Historizität nach Coserius eigener Interpretation auch ein Konstitutivum des allgemeinen Verständnisses der Sprache (bzw. des Sprechens) ist. Die von Koch gezogene Konsequenz ist bei einer derart modifizierten Voraussetzung aber nicht mehr haltbar. Dies ist umso gravierender, als Koch (ebenso wie Oesterreicher) die Konzeption von Mündlichkeit und Schriftlichkeit (Sprache der Nähe, Sprache der Distanz) genau an dieser Stelle in Coserius Sprachtheorie einzupassen versucht. Der normative Bereich des Sprechens im Allgemeinen ist seiner Meinung nach im Prinzip gar nicht normativ, sondern durch 'universale Regeln des Sprechens' (Sprechregeln) besetzt, die er nach den Prinzipien des Nähe-Distanz-Kontinuums interpretiert. Es muss indes darauf hingewiesen werden, dass diese Interpretation zu Coserius eigenen konzeptionellen Vorstellungen widersprüchlich ist. Man kann sich in diesem Sinne sprachtheoretisch nur für Koch / Oesterreicher oder für Coseriu entscheiden. Ich habe bereits dargelegt, aus welchen Gründen ich die Konzeption Coserius vorziehe. Coseriu geht eindeutig von der historisch verankerten normativen Ebene des Sprechens im Allgemeinen aus:

Der naive Sprecher kennt auf der Ebene des Sprechens im allgemeinen noch keine gemachten Einheiten. Er kennt aber Verfahren zugleich mit der ihnen innewohnenden Norm, d.h. er weiß intuitiv, welches die Normen des Sprechens im allgemeinen sind. Dieses Wissen zeigt sich gerade in den negativen Urteilen über das Sprechen anderer. Die Norm, die diesen Verfahren innewohnt, ist die Norm der Kongruenz mit den Prinzipien des Denkens, die nicht mit denen des logischen Denkens identifiziert werden dürfen, und mit der allgemeinen Kenntnis der Sachen. Die Norm der Kongruenz zeigt sich auch - indirekt - in der Verhaltensnorm der Toleranz: Der Sprecher erwartet, daß die anderen sinnvoll und kongruent sprechen. Er lehnt darum auch das Inkongruente nicht einfach $a b$, sondern akzeptiert es wenigstens provisorisch und versucht, es als sinnvoll und kongruent zu interpretieren. Wir haben also auf der Ebene des Sprechens im allgemeinen einerseits die Norm der Kongruenz und die Verhaltensnorm der Toleranz, und wir haben andererseits ein Verfahren der Interpretation des Sprechens anderer, dem diese beiden Normen innewohnen.

(Coseriu 1988a, 248)

Meine Interpretationen der Textcorpora zu fachkontextuellem Sprechen werden sich immer wieder auf die hier beschriebenen Normen des Sprechens beziehen. Die gesprochenen Texte (Diskurse) mit fachinhaltlichen Bezügen ganz gleich ob sie in der Form von Erklärungen, Beschreibungen, Exemplifizierungen oder Erzählungen gegeben werden - stellen in kommunikativer Hinsicht beständig Herausforderungen an eine 'Norm der Kongruenz' und an eine 'Norm der Toleranz' dar. Meine Interpretationen des empirischen Materials werden daher auch in diese Richtung weisen. Dabei zeigt sich die Tendenz, dass der von mir untersuchte Sprachgebrauch in Fachkontexten die 'Norm der Kongruenz' insbesondere in Bezug auf die Kenntnis der Sachen 
(die nicht sprachspezifisch ist) zu berücksichtigen hat. Die 'Norm der Toleranz' hingegen bezieht sich im Allgemeinen auf die interpretativen Verfahren des Textverständnisses, da fachliche Gegenstände im Alltag (selbst von Fachleuten) oft so dargestellt werden, dass die Kongruenz $\mathrm{zu}$ den Sachen (und teilweise zu den Prinzipien des Denkens) nicht vollkommen gewährleistet ist. Solche Inkongruenzen behindern aber nicht die Kommunikation, solange die Toleranznorm auf ein Wissen von Regularitäten und Normalitäten rekurrieren kann, das ein Substitut für die fachlich exakte Versprachlichung (bzw. einen exakten Fachsprachengebrauch) darstellt. Dieses Wissen interpretiere ich als ein regional definierbares, sozial stabilisiertes Wissen, das ebenfalls den Umgang mit 'Normen' voraussetzt. Vereinfachend spreche ich hier von 'Regionalnormen', auf deren Verständnis ich noch näher eingehen werde.

Auch auf der Ebene des Textes bzw. Diskurses sind die Normen entscheidend. Ich brauche dies an dieser Stelle nicht noch weiter auszuführen, da es schon mehrfach erwähnt und erläutert wurde. Die Rezeption tut sich in diesem Bereich weniger schwer, die konzeptionellen Grundlagen von Coserius Theorie zu akzeptieren. Entscheidend ist dabei m.E. die Einflussnahme von Brigitte Schlieben-Lange, die immer wieder auf die Existenz von Diskurs- und Texttraditionen (und damit auch auf die entsprechenden Normen) hingewiesen hat. Es entspricht dabei der allgemeinen Auffassung, Diskurs- und Textnormen nicht mit Individualnormen des Sprechens gleichzusetzen, was in der Tat einer oberflächlichen Schlussfolgerung aus der Zugrundelegung der individuellen Betrachtungsebene des Sprechens bei Coseriu gleichkäme.

Wenn also 'Normen' nach Coseriu auf allen Betrachtungsebenen des Sprechens konstitutiv sind, so muss die Frage gestellt werden, welche Position der Begriff der 'Norm' in Coserius Sprachtheorie - und nicht nur in seinem strukturalistischen Beschreibungsansatz - tatsächlich einnimmt. M.E. hat Luís Fernando Lara hierauf die überzeugendste Antwort gegeben. Lara entwickelt den Norm-Begriff in Bezug auf Coseriu auf der Basis einer genauen Analyse der Konstitution und Genese der Sprachtheorie Coserius. Dabei stellt er die absolute Geschichtlichkeit der Sprache in den Mittelpunkt der Betrachtung:

'L'histoire qui se déroule' [Coseriu im Original: historia que ocurre] constitue l'unique donnée, l'unique objet du linguiste, car il faut lui supposer une existence en ellemême non formelle quoique d'une certaine façon 'substantielle' (ici, l'adjectif ne sert qu'à des fins purement explicatives). Certes, il existe des 'modèles antérieurs' à l'acte individuel de la parole mais il semble que leur antériorité ne soit qu'historique, c'est-à-dire antériorité dans le temps et non dans une région plus profonde de l'entité linguistique. Ainsi, la langue serait un résultat et un fait intrinsèquement historique: 'Le pouvoir parler serait alors structuré à partir de certaines traditions historiques. 
Lara weist nun in einer detaillierten Auseinandersetzung nach, dass der strukturalistische Ansatz den 'monistischen' Sprachbegriff Coserius nicht vollständig erfasst, ja mehr noch: Er betont sogar, dass Coseriu gar kein formalistisches Erklärungsmodell der Sprache vertritt und sich in dieser Hinsicht deutlich von den Vertretern des Strukturalismus (wie z.B. von Hjelmslev) absetzt. Das Wesentliche der Sprache geht in Coserius Theorie (in Anlehnung an Humboldt) auf die Tätigkeit des Sprechens und nicht auf die Formalisierung des Produkts durch Abstraktion und Verallgemeinerung zurück. Lara weist darauf hin, dass Coseriu den Normbegriff in die Sprachbeschreibung integriert, da sein Sprachbegriff nicht auf die Komponente des Sozialen verzichten kann. Allerdings bemerkt er auch:

L'image de la société projetée par Coseriu n'est pas aussi clairement expliquée que sa conception du langage. Je crois que Coseriu tente de faire une équation en établissant un lien entre l'histoire et la tradition ainsi qu'entre la tradition et la société, lien si étroit qu'il lui permet de définir la norme en ajoutant un aspect supplémentaire: 'La norme comprend tout ce qui $[\ldots]$ est tout de même traditionnellement (socialement) fixé, qui est usage commun et courant de la communauté linguistique' [...].

(Lara 1983, 173)

Die gesellschaftliche Einbindung des Sprachgebrauchs und der Status sozialer Normen wird in der Sprachtheorie Coserius in der Tat nicht deutlich genug hervorgehoben. Ich bin aber bereits in Teil II.1 ausführlich darauf eingegangen, in welcher Form dieser Aspekt ergänzt werden kann, ohne die Theorie Coserius wesentlich modifizieren oder gar 'vom Kopf auf die Füße stellen’ zu müssen. Es geht ganz einfach um die Hervorhebung einer normativen Betrachtungsebene des Sprechens als Tätigkeit, auf die Coseriu selbst nicht eindeutig verweist, da in seiner humboldtianischen Konzeption das Sprechen in erster Linie eine Tätigkeit des Subjekts und keine intersubjektive (bzw. interaktive) Tätigkeit darstellt. Dieses Manko des Coseriuschen Abstraktionsmodells ist jedoch auf der anderen Seite ein methodologisch ausschlaggebender Impuls für die Einbeziehung des Subjekts in eine formalisierende Sprachbetrachtung. Denn die Sprachkompetenz ist nach Coseriu immer zu allererst die eines Sprechers, d.h. jede Formalisierung muss an der Tätigkeit des Subjekts ansetzen und diese erst in einem weiteren analytischen Schritt verallgemeinernd erklären. Auf dieser verallgemeinernden Erklärungsstufe ist aber die Anerkennung sozialer Normen eine methodisch unverzichtbare Voraussetzung. Coserius Sprachtheorie gibt somit auch einen methodischen Leitfaden für die empirische Untersuchung des Sprachgebrauchs an die Hand.

Gerade im Hinblick auf die Prinzipien und Möglichkeiten der Deskription, die für die sich anschließende empirische Untersuchung bestimmend sind, möchte ich abschließend noch auf die Probleme der Definition und Status- 
bestimmung von Sprachnormen eingehen. Im Rahmen der hier gebotenen Kürze bei der Behandlung dieses extrem schwierigen Themas verzichte ich auf eine kritische Gegenüberstellung verschiedener Konzeptionen und berufe mich im Wesentlichen auf den theoretischen Ansatz von Klaus Gloy, den ich für überzeugend halte. Hierzu sind einige Vorbemerkungen vonnöten.

Die Sprachnormentheorie ist ein weites und verwirrendes Feld der sprachwissenschaftlichen Forschung. Der Grund hierfür liegt darin, dass Sprachnormentheorie immer zugleich auch Sprachtheorie im anspruchsvollsten Sinne des Wortes ist und daher zu sehr komplexen Darstellungen der verschiedenen Sprachbegriffe einzelner Autoren führt. Gloy betont in diesem Sinne, dass es keine ausgearbeitete Methodologie der Sprachnormenforschung gebe, dass es aber dennoch sinnvoll sei, sich auf eine bestimmte begriffliche Konzeption der Sprachnorm zu einigen. Sprachnormen, sofern sie nicht einfach statistische Normen sind, implizieren immer das Merkmal einer von außen auferlegten 'Verpflichtung', sei es durch die Vorschrift einer Instanz (Kodifikation), durch die Regel eines gültigen Systems (einzelsprachliche Grammatik) oder durch die Zweckrationalität eines zu erreichenden Ziels (z.B. einer kommunikativen Absicht; vgl. Gloy 1995, 75). Im Gegensatz zu dem extensionalen Verständnis der Sprachnorm impliziert das Merkmal der Verpflichtung, dass Normen in der Empirie 'schon bezüglich eines einzelnen Sprachvorkommnisses behauptet werden können' (ebd.). Im Hinblick auf meine Untersuchung gehe ich von dieser möglichen Form der individuellen Eruierung von Sprachnormen aus. Dabei konzentriert sich die Erklärung des regionalen Sprachgebrauchs in Fachkontexten auf die Anerkennung zweckrationaler Normen der Kommunikation und auf ihre einzelsprachliche Umsetzung.

Welchen Status nun haben solche Sprachnormen? Sind sie als Regularitäten des Sprachgebrauchs empirisch beschreibbar? Gloy vertritt die Sichtweise, dass Sprachnormen 'regulative Ideen des jeweiligen Sprachereignisses seien' (S. 77) und dass auf der Textebene daher nur das sprachliche 'Produkt einer Norm', nicht aber die Norm selbst dokumentiert würde. Das Erkennen von Normen ist somit im Wesentlichen ein Interpretationsvorgang (ebd.). Dadurch wird eine Methodik vorgegeben, nämlich das heuristische Verfahren der Interpretation, das ich als Analyseinstrumentarium in meiner Untersuchung anwenden werde. Auf die notwendige Sachbezogenheit des Interpretationsvorgangs werde ich noch genauer eingehen.

Es ist schwierig, Sprachnormen, die nicht Vorschriften oder Regeln darstellen, genau zu formulieren. Dies stellt jedoch kein methodisches Problem dar, da 'die Normformulierung gegenüber der Norm nur das Sekundäre ist' (S. 80). Eine Norm, die durch Sprachteilhaber als eine solche formuliert wird, ist aufgrund dieser Tatsache allein noch nicht auf den Status einer Norm zu erheben. Der Sprachwissenschaftler bevorzugt daher meistens beobachtbare 
Regelmäßigkeiten (Rekurrenzen) des Sprachgebrauchs, um eine Norm überhaupt zu identifizieren. Allerdings müssen auch solche Regelmäßigkeiten erst noch 'mit Hilfe von Zusatzannahmen' normativ interpretiert werden (S. 82).

Die Frage nach der für die Identifikation einer Sprachnorm erforderlichen Abstraktion stellt sich insbesondere im Hinblick auf die Gleichsetzung von Norm und Standard-Varietät einer Sprache (S. 83). Selbst wenn diese Gleichsetzung mit der Anerkennung anderer Normen für Nicht-Standard-Varietäten einhergeht, so liegt ihr problematischer Aspekt doch in der homogenen Konzeption der Varietät als Sprachteilsystem begründet. Die sprachliche Varianz muss nämlich auch in der ausschnittsweisen Betrachtung einer Varietät noch erkannt und analysiert werden. Dieser Aspekt, den Gloy aus der sprachnormentheoretischen Perspektive anspricht, wird auch in der von mir vorgeschlagenen Theorie sprachlicher Standardisierung hervorgehoben. Dementsprechend ist das normative Verständnis der Standard-Varietät gerade in Bezug auf die formal unscharfen Abgrenzungen dieser Varietät von interpretativem Wert. Die Tatsache, dass Normen als Vorschriften und Regeln des Sprachgebrauchs in Bezug auf eine Standard-Varietät beschrieben werden können, erklärt nur den exogenen Standard der Sprache. Die Realität des endogenen Standards hingegen wird erst erkannt, wenn die zu untersuchenden Normen auch als Konstitutiva eines regionalen Standards verstanden werden, der durch einen bestimmten Grad an Offenheit und Flexibilität charakterisiert ist. Dies gilt nicht nur für die Verwendung des Sprachsystems (Aussprache, Wortschatz, grammatische Eigenheiten, etc.), sondern gerade auch für Fakten des Sprachgebrauchs in sprachinhaltlicher Interpretation (Zweckrationalität bzw. lebenspraktische Funktionalität nach H. Steger). Gloy verweist in diesem Zusammenhang auf die methodologische Bedeutung der Hinwendung zur Alltagssprache, die den Aspekt sprachlicher Variation hervorhebt:

Statt zu unterstellen, dass die von der Forschung selbst formulierten Normen auch im Alltag existieren, und statt die angetroffene Sprachpraxis nur noch als in diesem Sinne normgerecht oder normabweichend zu klassifizieren, sollten Sprachwissenschaftler Normen stärker aus der von ihnen nicht frisierten Sprachpraxis ableiten.

(Gloy 1995, 84)

In meinen Untersuchungen versuche ich, dieses Prinzip zu verwirklichen. Dabei gehe ich mit Gloy darin einig, dass Sprachnormen nicht über die Sprecher als Informanten eruiert werden sollten, da metalinguistische Befragungen dieser Art 'methodologisch mehr Probleme aufwerfen, als eine empirische Sprachnormenforschung wohl gemeinhin unterstellt' (S. 86). ${ }^{86}$ Die von Gloy

${ }^{86}$ Selbstverständlich haben auch metalinguistische Befragungen ihre Berechtigung. Sie sind jedoch nicht als direkter Ausdruck einer Sprachnormen-Realität zu verstehen: „Ansätze, die gezielt das Sprachnormenwissen und -bewußtsein der Sprecher thematisieren, haben die bes- 
geforderte Analyse der Sprachpraxis gerät aber unweigerlich in einen Konflikt mit der sprachwissenschaftlichen Konzeption von Sprachnormen, insofern diese als 'theoretische Konstrukte' für die Sprachteilhaber nicht handlungsleitend sind. Die soziale Wirklichkeit der Sprachnormen hängt stattdessen mit der 'Erfassung von Lebensprozessen in ihrer Bewegung' (S. 87) zusammen, d.h. Sprachnormen entwickeln sich innerhalb dieser Lebensprozesse und werden auch mit ihnen beständig verändert. Ein solches dynamisches Konzept der Sprachnormenanalyse passt hervorragend $\mathrm{zu}$ der sprachtheoretischen Einbettung meiner Untersuchung, die das Sprechen als eine zugleich produzierende und normativierende Tätigkeit ansieht, deren wesentliches Resultat nicht allein das Produkt (der Text) oder die (Sprach-)Norm ist, sondern das sprachliche Wissen, in dem sich Produkt und Norm auf einer nicht statischen Ebene wiederfinden. Die kommunikative Ausgestaltung eines gesellschaftlich relevanten Sachbereichs ist dabei eine geeignete empirische Grundlage für die Beschreibung solcher sprachnormativen Gegebenheiten und Prozesse.

Methodisch entscheidend ist nun die Frage, wie die Sprecher die sprachnormativen Fakten in ihr sprachliches Handeln integrieren. Gloy spricht hier von individuellen 'Aneignungsprozessen' und dem Prinzip einer 'variierenden Übernahme':

[...] in der Regel handelt es sich um eine Verfestigung dessen, was von den Sprechern gesprächsweise, mithin intersubjektiv hergestellt wurde (z.B. als 'gelungene' Äußerung; als akzeptierte Art, über ein Thema zu sprechen, u.ä.). In diesem Sinne sind Normen Sedimente einer Praxis und müssen folglich als Praxisformen untersucht werden. Die vom Wissenschaftler ex post zugeschriebene Bedeutung der Praxisformen, schreibt Bordieu [...], sei nicht identisch mit dem subjektiven Zweck des Handelns der Produzenten dieser Praxisformen. Demzufolge muß die Erforschung der Sprachnormen auf der Ebene der Sprecher selbst und wegen der jeweils nur lokalen Aneignungsprozesse mikroanalytisch erfolgen, d.h. vorzugsweise im Rahmen von Gesprächsanalysen.

(Gloy 1995, 88)

Meine empirische Untersuchung bewegt sich in diesem methodischen Rahmen. Sie untersucht auf der Basis einzelner Gespräche als Beispiele fachkontextueller Kommunikation den Sprachgebrauch und die in ihm wirksamen 'subsistenten Normen' (Gloy 1995, 89). Solche Normen lassen sich nicht direkt beschreiben. 'Sie bestehen aus den normativen Erwartungen, die ein Sprecher - im Anschluss an seine diskursiven Erfahrungen - bezüglich des Sprachhandelns eines anderen Sprechers hegt' (S. 89). ${ }^{87}$ Die angemessene Einschät-

seren Chancen, gesellschaftliche Realität zu rekonstruieren. Sie müssen sich allerdings ihre Distanz zu den Ideologemen dieses Alltagsbewußtseins gesondert erarbeiten“ (Gloy 1995, 87).

${ }^{87}$ Sehr aufschlussreich für die Konzeption der 'subsistenten Normen' ist Gloys Beitrag 
zung solcher Sprechererwartungen als Normen verlangt einen aufwendigen Interpretationsvorgang, der sich keinesfalls ausschließlich auf die Intuition des Sprachwissenschaftlers verlassen sollte. Ich habe daher kommunikative Lebensbereiche ausgewählt, deren Sachbezogenheit die Art und Weise der normativen Gestaltung des Sprechens maßgeblich determiniert. Auf diese Weise lassen sich Normen als Sprechererwartungen wiederum auf Sachnormen zurückführen. Diese Sachnormen, die als solche objektiv beschreibbar sind, werden jedoch in jedem Fall als subsistente Sprachnormen durch den einzelnen Sprecher in intersubjektiven (oder besser: interaktiven) Kommunikationssituationen anverwandelt. Sie bilden in der Regel in Bezug auf den untersuchten Sachbereich 'Regionalnormen', da - wie ich im Einzelfall nachweisen werde - die soziale Wirklichkeit der normativen Erfahrungen im Sachbereich regional gebunden ist. Neben diesen regionalen Bindungen der Sachnormen ist jedoch in jedem einzelnen Fall auch die persönliche Betroffenheit der Sprecher in Rechnung zu stellen. Dabei handelt es sich um dependente normative Erfahrungen, die in der folgenden Abhängigkeitsfolge zu interpretieren sind: Sachnormen ' als Regionalnormen ' als persönliche Erfahrungen. Im Hinblick auf die letzte, die persönliche Erfahrungsebene des Einzelnen spreche ich von 'biographischen Normen', um die normativen Zusammenhänge nicht aus dem Blick zu verlieren.

Auf allen drei Ebenen der Normenkonstitution, also dem allgemeinen Sachbezug, dem Regionalbezug und dem biographischen Bezug, gibt es eine Anverwandlung und variierende Übernahme dieser Normen als Sprachnormen in dem von Gloy definierten Sinne. Für meine Untersuchung sind dabei das $\mathrm{Zu}-$ sammenspiel der normativen Ebenen und ihre gemeinsamen Auswirkungen auf den Sprachgebrauch wichtig. Vereinfachend gehe ich so von der Beschreibungsmöglichkeit eines 'regionalen Sprachgebrauchs' aus. Dieser regionale Sprachgebrauch ist unter normativem Aspekt prinzipiell unabhängig von der Wahl der historischen Sprache. In Sprachkontaktsituationen gibt es jedoch besondere Affinitäten von regional wirksamen Sprachnormen und der Verwendung einer regionalen Sprache. In diglossischen Situationen übernimmt daher meistens der Dialekt oder die Minderheitensprache solche kommunikativen Funktionen, die mit der regionalen Normierung der Sprachverwendung in einem engen Zusammenhang stehen. Erst wenn die Regionalsprache kaum noch gebraucht wird, tritt diese Funktionalität verstärkt in den Bereich der Sprachverwendung der dominanten Sprache ein. Es handelt sich dann um eine Übertragung von Sprach- und Diskurstraditionen, die wiederum zu einer regionalen Form des Sprachgebrauchs führen, den ich in terminologischer Anleh-

„Sprachnormen als 'Institutionen im Reich der Gedanken' und die Rolle des Individuums in Sprachnormierungsprozessen“ (Gloy 1997). In diesem Beitrag erläutert Gloy auch die Zusammenhänge von Sprachnormen- und Sprachwandeltheorie. 
nung an Stehl als Ausprägung des 'endogenen Standards' charakterisiert habe. Dieser endogene Standard ist so offen konzipiert, dass er selbst Elemente aus der regressiven Sprache noch integrieren kann. Das Phänomen des Aufbaus regionalspezifischer Sprecherkompetenzen ist aber in jedem Fall normkonstituierend, impliziert also keine Normverstöße und wird in der Konzeption der interferenzorientierten Sprachkontaktanalyse nur unvollkommen beschrieben. 


\title{
III. Empirischer Teil:
}

\author{
Exemplarische Untersuchungen zum regiona- \\ len Sprachgebrauch in Fachkontexten mit Be- \\ zug auf zwei Bereiche der wirtschaftlichen \\ Nutzung von Baumbeständen in zwei di- \\ glossischen Regionen der europäischen Roma- \\ nia
}

\section{Grundsätzliche Darstellung des gesamten Unter- suchungsprojekts}

\subsection{Allgemeine Zielsetzung}

Im ersten Teil dieser Arbeit habe ich versucht, die Relevanz und Komplexität meines Untersuchungsobjekts in theoretischer Hinsicht zu erläutern. Die Ausrichtung des erkenntnisleitenden Interesses ergibt sich aber nicht ausschließlich aus den theoretischen Prämissen, sondern ist auch eine Folge der Beobachtung des alltäglichen Lebensvollzugs. Der Sprachgebrauch spielt unter den hier hervorgehobenen Bedingungen fachlicher Bezüge eine besondere Rolle bei der normalen Alltagsbewältigung und stellt zugleich ein konstitutives und expressives Element der Identitätsfindung der Sprecher dar. Das Sprechen vermittelt dabei zwischen den Normen der Tradition, der regionalen Lebensrealität und der biographischen Existenz, also zwischen drei Faktoren, die eine signifikante Rolle in der Dynamik der Lebensbewältigung spielen, und die - so meine These - gerade durch die spezifische Form des regionalen Sprachgebrauchs in einem Gleichgewicht gehalten werden. Wenn es aber einen spezifisch sprachlichen Ausdruck der Lebensbewältigung gibt, so lässt sich dieser in einem empirischen Zugriff am ehesten unter der Berücksichtigung von drei Bezügen der kommunikativen Tätigkeit darstellen. Diese sind:

1. der thematische Bezug der Kommunikation bzw. der fachliche Kontext, in dem sich der Sprecher / die Gesprächspartner bewegen 
2. der regionale, bisweilen auch lokale Bezug der Kommunikation bzw. die regionalen und lokalen Faktoren, durch die Inhalt und Form der sprachlichen Mitteilung / des Gesprächs geprägt werden, und

3. der biographische Bezug der Kommunikation bzw. die persönliche Betroffenheit des (der) an dem Gespräch beteiligten Person(en)

Hinzu kommt ein vierter Aspekt, der in mehrsprachigen Gebieten in Erscheinung tritt, dann aber - wie in der hier vorliegenden Untersuchung - von ganz besonderer Relevanz ist:

4. die in der Kommunikation verwendete Sprache bzw. auch die verwendeten Sprachen, wobei - zumindest in di- oder triglossischen Gebieten unterstellt werden kann, dass eine der Sprachen (bzw. der Dialekt) deutlich als regionale Sprachform ausgewiesen ist.

Jeder Kommunikationsakt steht in einem Bezug zu Traditionen, durch die er sich in einem Spannungsfeld zwischen früher und heute bewegt. Die Traditionen konstituieren eine innere Dynamik des Sprechens, deren Maßstab und Orientierung an die Normen aller vier genannten Aspekte gebunden sind. Sprachveränderungsprozesse, die den Wandel kommunikativen Verhaltens und die Modifikation typischer Diskursgestaltungen beinhalten, können daher am besten anhand des Zusammenspiels vielfältiger Normen beschrieben werden. Dabei lassen sich vier relevante Normenbereiche unterscheiden:

1. Normen des Sachgebiets der Kommunikation bzw. fachliche Normen, die ich in einem umfassenden Sinn als Sachnormen bezeichne.

2. Normen der regionalen Lebensrealität, die sowohl in der Form äußerer Normen im faktischen Bereich (z.B. geographische Gegebenheiten, wirtschaftliche Produktionsverhältnisse, etc.) als auch in der Form interner Normen auf der Ebene des Bewusstseins (Erwartungshaltungen, Bewertungsmaßstäbe, etc.) angesiedelt sind. Sie konstituieren in meiner Analyse die sog. Regionalnormen.

3. Normen der biographischen Eingebundenheit der Sprecher, die den Grad der persönlichen Betroffenheit (bzw. die 'Normalität' des existentiellen Bezugs) bestimmen und auf die ich als biographische Normen verweise.

4. Normen sprachlichen Verhaltens, die bekanntermaßen sehr komplex sind und die ich im Hinblick auf meinen Untersuchungsgegenstand als nicht einzelsprachlich determinierte Normen betrachte. Diese Sprach- und Diskursnormen differenzieren sich nach ihrem Bezug auf die oben genannten Normenbereiche in a) Normen fachlichen Sprechens, b) Normen regionalen Sprechens und c) individuelle Normen des Sprechens. 
Die Umsetzung der Diskursnormen in der Kommunikation erfolgt in spontanen mündlichen Texten, die somit den hauptsächlichen Untersuchungsgegenstand konstituieren. Dabei muss darauf hingewiesen werden, dass die von mir hervorgehobenen Sprach- und Diskursnormen nicht mit den Sprachnormen im üblichen Begriffsverständnis zusammenfallen und sich auch nicht allein auf die Ebene des 'Diskurses' im Sinne Coserius beziehen. Im Hinblick auf Coserius Theorie fasse ich vor allem das sog. 'allgemeinsprachliche Wissen', in Abhängigkeit von ihm auch das 'einzelsprachliche Wissen' und das 'textuelle Wissen' ins Auge. Insgesamt ist das sprachliche Normverständnis in meiner Untersuchung nicht in gleicher Weise systematisiert wie bei Coseriu, d.h. zwar nicht grundsätzlich abweichend, aber doch anders ausgerichtet durch die vorrangige Betrachtung der faktischen Verbindung der einzelnen sprachlichen Normbereiche untereinander. Um diese Verbindung auf Diskursebene verdeutlichen zu können, fixiere ich die Untersuchung - und dies ist meiner Meinung nach ein Novum - auf Bereiche des allgemeinen Sprechens, insofern dieses die 'Übereinstimmung mit den Sachen' erfordert, wie es in Fachkontexten der Fall ist. Ausgehend von dieser Fixierung auf Fachkontexte untersuche ich das Sprechen unter seinen normalen Bedingungen als Diskurs des einzelnen Sprechers in einer bestimmten Region, durch deren erfahrbare Wirklichkeit sein Sprachverhalten geprägt wird.

Damit ergibt sich für die Untersuchung der enge Zusammenhang von Sachnormen, Regionalnormen, biographischen Normen und Diskursnormen, dessen Hervorhebung und Dokumentation das wesentliche Ziel dieses empirischen Teils ist. Ich hoffe, auf diese Weise unter konkretem Bezug auf spontan formulierte Texte Einblick in die Gestaltung und Dynamik mündlichen Diskursverhaltens nehmen zu können. Die differenzierte Beschreibung dieses Diskursverhaltens kann Aufschluss über die Bedingungen und die Relevanz eines regionalen Sprachgebrauchs geben. Unter dem konkreten Bezug auf diglossische Sprachsituationen, die durch die soziale Benachteiligung der Regionalsprache gekennzeichnet sind, ergibt sich dabei eine den traditionellen soziolinguistischen Ansatz ergänzende neue Sichtweise des Problems sprachlicher Konfliktlösungen. Vereinfacht gesagt versuche ich, die Bedeutung des regionalen Sprachgebrauchs am Beispiel fachkontextuellen Sprechens aufzuzeigen, um diese Erkenntnis für eine Bewertung der diglossischen Konfliktlösungsstrategien (Prädominanz, Koexistenz, Substitution) verwertbar zu machen. Ich möchte daher mit meiner Untersuchung nicht primär aufzeigen, wie und in welchen Situationen sich der Sprachgebrauch ändert, sondern warum, unter welchen Bedingungen und mit welcher notwendigen Konstanz kommunikatives Verhalten auch - und gerade - in diglossischen Situationen seinen typischen Modifikationen unterworfen ist. 


\subsection{Die Auswahl der geographischen Untersuchungsgebiete und regi- onaltypischen Sachbereiche}

Im konkreten Fall erfolgt die Untersuchung mit einer Beschränkung auf zweisprachige Gebiete der europäischen Romania, in denen die diglossischen Verhältnisse durch den Kontakt einer regressiv gebrauchten Minderheitensprache (bzw. eines regionalen Dialekts) zu einer dominanten Standardsprache charakterisiert sind. Dazu wurden die Regionen Béarn in Südwestfrankreich (Gaskogne, Aquitanien) und Horta de València (Comunitat Valenciana) in Ostspanien (SW der Katalanischen Länder) ausgewählt. Beide Gebiete sind dem Untersuchenden durch mehrere Aufenthalte seit Beginn der 80er Jahre und durch die Pflege persönlicher Kontakte gut bekannt. Zu dieser örtlichen und sozialen Vertrautheit kommt die aktive Sprachkenntnis der jeweiligen Regionalsprache - Gaskognisch und Katalanisch - hinzu.

Neben diesen günstigen persönlichen Voraussetzungen gibt es auch eine Anzahl sachlicher Vorzüge der Gebietsauswahl. Hervorzuheben ist insbesondere, dass es sich um zwei Regionen handelt, deren grundsätzliche Vergleichbarkeit in Bezug auf die Untersuchung gegeben ist, die aber dennoch signifikante Unterschiede aufweisen. Interessante Vergleichsmomente sind insbesondere durch folgende Gegenüberstellung gegeben:

\section{Béarn}

geographische Binnenlage, Gebirgslandschaft (Pyrenäen), schlechte infrastrukturelle Anbindung

gemäßigtes und relativ feuchtes Klima

marginale wirtschaftliche Bedeutung in Frankreich (agrar- und forstwirtschaftliche Orientierung)

wirtschaftlich bedeutende Zone in Spanien (monokulturelle Landwirtschaft, Seewirtschaft und Industrie) Teil der Région d'Aquitaine; zentralistisch organisierte Einbindung in den französischen Staat

\section{Horta de València}

maritime Lage (Mittelmeer) mit guter infrastruktureller Anbindung an das In- und Ausland sonnig-warmes und trockenes Klima

Wirtschaftlich bedeutende Zone in Spanien (monokulturelle Landwirtschaft, Seewirtschaft und Industrie)

Teil der Comunitat Autònoma de València; föderative Einbindung in den spanischen Staat 
noch teilweise recht vitaler Sprachverwendungsraum des Bearnesischen/Okzitanischen mit gefährdeter Diglossie (durch die monolingual ausgerichtete sprachpolitische Tradition Frankreichs) starke Verbreitung des Valenzianischen in nicht offiziellen Funktionen, durch einen gewissen institutionellen Schutz stabilisiert; von der Normalisierung des Katalanischen profitierendes Sprachbewusstsein

Die Fachgebiete, auf die sich meine Untersuchung bezieht, sind für die jeweilige Region charakteristische bzw. bestimmende Erwerbsbereiche des primären Wirtschaftssektors. Im Béarn handelt es sich um 'Waldbau und Forstwirtschaft' (sylviculture et foresterie), in der Horta de València um 'Zitrusfruchtanbau' (citricultura). In beiden Fällen geht es also im allgemeinsten Sinn um die wirtschaftliche Nutzung von Baumbeständen mit großer Bedeutung für die jeweilige Region. Die wesentlichen Unterschiede liegen jedoch auf der Hand und machen einen Vergleich wiederum interessant.

Im Béarn, also dem historischen Gebiet um die Stadt Pau, ist die Waldwirtschaft nur im Süden, der eigentlichen Gebirgsregion, ein bestimmender Wirtschaftsfaktor. An den Hängen und Ausläufern des Vorgebirges ist die Landschaft zu einem Viertel bis Fünftel bewaldet. Es handelt sich hier um ein sehr fruchtbares Gebiet, das von einer vielfältigen landwirtschaftlichen Nutzung geprägt ist. Dies gilt insbesondere für den Nordosten des Béarn, meinem Untersuchungsgebiet im engeren Sinne, wo der Wald immer wieder von landwirtschaftlichen Nutzflächen unterbrochen wird, zu mehr als zwei Dritteln in Privatbesitz ist und überwiegend den einzelnen Landwirten in einer Art Streubesitz gehört. Diese privaten Waldeigentümer stehen häufig vor dem Problem, die Pflege und wirtschaftliche Nutzung ihres Waldes ausschließlich mit der eigenen Arbeitskraft bewerkstelligen zu müssen. Der z.T. erhebliche Waldbesitz konfrontiert sie und ihre Familien dabei mit einer Lebensrealität, deren Bewältigung ganz offensichtlich zwischen Tradition und technischer Innovation angesiedelt ist. Das Spannungsfeld von Experten- und Laientum zum Sachbereich 'Waldbau' und seine sprachliche Umsetzung im Bearnesischen wie im Französischen ist daher für dieses Gebiet unter der Themenstellung des Projekts ein ganz besonders signifikanter Untersuchungsbereich.

In der Küstenregion des País Valencià bilden die sog. horticultura und die citricultura, also der Plantagenanbau von Obst und Gemüse - insbesondere Zitrusfrüchten - sowie gebietsweise auch Reis den landschaftlich und ökonomisch bestimmenden Erwerbsbereich des Agrarsektors. Die Horta de València 
mit ihren ausgedehnten Orangenbaumkulturen ist zu einem wichtigen Symbol der Region geworden. Gleichwohl ist die Prädestination der Landschaft für den Zitrusfruchtanbau nicht ohne weiteres gegeben. $\mathrm{Zu}$ einem sonnigen Klima und einem fruchtbaren Boden fehlt es nämlich an natürlicher Bodenfeuchte, um den Erfolg der citricultura zu garantieren. Das Gebiet ist daher landwirtschaftlich von einer ausgefeilten Bewässerungstechnik abhängig, deren Tradition bis auf die Maurenzeit zurückgeht, deren Umsetzung zu einer modernen wirtschaftlichen Intensivnutzung (Monokultur) jedoch erst in diesem Jahrhundert vollzogen wurde. Aufgrund der künstlichen Bewässerung expandierte der Orangenanbau im Küstenbereich in den vergangenen Jahrzehnten explosionsartig und zog eine potente valenzianische Exportwirtschaft sowie die Ansiedlung weiterverarbeitender Industrie nach sich. Die landwirtschaftliche Intensivnutzung hat jedoch auch zur Folge, dass nur noch ein Zehntel der erwerbstätigen Bevölkerung des Valenzianischen Landes im Agrarsektor tätig ist. Diese wirtschaftlichen Spezifika der Region machen es interessant, der Frage nach Wissen und Sprachgebrauch der valenzianischen Küstenbewohner im Fachkontext der citricultura nachzugehen. Immerhin trifft man hier auf einen jungen, d.h. nicht traditionsreichen Wirtschaftssektor des regionalen Agrarbereichs, dessen kommunikative Bewältigung mittels Valenzianisch und/oder Kastilisch besonderen Bedingungen, Gewohnheiten und Problemen unterworfen ist. 


\subsection{Hinweise zu Gestaltung, Durchführung und Auswertung der Un- tersuchung}

Die Anlage der empirischen Untersuchung erfolgte unter der Zielsetzung, Aufschluss über mehrere Fragestellungen, die den Untersuchungsgegenstand bestimmen, geben zu können. Sie lassen sich grob wie folgt differenzieren:

1. das Vorhandensein und der Zusammenhang von Sach- und Sprachwissen zu bestimmten fachlichen Kontexten mit regionaler Relevanz, insbesondere im Hinblick auf lexikalische Kenntnisse

2. die inhaltliche Gestaltung von spontanen mündlichen Texten mit regionalem fachlichen Bezug, wobei zwischen verschiedenen Texttypen (explikativ, narrativ, situativ-pragmatisch, etc.) zu unterscheiden ist

3. die sprachliche Gestaltung mündlicher Diskurse, deren Realisierung sich spontan in einem fachkontextuellen Rahmen des regionalen Lebens (als fachliche Alltagskommunikation) vollzieht

4. die Differenzierung des regionalen Sprachgebrauchs in Fachkontexten in einer diglossischen Situation je nach der verwendeten Sprache, wobei nicht nur die Sprachenwahl an sich, sondern insbesondere der Vergleich der Diskursgestaltung in beiden zur Verfügung stehenden Sprachen im Mittelpunkt des Interesses steht.

Um diese Zielsetzungen im Rahmen einer empirischen Untersuchung verfolgen zu können, waren einige Vorbedingungen notwendig. Zu ihnen gehörten:

- Die Auswahl der Regionen als Untersuchungsgebiet (in unserem Fall unter der Prämisse der Zweisprachigkeit) und die Bestimmung eines Fachgebiets, dessen Relevanz für die jeweilige Region außer Zweifel steht.

Die konkrete Auswahl der Regionen und Fachgebiete für meine Untersuchung wurde bereits im vorangegangenen Kapitel begründet. Dabei ist zu beachten, dass ich bewusst Bereiche des primären Wirtschaftssektors der jeweiligen Region ausgewählt habe, um sowohl das Faktum der regionalen Gebundenheit der Produktionsverhältnisse als auch die persönliche Betroffenheit der Probanden eindeutig gewährleisten zu können. Insbesondere erweist sich die Abhängigkeit der land- und forstwirtschaftlichen Produktion von den geographischen Bedingungen der Region als eine sehr geeignete Voraussetzung für die Unter- 
suchung des regionalen Sprachgebrauchs. Außerdem boten sich durch den gemeinsamen Nenner der wirtschaftlichen Nutzung von Baumbeständen in beiden Fällen gewisse, für den Gesamtzusammenhang des Untersuchungsprojekts vorteilhafte Vergleichsmomente.

- Die aktive Verwendung aller in den jeweiligen Gebieten diglossisch vertretenen Sprachen im Rahmen von standardisierten Befragungen. Im konkreten Fall handelte es sich dabei um Französisch, Bearnesisch, Spanisch und Katalanisch (Valenzianisch).

Ich habe zu diesem Punkt ebenfalls bereits kurz im vorangegangenen Kapitel Stellung genommen. Idealerweise hätten die Befragungen durch Muttersprachler stattfinden sollen, da dies u.U. ein authentischeres Sprachverhalten der Probanden, insbesondere in den nicht konfliktfreien diglossischen Situationen, bewirkt hätte. Dies war im Rahmen der für mich maßgeblichen Untersuchungsbedingungen nicht möglich. Es stellte sich jedoch heraus, dass die Durchführung der Befragung durch einen nicht-muttersprachlichen enquêteur kein Hindernis für die Erreichung des Untersuchungsziels war. Ich werde noch darauf zurückkommen, warum gerade der Status des Befragers als Ausländer (also Nicht-Einheimischer) im Rahmen der Untersuchungen sogar von Vorteil war. Das Problem der Zweisprachigkeit wurde im Falle des Béarn durch die Auswahl unterschiedlicher Probanden für Französisch und Bearnesisch, im Falle der Horta de València durch die Wiederholung der Befragung im Abstand von ca. einem halben Jahr durch zwei verschiedene Personen (die eine als kastilischsprachig, der andere als katalanischsprachig auftretend) gelöst.

- Die intensive Einarbeitung in die jeweiligen Fachgebiete, einerseits durch Lektüre, andererseits durch persönliche Information vor Ort.

Der Untersuchungsgegenstand erfordert eine interdisziplinäre Arbeitsweise und damit die Bereitschaft des Linguisten, sich in fachfremde Bereiche technischen und teilweise auch wissenschaftlichen Charakters einzuarbeiten. In einem ersten Schritt gehörte dazu die Beschaffung und das Durcharbeiten von Fachliteratur, die in beiden Fällen, der sylviculture in Frankreich und der citricultura in Spanien, äußerst reichhaltig zur Verfügung steht. ${ }^{88}$ Die rein literaturbasierte Aufnahme von Fachwissen erwies sich aber im Hinblick auf die Zielvorstellung des Projekts schnell als problematisch, da auf diese Weise nur schwer zu entscheiden war, welche Relevanz die entsprechenden Fachinhalte für die zu untersuchende Region bzw. die alltägliche Beschäftigung mit den

${ }^{88}$ Vgl. hierzu die entsprechenden Teile des Literaturverzeichnisses am Ende der Arbeit 
fachlichen Inhalten in der Region genau haben. Um hierzu präzisere Informationen zu erlangen, nahm ich Kontakte zu mehreren fachspezifischen Institutionen in Aquitanien und im Valenzianischen Land auf. Meine Erfahrungen waren hier durchweg positiv und ermutigend, sowohl im Hinblick auf fachliche Hilfestellungen, als auch bezüglich der sehr hilfreichen Vermittlung von Probanden vor Ort. Ich werde hierauf bei der Beschreibung der Teilprojekte noch genauer eingehen. An dieser Stelle mag der Hinweis darauf genügen, dass im Béarn die hauptsächliche Kontaktnahme über den Centre Régional de la Propriété Forestière d'Aquitaine (CRPFA, Bordeaux, Orthez) und den Centre d'Études Techniques et d'Expérimentation Forestières (CETEF, Pau) erfolgte, in der Horta de València über den Instituto Valenciano de la Investigación Agraria (IVIA) mit Sitz in Moncada.

- Die Kontaktnahme zu und Auswahl von geeigneten Probanden

Das vorrangige Ziel der Befragungen war es, Kontakt zu Probanden aufzunehmen, die einerseits in einem gewissen Bezug zum Fach standen, andererseits in sprachlicher Hinsicht geeignete Voraussetzungen für die Befragung boten. Dank der Hilfestellungen durch die Institutionen vor Ort, aber auch durch persönliche Bekanntschaften und weitere Vermittlungen in den jeweiligen Gebieten war es möglich, an eine relativ große Zahl von bereitwilligen Probanden heranzutreten. Die Kriterien für die Auswahl der Personen variierten dabei je nach Art und Gebiet der Befragung.

Im Béarn wurden die Probandengruppen für das Bearnesische und das Französische personell getrennt zusammengestellt. Eine erste Feldforschung widmete sich dabei ausschließlich den im Bearnesischen noch vorhandenen einschlägigen lexikalischen Kenntnissen und ermittelte gleichzeitig beispielhaft eine Reihe spontaner Diskurse zum Thema. Die zweite enquête wurde in Form einer systematischen fachinhaltlichen Befragung gleichzeitig auf das Französische und Bearnesische ausgerichtet. Das Durchschnittsalter der Probanden fällt in beiden Fällen relativ hoch aus, und zwar vor allem wegen der mangelnden Betroffenheit der jüngeren Generation, die es in der Regel den Älteren, meist Rentnern überlässt, sich um den privaten Waldbesitz zu kümmern. Die Befragung von jüngeren, weniger oder gar nicht durch das Fachgebiet betroffenen Personen erwies sich im Béarn als ineffektiv und für den Untersuchungszweck wenig aufschlussreich. Zudem bestätigte sich das bekannte Phänomen einer abnehmenden Sprachkenntnis des Bearnesischen im unteren Teil der Alterspyramide.

Anders gestaltete sich die sprachliche Materialsammlung in der Comunitat Valenciana. Sie wurde in zwei Serien systematischer fachinhaltlicher Befragung mit zeitlichem Abstand voneinander realisiert, wobei die Interviews von 
verschiedenen Personen jeweils in einer Sprache durchgeführt wurden. Die Kriterien für die Auswahl der Probanden waren dabei eine gewisse Varianz hinsichtlich der Altersstruktur und der Einbindung in das Fach. Zudem wurden mehrere Probanden zu Vergleichszwecken in der zweiten Interviewserie erneut befragt. Das hauptsächliche Ziel der Materialbeschaffung war hier die Verfügbarkeit von vergleichbaren Diskursen als Antwortverhalten auf bestimmte Fragen. Durch den besonderen Status der citricultura als dominantem Wirtschaftssektor in der Comunitat Valenciana war es dabei möglich, den Aspekt der Unterscheidung von Experten- und Laientum konsequent in die Auswahl der Probanden einzubringen. Grund hierfür ist die Tatsache, dass es im Raum Valencia auch vielen durch die citricultura weniger betroffenen Personen nicht befremdlich vorkommt, sich einer Befragung $\mathrm{zu}$ diesem Themengebiet $\mathrm{zu}$ stellen, da sie oft zumindest in einer mittelbaren Verbindung zu diesem Berufsfeld stehen.

Abschließend bleibt darauf hinzuweisen, dass es im Hinblick auf die Anlage und Dimensionierung der gesamten Untersuchung nicht angeraten schien, eine statistische Verteilung der Probanden nach Experten- oder Laienstatus, Alter, sozialer Stellung usw. anzustreben, und auch nicht möglich war, eine statistische Repräsentativität der Probandengruppen zu erreichen. Die Gründe hierfür sind vielfältig und werden bei den einzelnen Teilprojektbeschreibungen noch genauer erläutert. Insgesamt aber kann schon hier festgehalten werden, dass die Auswahl der Probanden im Prinzip vorrangig den Kriterien einer exemplarischen, gleichwohl aber empirisch fundierten Dokumentation der grundlegenden Thesen zu entsprechen versucht.

- Die Wahl einer geeigneten Befragungsform

Im gesamten Untersuchungsprojekt wurden zwei unterschiedliche Formen der Befragung realisiert, von denen die eine nur zur Ermittlung des im Bearnesischen noch verfügbaren Sprachwissens diente, die andere in insgesamt vier verschiedenen Befragungsserien in jeweils ähnlicher Form für das Französische, Bearnesische, Kastilische und Valenzianische Anwendung fand.

Die enquête zum bearnesischen Sprachwissen im Bereich von Wald und Waldbau wurde als offene mündliche Befragung auf der Grundlage einer ausführlichen Vokabelliste auf Bearnesisch durchgeführt. In den Aufzeichnungen der Antworten manifestierten sich dabei sowohl spezifische lexikalische Kenntnisse der Probanden, als auch Spontandefinitionen zu Begriffen und eine Reihe ebenfalls spontaner Diskurse und Konversationen $\mathrm{zu}$ den entsprechenden Themen.

Die vier übrigen Befragungen wurden auf der Basis eines jeweils vorbereiteten Fragebogens zum Fachgebiet durchgeführt, wobei die Befragung selbst 
darauf abzielte, einen eher informellen Charakter und die Bereitschaft zu einer offenen, häufig auch abschweifenden Beantwortung der Fragen durch die Probanden $\mathrm{zu}$ erhalten. Es handelte sich daher im Prinzip um strukturierte Gespräche bzw. 'standardisierte Interviews' zu verschiedenen Themen des Fachs mit dem Ziel, durch die konstante Wiederholung derselben Fragen bei den einzelnen Probanden eine gewisse Vergleichbarkeit der Antworten zu erhalten.

Die Vorbereitung der Fragebögen war vor allem ein fachliches Problem. In diesem Sinne stellen sie das Resultat einer intensiven inhaltlichen Durchdringung und Strukturierung des Fachs für den Untersuchungszweck dar. Der genauere Aufbau der Fragebögen wird an den entsprechenden Stellen dieser Arbeit erläutert. Dabei werde ich auch noch auf die verschiedenen Fragetypen Bezug nehmen. Insgesamt handelt es sich in allen Fällen um eine thematische, teilweise begrifflich strukturierte Form der Befragung, deren fachlicher Maßstab, soweit dies möglich war, die Relevanz der erfragten Inhalte in der fachlichen Domäne des beruflichen bzw. alltäglichen Lebens der Region war. Anders ausgedrückt wurden nur Fragen verwendet, von denen auch angenommen werden konnte, dass ihre Beantwortung durch die Probanden aus deren praktischer Berufs- oder Alltagserfahrung heraus erfolgen würde. Der Bereich einer wissenschaftlichen Durchdringung des Fachs, der so häufig typisch für fachsprachenorientierte Befragungen ist, wurde daher bewusst weitgehend ausgeklammert.

Insgesamt sind die Ergebnisse der Befragung sehr reichhaltig und zufriedenstellend. Es zeigte sich, dass die Probanden gern und ausführlich über ihr Wissen und ihren Bezug zum Fach Auskunft gaben. Es konnten dabei in der Regel sehr frei und natürlich formulierte Diskurse aufgezeichnet werden, die selbstverständlich im Rahmen des Gesamtspektrums fachbezogener Kommunikation einen besonderen Charakter als explikativer Texttyp einnahmen. Die Ermittlung genau dieses Texttyps durch die strukturierte Befragung erfolgte zielgerichtet, da hier mit großer Sicherheit möglichst authentische Texte erlangt werden konnten. Zudem gilt, dass der Texttyp 'Erklärung' gerade auf fachlichem Gebiet ein besonderes Gewicht einnimmt und im Zusammenspiel mit der persönlichen Betroffenheit der Probanden eine interessante Verbindung von 'das Fach erklären' und 'sich erklären' eingeht. Diese Verbindung aber entspricht dem generellen Untersuchungsziel in idealer Weise.

- Die Bearbeitung, Strukturierung und Auswertung des Datenmaterials

Das gewonnene Datenmaterial von insgesamt vier Feldforschungsreisen (zwei nach Frankreich und zwei nach Spanien) umfasst viele Stunden Tonbandaufzeichnungen der oben genannten Befragungen. Aufgrund der Fülle des 
Materials wurde zunächst eine erste Vorauswahl der am besten verwertbaren Aufnahmen vorgenommen.

Die der Untersuchung zugrunde gelegten analogen Tonbandaufnahmen wurden dann in einem weiteren Schritt mit den Methoden der heutigen Computertechnologie digitalisiert und auf Compact-Disc-Tonträger (CD-ROM) gebrannt. Dabei entschied ich mich für eine Komprimierung der Dateien nach dem zurzeit fortschrittlichsten Verfahren namens MPEG Layer-3 (MP3), das vom Institut für Integrierte Schaltungen (IIS) in Fraunhof entwickelt wurde. Dieses Verfahren erlaubt bei der von mir gewählten Komprimierungsstufe von $128 \mathrm{kBit} / \mathrm{sec}$. annähernd die Beibehaltung normaler CD-Qualität $(44.100 \mathrm{~Hz}$, Stereo) bei einem Komprimierungsverhältnis von ca. 1:12 und damit schließlich die Aufzeichnung von mehr als 12 Stunden Audiodateien auf einer einzigen $\mathrm{CD} .{ }^{89}$ Bei der Nutzungsmöglichkeit komfortabler MP3-Player per PCSoftware bot dies eine hervorragende Möglichkeit für die vergleichende Auswertung des bearbeiteten Audio-Materials. Die Möglichkeiten der neuen Technologie konnten insbesondere auch für die sehr exakten Verweise auf aufgezeichnete Textstellen verwendet werden. Mit diesem eindeutigen Verweisverfahren, das zugleich eine exakte Strukturierung des Datenmaterials impliziert, ist die Überprüfbarkeit der Textbelege in direkter Weise gegeben. Für die Darstellung der Auswertungsergebnisse in der vorliegenden Untersuchung ergeben sich hieraus folgende Konsequenzen:

a) Die Angabe von Zitaten aus den ausgewerteten Interviews wird von dem dargestellten Verweissystem begleitet. Die Zitate sind dadurch leicht überprüfbar und ihre Position im zeitlichen Gesamtzusammenhang des Interviews wird nachvollziehbar.

b)Verweise auf Textstellen können z.T. auch ohne explizite Zitierung vorgenommen werden, bleiben aber ebenfalls schnell überprüfbar. Hierdurch wird der Gesamtzusammenhang der komplett ausgewerteten Interviews transparent und der Vergleich von Antworten zu denselben Fragen übersichtlich strukturiert.

c)Die Transkription gesprochener Diskurse wird aufgrund des Untersuchungszwecks vereinfacht. Die üblicherweise komplizierten Transkriptionsverfahren spontaner mündlicher Texte wurden bei der Auswertung des Datenmaterials nicht angewendet. Dies rechtfertigt sich zum einen durch die wesentlich bessere Lesbarkeit des Diskurses als Text (d.h. seine Erfas-

${ }^{89}$ Genauere Informationen zu diesem Komprimierungsverfahren sind z.B. zu finden in der Fachzeitschrit c't. magazin für computer technik 21, 1998, 242ff. Bei der Leistungsstärke des Computers, der mir für die Konvertierungen zur Verfügung stand (Pentium 100) musste ich allerdings - neben der in Echtzeit vorzunehmenden Digitalisierung - noch eine Komprimierungsdauer von durchschnittlich dem 6-fachen der jeweils digitalisierten Audio-Länge in Kauf nehmen. Die großen Vorteile der Handhabung komprimierter MP3-Dateien bei der Auswertung des Datenmaterials haben diesen enormen Aufwand jedoch gerechtfertigt. 
sung als Sinneinheit) und dadurch, dass in der vorliegenden Untersuchung keine phonetischen, grammatischen oder syntaktischen Analysen im Vordergrund stehen. Der z.T. durch das vereinfachte Transkriptionsverfahren dennoch unvermeidbare Verlust an Information-insbesondere im phonetischen und phonotaktischen Bereich-kann leicht durch die Anhörung der entsprechenden Textstellen in den Audio-Dateien kompensiert werden. ${ }^{90}$ Zudem habe ich mich teilweise zu einer leichten Adaptation der Verschriftung (Abweichung von der orthographischen Norm) entschlossen.

Aus linguistischer Sicht sind die im Rahmen der Untersuchung aufgenommenen Diskurse im Bearnesischen aufgrund der akuten Regression dieser Sprache von besonderem Dokumentationswert. Zugleich stellen sie in einer sehr aufschlussreichen Weise die Charakteristika des regionalen Sprachgebrauchs in für die Region typischen Fachkontexten dar, wobei es mir gelungen ist, mehrere Arten von Diskursen in offenen Gesprächen zum Thema Wald und Waldbau einzufangen. Ich lege daher bei der Auswertung der Ergebnisse ein sehr starkes Gewicht auf die Dokumentation dieser bearnesischen Diskurse in Form von Transkriptionen, aber auch in Form einer repräsentativen Auswahl dieser Texte auf einer Audio-CD, die mit jedem normalen CD-Spieler abgehört werden kann und allen Exemplaren dieser Arbeit beigelegt wird. Die hierdurch zu erlangende Nähe zu den spontanen mündlichen Diskursen ist aus meiner Sicht ein wichtiger Beitrag zu dem angemessenen Verständnis des grundlegenden Anliegens dieser Arbeit.

Neben der skripturalen und auditiven Dokumentation exemplarischer Diskurse gehört auch eine systematische Auswertung des Datenmaterials zu den analytischen Zielsetzungen dieser Untersuchung. Hierbei unterscheide ich zwischen drei Untersuchungsbereichen: der Ermittlung domänenspezifischen lexikalischen Wissens bei den Sprechern des regressiven bearnesischen Dialekts, der Repräsentation von Sach- und Sprachwissen in den auf Französisch geführten Interviews und dem Vergleich der inhaltlichen und formalen Diskursgestaltung an Beispielen aus den auf Kastilisch und Valenzianisch geführten Interviews. Die für den jeweiligen Zweck gewählte Form der Systematik wird zu Beginn einer jeden Auswertung begründet. In allen Fällen musste ich mich jedoch aus quantitativen Gründen auf eine Auswahl von Probanden bzw. auf eine Auswahl bestimmter Befragungsteile beschränken. Dennoch wurde

${ }^{90}$ Sollte in besonderen Fällen Interesse an der Verfügbarmachung der Audiodateien, die den Interview-Auswertungen zugrunde liegen, bestehen, so können diese auf Nachfrage zur Verfügung gestellt werden. Dabei bitte ich jedoch um Verständnis dafür, dass ich mir vorbehalte, nicht alles zur Verfügung stehende Material öffentlich freizugeben. Die Auswertungen im Rahmen der vorliegenden Arbeit können die mit dem gesamten von mir ermittelten Datenmaterial zur Verfügung stehenden Ressourcen nur zu einem Teil nutzen. Es besteht daher die Absicht, auf der Grundlage des vorhandenen Materials noch weitere Forschungen zu betreiben. 
versucht, die jeweilige Materialgrundlage nur soweit zu beschränken, dass das evaluierende Verfahren des systematischen Vergleichs noch sinnvoll erscheint und $\mathrm{zu}$ aufschlussreichen Erkenntnissen führt. Dass dieses Vorgehen immer auch eine Kompromisslösung beinhaltet, steht selbstverständlich außer Frage.

Wenden wir uns zum Abschluss der Erläuterungen zu Gestaltung, Durchführung und Auswertung der Untersuchung noch der Frage der Interpretation des Datenmaterials zu. Ich halte es für angebracht, den Großteil dieser Interpretation an die Darstellung und Auswertung der Untersuchungsergebnisse direkt anzuschließen, da es gilt, vielfältige Aspekte des Untersuchungsgegenstands in unmittelbarer Verbindung mit dem exemplarischen Datenmaterial hervorzuheben und $\mathrm{zu}$ beschreiben. Dabei bleibt die Kontinuität des Interpretationsansatzes im Sinne der Darlegungen des theoretischen Teils der Arbeit selbstverständlich gewahrt. Insbesondere spielt der kontinuierliche Bezug auf das Ineinandergreifen von fachsprachlichen und regionalsprachlichen Wissensdimensionen eine wesentliche Rolle. Es wird - sozusagen als analytische Substruktur - immer wieder auf die verschiedenen Aspekte des allgemeinsprachlichen, einzelsprachlichen und textuellen Wissens (im Sinne Coserius) eingegangen. Entscheidend ist auch - in Konformität mit dem theoretischen Ansatz - die beständige interpretative Einbeziehung der normativen Gegebenheiten in die Analyse der sprachlichen Darstellung der Probanden. Im Sinne der Darlegungen des Kapitels 1.1 hebe ich dabei vor allem 'Sachnormen', 'Regionalnormen' und 'Diskursnormen', in geringerem Maße auch 'biographische Normen' hervor. Eine zusammenfassende Bewertung der Untersuchungsergebnisse erfolgt schließlich sowohl am Ende der Beschreibung der einzelnen Teilprojekte als auch als resümierendes Fazit aus der gesamten empirischen Untersuchung am Ende der Arbeit. 


\section{Die sprachlichen Untersuchungen zum Sachbereich 'Wald und Waldbau' im Béarn (Gaskogne, Frank- reich)}

\subsection{Das Untersuchungsgebiet}

\subsubsection{Die Region Aquitanien}

Die historischen Bedingungen für den Aufbau eines regionalen Bewusstseins in Frankreich und die dezentralen politisch-administrativen Strukturen des französischen Staates greifen in einer sehr komplexen Weise ineinander. Im Südwesten Frankreichs wird dabei die Kontinuität eines 'aquitanischen' Regionalbewusstseins postuliert, dessen Anfänge bis in die Antike zurückreichen (Cäsar, Strabon). Als Kriterium der regionalen Eigenständigkeit Aquitaniens spielt bis heute vor allem die natürliche Grenzziehung durch die Pyrenäen, den Atlantik und die Garonne eine wesentliche Rolle. Unberücksichtigt bleiben hingegen die problematischen Faktoren der ethnischen Heterogenität und die mangelnde Orientierung an einer Hauptstadt. In Aquitanien gibt es bis heute profunde kulturelle Unterschiede zwischen den Gaskognern und den Basken. Darüber hinaus ist Bordeaux als Hauptstadt ganz Aquitaniens im Laufe der Geschichte ebenso wenig akzeptiert worden wie Bayonne, Orthez oder Pau.

Es mag hingegen mit der französischen Geschichte zu tun haben, dass die Anerkennung einer regionalen Eigenständigkeit Aquitaniens in Frankreich bis heute erhalten geblieben ist. Schon im 12. Jahrhundert gelangte das Herzogtum Aquitanien durch die Heirat Eleonores von Aquitanien mit Heinrich II. von Anjou-Plantagenêt zum Angevinischen Reich, wo es zusammen mit der Gaskogne zwei Jahrhunderte länger verblieb als die übrigen Gebiete Süd- und Westfrankreichs: erst 1453 wird Aquitanien - bis auf das seinerzeit selbständige Béarn - aus dem Besitz der englischen Krone dem französischen Reich einverleibt. In der Gaskogne und ganz besonders im Béarn erinnert man noch immer gern an den ersten und letzten französischen König bearnesischer Provenienz, Heinrich IV., der als le bon roi Henri einen legendären Platz in der Geschichte Frankreichs einnimmt und dessen positives Image vor allem auf eine liberale Politik der Religionsfreiheit zurückgeht.

In der Neuzeit ist Aquitanien-und ganz besonders die Gaskogne-aus dem Blickwinkel des französischen Zentralstaates immer 'das etwas andere Frankreich' gewesen. Seine geographische Rand- oder besser: Ecklage, sein rurales, oft als 'hinterwäldlerisch' betrachtetes Ambiente und seine als korrumpiertes Französisch (patois) interpretierte Landessprache haben zu einem Bild dieser 
Region beigetragen, das - so ungerecht es sein mag - auch heute noch nicht ganz aus den Köpfen der Franzosen verschwunden ist. Demgegenüber steht ein vor allem in der Nachkriegszeit gefestigtes Wissen um die ökonomische Bedeutung Aquitaniens für Frankreich, das auf verschiedene, teilweise sehr potente Wirtschaftssektoren der Region zurückzuführen ist. Die meisten dieser Wirtschaftsbereiche - es mögen stellvertretend der Weinbau in der Gegend um Bordeaux, der Waldbau in den Landes oder die Erdgasgewinnung im Béarn genannt sein - erfahren in jüngerer Zeit einen Strukturwandel, der zusammen mit der typischen Landflucht, der Stilllegung agrarwirtschaftlicher Produktionsflächen und dem Aufblühen des tertiären Wirtschaftssektors zu erheblichen sozio-ökonomischen Veränderungen in der Region führt.

Seit den 50er Jahren ist sich Frankreich der Tatsache bewusst, dass die politisch-administrative Dezentralisierung von Kompetenzen insbesondere im Bereich infrastruktureller Entwicklungsplanung von erheblichem Vorteil für die gesamtstaatliche Organisation ist. Aus den anfänglichen Programmes d'Action Régionale wurden schließlich 1960 mehrere circonscriptions d'action régionale im europäischen Frankreich bestimmt, denen vier Jahre später eine erste politisch-administrative Struktur zugewiesen wurde. Im Jahre 1972 erhält diese politisch-administrative Struktur der Regionen Frankreichs ihre heutige Form mit der Einsetzung der Conseils Régionaux als parlamentarische Institutionen und den Comités Économiques et Sociales als beratende Instanzen. Zehn Jahre später greift die loi de décentralisation der sozialistischen Regierung unter Staatspräsident Mitterrand, durch die den Regionen der Status von 'collectivités territoriales à part entière' mit einer geringfügig erweiterten Autonomie zugewiesen wird. Nach dem Wortlaut des Gesetzes von 1982 fällt dem Regionalrat folgende grundsätzliche Aufgabe zu: $:^{91}$

Le Conseil Régional a compétence pour promouvoir le développement économique, social, sanitaire, culturel et scientifique de la région et l'aménagement de son territoire et pour assurer la préservation de son identité, dans le respect de l'intégrité, de l'autonomie et des attributions des départements et des communes.

Aquitanien ist die drittgrößte der 22 offiziellen Regionen Frankreichs. Es umfasst 5 Départements (Gironde, Dordogne, Lot-et-Garonne, Landes und Pyrénées-Atlantiques), 235 Kantone und 2290 Kommunen mit einer Gesamtzahl von 2.795.830 Einwohnern und einer Oberfläche von $41.323 \mathrm{~km}^{2} .^{92}$ Die 1995 in Bordeaux (bei L'Horizon chimérique) erschienene Publikation 50 ans en Aquitaine. Bilans et prospective. 1945-1995 vermittelt ein gutes Porträt der

\footnotetext{
${ }^{91}$ Zitiert aus dem Internet unter: http://web.cr-aquitaine.fr/Web/Institutions/Competences/ cra_comp.html (1998)

92 Zahlen nach Angaben im Internet unter: http://web.cr-aquitaine.fr/Web/Institutions/Chiffres/ cra_chiffres.html (1998)
} 
Region, ihrer Probleme und ihrer sozio-ökonomischen Aufgaben für die Zukunft. Die aufmerksame Lektüre dieser detaillierten Darstellung lässt jedoch Zweifel an der Homogenität der Région d'Aquitaine als Region aufkommen. Die unterschiedlichen geographischen und demographischen Gegebenheiten der fünf zusammengefassten Departements, die Diversität ihrer wirtschaftlichen Binnenstrukturen und die verteilte Urbanisierung der Region mit den vier Zentren Bordeaux, Bayonne/Anglet/Biarritz, Pau und Périgueux vermitteln ein recht uneinheitliches und variantenreiches Bild. Der politisch-administrative englobement dieses Gebiets durch den Conseil Régional ist dabei kaum in der Lage, effektiv zu wirken, da die autonomen Befugnisse der Exekutive in politischer Hinsicht nicht weit genug reichen. ${ }^{93}$ Rat und Präsident der Region Aquitanien sind nicht dazu in der Lage, handlungspolitische Entscheidungen zu treffen und ihr Einfluss reicht auch nicht aus, um ein allgemeines Bewusstsein regionaler Zusammengehörigkeit über ihren institutionell begrenzten Wirkungsgrad hinaus zu fördern. Stattdessen beteiligen sie sich in einem subtilen dezentralisierten Handlungsspielraum an der zentralistischen Entwicklungsplanung. ${ }^{94}$

Die offizielle Regionalstruktur Frankreichs ist für die hier vorliegende Untersuchung von Interesse, da der regionale Charakter des Sprachgebrauchs in einer für die analytische Zielvorstellung geeigneten Weise normativ bestimmt und abgegrenzt werden muss. Aquitanien als politisch eher schwach institutionalisierte Region ist aufgrund ihrer Heterogenität keine geeignete Bezugsgröße für diesen Untersuchungszweck. Selbst wenn der Begriff der Région d'Aquitaine aus einer gewissen historischen Kontinuität abgeleitet werden kann, so korrespondiert dieses Faktum zumindest heute nicht mehr mit einer Einheit ihrer sozialen und/oder ökonomischen Bedingungen. Darüber hinaus ist auch das Regionalbewusstsein der Bewohner des Südwestens Frankreichs im Sinne ihrer Identitätsfindung nicht auf die Région d'Aquitaine konzentriert. Die Bewohner Aquitaniens stehen, je nach lokaler Herkunft, in z.T. recht un-

${ }^{93}$ In der der französischen Sprache eigenen gefälligen Diktion drückt sich die politische Ohnmacht der Region auch in dem Beitrag 'L'Aquitaine instituée' aus, den Pierre Sadran für 50 ans en Aquitaine verfasst hat: „Si l'institutionnalisation régionale n'a donc pas accouché d'un système politique autonome, la Région n'en joue pas moins un rôle, celui de joker du jeu politique en Aquitaine. Ce qui n'est pas une carte maîtresse peut, selon la configuration du moment, devenir un atout dont il faut savoir - et l'exercice est subtil B tirer le meilleur profit. La Région peut, selon les cas, être un incubateur, une compensation ou une position de repli. “ (p. 53) - Die mots-clé dieses Zitats zeigen in ihrer Vagheit deutlich an, welch letztlich undankbare Rolle die Regionalpolitik in Frankreich immer noch spielt.

${ }^{94}$ Dieses Faktum hat auch Auswirkungen auf europäischer Ebene, da Frankreich seine 22 Regionen in ein Geflecht regionaler Strukturen der Europäischen Union eingebettet sehen möchte (vgl. 50 ans en Aquitaine, p. 30). Es stellt sich unter diesem Gesichtspunkt die Frage nach der politischen Realität und Sinngebung eines 'Europas der Regionen', das seine Entitäten per definitionem frei von nationalstaatlichen Interessen zu bestimmen hat. 
terschiedlichen Traditionen und Lebensrealitäten. Ein linguistisches Anzeichen dafür ist die Tatsache, dass das Adjektiv aquitanien bis heute nur in einem geologischen und nicht in einem ethnischen Sinne Verwendung findet.

\subsubsection{Das Land Béarn}

Im Vergleich zu der politisch-administrativen Einheit Aquitanien ist der Béarn mit Pau als zentral gelegener Hauptstadt eine echte, historisch gewachsene Region, dessen bodenständige Einwohner sich spontan und meist mit Stolz als 'Bearnesen' bezeichnen. Darüber hinaus verwenden sie diesen Begriff-ganz im Gegensatz zu Gaskognisch oder Okzitanisch-selbstverständlich auch zur Bezeichnung der in ihrem Gebiet gesprochenen Regionalsprache, einem südokzitanischen Dialekt. Dies gilt unbeschadet der Tatsache, dass viele ältere Bearnesisch-Sprecher ihre Sprache als patois bezeichnen. Eine besondere negative Konnotation ist m.E. heute mit der Verwendung dieses Begriffs im Allgemeinen nicht mehr verbunden. Viele Bearnesen haben Kenntnisse von der Geschichte ihrer Region. Sie kennen bearnesisches Brauchtum ebenso wie die bearnesische Küche und haben in der Regel auch eine klare Vorstellung von der sozio-ökonomischen Prägung des Gebietes, in dem sie leben. Als Heimat wird der Béarn von den angrenzenden Regionen der Bigorre (im Département Hautes-Pyrénées), des Gers (gleichnamiges Département), der Landes (gleichnamiges Département) und des Pays Basque (in demselben Département Pyrénées-Atlantiques) unterschieden. Im Süden grenzt der Haut Béarn mit seinen drei Pyrenäentälern, der Vallée d'Aspe, der Vallée d'Ossau und der Vallée de Baretous, an die Region Aragón in Spanien. In einer groben landschaftlichen Binnendifferenzierung des Béarn ist die Hochgebirgsregion der Pyrenäen von der hügeligen Landschaft der Ausläufer des Gebirges, dem sog. piémont zu unterscheiden. Die Landschaftsform der landes hingegen, die dem westlichen Küstenbereich zugeordnet ist, gehört bereits zum Baskenland.

Die regionale Identität des Béarn wird durch seine besondere Geschichte fundiert. Der Béarn beginnt sich schon im 11. Jahrhundert als Fürstentum in seiner vollständigen Größe auszubilden. Er wird über Jahrhunderte von sog. vicomtes regiert. Von 1154 bis 1242 unterstehen die vicomtes du Béarn als Vasallen freiwillig dem König von Aragón. Damit distanziert sich der Béarn schon früh von der Gaskogne, die seinerzeit dem Angevinischen Reich einverleibt wird. Allerdings gelangt der Béarn unter Gaston VII Moncade im 13. Jahrhundert schließlich doch unter die englische Herrschaft. Eine wichtige Epoche der Unabhängigkeit und vorübergehenden Gebietserweiterung erlebte er schließlich im 14. Jahrhundert unter der Regierung des mächtigen Gaston X Febus (1343-1391), der für die Bearnesen zu einer identitätsstiftenden Legende geworden ist. 


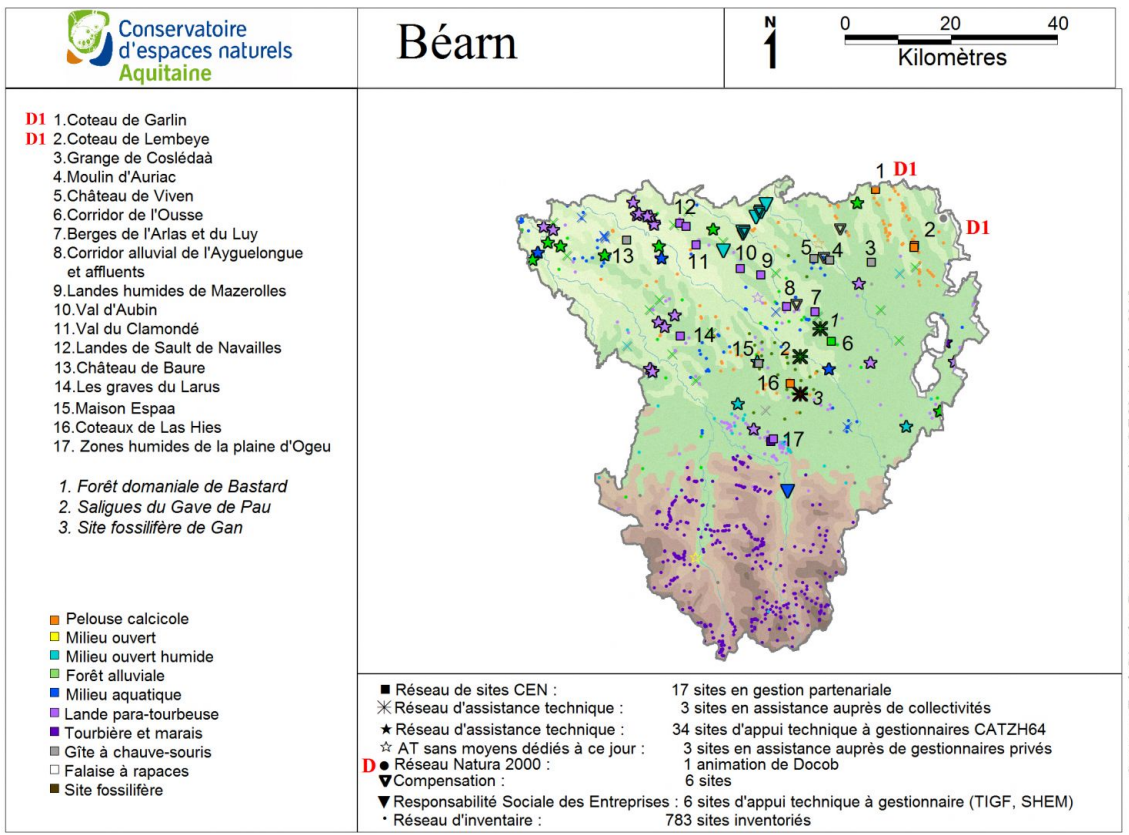

Abbildung nachträglich (2018) hinzugefügt (Zugriff über http://www.cenaquitaine.org/pyr\%C3\%A9n\%C3\%A9es-atlantiques am 13.09.2018)

Nach dem Hundertjährigen Krieg, in dem der Béarn eine neutrale Haltung eingenommen hatte, konnten die vicomtes ihre Unabhängigkeit weiterhin behaupten, gerieten aber in das Spannungsfeld der starken Königreiche Frankreich und Spanien. Das durch Heiratspolitik Ende des 15. Jahrhunderts annektierte Königreich Navarra holte sich die spanische Krone in den folgenden Jahrzehnten weitgehend zurück (bis auf die heute im Baskenland liegende Region Basse Navarre). Heinrich III. von Béarn-Navarre (seit 1572) wird schließlich als Thronerbe König Heinrich IV. von Frankreich (s.o.) und überlässt die Regierung des Béarn-Navarre weitgehend seiner Schwester Katharina. Nach der Ermordung des beliebten Königs, den die Bearnesen liebevoll lo noste Enric nannten, vollzog Ludwig XIII. im Jahre 1620 mit Gewalt die endgültige Annektierung des Béarn an Frankreich. Erst zu diesem Zeitpunkt wurde das Französische auch im Béarn zur Amtssprache.

Heute ist der pays de Béarn zwar nicht in politisch-administrativer Hinsicht, wohl aber im historisch verankerten Bewusstsein seiner Bewohner eine regionale Einheit. Er bildet den östlichen Teil des Département Pyrénées-Atlantiques und gliedert sich, flächenmäßig ungefähr jeweils zur Hälfte, in die Arrondissements Pau (im NO mit 22 Kantonen und 266 Kommunen) und Olo- 
ron-Ste-Marie (im SW mit 10 Kantonen und 120 Kommunen, die zum Béarn, und 2 Kantonen und 55 Kommunen, die zum Pays Basque gehören). Die Tatsache, dass der Béarn und das französische Baskenland mit ihren Territorien jeweils vollständig in das Département Pyrénées-Atlantiques integriert sind, bedingt z.T. eine gemeinsame Verwaltung und den regen wirtschaftlichen Austausch zwischen beiden Ländern. Davon unabhängig bleibt die feste kulturelle und sprachliche Abgrenzung der jeweiligen Ethnien.

In wirtschaftlicher Hinsicht zeigt der Béarn ein vielseitiges Profil. Dabei ist das Land traditionell agrarstrukturell geprägt und lebt auch heute noch zu einem großen Teil von der Viehhaltung (Rinder- und Schweinezucht, aber auch Milchwirtschaft) und vom Futtermaisanbau. Insbesondere die Vegetationsverhältnisse und die Bodenqualität haben die Prädominanz dieser Erwerbsbereiche im piémont hervorgerufen. Die Landschaft ist im Allgemeinen hügelig und stark bewaldet. Die landwirtschaftlichen Nutzflächen liegen verstreut zwischen kleineren Waldgebieten, denen sie häufig durch Rodungen in der Nachkriegszeit abgerungen wurden. Vielfach reicht die Qualität des Bodens nur für eine weidewirtschaftliche Nutzung, die zudem noch durch eine ungünstige Hanglage der Nutzflächen erschwert wird. Andererseits wurden in jüngerer Zeit sog. 'hybride' Maissorten entwickelt, die eine intensivere landwirtschaftliche Nutzung ermöglichen. Die Verwaltung dieses Produktionssektors durch eine große Kooperative (Coop de Pau, heute: Euralis mit Sitz in Lescar) hat erheblich zur Rentabilitätssteigerung und zu einer exportorientierten Samenforschung und -zucht beigetragen. Die landwirtschaftliche Produktion der einzelnen Betriebe umfasst in der Regel mehrere Sektoren gleichzeitig (Mais- und Getreideanbau, Heu- und Strohproduktion), was landesüblich als polyculture bezeichnet wird. Früher gehörte zu dieser polyculture in geringerem Umfang auch der Anbau von Wein. Aufgrund des für den einzelnen Landwirt nicht mehr zu leistenden Arbeitseinsatzes ist die lokale viticulture in den letzten Jahrzehnten jedoch stark zurückgegangen und wird heute nur noch in dem bekannten Anbaugebiet um Jurançon südlich von Pau intensiv betrieben. Vor allem im tieferen Süden des Landes, also dem gebirgigeren Teil, ist neben der Schafhaltung (Milch- und Käseproduktion) auch die Forstwirtschaft als ökonomisch bedeutender Erwerbsbereich vertreten. Unter landschaftlich schwierigen Bedingungen werden hier vor allem Buchen und Tannen für die weiterverarbeitende Holzindustrie geschlagen.

${ }^{95} \mathrm{Vgl}$. jedoch folgende Aussage in 50 ans en Aquitaine (p. 187): „Malgré l'antagonisme bascobéarnais, un agriculteur de Basse-Navarre ou du Labourd se sentira toujours plus d'affinités avec un berger de la vallée d'Aspe, qu'avec un producteur de fraises de Dordogne. Il y a dans les Pyrénées, et leur piedmont, un fort sentiment d'identité, que l'évolution des données économiques de ces dernières années aura contribué à renforcer.“ 
Im Zentrum des Béarn und in der Hauptstadt Pau spielen neben der landwirtschaftlichen Produktion noch weitere Erwerbszweige des primären, sekundären und tertiären Wirtschaftssektors eine bedeutende Rolle. Hervorzuheben sind vor allem der Erdgasabbau im NW von Pau und eine im Dienste des Flugzeugbaus stehende metallverarbeitende Industrie. Da für die Zwecke meiner Untersuchung jedoch nicht genauer auf diese ökonomischen Strukturen des Landes eingegangen werden muss, verweise ich zur ergänzenden Darstellung auf weiterführende Literatur $^{96}$ und beschränke mich auf ein zusammenfassendes und informatives Zitat aus dem bereits erwähnten Rechenschaftsbericht 50 ans en Aquitaine (p. 187):

L'économie de Pau et du secteur Lacq-Orthez, repose, pour l'essentiel, sur le tryptique d'Elf-Aquitaine, du maïs et d'une industrie métallurgique qui dépend pour une large part du motoriste Turbomeca. En trente ans, ces trois secteurs ont transformé le Béarn et sa métropole. Ville naguère essentiellement touristique et administrative, Pau est devenu un des principaux réservoirs d'ingénieurs et de chercheurs du Sud de la France, tandis que le complexe de Lacq donnait naissance à un pôle chimique conséquent. Une industrie métallurgique de qualité s'est développée grâce à la recherche pétrolière, mais aussi à Turbomeca, dans les domaines comme la mécanique de précision et la chaudronnerie. Et la culture intensive du maïs, encouragée par la géographie et les mécanismes communautaires, a entraîné, avec la Coop de Pau, l'émergence d'une des plus fortes structures coopératives françaises.

Mein Untersuchungsgebiet zum regionalen Sprachgebrauch im Themenbereich 'Wald und Nutzung des Waldes im Béarn' liegt in einem Umkreis von ca. 35 $\mathrm{km}$ um die Stadt Pau. Ich werde im Folgenden als Einleitung zu der Untersuchung sowohl auf den Gebrauch des Bearnesischen als auch auf die Bedeutung des Forstwesens in dem betreffenden Gebiet näher eingehen.

\footnotetext{
${ }^{96}$ Lerat / Tucoo-Chala 1974; INSEE-Aquitaine, dossier 15, 1995; 50 ans en Aquitaine 1995.
} 


\subsubsection{Der Gebrauch des Gaskognischen im Béarn}

Das heute im Béarn gesprochene Bearnesisch ist ein romanischer Primärdialekt, der sich im Mittelalter in der offiziellen Funktion als Amtssprache der vicomté de Béarn konsolidierte. Seine größte Blüte und territoriale Ausdehnung fand diese politisch-administrative Einheit unter dem mächtigen vicomte Gaston III de Foix-Béarn, bekannt als Gaston Febus ${ }^{97}$, der 1347 als Sechzehnjähriger die Unabhängigkeit des seinerzeit schon selbständigen Béarn gegenüber dem französischen König erklärte und bis 1391 regierte. Insgesamt überstand die Grafschaft Béarn vom 12. bis zu Beginn des 17. Jahrhunderts einen Zeitraum von über 400 Jahren weitgehender Autonomie, in dem sich die Ausbildung und nachhaltige Festigung des Bearnesischen als offiziell gebräuchliche Schriftsprache vollzog:

Dès le XIIe siècle, les communautés locales participaient effectivement au gouvernement de la vicomté. Les représentants des principaux villages constituaient la Cour des Communautés. Des fors (des chartes de coutumes) réglaient les rapports entre le vicomte et la population. Dans les vallées surtout, le pouvoir vicomtal était assez limité. Les fors comme toutes les pièces administratives et judiciaires étaient rédigés exclusivement en béarnais. BRUN (1923b: 15) écrit que le béarnais prévaut 'dans la rédaction des fors, dans la chancellerie comtale, dans les actes des États, dans les pièces concernant l'impôt, dans les serments et pareillement chez les notaires; le latin n'intervient qu'à titre accessoire'. Le béarnais avait donc toutes les fonctions d'une langue officielle, d'une langue d'État et les gardera jusqu'au XVIIe siècle et en partie jusqu'à la Révolution.

(Keller 1985, 65)

Die kulturelle Bedeutung des Bearnesischen beschränkt sich in dieser gesamten Phase auf die Hervorbringung von Sachprosa, die vor allem für politisch-administrative und legislative Zwecke verfasst wurde. An der großen literarischen Blüte des Okzitanischen, die durch die Verwendung einer Art koinè in der mittelalterlichen Trobador-Lyrik gekennzeichnet ist, partizipiert das Bearnesische hingegen nicht. Die Partikularität der gaskognischen Dialekte findet in der anerkannten Referenzform dieser in ganz Südfrankreich verbreiteten und weit über seine Grenzen ausstrahlenden literarischen Gattung keine Berücksichtigung.

Aber auch als Dokumentensprache tritt das Bearnesische erst Ende des 13. / Anfang des 14. Jahrhunderts in Erscheinung, da bis in diese Zeit hinein hauptsächlich das Lateinische für schriftliche Zeugnisse verwendet wird. Das Bearnesische konstituiert sich daher zu Beginn des Mittelalters vornehmlich als gesprochene Sprache des privaten wie öffentlichen Lebens. Es steht dabei im

${ }^{97}$ Febus (< griech. $\varphi$ oĩßos, 'leuchtend, rein'), den aus der griechischen Antike überlieferten Beinamen des Gottes Apollon, hat sich Gaston III in dieser bearnesierten Form selbst gegeben und auch so signiert. 
Westen seines Sprachgebiets im engen Kontakt zum Baskischen, durch das es im Zuge seiner territorialen Expansion schon frühzeitig prägende Adstrateinflüsse erfährt (vgl. hierzu z.B. Haase 1997b).

In der Phase der Ausbildung der romanischen Sprachen konsolidiert sich ein weit über die Grenzen der späteren Grafschaft Béarn hinausgehendes Gebiet relativer sprachlicher Einheit, dessen dialektale Formen heute üblicherweise als Gaskognisch zusammengefasst werden. ${ }^{98}$ Neben dem Bearnesischen umfasst das Gaskognische auch die weiter östlich liegenden Sprachvarietäten der Pyrenäen in den Départements Hautes-Pyrénées (Bigorre), Haute-Garonne und Ariège (Couserans im SW) sowie den Dialekt des Val d'Aran auf spanischer Seite; weiter nördlich das gesamte Gebiet der Départements Gers (Armagnac) und Landes sowie vorwiegend linksseits der Garonne Teile der Départements Gironde (im S, inkl. der parlers du Médoc und des heute fast ausgestorbenen bordelais), Lot-et-Garonne und Tarn-et-Garonne. Damit verteilt sich das gaskognische Sprachgebiet heute auf die Regionen Aquitanien und MidiPyrénées, wobei im Zuge der allgemeinen Dialektregression vitale Varietäten nur noch in den Pyrenäentälern und in den Gebieten der Gebirgsausläufer, also insgesamt weiter im Süden zu finden sind.

Die sprachwissenschaftliche Klassifikation des Gaskognischen - und mit ihm des Bearnesischen als seiner prominentesten Varietät - ist bis heute nicht unumstritten, obwohl die Zuordnung zum Okzitanischen inzwischen als allgemein anerkannt gelten kann. Unter rein linguistischen Gesichtspunkten wird zurecht immer wieder auf den Sonderstatus des Gaskognischen hingewiesen, der - ebenso wie im Fall des Katalanischen - die Bestimmung dieser Dialektgruppe als eigenständige romanische Sprache rechtfertigen würde. Die Tatsache, dass das Gaskognische bis heute dennoch zu den okzitanischen Dialekten gerechnet wird, hängt dabei m.E. mit einer sprachpolitisch motivierten und institutionell gestützten Reaktion auf seinen Status als Minderheitensprache in Frankreich zusammen. ${ }^{99}$ Allerdings findet diese wissenschaftlich fundierte

${ }^{98}$ Dabei ist die Abgrenzung des Gaskognischen vom Aragonesischen im Süden aus historischer Sicht nicht unproblematisch. Einflussreiche Sprachforscher wie Gerhard Rohlfs (1938) und Kurt Baldinger (1958) haben auf die enge sprachliche Verwandtschaft der Dialekte des Pyrenäensprachraums hingewiesen

99 Die Zusammenhänge sind sehr komplex und können in der hier gebotenen Kürze nicht transparent gemacht werden. Es sei aber angemerkt, dass sich die Institutionalisierung sprachpflegerischer Maßnahmen im Béarn seit dem 19. Jahrhundert in der Folge entsprechender Aktivitäten im okzitanischen Sprachraum außerhalb der Gaskogne entwickelt. Dabei konkurrierte in jüngerer Zeit die aus dem provenzalischen Renouveau der Romantik abgeleitete regionalistische Haltung der Escole Gastoû Febús in der Tradition des Félibrige mit dem okzitanistischen Anliegen des Institut d'Estudis Occitans (I.E.O.) in Montpellier, dessen Sektion Per Noste seit 1967 im Dépt. Pyrénées-Atlantiques aktiv ist. Die Ableitung der durch das I.E.O. und in seinem Umfeld vertretenen sprachpolitischen Haltung aus der soziolinguistischen Erforschung des Okzitanischen prägte in den 60er und 70er Jahren das sprachwissenschaftliche 
Interpretation bei den Sprechern des Bearnesischen bzw. Gaskognischen bis heute kaum Rückhalt, da die sprachhistorische Ausbildung eines (pan)okzitanischen Bewusstseins zumindest in der älteren Generation vollkommen fehlt.

Mit dem wachsenden Einfluss der französischen Krone auf den Béarn im 17. und 18. Jahrhundert geriet das Bearnesische immer stärker unter den Druck einer zentralistischen, der sprachlichen Vielfalt Frankreichs gegenüber intoleranten Politik, die bekannterweise gerade auch für die Epoche der Französischen Revolution kennzeichnend war. Die Konsequenzen dieser Politik, mit deren Hilfe die Regionalsprachen Frankreichs zu patois degradiert wurden, sind auch im Béarn deutlich zu spüren. Allerdings wurde der Gebrauch des Bearnesischen als alltägliche Gebrauchssprache - insbesondere im ruralen Milieu - bis ins 19. Jahrhundert hinein kaum eingeschränkt und ging auch danach bis zur Mitte des 20. Jahrhunderts nur langsam zurück. Von dieser regionalsprachlichen Standhaftigkeit im Béarn und in der Gaskogne zeugt u.a. die bekannte Gaskognismen-Jagd (la chasse aux gasconnismes) der französischen Zentralgewalt, die vor allem im 19. Jahrhundert stattfand und die von der Angst um eine allgemeine Korrumpierung des französischen Sprachgebrauchs durch den Einfluss der patois des Südwestens ausgelöst wurde (vgl. zu diesem Thema: Lepinette 1989 und Moreux, B. 1989).

Vom Zeitalter der Aufklärung bis nach dem ersten Weltkrieg war der Béarn ein zweisprachiges Gebiet, in dem größere Teile der Bevölkerung sowohl das Bearnesische als auch das Französische regelmäßig verwendeten. Beide Sprachen befanden sich in einer diglossischen Funktionsverteilung, die offenbar von Anfang an durch institutionellen Druck auf mehreren Ebenen mit einem sozialen Sprachkonfliktpotential einherging und sich schließlich immer stärker zu Ungunsten des Bearnesischen entwickelte. Christian Desplat weist darauf hin, dass die öffentlichen Bestrebungen zur Stärkung der Regionalsprache im 18. Jahrhundert noch eine große Rolle spielten:

Les Béarnais du XVIII ${ }^{\mathrm{e}}$ siècle étaient bilingues et vivaient cette situation sans tension, sauf provocation administrative ou cléricale. Or celle-ci exista bel et bien car il faut le répéter: le clergé et l'intendant, les élites en général devinrent les partisans du prône en idiome et du retour à son usage en milieu populaire en même temps qu'ils

und in seinem Umfeld vertretenen sprachpolitischen Haltung aus der soziolinguistischen Erforschung des Okzitanischen prägte in den 60er und 70er Jahren das sprachwissenschaftliche Verständnis des Gaskognischen als okzitanische Dialektgruppe ganz erheblich mit und wirkt bis in die gegenwärtige Forschung nach (vgl. hierzu z.B. das Vorwort von Michel Grosclaude in Kristol/Wüest 1985, V, sowie in der Einleitung der Autoren, ebd. 9-12). Der Gedanke eines Pyrenäensprachbundes etwa, den G. Rohlfs in den 30er Jahren in die sprachgeographisch orientierte Diskussion gebracht hatte, wurde durch diesen Aufschwung soziolinguistischer Forschung mit Konzentration auf das Okzitanische völlig aus dem sprachwissenschaftlichen Blickfeld verloren. 
s'élevaient contre la multiplication des petites écoles rurales qu'ils jugeaient tout juste à produire des avocats et des praticiens contestataires.

(Desplat 1989, 173)

Scheinbar etablierte sich das Französische im Béarn schon sehr frühzeitig durch die Ausbreitung des Schulwesens in einer intensiveren Weise als in den umliegenden Regionen. Eine offizielle Umfrage des französischen Erziehungsministeriums im Jahre 1864 ergab in Bezug auf das damalige Département Basses-Pyrénées, dass zwar ca. die Hälfte der gesamten Bevölkerung des Französischen noch unkundig war, aber bereits 70-80\% der Kinder zwischen 7 und 13 Jahren das Französische erlernten. Judith Keller kommentiert hierzu:

Ce qu'il faut surtout retenir, c'est que la connaissance du français y était nettement plus répandue que dans les départements avoisinants, malgré le retard probable du pays basque. Dans le Gers, le pourcentage de ceux qui ne parlaient pas français était même supérieur à $90 \%$.

Cela montre que les résistances qui ont marqué l'introduction du français au niveau officiel, n'ont pas empêché les Béarnais d'apprendre le français. (Keller 1985, 73)

Die entscheidende Phase der institutionell gesteuerten Verdrängung des Bearnesischen setzte schließlich - wie überall in Frankreich - Ende des 19. Jahrhunderts ein, nachdem 1881 die allgemeine Schulpflicht eingeführt worden war (vgl. Kremnitz 1981, 31). Das französische Schulsystem sah von Anfang an keinen Platz für den Unterricht der Regionalsprachen (oder in den Regionalsprachen) vor und ist sich in dieser grundsätzlichen Ausrichtung bis heute weitgehend treu geblieben. ${ }^{100}$ Die Auswirkung der kombinierten Schul- und Sprachpolitik in Frankreich ist dabei der eindeutige Verlust der kulturellen Wertschätzung von Minderheitensprachen im Sinne eines modernen civilisation- Begriffs. Zwar wird das Bearnesische offiziellerseits immer gern als wertvoller Teil des kulturellen patrimoine etikettiert, doch kommt ihm in dieser Bestimmung keine aktive Funktion im sozialen Leben mehr zu. Das irreversible Ergebnis dieses Funktionsverlusts der Regionalsprache findet man heute schon im nördlichen und mittleren Béarn vor, wo das Bearnesische innerhalb der jüngeren Generation, die bereits bis zu einer Altersstufe von ca. 40 Jahren reicht, absolut kein gesellschaftlich relevantes Kommunikationsmittel mehr darstellt. ${ }^{101}$

${ }^{100}$ Auch der späte Erlass der loi Deixonne zur Förderung des Unterrichts von Minderheitensprachen an höheren Schulen im Jahre 1951 hat hieran nichts Wesentliches geändert (vgl. Kremnitz 1981, 77 f.). Der ausschlaggebende Faktor ist die mangelnde - wenn auch nicht völlig inexistente - Unterrichtung der Regionalsprachen in der Primarausbildung. Zur Pflege des Gaskognischen in Kindergärten und Grundschulen aktivieren sich daher, besonders im Béarn, einige okzitanistische Institutionen (sog. calendretas), die jedoch auch nur einen kleinen Teil der Bevölkerung erreichen (vgl. Pusch 1998, 7).

${ }^{101}$ Die von A. M. Kristol und J. Th. Wüest veröffentlichten jüngeren soziolinguistischen Studien zum Bearnesischen im Vallée d'Aspe (1985) und zur gaskognischen Varietät des Couserans 
Die aus der Sicht der Sprachbefürworter - und unter dieser Bezeichnung lassen sich die meist jüngeren Okzitanisten und die meist älteren BearnesischSprecher vereinen - trostlose Zukunft des Gaskognischen im Béarn ist ein Faktum, das heute nicht mehr negiert, aber immer noch unterschiedlich interpretiert werden kann. Der Conseil Général des Département Pyrénées-Atlantiques gab 1994 eine Umfrage in Auftrag, um die Situation der Regionalsprache im Département genauer zu eruieren. Ein Bericht und ausführlicher Kommentar zu den Umfrageergebnissen findet sich in der okzitanistischen Zeitschrift Lengas (43, 1998). Die Verfasserin Marie Anna Châteaureynaud analysiert die Befragung nach verschiedenen Kriterien, von denen ich hier nur die des Alters und des Berufs ansprechen möchte.

Es werden drei Altersgruppen unterschieden: die der 'Alten' (55 Jahre und älter), die der 'Jungen' (15-24 Jahre) und die der altersmäßig zwischen jung und alt Liegenden (25-54 Jahre). Alt und Jung stehen sich dabei in ihrem $\mathrm{Zu}$ gang zum Bearnesischen diametral gegenüber. Ich zitiere die Zusammenfassungen von Châteaureynaud: ${ }^{102}$

Lo grop deus vielhs

[...] Son eths que (qui) an las competéncias miélhers sia tà la compreension (comprenença) sia tà la produccion. Los de mèi (mei) de 55 ans mèrcan tanben un estacament prigond a la lenga, son los auditors mèi (mei) regulars de las emissions en òc. Mes lo lor estatut de retirat mia sovent un comportament d'indiferéncia quasi completa (complèta) de cara a las marcas de reconeishença publica de lenga. [...] Donc, lo grop mèi (mei) competent n'ei pas benlèu (lhèu) pro dinamic peu desvolopament (?) de la lenga, per un sarròt de motius aqueth grop a deishat de transméter la lenga au (aus) sons mainatges. S'ei (Si ei) interessat e s'ei (si ei) lo detentor de la miélher lenga, n'ei pas dispausat a obrar per era per rasons sociaus e afectivas.

Lo grop deus joens

[...] Un grop que (qui) ne compren pas aisidament l'òc (18\% n'a (n'an) pas jamei entenut l'òc), la produccion que demòra (demora) donc excepcionalament (excepcionaument) reala. Ne legen pas jamèi (jamei) en òc. Que pensan que lor (la lor) pratica s'amendreish (peus que (taus qui) pòden practicar, solide, et (e) pensan que ne va pas desvolopà's (har progrès ?)). [...] Ei lo grop mèi (mei) desoccitanizat (desoccita-

im südwestlichen Ariège (1993) erlauben hier teilweise noch eine positivere Interpretation. Das Voranschreiten des kommunikativen Funktionsverlustes unter jungen Leuten scheint aber dennoch auch in den Pyrenäen-Gebirgstälern unaufhaltsam zu sein.

${ }^{102}$ Die kursiven Zusätze in Klammern sind sprachliche Korrekturen des Textes, die ich ergänze. Nicht nur diese Normverstöße, auch der gesamte (teilweise sehr archaische) Stil der Verfasserin zeigt in exemplu den schwierigen Zugang der jüngeren Generation zum Bearnesischen. Marie Anna Châteaureynaud gibt somit selbst ein Beispiel für die von ihr zurecht getroffene Feststellung: ,Qu'existeish alavetz ua fractura enter un occitan intelecutalizat (sic) e un biarnés quotidian... " (p. 119) 
nisat) o meilèu pas jamèi (jamei) *occitanizat+ $\left({ }^{*}\right.$ occitanisat + ), la lenga n'a (n'ei) pas estada transmesa, l'escòla n'a pas supleat aquera omission e donc ne se senteishen (senten) pas pertocats. Totun, quauquas manifestacions de curiositat e benlèu (lhèu) d'interés (interès) apareishen que (qui) pòden representar ua potencialitat. Per eths, l'occitan ei (n'ei) pas quitament un objècte culturau, ei subretot (sustot) ua causa desconeguda.

Aus der Perspektive der 'Alten' vollzieht sich innerhalb weniger Generationen ein vollkommener Bruch mit der bearnesischen Muttersprache, die schon bald von niemandem mehr in der tradierten Form gesprochen werden wird. ${ }^{103}$ Die okzitanistische Bewegung setzt ihre Hoffnung angesichts dieser Situation z.T. auf die mittlere Altersgruppe, innerhalb deren sie noch Potential für das Wiederaufleben des Okzitanischen im Béarn zu finden glaubt. Diese Überzeugung spricht zumindest aus Châteaureynauds Interpretation der Umfrageergebnisse von 1994 (vgl. dies. 1998, 124) und es scheint so, als stehe Châteaureynaud mit ihrer engagierten Haltung nicht ganz allein.

Als sprachsoziologische Voraussetzung der von mir durchgeführten Untersuchung bleibt allerdings festzuhalten, dass nur noch in der von Châteaureynaud als vielhs bezeichneten Gruppe geeignete Informanten zu finden sind. Es macht wenig Sinn, die noch vorhandenen lexikalischen Kenntnisse zu einem Fachgebiet oder die spontanen Diskursgestaltungen im Kommunikationsbereich dieses Fachs in einer Probandengruppe zu eruieren, deren Zugang zur Regionalsprache ausschließlich durch Neugier (cursiositat), Interesse (interès) oder sprachpolitische Überzeugungen (volentat) motiviert wird (vgl. hierzu noch mal die Interpretationen in Châteaureynaud 1998).

Das Kriterium für die Auswahl der Probanden war aber dennoch keine altersmäßige Beschränkung, sondern die Tatsache, dass das Bearnesische a la popa, d.h. als Muttersprache erlernt worden ist und noch aktuell in gewissem Umfang weiter verwendet wird. Mit dieser Maßgabe habe ich immerhin noch Probanden in der Altersgruppe zwischen 40 und 50 Jahren ausfindig machen können.

Eine weitere Beschränkung meiner Probandenauswahl war durch das Kriterium des Zugangs zum Sachbereich gegeben. Dieser Zugang findet sich, wie nicht anders zu erwarten, fast ausschließlich auf dem Land und hier ganz be-

${ }^{103}$ In einem Beitrag zum Thema 'La transmission du béarnais en milieu rural aujourd'hui' ziehen Colette und Bernard Moreux (1989, 255 f.) folgendes Fazit: „Est-ce à dire que le béarnais a perdu toute signification sociale dans l'éducation des enfants? Ce serait aller trop loin; on voit des grands-parents fiers d'apprendre des mots béarnais à leurs petits enfants, de les aider à traduire les chants béarnais qu'on leur enseigne à l'école, fiers aussi de constater qu'ils comprennent la langue des ancêtres. Toutefois cette attitude, qui est du reste loin d'être générale, même si elle est favorisée par la revalorisation, pressentie par beaucoup, du 'patois', n'a apparemment pas changé les comportements de façon telle que la transmission de la langue puisse être assurée par cette voie.“ 
sonders in der Berufsgruppe der Landwirte und bei den Rentnern (häufig auch in Kombination, d.h. unter ehemals aktiven Landwirten). Die nach Berufssparten differenzierte Auswertung der Umfrageergebnisse von 1994 zeigt eindeutig, dass nur noch im Agrarsektor und bei den Rentnern ein hohes Maß an aktiver Sprachverwendung und persönlicher Bindung zum Bearnesischen zu finden ist: ${ }^{104}$

\begin{tabular}{|c|c|c|c|c|c|c|c|c|}
\hline prof & \multicolumn{2}{|c|}{ Comp. } & \multicolumn{2}{c|}{ 'Prod. } & \multicolumn{2}{c|}{ 'Denom } & \multicolumn{2}{c|}{ 'Estac. } \\
\hline & non & parf & non & oui & Biarnès & Oc & très & $\begin{array}{c}\text { pas } \\
\text { lié }\end{array}$ \\
\hline A & 12,5 & 59,4 & 17,9 & 46,4 & 50 & 0,0 & 59,4 & 6,3 \\
\hline B & 28,9 & 22,2 & 34,4 & 21,9 & 51 & 4,4 & 46,7 & 8,9 \\
\hline C & 52,2 & 17,4 & 31,8 & 18,2 & 50 & 4,3 & 41,3 & 28,3 \\
\hline D & 46,4 & 16,5 & 30,8 & 23,1 & 48,5 & 5,2 & 41,2 & 21,6 \\
\hline E & 40,8 & 16,4 & 24,4 & 11,1 & 45,4 & 5,9 & 42,1 & 17,1 \\
\hline F & 41,3 & 12,3 & 38,3 & 14,8 & 44,9 & 3,6 & 26,1 & 24,6 \\
\hline G & 27,2 & 35,3 & 18,3 & 40,8 & 41,1 & 3,0 & 57,8 & 14,2 \\
\hline H & 65,1 & 4,6 & 50,0 & 2,6 & 44,0 & 9,2 & 16,5 & 31,2 \\
\hline I & 49,7 & 14,1 & 37,3 & 16,0 & 41,9 & 5,4 & 30,9 & 24,8 \\
\hline
\end{tabular}

A: agriculteurs-exploitants; B: artisans, marchands, entrepreneurs; C: cadres, professions intellectuelles; D: professions intermédiaires; E: employés; F: ouvriers; G: retraités; H: étudiants; I: autres professions

Comp.: compréhension; Prod.: production linguistique; Denom.: dénomination de la langue; Estac.: attachement à la langue béarnaise

Auf die mikrodiglossische Funktion, die das Bearnesische in der Gruppe der Probanden typischerweise einnimmt, werde ich zu Beginn des Kapitels 2.3.3 noch eingehen.

In einer globaleren Sicht der sozial verteilten Sprachkompetenz bleibt festzuhalten, dass mein Untersuchungsinteresse zurzeit immerhin noch den Bezug zu einem Fünftel bis einem Viertel der Bevölkerung im Département PyrénéesAtlantiques aufweist. ${ }^{105}$

${ }^{104}$ Die folgende Tabelle ist in verkürzter Form aus Châteaureynaud 1998, 136 entnommen. Die Erläuterung der Abkürzungen wird hier in einer französischen Übersetzung wiedergegeben.

${ }^{105}$ Die genaueren Angaben lauten als Ergebnis der Umfrage von 1994: 26 \% sprechen Bearnesisch, $11 \%$ sprechen es häufig und $41 \%$ verstehen es. Bei einer vergleichbaren Umfrage im Dépt. Hautes-Pyrénées wurden 1995 die etwas höheren Anteile von $35 \%$ (sprechen), $19 \%$ (sprechen oft) und $56 \%$ (verstehen) ermittelt. Dies spricht für das konservativere Sprachverhalten in den Pyrenäentälern. Eine tabellarische Darstellung mit Vergleichen zur Region Languedoc-Roussillon und zum Val d'Aran gibt Pusch 1998, 9. 


\subsubsection{Der Wald im Béarn}

Der Wald ist in Frankreich insgesamt ein landschaftlich und ökonomisch sehr wichtiger Faktor, stellt sich aber in den einzelnen Regionen des Staatsgebietes z.T. in ganz unterschiedlichen Realitäten dar. Obwohl mehr als ein Viertel, genau 28\% der Fläche des europäischen Staatsgebiets Frankreichs bewaldet ist, wird der Norden und Westen des Landes aufgrund des ihm weitgehend fehlenden Waldes gern als la France chauve bezeichnet. Die hauptsächlichen Waldvorkommen in Frankreich konzentrieren sich auf eine Reihe ausgedehnter massifs forestiers, zu denen die Vogesen, die Landes, das Massif Central und der Jura gehören. Aber auch außerhalb dieser dichten Gebiete erreicht die Bewaldung in Frankreich häufig einen Prozentsatz von über 25\%. Aquitanien (16\%), Lothringen (9\%), Rhône-Alpes (7\%) und Burgund (7\%) gehören zu den am dichtesten bewaldeten Regionen Frankreichs. ${ }^{105}$

Es ist eine Tatsache, die selbst vielen Franzosen unbekannt ist, dass der französische Wald seit ca. 100 Jahren kontinuierlich an Territorium hinzugewinnt. Nachdem Frankreich durch Rodungen - zur Brennholzgewinnung, zur landwirtschaftlichen Nutzung und für diverse handwerkliche und industrielle Produktionsbereiche - im 19. Jahrhundert seinen Waldbestand bis auf 15\% der Staatsfläche reduziert hatte, setzte nach der Französischen Revolution eine administrativ und später auch durch Gesetzgebung gestützte Waldpolitik ein, deren Ziel die Bestanderhaltung, Pflege und Flächenerweiterung des französischen Waldes war und ist. Zusätzlich greift heute die in der Europäischen Union verfolgte Politik der Stilllegung unrentabler Agrarflächen, die mit einer massiven Subvention von Neu- und Wiederbewaldungsmaßnahmen einhergeht. Nicht zuletzt ist auch der ökologische Gedanke ein motivierendes Element der aktuellen Waldpflegemaßnahmen des französischen Staates.

Eine Besonderheit der französischen Waldwirtschaft liegt in den Eigentumsverhältnissen begründet: $70 \%$ des französischen Waldes (in Europa) sind Privateigentum, d.h. bei einer Gesamtfläche von 14,7 Mio. ha mehr als 10 Mio. ha:

La forêt française appartient à de très nombreux propriétaires, quelque 3800000 . C'est qu'en France est qualifié de "forestier" tout propriétaire de parcelle boisée, même de surface très réduite. [...]

Les superficies des propriétés sont aussi très variables : elles vont de moins de 1 ha à plus de 100 ha $(25 \%)$. Les pessimistes remarquent que plus de la moitié des propriétés privées sont de superficie inférieure à 25 ha. Ils présentent ce morcellement comme une faiblesse de notre patrimoine forestier. Il est certain que $8 \%$ de la super-

${ }^{105}$ Die Prozentangaben beziehen sich auf den Anteil an der Gesamtwaldfläche Frankreichs. 
ficie forestière française sont constitués de parcelles inférieures à 1 hectare, et que les coûts excessifs de leur mise en valeur peuvent décourager bien des propriétaires.

(Lorette 1996, 49 f.)

Die Zerstückelung des privaten Waldeigentums ist ein Phänomen, das auch für den Béarn typisch ist. Die untersuchte Region entspricht damit einer allgemeinen Problematik der Waldpflege und Waldnutzung in Frankreich. Ich werde auf die Implikationen und Konsequenzen dieses Problems noch zurückkommen. Die meisten Waldbesitzungen im nördlichen und mittleren Béarn gehören zur Kategorie der petits lots. Oft sind (oder waren) ihre Besitzer landwirtschaftlich tätig bzw. Erben von Agrarland (das oft auch verpachtet oder fremdbearbeitet wird). Sie repräsentieren damit einen bestimmten Typus privater Waldbesitzer in Frankreich:

Dans ce registre, nous trouvons aussi des "agriculteurs forestiers". Ce sont des personnes habituées à la culture, équipées de matériel lourd (tracteurs, charrues...) dont la principale activité est l'agriculture. La sylviculture devient pour eux une activité accessoire. Tel maïsiculteur dans les Landes, par exemple, tire du maïs ces revenus réguliers, tandis que la forêt, qu'il entretient à temps partiel, devient pour lui un capital rentable à plus long terme, qu'il transmettra, revalorisé.

(Lorette 1996, 49 f.)

Allerdings zeigt sich meiner Beobachtung nach zumindest im Béarn das Problem, dass die kleinen Waldbesitzungen von den aktiven Landwirten (25\% der privaten Waldbesitzer) aus Überlastungsgründen kaum zu einer effektiven wirtschaftlichen Nutzung gebracht werden. Der Wald fängt erst den Rentner an $\mathrm{zu}$ interessieren, der sich auf diese Weise eine naturverbundene Aufgabe schafft, deren Sinn er meist nur in der Nutzung durch die nachfolgenden Generationen erblickt. ${ }^{106}$ Natürlicherweise ist der Rentabilitätsgedanke bei diesen 'aktiven' Waldbesitzern nicht stark ausgeprägt und ihre Investitionsbereitschaft hängt häufig ausschließlich von der Subventionsvergabe durch die forstwirtschaftlichen Institutionen ab.

In wesentlich geringerem Maße ist im Béarn auch der großflächige private Waldbesitz mit einer jeweiligen Eigentumsfläche von über 25 ha vertreten. Ich habe in drei Fällen ausführlichere Interviews mit Besitzern solcher grandes surfaces führen können. Diese größeren Waldeigentümer sind durch die staatliche Waldgesetzgebung aus dem Jahre 1963 zu der Vorlage eines sog. plan simple de gestion verpflichtet, aus dem u.a. eine genauere Anbauplanung (Erschließung, Pflanzung, Abholzung, Wiederbewaldung, etc.) ihrer Waldbestände hervorgeht. ${ }^{107}$ Sie wenden sich häufig an eine Forstkooperative, um

${ }^{106} 21 \%$ der privaten Waldbesitzer gehören zur Gruppe der retraités; siehe Husson 1995, 75.

${ }^{107}$ Genaueres zu dem plan simple de gestion (P.S.G.) ist zu finden in: Husson 1995, 77 f., u.a.: „Depuis 1985, le plan doit être en harmonie avec les orientations régionales de production 
professionelle Beratung und Hilfe für den von ihnen zu leistenden Waldbau zu erlangen und sind in ihrer forstwirtschaftlichen Tätigkeit grundsätzlich stärker gewinnorientiert.

Kleinere wie größere private Waldbesitzer in Frankreich finden in technischen und administrativen Fragen der gestion forestière in der Regel Hilfe bei dem zuständigen Centre Régional de la Propriété Forestière (CRPF):

Ce sont des établissements publics à caractère administratif et professionnel institués par la loi du 6 août 1963, qui ont compétence dans le cadre de la politique forestière nationale pour orienter et développer la production des forêts privées, notamment par:

- la création de groupements forestiers;

- le développement de la coopération, tant pour la gestion des forêts que pour l'écoulement des produits;

- la vulgarisation des méthodes de sylviculture intensive;

- l'élaboration d'orientations régionales de production;

- l'approbation de plans simples de gestion demandés aux propriétaires de forêts. (Lorette 1996, 49 f.)

Insgesamt gibt es 17 solcher $C R P F$ in Frankreich, die sich prinzipiell an der administrativen Aufteilung in Regionen orientieren. Zur Vorbereitung und Durchführung der vorliegenden Untersuchung habe ich Kontakt zu dem Centre Régional de la Propriété Forestière d'Aquitaine in Bordeaux aufgenommen. ${ }^{108}$ Die konkrete Arbeit dieses Zentrums wird von verschiedenen Außenstellen ('antennes') in der Région d'Aquitaine realisiert. Meine Ansprechpartner, denen ich für ihre engagierte Hilfe zu großem Dank verpflichtet bin, waren in der Chambre d'Agriculture des Pyrénées-Atlantiques mit Sitz in Pau Herr Jean Touyarou und in der Maison de la Forêt in Orthez Herr Alain Berton.

Die Arbeit des CRPF d'Aquitaine zeigt deutlich, dass dem Wald, seiner Pflege und seiner rentablen Nutzung auch im Béarn eine große Bedeutung zugemessen wird. Dabei sind die spezifischen geographischen und sozioökonomischen Bedingungen dieser Region besonders zu berücksichtigen. Ich werde versuchen, diese Aspekte ein wenig zu erläutern.

Der gesamte Waldbestand in der Région d'Aquitaine lässt sich in drei große Zonen aufteilen:

\footnotetext{
définies en conformité avec les orientations régionales forestières. “

${ }^{108}$ Ich möchte an dieser Stelle dem Direktor des CRPF d'Aquitaine, Herrn Bernard Dalisson und auch Herrn Jean de Bertier, Präsident des Syndicat des Sylviculteurs des PyrénéesAtlantiques und ehemaliger Directeur Régional de l'Office National des Forêts für ihre freundliche Unterstützung danken. Durch ihre Vermittlung war es mir möglich, schnell und effektiv Kontakte zu den regionalen Institutionen der Forstverwaltung im Béarn aufzubauen.
} 


\section{1. das massif des Landes de Gascogne}

Hier handelt es sich um das größte zusammenhängende Waldmassiv Europas mit einer Gesamtfläche von 998.000 ha in einem Gebiet, das durchschnittlich $\mathrm{zu} 75 \%$ bewaldet ist, wohingegen die ursprüngliche Landschaftsform der Heide (lande) nur noch mit 2\% vertreten ist. Der Ursprung des Waldes in den Landes, der zu über $90 \%$ aus Pinien besteht, ist künstlicher Natur und geht auf eine von Napoleon III. angeordnete Bewaldungsmaßnahme im Jahre 1857 zurück. Im Zuge dieser Maßnahme, deren Grundlage die systematische Befestigung der Dünenlandschaft durch Baumbepflanzungen entlang eines Küstenstreifens von über $200 \mathrm{~km}$ Länge war, wurde den Kommunen auferlegt, die das angrenzende Heideland durchziehenden Sumpfgebiete trockenzulegen und das gesamte Territorium mit den schnellwachsenden und widerstandsfähigen pins maritimes zu bepflanzen. Diese massive Anpflanzung von Pinien hat die wirtschaftliche Struktur des Landes grundlegend geprägt. Während früher neben der Holzgewinnung auch die Harzernte (gemmage) eine ökonomisch wichtige Rolle gespielt hat, konzentriert sich der Wirtschaftssektor heute auf Abholzung, Sägebetrieb und weiterverarbeitende Industrie (insbesondere Papier und Karton).

\section{2. die forêts de Dordogne-Garonne}

Dieses Waldgebiet mit einer Gesamtfläche von über 500.000 ha produktiven Privatbesitzes ${ }^{109}$ lässt sich unter forstwirtschaftlichen Gesichtspunkten in nicht weniger als 8 verschiedene Zonen mit erheblich schwankender Bewaldungsdichte unterteilen. Die hauptsächliche Konzentration der Bestände befindet sich im Périgord, dessen Bewaldung größtenteils knapp die Hälfte der Landesfläche ausmacht. Die im Gebiet Dordogne-Garonne überwiegend anzutreffenden Baumarten sind Eiche (39\%), Pinie (27\%) und Esskastanie (17\%). Darüber hinaus spielt gerade in jüngerer Zeit auch die Nussbaumproduktion (noyer à bois) eine wichtige Rolle. Insbesondere die großen Vorkommen an Pinien und Kastanien (im südlichen Périgord Noir als charakteristischer Mischwald zu finden) geben dem massif du Périgord dabei ein gegenüber den südgaskognischen Wäldern eigenes Gepräge.

\section{3. die forêts d'Adour-Pyrénées}

In diesem Gebiet, das insgesamt etwa 200.000 ha Wald umfasst, sind 168.815 ha produktiver Privatbesitz (ca. 85\%). Es lassen sich insgesamt 4 west-östlich verlaufende Zonen unterscheiden:

${ }^{109}$ Angaben zum kommunalen und staatlichen Waldbesitz konnten von mir für dieses Gebiet nicht ausgemacht werden. Allein im Département Dordogne liegen insgesamt 370.000 ha Wald, was einer durchschnittlichen Bewaldungsdichte von $41 \%$ entspricht (vgl. 50 ans en Aquitaine, p.111). Da das Département Garonne nur im Süden (im Bazadais und Néraçais) stark bewaldet ist (ca. 50\%), scheinen die öffentlichen Waldgebiete insgesamt eine kaum nennenswerte Größe zu erreichen. 
a) das Tal des Adour

b) die Ausläufer der Pyrenäen (plaines et coteaux)

c) das Pyrenäen-Vorgebirge (basse montagne)

d) das Pyrenäen-Gebirge

Die am häufigsten anzutreffende Baumart der Tiefebene und des Vorgebirges ist die Stieleiche (chêne pédonculé), die oft auch als chêne de pays bezeichnet wird und in mehreren Varietäten vorkommt. Daneben sind im Ardour-Gebiet vor allem Pappeln und Erlen vertreten. Weiter südlich gibt es neben der typischen Eiche eine Reihe weiterer für die Region charakteristischer Laubbaumarten (u.a. die Esskastanie), auf die ich im Einzelnen bei der Beschreibung der Bestände noch näher eingehen werde. Auffallend ist jedoch die natürliche Armut an Nadelbäumen (ca. 5\%), die auch für das Mittelgebirge noch typisch ist. Mittel- und Hochgebirge weisen schließlich einen hohen Prozentsatz an Buchenbeständen auf. Im Hochgebirge setzen ab einer gewissen Höhe Nadelwälder mit vorwiegendem Tannenbestand ein.

Unser Untersuchungsgebiet, das vor allem im Nordosten und im Südwesten der Stadt Pau liegt, umfasst die Landschaft der plaines et coteaux im Norden und der basses montagnes im Süden. Die Prädominanz der Eiche und das Fehlen von natürlichem Nadelwald ist dabei für das gesamte Gebiet charakteristisch. Allerdings unterscheiden sich die beiden Zonen dennoch durch ihren landschaftlichen Charakter. Auf den plaines et coteaux im Norden ist die Landwirtschaft (polyculture) vorherrschend. Der Wald, der dort immer noch das gesamte Territorium zu ca. einem Fünftel bedeckt, ist in viele kleine Parzellen aufgeteilt, die um die Felder und Weiden herum in agrartechnisch schwierig zu nutzenden Bereichen das typische Bild der bearnesischen Landschaft prägen. Der Landwirt bzw. Landeigentümer im Béarn besitzt in aller Regel auch einige Waldgebiete, ohne sie allerdings in den meisten Fällen forstwirtschaftlich zu nutzen. Die meisten Wälder sind aus Sicht des sylviculteur verwahrlost und daher nutzlos. Das typische Dornengestrüpp der Region, die ronces, machen viele Waldgebiete nur schwer zugänglich. Der Wildwuchs bringt oft nur Bäume mit kleineren und unförmigen Stämmen hervor. Vielfach trifft man den chêne tauzin an, eine landestypische Varietät der Eiche, die sich nur zur Gewinnung von Brennholz eignet.

Im Süden von Pau, dem Gebiet der basse montagne, nimmt die Dichte der Landwirtschaft ab und die Bewaldung zu. Gleichzeitig ändert sich die Verteilung der Baumarten durch die Zunahme von Buchen und gebietsweise auch Esskastanien. Obwohl hier größere Waldflächen anzutreffen sind, bleibt die Qualität der Wälder größtenteils schlecht, da auch diese Gebiete-ebenfalls meist auf kleinere Parzellen verteilt-wegen ihrer schwierigen Zugänglichkeit forstwirtschaftlich vernachlässigt worden sind. 
In wirtschaftlicher Hinsicht ist der Wald im mittleren und nördlichen Béarn normalerweise keine Erwerbsgrundlage seiner Besitzer. Er dient noch heute zur Gewinnung von Brennholz und oft als Jagdgebiet oder trägt ganz einfach im Bewusstsein der Einheimischen zur Schönheit der bearnesischen Landschaft bei. Die Bearnesen lieben es nicht unbedingt, ihre Bäume zu fällen, aber sie betrachten ihren Waldbesitz dort, wo es wirtschaftlich produktive Bestände gibt, doch als finanziellen Rückhalt für schlechte Zeiten. Die Möglichkeit der Eigensanierung durch Holzverkauf in einer Notlage ist bis in die jüngste Zeit ein wesentlicher Faktor des privaten Waldbesitzes.

Angesichts der beschriebenen Situation liegt die Arbeit des CRPF d'Aquitaine und weiterer privatforstwirtschaftlich orientierter Institutionen im Béarn auf der Hand. Es geht in erster Linie darum, einen Sinn für sylviculture in der Region zu entwickeln und geeignete Maßnahmen zu fördern, um den Zustand der Wälder zu verbessern, ihre wirtschaftliche Nutzung zu ermöglichen und gleichzeitig ein marktwirtschaftliches Rentabilitätsziel zu verwirklichen. In diesem Bemühen stoßen regionale Traditionen und innovative Vorstellungen aufeinander. Die Institutionen setzen daher auf eine uneigennützige und kooperative Aufklärungsarbeit sowie auf das Angebot konkreter Hilfeleistungen. Insbesondere fachliche Begutachtungen vor Ort (visites diagnostiques), technische Ratschläge und Dienstleistungen bei der Vermittlung von staatlichen Subventionen sind für die privaten Waldbesitzer ein Anreiz zur Kontaktnahme mit diesen Organisationen, deren Zuständigkeitsbereiche entweder die Region oder das Département sind. Im Einzelnen stehen den bearnesischen Waldbesitzern vor allem folgende Anlaufstellen zur Verfügung:

- Centre Régional de la Propriété Forestière d'Aquitaine, Bordeaux (bearnesische 'antenne' in Orthez)

- Syndicat des Sylviculteurs des Pyrénées-Atlantiques, Pau

- Centre d'Études Techniques et d'Expérimentations Forestières, Pau

- Coopérative des Producteurs de Bois des Pyrénées-Atlantiques, Navarrenx

- Groupement des Producteurs de Bois des Pyrénées-Atlantiques, Navarrenx

Welche Rolle der Wald im Béarn für die Bewohner des Landes, für die Landwirte und speziell für die Waldbesitzer spielt, lässt sich weder allein auf der Grundlage von Daten und Zahlen noch an Hand der institutionellen Aktivitäten ermessen. Es handelt sich vielmehr um eine Frage, die die regionale Lebensgestaltung im typischen Spannungsfeld zwischen Tradition, Aktualität und Innovation betrifft. Mit meiner Untersuchung möchte ich zeigen, dass das Sprechen über den Wald und seine Nutzung in der Region ein wesentlicher, empirisch erfassbarer Maßstab dieser Lebensgestaltung ist. Dabei werde ich dokumentieren, dass der regionale Sprachgebrauch zum Ausdruck von Alltagserfahrung, Realitätsbewältigung und Identitätsfindung wird. Dies ist nicht 
selbstverständlich, insofern es sich um die Thematisierung eines Sachbereichs handelt, dessen fachliche Aspekte weitgehend überregionale Geltung haben und dessen Verfahren der Problemanalyse und Konfliktlösung über den regionalen Rahmen hinausreicht. Ich verfolge also letztlich die Frage, wo der Sinn und Wert eines regionalen Sprachgebrauchs in Bezug auf einen Gegenstand liegt, dessen Implikationen und Probleme sich in rein fachlicher Hinsicht auBerhalb des regionalen Bezugsrahmens darstellen, so wie dies auch für die professionelle Ausbildung zur kommunikativen Bedingung wird. ${ }^{110}$

${ }^{110}$ Dies gilt auch, wenn in einer Ausbildungssituation regionale Fakten erklärt bzw. beschrieben werden. Die zu verwendende Fachsprache erlaubt auch in diesem Fall nicht die Anwendung einer regionalsprachlichen Diskursgestaltung. 


\subsection{Der bearnesische Wortschatz im Sachbereich 'Wald und Nutzung des Waldes'}

\subsubsection{Lexikographische Bestandsaufnahme und kommunikativer Wert}

Um die sprachlichen Traditionen des Kommunikationssektors 'Wald' im Béarn ausfindig zu machen, erscheint es sinnvoll, in einem ersten Schritt das domänenspezifische Vokabular des Bearnesischen näher zu untersuchen. Dies erfordert zunächst die Bestandsaufnahme des fachbezogenen Vokabulars, auf der aufbauend dann die Frage nach der heutigen Lebendigkeit dieses lexikalischen Sprachbereichs gestellt werden kann. Meine Untersuchung erfolgte daher in zwei Schritten:

1) Eruierung des Vokabulars zum Sachbereich 'Wald und Waldnutzung' im Bearnesischen anhand von Wörterbüchern

2) Empirische Überprüfung der Kenntnis und Verfügbarkeit des Wortschatzes mittels Befragungen

In diesem Kapitel wende ich mich zunächst dem ersten Punkt zu.

Das Bearnesische verfügt über eine sehr reichhaltige, wissenschaftlich fundierte Lexikographie. Für meine speziellen Zwecke habe ich die folgenden Quellen zu Rate gezogen:

- Jean-François d'Estalenx, Dictionnaire français-gascon. Des notions aux mots. 2 tomes, Toulouse: Éd. Univ. du Sud 1993.

Sehr ausführliche, nach Sachgebieten geordnete Darstellung des gaskognischen Vokabulars. Zu dem hier interessierenden Thema gibt es eine Fülle von mots-clé mit weiteren Querverweisen. Neben den hauptsächlichen, in sich weiter unterteilten Referenzen ARBRE (43-45), BOIS (109-113), FORET (346-348) finden sich eine Reihe weiterer themenspezifischer Stichworte, insbesondere zu Teilen des Baums: BOURGEON, BRANCHE, FEUILLE, ÉCORCE, ÉPINE, RACINE, TIGE, und zu verschiedenen Baumarten: BOULEAU, CHÂTAIGNE, CHÊNE, HÊTRE, $P I N$.-Im Anschluss an den französischen Begriff ${ }^{12}$, der im Bedarfsfall genauer präzisiert wird, führt das Wörterbuch jeweils einen oder mehrere bearnesische Begriffe an, die z.T. regional situiert werden (Bsp.: 'arbre jeune et vigoureux, qui a des repousses au pied: garroùlho (GERS); garroulhàt').

112 ,Begriff“ wird hier und nachfolgend des Öfteren in der Arbeit nicht als philosophischer oder linguistischer Fachterminus benutzt, sondern ganz einfach im umgangssprachlichen Sinne von, Wort, Ausdruck'. 
- $\quad$ Simin Palay, Dictionnaire du Béarnais et du Gascon modernes (Bassin aquitain), Paris: Éd. du CNRS 1991 (réimpr. de ${ }^{3} 1980$ ).

Bekanntes Referenzwerk zum bearnesischen und gaskognischen Vokabular, in alphabetischer Reihenfolge. $\mathrm{Zu}$ den einzelnen Lemmata werden eine oder mehrere französische Entsprechungen, Beispielsätze bzw. idiomatische Wendungen und weitere Informationen (u.a. regionale Zuordnungen) gegeben.

- 'Glossaire' (français-béarnais), dans: Le bois en Béarn \& son exploitation. Exposition temporaire Musée Béarnais, Château de Pau, juin-novembre 1979, Pau: Impr. de la Monnaie 1979, 20-24.

Angabe einer Auswahl von ca. 300 Begriffen aus dem Bearnesischen (teilweise mit Synonymen), die das Thema der Ausstellung betreffen.

Die genannten Quellen sind sehr unterschiedlicher Natur und liefern eine große Menge an lexikalischem Material, das für die Befragungen eine zu breite Datenbasis darstellte und dementsprechend erst aufbereitet werden musste. Dennoch blieb die umfassende Zusammentragung einer maximalen Anzahl von Wörtern und Begriffen zum Thema zunächst die einzige durch die schriftlichen Quellen gegebene Voraussetzung der empirischen Arbeit. Wie nicht anders zu erwarten, enthalten die beiden Wörterbücher mit ihrem im Prinzip exhaustiven Anspruch keinerlei Hinweise auf den Bekanntheitsgrad oder die Gebrauchsfrequenz der aufgeführten lexikalischen Einheiten. Auch der zu Rate gezogene glossaire berücksichtigt nicht explizit das Kriterium der kommunikativen Relevanz, sondern ist vorrangig an der Darstellung eines Wortschatzbereichs traditionellen Charakters interessiert. ${ }^{113}$

Um das Untersuchungsziel zu erreichen, habe ich in einem ersten Schritt möglichst viele Begriffe zum Thema zusammengetragen. Die systematische Durchsicht der beiden genannten Wörterbücher führte dabei zu einer Liste mit über 1000 Lemmata, denen ich jeweils die Erläuterungen des Wörterbuchs von Palay hinzufügte. Durch eine noch konsequentere Verfolgung der Verweisstrukturen in beiden Wörterbüchern, die ich in Einzelfällen exemplarisch nachvollzogen habe, hätte sich diese Liste um weitere 200 bis 400 Wörter (je nach inhaltlichen Ausschlusskriterien) erhöhen lassen, so dass ich insgesamt von einer Größenordnung des im Bearnesischen bekannten Vokabulars zum Themenbereich Wald von 1200 bis 1400 Lexemen ausgehe. ${ }^{114}$ Dies ist für ein relativ gut eingrenzbares Sachgebiet ein erstaunlich hoher Anteil am Gesamt-

${ }^{113}$ Dennoch erwies sich diese praxisnah zusammengestellte Vokabelliste als eine hilfreiche Datenquelle für meine empirische Untersuchung.

${ }^{114}$ Bei dieser Zahlenangabe ist zu berücksichtigen, dass keine regionale Differenzierung des Wortschatzes vorgenommen werden konnte. Unter begrifflichem Aspekt sind die Lexeme zu einem erheblichen Teil Synonyme bzw. fanden und finden nicht überall in der Gaskogne Verwendung. Allerdings sind die häufigen Phänomene regionaler und/oder lokaler phonetischer Differenzierung (z.B. àbre, àrbe, àrbre, àubre, àure für 'Baum') von mir prinzipiell nicht als unterschiedliche Lexeme bewertet worden. 
vokabular und belegt die große Bedeutung, die der Wald im Béarn seit jeher gespielt hat.

Da die Veröffentlichung der gesamten von mir zusammengetragenen Wortschatzliste im Rahmen dieser Arbeit aus quantitativen Gründen nicht möglich ist, beschränke ich mich darauf, exemplarisch die Vielfalt des Vokabulars durch die Wiedergabe der aufgefundenen Bezeichnungen zum Themenbereich 'Eiche', der wichtigsten Baumart im Béarn, vor Augen zu führen. Im Einzelnen finden sich in der gaskognischen Lexikographie hierzu folgende Einträge: ${ }^{115}$

\section{BEZEICHNUNGEN FÜR DIE EICHE}

càssou. - C. càsse, chêne. (càssou est généralement employé en B. préférablement à càsse employé surtout dans la G. et les L.). N. de p., Càssou, Cassoulet. - Dans le G., càssou négre désigne le quercus sessiliflora; $c$. blanc le $q$. pedunculata; $c$. bastàr, le q. pubescens; c. bért, le q. ilex; dans l'E. du G., càsse signifie aussi chrysanthème.

càssi (G.L.); sm. - Chêne.

càsse, càssou; sm. - Chêne; fromage (rare). N. de p., Casse, Ducasse, Péducasse, Cassou, Pèccassou.

\section{VARIETÄTEN DER EICHE}

taudin. - C. tausî, tauzin, chêne blanc en Magnoac, Médoc, Gr. Lande, Rustan. tausî; sm. - Tauzin, chêne blanc (quercus coriaria). Nom de p.., Tausin, Tauzin. tausiâ; tausinàt (Bay.); sm. - Bois de tauzins. N. de 1. et de p., Tauzia, Dutauzia. tausiàt; sm. - Jeune tauzin.

tausic, -sie; s. - Gland du tauzin.

tausière; sf. - Pépinière de tauzins, bois de tauzins. V. tausiâ.

tausiét; sm. - Petit tauzin, jeune tauzin. N. de 1. et de p., Tauziet, Dutauziet.

tousià (L.); - Forme de tausià, chêne blanc.

droulh; sm. - Chêne rouvre (quercus robur) et chêne lanuguineux (quercus pubescens).

miey-tausî; sm. - Variété de chêne, hybride du chêne commun et du rouvre.

${ }^{115}$ Ich zitiere im Folgenden die gefundenen Lexeme entsprechend der Einträge im Wörterbuch von S. Palay. Der inhaltliche Gliederungsvorschlag stammt von mir. 
garric, garrig; ${ }^{116} \mathrm{sm}$. - Chêne. Le mot est tombé en désuétude; on dit aujourd'hui plutôt, càsse, càssou. Toutefois, au Médoc on a conservé garric. N. de p. V. garrits.

càssou-lèuje; ${ }^{117} \mathrm{sm}$. - Chêne-liège. Cf. coursiè, surrè.

èuse; sf. - Yeuse, chêne-.vert

eutze (Méd.); sm. - C. èuse, yeuse. On dit aussi éutzey.

\section{BEURTEILUNG VON GRÖßE UND FORM}

cassourràs; sm. - Chêne énorme.

cassourre; sf. - Chêne grand et fort; vieux chêne étêté, "décoiffé". V. cassourrà cassoue (Bas-Arm.). - C. cassourre.

garaboùsto (G.); sf. - Chêne mal venu, rabrougri; tige rabrougrie

cassourràt; sm. - Chêne de mi-force. Dans les L. chêne jeune.

cassarrî; sm. - Jeune chêne. V. cassiole, cassoulisse, cassouràt.

cassarrouat (Lom.). - C. cassarri.

cassoulét (B.-L.); sm. - Petite casserole. Ailleurs petit, jeune chêne.

cassenot; sm. - Petit, jeune chêne.

cassiole; sf. - Jeune chêne. V. cassarì, cassoàt.

cassoulisse; sf. - Jeune ou très jeune chêne. V. cassiole.

cassoàt, -e; s. - C. cassiole.

\section{EICHENWÄLDER, KONZENTRIERTE VORKOMMEN}

cassouadèy (L.); s. - Chênaie.

cassoulà, -làt, -rà; sm. - Chênaie à taillis, composée d'arbres jeunes. N. de p.

cassoulère; sf. - C. cassià; allée de chênes; bosquet de chênes.

cassià; sm.; cassie, cassière; sf. - Chênaie; quartier où le chêne domine. N. de p. et de 1., Cassie, Lacassie, Lascassies.

cassiàu; adj. des 2 g. - Qui est du chêne. Bosc cassiàu, bois de chêne.

116 'Garric' dient im Wesentlichen zur Bezeichnung einer mediterranen Variante der Eiche, die im Französischen chêne kermès genannt wird, von kleinerem, strauchartigem Wuchs ist und (ähnlich der Stechpalme) sehr harte Blätter hat. Diese für den Médoc typische Baumart ist im Béarn nicht zu finden. Ich habe daher darauf verzichtet, eine ganze Reihe von Ableitungen, die es von diesem Wort im Gaskognischen gibt, in meine Liste mit aufzunehmen.

${ }^{117}$ Auch bei der Korkeiche handelt es sich - ebenso wie bei der nachfolgend aufgeführten Grüneiche - um einen mediterranen Typus, der auch am Atlantik, nicht aber im Béarn vorkommt. Einige Lexeme, die im Umfeld der chêne-liège zu finden sind, habe ich daher ebenfalls nicht in meine Liste aufgenommen. Vgl. hierzu: Estalenx 1993, t. II, p. 797. 
cassiét; sm. - Petit bois. N. de 1.

cassagnau; s. des 2 g. - Chênaie; adj. qui est du chêne, propice au chêne; terre cassagnau. N. de p.

cassagne, cassagnère, cassière; sf. - Chênaie. $\mathrm{N}$. de p. et de 1 .

cassarrà; sm. - C. cassagne avec une nuance d'augm. N. de 1. et de p.

cassenàdo (G.); sf. - Forêt de chênes. V. cassière.

cassouléts; sm. pl. - On appelle ainsi communément les bosquets de jeunes chênes, les quartiers où se trouve un bosquet de chênes de haute futaie.

cassourrà, cassoure; s. - Lieu planté de chênes âgés et gros, cassourres.

cassourrùt, -de; adj. et $\mathrm{s}$. - Terrain où il y a beaucoup de chênes.

fourguéte; sf. - Petite chênaie. V. fourcade. N. de p. et de 1. Fourguette, Lafourguette.

fourcade; sf. - Ancien(t) chênaie. N. de p., Forcade, Fourcade, Lafourcade. V. hourcade.

garroulhe (Méd.); sf. - Coupée, taillis de chênes. En Arm., au pl., rejets qui poussent sur un tronc de chêne coupé.

cassagnàr, -e, -de; adj. - C. cassagnè, avec une nuance péjor. N. de p.

cassagnè, re; adj. - Qui est du chêne, propice au chêne. V. cassagnau.

cassiu, -ibe; adj. - Qui se rapporte au chêne; sol qui lui est favorable; loc cassiu. Cf. cassagnau.

cassouliu, -ibe; - C. cassiu.

\section{Abholzung, Entastung}

descassoulà; v. - Oter les chênes d'une chênaie.

escassoulà; v. - Couper des chênes, ébrancher, émonder des chênes, mais s'emploie aussi en général pour les grands arbres de toutes essences; au fig. essoriller.

escassoulade; sf. - Ebranchage, émondage.

escassoulàyre, -e; s. - Bûcheron.

\section{FRUCHT (EICHEL)}

aglàn; sm. - Gland.

aglanà; v. - Récolter la glandée; aglanà-s, se détacher, tomber comme des glands.

aglanade; sf. - Glandée.

aglanàdje; sm. - Panage, droit de mener à la glandée.

aglanadoù, -re; s. - Celui, celle qui cueille les glands.

aglandère; sf. - Quantité de glands; glandée. L'an de l'aglandère, l'an de la misère (dict.).

desglanà; v. - Dépouiller un chêne de ses glands; récolter des glands.

desglanade; sf. - Glandée.

esglanà; v. - Faire tomber les glands; faire la glandée; s'emploie au fig. avec le sens d'essoriller, de donner une frottée. 
glan. - C. aglàn, gland et dérivés.

glandàdje, glandade; $s$. - Glandée.

glandejà; v. - Faire la glandée.

glandère; sf. - Abondance de glands. - An de glandère, an de misère, année abondante en glands, année de misère (dict.).

glandoùs, -e; adj. - Glanduleux, -euse.

glanìu, -ibe; adj. - Qui produit des glands, an glaniu.

\section{KRANKHEIT (GALLE, TUMOR)}

cascorre (L.); sf. - Galle du chêne. Syn. chaborre, coucure. Dans la région de Chapbreton, la cascorre se nomme gargale si elle est grosse, gargaloùn si elle est petite. cassanère (Méd.); sf. - Noix de galle du chêne. Syn. cascarre. galhe (L.); sf. - Boule, galle du chêne. V. cascorre, gaherole, garole.

garole; sf. - Boule, bille, galle du chêne; ampoule, échauboulure. V. canique, bourole, paulhe, balohe, bàmpou, galhe.

gougale (As.); sf. - Boudin. V. gogue; ailleurs, galle du chêne. V. cascorre.

poudorcle $\left(\mathrm{M}^{\mathrm{t}}\right)$; poudòrle; sf. - Galle, boule du chêne. Cf. cascorre, gourre.

pouricane (Navarrenx); sf. - Galle de chêne, boule de bois; v. cascorre, garole.

Die hier aufgeführten 80 Lemmata mit direktem Bezug auf die Eiche spiegeln die oft hervorgehobene Vielfalt und den lexikalischen Reichtum der okzitanischen Dialekte wider. Unter dem Gesichtspunkt des heute noch vorhandenen und verifizierbaren Gebrauchs dieser Sprachformen ist eine solche Auflistung jedoch nicht informativ, da sie viel lexikalisches Material enthält, das in bestimmten Regionen nie gebräuchlich war oder bereits in Vergessenheit geraten ist. Dabei ist es voreilig, den Schluss zu ziehen, dass die Abnahme eines differenzierten lexikalischen Wissens in einem Dialekt ein direktes Anzeichen für das Schwinden seiner kommunikativen Funktion darstellt. Nicht nur in unserem Fall gibt es eine Reihe von Argumenten gegen diese Behauptung. Ich führe nachfolgend die wichtigsten Aspekte an und belege sie-teilweise im Vorgriff auf die Auswertung meiner empirischen Untersuchung-jeweils mit einer Beispielgebung aus dem oben dargestellten lexikalischen Umfeld der 'Eiche' bzw. auch der Begrifflichkeit für andere Baumarten:

(a) Es gibt eine vereinheitlichende Tendenz zu der Verwendung von Lexemen mit regional weiter gefasstem Geltungsbereich.

So setzt sich z.B. im gesamten Béarn càssou als Bezeichnung für die Eiche auch gegenüber den Varianten durch (vgl. in diesem Sinne auch die Aufgabe des Wortes garric zugunsten von càssou im Médoc). Dieses Phänomen erstreckt sich auch auf gebräuchliche Wortableitungen, die entweder standardi- 
siert werden oder immer regelhafter der Anwendung gängiger Ableitungsverfahren (Diminutiv, Augmentativ, etc.) entsprechen. Ein interessanter Fall ist z.B. das im gesamten Béarn bekannte Wortbildungsprodukt cassourre, das sich heute in der Bedeutung 'große, dominante, schöne Eiche' durchsetzt, so wie es einer regelhaften, aber seltenen Augmentativ-Suffigierung im Bearnesischen entspricht (vgl. Hourcade 1986, 204 f.). Demgegenüber hält sich z.B. im SW von Pau der Gebrauch dieser Ableitung im gegensätzlichen Sinn von 'kleine Eiche', obwohl die Benutzer eigenen Angaben zufolge wissen, dass es eigentlich 'große Eiche' bedeutet bzw. andernorts so gebraucht wird.

(b) Vielen Dialektsprechern sind variierende Regionalbezeichnungen eines Begriffs bekannt, ohne dass sie sie selbst verwenden.

Ich habe diese Erfahrung z.B. im Hinblick auf die Buche gemacht, für die mir von fast allen Probanden die alternativen Lexeme hag oder hau (mit jeweils nur einer lokal gängigen Form) genannt wurden. Z.T. war auch bekannt, dass für die Tanne, im Untersuchungsgebiet als sapî (oder fälschlicherweise als $p \hat{\imath}$ ) bezeichnet, im Gebirge abét verwendet wird. Bezüglich der Eiche konnte ich feststellen, dass z.B. die Varietät des tausî, die in der basse montagne seltener vorkommt, von Sprechern dieser Gegend dennoch als woanders verbreitete Varietät gekannt wurde. Insgesamt ist feststellbar, dass die mangelnde Normierung des Bearnesischen als Dialekt zu einer großen Toleranz der Gesprächspartner in Bezug auf die von anderen verwendeten Sprachformen führt, solange die kommunikative Verständigung gesichert ist. ${ }^{118}$ Allerdings darf dieses Phänomen nicht mit der höflichen Akzeptanz fehlerhafter Formen (wie sie vor allem jüngeren Dialektsprechern, aber auch Nicht-Bearnesen beim Gebrauch des Gaskognischen unterlaufen) verwechselt werden.

(c) Große Bereiche lexikalischer Differenzierung des Dialekts büßen ihre Funktionalität durch die Einflussnahme des Französischen ein.

Hierzu gehört das bekannte Eindringen von Französismen, das jedoch differenziert $\mathrm{zu}$ beurteilen ist und nicht verallgemeinernd als mangelnde oder schwindende Sprachkompetenz im Dialekt gewertet werden darf. Eine wichtige Rolle spielt z.B. der im Alltag beständig erforderliche Wechsel der Sprache bzw. die Dominanz des Französischen, als deren Folge z.B. die Kenntnis von im Dialekt seltener gebrauchten Begriffen nicht mehr vorausgesetzt werden kann. Ein solcher Fall liegt im Bearnesischen z.B. bei der Bezeichnung der

${ }^{118}$ Ich habe diese Erfahrung auch immer dann machen können, wenn ich die Hilfe von Bearnesen bei der Transkription von aufgezeichneten Texten anderer Sprecher in Anspruch genommen habe. 
Baumart Esche vor, die früher im Béarn nicht sehr verbreitet war, deren Vorkommen aber in jüngerer Zeit an Bedeutung zunimmt. Das Wort arrèchou, das im Bearnesischen nie so frequent war wie z.B. càssou, wird heute häufig durch den Gebrauch des französischen frêne verdrängt. Diesen Prozess setzen aber meiner Beobachtung nach nicht diejenigen in Gang, die das Wort arrèchou nicht mehr kennen (denn sie würden meist gar nicht mehr über die Esche auf Bearnesisch sprechen), sondern Bearnesisch-Sprecher, denen arrèchou zwar noch bekannt, aber nicht mehr vertraut ist und die das Wort in fachlichen Kontexten benutzen, die kommunikativ überwiegend durch den Gebrauch des Französischen charakterisiert werden.

Der beständige Wechsel zwischen Französisch und Bearnesisch drängt auch die Verwendung typisch bearnesischer Wörter zugunsten eines dem Französischen näher stehenden Wortgebrauchs zurück. Mir fiel z.B. auf, dass manche Probanden das bearnesische bàde (bzw. bàye) für 'wachsen' selten verwendeten und durch das dem Französischen ähnliche poussà ersetzten. Die mangelnde Kenntnis des Verbs bàde ist in diesem Fall allerdings auszuschließen, da bàde in der Bedeutung 'geboren werden' (naître) allgemein bekannt ist.

Interessant ist in diesem Zusammenhang auch die in den Befragungen konstatierte völlige Unkenntnis des Begriffs escassoulà und seiner Ableitungen. Das Fällen von Eichen als der typischen Baumart des Béarn hat diese Wortschöpfung zustande gebracht. Die Tatsache, dass der Begriff heute in Vergessenheit geraten ist, liegt aber nicht daran, dass die Eichenbestände der Region an Bedeutung verloren hätten. Vielmehr ist zu vermuten, dass die mangelnde Entsprechung im Französischen und die leichte Ersetzbarkeit durch Wörter, die denselben lexikalischen Inhalt ohne Einschränkung auf die Eiche zum Ausdruck bringen (hà càde, abàte, coupà, fr. faire tomber, abattre, couper) zu dem Untergang des Begriffsfelds geführt haben.

Auch die Tatsache, dass der Reichtum an Derivationsstrukturen des bearnesischen Dialekts im Französischen keine Entsprechung findet, beschleunigt im Sprachkontakt die Aufgabe einer Reihe von dialektalen Wortbildungsprodukten. Die vielen Formen beispielsweise, die das Bearnesische für den 'Eichenwald' bereithält, können im Französischen nur durch chênaie oder bois / forêt de chênes wiedergegeben werden, wobei die Verwendung des mehrgliedrigen Ausdrucks weitaus frequenter ist. Die Sprecher des Bearnesischen passen sich hier an und benutzen immer weniger die möglichen Wortbildungen (nach meiner Beobachtung setzt sich heute nur noch cassourrà durch), um vielfach wie im Französischen von einem bòs de càssous oder auch von einer 'forêt' de càssous zu sprechen. 
(d) Der Dialektwortschatz verändert sich durch die sachliche Bedeutungsabnahme vieler lexikalischer Bereiche und durch das Hinzukommen neuer Bezeichnungsnotwendigkeiten.

Dieses allgemein bekannte Faktum hat große Auswirkungen auf die Strukturveränderungen des dialektalen Wortschatzes. Das Beispiel der 'Eichel' zeigt, dass mit dem Rückgang der wirtschaftlichen Bedeutung dieser Baumfrucht (insbesondere für die Schweinefütterung) auch die entsprechende Bezeichnungsvielfalt aufgegeben wurde. Allerdings gilt dies mit Einschränkungen. Selbstverständlich bleibt der zentrale Begriff aglàn bzw. glan allgemein bekannt. Dies gilt auch für die transparenten Wortableitungen, im besonderen Fall also für nahezu das gesamte Begriffsfeld, das zumindest passiv für die meisten Sprecher verständlich bleibt. Im Zusammenhang mit dieser passiven Kenntnis werden auch feine Differenzierungen noch aufrecht erhalten. So bestätigten mir die meisten Probanden, dass aglanà das Aufsammeln von Eicheln zur Verfütterung bezeichne, also die menschliche Tätigkeit (die es schon längst nicht mehr gibt!), während glandejà in Bezug auf Tiere (z.B. Tauben) angewendet werde, die natürliche Vorkommen von Eicheln zur Futteraufnahme nutzen (z.B. las paloumes glandèjen). ${ }^{119}$ Damit geht der Differenzierungsgrad des Wortschatzes an dieser Stelle sogar über die lexikographische Erfassung hinaus. Insgesamt bilden die Lexeme im Begriffsfeld der Eichel den interessanten und gar nicht seltenen Fall, dass eine sachbereichsbezogene Vielfalt an Lexemen den Dialektsprechern noch bekannt ist, obwohl die meisten der Lexeme wegen des Fehlens kommunikativer Relevanz von ihnen nicht mehr aktiv verwendet werden. Diese lexikalischen Sachbereiche haben, wenn ich nach ihnen fragte, die Sprecher immer wieder zu Erzählungen von früher veranlasst.

Anders verhält es sich bei der Kenntnis der verschiedenen Eichenarten, die heute-mit Ausnahme des tausî-im Bearnesischen nicht mehr sprachlich genuin unterschieden werden. Hier hat der fachliche Zugang zum Kommunikationsbereich entscheidende Veränderungen bewirkt. Während es früher scheinbar eine aus der bearnesischen Alltagserfahrung heraus gewonnene Begriffsdifferenzierung gab (càssou, doulh, tausî, miey-tausî́) ${ }^{120}$, wird diese

${ }^{119}$ Diese Bedeutung spielt regional weiterhin eine wichtige Rolle, da sie in das kommunikative Feld der Taubenjagd gehört, die im Béarn eine lange Tradition hat und noch heute leidenschaftlich betrieben wird.

${ }^{120}$ Ich verweise an dieser Stelle zurück auf die weiter oben in den Zitaten zu findenden Versuche einer botanischen Einordnung der gaskognisch bezeichneten Eichenarten im Wörterbuch von S. Palay. Verglichen mit der durch die heutigen Fachinstitutionen erläuterten Klassifikation (siehe den nachfolgenden Text) entsprechen diese Einordnungen des gaskognischen Wörterbuchs nicht dem botanischen Kenntnisstand. Die Logik der bearnesischen Differenzierungen lässt sich aus dem lexikographischen Befund leider nicht rekonstruieren. 
heute vollkommen durch die französisch geprägte botanisch exakte Unterscheidung der Eichenarten abgelöst. An dieser Unterscheidung jedoch hat das Bearnesische kaum noch einen eigenen Anteil. Die im Béarn hauptsächlich vertretenen Eichenarten werden heute im Französischen wie folgt differenziert:

- chêne pédonculé (quercus robur, quercus pedunculata), dt. 'Stieleiche'; $80 \%$ der einheimischen holzproduzierenden Eichen in Aquitanien, wird in Frankreich auch als chêne commun bzw. landesüblich als chêne de pays bezeichnet, kommt in mehreren Subvarietäten vor, eignet sich zur Edelholzgewinnung

- chêne rouvre (quercus sessilis, quercus sessiliflora, quercus petraea), dt. 'Steineiche'; 20\% der einheimischen holzproduzierenden Eichen in Aquitanien, meist angepflanzt, eignet sich zur Edelholzgewinnung

- chêne pubescent (quercus pubescens), kleinere Eichenart, liebt Kalkböden, nur für minderwertige Holzgewinnung geeignet

- chêne tauzin (quercus pyrenaïca), für den mittleren und nördlichen Béarn typische kleinwüchsige Eichenart, liebt saure Böden, teilweise zur Brennholzgewinnung genutzt

- chêne rouge d'Amérique (quercus rubra, quercus borealis), aus Nordamerika importierte, schnellwachsende Eichenart, verträgt saure Böden, zur Edelholzgewinnung geeignet, im Béarn selten, Anpflanzung wird staatlich gefördert

Im Fall des chêne tauzin wurde die französische Bezeichnung aus dem auch heute noch im Bearnesischen allgemein bekannten tausî entlehnt. Ansonsten gibt es keine lexikalischen Entsprechungen im bearnesischen Vokabular. Der chêne pédonculé wird meist als càssou dou pèis bezeichnet, selten - in fachspezifischen Zusammenhängen - auch als càssou pedonculàt (oder sogar càssou 'pédonculé'). Die Verwendung von càssou allein schließt auch den chêne rouvre mit ein. ${ }^{121} \mathrm{Ob}$ es eine besondere Bezeichnung für den chêne pubescent im Bearnesischen gibt, konnte von mir nicht ermittelt werden. ${ }^{122}$ Die quercus rubra wird im Bearnesischen meist als càssou d'Amerique bezeichnet und als nicht landestypische Varietät von allen, die sie kennen, ${ }^{123}$ klar identifi-

${ }^{121}$ Meinen Untersuchungen zufolge haben die fachlich nicht speziell interessierten Bearnesen in der Regel keine Kenntnis von der Artendifferenzierung in pédonculé und rouvre, obwohl das Identifikationskriterium der Eichelaufhängung an einem pédoncule (dt. Stiel) für die Landeseiche sehr charakteristisch und gut zu erkennen ist.

${ }^{122}$ Die von S. Palay angegebenen Bezeichnungen càssou bastàr (Gers) und doulh für die quercus pubescens wurden in meinen Befragungen im Béarn nicht bestätigt.

${ }^{123}$ Es ist zu berücksichtigen, dass der chêne rouge d'Amérique aufgrund seiner wirtschaftlichen Lukrativität heute einen breiteren Platz in der sektoriellen Kommunikation einnimmt als der traditionell schon immer vorhandene, aber weitgehend wertlose tausî. 
ziert (zumindest an der herbstlichen Rotfärbung der Blätter). Als Fazit kann also festgehalten werden, dass es keine Bezeichnungsschwierigkeiten in Bezug auf die Unterscheidung der Eichenvarietäten im heutigen Bearnesisch gibt, dass aber andererseits die traditionelle lexikalische Differenzierung des Bearnesischen in diesem Bereich nur noch in einer Ausnahme greift.

Hierzu ergänzend lässt sich feststellen, dass die institutionell geförderte Nutzung des Waldes im Béarn einige Baumarten an Bedeutung gewinnen lässt, denen früher diese Bedeutung kaum oder gar nicht zukam. Die Beispiele der Esche (frêne) und der Roteiche (chêne rouge) habe ich schon angeführt. In sprachlicher Hinsicht bringt auch der Vogelkirschbaum, fr. merisier, dessen forstwirtschaftliche Bedeutung im Béarn zunehmend betont wird, eine Schwierigkeit mit sich. Da das Bearnesische für diese Baumart nur den unpräzisen Begriff serisè (entsprechend dem fr. cerisier, also 'Kirschbaum') zur Verfügung stellt, bedient man sich heute im Bearnesischen meist des eindeutigeren französischen Begriffs. Andere Baumarten, die in die forstwirtschaftliche Diskussion geraten, wie z.B. die Weißbuche, fr. charme oder die Schwarzerle, fr. vergne (aulne glutineux), sind im Béarn selten anzutreffen und ihre traditionellen Bezeichnungen (charmilhe, bèr) werden kommunikativ so schwach repräsentiert, dass sie in der Regel nicht mehr reaktiviert werden können. Es liegt also die Logik vor, dass autochthone Begriffe der Regionalsprache gerade deshalb nicht mehr verwendet werden, weil sie plötzlich einen besonderen kommunikativen Stellenwert bekommen, der den Traditionen der Sprachverwendung nicht entspricht. ${ }^{124}$

Veränderungen in der Konfrontation mit dem Sachbereich sind auch der Grund für die heute im Bearnesischen üblicherweise nicht mehr verbreiteten lexikalischen Kenntnisse zum Phänomen der Tumorbildung bei der Eiche. Die Auseinandersetzung mit dieser Baumerkrankung ist für die meisten privaten Waldbesitzer heute keine Lebensrealität mehr. Dies liegt weniger an einem Rückgang der Krankheit als vielmehr an dem Wandel des Verhältnisses von Mensch und Natur. Der Wald wird im Béarn - wie anderswo auch - vorwiegend unter dem Aspekt seiner Nutzbarkeit betrachtet bzw. dort, wo er nicht nutzbar ist (wie vielerorts im Béarn) nur als Dekor wahrgenommen. Gallenbläschen auf Eichenblättern oder Tumorauswüchse an den Stämmen spielen in dieser Wahrnehmung keine beachtenswerte Rolle. Sie bilden somit üblicherweise auch keinen Kommunikationsgegenstand. Wenn Krankheiten dennoch den Erfolg des Waldbaus bedrohen, so sind Rat und Hilfe durch die fachlichen Institutionen gesichert. Die Kommunikation läuft in diesem Fall rein auf Fran-

${ }^{124}$ Dies ist z.T. auch ein sprachpsychologisches Problem. Gerade der spezifische Gebrauchswert eines Begriffs - und nicht etwa sein Nicht-Vorhandensein - rechtfertigt häufig seine Übernahme als Entlehnung aus einer fremden Sprache. Dieses Phänomen ist z.B. bei der Anglizismenflut in den europäischen Sprachen zu konstatieren. 
zösisch (im konkreten Fall würde evtl. eine Konfrontation mit dem Fachvokabular chancre, broussin, galle erfolgen). Kurz gesagt, macht es keinen Sinn mehr für die Bearnesen, sich ihr vorhandenes bearnesisches Spezialvokabular zu manchen Sachbereichen zu erhalten, wenn veränderte Traditionen der Lebensbewältigung, zu denen auch neue sprachliche Normsetzungen gehören, den kommunikativen Wert der sprachlichen Tradierung in der Regionalsprache in Frage stellen.

Was ist nun die Quintessenz all dieser Feststellungen? Zunächst einmal gilt es festzuhalten, dass die lexikographisch überlieferte Fülle des fachspezifischen Vokabulars, dort wo sie in einer regressiven Regionalsprache traditionell vorhanden ist, aufgrund der veränderten Kommunikationsbedingungen drastisch abnimmt und in großen Teilen von den Sprechern allenfalls nur noch passiv beherrscht wird. Diese Beobachtung ist jedoch keine Verifikation des langsamen 'Aussterbens' der Regionalsprache, vielmehr spiegelt sie die Anpassung an neue Sprechtraditionen wider, die in einer kontaktsprachlichen Situation von der dominanten Sprache oktroyiert werden. Die entsprechenden Anpassungsmechanismen reduzieren die sprachliche Vielfalt des Dialekts bzw. der Regionalsprache auf das normale Maß einer normierten Sprache. Der Normierungsprozess wird dabei indirekt (durch den Gebrauch des Französischen) vermittelt. Zugleich bewirkt der Anpassungsdruck an die dominante Sprache die schnelle Aufgabe autochthoner Wortschatz- und Wortbildungsstrukturen, deren Resultat in der Regel eine sprachliche Verarmung und Fremdbestimmtheit ist. Unter dieses Phänomen fällt auch das massive Eindringen von lexikalischem Lehngut aus der dominierenden Sprache. Zuletzt bleibt noch zu erwähnen, dass die dominierende Sprache in einer Sprachkontaktsituation die Veränderungen der Lebensrealität weitaus schneller und effektiver in Kommunikationssituationen verarbeitet und in Sprechtraditionen umsetzt als die dominierte Sprache. Dieser bleibt dann häufig nur noch die Nachahmung der neuen Sprechtraditionen mit ihren eigenen Mitteln.

Es wäre falsch, aus dieser Quintessenz den Schluss zu ziehen, das Bearnesische sei im Kontakt zum Französischen grundsätzlich verarmt und verliere an kommunikativem Wert. In der Tat kann dies nicht das Ergebnis einer kommunikationsstrukturell orientierten Anpassung des Bearnesischen an das Französische sein. Zudem muss in Rechnung gestellt werden, dass das Anpassungsmodell selbst in der regionaltypischen Alltagskommunikation sprachlich reduziert und teilweise sehr einfach strukturiert ist. Ich werde dieses Phänomen in Bezug auf den untersuchten Sachbereich an späterer Stelle noch ausführlich dokumentieren. Zuvor aber geht es mir darum, am Beispiel des bearnesischen Vokabulars zum Wald und seiner Nutzung aufzuzeigen, dass unter den tatsächlichen Sprechern des Bearnesischen ausreichende lexikalische Kenntnisse 
vorhanden sind, um diesen Sachbereich kommunikativ zu bewältigen. Dabei stelle ich die These auf, dass die durch das Lexikon gegebenen regionalen Inhaltsbezüge des Sachbereichs im Bearnesischen großenteils noch heute die sprachliche Alltagsbewältigung in einer viel authentischeren und identifikationsstiftenderen Weise ermöglichen als der ansonsten übliche regionale Sprachgebrauch des Französischen. 


\subsubsection{Empirische Überprüfung der Kenntnis und Verfügbarkeit des bearnesischen Wortschatzes im Kommunikationssektor 'Wald und Nutzung des Waldes'}

Um das notwendige Datenmaterial zu sammeln, habe ich im März 1997 eine Feldforschungsreise in den Béarn unternommen. Mein Untersuchungsgebiet lag in einem Radius von ca. $35 \mathrm{~km}$ um die Stadt Pau. Neben vielen informellen Fachgesprächen vor Ort führte ich insgesamt 8 systematische Probandenbefragungen durch, deren Ergebnisse aufgezeichnet und ausgewertet wurden. Im Einzelnen danke ich den folgenden Gesprächspartnern für ihre Auskünfte:

P1: Francis C., Maspie-Lalonquère-Juillacq (C. Lembeye)

49 J., Landwirt, Waldbesitz ca. 10 ha, traditionelle Waldnutzung und Jagd, kein Waldbau

Gesprächsdauer: ca. 45 Min. (Q.mp3: 44:01)

P2: Mauricette R., Maspie-Lalonquère-Juillacq (C. Lembeye)

39 J., Landwirtin, verheiratet mit P1, verrichtet selbst keine Tätigkeiten im Wald

Gesprächsdauer: ca. 70 Min. (Q1.mp3: 45:37, Q2.mp3: 24:52)

P3: Joseph B., Coslédaà-Lube-Boast (C. Lembeye)

63 J., ehem. Landwirt und Schweinezüchter, Waldbesitz ca. 50 ha, davon 25 ha umgewandeltes Agrarland (Anpflanzungen), betreibt Waldbau mit staatlicher Förderung, verrichtet leichtere Waldpflegemaßnahmen selbst

Gesprächsdauer: Erklärungen auf Anpflanzungen und im Wald ca. 2 Std. 30 Min. (E1.mp3: 46:21, E2.mp3: 45:29, E3.mp3: 51:23), als Befragung ca. 90 Min. (Q1.mp3: 33:31, Q2.mp3: 57:46), gesamt: ca. 4 Std.

P4: Jean Marie Albert Mené, ${ }^{125}$ Conchez-de-Béarn (C. Garlin)

70 J., ehem. Landwirt, Waldbesitz ca. 8 ha; lässt sich vom CRPF beraten, bislang keine aktiven Waldbaumaßnahmen

Gesprächsdauer: ca. 75 Min (Q1.mp3: 46:26, Q2.mp3: 27:14)

P5: Albert P., Aubertin (C. Lasseube)

65 J., ehem. Lehrer (Englisch, Französisch, Okzitanisch), kein Waldbesitz, Interesse an bearnesischer Sprache (Autor von Regionalliteratur)

Gesprächsdauer: ca. 90 Min. (Q1.mp3: 44:30, Q2.mp3: 45:28)

${ }^{125}$ Bei der Befragung war auch seine Frau Charlotte (70 J.) anwesend, der ich für ihre Mitwirkung ebenfalls danke. 
P6: Roger H., Lasseube (C. Lasseube)

69 J., ehem. Landwirt und Fischzüchter, bewirtschaftet mehr als 100 ha Wald, größtenteils Eigenbesitz; widmet sich intensiv dem Waldbau, Fachmann mit leitenden Funktionen in forstwirtschaftl. Institutionen

Gesprächsdauer: ca. 80 Min. (Q1.mp3: 46:43, Q2.mp3: 32:49)

P7: Hubert S.-B., Monein (C. Monein)

70 J., ehem. Bankangestellter (anfängl. Landwirt), Waldbesitz ca. 24,5 ha, betreibt keinen Waldbau, Interesse an bearnesischer Sprache (sporadische Kontakte zur okzitanistischen Organisation Per Noste)

Gesprächsdauer: ca. 90 Min. (Q1.mp3: 46:03, Q2.mp3: 46:28)

P8: Pierre M.-C., Audaux (C. Navarrenx)

ca. 70 J.; ehem. Landwirt, stammt aus Lons (C. Lescar), Waldbesitz ca. 50 ha, betreibt aktiv Waldbau, Fachmann mit leitenden Funktionen in forstwirtschaftl. Institutionen, Interesse an bearnesischer Sprache (Anhänger der traditionellen Schule Gastô̂ Febús)

Gesprächsdauer: ca. 90 Min. (Q1.mp3: 44:27, Q2.mp3: 46:25)

Die Gespräche wurden mit allen Probanden in ihrem eigenen Haus geführt. Die Wohnorte von P1-P4 liegen im Nordosten von Pau, diejenigen von P5-P8 westlich der Hauptstadt. Dadurch ergab sich eine mikroregionale Vergleichbarkeit der Ergebnisse, die jedoch insgesamt nur marginale Unterschiede im lexikalischen Sprachgebrauch erkennen ließ. ${ }^{126}$

Eine grobe Aufteilung in Experten und Laien würde P3, P6 und P8 der Gruppe der Fachleute zuordnen. Darüber hinaus sind auch P1 und P4 in ihrer Lebensrealität mit dem Sachbereich direkt konfrontiert. $\mathrm{Zu}$ den absoluten Laien hingegen zählen P2, P5 und P7. Damit ergibt sich ein ausgeglichenes Verhältnis im fachlichen Kenntnisstand der Probanden. ${ }^{127}$

${ }^{126}$ Diese Aussage gilt selbstverständlich mit den üblichen Einschränkungen einer dialektalen Sprachvariation, die bis zu der lokalen Bindung bestimmter Sprachformen reicht. Mein Untersuchungsinteresse war jedoch nicht sprachgeographisch ausgerichtet.

${ }^{127}$ Ich kann im Rahmen dieser Auswertung auf die Unterschiede des lexikalischen Kenntnisstands bei den Experten und bei den Laien nicht im Einzelnen eingehen. Insgesamt aber fiel auf, dass alle Probanden ein sehr ähnliches Wissensniveau aufwiesen. Der erfragte Wortschatz erwies sich in diesem Sinne nicht als typischer Fachwortschatz terminologischen Charakters, der nur wenigen Fachleuten zugängig ist. Die Kenntnis entlegenerer oder veralteter Wörter hing meiner Beobachtung nach eher von dem Grad der allgemeinen Vertrautheit mit der bearnesischen Sprache ab. Die beiden jüngeren Probanden P1 und P2 stellten in diesem Sinne, obwohl sie keine Experten sind, ein erstaunlich differenziertes Wissen unter Beweis, da sie beide in einem sehr engen Kontakt zum Bearnesischen als der vorrangig benutzten Alltagssprache in ihren Familien sozialisiert worden sind. Gleiches gilt für die Laien P5 und P7, die beide nicht nur authentische Sprecher sind, sondern als 'Sprachliebhaber' auch einen intellektuellen Zugang zum Bearnesischen dokumentieren. 
Weniger ausgeglichen ist hingegen die Altersstruktur. Die Gründe hierfür wurden bereits genannt, nämlich zum einen die abnehmenden Sprachkenntnisse des Bearnesischen in der jüngeren Generation, zum anderen die typische Interessennahme am Wald erst nach dem Ausscheiden aus dem aktiven Berufsleben (alle drei Experten sind retraités!).

Die Tatsache, dass unter den Probanden nur eine Frau ist, entspricht der traditionellen Aufgaben- und Rollenaufteilung, aufgrund deren die Frauen bis in die Gegenwart hinein in der Regel keinen Zugang zu Waldnutzung und Waldbau haben.

Die Befragungen wurden offen als Gespräche auf der Grundlage einer sehr ausführlichen Wortliste geführt. Die verwendete Sprache war in allen Fällen das Bearnesische. ${ }^{128}$ Die Wortliste umfasste insgesamt 500 Begriffe, die einer Auswahl von $50 \%$ des als Vorbereitung auf die enquête lexikographisch erfassten Materials entsprach (siehe Kapitel 2.2.1). Die Reduzierung wurde nach fachinhaltlichen, linguistischen und pragmatischen Kriterien vorgenommen, um die lexikographische Datenbasis überschaubar zu halten. Mit derselben Zielsetzung wurden alle in der Datenbasis verbleibenden Begriffe inhaltlich gruppiert und durch Markierung schließlich einer weiteren Auswahl in der Größenordnung von $20 \%$ unterzogen. Die so vorbereitete Wortliste (500 bearnesische Begriffe thematisch geordnet, davon 100 markiert) bildete eine geeignete Grundlage für die einzelnen Befragungen. ${ }^{129}$

Einen Sonderfall stellten die Gespräche mit P3 dar. Herr Bourguinat war so freundlich, mir zweieinhalb Stunden lang spontane Erklärungen zum Thema bei einer Begehung vor Ort in seinen Anpflanzungen und Wäldern zu geben. Er bediente sich dabei ausschließlich des Bearnesischen, weshalb die Tonbandaufzeichnung des gesamten Gesprächs ein wichtiges Sprachdokument darstellt (siehe auch Kapitel 2.3). Um Wiederholungen zu vermeiden, habe ich die nachfolgende Befragung von P3 entsprechend angepasst.

Die Probanden im nordöstlichen Béarn (P1B P4) haben mir zusätzlich eine Liste von ca. 50 Wörtern kommentiert, die ich aus der in Kapitel 2.1.1 zitierten Quelle, dem Glossar des Ausstellungsbegleitheftes Le bois en Béarn \& son

${ }^{128}$ Dies erwies sich als sehr vorteilhaft für die Gewinnung unverfälschter und möglichst präziser Informationen. Die Probanden wurden auf diese Weise nicht auf Französisch über eine andere Sprache befragt, sondern in einen kommunikativen Bereich ihrer eigenen Sprache versetzt. Sie bewiesen dabei durchweg eine große Auskunftsfreudigkeit und gaben spontan Definitionen und Erklärungen, aber nur selten französische Übersetzungen zu den erfragten Begriffen.

${ }^{129}$ Die schriftliche Zusammenstellung des thematischen Vokabulars weckte bei den Probanden P2, P3 und P5 Interesse an einer Einsichtnahme während der Befragung, die ich allerdings weitgehend vermied. P7 wurde die Liste durch Per Noste im Vorfeld der Befragung übermittelt, woraufhin dieser Proband so freundlich war, eine Reihe schriftlicher Kommentare und Ergänzungen vorzunehmen. 
exploitation (Pau 1979) kurzfristig extrahiert habe. ${ }^{130}$ Der Sinn dieser Zusatzbefragung lag darin, die in dem besagten Glossar von ca. 300 Wörtern etwas anders gewichtete Selektion von Begriffen in meiner enquête mit $\mathrm{zu}$ berücksichtigen.

Alles in allem führte die empirische Untersuchung im März $1997 \mathrm{zu}$ einem Datenmaterial von 13 Stunden Tonbandaufzeichnung, die ich anschließend mit dem in Kapitel 2.1.1 dargestellten Verfahren digitalisiert und systematisch ausgewertet habe. ${ }^{131}$ Die Ergebnisse dieser Auswertung sollen, soweit sie das Thema der Untersuchung betreffen, im Folgenden zusammenfassend dargestellt werden.

\subsubsection{Die Bezeichnungen für 'Wald, Holz, Waldarbeit und Wald- arbeiter'}

Im Bearnesischen (' B.) gibt es nur das Lexem bos(c) [bòsc ${ }^{132}$, üblicherweise im Plural verwendet (lous bos), zur Bezeichnung des Waldes. Prinzipiell ist bos damit auch eine Übersetzung von fr. forêt (und nicht nur von fr. bois in der Bedeutung von 'Wald'). ${ }^{133}$ Allerdings wiesen die Sprecher darauf hin, dass fr. forêt keine Entsprechung im B. finde, da es keine großen Wälder im Béarn gebe, und schlugen nötigenfalls ersatzweise sogar die Übernahme von forêt ins B. vor (z.B. ue 'forêt' de càssous, vgl. P4, Q1.mp3, 4:37 u. 39:20). ${ }^{134} \mathrm{Die}$ älteren Bezeichnungen für den Wald im B., séube und hourc, leben heute nur

${ }^{130}$ Durch einen freundlichen Hinweis von Herrn Peyroutet aus Aubertin (P5) bin ich erst während meines Feldforschungsaufenthalts in den Besitz dieses Ausstellungsheftes gelangt.

${ }^{131}$ Ich behalte mir vor, diese Auswertung an anderer Stelle ausführlicher darzulegen. Im Rahmen dieser Arbeit würde dies zu weit führen und auch dem thematischen Anspruch der hier vorgelegten empirischen Untersuchung insgesamt nicht mehr entsprechen.

${ }^{132}$ Ich verwende in diesem Kapitel die von S. Palay in seinem Wörterbuch benutzte Graphie, die - in der Tradition des Félibrige - sich weitgehend nach den Ausspracheregeln der französischen Orthographie richtet und ein differenziertes Bild von der lautlichen Partikularität der Wörter gibt. In den Fällen gebräuchlicherer Lexeme ergänze ich in eckigen Klammern die Schreibung nach den Regeln des I.E.O., die auf dem Kodifikationsvorschlag von Louis Alibert (vgl. Alibert 1966) beruht und, wohl aufgrund ihrer etymologisierenden Prinzipien, im Béarn als graphie classique bekannt ist. Die Schwierigkeiten hinsichtlich der Durchsetzung einer normierten Rechtschreibung des Okzitanischen werden sehr ausführlich in Kremnitz 1974 und 1979 aufgearbeitet.

${ }^{133}$ Herr Michel Grosclaude bedauerte mir gegenüber in einem Gespräch, dass das moderne B. eigentlich über kein Wort zur Übersetzung von fr. forêt mehr verfüge, und schlug die Wiederbelebung des altbearnesischen séube [seuva] ( $<$ lat. silva) vor. Dieser Begriff ist heute allerdings gänzlich unbekannt, obwohl er sich noch in der Toponymie des Landes findet (P5 und P6 wohnen im Canton Lasseube, betrachten das entsprechende Lexem aber als nicht (mehr) zum B. gehörig!).

${ }^{134} \mathrm{Vgl}$. in diesem Zusammenhang auch den Titel der Studie von Alain Berton (1993): La Forêt $d u$ Nord-Est du Béarn. In offiziellen fachlichen (forstwirtschaftlichen) Kontexten wird fr. 
noch in Orts- und Personennamen weiter (z.B. Lasseube, Hourcade). ${ }^{135}$

Die Unterscheidung von bòs und boès bzw. bòy, die beiden Letzteren zur Bezeichnung des Holzes, wird im B. sehr bewusst getroffen (z.B. P8, Q1.mp3, 0:50, der zur Bedeutungsspezifizierung von boès auf span. madera hinwies). Dabei ersetzen, je nach Region, heute boès oder bòy das alte b. Wort hust(e) (vgl. katal. fusta), dessen Wiederbelebung durch die Okzitanisten noch angeregt wird (vgl. P7, Q1.mp3, 4:14, 6:22, 7:08, der einen intellektuellen Zugang $\mathrm{zu}$ hust (e) dokumentiert und auf die etymologischen Zusammenhänge von hust und fr. fût verweist), obwohl es nach den Ergebnissen meiner Befragung inzwischen völlig unbekannt ist (so auch bei den stärker durch das Sachgebiet Betroffenen wie z.B. P3, Q2.mp3, 1:36 u. P8, Q1.mp3, 3:06).

Aus etymologischer Sicht ist hervorzuheben, dass das B. traditionell eine lexikalisch-semantische Differenzierung des Holzes nach seinem Verwendungszweck vornimmt, die sich jedoch nur noch rudimentär im aktuellen Sprachgebrauch erhalten hat. So wurden hust und huste für das Bauholz verwendet (daher auch die Ableitung hustè 'charpentier'), während légne [lenha] (vgl. kat. llenya, kast. leña) zur Bezeichnung des Brennholzes diente und als Ableitung u.a. legnadoù bzw. legnassè (gebietsweise in der erweiterten Bedeutung 'bûcheron') hervorbrachte. Diese funktionelle Differenzierung des HolzBegriffs ist heute weitgehend aus dem B. verschwunden. Als einzige Ausnahme konnte ich die noch vorhandene (bzw. reaktivierbare) Kenntnis des Lexems légne konstatieren (so auch bei den noch jüngeren P1, Q.mp3, 1:03 u. P2, Q2.mp3, 2:05). ${ }^{136}$

Das Wort légne ist ein interessantes Beispiel für den Erhalt einer spezifischen Bedeutung. So scheint légne traditionell Zweige und Reisholz zu be-

forêt zur Bezeichnung des Waldes bevorzugt. Dennoch bestätigt der Dictionnaire Forestier Multilingue $(1975,29)$ unter den Kennzahlen 6703 und 6704 die Bedeutung 'Wald' von fr. bois: „(1) Ensemble d'arbres poussant plus ou moins près les uns des autres et couvrant un certain espace. (2) L'ensemble de ce terrain et du bois qui le couvre." Als Anmerkung wird u.a. ergänzt: ,(1) d'une façon générale un bois couvre une surface de moindre étendue qu'une forêt; il peut ou non comporter un (ou des) peuplement(s) forestier(s) bien défini(s); [...]“. Die Bezeichnung forêt passt streng genommen nicht zur Realität der kleineren Waldvorkommen im Béarn, was typischerweise von Béarnesisch-Sprechern auch so empfunden und geäußert wird. Auch im regionalen Gebrauch des Französischen ist das Wort bois 'Wald' wesentlich frequenter als forêt.

${ }^{135}$ Bei meinen lexikographischen Recherchen bin ich auf eine Vielzahl von Bezeichnungen für den Wald und bestimmte Waldtypen gestoßen, die im B. nicht mehr bekannt sind, aber von einer außergewöhnlichen Differenzierung des traditionellen Wortschatzes in diesem Bereich zeugen. Die meisten dieser Wörter leiten sich aus den drei Grundlexemen bòs, séube und hourc ab, so z.B. bouscàs (bouscassà) 'bois mal entretenu, vilain bois', seubole 'forêt de peu d'étendue', hourcàu (hourcade) 'bois, terrain boisé'.

${ }^{136}$ Allerdings scheint sich die Bed. von légne heute so zu verlagern, dass es nur noch zur Bez. der kleineren Brennholzscheite und Äste (zum Anfeuern) verwendet wird. 
zeichnen, die zu sog. fagots (fr. fagot 'Reisigbündel') gebunden wurden und zur Anfeuerung des Kamins dienten. P1 z.B. präzisiert: ${ }^{137}$

La légne qu'ey meilèu, au cap dous grans tros, la petite brouste qué?...La légne d'abitude que serbibe endà hà lous fagòts... Me lou fagòt autes-còps que hasèn û fagòt endà ahumà lou houèc, a la cheminèje. Qu'ère lou boès hère fî. $E$ après que hicaben las gròsses ascles.

(P1, Q.mp3, 1:21)

Obwohl die Kaminfeuerung immer noch eine intensive Form der Holznutzung im Béarn darstellt, wird légne heute kaum mehr verwendet und gerät in Vergessenheit (so z.B. bei P3 und P4). Die funktionelle Differenzierung der Holzart erfolgt daher im B. begrifflich inzwischen ebenso wie im Fr. durch boès d'òbre (fr. bois d'ouvre) und boès de cauhàdje (fr. bois de chauffage). Dabei sind die Begriffsfelder zu beiden Bereichen der Holzverwertung noch relativ gut bekannt.

Kommen wir noch einmal auf die Bezeichnungen des Waldes im Béarn zurück. Mir fiel auf, dass neben dem neutralen bos häufig speziellere, auf die regionalen Gegebenheiten abgestimmte Begriffe Verwendung finden. Hierzu zählen zum einen Lexeme für Ansammlungen bestimmter Baumarten (z.B. castanhét 'kleiner Kastanienwald' oder cassourà 'Wald von großen Eichen', vgl. P3, Q1.mp3, 5:16, 26:19), zum anderen aber auch Wörter, die den für die Region so typischen Wildwuchs forstwirtschaftlich nicht gepflegter Waldparzellen zum Audruck bringen. Der zentrale Begriff ist hier fourastà oder fourastè, den z.B. P5 (Q1.mp3, 10:00) wie folgt definiert: ' $\hat{u}$ tros de bos oun i a arbes e sègues e bruchagues' (fr.: 'un morceau de bois où il y a des arbres, des ronces et des broussailles'). ${ }^{138}$ Sègues und bruchagues sind zwei zentrale Begriffe zur Charakterisierung des bearnesischen Waldes. Der Béarn ist ein pays des ronces (so eine spontane Formulierung des technicien forestier Alain Berton, CRPF, Orthez), d.h. eine Gegend, in der die Wälder in extrem starker Weise von dichtem Dornengestrüpp durchdrungen sind. Dabei gehören die ronces nicht nur einfach zu der bearnesischen Waldlandschaft, sie stellen aufgrund der durch sie gegebenen Behinderung auch einen stark hemmenden Faktor für den effektiven Waldbau dar. Zusammen mit ihnen wächst in den dichten Wäldern des Béarn viel Gestrüpp und Buschwerk (bruchagues), das den Nutzbäumen die Kraft nimmt, hoch genug zu wachsen, um eine respektable futaie (dt. 'Hochwald') zu bilden. Dementsprechend gibt es auch keine

${ }^{137}$ Vgl. hierzu folgende Definitionen des Wörterbuchs von Palay: brouste 'brout, jet d'arbre, pousse, branche'; ascle 'morceau de bois fendu, éclaté'; légne 'bûche, branche de bois de moyenne grosseur pour le chauffage'. Die Bedeutungsspezifikation von légne, die auch P2, P3 und P8 bestätigen, ist aus der Definition von Palay nicht zu entnehmen.

${ }^{138}$ Ich werde im folgenden Kapitel eine auch unter diskursanalytischem Gesichtspunkt interessante längere Definition des Begriffs fourastà durch P2 wiedergeben. 
Übersetzung für fr. futaie im B., wohingegen talhis als autochthone Bezeichnung (fr. taillis, dt. 'Niederwald') gängig ist. ${ }^{139}$

Die forstlandschaftlichen Gegebenheiten des Béarn - und hierzu gehört neben der dichten Vegetation auch die Hanglage vieler Waldgebiete - haben bis heute eine kommerzielle Nutzung der Wälder im großen Stil verhindert. Dies ist auch der Grund dafür, dass ein Begriff wie fr. bûcheron im B. heute nicht mehr existiert und daher einfach aus dem Französischen übernommen wird. Die Logik dieses Begriffsverlustes ist dabei erst auf den zweiten Blick zu durchschauen, denn früher gab es sehr wohl b. Ausdrücke, die das entsprechende Berufsfeld besetzten. Im Wörterbuch von Palay finden sich als Entsprechungen $\mathrm{zu}$ fr. bûcheron b. bouscassè, estrouncàyre und escassoulàyre, von denen jedoch keines durch die Probanden bestätigt wurde. Demgegenüber war P7 so freundlich, mir alle ihm noch bekannten métiers $d u$ bois auf B. schriftlich niederzulegen. Aus dieser Liste beziehen sich folgende Begriffe auf das Fällen der Bäume (mit Bedeutungsangabe durch P7): piquè 'abatteur à la hache', legnassè 'celui qui fait du bois de chauffage' und hustè 'terme général: désigne tous métiers du bois'.

Der einzige Berufszweig, der mit dem Fällen von Bäumen zu tun hat und sich bis heute im Béarn erhalten hat, wird im $\mathrm{B}$. nach wie vor mit marchàn de boès (fr. marchand de bois) bezeichnet. Diese Holzhändler gibt es traditionell recht zahlreich in der Gegend. Dabei sind sie aufgrund ihres eher schlechten legendären Rufs und der durch sie gegebenen Konkurrenz zur Arbeit der Forstkooperative bis heute des öfteren Gesprächsthema. ${ }^{140}$ Das eigentliche Fällen der Bäume übernehmen für sie Arbeiter, die man im B. prinzipiell als coupàyres $(<$ coupà) bezeichnen könnte, doch handelt es sich bei diesem Begriff, der im B. verstanden, aber selten gebraucht wird, um die Entlehnung aus dem fr. coupeur, das einen in den benachbarten Landes verbreiteten Berufsstand benennt.

Um berufliche Tätigkeiten zu bezeichnen, die mit dem Wald in Verbindung stehen, benutzt man im B. heute so wie im Französischen das Adjektiv fourestiè [forestier], das auch in substantivierter Form üblich ist (lous fourestiès), meist aber in Verbindungen wie aubrè fourestiè (fr. ouvrier forestier) oder cououperatibe fourestière (fr. cooperative forestière), ja selbst in einer hybri-

${ }^{139} \mathrm{Oft}$ wird auch das fr. sous-bois verwendet, das keine Übertragung in das B. gefunden hat. Auf meine Frage, wie sous-bois im B. wiederzugeben sei, hörte ich häufig die Antwort salouperie (fr. salopperie). Die diaphasischen Eigenheiten des B. geben dieser Entsprechung durchaus Glaubwürdigkeit.

${ }^{140}$ Ich gebe im nächsten Kapitel hierzu ein Diskursbeispiel von P2 mit weiteren Erläuterungen. Ein sehr informatives Sprachdokument (b./fr.) zum Thema marchàns de boès habe ich auch mit P6 aufzeichnen können (Q2.mp3, 6:26 - 20:32). 
den Form wie tecnicièn fourestiè gebraucht wird (vgl. z.B. P2, Q1.mp3, 7:13; P7, Q1.mp3, 3:43).

Trotz dieser Angleichung an das Französische bleiben dem B. auch heute noch einige genuine Ausdrücke, die eine Verbindung zum Wald herstellen und als typisch regionalsprachlich gekennzeichnet sind. Zu ihnen gehört z.B. das Substantiv bouscassè, dessen Bedeutung von Palay mit 'garde-forestier, bûcheron, coureur de bois' angegeben wird, das aber von denen, die es noch kennen und benutzen, heute spezifischer verwendet wird. P6 machte mich auf diesen Ausdruck als Übersetzung von fr. bûcheron (!) aufmerksam, präzisierte dann aber die noch heute gebräuchliche, wenn auch sehr seltene Verwendungsweise des Wortes durch folgende Definition:

N'èy pas a propimén parlà lou bucheroû, qu'ey lou... la persoune qu'ey toustèms au bos, qu'ey... qu'ey au bos tà'y cassà [fr. 'chasser'], qu'ey au bos tà'y cercà céts [fr. 'champignons']...

(P6, Q1.mp3, 0:40)

Bouscassè ist jemand, der es liebt, sich im Wald zu seinem Vergnügen aufzuhalten (zu Spaziergängen, Jagd oder Pilzesammeln), dort aber nicht arbeitet. P7, der diese Bedeutung des Wortes bestätigte, ergänzte hierzu die Eigenschaft des misanthrope, der gewollten Isolation. Auf einen ähnlichen Aspekt kam auch P6 an anderer Stelle zu sprechen, als er das Adjektiv enhouratàt in seinem Bezug zum Wald erklärte. Nach Palay bedeutet enhouratàt allgemein 'enfoncé, qui est dans un bas-fond, un trou (houràt), caché'. Im semantischen Umfeld des Waldes präzisiert P6 nun zwei Bedeutungen: eine, die in seiner Gegend nicht üblich sei - er gibt das Beispiel des Viehs, das sich (beim Weiden) im tiefen Wald versteckt (' $\hat{u}$ bèsti qui s'ey enhouratàt dens $\hat{u}$ talhis, dens $\hat{u}$ founciè, tà s'y estujà') -, und eine andere, die er als lokal geläufig charakterisiert und wie folgt beschreibt:

...s'enfoncer dans les bois, vivre dans un écart boisé, s'en aller loin du monde pour vivre une vie de forestier; enhouratàt que's dits tabé d'ue maisoû qui es tròbe en û endrét reculàt, y a pas nat camî tà y anà: que son enhouratàts... en û coègn... ça veut dire 'isolé'..., mais 'isolé dans le bois'.

Ich habe selbst mehrere solcher enhouratàts im Béarn kennengelernt und kann die regionalspezifische Besonderheit dieses Wortgebrauchs (insbesondere im westlichen Untersuchungsteilgebiet) aus dieser Erfahrung heraus bestätigen. Das Französische hat es schwer, hier durch ein einziges Wort eine Entsprechung zu geben, die in der Lage ist, denselben semantischen Gehalt zum Ausdruck zu bringen. 


\subsubsection{Der lexikalische Bereich 'Brennholzproduktion'}

Die Produktivität der bearnesischen Wälder liegt zu einem Großteil im Bereich der Brennholzgewinnung. Diese Gewichtung spiegelt sich auch im Wortschatz wider. Dabei lassen sich die vorhandenen Lexeme nach forstlicher Betriebsart und Stückholzproduktion differenzieren.

Die geplante Produktion von Brennholz ist heute keine gängige Praxis mehr. Allerdings sind den meisten $b$. Muttersprachlern aus ihrer Kindheit oder Jugend noch zwei Verfahren bekannt: der Niederwald und der Kopfholzbetrieb, die beide als landwirtschaftliche Nebennutzungen im Béarn verbreitet waren.

Der Niederwald oder Ausschlagwald ist eine Form der wirtschaftlichen Nutzung des Waldes, bei der kleinere Laubbaumbestände meist einer vorherrschenden, für diese Nutzung geeigneten Baumart in regelmäßigen Abständen knapp über dem Boden abgeholzt werden, so dass der gesamte Bestand wieder neu ausschlagen kann. In meinem Untersuchungsgebiet (dem Teil westlich von Pau) wurde dieses Verfahren vor allem in kleineren Kastanienbeständen angewendet. Diese Kastanienniederwälder werden im B. pacherà [paisherar] genannt. Ihre Bestimmung war es ursprünglich, pachèts (fr. échalas, dt. 'Rebenpfähle') hervorzubringen, die im Weinbau verwendet wurden. Die pacheràs waren aber auch eine gute Quelle für die Produktion von Weidezaunpfählen (b. piquéts), wozu sie teilweise heute noch gebraucht werden. Allerdings ist mit dem Rückgang des Weinbaus im Béarn die wirtschaftliche Bedeutung der pacheràs heute nicht mehr gegeben. Es gibt daher nur noch eine vereinzelte Nutzung von Stockausschlägen zur Gewinnung von Brennholz. Das Wort pachèt und seine zahlreichen Ableitungen sind aber weiterhin im B. gut bekannt (vgl. P1, Q.mp3, 5:28; P6, Q1.mp3, 26:20, bzw. CD, Track 14).

Auch der Kopfholzbetrieb ist eine Form der Produktion schnellwachsenden jungen Holzes, der im Béarn sowie in vielen Waldgebieten Europas verbreitet war. Im Französischen wird für das entsprechende Verfahren der Begriff émondage verwendet, der aber-nach meinen Recherchen zu urteilen-heute kaum noch in seiner ursprünglichen Bedeutung bekannt ist. ${ }^{141} \mathrm{Da}$ die terminologische Überschneidung von 'entasten' und 'abkappen' in diesem Zusammenhang eine komplizierte Semantik des Wortes bedingt, gebe ich im Folgenden zunächst die Definition des Dictionnaire Forestier Multilingue wieder:

EMONDAGE-(pollarding-Abkappen-trasmochar, descabezar $)^{142}$

${ }^{141}$ Selbst die techniciens forestiers des CRPF d'Aquitaine hatten Schwierigkeiten, diesen Begriff noch richtig einzuordnen bzw. zu erklären. Auf die terminologische Unterscheidung von élaguer, ébrancher und émonder wird im Rahmen der systematischen Befragung in Kapitel 2.4 noch genauer eingegangen.

${ }^{142}$ Die zitierte Bedeutung von émondage findet sich unter der Kennziffer 4472 . Unter der Kennziffer 6388 gibt es daneben noch folgende Bedeutung des Terminus: émondage - triming out 
Élagage au sens large, mais étymologiquement élaguer c'est retrancher, tandis qu'émonder c'est rendre net, rendre propre, non seulement en éliminant certaines branches au ras du tronc, mais en coupant aussi l'extrémité des branches ou des rameaux, à la périphérie de la cime. [... ] un arbre émondé sur toute la hauteur de sa tige pour en obtenir des rameaux ou du feuillage est un arbre d'émonde; un arbre dont on a coupé la tige à une faible hauteur pour en obtenir des rejets ou du feuillage est un têtard; $[\ldots]$

'Kopfholzstämme' (fr. têtards), insbesondere auch von Eichen, waren früher im Béarn keine Seltenheit. Sie dienten vor allem zur Brennholzgewinnung. P1 gibt eine präzise Definition: ${ }^{143}$

Acouta que vòu díse, autescòps, quoan calèbe hèra de boès de cauhàdje, que $\mathrm{y}$ abèbe per exemple càssous, sustout qu'ère sus càssous aquò; que hasèben tres ou quate mètres de hàut, e qu'èren estàts coupàts, e aquìu touts lous quinze ans, qui $\mathrm{y}$ abèbe lègne qui poussabe, brànques-au càp de quinze ans qu'èren hère bérs-labèts au lòc de coupà lou càssou au pè que coupaben aquère lègne, en ue certèn' epòque, $\mathrm{e}$ pas tròp ràs, endà qui tournésse bàlhe d'autes lègnes mey tard. Aquìu que n'y a au bòs, càssous a acoutà, mè bitare, meylèu que de'ous acoutà, qu'ous coupàm au pè. Que t’en bàu amushà, qu'aperàm aquò û cougòt.

(P1, Q.mp3, 21:35)

Interessanterweise gibt es hier nicht nur klare lexikalische Entsprechungen: fr. émonder-b. acoutà, fr. arbre d'émonde-b. càssou a acoutà, fr. têtard-b. cougòt, sondern es sind darüber hinaus die b. Begriffe, die den Sprechern in ihrer Bedeutung im Allgemeinen vertrauter sind als die französischen. Es scheint in diesem Fall also noch ein Restbestand mikrodiglossischer Funktionsverteilung der Sprachen vorzuliegen, wenn dieser auch in wenigen Jahren voraussichtlich kaum mehr zu verifizieren sein wird.

Der Wortschatz für das Abkappen der Bäume und sein Resultat ist traditionell sehr reich und noch heute je nach Gebiet stark differenziert. Die Probanden verwendeten / kannten für den Kopfholzbetrieb die folgenden Ausdrücke:

- $\approx$ Entasten - mondar: Opération culturale qui consiste à émonder, c.à.d. supprimer les pousses ou bourgeons ( $\approx$ ébourgeonnage) latéraux d'un jeune plant

${ }^{143}$ Diese sprachlich schöne und präzise Spontandefinition des Probanden P1 (49 J.) findet sich auf der dieser Arbeit beiliegenden CD als Track 13. Zum besseren Verständnis gebe ich im Folgenden eine (angepasste) Übersetzung auf Französisch:

„ACOUTÀ, ça veut dire, autrefois, quand il fallait beaucoup de bois de chauffage, il y avait par exemple des chênes, c'était surtout sur des chênes ça; ils faisaient trois ou quatre mètres de haut, et ils ont été coupés, et là, tous les quinze ans, il y avait le jeune bois qui poussait, des branches - après quinze ans ils étaient très verts - alors au lieu de couper le chêne au pied, on coupait ce jeune bois, dans une certaine époque, et pas trop bas, pour qu'il repousse d'autre jeune bois plus tard. Là, il y en a au bois, des arbres d'émonde, mais maintenant, plutôt que de les émonder, nous les coupons au pied. Je vais t'en montrer, nous appelons cela un cougòt (têtard).“ 
P1 (s.o.): acoutà-cougòt (sehr geläufig)

P2 (Q1.mp3, 3:10): cougòt (kennt nur noch den Begriff, aber nicht mehr seine Bedeutung)

P3 (Q1.mp3, 23:05): escouhà (gut bekannt)-coudòch, còhou (erinnert sich mit Mühe, cougòt ist unbekannt)

P4 (Q1.mp3, 18:42): escoudouchà-coudòch (geläufig)

P5 (Q1.mp3, 34:13): acoutà-tarè (geläufig; cougòt ist unbekannt)

P6 (Q1.mp3, 14:43): estouhà-tòhou (sehr geläufig, kennt auch tarè).

Besonders interessant waren in diesem Zusammenhang die Hinweise von P7 und P8.

P7 kennt den Begriff cougot in einer etwas anderen Bedeutung als 'le centre de toutes les branches' (Q1.mp3, 13:17), was von seiner anwesenden Schwester spontan bestätigt wird, und er erklärt: 'Ça suppose un arbre qui n'a pas de branches, depuis la base, échelonnées comme ça; qui fait un bouquet comme ça.' Des Weiteren weist P7 darauf hin, dass fr. têtard nicht die Übersetzung von cougòt sei, sondern dass das B. für têtard den Ausdruck tarè (' ' $\hat{u}$ arbre qui ey estàt essoumàt / qui a été écimé et qui est reparti comme ça') verwende. Die Begriffsdifferenzierung von cougòt und tarè ist also nach den Angaben von P7 einerseits sehr scharf, andererseits sehr subtil und im referentiellen Bereich nicht eindeutig trennbar. Ich gehe davon aus, dass mich P7 dabei auf semantische Nuancierungen aufmerksam gemacht hat, die im regionalen Sprachgebrauch eine Rolle gespielt haben, aber heute weitgehend verloren gegangen sind.

Geradezu verblüfft war ich von den Erläuterungen des Probanden P8, der ein guter Kenner des B. und ein Fachmann in Angelegenheiten des Waldes ist. P8 kannte das Wort cougòt nicht, gab aber als Übersetzung für fr. têtard spontan b. $\operatorname{tarè}(r)$ an. Seine weitere Erklärung lautete: ${ }^{144}$

Vedèt, que hem..., qu'ey sustout ... pour les chênes, lous càssous, e que hem la diferènce énter lou chêne de haute futaie qui aperam la cassourre, et le chêne têtard, le chêne qui a été 'accoté' ['étêté], qu'ey lou càssou. Mé la cassourre qu'ey û càssou [...] un chêne de haute futaie, c'est-a-díse lou qui n'ey pas estat 'accoté', n'ey pas estat coupàt, què?

(P8, Q1.mp3, 16:39)

\footnotetext{
${ }^{144}$ Die zitierte Definition ist ein gutes Beispiel für Code-Switching, das in diesem Fall insbesondere durch die Textsorte Sacherklärung hervorgerufen wird. Auffällig ist der Gebrauch der Entlehnung fr. 'accoté' ( $<$ b. acotàt 'étêté'), die von P8 sogar innerhalb eines b. Syntagmas verwendet wird. $\mathrm{Ob}$ es fr. accoter regional auch mit der Bedeutung von b. acoutà gibt, konnte ich leider nicht eruieren.
} 
Diesen Ausführungen zufolge wird also, zumindest in dem Heimatgebiet des Probanden, einfach zwischen cassourre 'große Eiche' und cassou 'geköpfte Eiche' unterschieden. Dies lässt darauf schließen, dass der Praxis des Köpfens oder Abkappens von Eichen regional eine besonders große Bedeutung zukommt, die sie sicherlich in dieser Form nicht in allen Teilen des Béarns gehabt hat. Der Hintergrund dieser Unterscheidung ist in der gebietstypischen Holzverwertung zu suchen. Während die wenigen cassourres wertvolles Holz, u.a. zur Möbelfabrikation, lieferten, eigneten sich die normalen càssous zur intensiven Gewinnung von Brennholz. P8 betont an anderer Stelle, dass dieses Brennholz seinerzeit in großen Mengen benötigt wurde, und zwar sowohl für den privaten Gebrauch, als auch für die Feuerung von Ziegel- und Kalköfen in der Gegend. ${ }^{145}$ Man sieht an diesem Beispiel deutlich, dass manch nunancierter Wortgebrauch in der Regionalsprache, der heute noch verifizierbar ist, aus vergangenen normativen Gegebenheiten des Sprachgebietes abgeleitet werden muss.

Neben der Produktion des Brennholzes im Wald spiegelt der b. Wortschatz auch die Tätigkeiten der Aufbereitung nach dem Schlagen zur Verfeuerung im Kamin wider. Es gibt diesbezüglich einen Grundstock an Lexemen, die noch vielen Sprechern bekannt sind, da sie sich auf Aktivitäten am oder im Haus und nicht auf die Arbeit im Wald beziehen. Im Zentrum steht das 'Hacken' des Holzes, das im B. héne [héner] (fr. fendre) heißt. Neben diesem Zentralbegriff kennt das B. aber noch die aus den jeweiligen Grundwörtern abgeleiteten Verben escalhà, arralhà und (e)chasclà, deren Bekanntheitsgrad ebenfalls recht groß ist, und nach Wörterbuch auch asclà bzw. asclassà, die meine Probanden jedoch nicht bestätigt haben. Es handelt sich bei diesen fünf Ableitungen nach lexikographischem Befund um verschiedene Bedeutungen, die man am besten aufgrund der Semantik der Basiswörter nachvollziehen kann. Ich zitiere daher im Folgenden die einzelnen Erklärungen nach dem Wörterbuch von Simin Palay:

escàlh, -e; s. - Ecaille; éclat de bois, copeau épais; bûche éclatée, fendue à la cognée. V. ascle, arralhe. - Au càssou cadùt, touts que hèn escàlhs, au chêne abattu tous font des copeaux (prov.). V. estère.

escalhà, -lhoutà; v. - Ecailler; faire des escàlhs; fendre du bois; escalhà-s, en terme plaisant, s'écorcher, se blesser légèrement; s'écailler.

arralhe (Mt); sf. - Gros éclat, copeau épais de bois, bûche, souche fendue par éclatement. L'arralhe est plus épaisse, plus volumineuse que l'escalhe. V. ascle. En Gr. L., sornette, blague, conte.

arralhà (Mt.); v. - Faire des arralhes, fendre du bois; arralhà-s (Gir.), s'amuser.

${ }^{145}$ Vgl. hierzu die CD, Track 19, den ich im folgenden Kapitel 2.3 zitiere. 
chascle, chiscle; sf. - Eclat de bois; écharde. - La chascle est plus petite que l'ascle et plus grande que la chiscle. - Syn. bichascle, eschascle.

chasclà, eschasclà; v. - Faire éclater du bois, le couper en bûches ou morceaux éclatés; par anal. fracasser, faire voler en éclats, tout casser.

ascle; sf. - Morceau de bois fendu, éclaté; gousse d'ail. V. arralhes, estrouncadis, escalh, eschascle. - Sâ coum ue ascle d'alh, sain comme une gousse d'ail.

asclà, chasclà; v. - Faire éclater, fendre du bois; pourfendre; tout casser, briser. V. escalhà.

asclasse, sf. - Forte, grosse ascle; bûche fendue; gros cayeu.

asclassà; v. - Fendre du bois très grossièrement.

Meine Befragung ergab hinsichtlich dieses Begriffsfelds kein einheitliches Bild. Auffällig war, dass die Probandengruppe P5-P8 westlich von Pau ein differenzierteres Wissen unter Beweis stellte als die Gruppe im Nordosten des Béarn (was bei der mangelnden Repräsentativität der Probandenauswahl auch Zufall sein kann). Arralh(e) und arralhà z.B. waren P1-P4 durchweg nicht bekannt, während P5-P8 die Begriffe noch bestätigten. Das Verb escalhà kannten alle Probanden mehr oder weniger (vielleicht auch aufgrund seiner Ähnlichkeit zu fr. écailler), allerdings scheint es in seiner spezifischen Bedeutung ('schuppiges Absplittern des Holzes') im Bereich des Holzhackens heute wenig Anwendung zu finden und daher im aktiven Sprachgebrauch kaum noch eine Rolle zu spielen. ${ }^{146}$ Die Kenntnis von chascle im Sinne von fr. écharde 'Splitter, Span, Dorn' war im Allgemeinen gegeben (mit Ausnahme von P2, die dafür den Französismus echàrde verwendete, Q1.mp3, 6:00, und P8, der das Wort als aus der Bigorre stammend kennzeichnete). Das Synonym chiscle bestätigten P3 (Q1.mp3, 19:58) und P4 (Q1.mp3, 13:48), jedoch ist das Wort im B. gebietsweise nur als 'Mann oder männliches Tier mit nur einem Hoden; halb kastriert' bekannt (vgl. P1, Q.mp3, 26:40 und Palay, der dieses Homonym ebenfalls anführt). P6 (Q1.mp3, 7:23) erklärt ausdrücklich, dass chascle den typischen Splitter bzw. Holzkiel im Finger bezeichnet, führt aber ebenso die allgemeine Bedeutung im Sinne von 'abgespaltenes Holzstück' an, als dessen Ableitung (e)chasclà im $\mathrm{B}$. synonym zu héne verbreitet ist (in meiner Befragung bestätigt von P4, P5 und P6). In Bezug auf das Holzhacken wird chascle im B. heute ähnlich gebraucht wie ascle (der Hinweis von Palay, dass ein chascle kleiner sei als ein ascle findet sich bei keinem der Probanden wieder). Dabei scheint sich ascle als 'terminus communis' für fr. bûche weitgehend durchgesetzt zu haben. Alle Probanden kannten dieses Wort und verwenden es auch noch aktiv. Auf die Verbalableitung asclà hingegen verwies nur P1 (Q.mp3, 10:44), und zwar in der reflexiven Form als Synonym zu henhalà-s

${ }^{146}$ Im Gegensatz zu dieser verallgemeinernden Beobachtung verwies mich P3 zweimal explizit auf dieses Wort als Synonym zu b. héne (vgl. P3, E1.mp3, 20:43 u.Q1.mp3, 19:58). 
fr. 'se fendiller' (dt. 'rissig werden'). Das Augmentativ asclasse und seine Ableitung asclassà scheinen, zumindest in meinem Befragungsgebiet, heute ungebräuchlich zu sein.

Neben den genannten gibt es noch eine Reihe weiterer Lexeme, die den Teilbereich 'Brennholzverwertung' betreffen und nicht alle hier angeführt und kommentiert werden können. Ich beschränke mich daher darauf, noch einmal an das zentrale Wort légne zu erinnern, das bereits im vorangegangenen Kapitel 2.2.2.1 besprochen worden ist.

\subsubsection{Der lexikalische Bereich 'Wertholzproduktion'}

Die Wertholzproduktion spielt in dem Untersuchungsgebiet traditionell eine untergeordnete Rolle und ist bis heute meistens auf den Bedarf des eigenen Hauses oder Hofes konzentriert. Typischerweise übernehmen die privaten Waldbesitzer-vielfach handelt es sich ja um Landwirte oder Personen mit $\mathrm{Zu}$ griff auf landwirtschaftliche Geräte-die im Wald zu verrichtenden Arbeiten selbst: Sie pflegen die Bestände, soweit dies erforderlich ist, wählen die zu schlagenden Bäume aus, fällen sie, erledigen die ersten, groben Bearbeitungsschritte und transportieren das Holz schließlich zum Sägewerk, von wo aus es an den Ort der Weiterverarbeitung gelangt.

Aus der Sicht des heutigen Sprachgebrauchs ist der typisch b. Wortschatz in Bezug auf all diese Tätigkeitsbereiche nicht (mehr) sehr reichhaltig. Dies hat vor allem zwei Gründe: Zum einen ist die regionale wirtschaftliche Bedeutung der Wertholzproduktion nicht groß und tritt gegenüber der landwirtschaftlichen Tätigkeit in den Hintergrund. Zum anderen werden sämtliche Maßnahmen, die eine Produktionssteigerung von Wertholz im Béarn zum Ziel haben, durch französischsprachige Institutionen gesteuert, so dass die lexikalischen Voraussetzungen der b. Sprache bei der kommunikativen Bewältigung der Veränderung und Modernisierung dieses Sachbereichs kaum noch eine aktive, gestalterische Rolle spielen. Ich werde in den nachfolgenden Kapiteln den Umgang der Betroffenen mit dieser Situation in einer ausführlichen Beispielgebung sowohl vonseiten des b., als auch vonseiten des französischen Sprachgebrauchs beleuchten.

Im Rahmen dieses Kapitels möchte ich-auch zur Hinführung auf die nachfolgenden Darstellungen-auf die wichtigsten Wortschatzelemente hinsichtlich der angesprochenen Tätigkeiten eingehen. 
2.2.2.3.1. Waldbauliche Maßnahmen zur Pflege und Rentabilitätssteigerung der natürlichen Wälder sind im Béarn unüblich. Daher gibt es im B. auch kaum ein spezielles hierzu gehöriges Vokabular. Allerdings gilt diese Feststellungsowohl aus traditioneller, als auch aus aktueller Sicht-nur mit Einschränkungen.

Das B. verfügt über einige alte Begriffe, die die Rodung und Urbarmachung der Wälder, sowie das vegetative Verwildern nicht mehr wirtschaftlich genutzter Flächen bezeichnen. Sie kennzeichnen die innere Logik von primärer landwirtschaftlicher Orientierung und Vernachlässigung der Wälder. Die zentralen Lexeme dieses Begriffsfeldes sind:

eschartìc; sm. - Sol défriché et mis en culture; essartage.

bousigue ou bouzigue; sf. - Etat d'un sol inculte, devenu terre à broussailles, ronceraie; friche, patis. [...]

artigue; sf. - Terre défrichée; pré; clairière. N. de p. Artigue, Lartigue, Dartigue. - En certains lieux l'artigue désigne particulièrement des prés au bord de l'eau, dans les fonds.

treyture; sf. - Terre qui est à défricher ou qu'on vient de défricher; défrichement.

Wie zu erwarten spielen diese Begriffe im aktuellen Sprachgebrauch kaum noch eine Rolle und sind nur noch vereinzelt in Ortsnamen zu finden. Das Lexikon führt jedoch eine große Anzahl von Ableitungen und auch noch weitere Begriffe auf, die von der ehemaligen Wichtigkeit dieses lexikalischen Bereichs zeugen. Meine Befragung ergab, dass bousigue und artigue heute nicht mehr zum gebrauchsfähigen Wortschatz des B. gehören, ${ }^{147}$ während eschartic und treyture, ebenso wie die Verbalableitungen eschartigà und treytà noch mehreren Probanden bekannt waren. Die genannten Verben werden jedoch heute normalerweise durch den Französismus de(s)frichà ersetzt (so die übereinstimmende Angabe aller Probanden).

Das Lichten zu dichter Bestände gehört zu den wenigen forstlichen Aktivitäten, die im Béarn eine gewisse Tradition haben. Die zentralen Begriffe sind in diesem Zusammenhang esclarì fr. 'éclaircir' und esclarida fr. 'éclaircie', die ebenso gängig sind wie ihre französischen Entsprechungen. P1 gab zusätzlich noch das Wort claresse für fr. 'clairière' an (Q.mp3, 6:18).

Die Bemühungen des privatwirtschaftlich orientierten CRPF d'Aquitaine um die Etablierung und Förderung eines effektiven und modernen Waldbaus im Béarn erreichen vor allem die älteren Waldbesitzer im Ruhestand. Unter ihnen sind viele Béarnais de souche, die das B. in ihrem neuen Tätigkeitsfeld weiter verwenden. Von den Probanden gehören P3, P6 und P8 zu dieser Personen-

${ }^{147}$ P5 (Q1.mp3, 18:13 u. 28:20) kannte beide Begriffe noch und erklärte sie korrekt. Ich vermute, dass sein besonderes Interesse für das B. als Lehrer und Regionalschriftsteller der Grund hierfür ist. 
gruppe. Ich werde mich in den nachfolgenden Kapiteln 2.3, 2.4 und 2.5 noch ausführlich mit dem Anteil des B. an der kommunikativen Gestaltung des Sachbereichs 'Waldbau' beschäftigen. Vorwegnehmend sei bereits darauf hingewiesen, dass die Verfügbarkeit des notwendigen Vokabulars im B. grundsätzlich gegeben ist und sich, systematisch betrachtet, aus drei lexikalischen Quellen speist. Ich gebe hierzu das Beispiel der Baumbeschneidung, die insbesondere bei der Pflege von Anpflanzungen und jungen Wäldern eine wichtige Rolle spielt.

(1) Das B. stellt ein autochthones Vokabular zur Verfügung, das bei fachkontextuellen Gesprächen verwendet werden kann. Das Verb esbrancà, das als Ableitung aus b. branque 'Ast, Zweig' allgemein bekannt ist, gibt hierfür ein gutes Beispiel. Es findet eine Entsprechung im fr. ébrancher, das als Fachterminus im Dictionnaire Forestier Multilingue unter den Kennziffern 3618 und 6389 wie folgt definiert wird: 'couper une (ou des) branche(s) d'un arbre, aussitôt avant ou après l'abattage'. Ich konnte allerdings feststellen, dass das b. esbrancà trotz seiner Entsprechung zum Französischen nicht gern im Sinne des angegebenen Fachterminus benutzt wird, da es in seinem regionalen Gebrauch auf den traditionellen Kopfholzbetrieb bezogen wird und in diesem Sinne eher émonder, genauer: das Entasten beim Abkappen eines Baums bezeichnet. ${ }^{148}$ Die Probanden zogen daher die Lexeme esbrouncà und eslagà, deren Herkunft ich nachfolgend erkläre, zur Bezeichnung der Tätigkeit des Entastens vor.

(2) Das B. übernimmt Termini aus anderen Domänen zur kommunikativen Ausgestaltung des neuen Sachbereichs. Einen Fall dieser Art stellt das allen Probanden bestens bekannte Verb esbrouncà (auch in der Variante esbourroungà bei $\mathrm{P} 5$ und $\mathrm{P} 6$ ) dar. Es leitet sich aus b. b(our)rounc fr. 'nœud dans le bois' ab, das im Deutschen nach der internationalen Konvention der Forstfachsprache, Kennz. 3390) mit 'Ast' zu übersetzen ist. ${ }^{149}$ Die regelmäßige

${ }^{148}$ Ich werde in Kapitel 2.4 zeigen, dass ein bearnesischer Proband, der des B. nicht mächtig ist, das fr. ébrancher als Regionalterminus charakterisiert (seine Bedeutung allerdings nicht mehr spezifizieren kann). - Ein paralleler Fall scheint mir übrigens auch mit dem Wort escharramà vorzuliegen, dessen Bedeutung zu der von esbrancà synonym ist, das aber im Béarn weniger geläufig ist. P5 (Q1.mp3, 29:45) hat mich auf dieses Verb aufmerksam gemacht.

${ }^{149}$ Es ist wichtig, an dieser Stelle darauf hinzuweisen, dass das Deutsche die lexikalische Unterscheidung von branche und næud im Französischen (bzw. von branque und brounc im B.) nicht präzise nachvollziehen kann. Ich gebe im Folgenden die entsprechenden Definitionen des Petit Robert (Electronique) wieder:

NEUD: 'Protubérance à la partie externe d'un arbre, constituée par un faisceau plus ou moins contourné de fibres et de vaisseaux ligneux. Nœuds d'un tronc, d'un bâton (_noueux). C_Partie très dense et dure, à l'intérieur de l'arbre (visible dans les planches de menuiserie).'

BRANCHE: 'Ramification latérale de la tige ligneuse (d'un arbre).'

Anmerk.: Die deutschen Komposita 'Astgabel' und 'Astloch' sowie das veraltete 'Knorren' beziehen sich auf das Phänomen des næud, ohne es jedoch genau zu bezeichnen. Evtl. würde 
Entfernung aller Äste (nœuds), die bis zu einer bestimmten Höhe aus dem Stamm herauswachsen, ist eine notwendige Maßnahme zur Qualitätserhaltung des Holzes. Der Begriff esbrouncà eignet sich daher in hervorragender Weise für die Domäne des Waldbaus. Er entspricht in dieser Verwendung in etwa dem fr. élaguer, auf das ich noch genauer eingehen werde. Der hohe Bekanntheitsgrad von esbrouncà im Béarn, den ich bei meiner Befragung konstatieren konnte, resultiert aber nicht aus dem forstwirtschaftlichen Aspekt seiner Bedeutung. Vielmehr handelt es sich um einen traditionellen Terminus des Weinbaus, der noch heute in dem Weinbaugebiet um Jurançon Anwendung findet. Die Probanden P5 und P6, die aus dieser Gegend stammen, haben von sich aus ausdrücklich auf diese Herkunft des Wortes hingewiesen (P5, Q1.mp3, 30:25; P6, Q1.mp3, 13:45). Ich zitiere im Folgenden den Kommentar von P5, der dem Leser zugleich auch einen Einblick in die Detailfülle der Erklärungen zu manchen Wörtern in meiner Befragung zu geben vermag: ${ }^{150}$

Qu'emplegàm aqueste mout, 'esbourroungà', que vòu díse [...], coupà que las arràmes, coupà, coupà aquìu, voilà, tà dechà sounque lou trounc, lou trounc, tà dechà lou trounc sounque, aquò que s'apèra 'esbourroungà'. [...]

Ací qui y a û mout..., lou mout 'esbourroungà' qui ey emplegàt, qui s'a(-d) emplegàt hère tà díse quoan..., eh bon, tà las bits, tà las bits, hein?, tà las bits. Quoan ey..., û còp talhade, que la càu ligà, ací, que la càu ligà, que la càu ligà sus... sus û hiéu. $\mathrm{E}$ alabéts, tad aquò que's serbéishen de..., que's serbéishen de 'û bìme', û bìme qu'ey, ah, en francés qu'ey l'osier, l'osier, qu'ey... que coumprenét? ... l'osier, bon, alabéts aquét bìme quoan... qu'ou... que bàd sus... com açò su... éts qu'ous coupen e après

eine spontane deutsche Wortbildung wie 'Astansatz(stelle)' den Begriff nøud am besten wiedergeben.

${ }^{150} \mathrm{P} 5$ ging sogar so weit, parallel zu der wiedergegebenen Erklärung noch zwei kleinere Zeichnungen anzufertigen, die einerseits den Ausschlag der jungen Weidetriebe, andererseits die landesübliche Befestigung der Rebstöcke bildlich dokumentierten. Zum besseren Verständnis des Zitats gebe ich im Folgenden eine (stilistisch angepasste) französische Übersetzung an:

"Nous employons ce mot, 'esbourroungà', qui veut dire [...], couper que les branches, couper, couper là, voilà, pour laisser seulement le tronc, pour laisser le tronc seulement, ça s'appelle 'esbourroungà'. [...]

Ici il y a un mot..., le mot 'esbourroungà est employé, on l'a employé beaucoup pour dire quand..., eh bon, pour les vignes, pour les vignes, hein?, pour les vignes. Quand elle est..., une fois taillée, il faut la lier, il faut la lier sur... sur un fil. Et alors, pour ça ils se servent de..., ils se servent de 'û bìme', un 'bìme', c'est, ah, en français c'est l'osier, l'osier, c'est... vous comprenez? [oui] l'osier, bon, alors ce 'bime' quand..., on le... il pousse sur... comme ça su..., donc ils les coupent et après il y a encore de petits nœuds, là, petites branches. Alors il faut les couper, et on les coupe avec une paire de... de ciseaux speciaux, et ça s'appelle 'esbourroungà'. Alors tout le monde faisait ça autrefois, le soir. Après avoir soupé, le soir, il fallait 'esbourroungà' un grand fagot de brins d'osier; ça, ces brins d'osier, on les appelait les... 'las ligues', elles servaient pour... pour lier, pour lier la vigne. [...] ça, 'esbourroungà', c'est connu, tout le monde connaît ça ici, 'esbourroungà', parce que c'est un pays de vignes." 
que $\mathrm{y}$ a encoère de petits bourroùncs, aquìu, petites arràmes. Alabéts que las càu coupà, e las coupen dab û pa de... de cisèus especiàus, e aquò que s'apère 'esbourroungà'. Alabéts tout lou mounde que hesè aquò quauque còp, lou sé. Après soupà, lou sé, que calè esbourroungà û gran hèch de ligues, aquò... aquets bìmes, bìmes qu'ous aperàben las... las 'ligues', que serbiben tà... tà ligà, tà ligà la bit. [...] aquò, 'esbourroungà' qu'ey counegùt, tout lou mounde que counéch acì, 'esbourroungà', permoù qu'ey û pèys de bits.

(P5, Q1.mp3, 30:36, 31:41)

Der Einfluss der Sprache des Weinbaus auf das für den Waldbau zur Verfügung stehende Vokabular fiel mir auch noch in anderen Zusammenhängen auf. P3 z.B., der mir ausführliche Erklärungen zu Wald und Waldbau gab, verwendete für das Beschneiden der Bäume in seinen Anpflanzungen das Verb poudà, das im Bereich des Waldbaus ansonsten unüblich ist, aber im Wein- und Obstanbau die gängige Bezeichnung für diese Tätigkeit darstellt (daher auch der Hinweis auf das typische Syntagma poudà la bigne in Palay). ${ }^{151}$ Wie ich weiß, wurde auf den Ländereien von P3 in seiner Jugend Weinbau betrieben, so dass dieser Wortgebrauch biographisch erklärbar ist.

(3) Das B. entlehnt Fachbegriffe aus dem Französischen. Dieser Fall ist nicht unerwartet und erklärt sich aus der Dominanz des Französischen im fachlichen (und fachinstitutionellen) Bereich. In Bezug auf das Beispiel des Baumbeschneidens ist fr. élagage (< élaguer) der eigentliche forstliche Fachterminus. Der Dictionnaire Forestier Multilingue definiert ihn unter der Kennziffer 4639 wie folgt:

Élagage-pruning-Aufasten, Aufastung-poda(r): [...] Coupe, à proximité ou au ras du tronc, des branches latérales, vivantes ou mortes, (ou d'une partie des fourches) d'un arbre (notamment dans une plantation) de façon à améliorer ce dernier et (ou) le bois qu'il donnera.

Die deutsche Fachsprache des Waldbaus kennt für diese Tätigkeit auch den Begriff 'Wertästung' (vgl. Das Kosmos Wald- und Forstlexikon, 1998, 827). In der speziellen Bedeutung dieses Terminus ist élaguer kaum in das B. übersetzbar. Die aktiven Waldbauern verwenden daher in Fachkontexten im B. meist die entsprechende Entlehnung b. elagà bzw., in sprachlicher Anpassung an die Verben esbrancà und esbrouncà, auch die Form eslagà. Einen besonders intensiven Gebrauch dieses Wortes stellte ich bei P6 fest, der mir im Rahmen des längeren fachbezogenen Interviews, das ich in Kapitel 2.5 ausführlich kommentieren werde, darauf aufmerksam machte, dass eslagà ein 'neues

${ }^{151}$ Vgl. hierzu das Zitat des Tracks 1 der beiliegenden CD in Kapitel 2.3. P3 gibt in diesem Text poudà als die passende Vokabel für das Beschneiden der Bäume an. B Welche zentrale Rolle die poude[poda] (der Begriff existiert im Okzitanischen, Katalanischen und Spanischen) im Fruchtbaumanbau spielt, werde ich im zweiten Teil der empirischen Untersuchung am Beispiel der Regionalsprache des Orangenanbaus in Valencia verdeutlichen. 
Wort' im B. darstellt, und seine Entlehnung darauf zurückführte, dass früher niemand im Béarn diese Tätigkeit ausübte.

Hinsichtlich der Übernahme von fachsprachlichem Lehngut aus dem Französischen ist allgemein anzumerken, dass insgesamt kein allzu großer Bedarf vorhanden ist, da das B. traditionell ein reichhaltiges Vokabular zur Verfügung stellt. Allerdings gibt es auch Fälle von semantischen Lehnübertragungen (calques), so etwa wenn im B. von einem 'Auslesebaum' als von einem àrbe d'abiéne ( $<$ fr. arbre d'avenir), von einer 'Baumart' als von einer essénce (< fr. essence) oder von einem plan simple de gestion (P.S.G.) als von einem plan (simple) de gestioû gesprochen wird. ${ }^{152}$ Demgegenüber lassen sich die Internationalismen, deren Verwendung ich auch im B. konstatieren konnte, prinzipiell nicht als Entlehnungen aus dem Französischen charakterisieren (z.B. lou Douglàs 'Douglasie' oder dendroumètre 'Dendrometer').

2.2.2.3.2. Das Fällen der Bäume und das Bearbeiten des Holzes im Wald sind Arbeiten, mit denen die privaten Waldbesitzer im Béarn in der Regel recht gut vertraut sind. Die entsprechenden Wortschatzbereiche sind im B. reich besetzt, aber zu einem erheblichen Teil veraltet bzw. in Vergessenheit geraten. Dies liegt hauptsächlich an den großen Veränderungen, die dieser Tätigkeitsbereich in den vergangenen Jahrzehnten erfahren hat.

Interessanterweise haben sich die einzelnen Tätigkeiten und Arbeitsschritte selbst kaum verändert. Die wesentliche Neuerung aber liegt in der Nutzung moderner Maschinen, insbesondere der Motorsäge und des Traktors, die es den Waldbauern ermöglichen, die seinerzeit schwierigen Arbeiten auf eine leichtere Weise zu erledigen. ${ }^{153}$

Mit der grundsätzlichen Technik des Bäumefällens waren alle männlichen Probanden vertraut. Die Grundlexeme dieses Bereichs wurden ausnahmslos beherrscht. Als Begriffe für das Fällen selbst fand ich hà càde (bzw. hà càye) fr. 'faire tomber' und coupà fr. 'couper' bestätigt. Abàte, das lexikographisch erfasst ist, erfuhr durchweg eine Ablehnung als Französismus. ${ }^{154}$

${ }^{152}$ Eine Reihe fachsprachlicher Bildungen wie z.B. coupe rase oder surface forestière können hingegen als autochthon gewertet werden. Deutlich als Entlehnungen aus dem Französischen gekennzeichnet sind jedoch Bildungen, die zwar auf einer lexikalischen Basis des B. beruhen, aber in ihrer untypischen morphologischen Gestaltung dem Französischen nachempfunden sind, wie z.B. trounçounuse $(<\mathrm{fr}$. tronçonneuse) oder poublamén $(<\mathrm{fr}$. peuplement).

${ }^{153}$ Es ist eine scheinbar banale, aber doch wichtig erscheinende Anmerkung, dass die Nutzung lauter, motorengetriebener Geräte bei der Waldarbeit heute jegliche Kommunikation vor Ort unmöglich macht. Dieses Phänomen ist bei der Beurteilung des sektoriellen Sprachgebrauchs mit zu berücksichtigen.

${ }^{154}$ Ich vermute, dass dies mit dem spezifischen (traditionellen) Wortgebrauch im Béarn zusammenhängt. Nach der Erläuterung von Palay zu urteilen wird / wurde abate einerseits als Ausdruck für das Schlachten von Tieren, andererseits als Bezeichnung bei der Ernte von Nüssen 
Von den Werkzeugen, die früher für das Fällen benutzt wurden, kannten alle Probanden die Axt, im B. je nach Gebiet piòle (/ piolète) oder destràu (/ destralète) genannt, und die 'Handgegenzugsäge', eine von zwei Leuten zu führende große Säge, die im B. passe-pertoùt (vgl. fr. passe-partout) heisst. Z.T. wurde in diesem Zusammenhang auch auf die Verwendung von 'Keilen', b. coégns (vgl. fr. coins), hingewiesen (P5, Q1.mp3, 25:04 gab die bearnesischere Variante cougn [conh] an).

Das 'Allround'-Werkzeug des modernen bûcheron ist die Motorkettensäge, die im Französischen tronçonneuse genannt wird. Das B. übernimmt diesen Begriff als trounçounuse, teilweise aber auch unverändert in der französischen Aussprache. Bei der Erklärung des Geräts durch die Probanden fiel mir auf, dass immer der Begriff chène (vgl. fr. chaîne) fiel, obwohl im B. für 'Kette' eigentlich das Lexem cadène benutzt wird. Hierzu erhielt ich eine interessante Erklärung von $\mathrm{P} 3:^{155}$

Lou mout francés chaîne, bon, you qu'emplègui... qu'y a hòrts qui dìsen 'ue chène, ue chène'. You qu'èy, qu'èy... qu'emplègui lou mout 'chène' quoan ey questioû d'ue chène de tronçonneuse, d'ue chène de trounçounuse, e qu'èy toutû hàmi de díse 'ue cadène de trounçounuse', més que que soue... que hè drin recercàt. Mé autademén, lou mout chaîne, quoan ey une chaîne pour tirer une machine, pour tirer un tronc d'arbre, aquìu qu'emplègui 'la cadène', e lous de per ací que dìsen toustém 'ue cadèna', ne dìsen pas yaméy 'ue chène', * que vam atelà ue cadèna + .

(P3, Q2.mp3, 45:59)

Mit der Motorsäge wird der gefällte Baum (1) von der Baumkrone und (2) von allen übrigen Ästen getrennt (b. (1) essoumà ${ }^{156}$ (2) esbrancà ${ }^{157}$ ). Das was außer dem Stamm (und evtl. noch verwertbarem Brennholz) dabei übrigbleibt, nennt man im B., analog zum Französischen, despulhe oder despoulhe (vgl. fr. dépouille). Der 'Wurzelstock' (Baumstumpf) im Boden wird la souque (vgl. fr.

und Esskastanien verwendet: abàte lous esquilhòts, las castagnes.

155 „Le mot français 'chaîne', bon, moi j'emploie... il y a beaucoup qui disent 'ue chène, ue chène'. Moi, j'ai, j'ai... j'emploie le mot chène quand il est question d'une chaîne de tronçonneuse, et $\mathrm{j}$ 'ai quand même envie de dire 'ue cadène de trounçounuse', mais ça sonne... ça fait un peu recherché. Mais autrement, le mot 'chaîne', quand c'est une chaîne pour tirer une machine, pour tirer un tronc d'arbre, là j'emploie 'la cadène', et ceux qui sont d'ici, ils disent toujours 'ue cadène', ils ne disent jamais 'ue chène', «nous allons atteler 'ue cadène'»."“

Anmerk.: Die Verlässlichkeit einer solchen Äußerung in Bezug auf andere Sprecher bleibt kritisch zu hinterfragen. Allerdings erscheint es glaubwürdig, dass die beschriebene sachgebundene Differenzierung des Gebrauchs von chène und cadène ein allgemeiner verbreitetes Phänomen darstellt. Im Übrigen gehörte P3 zusammen mit P5, P7 und P8 zu den Probanden, aus deren metasprachlichen Äußerungen eine zumindest leicht sprachpuristische Grundhaltung ableitbar war.

${ }^{156}$ Der Begriff wird im B. aus dem Bereich des Maisanbaus übernommen.

${ }^{157}$ Ich beziehe mich hier nur auf die forstliche Bedeutung des Lexems (vgl. P8, Q2.mp3, 6:08) 
souche), aber auch troungue genannt. P1 und P2 bestätigten zusätzlich noch das Wort trouch. Besonders interessant war die Erklärung von P6, der zwischen souque (bzw. dem französisierten b. souche) und troungue wie folgt differenzierte:

Que ban dìse dou càssou, ço qui ey lou soû pè qu'ey la troungue, 'la troungue dou càssou'. Que ban parlà d'û pacherà-qu'èm parlàt d'ous piquéts, de castagnè tà hà piquéts-que ban dìser [...] 'ue souche de castagnè'. [...] C'est deux mots qui veulent dire la même chose, mais qu'on utilise en fonction de l'arbre dont on parle.

(P6, Q2.mp3, 2:24)

Die klare Unterscheidung zwischen souche ('Wurzelstock') und tronc ('Stamm') im Französischen ist in dem traditionellen Vokabular des B., insbesondere in Bezug auf die Eiche, nicht gegeben. Die Lexeme pè, trounc, trouch, troungue (bzw. trounque) können sich sowohl auf den einen wie auf den anderen Inhalt beziehen. Die Erklärung liegt darin begründet, dass der Baum im B. als Ganzes, d.h. vor dem Fällen bzw. unter Abstraktion von den durch den Abhieb erfolgten Holztrennungen beurteilt wird. Dies lässt sich am Besten am Beispiel der Semantik des Adjektivs trouncùt vor Augen führen. Der Satz 'Aquét càssou qu'ey trouncùt.' bedeutet im B. soviel wie fr. 'Ce chêne a un fort tronc sur une forte souche.' (vgl. hierzu die entsprechende Worterklärung von Palay sowie P5, Q2.mp3, 24:01).

Insgesamt stellt die Beurteilung der Schönheit eines Baumes ('Wohlgeformtheit unter dem forstwirtschaftlichen Gesichtspunkt der Nutzholzqualität) einen wichtigen kommunikativen Teilbereich dar. Ich habe des öfteren bei Begehungen im Wald 'Gesprächsfetzen' dieser Art 'aufschnappen' können, ohne sie jedoch auf Tonträger zu konservieren. Prototypische Sätze zu diesem Thema sind etwa: 'Aquò qu'ey ue beroye came!' (fr. 'C'est un beau sujet (avec un gros tronc)', 'N'ey pas fourcùt, aqueste.' (fr. 'Il n'est pas fourchu, celuici.'), 'Que hè cheys mètres de hàut chens nat brounc.' ('Il fait six mètres de haut sans aucun næud') usw. Hinzu kommt, dass ein Qualitätsurteil bestimmter Baumarten bereits durch die entsprechende lexikalische Derivation gegeben sein kann. So bezeichnet cassourre in der Regel eine schöne große Eiche (vgl. z.B. P2, Q1.mp3, 12:10) und hayòle, zumindest gebietsweise, eine schöne große Buche (vgl. z.B. P3, E1.mp3, 9:02).

Oft sind bei den kurzen Gesprächen über den Zustand einzelner Bestände allerdings kaum spezielle (Fach-)Vokabeln vonnöten. Die Diskurse sind hier sehr einfach gehalten. Ich gebe im Folgenden ein Beispiel: ${ }^{158}$

${ }^{158}$ „Regarde les chênes, ils ont fait une poussée terrible, terrible, ces chênes-là, en... en quatre ans, ceux-là, ils ont été plantés, ils sont plus grands que ceux que nous avons vus au sommet, qui ont cinq ans ceux-là, regarde, il y a des chênes qui ont poussé très, très bien, très vite." 
Espìe lous càssous, qu'an hèyt ue bayude tarrìble, tarrìble, aquéts càssous, en.. en quate ans aquéts, que soun estàts plantàts, que soun màyes que lous qu'abèm vist au soum, qui an cinc ans aquéts, espie que y a càssous qui an bayùt hère hère plâ, hère biste.

(P3, E2.mp3, 38:00)

Das Wertholz des gefällten Baums befindet sich allein im Stamm. Der abgetrennte Stamm (Schaft) wird im B. weiterhin als troungue, trounc oder came bezeichnet. Das französische Fachwort fût (vgl. Dictionnaire Forestier Multilingue, Kennz. 623) findet im B. keine Entsprechung. ${ }^{159}$ Doch ist fr. fût zur Bezeichnung des gefällten Stammes auch eher unüblich. Die korrekten und häufig verwendeten Termini für den (weiter zu verarbeitenden) Baumschaft sind im Französischen sowohl grume als auch synonym bille (DFM, beide Kennz. 3557), die eine direkte Übersetzung in b. bilhe und bilhô̂ finden. ${ }^{160} \mathrm{P} 6$ z.B. definiert bilhe als 'lo trounc qui partéch dou pè enlà' (fr. 'le tronc qui part du pied en haut'; P6, Q2.mp3, 2:02).

Als Verb zur Bezeichnung des ersten groben Zerschneidens des Schaftes vor Ort ist b. abilhoà allgemein bekannt (vg1. P1, Q.mp3, 14:58, 'coupà lous àrbres endau tribalh a boune mesure'; Palay: 'partager un arbre en billons'). Daneben habe ich noch in Einzelfällen die Verben b. estrouncà (P5, Q1.mp3, 16:04) und b. estrouchejà (P6, Q1.mp3, 9:36) mit synonymer Bedeutung eruieren können.

Der erste Bearbeitungsschritt am Teilschaft ist die Erstellung des sog. 'Kantholzes'. Auch diese Tätigkeit ist den privaten Waldbesitzern im Béarn in der Regel bekannt oder sogar vertraut. Das Französische verwendet hierfür fachsprachlich équarrir (' équarri, DFM, Kennz. 5456/5671), das im B. durch das autochthone escarri wiedergegeben wird. P1 gab folgende Definition: ${ }^{161}$

${ }^{159}$ Allerdings werde ich in Kap. 2.4 zeigen, dass der fachsprachliche Gebrauch von fût auch im französischen Sprachgebrauch nicht sehr verbreitet bzw. präzise ist.

${ }^{160}$ Die Synonymenentsprechung lautet als Ergebnis meiner Befragung fr. grume, bille B b. bilhe, bilhoû. Allerdings bedeutet fr. billon fachsprachlich (nach dem Petit Robert Electr.) 'bille de bois courte'. Die Übertragung dieser fr. Bedeutung auf b. bilhou ist bei einem differenzierteren lexikalischen Wissen der Sprecher verifizierbar. So gab P1 (Q.mp3, 14:38) an, b. bilhô sei 'mey petit' als bilhe.

${ }^{161}$ Übers.: ,' 'Escarrì', c'est tirer la... ce qui en sort c'est le 'hòre-pèt'; 'hòre-pèt', c'est les premières... ce n'est pas de planches, c'est là où est l'écorce, une partie du bois; pour faire par exemple une poutre il faut équarrir un chêne; c'est lui donner une forme carrée ou rectangulaire, soit pour faire une poutre, soit pour faire des planches ou des madriers ou n'importe quoi, ou des solives. Il faut d'abord tirer les premiers morceaux de tout autour de la bille pour faire ça. “

Anmerk.: P8 (Q1.mp3, 13:24) gab als Synonym zu esquarrì auch das Verb doulà an, das ursprünglich aus dem Bereich des Fassbinderwesens stammt. 
'Escarrì' qu'ey tirà la... ço qui ne sort qu'ey lou horepèt; ${ }^{162}$ 'horepèt' qu'ey las prumères... n'ey pas planches, qu'ey doun ey l'escorce, ue partida dou boès; endà hà per exemple û piteràu que càu escarrì û càssou; qu'ey balhà'ou ue forme carrade ou rectangulàri ou soà endà hà û piteràu ou soà endà hà planches ou madrièrs ou n'importe, ou soulibes. Que càu tirà endabòr lous prumèrs tros a tout autoùr de la bilhe endà hà aquò.

(P1, Q.mp3, 8:29)

Zum Abschluss dieses Kapitels gehe ich noch kurz auf den Abtransport des Holzes aus dem Wald zu einem Ort der weiteren Bearbeitung ein. Das Französische kennt hierfür die Fachbegriffe débusquer (' debusquage, DFM, Kennz. 6775) und débarder ('débardage, DFM, Kennz. 2949), ${ }^{163}$ die jedoch nach meinen Befragungsergebnissen im regionalen Sprachgebrauch des Untersuchungsgebietes keine große Rolle spielen.

P7 nannte mir das alte Wort desbouscàyre mit der Bedeutungsangabe 'celui qui débarde les bois'. Da im Wörterbuch von Palay nur b. desbouscà in der Bedeutung 'déboiser, essarter' zu finden ist, stellte ich einem anderen Probanden, P3, die Frage, ob ihm dieses Wort noch bekannt sei. P3 bestätigte die Kenntnis des Begriffs, gab aber dann eine interessante Erklärung, aus der hervorgeht, dass der Holzabtransport für den einzelnen Waldbesitzer früher ein wichtigeres Thema darstellte als heute, weil es mit mehr Aufwand verbunden war und die modernen technischen Möglichkeiten noch nicht gegeben waren. Die Antwort von P3, die sich als Track 10 auf der beiliegenden CD (P3, Q2.mp3, 37:30) findet, ist ein gutes Dokument für das biographische und auf regionale Normen bezogene Antwortverhalten der Probanden. P3 betont, dass der Abtransport der Stämme schon immer die private Angelegenheit des einzelnen Waldbesitzers im Béarn war, d.h. nie ein forstwirtschaftliches Berufsfeld konstituierte.

Ich fand diesen Aspekt u.a. in einem Gespräch mit P1 bestätigt, das sich ebenfalls auf der CD (als Track 12) befindet. Auf die Frage nach einer Übersetzung von fr. débarder antwortete $\mathrm{P} 1$ schlicht: 'Bò, you qu'apèri 'tirà', tirà $\hat{u}$ càssou.' (P1, Q.mp3, 41:27). Diese Antwort verdeutlicht exemplarisch, dass es

${ }^{162} \mathrm{Vgl}$. zu b. horepèt die Erklärung von P7 (Q2.mp3, 10:44): ,, 'Horepèt', ça veut dire, c'est la première pla... la première... le premier morceau qu'enlève la scie et qui n'est bon en rien. Alors ça veut dire 'la peau enlevée', en bon béarnais ça se dit 'horepèt', [...] et on appelle aussi 'las croustes', mais c'est surtout 'horepèt'. '“

Vgl. fr. dosse 'première ou dernière planche sciée dans un tronc d'arbre, et dont la face bombée est recouverte d'écorce' (Petit Robert Electr.)

${ }^{163}$ Der Terminus débarder wird für die technisierte Holzabfuhr im Rahmen größerer Hiebe verwendet. Der b. Wortschatz stellt das Verb desbardà 'débarder, ôter la barde, la boue' (nach Palay) zur Verfügung. In einem Fall (P4, Q2.mp3, 7:52) habe ich in meiner Befragung einen fachspezifischen calque durch eine forstwirtschaftliche Bedeutungsannahme dieses Verbs feststellen können. 
keinen Sinn macht, die Analyse des regionalen Sprachgebrauchs in Fachkontexten zu stark auf die Suche nach Fachvokabular auszurichten. Ich werde daher in Kapitel 2.3 eine genauere Untersuchung auf der Ebene der Diskursgestaltungen vornehmen. Zuvor aber bleibt noch ein letzter wichtiger Teilbereich des fachspezifischen Vokabulars zu 'Wald und Nutzung des Waldes' im Béarn zu erläutern.

\subsubsection{Der lexikalische Bereich 'Botanik und Nomenklatur des Baums'}

Es lässt sich einleitend feststellen, dass der Kenntnisstand in diesem Bereich bei allen Probanden auffällig gut und differenziert war. Meine Fragen bezogen sich zum einen auf die wichtigsten Teile des Baums als pflanzlichem Organismus, zum anderen auf die verschiedenen im Béarn anzutreffenden Arten von Waldbäumen. Das abgefragte Wissen war also rein nomenklatorischer Natur. Ich werde die Ergebnisse der Befragung im Folgenden zusammenfassend (d.h. in der Regel ohne auf das Antwortverhalten der einzelnen Probanden einzugehen) darlegen.

2.2.2.4. Die grundlegende Konstitution des Baums wurde von den Probanden terminologisch beherrscht. Ich kommentiere nacheinander die gängigen Benennungen seiner wichtigsten Teile.

Die Wurzeln werden im B. arradits oder auch racines ${ }^{164}$ genannt, wobei häufig beide Ausdrücke bekannt sind.

Als Bezeichnung für den Wurzelstock ('Stumpf') sind in dem Befragungsgebiet vor allem souque, troungue und trouch gebräuchlich. In manchen Gebieten werden die Lexeme je nach Baumart (bzw. forstlicher Betriebsart) differenziert. Im vorangegangenen Kapitel habe ich bei der entsprechenden Erklärung hierzu darauf hingewiesen, dass Wurzelstock und Stamm im B. häufig undifferenziert betrachtet und auch benannt werden.

Der gesamte Stamm (inklusive Stammansatz) des ungeschlagenen Baums hat eine ganze Reihe von Benennungen, von denen neben den sehr frequenten metaphorischen Ausdrücken pè (fr. pied) und came (fr. jambe) auch trounc oder troungue verwendet werden.

Die Astansatzstellen am Stamm werden, gleichwertig zu fr. nœud, im B. als brounc oder bourrounc bezeichnet.

Für die Gabelung des Stammes (Schaftteilung) steht das Lexem hourque und die Adjektivableitung hourcùt (vgl. fr. fourche, fourché) zur Verfügung. ${ }^{165}$

\footnotetext{
${ }^{164}$ B. racines geht sicher auf französischen Einfluss zurück, findet sich aber als Lemma auch im Wörterbuch von Palay.

${ }^{165}$ Meine Befragung umfasste diesen lexikalisch-semantischen Bereich leider in keiner systema-
} 
Die Baumkrone, im Fr. houppier, ist fachsprachlich definiert als die Gesamtheit des oberen Teils eines älteren Baums, zu dem alle Äste, Zweige und Blätter oberhalb des reinen Stamms (fr. fût) gehören, also auch der Bereich des Kronenansatzes am Schaft. Ich habe die Erfahrung gemacht, dass houppier in der fr. Gemeinsprache relativ wenig bekannt ist (und falls bekannt, meistens von den Sprechern nicht genau definiert werden kann). ${ }^{166}$ Als Fachterminus findet der Begriff keine genaue Entsprechung im B., so dass im Bedarfsfall die Lehnbildung houpiè verwendet wird (vgl. P6, Q2.mp3, 0:16). Dabei ist zu beachten, dass das Basiswort houpe (fr. houppe) im B. erbwörtlich existiert.

Der Baumwipfel, fr. cime, bezeichnet fachsprachlich die Spitze der Sprossachse (fr. tige) des Baumes, also letztlich nur die Markierung seiner Gesamthöhe. Laut Wörterbuch existiert im B. cim (m.) in dieser Bedeutung, was ich jedoch in keinem Fall bestätigt fand. ${ }^{167}$ Stattdessen gaben die Probanden b. soum (fr. sommet) als Entsprechung an. Zusätzlich (und in einer spezieller auf den Baum bezogenen Bedeutung) war allen Probanden des westlichen Untersuchungsgebiets noch b. capùtch geläufig.

Die Äste, fr. branches, werden im B. als branques bzw. brangues teilweise auch als arrames (P5, P7) bezeichnet. Dabei entspricht b. arrames eigentlich fr. rameaux in der Bedeutung 'kleinere Äste, Zweige'. ${ }^{168}$

Für 'Blatt' ist im B. hoélhe [huelha] allgemein bekannt. Die Probanden verwiesen immer wieder auf den Gebrauch von hoélhe im Sinne von fr. feuil-

tischen Weise. Es fiel mir aber auf, dass der Einfluss des Französischen hier teilweise recht groß ist (Gebrauch von fourque oder sogar fourche im B.). Anzumerken ist ebenfalls, dass das Begriffsfeld früher eine viel wichtigere Rolle im B. spielte als heute. So bedeutete hourcùt ehemals auch 'boisé, couvert de bois' (nach Palay). Ich vermute, dass die typische systematischen Weise. Es fiel mir aber auf, dass der Einfluss des Französischen hier teilweise recht groß ist (Gebrauch von fourque oder sogar fourche im B.). Anzumerken ist ebenfalls, dass das Begriffsfeld früher eine viel wichtigere Rolle im B. spielte als heute. So bedeutete hourcùt ehemals auch 'boisé, couvert de bois' (nach Palay). Ich vermute, dass die typische Wuchsform der Eichen im Béarn mit vielen 'Zwieseln' (Stammteilungen) und Gabelungen für eine semantische Ausweitung des Begriffs hin zu 'Wald im Allgemeinen' verantwortlich war. Vgl. in diesem Zusammenhang die heute im B. veralteten Begriffe hourc und hourcade für 'Wald'. Palay merkt u.a. an: „On dit encore $\hat{u}$ lè hourc pour un vilain coin de bois.“

${ }^{166} \mathrm{Vgl}$. hierzu die Def. von houppier im Petit Robert Electr.: 'Arbor. Sommet d'un arbre ébranché, et par_ext. cet arbre.' Im Gegensatz hierzu die Fachbedeutung: 'Ensemble des ramifications (branches et rameaux) de l'arbre et partie du tronc non comprise dans le fût.' (Précis de Sylviculture, ENGREF, 1994, 463).

${ }^{167}$ Von P1 und P2 wurde der Gebrauch la cime im B. bestätigt (Französismus?). Die Ableitung cimalh, laut Glossar der Ausstellungsbegleitschrift Le bois en Béarn \& son exploitation, Pau 1979, in der Bedeutung 'branchages de l'arbre en pied', war keinem der Probanden bekannt.

${ }^{168}$ Die semantischen Abgrenzungen scheinen hier nicht eindeutig fixiert zu sein. P8 z.B. bevorzugt den undifferenzierten Gebrauch von branques. Die maskulinen Formen branc und arràm, die das Wörterbuch angibt, sind zumindest in meinem Untersuchungsgebiet ungebräuchlich. Arràm wird als veraltet bewertet, dient heute aber noch zur Bezeichnung des Palmsonntags (fr. les Rameaux): lous Arràms (nach P4: lous Ràms, nach P2: lous Arramèus). 
lage, so etwa in Sätzen wie 'que sòr la hoélhe' oder 'que va càde la hoélhe.'. ${ }^{169}$ Allerdings ist auch die Ableitung b. hoelhàdje durchaus gängig. P6 (Q2.mp3, $0: 45)$ verwies mich darüber hinaus auf das abgeleitete Verb eshoelhà (fr. éfeuiller), das im Béarn im Bereich des Maisanbaus verbreitet ist ('eshoelhà lou milhòc'), allerdings auch in Bezug auf Bäume Verwendung findet: 'Lous àrbes que s'eshoélhen.' (zitiert nach Palay).

Für 'Rinde' existiert im B. nur der metaphorische Ausdruck pèt (fr. peau), doch verwendeten z.B. P2 und $\mathrm{P} 4$ ebenso b. $e(s)$ còrce, das offensichtlich einen Französismus darstellt.

Probeweise fragte ich auch nach der begrifflichen Kenntnis der einzelnen Holzschichten im Aufschnitt eines Stammes. Dabei setzte ich nur eine grobe Kenntnis voraus, ${ }^{170}$ die im Allgemeinen von den Probanden auch unter Beweis gestellt wurde. Neben der Rinde als der äußeren Schicht des Stammes war die Unterscheidung in das weichere Splintholz (fr. aubier) und das innere harte Kernholz (fr. (bois) parfait, bekannter als bois de cœur) allen geläufig. Die Begriffe wurden auf $\mathrm{B}$. mit aubà und couràu (bzw. boès dou cò oder cò dou boès) korrekt wiedergegeben. Schwerer fiel den Probanden hingegen die korrekte Bezeichnung der 'Jahrringe' (fr. cernes, weiterer Fachterminus: couches d'accroissement) im B. Zwar war das Phänomen allen bekannt, doch fiel nur P6 und P8 die richtige b. Bezeichnung lous rouns [los ronds] dafür ein. ${ }^{171}$

Insgesamt lässt sich feststellen, dass das terminologische Wissen zur biologischen Konstitution des Baums im Französischen und Bearnesischen keine qualitativen Unterschiede aufweist und eindeutig nach lebenspraktischen Bezügen dimensioniert und strukturiert ist. Ganz gleich, welche Sprache benutzt wird, stehen der Umgang mit reinem Fachvokabular und die Respektierung fachbegrifflicher Präzision nicht im Vordergrund, wenn es um die Benennung von Teilen des Baumes geht.

2.2.2.4. Ein lebenspraktischer Bezug zeigt sich auch in dem nomenklatorischen Wissen der Probanden zu den einzelnen Baumarten (fr. essences), die im B. meist als varietàts oder espèces, seltener auch als oùrdis bezeichnet werden. Grundsätzlich ist es möglich, hier eine Klassifikation nach quantitativem Vorkommen oder nach Nutzungsart vorzunehmen, da beide Aspekte für die Verfügbarkeit des entsprechenden lexikalischen Wissens wichtig sind.

\footnotetext{
${ }^{169}$ Die Bedeutung ist auch im gesprochenen Fr. geläufig, z.B. 'L'arbre a sorti la feuille.'

${ }^{170}$ Insbesondere fragte ich nicht nach dem genaueren Aufbau der Rindenschicht, da es sich hierbei um eine Überprüfung detaillierter biologischer Kenntnisse gehandelt hätte, die nicht zu meinen Untersuchungszielen gehörte.

${ }^{171}$ Es ist jedoch hervorzuheben, dass auch die französischen Fachtermini den Probanden meistens nicht bekannt sind und das Phänomen dann häufig mithilfe des Ausdrucks cercle beschrieben wird.
} 
In quantitativer Hinsicht spielt im Béarn, wie schon mehrfach erwähnt, die Eiche die herausragende Rolle. Daneben gibt es besonders reiche Vorkommen an Kastanien (vor allem in meinem westl. Untersuchungsgebiet mit ehemals wirtschaftlicher Nutzung), an Buchen (allerdings weniger in meinen U.-gebieten, sondern mehr im Süden), an Weiden (vor allem entlang der Gebirgsbäche, b. gàbes [gavas]) und immer mehr auch an Eschen (die sich im Jungwuchs gut durchsetzen und als Wertholzbäume mehr und mehr gefragt sind). Im Gebirge, das nicht zu meinem Untersuchungsgebiet gehörte, dominiert neben der Buche vor allem die Tanne.

Die im B. gängigen Bezeichnungen der einzelnen Baumarten werde ich im Folgenden zusammen mit einer nutzungsorientierten Klassifikation erläutern. Es lassen sich grob vier Gruppen unterscheiden, die ich ihrer traditionellen Wichtigkeit nach ordne:

\section{(1) Brennholz}

Der ehemals sehr große Bedarf ist auch auf dem Land stark zurückgegangen. Wegen des großen Vorkommens an Eichen, b. càssou bzw. tausî, wird fast ausschließlich diese Baumart zur Brennholzgewinnung genutzt. Die mögliche Verwendung jungen Holzes lässt z.T. auch die Erle, fr. vergne, b. bèr, zu einem beliebten Brennholzlieferanten werden.

\section{(2) landwirtschaftliche Nutzungen}

Vorherrschend war die Produktion von Rebstecken und Weidezaunpfählen aus Niederwaldbetrieb. In der Viehhaltung verfütterte man Eicheln an Schweine. Jüngeres Geäst wurde z.T. als Stallunterlage verwendet. Gebietsweise war der Verkauf geernteter Esskastanien ein regelrechter Wirtschaftsfaktor. Diese und andere Nutzungen (z.B. Tanninproduktion für die Gerberei), die es heute kaum noch gibt, bezogen sich fast ausschließlich auf den Kastanienbaum, b. castagnè, und die Eiche, b. càssou bzw. tausî. Zudem wurde auch das Holz der Robinie, fr. (faux-)acacia, b. a(r)cacià, gern für Weidezaunpfähle genommen. Die Esskastanien sind aufgrund infektiöser Krankheitsbefälle in den vergangenen Jahrzehnten im Béarn stark dezimiert worden.

\section{(3) Werkzeug- und Geräteherstellung}

Die manuelle Fabrikation von (landwirtschaftlich genutzten) Werkzeugen und Geräten aus Holz ist heute kein Wirtschaftsfaktor mehr. Traditionell erinnert man sich noch an viele Produktionsbereiche, die einzelnen Holzarten zugeordnet waren. Neben der Eiche spielten Buche, fr. hêtre, b. hag oder hau, und Esche, fr. frêne, b. (ar)rèche bzw. (ar)rèchou ${ }^{172}$, eine wichtige Rolle.

\section{(4) Bauholz und Möbelproduktion}

Seit jeher hauptsächlich für den privaten Bedarf. Besondere Bedeutung kommt in diesem Bereich wiederum der Eiche, aber auch einigen anderen Baumarten

${ }^{172}$ In der Lexikographie finden sich vor allem herèche und herèchou. Diese Formen konnten in meiner Befragung allerdings nicht bestätigt werden. 
zu. Zu erwähnen sind u.a. die Ulme, fr. ormeau (orme), b. auméte (oum) und die Vogelkirsche, fr. merisier, b. cerisè, deren Holz sehr hart ist, die jedoch beide im Béarn nur selten vorkommen. Eschenholz (s.o.) wurde traditionell gern für Küchen verwendet. Auch das weichere Holz der Pappel, fr. peuplier, b. pupliè (Französismus), z.T. auch bigou, und der Espe, fr. tremble, b. tremoulét $^{173}$ (tremoulè), findet Verwendung.

Die begriffliche Kenntnis der einzelnen Baumarten umfasste bei allen Probanden weit mehr als die genannten Arten. Ich möchte hier nur noch auf einige der wichtigeren eingehen.

Der Walnussbaum, fr. noyer, b. nouguè oder esquilhoutè (meist waren beide Lexeme als Synonyme bekannt), ist wegen seiner essbaren Früchte (fr. noix, b. nougues, esquilhòts), aber auch wegen seines wertvollen Holzes bekannt. Der Haselnussbaum, fr. noisetier, b. aberagnè, hingegen gehört eher zu den Sträuchern als zu den Bäumen. Er ist heute kein Holzlieferant mehr, wird aber noch gern für kleinere Ernten von Haselnüssen, fr. noisette, b. aberâ, genutzt.

Die beiden botanisch recht verschiedenen Varietäten des Weißdorns, fr. aubépine (seltener auch épine blanche), und des Schwarzdorns (Schlehe), fr. prunellier (auch épine noire), bezeichnet man im B. ähnlich wie im Französischen und Deutschen als broc blanc und broc né(g)re. Alle Probanden waren in der Lage, die beiden Arten faktisch und begrifflich zu unterscheiden. Auffällig war, dass die fr. Bezeichnung für den Schwarzdorn den meisten Probanden nicht so geläufig war wie broc nére.

Haselnuss, Weißdorn und Schlehe gehören - ebenso wie die ronces (b. sègues) - zu der typischen Vegetation des dichten, dornigen und stellenweise undurchdringbaren Unterwaldes der bearnesischen Wälder. Hinzu kommt mancherorts ein abundantes Vorkommen an Weiden, die das B. undifferenziert mit dem Begriff saligues benennt. Saligues umfasst verschiedene Varietäten der botanischen Gattung salix, die im Béarn teilweise so üppig und schnell wachsen, dass sie aus der Sicht des Waldbaus, insbesondere in Anpflanzungen, als Störvegetation empfunden werden. Zu der Gruppe der saligues gehören auch einige Arten des fr. osier, für den es im B. die Bezeichnung bimi (oder bime) gibt.

Als Letztes möchte ich noch auf zwei Fälle hinweisen, in denen sich die Probanden bei der Bestimmung und Benennung von Baumarten nicht als so

${ }^{173}$ Die Espe ist im Béarn recht verbreitet, jedoch vom Holz her eher wertlos. P1 (Q.mp3, 34:01) gab mir zusätzlich zu tremoulét noch came gris als metaphorische Bezeichnung an. Auch der Ausdruck pèt-nére ist in dem Untersuchungsgebiet bekannt. B B. tremoulét wird auch zur Benennung eines Pilzes verwendet, der typischerweise unter den Espen wächst (lat. boletus luteus nach Angaben von Palay, fr. bolet rude, b. baqués nach Angaben von P4, Q1.mp3, 45:29). Neben der einheimischen Espe gibt es eine wertvollere amerikanische Varietät, fr. caroulin, die im B. ebenfalls unter dieser Bezeichnung bekannt ist. 
sicher wie üblich erwiesen. In beiden Fällen erklärt sich dies aus der Seltenheit der jeweiligen Gattung in der Region.

So war festzustellen, dass im Untersuchungsgebiet die klare Unterscheidung von fr. pin und sapin nicht unbedingt geläufig ist (vgl. z.B. P6, Q1.mp3, 45:06, der von pîs de Nadau spricht). Jedenfalls wird b. pî gern verallgemeinernd für 'Nadelbaum' benutzt, während resinoûs als Entlehnung aus dem Fr. résineux eher eine Art nicht akzeptiertes Kunstwort bleibt. ${ }^{174}$ Hinsichtlich der Tanne, im Untersuchungsgebiet als b. sapî bekannt, verwiesen die Probanden auf das starke Vorkommen dieser Nadelbäume im Gebirge, wo die Bezeichnungen abét oder abete geläufig sind (was aber nur einige der Probanden wussten). Z.T. werden heute im Béarn auf Initiative der Forstinstitutionen auch eine Reihe regional untypischer Nadelbaumarten angebaut. Die entsprechenden Bezeichnungen sind internationaler Natur (pin Laricio, épicéa, Douglas) oder existieren nur im Fr. (mélèze) und werden im B. unverändert übernommen.

Erstaunlich waren die Unsicherheiten in Bezug auf die Birke, die in dem Untersuchungsgebiet zwar seltener, aber durchaus vertreten ist. Zunächst einmal fiel die große Bezeichnungsvielfalt dieses Baums auf: Für fr. bouleau nannten die Probanden als b. Entsprechungen pèt-blanc, betoutch, betoure, blanguét und sogar boulèu, das aber einen offensichtlichen Französismus darstellt. Vier der Befragten wiesen zudem darauf hin, dass die Birke im B. oft mit dem tremoulét, also der Espe (im B. auch pèt-nére), verwechselt wird, was wohl auf die botanische Verwandtschaft beider Baumarten zurückzuführen ist.

In einer resümierenden Bewertung des ermittelten Kenntnisstands hinsichtlich der Nomenklatur der Baumarten lässt sich festhalten, dass alle Probanden - aufgrund ihres lebenspraktischen Bezugs zum Wald und teilweise auch zum Waldbau - ein sehr differenziertes Wissen unter Beweis stellten, das geeignet ist, dem Städter vor Augen zu führen, wie weit er sich von der natürlichen Realität des Waldes entfernt hat. Dieser unmittelbare Bezug lässt die begriffliche Verfügbarkeit in beiden regional verwendeten Sprachen als selbstverständlich erscheinen. Schwierigkeiten, den korrespondierenden Begriff in der jeweils anderen Sprache zu finden, tauchen sporadisch in beiden Richtungen (Fr. ' B., B. ' Fr.) auf und werden in der Regel durch die (okkasionelle) Übernahme des Begriffs aus der jeweils anderen Sprache gelöst. Die Kenntnis der b. Nomenklatur ist dabei bis zu einem gewissen Grad selbst unter reinen Französischsprechern noch verbreitet. So habe ich z.B. die Erfahrung gemacht, dass Kinder von Landwirten, auch wenn sie nicht mehr selbst aktiv B. sprechen, noch eine ganze Reihe von Bäumen auf B. benennen können.

${ }^{174}$ B. hoelhùt als Übersetzung von fr. feuillu 'Laubbaum' wird hingegen allgemein verstanden und akzeptiert, aber meiner Beobachtung nach selten aktiv im B. verwendet. 
Insgesamt zeigt sich im Teilbereich des Wortschatzes, den das B. zu 'Wald und Nutzung des Waldes' heute zur Verfügung stellt, sehr deutlich die Komplexität der lexikalischen Strukturveränderungen, die sich in der Regionalsprache vollzogen haben und heute weiterhin vollziehen. Diese Komplexität resultiert aus dem gleichzeitigen Anpassungsdruck an sozio-ökonomisch gegebene Sachveränderungen (allgemeinsprachliches Wissen) und an die durch Sprachkontakt vermittelten Strukturen des Französischen (einzelsprachliches Wissen), ferner aus der sprachsoziologisch erklärbaren Regression des B. und der mit ihr in Zusammenhang stehenden 'Erosion' von Formen der Diskursgestaltung (textuelles Wissen), für die der zur Verfügung stehende Wortschatz wiederum eine wichtige Grundlage bildet.

Es wäre falsch, zu behaupten, das B. stelle für diejenigen, die es noch in der alltäglichen Kommunikation verwenden, ein unvollständiges, allenfalls fragmentarisches Kommunikationssystem dar. Im Gegenteil lässt sich auch heute noch für den b. Muttersprachler alles ebenso gut auf B. wie auf Fr. ausdrücken. (Ich habe diese Erfahrung längst nicht nur im Bereich des Waldbaus, sondern z.B. auch bei Gesprächsthemen wie dem Euro oder dem Rinderwahnsinn machen können.) Allerdings wird diese kommunikative Funktionalität für einen hohen Preis erkauft: der sprachstrukturellen Modifikation des B. nach den Maßstäben der regionalen Adaptation(sfähigkeit) des französischen Sprachgebrauchs. Das B. kann seine sprachlichen Traditionen in diesen Prozess nur in einem sehr geringen Maße einbringen. 


\subsection{Beispiele bearnesischer Diskurse im Sachbereich 'Wald und Nut- zung des Waldes'}

\subsubsection{Der bearnesische Sprachgebrauch in Fachkontexten des Waldes}

Jede sprachwissenschaftliche Enquête ist auch ein kleines Abenteuer. So gestaltete sich meine Probandenbefragung zum Vokabular des Waldes im Béarn vor Ort ein wenig anders, als ich mir das vorher gedacht hatte. Die von mir vorbereiteten Arbeitsgrundlagen waren ursprünglich weitaus stärker auf eine formalistische Befragungsmethode ausgerichtet, als es dem Antwortverhalten der Probanden entsprach. Ich war überrascht festzustellen, wie sehr das 'trockene' Abfragen von Vokabeln bei meinen Informanten spontan immer wieder Erklärungen, Beispielgebungen, Stellungnahmen und auch kurze Erzählungen herausforderte, die sich im Laufe der Enquête wie ein Mosaik zu einem umfassenden Bild der mit dem Wald im Béarn verbundenen Lebensrealität zusammenschlossen. Da ich alle Gespräche aufgezeichnet habe, ermittelte ich auf diese Weise zusammen mit den gewünschten Auskünften zum Vokabular eine ganze Reihe authentischer Diskurse im Sachbereich. Die Bereitschaft der Probanden, sich über die lexikalischen Kenntnisangaben hinaus zu äußern, bekam durch die Wahl des Bearnesischen als Konversationssprache eine besondere Dimension. Bei der Bearbeitung des Aufnahmematerials fiel mir auf, dass ich teilweise sehr wertvolles Sprachmaterial zusammengetragen hatte, dessen Dokumentation sowohl im Sinne des Themenschwerpunkts dieser Arbeit als auch aus der Perspektive der okzitanistischen Sprachforschung von Interesse ist. Ich habe mich daher entschlossen, die entsprechende Dokumentation in schriftlicher wie auch in akustischer Form in die Darlegung meiner Untersuchungsergebnisse zu integrieren.

Es erscheint angebracht, einleitend eine kurze Charakteristik des ermittelten Textcorpus zu geben: Es handelt sich um Gesprächsausschnitte monologischen Charakters, die sich aus der kommunikativen Konstellation eines Fragenden und eines Antwortenden (Erklärenden) ergeben haben. Maßgeblich war dabei die grundsätzlich vorgegebene Themenfixierung des Gesprächsinhalts, auf die sich die Gesprächspartner in allen Fällen bereitwillig eingelassen haben. Eine solche Themenfixierung zwischen Eruierendem und Probanden ist bislang hauptsächlich aus der soziolinguistischen Empirie bekannt. Sie bezieht sich in der Regel auf eine metalinguistische Thematik, die den Sprecher einer Sprache zu der Preisgabe von Informationen über diese Sprache herausfordern soll. Für den Zweck der hier vorgelegten Untersuchung, deren Ausrichtung in diesem Sinne nicht der klassischen Soziolinguistik entspricht, habe ich einen anderen Weg gewählt. 
Als Fragesteller wollte ich die Sprecher einmal nicht 'als Linguisten' - also nicht fachfremd - interviewen, sondern als Repräsentanten eines Fachs, das ihnen vertraut ist und, was mir ebenso wichtig erscheint, als Gesprächspartner auf gleicher Ebene ${ }^{175}$. Die Kombination dieser beiden Aspekte führte zu der Aufzeichnung von Textcorpora, die im Rahmen der empirischen Sprachforschung - sei es von Seiten der Soziolinguistik oder auch der strukturell orientierten Sprachwissenschaft - bislang nicht bereitgestellt worden sind. Diese Tatsache hat weitreichende Konsequenzen für die verbreitete Interpretation des sprachlichen Verhaltens in Regional- und Minderheitensprachen. Ich möchte dies kurz unter Bezug auf die Erforschung des Gaskognischen durch Jakob Wüest und seine Arbeitsgruppe herausstellen.

Die beiden von J. Wüest und M. Kristol herausgegebenen Monographien zur sprachlichen Situation des Gaskognischen $(1985,1989)$ sind eine hervorragende wissenschaftliche Leistung, deren besonderes Verdienst es ist, die Realität der Sprache ohne ein festes Korsett methodischer Konzeptionen untersucht zu haben. Die empirische Arbeit stand für die Arbeitgruppe um Wüest und Kristol eindeutig an erster Stelle der Untersuchung. Die sprachstrukturellen und sprachsoziologischen Befunde wurden von den Wissenschaftlern erst in einem zweiten Schritt an die ihnen am besten geeignet erscheinenden Interpretationsmethoden herangeführt. Zur Verdeutlichung der Zielsetzung meiner eigenen Untersuchung möchte ich hier kurz auf den Beitrag „ "Que cau diser’u en francés». La conversation occitane en situation de diglossie" von Jakob Wüest eingehen. ${ }^{176}$

Wüests Beitrag greift ein in der soziolinguistischen Erforschung des Okzitanischen selten behandeltes Thema auf: die Gestaltung der Kommunikationsebene des Textes. Dabei geht auch Wüest von den Grundprinzipien der diglossischen Forschung aus, die für dieses Untersuchungsfeld eine geeignete me-

${ }^{175}$ Mit der 'gleichen Ebene' der Gesprächspartner meine ich die weitgehende Ausblendung der Einflussnahme sozialer Positionen, die meiner festen Überzeugung nach in vielen emprischen Untersuchungen ein Hindernis für die Eruierung authentischen Sprachverhaltens darstellt. Die typischen metalinguistischen Befragungsformen sind in diesem Sinne kaum gegen die verfälschende Wirkung von Konstellationen wie 'Akademiker fragt Landwirt', 'Städter fragt Landbevölkerung' oder 'Sprecher der gepflegten (nicht-regionalen) Hochsprache fragt Dialektsprecher' gewappnet. Die sachbereichsbezogenen Enquêtes meiner Untersuchung in der Regionalsprache gaben hier wesentlich bessere Möglichkeiten einer unkomplizierten Beziehung der Gesprächspartner untereinander, die von Offenheit bis hin zu Freundschaft reichte. Es tat der spontanen Entwicklung solcher Beziehungen gut, dass mein Gesprächspartner prinzipiell der Gebende (d.h. sein Fachwissen Mitteilende) war und sich zu etwas äußern konnte, das ihn interessierte und betraf.

${ }^{176}$ Der Beitrag findet sich in Wüest / Kristol 1993, 227-257. Anmerk.: Nach den orthographischen Normen des I.E.O. wäre die korrekte Wiedergabe des den Titel bildenden Zitats: „Que cau díse'u en francés“. Nach den Normen des gaskognischen Sprachgebrauchs wäre der Gebrauch des Indefinitpronomens $a c$ (at) zu erwarten. Der Titel ist die Wiedergabe eines Zitats aus den Sprachaufnahmen des Autors (S. 248). 
thodische Basis abgeben. Wüest schließt sich speziell dem von John Trumper in der italienischen Soziolinguistik (vgl. 1977) entwickelten Modell der Unterscheidung von Makro- und Mikrodiglossie an und definiert die Verhältnisse in Südwestfrankreich entsprechend dieser Unterscheidung als 'mikrodiglossisch'. Ich gebe im Folgenden die von Wüest prägnant zusammengefassten definitorischen Aspekte der Mikrodiglossie wieder:

$1^{\circ}$ La langue L (l'occitan, en l'occurrence) ne s'emploie qu'entre membres de la famille et entre amis, c'est-à-dire à l'intérieur d'un petit groupe de gens qui se connaissent.

$2^{\circ}$ Il n'y a qu'un petit nombre de domaines qu'on a l'habitude de traiter en langue $\mathrm{L}$, de sorte que les interlocuteurs se trouvent facilement déroutés quand ces limites ne sont pas respectées.

$3^{\circ} \mathrm{Il}$ n'arrive pour ainsi dire pas qu'on mélange les deux langues à l'intérieur d'un énoncé.

$4^{\circ}$ A l'encontre de la macrodiglossie, état très durable, la microdiglossie peut mener à la disparition graduelle des dialectes.

(Wüest/Kristol 1993, 227 f.)

Prinzipiell, so stellt Wüest fest, treffen die beschriebenen Phänomene des Sprachgebrauchs auf die Situation des Gaskognischen / Bearnesischen zu. Allerdings gilt dies seiner Meinung nach nur mit Einschränkungen für den Punkt 3, den er in dem genannten Beitrag ausführlich diskutiert. Ich möchte im Folgenden diese Diskussion kurz aufnehmen und zudem auch den Punkt 2 der Auflistung kommentieren. Die Faktizität der Punkte 1 und 4 habe ich bereits in früheren Zusammenhängen bestätigt.

Ad 2) Die diglossische Forschung hat darauf hingewiesen, dass die dominierte Sprache insbesondere im Falle ihrer akuten Regression sich auf klar begrenzte Kommunikationsbereiche zurückzieht. Dieses bekannte Phänomen zeigt in der dynamischen Entwicklung diglossischer Verhältnisse zwei Wirkungen. Zum einen werden die Gesprächsanlässe in den verbleibenden Domänen der Sprachverwendung des Dialekts bzw. der Minderheitensprache kontinuierlich reduziert. Zum anderen fallen nach und nach ganze Bereiche völlig aus der gesellschaftlichen Kommunikationsfunktion der benachteiligten Sprache heraus. Es ist aber zu berücksichtigen, dass das zuletzt genannte Phänomen in der ersten Phase diglossischer Reduktions- und Substitutionsprozesse vorherrschend ist, während das zuerst genannte Faktum die den Sprachverwendungsumfang beherrschende Realität in einer zweiten Phase darstellt. Das Bearnesische kann wie das Okzitanische insgesamt kaum noch gesellschaftliche Verwendungsdomänen verlieren, ohne dabei seine Existenz völlig aufzugeben. Aber selbst da, wo es heute noch gesprochen wird, ist es, aus der Perspektive diglossischer Funktionsverteilung betrachtet, immer weniger als normal oder üblich zu bezeichnen. Die Restdomänen der Sprachverwendung des Bearnesischen bilden in der Tat gewisse 'Nischen', in denen immer weniger 
Sprecher immer weniger Anlässe finden, die Regionalsprache zur Kommunikationsgrundlage zu machen.

Vor diesem faktischen Hintergrund sind auch meine Sprachaufnahmen zu betrachten. Ihr Zustandekommen stellte für die Sprecher eine ungewöhnliche Situation dar, da sie eine Funktionalität der Sprache implizieren, die in der Sprachgemeinschaft nur noch ausnahmsweise gegeben ist. Diese Exzeptionalität hängt jedoch nicht mit der Domäne der Sprachverwendung zusammen, sondern mit der Intensität der Nutzung der Sprache in dieser Domäne, wodurch ein wesentlicher Unterschied gegeben ist. Der Gebrauch des Bearnesischen in den speziellen Fachkontexten des Waldes und seiner Nutzung stellte für die Probanden kein Problem dar und wurde von ihnen offensichtlich als natürlich und sogar angenehm empfunden. Ungewohnt war einzig und allein die Tatsache, mit mir als Fragesteller auf Bearnesisch über den Wald zu sprechen, was jedoch als gegebene Gesprächssitutation stets schnell akzeptiert wurde und der sprachlichen Authentizität der spontanen Diskurse keinen Abbruch tat. Die längeren Transkriptionen und der direkte Kontakt zum gesprochenen Text via Tonträger werden dem Leser und Hörer deutlich machen, dass der Beweis dieser Authentizität in einer vollkommenen Natürlichkeit des Sprechens und in einem erstaunlich hohem Maß an Sprachkompetenz zu finden ist.

Ad 3) Die im Rahmen dieser Untersuchung wiedergegebenen Diskurse sind bis auf wenige Ausnahmen rein auf Bearnesisch gesprochen und stellen damit ein für die aktuellen gesellschaftlichen Sprachverhältnisse außergewöhnliches Sprachdokumentationsmaterial dar. Die angemessene Beurteilung dieses bearnesischen Sprachgebrauchs ohne Interferenzen und Code-Switching erfordert einen grundsätzlichen Kommentar. Zum einen schließe ich mich der Sichtweise von Wüest an, der darauf hinweist, dass eine sprachpuristische Haltung in der Bewertung des heute gesprochenen Okzitanisch wenig Sinn macht. Es ist selbstverständlich und auf mehrere Gründe zurückzuführen, dass der mündliche Sprachgebrauch des Bearnesischen nicht frei von fremdsprachlicher Einflussnahme ist und dass es sich bei dieser Einflussnahme in der Regel um eine Auswirkung des engen Sprachkontakts zum Französischen handelt. Wüest argumentiert zu Recht, dass es in dieser Situation ausschließlich Sinn macht, dem sprachnormativen Bewusstsein der Sprecher selbst zu folgen, auch wenn dies hinsichtlich der Bewertung aufgezeichneter Texte empirisch kaum zu leisten ist. Aus der Erfahrung der von mir geführten Gespräche kann ich die Beobachtung von Wüest bestätigen, dass es eine genaue Grenze der Akzeptanz von Lehngut und Interferenz im bearnesischen Sprachgebrauch gibt. In diesem Sinne gehören z.B. histuèra (statt histori), quand-mème (statt totun) und c'éstà-diser heute zur Norm des Sprechens, während ua 'forêt' oder lo bucheron zwar hin und wieder zu hören sind, aber allgemein nicht als bearnesisch akzeptiert werden. 
Die Sprecher benutzen gelegentlich ohne nachzudenken Französismen und kehren ebenso problemlos kurze Zeit später wieder zum bearnesischen Begriff zurück. Der Umgang mit der Sprache gestaltet sich in diesem Sinne zwangloser als es manche Linguisten wahrhaben wollen. Zum Beispiel wechselte einer meiner Probanden im Laufe seines Diskurses von dem bearnesischen Wort compraire 'Käufer' zu dem Französismus achetur und wieder zurück zu compraire. Das Eindringen nicht normativ akzeptierten Lehngutes in den bearnesischen Sprachgebrauch ist ein interessanter Analysebereich, dem ich mich aber im Zusammenhang dieser Untersuchung nicht widmen möchte. Ebenso sind in dieser Arbeit die Phänomene des Code-Switching und des CodeMixing, auf die Wüest aufmerksam macht, nur von marginalem Interesse. Es lässt sich nämlich feststellen, dass das massive Eindringen französischer Sprachstrukturen in den Gebrauch des Bearnesischen für die Probandengruppe, auf die sich die vorliegende Untersuchung konzentriert, nicht charakteristisch ist. Die Anzeichen eines sprachstrukturellen Verfalls der Regionalsprache lassen sich grundsätzlich nicht bei Muttersprachlern feststellen, denen der Gebrauch der Sprache noch in recht hohem Maße vertraut ist. Genau zu dieser Gruppe aber gehörten meine Gesprächspartner.

Kommen wir noch einmal auf die Argumentation Wüests hinsichtlich der Einflussnahme des Französischen zurück. Die gaskognischen Sprachaufnahmen, auf die sich Wüest bezieht, belegen, dass es Sprecher gibt, die einen langage mélangé bevorzugen und deren Kommunikationsverhalten durch ein sehr frequentes Code-Switching charakterisiert ist. In Auseinandersetzung mit der These Trumpers sucht Wüest nun den Grund für dieses Phänomen einerseits in der mangelnden Sprachkompetenz des Sprechers, andererseits in der alltäglichen Omnipräsenz des Französischen. Diese Argumente sind sicher nicht von der Hand zu weisen, gehören aber inzwischen auch schon zum Gemeingut soziolinguistischer Interpretation. Demgegenüber versucht die von mir vorgenommene Dokumentation der bearnesischen Sprachkompetenz in einem Sachbereich zu zeigen, dass die Faktoren, die Wüest als allein ausschlaggebend für den Erhalt des reinen Sprachgebrauchs ansieht, nämlich die hohe Gebrauchsfrequenz der Sprache und die Abgeschiedenheit des Gebirges, in die die französische Zivilisation nicht ganz so massiv eindringt, letztlich nicht so bestimmend sind, wie es scheint.

Das von mir gewählte Untersuchungsgebiet liegt in einem Umkreis von $35 \mathrm{~km}$ um die Stadt Pau. Es ist heute durch eine für das Bearnesische erdrückende Dominanz des Französischen gekennzeichnet. Auf den Höfen wird zwar noch viel Bearnesisch gesprochen, aber der Kontakt zu der jüngeren Generation (in der Familie) und die Teilnahme am öffentlichen Leben lassen auch für ältere Bearnesischsprecher nur noch wenig Gelegenheit, sich der Regionalsprache zu bedienen. Es ist daher durchaus gerechtfertigt, alle von mir 
befragten Personen als 'okkasionelle Sprecher' zu bezeichnen, die auch im privaten Bereich das Bearnesische nicht mehr kontinuierlich verwenden. Die Gestaltung des sozialen Lebens lässt diesen 'okkasionellen Sprechern' keine andere Möglichkeit mehr, als das Verfahren des Code-Switching anzuwenden. Es wäre in diesem Sinne eine interessante, aber empirisch schwer zu behandelnde Aufgabe, die heute gängigen kommunikativen Strukturen des bearnesischen Sprachgebrauchs aufzuzeigen, die darin bestehen, immer wieder bearnesische Diskursteile in französische Kurzerzählungen einfließen zu lassen oder auch bestimmte typisierbare Gesprächssituationen zum Ausgangspunkt kürzerer bearnesischer Äußerungen zu machen. Eine solche konversationsanalytische Untersuchung wäre geeignet, Verfahren der Diskurstradierung im Vollzug eines diglossisch bedingten Sprachenwechsels aufzuzeigen. Sie betrifft aber ebenfalls nicht die Zielsetzung der vorliegenden Untersuchung.

Die Dokumentation der in meiner Befragung ermittelten Diskurse in der Regionalsprache ist angesichts der diglossischen Rahmenbedingungen überraschend. Sie zeigt, dass das Bearnesische für viele Sprecher, die diese Sprache von klein auf strukturell internalisiert haben, ein leistungsfähiges Kommunikationsmedium ist und bleibt, obwohl eine mit dieser Sprache verbundene soziale Funktionalität weitgehend fehlt. Die kontinuierlich reduzierte Sprachfunktion des Bearnesischen bringt diese Sprecher in ein Spannungsverhältnis zu ihrer eigenen Sprachkompetenz, deren Aneignung zu einer Zeit erfolgte, in der die mikrodiglossischen Rahmenbedingungen noch die Erlernung und den intensiven Gebrauch der Regionalsprache in der Familie ermöglichten. Es ist aus meiner Sicht unverkennbar, dass solche authentischen Sprecher, um die ich mich in der Befragung bemüht habe, eine latente Sprachkonfliktsituation mit sich herumtragen, die im Einzelfall zu ganz unterschiedlichen Reaktionen führt. Diese Reaktionen konkretisieren sich sowohl in den Bewertungsmaßstäben sprachlichen Verhaltens (z.B. in dem Glauben, mit seinen Kindern Bearnesisch zu sprechen, obwohl man es gar nicht tut), als auch auf der Ebene der sprachlichen Kommunikation selbst (z.B. durch ein erhöhtes Maß an CodeSwitching von Sprechern, die eigentlich für dieses Sprachverhalten viel zu sicher in der Regionalsprache stehen) und nicht zuletzt in der Form eines sozialen Engagements für die Sprache, das sich bisweilen auch in sein Gegenteil, d.h. zu einer Verweigerungshaltung verkehren kann. Die psycholinguistischen Dimensionen sind hier sehr komplex und noch lange nicht erschöpfend behandelt.

Stellen wir zum Abschluss dieser Überlegungen die Frage nach dem Dokumentationswert des betreffenden Sprachmaterials, so gilt es, eine klare Aussage zu treffen. Was ich dokumentieren möchte, ist die heute noch verifizierbare, aber nicht mehr leicht zu eruierende Potentialität des Sprechens im Bearnesischen, die klar zu erkennen gibt, dass es eine Verbindung von Sprachtraditio- 
nen auf den verschiedenen Ebenen des Sprechens gibt. Das Bearnesische ist an der Fortführung dieser Sprachtraditionen beteiligt und erhält seinen besonderen Wert durch die Aufrechterhaltung der einzelsprachlichen Kompetenz in Sachbereichen, die für die Gestaltung des regionalen Lebens von Bedeutung sind. Am Beispiel des Waldes lässt sich zeigen, welche kommunikative Leistung das Bearnesische in einem Sachbereich mit regionalem Bezug vollbringt. Die Gestaltungsformen und die Dynamik dieser kommunikativen Leistung sind eng mit der Sprache verbunden. Sie hängen aber auch entscheidend von dem Erleben und Verarbeiten der fachlichen Kontexte selbst ab. Der Rückzug des Bearnesischen aus einer traditionellen Domäne wie der des Waldbaus ist in diesem Sinne sehr differenziert zu beurteilen. Der Gebrauch der Regionalsprache ist nämlich in normativer Hinsicht mit seinen referentiellen Bezügen und den üblichen Formen der Diskursgestaltung eng verbunden. Diese Verbindung ist verifizierbar, solange die Regionalsprache noch verwendet wird, und verleiht ihr eine Funktionalität, die in einem krassen Missverhältnis zu der diglossischen Wirklichkeit steht.

\subsubsection{Die Dokumentation der bearnesischen Sprachaufnahmen auf dem beiliegenden Tonträger (Audio-CD)}

Die Auswahl von Gesprächsausschnitten, die sich auf der beiliegenden CD befindet, kann in gewisser Hinsicht als repräsentative Dokumentation der normalen kommunikativen Behandlung des Themenbereichs 'Wald und Nutzung des Waldes' im Béarn gelten. In theoretischer Hinsicht knüpfe ich dabei an eine These an, die mir aufgrund meiner Erfahrungen bei der empirischen Arbeit überprüfenswert erscheint. Es handelt sich um das Postulat einer prinzipiell als endlich definierbaren Menge an Themen, die in der kommunikativen Ausgestaltung eines Sachbereichs mit regionaler Bindung von erkennbarer (und begründbarer) sozialer Relevanz sind. Anders ausgedrückt, gehe ich davon aus, dass die üblichen fachkontextuellen Gesprächssituationen immer wieder auf dieselben Themen im Sinne von typischen Problemkreisen zurückführen, was ein wesentlicher Faktor bei der Bestimmung von Sprach- und Diskurstraditionen wäre. Die These lässt sich nicht leicht beweisen und ist auch nicht mit der Forderung nach einer exhaustiven Darstellung des Kommunikationssektors zu verbinden. Jedoch wäre ihre Bestätigung eine weitere Begründung für die Annahme, dass sich die Sprecher einer Regionalsprache in besonderer Weise durch ein Diskursverhalten auszeichnen, das die normativen Bedingungen ihres Sprechens erkennen lässt. 
Die beiliegende CD enthält insgesamt 25 Tracks. Es handelt sich um Ausschnitte aus den Probandenbefragungen von März 1997 während meiner in Kapitel 2.2 dargestellten Enquête. Es ist daher an dieser Stelle nicht mehr notwendig, die Sprecher vorzustellen (vgl. die Aufstellung in Kap. 2.2.2). Im Einzelnen hat die CD mit einer Gesamtspieldauer von 72:45 Min. folgenden Inhalt:

\section{JOSEPH B., 63 J., Coslédaà-Lube-Boast (C. Lembeye) [= P3]}

1. vajudas-podar (2:38)-Transkription zeigt und erklärt vor Ort die jungen Triebe (jährlichen Zuwächse) bei Eichen; spricht im zweiten Teil über die notwendige Grünastung (Beschneiden lebender Äste). [E1.mp3: 1:55]

2. terras-'chevreuil' (1:55)-Transkription begründet sein Engagement im Waldbau mit der schlechten landwirtschaftlichen Nutzbarkeit seiner Ländereien; kommt unvermittelt auf einen Wildschaden zu sprechen, der ihm vor Ort auffällt. [E1.mp3: 13:58]

3. venta-cooperativa (3:55)-Transkription berichtet über zwei Verkäufe größerer privater Eichenbestände: das erste Mal in eigenständiger Weise, das zweite Mal über die Forstkooperative (mit wesentlich größerem Gewinn). [E1.mp3: 17:15]

4. sava-lua (1:03)-Transkription erklärt und zeigt vor Ort die Verwendungsmöglichkeit junger Weidentriebe für die Korbflechterei: die jungen Äste lassen sich leicht schälen, wenn die Bäume im Saft stehen; sie brechen nicht, wenn man sie zwischen Neumond und Vollmond schneidet. [E1.mp3: 44:56]

\section{5. plantusa $(2: 01)$}

berichtet über den einmaligen Einsatz einer Pflanzmaschine in seiner Jugend; begründet, warum er dieses Gerät für 'großen Blödsinn' hält. [E2.mp3: 21:10]

6. epiceà (1:55)-Transkription

argumentiert gegen die Vorstellungen eines Technikers des I.N.R.A, der in seinen Fichten-Anpflanzungen nach einigen Jahren systematisch jeden dritten Baum fällen will, um zu lichten; er hingegen zieht es vor, von Fall zu Fall nach der Wuchsform zu entscheiden, und lässt sich von dem Techniker nicht hereinreden; der Proband kommt dreimal im Verlauf der Begehung auf dieses für ihn wichtige Thema zurück. [E3.mp3: 3:25, 7:32, 10:26]

\section{7. charmilha $(3: 03)$}

weist auf eine Weißbuche hin und kommentiert ihre Bezeichnung im Bearnesischen; erklärt (auf Nachfrage) den Unterschied zur normalen Buche: beschreibt die verschiedenen Blattformen, geht auch auf den Stamm ein; vermutet, dass der kleine Weißbuchenbestand vor Ort durch natürliche Aussaat eines 
ehemaligen Bestandes in der Nähe des Wohnhauses zustande gekommen ist. [E3.mp3: 39:21]

8. castanh-malaudia (1:23)-Transkription

geht anhand eines konkreten Falls vor Ort auf die Krankheit der Kastanienbäume ein, die ihren Bestand erheblich dezimiert hat; erläutert, dass sein Vater versuchsweise eine japanische Varietät angepflanzt habe, die jedoch gegen die Krankheit auch nicht vollkommen resistent sei; zudem schmeckten die japanischen Kastanien nicht; er habe daher (wie schon zuvor sein Vater) teilweise den Versuch unternommen, auf die japanischen Varietäten die einheimische Kastanie wieder aufzupfropfen. [E3.mp3: 43:08]

9. histuèra deus lapins (1:54)-Transkription

erzählt die Geschichte, dass ihm vor einigen Jahren eine Neuanpflanzung 80 junger Pinien, die er selbst aus Saat gezogen hatte, über Nacht von Kaninchen abgefressen worden sei (bis auf eine einzige Pinie); daraufhin habe er mit seinem Sohn dort Fallen aufgestellt, wo sich die Kaninchen gerne aufhielten, um sich zu rächen: in einer Woche seien ihm 25 fette Kaninchen in die Falle gegangen... [E3.mp3: 44:52]

\section{0. desboscaire (1:56)}

kommentiert den Begriff, der jemanden bezeichnet, der die gefällten Bäume aus dem Wald zum Sägewerk abtransportiert; dies sei in der Region kein eigenes Metier, da die Landwirte die Arbeit stets selbst (mit ihren Traktoren) verrichten würden; erklärt dann, wie er diese Tätigkeit früher als Kind erlebt habe: beschreibt die ehemalige Technik, einen gefällten Stamm auf eine zweiteilige Rollvorrichtung aus Holz zu hiefen und ihn mittels einer Kette von Ochsen ziehen zu lassen; führt dann nochmals aus, dass diese Arbeit nicht von Fachleuten, sondern von den Waldbesitzern verrichtet wurde. [Q2.mp3: 38:05]

FRANCIS C., 49 J., Maspie-Lalonquère-Juillacq (C. Lembeye) [= P1]

11. hrèischo (1:26)-Transkription gibt Erläuterungen zur Verwendung des harten Eschenholzes früher (Räder für landwirtschaftliche Transportwagen) und heute als Wertholz (Fensterläden, Möbel, etc.); erwähnt auch die Produktion von Stielen für landwirtschaftliche Geräte (z.B. Äxte). [Q.mp3: 30:56]

12. bòsc-tribalh (3:46)-Transkription

im Anschluss an die Frage nach dem eigenen Waldbesitz kommt das Thema auf dessen Nutzung: er schlage in seinem Wald Brennholz, aber auch Bauholz; bestätigt, selbst Bäume fällen zu können; beschreibt auch die weiteren Arbeiten; hat noch nie Holz verkauft; ist an eigener Anpflanzung grundsätzlich interessiert, ihm fehlt aber die Zeit dazu; beschreibt seine (für die Landwirte der Region) typische Nutzung des Waldes: Brennholz und Weidezaunpfähle (aus Ausschlagholz); bestätigt, von Zeit zu Zeit ein wenig zu lichten, 
auch um einigen ausgesuchten Eichen ein gutes Wachstum zu ermöglichen. [Q.mp3: 39:59]

13. acotar (1:13)-Erläuterung (Transkription) in Kapitel 2.2.2.2 erklärt den früher üblichen Kopfholzbetrieb. [Q.mp3: 21:35]

Roger H., 69 J., Lasseube (C. Lasseube) [= P6]

14. castanhs (2:44)-Transkription

gibt eine ausführliche Erläuterung der ehemaligen Bedeutung des Kastanienanbaus für die Kommune Lasseube; geht auf den früheren Kastanienbestand des eigenen Familienbesitzes ein; beschreibt in groben Zügen seine Nutzung; erklärt die Bedeutung der Kastanienwirtschaft durch ihre Größenordnung (doppelt so viel Nutzungsfläche wie der Weinbau); erinnert sich an die Vermarktung der Kastanien bis in die 50er Jahre (der Wirtschaftszweig sei heute unbedeutend geworden); grenzt begrifflich den Kastanienwald und den Kastanienniederwald voneinander ab; erläutert, dass jede Familie noch heute einen Kastanienniederwald besitzt. [Q1.mp3: 26:20]

15. noguèrs-vita (7:26)-detaillierte Interpretation in Kapitel 2.5.3

antwortet auf die Frage nach der bearnesischen Bezeichnung für fr. noyer; sagt, es gebe traditionell nur einige Walnussbäume um die Häuser herum, er selbst aber habe eine Anpflanzung von Nussbäumen zur Wertholzproduktion, bei der es sich jedoch um eine hybride Baumart handle; weitere Bezüge auf nicht einheimische Varietäten in seinen Beständen; erläutert, dass oft fachlich interessierte Personengruppen zu ihm kommen; bestätigt, dass er sich alle technischen Kenntnisse und Fähigkeiten selbst angeeignet habe; skizziert zur Erklärung seine Lebensgeschichte; schließt eine Reflexion zur Arbeitshaltung und Lebenseinstellung der jüngeren Generation an; erklärt (unter geschichtlichen Bezügen) die Vernachlässigung der Wälder in der Region; geht auf die Wiederbewaldung verlassener oder unproduktiver Ländereien ein (die selten ist); stellt sein Engagement für den Waldbau als Sonderfall dar. [Q1.mp3: $36: 43]$

16. cama-tronga (1:14)-Erläuterung (Transkription) in Kap. 2.2.2.3.2 nennt Termini zur Bezeichnung des Stamms; differenziert die Begrifflichkeit von 'Wurzelstock / Baumstumpf' im Bearnesischen nach der Baumart. [Q2.mp3: 1:45]

JeAn Marie A. und Charlotte M., beide 70 J., Conchez-de-Béarn

17. buès-conversacion (9:39)-Teiltranskription

$$
\text { (C. Garlin) [= P4] }
$$

Beginn der Befragung: spontanes Gespräch (zu dritt) über den Wald und verschiedene Aspekte seiner Nutzung; beginnt mit der Kommentierung des eigenen Besitzes; weitere Themenfolge: verschiedene Eichenarten, die Nachfrage nach Brennholz; Kamin (die von ihm ausgehende Atmosphäre, seine Funktion 
als Grillplatz an einem konkreten Beispiel), die Bezeichnung für Brennreisig, Bedeutungsdifferenzierungen der Bezeichnungen für 'Wald' und 'Holz'; Terminologie zum Fällen der Bäume; Verwertung eigener Bäume als Bauholz, die heutige Praxis kleinerer Hiebe in der Region (französische Holzhändler, die spanische und portugiesische Arbeitskräfte einsetzen, um das Holz in Spanien weiterverarbeiten zu lassen). [Q1.mp3: 0:02]

\section{8. conselhèr forestièr $(5: 01)$}

Ausgangspunkt ist die Frage nach dem Grund für die Inanspruchnahme einer Beratung durch den CRPF: erklärt, dass er sich informiert habe, welche natürlichen Bestände besser abgeholzt und wiederbewaldet werden sollten und welche für eine Wertholzproduktion geeignet seien; spricht über ein wirtschaftlich interessantes Waldstück von 4 ha Größe mit Beständen an aliguèrs (fr. alisiers ' Mehlbeerbäume') und Eichen; es folgt ein Exkurs zu den großen Walddimensionen Frankreichs und zu der mangelnden Verjüngung (Pflege) der regionalen Waldgebiete im Béarn; wiederholt, dass er von dem Forstberater ein Urteil über seinen eigenen Waldbesitz erbeten habe; dieser habe ihm nach seiner visite diagnostique auch einen Plan überlassen (den er sucht und später findet); Frau Mené erwähnt, dass sich auch ihr Schwiegersohn (wohnhaft im Gers) beraten lassen sollte (wie viele Waldbesitzer hat er nach dem Verkauf wertvoller Eichenbestände dort nicht wieder gepflanzt); am Ende des Gesprächs wird die allgemein mangelnde Motivation zur Wiederbepflanzung thematisiert. [Q2.mp3: 14:34]

\section{PIERRE M.-C., ca. 70 J., Audaux (C. Navarrenx) [= P8]}

19. silvicultura (1:48)-Transkription

grundsätzliche Stellungnahme zu dem schlechten Zustand der Wälder im Béarn, deren Rentabilität nur zu einem Drittel des Möglichen gegeben sei; viele Naturwälder seien verkommen; es fehle an Arbeitseinsatz; früher sei der Wald eine wesentliche Existenzgrundlage gewesen (auch für Ziegel- und Kalköfen); man habe ihn seinerzeit so ausgebeutet, dass er heute nichts mehr wert sei. [Q2.mp3: 25:20]

\section{Albert P., 65 J., Aubertin (C. Lasseube) [= P5]}

20. eslagar (4:20)-Erläuterung (Transkription) in Kapitel 2.2.2.3.1 erläutert das Begriffsfeld des Astens im Bearnesischen; ist sich in Bezug auf das Sachgebiet 'Waldbau' unsicher und schlägt Begriffe aus anderen Sachgebieten vor: espleishar [fr. émonder les haies, enlever les ronces], das eigentlich das Zurückschneiden (Stutzen) von Dornenhecken meint, eisharramar, das meistens für das Beschneiden von Obstbäumen verwendet wird, und esborongar, das als Terminus aus dem Bereich des Weinbaus stammt. Setzt sich ausführlich mit Form und Bedeutung des Begriffs esborongar auseinander; erklärt dabei diese Tätigkeit aus der Perspektive seiner Kindheitserinnerungen. [Q1.mp3: 29:05] 
21. bòsc-Biarn (1:10)-Transkription

kommentiert auf Bitte die Situation des Waldes in seinem Heimatgebiet; glaubt, dass der Wald neben dem Weinbau die wirtschaftliche Zukunft der Region sei, da die Ländereien für die moderne Landwirtschaft zu mühselig zu bearbeiten seien. [Q2.mp3: 42:38]

MAuricette R., 39 J., Maspie-Lalonquère-Juillacq (C. Lembeye) [= P2]

22. bucheron-forastar (2:03)-Transkription

im ersten Teil Suche nach einem geeigneten Wort für fr. bûcheron: heute bietet sich nur noch der Französismus oder der Gebrauch von forestièr an; erklärt auf Nachfrage das Wort forastar, das eine typische vegetative Landschaftsform im Béarn bezeichnet und als 'verwildertes Dickicht' beschrieben werden kann. [Q1.mp3: 6:30]

\section{3. arrosia $(0: 53)$}

auf die Nachfrage nach dem Wort für 'Harz' ergibt sich sofort die Assoziation zu den Pinienbeständen in den Landes; Nadelbäume seien in der heimischen Region kaum vertreten; gibt darauf hin eine Erklärung zu arrosia: als Fachbegriff für eine Substanz, die beim traditionellen Schweineschlachten (pelaporrc) verwendet wird und mit deren Hilfe die Borsten von der Schweinehaut leichter entfernt werden können. [Q1.mp3: 39:00]

24. venta deu buès (1:06)-Transkription

Darstellung des für die Region typischen Holzverkaufs aus der Perspektive einer nicht direkt Betroffenen; gibt kritische Hinweise darauf, dass die Waldbesitzer von den Holzhändlern oft 'übers $\mathrm{Ohr}$ gehauen' werden. [Q1.mp3: 40:50]

HUBERT S.-B., 70 J. (und seine Schwester) [= P7], teilweise am Gespräch beteiligt: Michel C., Monein (C. Monein)

\section{5. saligues-regeneracion-valor (7:09)}

es geht zunächst um Weiden und ihre Vorkommen; M.C. weist auf die Verbreitung entlang der Gebirgsbachufer (a bòrd de gave) hin; H.S. erklärt, dass Weiden zu der ersten Vegetation gehören, die von gerodetem Land Besitz ergreift (durch Windaussaat); beschreibt dann das Prinzip der Entstehung des Waldes, in dem sich schließlich die Eichen durchsetzen, betont die Natürlichkeit der Entstehung des Waldes; auf Nachfrage nach der wirtschaftlichen Nutzbarkeit natürlicher Wälder werden einige Bedingungen erörtert (Standort zufällig, lange Wachstumszeit, unterschiedliche Holzqualität je nachdem, ob der Boden feucht oder trocken ist); geht auf das mangelnde Interesse am Waldbau ein (erwähnt die Bemühungen der Kooperative), Hauptgrund seien die vielen Auflagen (Beschneidung der eigenen Freiheit, wird von M.C. bestätigt); auf Nachfrage nach der wirtschaftlichen Lukrativität antwortet H.S., dass Bäume in der Region meist nur in Notfällen verkauft werden (bei Brandscha- 
den, Krankheitsfällen oder Tod); im Rahmen eines Resümees (auf Vorgabe) zur Nutzung der Wälder wird besonders auf die Produktion von Weidezaunpfählen eingegangen (Erklärung des Ausschlagbetriebs); Hinweis auf neuere Entwicklungen: Einfuhr aus dem Ausland und Nutzung von Akazien (statt Kastanienholz); es wird hervorgehoben, dass man das Pfahlholz immer bei zunehmendem Mond schneiden müsse. [Q1.mp3: 35:13]

\subsubsection{Transkription einer Auswahl fachbezogener Diskurse auf Bearne- sisch}

Die auf der Audio-CD zusammengestellten bearnesischen Diskurse bieten einen Einblick in den authentischen Sprachgebrauch in Fachkontexten des Waldes. Sie sind Beispiele spontanen, freien Sprechens, das für einen Großteil meiner Wortschatzbefragung charakteristisch war. Da es in Publikationen oder als dokumentarische Corpora nicht viele solcher Diskursbeispiele auf Bearnesisch gibt ${ }^{177}$, halte ich es für angebracht, einen Teil der auf der CD zu findenden Aufnahmen hier in einer Transkription wiederzugeben. Dies stellt vor allem auch eine geeignete Dokumentation zu dem in dieser Arbeit behandelten Thema dar. Zum Verständnis der analytischen Ausrichtung meiner Untersuchung ist es nämlich sehr wichtig, eine möglichst große Nähe zu der tatsächlich beobachtbaren Form des Sprechens in Fachkontexten zu erlangen. Dies ist im Falle einer seltener zu hörenden Sprache, wie sie das Bearnesische darstellt, zum Teil sicherlich nur über die gleichzeitige visuelle Aufnahme der gesprochenen Texte zu erreichen. Ich werde daher im Folgenden die mir besonders geeigneten Diskurse auch in geschriebener Form wiedergeben.

Als orthographische Grundlage der Verschriftung benutze ich ab jetzt die offiziellen Regeln der Sektion 'Per Noste' des Institut d'Estudis Occitans. Es handelt sich dabei um eine etymologisierende Graphie, die sich auf institutioneller Ebene im Béarn durchgesetzt hat. ${ }^{178}$ Die Grundlagen dieser Rechtschreibregelung gehen auf den Okzitanisten Louis Alibert zurück. Für den hier gegebenen Zweck ist diese Graphie besonders gut geeignet, weil sie die Wörter des Bearnesischen für einen Romanisten auch ohne spezifische Kenntnisse in dieser Sprache leicht erkennbar macht. ${ }^{179}$

\footnotetext{
${ }^{177}$ Vgl. z.B. den entsprechenden Hinweis in Thun 1994, 228.

${ }^{178}$ Der langjährige 'Streit' um die zu verwendende Kodifikation ist inzwischen beigelegt. Auch die Zeitschrift 'Reclams' der traditionellen Félibrige-Anhänger (Schule 'Gaston Febus') benutzt seit einiger Zeit die vom I.E.O. vorgeschlagene Rechtschreibung. B Nicht verwunderlich ist hingegen die Tatsache, dass in der bearnesischen Bevölkerung nach wie vor meistens eine französisierende Graphie vorgezogen wird, sofern die Verschriftung des Bearnesischen überhaupt eine Rolle im alltäglichen Leben spielt.

${ }^{179}$ Vgl. z.B. coumbersacioû (nach S. Palay) und conversacion (nach 'Per Noste').
} 
Der Nachteil, der für den Leser darin bestehen könnte, kein Verhältnis zu der Lautung des Bearnesischen zu gewinnen, wird durch die Möglichkeit, sich die transkribierten Textpassagen direkt anzuhören, aufgefangen.

Um die Gesprächsausschnitte auch für Nicht-Okzitanisten möglichst verständlich zu halten, habe ich mich entschlossen, in die laufenden Texte einige Worterklärungen auf Französisch einzufügen. Die graphische Form dieser Einfügungen erlaubt m.E. weiterhin das flüssige (Mit-)Lesen der Textpassagen, so dass die Nähe zu den Diskursen dadurch nicht behindert wird. ${ }^{180}$

Es ist nicht der Zweck der nachfolgenden Transkriptionen, sprachstrukturelle Analysen auf phonetischer, morphologischer oder syntaktischer Ebene zu ermöglichen. Ich habe daher auch kein differenziertes Transkriptionsverfahren gewählt. Die detaillierte Notation der phonetischen und phonotaktischen Ebene ist ohne einen 'Näheverlust' zum Text als Diskurs und zu seiner inhaltlichen Dimension im Besonderen nicht zu leisten. Ich verweise hier exemplarisch auf eine vorbildliche Dokumentation gesprochener bearnesischer Diskurse in Pusch 1998, 222-619, die für den Gegenstand der Arbeit von Pusch eine unverzichtbare Voraussetzung darstellt, aber beim Leser nur sehr schwer ein Verhältnis zu den Textinhalten des Corpus aufkommen lässt. Ich erwähne dies so ausführlich, weil ich es bedauerlich finde, dass die empirische Untersuchung von Minderheitensprachen heute zunehmend einseitig sprachstrukturell ausgerichtet ist und den Text als Ganzes, d.h. die Sinn-Ebene (nach Coseriu), der gesprochenen Sprache kaum noch berücksichtigt. Sprachwissenschaftliche Fragestellungen, die sich auf eine Strukturebene oberhalb des Satzes beziehen und die insbesondere an der semantischen Interpretation von Texten interessiert sind, sollten aber m.E. kein Privileg der großen und anerkannten Sprachen bleiben. Gerade im Hinblick auf Sprachkontaktsituationen muss auch untersucht werden, was die Sprecher weniger gebräuchlicher Sprachen wirklich sagen und wie sie sich dabei ausdrücken.

Die folgenden Transkriptionen beziehen sich auf die Darstellung des vorangegangenen Kapitels zum Inhalt der CD. Informationen, die dort bereits gegeben wurden, werden hier nicht wiederholt. Zur Einführung in die einzelnen Diskurse stelle ich jeweils einen kurzen Kommentar voran:

${ }^{180}$ Die Worterklärungen folgen im Prinzip der sukzessiven Textwiedergabe in diesem Kapitel. D.h., es wird auf Wiederholungen weitgehend verzichtet, um die Zahl der Anmerkungen so weit wie möglich zu reduzieren. 


\section{Track 1: vajudas-podar $(2: 38)$}

Kommentar: Es handelt sich um ein Beispiel situationsbezogenen Sprechens im Wald (hier in einer Anpflanzung), bei dem der Bezug auf den gegenständlichen Kontext besonders wichtig ist. Dementsprechend dominiert ein deiktisches Verfahren der Kommunikation (häufiger Gebrauch von Demonstrativa und beständige Wiederholung von veds?). Zum Inhalt: Die jährlichen Zuwächse (Triebe) werden gern von Besitzern junger Anpflanzungen kommentiert. Die Blickrichtung ist hier nicht botanisch, sondern auf den Aspekt der Produktivität ausgerichtet. Im zweiten Teil spricht J.B. über die Baumbeschneidung. Er verwendet dafür das Wort podar, das ihm aus dem Weinbau geläufig ist. Seine Technik konzentriert sich auf das Entfernen größerer Äste, um dem Baum eine gute Wuchsform zu geben.

U.H.: Òc, tanben aussi, que cau il faut aténder hèra beaucoup d'ans.

J.B.: Oh hèra, mes que sembla que ne vai pousse pas. Mes veds tu vois, aqueste celui-ci quand-mème qu'ei estat plantat que i a donc quate ans aqueste. Veds?

U.H.: Quate ans?

J.B.: $\quad$ E òc, veds, quan era plantat qu'avè aquera cette hautor aquiu là. La darrèra vajuda pousse de... d'aquest an darrèr que la vam nous allons trobar-la ací ici. Qu'a... qu'a hèit fait en quate... en tres còps fois, eh? Aquò qu'ei la... la... pensi je pense qu'ei aquiu que comença. La purmera vajuda qu'ei aquò c'est ça au primtemps, unhauta [ $\approx$ ua auta] vajuda a l'estiu en été e... e la darrèra vajuda a l'autona. Veds que hè il fait quandmème autorn d'un mètre de... de... de vajuda sus... sus un an. Mes que sembla que vai(-t) hèra a plaser lo casso chêne, mes lo casso...

U.H.: E... e continua atau ainsi?

J.B.: Ah, tots los... tots los ans, òc, òc.

U.H.: Tots los ans.

J.B.: Si, si, ah, ah que son joens jeunes, ne soun pas tots parièrs. Que n'i a quauques-uns, n'an pas vajut autant plan bien. Aceth ce petitàs très petit aciu n'a pas vajut autant plan. I a d'autes qui hèn font tostemps toujours ... lo casso deu pèis pays hè tostemps tres o quate vajudas cada an, tres o quate. La purmèra que vas véder voir drin un peu mei plus ací. Alavetz alors, la purmèra qu'ei souvent braca courte, n'ei pas hèra longa, veds, 
la purmèra au primtemps.

U.H.: Òc, que la vedi.

J. B.: La segonda qui a hèit qu'anava dinc jusqu'à aquiu, e la tresau troisième qu'ei anada allée dinc aquiu, qu'a hèit ua petita qua... veds la quartau aciu, o la darrèra de l'autona. Mes lo hred froid qu'ei arrivat aquiu que l'a arrestada aquiu. Alavetz que hè quand-mème ua vajuda de pas luenh loin d'un mètre tots los ans.

U.H.: Ne cau pas enqüèra copar las brancas?

J. B.: Podà'u le tailler, podà'u. Qu'at(-s) hèi je le fais... qu'at(-s) hèi bitara maintenant, lavetz que vau je vais... que't vau amuishar montrer, qu'at hèi(-s) en unhauta $[\approx$ ua auta] ... en unhaute $[\approx$ un aute $]$ camp on... qu'an un an de mei, que son hèra màgers plus grands-e que vas véder que n'i a qui son hèra màgers que aquò $\mathrm{B}$, e aquiu que podi nà pour... qu'aji, qu'at vau har je vais le faire quan aji acabat aciu, que vau passar ací nà copar çò de màgers ce qui reste parmi les plus grands. Lavetz aquera grana arrama branche que la cau tirar, aquesta tanben. Aquò de petit que s'i... que s'i pòt deishar laisser, per'mor parce que que hè ví(ver)..., que hè respirar l'arbre, que cau huelhas des feuilles, cau pas tir(ar), cau pas tirar tot, cau pas deishar sonque seulement la... la darrèra tira, comprenes, (lav)etz que cau eh... eh... que cau podar çò de...-podar qu'ei 'sécateur', eh? [wiederholt das Wort betonend] podar, podar.

U.H.: Podar...

J.B.: Que cau podar çò de màger, aquèras tres aquiu per exemple, per'mor que aquèras ne vajan pas autant, que van... que van gahar prendre fòrça e que la... que la van panar voler la fòrça a... a la... la deu som haut, a la tira deu som. Qu'ei tot. E aquò que calerà il faudra tornà'i tots los ans..., los purmèrs temps que passèi tots los ans nà, nà podar las... las màgers arramas.

\section{Track 2: terras-'chevreuil’ (1:55)}

Kommentar: Diskurstechnisch ein Beispiel dafür, dass eine thematische Ausführung durch das plötzliche Aufmerksamwerden auf etwas anderes (hier der Wildschaden an einem Baum) unterbrochen wird. Zum Inhalt: J.B. begründet hier ausführlich sein Engagement im Waldbau, dem er sich schon seit seiner Jugend widmet. Dabei steht der Proband (aufgrund nicht thematisierter regio- 
naler Normen) vor dem Rechtfertigungszwang, den Waldbau der Landwirtschaft vorgezogen zu haben. Er begründet das mit der mikroregionalen Lage seiner Ländereien, die aufgrund der Bodenverhältnisse für die Felderwirtschaft ungeeignet seien. Die unterschwellige Sinnebene des Textes (Verteidigung gegen den möglichen Vorwurf, der harten Landwirtschaft aus dem Weg gegangen zu sein, um der mußevolleren Waldwirtschaft zu frönen) wird nur im regionalen Sprachgebrauch verstehbar. Im zweiten Teil taucht das typische (Dauer-)Thema der Besitzer von Anpflanzungen auf: die Plage der chevreuils.

U.H.: ... de la causa forestièra?

J.B.: Ah, qu'aví j'avais començàt a m'i interessar, donc, disi je dis que i a vint ans quan comencèi a plantar las purmèras parcelas, qu'ei ad aqueth moment que plantèi sus la... las tèrras qui... qui... èran la... las mei... las mei mauaisidas difficiles a tribalhar, la... per'mor.... la tèrra ací, que cau díser, sus aquesta expluatacion la tèrra n'a pas ua hèra grana valor, voi je veux díser la valor endà pour la cultura, que voi díser, lo... suà soit qu'ei en panta pente, sua qu'ei calhabuda caillouteuse, qu'ei argeluda argileuse, n'ei pas... n'ei pas tèrra comparable a... a la tèrra de Sévignacq per exemple, qu'ei ua tèrra nera noire on vai lo milhòc maïs tant qui vòlhen. Ací qu'ei ua tèrra qui cranh craint la sequèra sécheresse, hèra, hèra. $\mathrm{E}$ veds, push puis ei mauaisit a tribalhar per'mor qu'ei ua tèrra pesanta, n'ei pas ua tèrra leugèra com... com la... de... la bona tèrra de cultura. Qu'ei per'mor d'aquò ne'm hasè pas dòu je ne regrettais pas de...de... de préner tèrras endà i hicar mettre arbres, per'mor que calè il fallait har faire auta causa que de har agricultura, comprenes? L'agricultura, que còsta hèra mei car de la har ací sus maishantas mauvaises tèrras que eh... que... que d'on ei mei aisit a har, e... e d'on vien lo frut ad aisa facilement. -

Veds, qu'avem ací un(h)aute, un(h)aute huelhut feuillu qu'èi que j'ai plantat e qu'ei eh... tè, ací qu'as lo tribalh deu 'chevreuil', veds, sèi pas quin comment s'apèra s'appelle lo 'chevreuil' en biarnés.

\section{U.H.: Ah, que passa per ací?}

J.B.: Lo 'chevreuil' e veds, que vien de'quiu enlà de là-bas vers là. Ei aquiu que hrobeishen ils frottent / fourbissent dab avec los còrs cornes e que hèn sautar la pèth peau, ecorce. E lavetz l'arbre, l'arbre qu'ei fotut foutu aquiu. Aqueth que posh je peux..., que vau passà'i la..., que vau podar aquiu dab lo secatur, que vau copar aquiu e deishar partir aquesta tira, que vau copar tot çò d'aute. 
U.H.: E's poderé hicar ua proteccion?

J.B.: E veds, qu'at èi hèit je l'ai fait aciu aus cerisèrs merisiers. Açò que son cerisèrs. Lo... lo casso, e veds, que l'ataca quauque còp quelque fois lo 'chevreuil', que s'i freta nà's $[. .$.$] que prefèran hèra hèra los cerisèrs.$ Los cerisèrs, si son pas protejats, tots, tots, que'us demoleishen tots.

\section{Track 3: venta-cooperativa (3:55)}

Kommentar: J.B. erzählt hier relativ ausführlich über zwei Eichenverkäufe, die seinen engen biographischen Bezug zum Waldbau dokumentieren. Der Diskurs ist narrativ und entspricht damit einer im Béarn häufig anzutreffenden Diskurstradition. Interessant ist wieder die doppelte Sinnebene des Textes. Zum einen wird eine sachliche Argumentation vorgebracht, die darauf hinausläuft zu erklären, dass der Verkauf von Waldbeständen über die Kooperative anzuraten sei, da er sich aufgrund der markttechnischen Ausnutzung des Wettbewerbprinzips für den Verkäufer am Ende als gewinnbringender erweise. Zum anderen spielt J.B. hier in persönlicher Hinsicht mit sehr offenen Karten (was jedoch wiederum nur in den regionaltypischen Bezügen des Diskurses verstanden werden kann): der zweimalige Verkauf größerer Eichenbestände war für J.B. eine Maßnahme des existentiellen dépannage. Dieses Faktum wird sowohl aus der Schilderung seiner Unerfahrenheit beim ersten Verkauf deutlich als auch durch den sprachlichen Ausdruck selbst (Lo purmèr còp que caló que hasossi partir... que hasossi partir quate cent cassos. [...] Mes après que estoi obligat de véner los sheis cent autes cassos.). Wir haben es also mit einem Beispiel für den Stereotyp zu tun, der zum Ausdruck bringt, dass Wälder im Béarn nur in Notsituationen verkauft werden. Beachtenswert ist im Weiteren die Ehrlichkeit des Probanden: Nicht nur, dass der eigene Misserfolg eingestanden wird (Malurosament. Avossi hèit atau lo purmèr còp.), es wird auch sehr offen mit Zahlen argumentiert. Sprachlich ist anzumerken, dass der Diskurs die synthetische Perfektform (also quasi das passé simple) als Erzähltempus der Vergangenheit benutzt und damit in dieser Hinsicht einen gegenüber dem Französischen eigenständigen Sprachgebrauch dokumentiert.

U.H.: E n'avetz pas avut un conselh, lo conselh d'un expèrt forestièr?

J.B.: Ah, oui... oui, oui, mès tota la... 'bon', qu'ei lo conselh purmerament, e que i a ua aida financièra tanben.

U.H.: Ah!

J.B.: E... e tot lo monde que i participa a aquera aida financièra, per'mor 
qui... qu'ei 'européenne', aquesta. Tot lo monde que paga drin. Oui, oui, la... l'aida tecnica qu'ei la cooperativa forestièra de Navarrenx.

U.H.: ... de Navarrenx.

J.B.: Oui, eths eux que m'an, purmerament que m'an aidat hèra endà véner vendre los cassos quan venoi j'ai vendu aqueths... cassos que viengón ils sont venus endà... endà hà'm ua expertisa, endà véder çò qui valèn. $\mathrm{E}$ atau jo que'm poderí defénder je pourrais me défendre en faça de... de los qui vienen crompar acheter los cassos. Per'mor que jo ne sèi pas çò qui vau ce que vaut un casso, mes eths qu'at saben. E lo qui crompa tanben qu'at sap çò qui vau. Comprenes? Alavetz, que m'èri hèit borrar je m'étais fait rouler qu'i a quauquas anadas en véner vendre per jo moi mèma e après còp qu'èi vist que m'èri hèit borrar. Quan los de la cooperativa son passats que m'an amuishat çò qui valèn los cassos. Dinc aquiu n'at sabevi pas je ne le savais pas jo. Alavetz qu'èi hèit la... la venta dab la cooperativa de duas faiçons. Lo purmèr còp que caló que hasossi il a fallu que je fasse partir... que hasossi partir quate cent cassos. Qu'avevi en ua purmèra parcela quate cent cassos, alavetz que me davan lo chuès choix. Eths qui vienèn endà har l'expertisa nà díser çò qui valèn, que'us classavan en tres o quate categorias, çò qui valèn los cassos, eh... per'mor qu'i son los... los petits, qu'i son los muagèns moyens, los grans, los drets, los qui son gelats o qui ne son pas gelats. Tot aquò que cambia la valor deu casso. Alavetz que'm dèn la valor totala deu lòt $\mathrm{e} . .$. que'm... que còsta hèra chic car, que calè que paguessi... que paguèi j'ai payé lhèu peut-être un per cent de la valor a la cooperativa, un o dus per cent, ne'm sovieni pas, chic de causa peu de chose.

U.H.: Òc, chic de causa.

J.B.: $E$ que tribalhèn quand-mème quauques dias. Alavetz jo qu'aví lo chuès. Que'm digón ils m'ont dit: "OU BIEN VOUS LES VENDEZ VOUSMEME», que me digón, «OU BIEN C'EST NOUS QUI LES VENDONS. A CE MOMENT-LA, ÇA VOUS COUTE TROIS POUR CENT. MAIS C'EST NOUS QUI FAISONS LA VENTE... AUX ENCHERES.»

U.H.: Ah, oui.

J.B.: Lavetz, lo purmèr còp, que'u digói: «BON, MAINTENANT QUE JE SAIS... QUE JE SAIS LA VALEUR, JE VAIS ME DEBROUILLER, JE VAIS ME DEBROUILLER POUR LES VENDRE, JE VAIS CONVOQUER TROIS OU QUATRE VENDEURS... TROIS OU QUATRE ACHETEURS», et 'voilà' qu'at hasoi atau je l'ai fait ainsi, que venoi pro plan, que... que venoi pro plan j'ai 
vendu assez bien dab lo prètz que m'avèn dit. Qu'en tirèi a push prètz à peu près çò qui m'avèn dit. Mes après que estoi j'ai été obligat de véner los sheis six cent autes cassos. E aquiu que digoi que vam sajar essayer l'auta... l'aute sistèmi. $\mathrm{E}$ donc l'aute sistèmi que'us avèn estimats a... vint-e-dus milhons de centimas los sheis cent cassos, per'mor qui i avè de tot, que n'i avè de beròis beaux, que n'i avè... n'èra pas... la màger part n'èra pas de beròias cassòrras, qu'èra cassos de quate-vint-dètz ans, mes que i avè de tot. 'Bon', que i avè... d'après eths que... l'estimacion qu'èra vint-e-dus milhons. Lavetz la venta que's passa d'aquesta faiçon: Que convòcan tots los crompaires acheteurs deu suduèst, que i avè quaranta crompaires eh... possibles, quaranta. Qu'ei ua venta qui se hè hen(h) dans ua... hen(h) ua sala, ua sala au public.

U.H.: Qu'ei ua competicion?

J.B.: Hein? Ua... ua... ua venta que son convocat lo monde les gens, mes que son convocat longtemps a l'avança. Que'us envian un calhèr cahier, que i a... shens sans que los mens cassos mes chênes, que i a la venta d'ua quinzèna o d'ua vintèna de... de forestièrs. E lavetz qu'an un calhèr los acheturs (gallicisme $=$ compraires), los quaranta acheturs qu'an un calhèr dab la descripcion de cada... cada parcela, cada... cada proprietat. Aquiu que pòden estudiar aquò, qu'an la carta endà s'i rénder, que pòden anar véder sus plaça avant. E qu'arriva lo dia de la venta. Lo dia de la venta: 'ENVELOPPE CACHETÉE'.

U.H.: Ah! [...] los prètz les prix...

J.B.: Que cau que hiquen lo... lo prètz 'enveloppe cachetada'. Alavetz aquiu... que son aquiu, que's coneishen tots, los crompaires. Son aquiu: «Aceth hilh-de-puta fils de pute(pas aussi péjoratif qu'en français) que'm va... que'u te voi har petar, aqueth...» Que n'i hican drin mei ils y en mettent un peu plus. Qu'èra estimat vint-e-dus milhons, que'n sortí trenta sèt milhons.

U.H.: Oh, qu'ei miélher mieux aquò.

J.B.: Alavetz que'm digoi. Malurusament! Avossi hèit atau si j'avais fait ainsi lo purmèr còp. 


\section{Track 4: sava-lua (1:03)}

Kommentar: Die Weidenkorbflechterei ist kein typisches Metier der Gegend. Die Darstellung vermittelt aber gerade durch die Thematisierung dieses entlegeneren Tätigkeitsgebiets den Eindruck einer besonders großen Vertrautheit mit den regionalen Gewohnheiten. Unter diesem Aspekt wird deutlich, wieso der Hinweis auf das Kriterium der Mondphase inhaltlich gut zu der Ausführung passt. Der Topos ist im übrigen auch auf die Erfahrungen im Niederwaldbetrieb übertragbar. Interessant am Diskursverhalten von J.B. ist auch, dass nicht nur etwas erklärt, sondern gleichzeitig auch vorgeführt wird. Dies ist beim fachkontextuellen Sprechen vor Ort häufig der Fall.

J.B.: Mes autes còps, eh... hòrt de monde beaucoup de gens qui n'avèn pas bimis osiers que podèn har... los... los... los gitanos en particulièr que hasèn... (hasè)n souvent tistets paniers de s... de saliga saule, per'mor que podèn..., que's pèla ad aisa! Au primtemps que gahavan ils prenaient ... que gahavan aquò... aquiu bitara quan i ei la sava sève que... que i a un muagèn de... Veds, que's pèla hèra ad aisa.

U.H.: Ah!

J.B.: Endà har tistets qu'ei hèra beròi joli aquò.

U.H.: Òc, òc.

J.B.: Mes aquò qu'at cau har quan i ha la sava, quan vienen de sortir las huèlhas. Endà har tistets aquò qu'ei... qu'ei extrà aquò, e veds? Eh, alavetz, ah que cau chausir choisir la lua lune. Per'mor a la... a la... la bona lua que's plèga ça se plie e a (la) maishanta lua que pèta.

U.H.: Ah, qu'ei vertat c'est vrai?

J.B.: Ah, qu'ei la lua.

U.H.: Qu'ei la lua?

J.B.: At pòden pas n'impòrta quan aquò. Mes d'un dia a l'aute que cambia. La lua que cambia. Pam! Lo... lo bimi, la salig...

U.H.: E qu'ei vertat o qu'ei ua faiçon de...

J.B.: Ah, qu'ei vertat, non, non, non, qu'ei vertat.

U.H.: Qu'ei vertat? Que's pòt...?

J.B.: Ah, oui, oui. Mes qu'ei... qu'ei vertat nà tots los bòis. 


\section{Track 6: epiceà (1:55)}

Kommentar: Oberflächlich betrachtet nur eine Meinungsverschiedenheit mit dem Vertreter der Fachinstitution. Allerdings spielen hier wieder mehrere nur aus der regionalen Perspektive verständliche Sinnebenen mit hinein. Der Techniker, um den es geht, ist Vertreter der nationalen Wissenschaftsinstitution I.N.R.A. (Institut National de la Recherche Agronomique) mit Sitz in Orléans. Der thematisierte Konflikt vollzieht sich daher auch auf den Ebenen 'Nation-Region' und 'Wissenschaft-Praxis'. Hinzu kommt die Unzufriedenheit über die zu geringe Subvention und ein psychologischer Aspekt, der (zugegebenerweise unwissenschaftlich) als 'Dickköpfigkeit der Bearnesen' bekannt ist. Erst alle diese Aspekte zeichnen die Sinnebene des Textes vollständig. Hinzu kommen diskurstechnisch interessante Beobachtungen: So ist der Sprachgebrauch stilistisch sehr prägnant: die Argumentation wird elliptisch vorgetragen (unter Einbeziehung der vor Ort gegebenen Situationen) und die Bewertung erfolgt in einer sehr saloppen Form: Mes a çò que m'an balhat, ne voi pas anar massacrar un beroi pin jo, e... e deishar un lèd a costat, endà har... endà har marchar los ordinaturs de Orleans. Què n'ei a foter jo d'aquò? Eh, non, eh! Der gesamte Text wird mit längeren Unterbrechungen in drei Situationen auf einer Begehung im Wald so geäußert. D.h., der Proband kommt zweimal auf das Thema zurück, was für den hohen Grad seiner Betroffenheit spricht.

J.B.: Lo tecnicièn de l'I.N.R.A. que volè [...] que volè préner au cap de

3:25 l'arrua au bout de la rangée 'UN, DEUX TROIS-COUPE; UN, DEUX, TROISCOUPE'. Jo non, per'mor 'UN-LAID, VILAIN', valè pas arren, 'DEUX'beròi, 'TROIS'-beròi. Oh, ha, ha. Atten, que copí j'ai coupé lo 'un'. N'èra pas content, oh uèra voilà (typischer Ausruf)! Aquiu... aquiu n'èi pas avut je n'ai pas eu de subvencion aquiu. Que m'an juste balhat donnée los pès pieds.

\section{U.H.: Ah!}

J.B.: Qu'ei tot çò qu'èi avut com subvencion. E si m'avèn pagat hòrt car endà que hasossi com volè que hasossi, hèra plan. Mes a çò que $m$ 'an balhat, ne voi pas anar massacrar un beroi pin jo, e... e deishar un lèd a costat, endà har... endà har marchar los ordinaturs de Orleans. Què n'èi a fóter foutre jo d'aquò? Eh non, eh!

$[\ldots]$

7:32 Que n'i a quauques-uns, espia regarde aquò, quauques-uns de beròis. Veds aquiu, aqueste qu'ei fotut, aqueth, per'mor eh... que hè puishèu $i l$ 
gêne a un beròi, 'bon'. Qu'ei dejà estat esclarit, mes un... un epiceà com aquò n'a pas nat aucun aviéner. Aqueth qu'ei fotut per'mor qu'aquiu i a dus grans a costat, que... en quate cinq ans d'ací que va estar estofat étouffé. Alavetz, n'ei pas la pena de'u deishar har puishèu aquiu. Que l'èi mercat marqué, [zischt] a tèrra! Aciu tanben, atencion, a tèrra. Aceth 'pareil', alavetz n'èi pas hèit 'UN, DEUX, TROIS', e veds, [lacht] qu'èi hèit sautar. Un copat, los... los après beròi, l'aute copat, l'aute beròi, l'aute copat. Veds, lo tecnicièn quan va véder aquò que va ronhar gronder drin, mes 'voilà'.

$[\ldots]$

10:26 Veds ací, que son estat esclarits ací qu'aví respectat a push prètz 'un, dus, tres - un, dus, tres', e veds? Lo tecnicièn qu' at volè tot atau. Quan se podè qu'at hasí, mes si devi si je dois deishar un lèd laid e copar un beroi, aquò 'non'... ei mei hòrt fort que jo aquò.

\section{Track 8: castanh-malaudia (1:23)}

Kommentar: Ein kranker Kastanienbaum vor Ort (mit trockenen Ästen) wird zum Anlass genommen, die 'Geschichte der Kastanienbäume' im Béarn kurz zu umreißen. Dominant ist nicht die Analyse der Krankheit, sondern ihre Folge: das weitgehende Verschwinden der Baumart. Die wirtschaftliche Bedeutung der Kastanien wird nur andeutungsweise erwähnt, der Niederwaldbetrieb in diesem Zusammenhang gar nicht. Die Verbindung von castanhets und heusars, d.h. ausgedehnteren Farnvorkommen ist eine Anspielung auf die regionalen Vegeatationsverhältnisse. Der Diskurs ist von Beginn an nicht auf grundsätzliche Erklärungen ausgerichtet (meine Zwischenfrage stört in diesem Sinne bloß!), sondern konstituiert seinen Sinn schon auf einer Ebene gegebener (und als bekannt vorausgesetzter) regionaler Fakten. Im zweiten Teil wird der Diskurs auf die biographische Ebene verlagert (Aktivitäten von Vater und Sohn). Der letzte Satz (der sich auf J.B. selbst in der dritten Person bezieht) ist für Uneingeweihte kaum zu verstehen. Die erzählte Begebenheit konstituiert als besondere Sinnebene des Textes das Spannungsfeld zwischen fremd (japonés) und vertraut (die einheimischen Kastanien, die auch besser schmecken). Die ungewöhnliche Maßnahme, eigene experimentelle Pfropfungen vorzunehmen, gibt einen Einblick in den Zusammenhang von Fach und regionaler Mentalität.

J.B.: Mes... veds, que i a malaudia aus castanhs châtaigniers tanben, veds aquò, aquò qu'ei malaudia, veds aquò. Ací, espia. Alavetz aquera 
arrama que sèca il sèche, veds. Que i a malaudia aus castanhs. Per'mor d'aquò à cause de cela, los castanhs qu'avèn... que n'i avè hèra autes còps, qu'èran castanhets bois de châtaigniers tot açò e d'on t'amuishavi aciu, qu'èra castanhets. Que i a hòrt d'endrets qui son heusars fougeraies , autes còps qu'èran un castanhet e qu'amassavan hèra hèra de castanhas lo monde. E au lòc de'quò au lieu de cela que i a avut malaudias, e los castanhs qu'an despareishcut quasi completament. Alavetz ací lo men pair père qu'avè crompat...

U.H. Que hè quants ans dejà?

J.B.: E?

U.H.: Que hè quants ans dejà?

J.B.: Ah, aquò qu'èra au sègle passat. Qu'èra, qu'èra eh... a la fin deu sègle darrèr aquò. E... lo men pair qu'avè crompat castanhs qui vienèn... castanhs deu Japon. Aquiu qu'a hèit un castanhet [...], lo men pair qu'avè crompat castanhs, qu'avè hèit viéner castanhs deu Japon. E aqueths, jà..., aqueths castanhs japonés que resi... que pensava que resistavan a la malaudia. Mes en fèit que son malauds tanben, que l'an crevat un sarròt beaucoup tanben. Alavetz que... E puish, çò qui i avè, aqueras castanhas châtaignes deu Japon ne son pas tant bonas com las castanhas deu pèis ací. Alavetz çò qui hèm nous faisons souvent, eth qui avè començat a embeudar greffer aqueths castanhs de..., castanhs deu Japon, que hicava varietats de castanhas deu pèis dessús.

U.H.: Ah!

J.B.: Voilà. ... Ei çò qui hè lo hilh fils.

\section{Track 9: histuèra deus lapins (1:54)}

Kommentar: Die 'Geschichte' ist eine im Béarn beliebte Diskursform. Sie ist meist biographisch verankert und gewinnt oft im Laufe der Jahre schmückendes Beiwerk. Solche Geschichten werden zur Unterhaltung erzählt und zeugen von Humor (Anekdoten). Besonders beliebt sind sie mit regionalem Bezug auf die Jagd. Auch die vorliegende Geschichte berührt dieses Kommunikationsfeld. Es ist typisch, dass der Diskurs hier meist recht ausführlich ausgestaltet wird. Diskurstechnisch interessant ist, dass die Geschichte mit einer moralisierenden 'Lehre' endet. 


\section{U.H.:: E tot aquò?}

J.B.: Ací que son pins qui an ua istuèra. En mei bon meilleur biarnés que caleré il faudrait díser 'ua istòri'. Mes ací que disem abitualament 'ua istuèra'. Que son... qu'ei lo pin 'insignis' pin radiata tanben, alavetz los qui vaien hèra viste que t'avè dit, eh?

U.H.: Òc.

J.B.: Alavetz que n'aví plantat aquiu au hons au fond, e veds que n'i a quauques-uns au hons. Qu'an donc vint ans aqueths. E tanlèu aussitôt qui avón quate o cinc ans que hasón semenças, que hasón... que hasón pinhas pommes de pin, tè!, veds, que hasón pinhas, e jo que'm... que m'amassèi je me suis ramassé pinhas, que prengoi la semença et que'us semièi hens dans... au casau jardin potager, que'us semièi en un cuenh coin, e après que'us plantèi. Que son estats... que'us èi despuish depuis la semença. Mes lo purmèr an que n'i plantèi quate-vints ací, quatevints. Qu'aví plan netejat nettoyé la tèrra, tot, tot laborat, tot près, quatevints. E en ua nuèit nuit, los lapins que'us se minjèn tots.

U.H.: Oh!

J.B.: Qu'èran hauts atau. Los lapins qu'us copèn tots en ua nuèit. Que n'i demorè un, qu'ei aciu au som. Lavetz, lend'an un an après que tornèi començar [?] e que'us tornèi plantar. Mes los lapins tanben que'us hasoi... que'us hasoi ua leçon. Dab lo men hilh fils, ad aqueth moment qu'avèm hèit las porcherias aquiu au hons e qu'eran bastidas sus... sus un camp. E que i avè vajut sègas e saloperia, mes que demoravan de grans plaps taches de gèrba herbe, e los lapins sauvatges que'us anava hèra ils aimaient bien d'i anar per aquiu. Alavetz, a las sègas ronces, que... que pareihè $1 . .$. l'endret d'on passavan nà... [?] au bòrd de la gèrba que pass... que's vedèn... que's vedèn los horats trous d'on passavan los lapins. Que'us i hiquèm quate-vint fil-de-fèrs, e veds çò qui ei un 'lassò', un 'lassò'? Que'n gahèm nous avons attrapé vint-e-cinc lapins.

U.H.: Oh!

En ueit huit dias vint-e-cinc lapins. E... e tots gahaders 'qui peuvent être pris' e bons à minjar manger, eh? Alavetz que'us hasoi pagar los pins que m'avèn minjat 


\section{Track 11: hrèischo (1:26)}

Kommentar: Die besondere Stellung des Themas 'Eschen' wird nur in den fachkontextuellen Zusammenhängen des Waldbaus deutlich. Es handelt sich um einen Bewertungswandel, der sich aus zwei regionalen Erfahrungen ableitet: Zum einen bemerken die Waldbauern, dass sich Eschen in den Vegetationsverhältnissen des Béarn sehr gut durchsetzen und auch attraktive Wuchsformen und Größen erreichen. Zum anderen kann die Holzindustrie heute besser mit dem harten Eschenholz umgehen als früher. Eschen, die immer schon Holzlieferanten waren (für Räder und Werkzeugstiele), werden daher heute als Wertholzproduzenten in einem anderen Licht gesehen und ihre Kultivierung erscheint den Waldbauern lukrativ. Vor diesem Hintergrund ist der nachfolgende Diskurs zu bewerten. Er zeigt, wie die moderne Entwicklung in einem Sachbereich kommunikativ verarbeitet wird.

\section{U.H.: Lo hrèischo frêne?}

F.C.: Un arrèischo? L'arrèischo qu'ei... que n'i a aquiu au hons au fond deu parc. Aquò que i a arrèischos.

U.H.: E l'arrèischo que balha donne un buès de valor?

F.C.: Autes còps que's servivan deu buès d'arrèischo entà har los cars chars, entà har l'arròda roue deu car. Per'mor que demorava a l'èr air e souvent dehòra. E qu'èra un buès resistent $a . .$. au maishant temps. E que'u hè gai plaisir estar a l'èr. $\mathrm{E}$ adara, aqueth buès vòu... n'a pas mei la... la..., s'en seveishen pas mei entà... entà d'aquò, qu'ei un buès qui vai monte de valor, qui seré presque autant beròi que lo càssou. Dab la... lo... la... los tretaments qui hèn actualament que se'n pòden servir entà har 'pareil' mubles o contrevents.

U.H.: Ah contrevents. Mes possan mei viste que... que las cass... los cassos?

F.C.: Non, non, non. Eh, deu... lo... lo... lo... los arrèischos, que s'en serveishen deus petits tanben entà har manges.

U.H.: Manges, que vòu díser?

F.C.: 'Les manches'. Mange de piòla hache, quan crompas en un ... en ua... ua venta de... d'on venen utís outils, què? Los manges que son hèits ací en arrèische. 


\section{Track 12: bòsc-tribalh (3:46)}

Kommentar: Ein typisches Gespräch mit einem bearnesischen Landwirt über die Nutzung seines privaten Waldbesitzes. In dem Diskurs werden in wenigen Minuten alle wichtigeren Aspekte spontan angesprochen. F.C. verfügt über ca. 10 ha Wald, den er im Prinzip nicht forstwirtschaftlich nutzt. Da sein Hauptbetätigungsfeld die Landwirtschaft ist, wird dies nicht als Manko empfunden. Der Wald bietet für den bearnesischen Landwirt ein gewisses setting, das er sich profitabel zu erhalten weiß. Dieses regionalspezifische Verhältnis zum privaten Waldbesitz, zu dem auch der Wald als Jagd- und Erholungsgebiet gehört, ist bei der Interpretation des Diskurses mit zu bedenken. Die typischen Bewertungskriterien des Waldes tauchen auf: der Wald wirft immer genügend Brennholz ab; in Sonderfällen liefert er Bauholz. (Man ist dann stolz darauf, dieses im eigenen Wald selbst geschlagen zu haben.) Die Geräteausstattung des Landwirts schafft günstige technische Bedingungen für den Gelegenheitswaldbau (Traktor und Motorkettensäge sind unverzichtbar). Der Wald wird nicht gern verkauft (Que me'u guardi per'mor que l'ei besonh.). Es besteht aber eine gewisse Bereitschaft dazu, an waldbaulichem Profit teilzuhaben: der Platz für die Anpflanzung ist schon ausgeguckt und bestimmte 'Zukunftsbäume' werden gesondert gepflegt. Zu der unvermeidbaren Arbeit im Wald gehört aber nur das Lichten von Zeit zu Zeit, um undurchdringliche Dickungen an einigen Orten zu vermeiden. Der Waldbau als Hobby ist (möglicherweise) für die Zeit nach dem aktiven Berufsleben eingeplant: Em vaga pas. Autament qu'at harèi. Man sieht, wie viel ein relativ kurzer Diskurs über die regionalen Lebensformen verrät. Diese Sinndichte des Textes ist aber nur unter dem Gesichtspunkt des regionalen Sprachgebrauchs zu entdecken:

U.H.: Quants combien d'ectaras de bòsc as tu?

F.C.: Oh, ua detzena d'ectaras

U.H.: Et serveish lo bòsc? Entà har...

F.C.: Que'm serveish.

U.H.: Entà har què?

F.C.: Entau pour le buès de cauhatge bois de chauffage. Entau buès de tribalh. Quan èi hèit la maison qu'èi hèit los piteraus poutres, en càsso, las solivas, la taula table en aumeta ormeau, los bancs, l'escalèr en aumeta.

U.H.: Hm, qui t'a copat los arbres?

F.C.: Un amic e jo tanben que m'us soi copats. 
U.H.: Ah, sèi eh ... saps copar tanben tu?

F.C.: Un casso au pè, òc.

U.H.: Òc?

F.C.: Òc, òc, òc. Que n'èi copat jo mèma, pas lo mei gran aquiu.

U.H.: Dab la tronçonusa?

F.C.: Òc, dab las tronçonusas, òc. Autes còps dab papà que'us copavam dab un passa-pertot.

U.H.: Mes tu sàps eh...

F.C.: Ah que sèi har càier faire tomber un casso dab la tronçonusa. Mes quauque còp qu'ei tròp gran lo casso, que'm vau cuélher un amic qui a ua hèra grana tronçonusa dab la lama hèra mei longa entà póder anar d'ua part a l'auta.

U.H.: E despuish, ehm, non, après d'aver ehm... hèit càier lo... l'arbre, quin comment cau har o què cau har?

F.C.: Que cau esbrancà'u, e après que cau abilhoà'u, e que depen de çò qui vòs hà'n de ce que tu veux en faire deu casso aqueth, si vòs...

U.H.: Pelar tanben?

F.C.: Non, pelar de... quauque còp qu'anà tocar toucher... qu'anà arossegar traîner a tèrra que cau pelar, oui. E après que cau portà'u a la sarra scie entà har çò qui vòs.

U.H.: Quin s'apèra 'débarder'?

F.C.: Bò, jo que l'apèri 'tirar'. Tirar un casso.

U.H.: Tirar dab lo tractur?

F.C.: Dab lo tractur que tiri un casso, e... e... après que'm vau cuélher... que'u tiri nà'u... que l'apèran un 'carcadèr' quauque còp, o que'u tiri dab un diable. Quan ei un casso que cau guardà'u hèra long, pòts pas hicà'u sus ua remòrca, que'u tiras dab un diable. E los forestièrs bitara que hèn dab camions.

U.H.: Dab camions. Qu'arriva que i a per ací marchands deu buès qui te demandan si vòs véner lo bòsc?

F.C.: Òc, mes que me'u guardi per'mor que l'èi besonh besoin.

U.H.: Eh bé, n'as pas jamei venut bòsc? 
F.C.: Jamei.

U.H.: E vòs har ua plantacion un dia?

F.C.: 'Pareil'. Que vau... qu'èi un tròç de tèrra aquiu, un... ua ectara de... de... de tèrra qui poderé en suportar ua... ua plantacion.

U.H.: E t'interèssa? Pas, pas enqüèra?

F.C.: Em vaga pas je n'ai pas le temps. Autament qu'at harèi je le ferai. Mes çò qui hèi aus... aus bòscs qu'ei que'us esclareishi. Que'n tiri lo buès de cauhatge, los lèds, e que deishi vàier cò qui ei beròi, lo buès d'aviéner. E jo que'm serveishi deus pachets rejets, piquets entà har cloturas. Atau lo pachèt que torna vàier. Mes actualament que'n aurèi a copar hèra mei per'mor... autes còps que i èra hèra de demanda de paus pieux entà las vits vignes. Mes ací n'i a pas mei nada vit. E entà har las barralhas clôtures que's servivan deus pachets. Mes bitara qu'at hèn meilèu plutôt dab petits paus de hèr fer. Lavetz los paus que demoran au bòsc.

U.H.: As dejà esclarit dens lo bòsc tanben? Pr'amor que ger hier au bòsc... [ich beziehe mich auf eine miterlebte Aktion des Holzschlagens am Vortag]

F.C.: Òc, qu'èi hèit esclaridas entà deishar quauqua beròia cama tronc de casso e en quauquas anadas que doblan de... aquiu au som sommet en pujar monter l'arriu la rivière que t'amuisharèi qu'èra lo buès tot petit, tot sarrat serré, qu'èi gessat laissé juste quauqua cama de casso, qu'an près un... ua amplor terribla.

U.H.: Ah, que fonciona!

F.C.: A òc!

U.H.: Aquò qu'ei plan.

\section{Track 14: castanhs (2:44)}

Kommentar: Wieder das Thema der Kastanienbestände, diesmal jedoch aus einer anderen Sicht als in Track 8. R.H. lebt in Lasseube, einer Kommune, die jahrzehntelang sehr intensiv auch vom Kastanienanbau gelebt hat. Das Verschwinden der Kastanienbäume und der Zusammenbruch des entsprechenden Wirtschaftssektors lassen das Problemfeld dramatischer erscheinen. Die Dramatik wird durch verschiedene Diskurstechniken hervorgehoben: Zunächst durch den biographischen Bezug auf die eigene proprietat. Dies schafft die 
Möglichkeit zu einer diskursiven Darstellung, die auf die eigene Erinnerung ausgerichtet ist. R.H. erinnert sich, wie das Leben früher war, als es noch die Kastanienwirtschaft gab. Er wechselt dann abrupt zu einer argumentativen Ebene, die durch die Anführung von Zahlen ihren objektiven Charakter erhält. Schließlich wird der Aspekt der Vermarktung reflektiert. Im Rahmen dieser Reflexion erfolgt ein Übergang zum Französischen. Es erscheint mir dabei nicht untypisch, dass die Äußerungen zum Verlust des vertrauten Regionallebens und die Skizzierung der aktuellen unsichereren wirtschaftlichen Verhältnisse schließlich vollkommen auf Französisch erfolgen. Das Bearnesische ist den Sprechern nur in Bezug auf Vertrautes vertraut. Die Tatsache, dass auch im zweiten Teil des Diskurses weitgehend Französisch verwendet wird, hat aber noch einen anderen Grund: In Kapitel 2.5.3 werde ich ausführlich begründen, dass erst die in Track 15 festgehaltene Gesprächssituation, die sich ca. 10 Minuten später ergab, in der Unterhaltung mit R.H. den Durchbruch zur Verwendung des Bearnesischen markierte. Zuvor war R.H. auch nicht ganz sicher, von mir auf Bearnesisch vollkommen verstanden zu werden und gab daher immer wieder Erklärungen auf Französisch. (In der Tat ist seinem sehr authentischen Sprachgebrauch streckenweise in keiner der beiden Sprachen leicht zu folgen.)

U.H.: Jo que soi estat estonat étonné drin tanben de véder que $\mathrm{i}$ a pas hèra de castanhas... de castanhs que's ditz, non?

R.H.: Castanhs? Hilh-de-puta!

U.H.: N'i a... n'i a hèras per ací?

R.H.: Per ací, mes qu'ei... qu'èra la... lo reviengut revenu de la meitat moitié deus agriculturs quauque còp autrefois.

U.H.: Ah! Pr'amor qu'a Lembeye...

R.H.: Non, aquiu non, mes per ací e n'i a hèras.

U.H.: Ah, que compreni.

R.H.: Mes qu'ei.... qu'èran castanhets 'grefats' que i avè. Tà díser, l'importènça... la... las surfaças, ací que i avè ua proprietat familiala de dètz-esèt ectaras que $\mathrm{i}$ avè cinc ectaras de castanhèr.

U.H.: Ouh!

R.H.: Castanhèrs grefats e qu'èra netejat tots ans. Qu'èra com açò, a partir deu mes d'aost mois d'août qu'amassavan ils ramassaient tot çò qui i avè, n'i anavan pas las bèstis tà non pas prestir pétrir, tasser lo terrin, qu'amassavan la héus fougère, que la copavan a la man e après que 
l'amassavan tà... tà sostrar lo bestiar, 'FAIRE LA LITIERE'. EH, DISONS QUE...ua comuna com a Lasseuva que n'i avè, que i avè lhèu dus cents ectaras... sus cinc mil ectaras qu'ei a la comuna que i avè dus cents vint ectaras de vits un moment balhat donné. N'i a pas que quate-vints adara maintenant, mèma mei chic, mes castanhèra bois de châtaigniers que n'i avè lhèu quate o cinc cents ectaras. JUSQU'AUX ANNEES... JUSQU'AUX ANNEES... aten, EH... CINQUANTE... JUSQU'AUX ANNEES CINQUANTE, CINQUANTE-CINQ, C'ETAIT RAMASSE. IL Y A EU DES MARCHES A LASSEUBE on n'i avè mei de cent tònas de castanhas, LE MERCREDI, A LASSEUBE MEME, EH! Que i avè set o uèit grossistes QUI VENAIENT RAMASSER ÇA POUR LES EXPEDIER UN PEU PARTOUT. MAINTENANT, ÇA VAUT PLUS RIEN. ÇA PAIE PAS LA MAIN D'EUUVRE... SI ON LES RAMASSAIT-ÇA A CREVE BEAUCOUP-MAIS SI ON LES RAMASSAIT, ÇA NE PAIERAIT PAS SON BONHOMME. ON NE GAGNE PAS... ON GAGNE PAS LA MOITIE DU SMIG A RAMASSER LES CHATAIGNES MAINTENANT. C'EST FICHU.

U.H.: Quin s'apèra l'endret on...

R.H.: La castanhèra.

U.H.: La castanhèra?

R.H.: Òc.

U.H.: La castanhèra que's pòt díser. E lo castanhet qu'ei...

R.H.: La castanhèra qu'ei un lòc lieu, ua parcela on n'i a pas que castanha. Mes d'on i a un talhís taillis de castanhèrs, SAUVAGES, DONT ON FAIT LES PIQUETS-VOUS SAVEZ QU'ON FAIT DES PIQUETS COMME DANS UN TAILLIS D'ACACIA-aquò qu'apèran un 'paisherar'.

U.H.: Ah, un paisherar.

R.H.: Paisherar. OUI, OUI, C'EST UN TALLIS DE CHATAIGNIERS QU'ON COUPAIT TOUS LES DOUZE OU QUINZE ANS POUR FAIRE DES PIQUETS POUR LA VIGNE ET POUR LES CLOTURES. COMME ON FAIT AVEC L'ACACIA MAINTENANT.

U.H.: N'ei pas trobat aqueth mot.

R.H.: Non? E paishe... eh be hòu! PAR ICI, IL Y EN A PARTOUT. Aquiu qu'ei lo paish... IL Y A DES PARCELLES: lo paisherar... DANS CHAQUE MAISON IL Y A UN 'paisherar'. PARCE QU'ILS PLANTAIENT DES CHATAIGNIERS EN TAILLIS, POUR FAIRE DES TAILLIS. C'ETAIT DES TETARDS, MAIS COUPES, PRATIQUEMENT DES SOUCHES DE CHATAIGNIERS QUI REPARTAIENT DU 
PIED.

\section{Track 17: buès-conversacion (9:39)}

Kommentar: Der längere Gesprächsausschnitt gibt einen Eindruck davon, wie meine Befragung zum bearnesischen Wortschatz des Waldes in der Regel ablief. Phasenweise wurden sehr viele Assoziationen und Kommentare durch die Probanden in die Befragung hineingebraucht. Die Diskurse waren dabei frei und ungezwungen, weshalb sie m.E. auch eine (wenn auch besondere) Form des authentischen Sprechens darstellen. Ich gebe im Folgenden zwei Teiltranskriptionen aus dem Gesprächsausschnitt dieses Tracks wieder. Dabei handelt es sich im ersten Fall um eine Reflexion über den Wert und Nutzen des Brennholzes. Typischerweise sind die Bezüge hier wieder biographisch. Hervorzuheben ist die durch C.M. und J.M. ergänzend kontrastiv dargestellte Funktion des Kamins. Neben seiner Wärmeproduktion wird er als Ort der Versammlung, der Essenszubereitung und auch als Platz zum 'Sinnieren' charakterisiert. Der Diskurs hebt hier auf Konstanten einer Erfahrung ab, die gerade in der sich wandelnden modernen Welt eine wichtige regulative Rolle spielen. Das Bearnesische erscheint als Kommunikationsmedium besonders geeignet, diese Konstante sprachlich zum Ausdruck zu bringen. Stilistisch bewegt sich der Sprachgebrauch dabei zwischen einer beinahe lyrischen Form und einer lebhaften Darstellung, die durch das Einstreuen wörtlicher Rede charakterisiert ist. Der zweite Teil der Transkription beginnt mit dem schon bekannten stolzen Hinweis auf die Verwertung privat geschlagenen Holzes im eigenen Haus, wobei die alte Technik des Holzfällens evoziert wird. Die Probanden bestehen aber auch in Bezug auf die heutige Zeit auf der Kontinuität der privaten Bauholzgewinnung, die für sie in einem Gegensatz zu der kommerziellen Nutzung der Wälder durch Holzhändler steht. Der Diskurs zeigt deutlich, dass eine Identifikation mit dem wirtschaftlichen Erwerbsbereich nicht gegeben ist. Im Gegenteil wird betont, dass der Nutzen der Holzwirtschaft ins Ausland fließt und der Region dadurch selbst nicht zugute kommt. Es eröffnet sich damit wieder eine regionalspezifische Sinnebene des Textes, die zugleich die Schwierigkeiten hinsichtlich einer Identifikation mit dem Fach deutlich macht.

$$
\text { (Q1.mp3: 2:12 - 3:58) }
$$

J.M.: ...e lo buès de cauhatge bois de chauffage. Buès de cauhatge, alavetz aqueth n'a pas ua grana valor marchanda pr'omor parce que que cauhan de mensh moins en mensh dab bòi. Adara maintenant qu'ei lo cauhatge electric, qu'ei lo cauhatge dab 'fuel'. 
C.M.: Mes 'enfin' que n'i a qui'n qui'n hèn engué encore endà's cauhar pour se chauffer eh?

J.M.: Oui

C.M.: e que vau car cher, que vau quand-mème... Ne sèi pas quan, mes que n'i a qui'ns en demanan, que n'avèm un... aquiu, au bòrd de la rota, aquiu que'ns telefona, quauque còp nse disè «E voletz véner lo bòi?» «Non, non.»

U.H.: Non.

C.M.: «Qu'ei endà la noste chemineia.» Ara que'ns en cauham... nosauts e los en... los joens en auta part tanben... qu'an ua chemineia, qu'an radiaturs, mes la chemineia qui... qui brula tot l'ivern.

J.M.: Qu'ei sustot un un confòrt d'aver ua ua chemineia a la maison. L'ivèrn nà alumar lo huec feu qui ei un gran plaser. La familha aquiu autorn de la chemineia.

U.H.: Oh, aquò qu'ei plan.

J.M.: E qui, pr'omor que vesetz vous voyez, la flama qu'ei com, qu'ei com la mar mer... la mar, 'c'est-à-díser' que que la pòden espià'la òres e òres, que cambia tostemps e qu'a... qu'ei quauqu'arren quelque chose qui, qui viu. E en parlar en parlant d'aquò, a cada maison, que que i a ua chemineia[.?.]

C.M.: E puish, e puish que hèm, e puish que hèm grilhar tanben. Qu'avem alucat allumé dissabte, qu'avem hèit biftec, qu'èra plan beròi. La la mia hilha fille que m'a dit: «Mamà, que hès huec tu! E qu'èi pres casso, pas tròp gròs, qu'èi hèit beròis carbons, e qu'avem hèit lo... l'entercòste de... deu bueu boeuf grilhada, e qu'èra plan bon!

(Q1.mp3: 7:00 - 9:12)

C.M.: Ací, la maison, son pair que l'a hèita har e que'ns a pro dit, eh: * Tot lo... la charpanta qu'ei qu'ei deu noste bòsc.»

U.H.: Òc, òc.

J.M.: Qu'ei tot arresegat scié ací! ... Alavetz, que lo lo 'castanh', e l'avetz, aqueth mot? Lo 'castanh' qu'ei lo 'CHÂTAIGN...'

C.M.: ATtENDS! IL VA...que va pausar los mots eth!

U.H.: Qui a abatut l'arbe entà har lo... las construccions vòstes? 
C.M.: Eh bé, son pair.

J.M.: Oui, papà a noste.

U.H.: Ah bé.

J.M.: Papà e jo tanben que n'èi abatut.

U.H.: Sabèva har aquò dab ua... dab ua piòla hache?

J.M.: Dab la piòla, dab la piòla de [?]

C.M.: La piòla e lo passa-pertot.

U.H.: $\mathrm{E}$ uei en dia que i a bucherons qui, qui at hèn.

C.M.: Ací non, cadun que's hasèva los sons... lo son tribalh. Solament que i a monde quand-mème qu'an hèit expluatar aquiu au som en haut, que i a bòsc qui ei tot expluatat. Los bucherons qui son demorats, sèi pas, un... lhèu peut-être un mes mois endà expluatar lo bòi.

J.M.: Los bucherons qui vienen copar bòi qu'ei sustot portugués, qu'ei sustot estrangèrs, espanhòls, portugués qui vienen copar quan i a un bòsc a copar.

C.M.: Que son...

U.H.: E los marchands deu buès que son francés...

C.M.: Eh, eh, oui, ben segur! Los marchands deu buès que son francés. Mes cada...

U.H.: ... e que hèn tribalhar los bucherons portugués.

C.M.: Voilà, voilà. E sovent, bitara, que disen que lo buès eh... lo... francés qu'ei expluatat en Espanha, hèra, que $i$ a hèra de, que $i$ a hèra de marchands espanhòls. E lou noste gendre, qu'ei eth qui avè venut bòi hens dans lo Gers aquiu pas luenh, qu'èra endà un... qu'èra endà Espanha.

J.M.: Oui, e alavetz, lo lo los espanhòls qui vienen copar lo bòi sur pè sur pied en França, que l'amian amènent en Espanha e e e que que tornan dab mubles meubles. Que transfòrman.

U.H.: A bé, qu'ei lo sistemi.

C.M.: Au lòc lieu (au sens spatial), en França i a pas tribalh travail, mes...

J.M.: Qu'ei aquiu donc ganhan, 'c'est-à-díser, a la transformacion. Non solament au bòi, mes a tot. 


\section{Track 22: bucheron-forastar (2:03)}

Kommentar: Die Tracks 22 - 24 sind Gesprächsausschnitte mit meiner jüngsten Probandin (39 J.), die das Bearnesische in einer auffällig sicheren und vertrauten Weise als ihre Muttersprache spricht. Der Bereich institutioneller Sprachpflege liegt M.R. fern; auch stellt sie kein besonders ausgeprägtes normatives Bewusstsein unter Beweis (sie ist z.B. eine der wenigen Sprecherinnen und Sprecher aus meiner Probandengruppe, die den Französismus truc verwenden). Track 22 zeigt nun in zwei Fällen, wie M.R. das typische Waldvokabular im Bearnesischen einsetzt und beurteilt (als Frau ist sie in die Domäne de facto allerdings nicht eingebunden). Im ersten Teil zeigt sich, dass die 'alten' Wörter für bûcheron im Sprachwissen von M.R. nicht (mehr) von Bedeutung sind und dass die dem Französischen ähnliche Begrifflichkeit vorbehaltlos angewendet wird (bucheron, forestièr). Allerdings betont auch M.R. das Faktum, dass der bûcheron als Metier in der Region keine Rolle spielt. Interessant ist in Gegenüberstellung nun die ausführliche Definition und gleichzeitige Kommentierung des typisch bearnesischen Begriffs forastar. Auf die Frage nach der Bedeutung des Wortes antwortet M.R. mit einem längeren Diskurs, der die begriffliche Semantik mit der Lebensrealität in einen sehr engen und differenzierten Bezug bringt. Aus meiner Sicht gibt die Definition auf diese Weise einen aufschlussreichen Einblick in die regionalspezifische Form der Konzeptualisierung wesentlicher Fachbegriffe:

U.H.: Be, lo tribalh deu bucheron. Per ací que se ditz on dit 'bucheron' tanben? Que i a un(h)aute mot mei biarnès entà...

M.R.: Mei biarnès, que i a...

U.H.: Qu'èi trobat dens lo diccionari 'boscassèr' o 'escassolaire' o 'estroncaire'. Non? Non son (pas) mots emplegats per ací? Pas tant.

M.R.: Non, qu'ei souvent lo proprietari qui s'at hè. Ne vam pas cuélher sovent nat... nat professionel, que s'at hèm nosauts nous. Autament qu'aperam los bucherons. Un... un fo... Ne sèi pas quin s'apèran autament.

U.H.: Los bucherons, hm.-'Forastar'? E coneishes lo mot?

M.R.: Un 'forestièr' que se ditz tanben, 'forestièr', òc.

U.H.: 'Forestièr', hm, òc, hm.

M.R.: Qu'ei tot.

U.H.: Coneishes lo mot 'forastar'? 
M.R.: Oui. 'Forastar'...

U.H.: Entà díser 'FOURRE, HALLIER, TERRE INCULTE'?

M.R.: Òc, un 'forastar' qu'ei aquò exactament, tè. Qu'ei un... qu'ei sovent un truc en..., 'bon', 'inculte', en panta, maishanta tèrra on an deishat vàier buès, sovent, qui ei pas bon tostemps endà har... endà har mubles $o$ com aquò, qu'ei buès de tot, sovent ordinari, eh? E qu'ei souvent un forastar on ne pòts pas anà'i per'mor que $i$ a sègas e totas las saloperias qui pòden vàier, pòts pas anà'i tròp dab machinas, qu'ei sovent a har a ponha poigne. E qu'ei sovent lo qui at a, lo proprietari, shens aperar nat... nat forestièr, en per'mor que... que revieneré hèra car de pagar quauqu'un endà's har tribalhar ua saloperia atau. Que cau meilèu tribalh avanciu, on pòden anar drin dab las machinas e las tronconusas, per'mor si començan a copar sègas un o dus dias nà hàr viéner lo professionel, per'mor aqueth tribalh que hè car de netejar sovent un forastar d'on lo buès n'ei pas terrible, què? Que i a aquò a espiar regarder tanben. Qu'ei per'mor d'aquò que i a sovent hòrt de forastars per ací. Los bòscs ne son pas expluatats com caleré tanben per'mor d'aqueths trucs. Hein?

\section{Track 24: venta deu buès (1:06)}

Kommentar: Die Probandin weist gleich zu Anfang darauf hin, dass sie über das Thema des Holzverkaufs fachlich nicht informiert sei. Interessanterweise hindert sie dies jedoch nicht daran, im Anschluss einen kleineren Diskurs zu eben diesem Thema zu geben. Die Motivation und Legitimation dieses Diskurses werden schnell erkennbar: Es handelt sich um die Wiedergabe von Erfahrungen und Bewertungen, die der regionalen Lebensrealität entsprechen. Dadurch dokumentiert der Diskurs sehr anschaulich, die oft übersehene Funktion fachkontextuellen Sprechens im Rahmen des regionalen Sprachgebrauchs: Das Expertentum ist hier weitaus weniger wichtig als der Erfahrungsschatz. M.R. kommentiert die Gefahren, die für den privaten Holzverkäufer von den als 'gerissen' geltenden Holzhändlern ausgehen. Was sie beschreibt, ist ein Topos, der einem im Béarn in Kontexten des Waldes immer wieder begegnet und der u.a. auch ein wesentliches (nützliches) Klischee für die Arbeit der Forstkooperative darstellt. Man mag bezweifeln, dass die Holzhändler heute noch diesem 'schlimmen Bild' entsprechen. Aber zu dem Aufbau und der Versprachlichung eines regionalen Bewusstseins gehört auch das Festhalten an gewissen Feindbildern. 
U.H.: Pòts parlar drin de la venta deu buès? En saps causas?

M.R.: Oh, chic de causa, aquiu, jo.

U.H.: La venta?

M.R.: Eh...Qu'arrivan marchands de buès, jà, quauque còp, mes... ne van pas ací, mes quan te crompan... 'mettons' que crompan...

U.H.: Mes, quin se hè normalament? La venta sus pè sur pied $\mathrm{o}$ la venta en...

M.R.: Òc, sus pè. Òc qu'ei sovent coneishurs connaisseurs de per ací qui at demandan 'pareil' a pepés o memés, qui's hèn aver qui se font avoir, jà, qu'en tiran un bon partit, que s'at calculan eths, mes los pepés sovent, o mèma nosauts, coneishem pas la valor, mes eths qu'an de tira tout de suite lo còp d'uelh coup d'xil, que n'i a qui's son hèits aver atau, jà. Qu'ei per'mor d'aquò que sovent los bòscs que'us deishan com son. Ne'us expluatan pas en per'mor que sus..., sèi pas, sus quate o cinc que n'i a tres qui's haràn aver, què? E vedes çò qui voi díser?

U.H.: Òc.

M.R.: E 'vu que' n'at hèn pas, ne saben... que n'i a hòrt qui ne saben pas la valor qui pòt aver lo buès. Mes los qui'u vienen crompar, que'us [. los prètz] saben. Eths que't propòsan viste quauqu'arren, que t'at netejan $\mathrm{e}$ que plegan ils filent, hein?

\section{Track 19: silvicultura (1:48)}

Kommentar: Zum Abschluss der hier getroffenen Auswahl an bearnesischen Diskursen möchte ich noch zwei grundsätzliche Stellungnahmen zum bearnesischen Wald wiedergeben. Man ist erstaunt festzustellen, wie häufig der regionale Sprachgebrauch auch die Darstellung allgemeiner Sichtweisen und Bewertungen einschließt. Die semantische Fülle des alltäglichen Sprechens kreist - ebenso wie meine kurze Darstellung - von der Kommentierung partikularer Erscheinungen des Fachlichen in der Lebensrealität (vgl. z.B. Track 1) bis hin zu der prinzipiellen Einordnung des ganzen Sachbereichs. Oft liegen Diskurse der beiden genannten Arten sogar sehr nah beieinander. In diesem Fall legt P.M. in einer authentischen Sprachverwendung des Bearnesischen seine pessimistische Sicht des Zustands der bearnesischen Wälder dar. Der Stil seiner Darlegung ist in hohem Maße einzelsprachlich geprägt und lässt sich nicht leicht in eine andere Sprache übertragen. Inhaltlich gibt der Diskurs ein altbekanntes Topos des Negativ-Urteils über die bearnesischen Wälder wieder, das 
einem im Béarn auf Schritt und Tritt begegnet. Um so interessanter war für mich die Erfahrung, als ich diesen Diskursausschnitt einigen bearnesischen Bekannten vorspielte und immer wieder die Reaktion nachdenklicher Betroffenheit feststellen konnte. Man könnte daher vermuten, dass dieser Text (für Bearnesischsprecher) über eine Sinnebene verfügt, die sich im Zusammenhang mit der einzelsprachlichen Form und ihrer regionalen Gebundenheit konstituiert und die bei der Übertragung des reinen Aussagegehaltes in eine andere Sprache (leicht) verlorengeht. Um eine solche These zu überprüfen, wäre es methodisch anzuraten, nicht nur die Sprecher, sondern auch die Hörer einmal zu Informanten zu machen.

U.H.: Per ací, que i a hèra de paisans, disem, qui... qui an bòsc, mes qui non vòlen (pas) har la silvicultura, qu'ei aquò?

P.M.: Non, n'entertienen pas briga pas du tout los bòscs, briga, briga, briga. Lo... lo bòsc, hens las Pirenèus Atlanticas que possa a... au tièrs de çò qui's poderé possar, pas lhèu mèma. Lo... com v'èi dit je vous ai dit dabans avant, qu'avem venut certenas ectaras de... de bòsc, on n'avem pas sortit vàle'u arren rien. E... e qu'èran autant vielhas que... que las autas. E... que $\mathrm{i}$ a hèra hèra de... en çò de men chez moi tanben. Hèra d'endrets on n'i possa pas que forastèr fourré, hallier com disèm dabans.

U.H.: Qu'ei de dòu har regrettable aquò.

P.M.: Ah, qu'ei hèra de dòu har.

U.H.: Lo clima qu'ei bon, que poderé...

P.M.: Qu'ei manca de man-d'òbra. Lo monde que parteishen tots. Parten tots. Autes còps lo... los bòscs qu'èran entertienguts entretenus per'mor qu'avèm besonh de la lenha, lo petit... lo petit buès, entà... entà har tot, que tà la cosina cuisine, tau cauhatge, tà har lo pan pain. Hens aquesta region que $\mathrm{i}$ avè hèra de horns a... a teulas tuiles-teulèras tuileries-e a causea chaux. Alavetz, tad aquò pour cela que calè hèra de boès. E... e de tota faiçon, tot aquò, mèma, qu'a... qu'a empechat la... lo bòsc de vàder de plan. Lo... que'u raspavan ils le râpaient tròp.

\section{Track 21: bòsc-Biarn (1:10)}

Kommentar: Im Gegensatz zu Track 19 beinhaltet Track 21 die Sichtweise eines Bearnesen, der nicht in den Waldbau eingebunden ist. Es handelt sich also gewissermaßen um eine 'Fachaußensicht', die jedoch durch die regionale 
Eingebundenheit des Sprechers wieder relativiert wird. A.P. verweist bescheiden darauf, dass seiner Meinung keine Autorität zukäme. Aber er deutet doch als 'regionaler Zeitzeuge' die Entwicklung in einer Weise, die auf eine alltägliche und zugleich langjährige Erfahrung rekurrieren kann. Der von A.P. prognostizierte Rückzug der Landwirtschaft aus der Gegend des Béarn, in der er lebt, und die Vermutung, dass sie durch eine Waldwirtschaft zu ersetzen sei, decken sich sicherlich mit den Plänen einiger einflussreicher Ökonomen. Doch scheint es mir wichtig, auf die 'Zwischentöne' des regionalen Sprachgebrauchs zu hören. Es ist nämlich wohl kein unbedachter Umgang mit der Sprache, dass A.P die Zukunft seines Landes nicht zwischen den drei Wirtschaftsbereichen vitatge, eslhevatge und silvicultura aufteilt, sondern dass er viel subtiler formuliert: Eh que crei que serà aquiu l'aviéner d'aquesta region, d'aver sustot bòscs, vitatge e bòscs.

U.H.: Un darrèr comentari lhèu sus lo bòsc en Biarn. I a quauqu'arren a diser?

A.P.: Ah, un darrèr comentari?

U.H.: Un darrèr comentari. Si i a quauqu'arren que...

A.P.: Que crei je crois... que crei que lo Biarn, sustot aqueste tròs morceau deu Biarn, aqueste parcela, Aubertin, qu'ei hèit tà estar un bòsc, per'mor uei ne's pòt pas tribalhar la tèrra dab las machinas de uei e los grans tracturs, tot aquò. Alavetz ne s'i pòt pas har mei que drin de vitatge viticulture, las vits vignes, tà har lo vin, tà har lo Jurançon, e lhèu tanben drin d'eslhevatge élevage. Mes sinon que $\mathrm{i}$ a hèra de tèrras qui ne son pas bonas tà, tà estar cultivadas. Alavetz que seré lhèu miélher mieux de... de deishar possar los bòscs. E que n'i a qui at an hèit, qui an hèit... qui an plantat bòsc. Eh que crei que serà aquiu l'aviéner d'aquesta region, d'aver sustot bòscs, vitatge e bòscs. Mes aquò n'ei pas un avís autorisat, per'mor jo ne soi pas hèra, hèra... ne m'i coneishi pas hèra.

Die genauere Textanalyse der einzelnen Diskurse würde noch eine Reihe von Strukturelementen aufdecken, die zu der Konstitution des regionalen Sprachgebrauchs in Fachkontexten beitragen. Ich überlasse eine solche minutiöse Zielsetzung jedoch späteren Einzelstudien, da es in der vorliegenden Dokumentation und Darstellung des Themenbereichs zunächst um die grundsätzliche Erfassung des Phänomens geht. In diesem Zusammenhang ist es nun angebracht, sich die Frage zu stellen, ob das 'Sprechen über den Wald', so wie ich 
es im bearnesischen Sprachgebrauch dokumentiert habe, primär einzelsprachlich gebunden ist, oder ob die Regionalnormen, die sich auf das Sprechen in Fachkontexten auswirken, auch in der Verwendung des Französischen nachzuweisen sind. Der Vergleich des Gebrauchs der beiden Einzelsprachen wird gerade durch dieselben oder zumindest ähnliche thematische Bezüge interessant. Allerdings ist das Verhältnis von Fachbezogenheit und funktionaler Verwendung im Falle des Französischen ganz anders als im Falle des Bearnesischen. Es ist daher notwendig, genau zu analysieren, welche kommunikative Realität der regionale Sprachgebrauch des Französischen in den Fachkontexten des Waldes konstituiert, um von diesem Ergebnis aus Rückschlüsse auf den Einfluss oder die Beeinflussung der Regionalsprache zu ziehen. 


\subsection{Fachbezogene Kommunikation auf Französisch im Sachbereich 'Waldbau im Béarn'}

\subsubsection{Zielsetzung, methodisches Vorgehen und Probandenauswahl}

Die Untersuchungen zur aktuellen Verfügbarkeit und Verwendung des bearnesischen Vokabulars und zur Gestaltung bearnesischer Diskurse im thematischen Sektor 'Wald und Nutzung des Waldes' haben die theoretischen Grundlagen der Arbeit bestätigt und erhärtet: Die Analyse des regionalen Sprachgebrauchs in Fachkontexten muss sich auf die Beschreibung des Sprechens in seiner normativen Wirklichkeit konzentrieren, um ein angemessenes Bild von den faktischen und sozialen Bedingungen regionaltypischer Fachgespräche zeichnen zu können. Die Ermittlung von Gestaltungsformen der vorhandenen Sprachkompetenz innerhalb bestimmter Sprechergruppen und ihr Vergleich in Bezug auf mehrere Sprachen hängen entscheidend von dieser Beschreibung $\mathrm{ab}$, die sich grundsätzlich auf einer empirischen Ebene zu vollziehen hat. Dies macht eine Methodik erforderlich, die letztlich eine Zusammenschau des lexikologischen bzw. begrifflichen und des textuellen bzw. diskursnormativen Wissens der Sprecher ermöglicht.

Meine bisherigen Darstellungen zum Bearnesischen verdeutlichen, dass die Konzentration auf lexikologische (terminologische) Fragestellungen einerseits und auf Aspekte der inhaltlichen Textkonstitution andererseits jeweils die Ergänzung durch den anderen Analysebereich herausfordern. Das lexikalische Wissen der Sprecher fokussiert in Fachkontexten sehr eindeutig auf begriffliche Kompetenzen, deren normative Verankerung nur in der kommunikativen Verwendung der mündlichen Sprache zum Ausdruck kommt. Dabei ist eine gewisse Form der Ungezwungenheit des Gesprächs die absolut notwendige Voraussetzung für die Eruierung authentischen Sprechens. Die weitere Untersuchung wird diese methodische Forderung in angemessener Weise berücksichtigen.

Eine linguistische Untersuchung zum Sachbereich der sylviculture in Frankreich muss sich, auch wenn sie unter dem Gesichtspunkt des regionalen Sprachgebrauchs in einem zweisprachigen Gebiet durchgeführt wird, der beherrschenden Funktionalität des Französischen in einer makrodiglossisch auf Substitution der Minderheitensprache ausgerichteten Sprachgemeinschaft bewusst sein. Ich habe bereits in Kapitel 2.1.4 darauf hingewiesen, welche fundamentale Bedeutung dem Forstwesen heute in ganz Frankreich zukommt und dass diese Signifikanz durch staatlich gelenkte institutionelle Aktivitäten sozial fundamentiert wird: Sich heute in Frankreich für den Waldbau zu interessieren, ganz gleich ob als Rentner oder als junger Mensch, setzt das Gefühl 
der Sicherheit voraus, sich einer sozio-ökonomisch anerkannten, gewinnbringenden Aktivität zu widmen.

Die Beschäftigung mit dem Wald, die immer den Einsatz von Arbeit und oft auch Finanzen erfordert, ist zwar in der Regel nicht kurzfristig gewinnorientiert. Sie geschieht aber, selbst bei den älteren Waldbesitzern, auch nicht in einer sentimentalen oder 'ökologistischen' Hinwendung zu Traditionen der Vergangenheit, sondern aus dem Bewusstsein der modernen (agrar-)kulturellen und ökologischen Wertschätzung dieses Betätigungsfelds. Der Wald und seine Pflege gewinnen in Frankreich von Jahr zu Jahr mehr öffentliches Prestige. Dieser Prestigegewinn wird durch eine gezielte Forstpolitik auf nationaler und internationaler Ebene gefördert und konsolidiert. Die Überzeugungskraft institutioneller Maßnahmen liegt dabei häufig weniger in der Schaffung eines analytischen Sachverständnisses auf Seiten der einzelnen Waldbauern als vielmehr in der Pragmatik einer zweckorientierten Verbindung von Protektion natürlicher Ressourcen, agrar-politischem Strukturwandel, fachspezifischer Aufklärungsarbeit und finanziellem Anreiz durch staatliche oder europäische Subventionen. ${ }^{181}$

Unter diesem sozio-politischen Aspekt wird verständlich, warum es das Bearnesische schwer hat, in der modernen Konzeption des Sachbereichs weiterhin kommunikativ Fuß zu fassen. In dem Maße, wie der Wald sein jahrhundertealtes Image als Gebiet des Rückzugs aus menschlicher Zivilisation im öffentlichen Bewusstsein verliert, passt sein Kommunikationssektor nicht mehr zu einer Regionalsprache, deren Status als patois in Frankreich bis heute durch keine aktive Sprachpolitik in Frage gestellt wird. Als Konsequenz der unbestreitbaren Diskrepanz von Wirtschafts- und Kulturpolitik ergibt sich somit die weitere Auflösung der kommunikativen Funktionalität des Bearnesischen (wie auch anderer Regionalsprachen in Frankreich) in Fachkontexten, zu deren primärer Ausgestaltung es traditionell verwendet wurde und, wie wir gesehen haben, noch heute von Muttersprachlern durchaus verwendet werden kann.

Die beschriebenen Fakten haben mich methodisch dazu geführt, die fachbezogene Kommunikation im Sachbereich 'Waldbau im Béarn' nicht sprachvergleichend $\mathrm{zu}$ analysieren, sondern die linguistische Untersuchung auf die vorhandene Sprachkompetenz im Französischen zu konzentrieren. Ich werde aber dennoch im Kapitel 2.5. noch einmal auf die potentielle Funktionalität des Bearnesischen unter denselben fachspezifischen Gesichtspunkten zurückkommen.

Um die fachbezogene Kommunikation zum Thema 'Waldbau' im Béarn realitätsnah analysieren zu können, habe ich ein Mindestmaß an persönlicher Be-

${ }^{181}$ Vgl. in dieser Hinsicht die Publikation La forêt française et son bois au seuil de l'an 2000, hg. v. D. Lorette, Bordeaux 1996. 
troffenheit des Einzelnen zur Voraussetzung der Untersuchung gemacht. Mein Auswahlkriterium für geeignete Probanden war daher der Privatbesitz von Wald in Verbindung mit einem grundsätzlichen, verifizierbaren Interesse an seiner Nutzung im Sinne der Wertholzproduktion. De facto habe ich die Probandengruppe auf Personen eingeschränkt, die schon einmal aus den verschiedensten Gründen mit einer regionalen Institution des privaten Waldbaus in Kontakt getreten sind. Für entsprechende Hinweise, Vermittlungsdienste und Hilfeleistungen danke ich ganz besonders den Organisationen Centre Régional de la Propriété Forestière d'Aquitaine (CRPFA, Bordeaux, Orthez), Centre d'Études Techniques et d'Expérimentation Forestières (CETEF, Pau) und Coopérative des Producteurs de Bois des Pyrénées-Atlantiques (CPB 64, Navarrenx).

Insgesamt habe ich auf der Basis eines fachlich durchkonzipierten standardisierten Interviews, dessen Prinzipien ich noch erläutern werde, 8 Gespräche mit 9 Probanden geführt und aufgezeichnet. Im einzelnen waren die folgenden Personen so freundlich, sich für ein Interview zur Verfügung zu stellen: ${ }^{182}$

EF1: Jean T., Pau

44 J., technicien forestier am CRPFA, Bordeaux, arbeitet als conseiller forestier für den CETEF in Pau, besitzt privat 10 ha Wald im Dept. HautesPyrénées. Gebürtiger Bearnese mit sprachlichen Grundkenntnissen im Bearnesischen (versteht es, aber spricht nicht).

Gesprächsdauer: ca. 1 Std. 18 Min. (F1.mp3: 44:39, F2.mp3: 33:14)

EF2: $\quad$ Paul A., St-Laurent-Bretagne (C. Morlaàs)

62 J., Präsident des CETEF in Pau, Mitglied des Syndicat des Propriétaires Forestiers Sylviculteurs, im Ruhestand, arbeitete zuvor als Ingenieur in der Düngemittel-Industrie, besitzt privat mehr als 13 ha Wald, der z.T. wirtschaftlich genutzt wird. Gebürtiger Bearnese, jedoch kaum aktive Sprachkenntnisse im Bearnesischen.

Gesprächsdauer: ca. 52 Min. (F1.mp3: 44:52, F2.mp3: 7:02)

EF3: $\quad$ Alain B., Orthez

50 J., technicien forestier am CRPFA, Bordeaux, arbeitet als conseiller forestier in der 'antenne' Orthez, Maison de la Forêt, besitzt privat 13 ha Wald als Anpflanzung. Aufgewachsen in der Charente (Mutter stammt aus dem Béarn), spricht kein Bearnesisch (versteht es auch nicht).

Gesprächsdauer: ca. 1 Std. 03 Min. (F1.mp3: 45:16, F2.mp3: 17:02)

${ }^{182}$ Ich benutze als Kennung der Probanden die Abkürzungen EF (' Experte, Französisch) und LF (' Laie, Französisch). Zur Unterscheidung von Experten und Laien siehe die weiteren Erläuterungen. 
EF4: $\quad$ Marie-Paule und Pierre J., Lalongue (C. Lembeye)

77 J. sie, er über 80, im Ruhestand, stammen beide aus der Chalosse (Landes), einer Gegend mit ähnlicher Waldlandschaft wie im Béarn, leben seit 10 Jahren auf einem Schloss (19. Jh., ehemalig russischer Besitz) in Lalongue; Frau Jambon kennt die Gegend schon länger, weil sie ihren Vater oft als seine Sekretärin auf Geschäftsfahrten begleitet hat; ihr Vater betrieb kommerziellen Waldbau in der Gegend, kaufte über 100 ha verlassenes Agrarland auf und wandelte es in Nutzwald um, insbes. durch Anpflanzung von Douglasien; Herr Jambon war zunächst als Hütteningenieur tätig, wechselte dann zur beruflichen Tätigkeit eines exploitant forestier im Betrieb seines Schwiegervaters; das Ehepaar besitzt insgesamt ca. 240 ha Wald, dessen wirtschaftliche Nutzung es der Société d'Exploitation des Bois du Sud-Oeust (SEBSO, StGaudens, Dpt. 31) übertragen hat. Beide haben Sprachkenntnisse des chalossais; verstehen auch gut Bearnesisch.

Gesprächsdauer: ca. 1 Std. 20 Min. (F1.mp3: 45:36, F2.mp3: 34:44)

LF1 Pierre de B., Salies-de-Béarn

78 J., Landwirt im Ruhestand, Kontakt zum CRPFA aufgrund des obligatorischen Plan Simple de Gestion, arbeitet ansonsten lieber ohne institutionellen Rückhalt, besitzt mehr als 25 ha Wald, z.T. Anpflanzungen. Gebürtiger Bearnese, jedoch war die Mutter nicht Bearnesin, daher nur passive Sprachkenntnisse.

Gesprächsdauer: ca. 1 Std. 11 Min. (F1.mp3: 44:05, F2.mp3: 26:21)

LF2 Paul D., Pau / Lombia (C. Morlaàs)

67 J., im Ruhestand, früher als Fahrer beim Erdgasunternehmen Elf Aquitaine Production tätig, Eltern waren Landwirte; kümmert sich um den nicht verpachteten Landbesitz seiner Frau in Lombia, hat dort mit institutioneller Hilfe Anpflanzungen anlegen lassen (ca. 4 ha). Gebürtiger Bearnese, die bearnesische Muttersprache ist ihm teilweise noch vertrauter als das Französische.

Gesprächsdauer: ca. 43 Min. (F.mp3: 43:06)

LF3 Philippe M., Gan (C. Jurançon)

62 J., im Ruhestand, wurde in Algerien geboren, wo er bis zum Alter von 27 Jahren lebte, kam dann in den Béarn (Familie stammt aus der Auvergne), war als Lastwagenverkäufer und in der Landwirtschaft tätig, privater Waldbesitz: 11 ha Anpflanzungen, 12 ha Naturwald, interessiert sich seit dem Rentenalter für den Waldbau, Kontakt zum CRPFA. Spricht kein Bearnesisch.

Gesprächsdauer: ca. 41 Min. (F.mp3: 40:44)

LF4 Georges L., Denguin (C. Lescar)

69 J., im Ruhestand, war früher Mathematik-Lehrer (in Tarbes), gebürtiger Bearnese (Familie stammt seit Generationen aus dem Béarn), besitzt 2 ha alten Naturwald, interessiert sich seit 3 Jahren intensiv für Waldbau, sucht engen Kontakt zu CRPF und CETEF (Informationsveranstaltungen, Kurse), quasi als Hobby, noch keine eigene waldbauliche Tätigkeit. Versteht und spricht ein wenig Bearnesisch, verwendet aktiv jedoch nur Französisch. 
Gesprächsdauer: ca. 1 Std. 5 Min. (F1.mp3: 44:40, F2.mp3: 19:56)

Die Gespräche wurden alle im September 1997 geführt. Für die nachfolgende Analyse in dieser Arbeit habe ich mich zu einer Auswahl von vier Probanden entschieden: zwei aus der Gruppe der Experten (EF1 u. EF2) und zwei aus der Gruppe der Laien (LF1 u. LF2). Die Unterscheidung in 'Experten' und 'Laien' entspricht dabei einer Vorabbeurteilung des jeweils biographisch gegebenen Zugangs zum Waldbau.

EF1 und EF3 sind durch ihren Beruf klar als Experten ausgewiesen. EF2 gehört aufgrund seiner ehrenamtlich ausgeübten Funktion als Präsident des CETEF in diese Kategorie. Die Zuordnung von EF4 habe ich vorgenommen, da es sich um Großgrundbesitzer von Waldflächen handelt, an deren Bewirtschaftung sie ehemals beruflich selbst beteiligt waren.

Die Gruppe der 'Laien' besteht aus vier älteren Personen, die alle erst nach ihrem Ausscheiden aus dem aktiven Berufsleben zum Waldbau gefunden haben. Unter ihnen stellen LF2 und LF4 Fälle eines hobbymäßigen Betreibens von Waldbau dar, während LF1 und LF3 größere Besitzungen haben, ihren privaten Waldbau mit mehr Aufwand betreiben und mit größeren wirtschaftlichen Ambitionen verbinden.

Die fachlichen Niveauunterschiede zwischen den Gruppen erweisen sich als fließend. So tendieren die Probanden EF4 zur Gruppe der 'Laien' und LF1 zur Gruppe der 'Experten'. Diese Tendenzen lassen sich in beiden Fällen sehr gut biographisch nachvollziehen. Überhaupt fällt auf, dass bei der Auswahl der 9 Probanden ein hoher Anteil an Individualität in den jeweiligen Bezügen zum Waldbau feststellbar ist. Andererseits zeigt sich in den geführten Gesprächen, dass sehr viel Übereinstimmung im Antwortverhalten sowohl in fachsprachlicher als auch in inhaltlicher Hinsicht gegeben ist. Ich führe dies auf die Wirkung der Regionalnormen des Sachbereichs zurück, die sich in der konkreten Behandlung des Themas gegenüber den biographischen Zugängen als bestimmend erweisen. Dennoch werde ich auch dokumentieren, dass gerade die Regionalnormen des Sachbereichs ihre kommunikative Ausgestaltung nur durch die enge Verbindung zur persönlichen Betroffenheit des einzelnen Sprechers finden.

Die analytische Zielsetzung der Untersuchung erfordert die intensive Beschäftigung mit dem Antwortverhalten des einzelnen Probanden. Aus diesem Grunde reduziere ich das Korpus auf vier Gespräche, die in voller Länge dargestellt und kommentiert werden sollen. Ich konzentriere mich dabei auf diejenigen Probanden, die mir im Sinne einer kategoriellen Bestimmung als typischere Vertreter der beobachteten Sprechergruppe erscheinen. Vor dem Beginn der eigentlichen Analyse muss jedoch noch das Instrumentarium des standardisierten Interviews im besonderen Fall kommentiert werden. 


\subsubsection{Das standardisierte Interview zum Thema 'Waldbau im Béarn'}

Der grundsätzliche Sinn des standardisierten Interviews, so wie ich es in meinen Untersuchungen verwende, liegt in der Kombination der systematischen Eruierung mündlichen Fachsprachengebrauchs zu Vergleichszwecken mit der Aufzeichnung möglichst authentischen Sprachverhaltens. Diese doppelte Zielsetzung lässt sich methodisch selbstverständlich nur in einer Kompromissformel erreichen, da die Natürlichkeit sprachlicher Alltagskommunikation und die strukturierte Abfrage kommunikativen Wissens in einem Fach prinzipiell disharmonisch sind. Allerdings hat sich in der Praxis gezeigt, dass das standardisierte Interview nicht nur eine Kompromiss- sondern auch eine Zauberformel ist, da es nämlich den Probanden durchaus in einem geplanten Kommunikationsschema mit thematischer Ordnung halten kann, ohne seine freie und authentische Sprechweise zu behindern.

Drücken wir es einfach aus: Die Probanden freuen sich in der Regel, beim Interviewer auf Interesse für ein Fachgebiet zu stoßen, von dem sie selbst betroffen sind und in dem sie sich kommunikativ sicher fühlen, weil sie etwas zu sagen haben, zu dem sie sich aufgrund von Fachwissen und Erfahrung berufen fühlen. Dabei spielt das tatsächliche Fachniveau keine ausschlaggebende Rolle, da die regionale Eingebundenheit der fachlichen Kenntnisse eben ein normatives Wissen konstituiert, das sich durch die Erfahrung selbst und nicht etwa durch eine Form der Ausbildung legitimiert. Die Freude des Gesprächspartners, sich über 'sein Fach' mitzuteilen, wird dabei noch ausgeprägter, wenn der Befrager von weit weg (oder zumindest nicht aus der Region) stammt und jede Information einen zu erwartenden Neuigkeitswert hat. Wenn es dem Fragesteller gelingt, in der Rolle des Interessierten und Wissensdurstigen zu bleiben, d.h. wenn sich seine Befragung nicht zu der unangebrachten Form einer Wissensüberprüfung gegenüber dem Probanden verkehrt, so ist ein hohes Maß an Offenheit und Spontaneität in den Antworten zu verzeichnen, die somit eine geeignete empirische Grundlage für diskursanalytische Betrachtungen zu fachkontextuellem Sprechen bilden.

Andererseits erfolgt durch die Strukturierung des Interviews ebenso wie durch die Anwendung verschiedener Fragetechniken ein systematischer Gesamtaufbau des Gesprächs, das im Idealfall einen relativ kompletten Streifzug durch die Berührungspunkte von Fach und regionalem Leben darstellt und es gleichzeitig ermöglicht, in exemplarischer Form eine Verifikation und Beschreibung fachsprachlichen Niveaus $\mathrm{zu}$ geben. Die spezifisch fachlichen Ansprüche an die inhaltliche Strukturierung des Interviews sind daher sehr hoch. Insbesondere dürfen die Fragen keine einseitige technologische Ausrichtung dokumentieren, sondern müssen stattdessen sehr genau auf die As- 
pekte regionaler Relevanz abgestimmt werden. Dieser Anspruch ist mittels einer rein auf Fachlektüre basierenden Einarbeitung kaum einzulösen. Ich bin daher zusätzlich zu der theoretischen Aneignung von Fachkenntnissen im Vorfeld den Weg einer möglichst umfassenden Kenntnisnahme fachspezifischer Lebensgestaltung vor Ort gegangen. Im konkreten Fall habe ich z.B. an einer Sitzung des CETEF in Lestelle-Betharram, an einer visite guidée für private Waldbauern in Bosdarros, an einem kleineren Lichtungshieb in Maspie, an vier privaten Einzelführungen durch Waldbesitzungen in Anoye, Lombia, Lasseube und Cosledaà teilgenommen sowie viele informelle Gespräche zum Thema geführt. Diese Aktivitäten haben mir eine für die Durchführung der Interviews entscheidende Sicherheit in der Beurteilung regionaler Relevanzen des Fachgebiets gegeben.

Einen ganz wesentlichen fachlichen Rückhalt und wichtige Anregungen erhielt die Untersuchung auch durch den zweimaligen Besuch im Centre Régional de la Formation Professionnelle Forestière in Bazas (ca. 60 km südöstlich von Bordeaux). Der Leiter dieses einzigen staatlichen Ausbildungszentrums im Bereich Forstwesen für die gesamte Région d'Aquitaine, Herr Jean-Bernard Carreau, nahm sich freundlicherweise sehr viel Zeit, mir alle notwendigen theoretischen und praktischen Informationen vor Ort zu geben. Eine besondere Hilfe war es zudem, dass Herr Carreau sich beim zweiten Besuch selbst für ein Interview zur Verfügung stellte. Die außerordentliche fachliche Kapazität, mit der Herr Carreau auf die einzelnen Fragen in insgesamt fast 3 Stunden Beantwortungszeit einging, lässt das aufgezeichnete Gespräch zu einer wichtigen Vergleichsfolie für die im Béarn ermittelten Antworten werden. Da ich es aber vermeiden will, die fachliche Dimension der durchgeführten Untersuchung in ein Ungleichgewicht zur linguistischen Analyse zu bringen, verzichte ich im Rahmen der nachfolgenden Auswertung dennoch auf die Einbeziehung dieses außerhalb des Béarns ermittelten detaillierten Fachgesprächs (Gesamtdauer: 2 Std. 50 Min., JeanBernard.Carreau.F1. mp3: 46:06, F2.mp3: 44:46, F3.mp3: 44:12, F4.mp3: 34:54).

Kommen wir nun noch kurz auf den Aufbau und Inhalt des vorbereiteten Interviews zu sprechen. Der Fragenkatalog gliedert sich in vier Teile:

A) Données biographiques

B) Rapport à la matière

C) Connaissance du béarnais

D) Vocabulaire techniques et compétences spéciales

Die Teile A-C dienen dazu, ein eindeutiges Bild von der befragten Person zu erlangen. Dabei wird dem Untersuchungsanliegen entsprechend sowohl auf den Zugang zum Fach als auch auf die sprachlichen Gewohnheiten ein besonderes Gewicht gelegt. Teil D schließlich bildet den Hauptteil des Interviews, in dem die bereits charakterisierte Eruierung mündlicher fachsprachli- 
cher Darstellung in einer systematischen Form erfolgt. In inhaltlicher Hinsicht gliedert sich dieser Teil wie folgt:

1) Peuplements forestiers et arbres: 8 Fragen

2) Parties et structure de l'arbre: 7 Fragen

3) Régénération et plantation: 9 Fragen

4) Sylviculture et écologie de la forêt: 7 Fragen

5) Exploitation du bois, techniques sylvicoles: 8 Fragen

6) Administration et loi forestières: 4 Fragen

Der vollständig formulierte Fragebogen findet sich im Anhang dieser Arbeit. Zudem wird im folgenden Kapitel eine detaillierte Auswertung der Gespräche mit EF1, EF2, LF1 und LF2 vorgenommen, in der die Antworten aller vier Probanden in Bezug auf die jeweilige Frage vergleichend dargestellt und kommentiert werden. Ich gehe daher davon aus, dass eine fachliche Begründung der Konstitution des Fragebogens, die ich ohne Mühe und an dieser Stelle geben könnte, weder das spezifische Interesse des Lesers trifft, noch zu einem besseren Verständnis der linguistischen Analyse beitragen würde. Ich beschränke mich daher auf die gegebenen Hinweise zur fachlichen Absicherung der verwendeten Fragen und Fragetechniken und gehe abschließend nur noch auf die terminologische Fundierung des Interviews ein.

Das Forstwesen verfügt schon seit längerem über eine genaue lexikographische Aufbereitung seines Fachvokabulars. 1949 wurde auf dem 3. Welt-Forstkongress in Helsinki die exakte Erfassung der Forstterminologie in mehreren Sprachen beschlossen. Als Resultat einer Zusammenarbeit mehrerer englischsprachiger Forstinstitutionen in diesem aufwendigen Projekt erschien 1971 die englische Version des sog. 'Mehrsprachigen Forstlexikons' mit einer systematischen Zusammenstellung von 6807 Termini. Dieser englischen Version folgte, ebenfalls als Leistung einer Vielzahl kooperierender Forstinstitutionen (in Frankreich und Québec), 1975 die französische Version, die vom Conseil International de la Langue Française unter dem Titel Terminologie forestière: sciences forestières, technologie, pratiques et produits forestiers (hg. von A. Métro) veröffentlicht wurde. Die französische Version der Terminologie Forestière Multilingue (VFTFM) ergänzt den englischen Bestand um fast 1000 weitere Begriffe, so dass insgesamt 7741 Termini im VFTFM verzeichnet sind. Alle Termini werden durch eine Referenznummer gekennzeichnet, was ihre Übertragung in andere Sprachen erleichtert. Hierzu ist anzumerken, dass die Termini als sog. termes-concept ausgewiesen sind, die jeweils einen klar definierten forstlichen Begriff zum Ausdruck bringen.

Als Grundlage für meine Arbeit erwies sich die hohe Zahl von 7741 Termini und ihre teilweise sehr differenzierte Definition im Dictionnaire Forestier Multilingue (' $D F M$ ) als zu fachspezifisch. Mir kam aber zu Hilfe, dass der $D F M$ wohl auch in der Berufswelt des Forstwesens einen ähnlichen Eindruck 
hinterlassen hat und sich in der Praxis als zu detailliert erweist. Auf Initiative von Karl-Hermann Simon wurde daher in Eberswalde 1981 das Projekt des Lexicon Silvestre auf den Weg gebracht. Die von Simon verfolgte Konzeption der lexikographischen Erfassung des Forst-Fachwortschatzes sieht die sukzessive Publikation von insgesamt sechs Teilen eines Wörterbuchs in mehreren Sprachen (darunter auch Esperanto) mit jeweils ca. 1000 Fachbegriffen vor. Der erste Teil dieses Lexicon Silvestre liegt seit 1996 auch in einer französischen Version vor. Die Vorteile, die ich aus der Arbeit mit diesem Band in meiner Untersuchung ziehen konnte, liegen auf der Hand. Es handelt sich im Wesentlichen um zwei Aspekte.

Zum einen ist die prima pars dieses Wörterbuchs auf die Darstellung der 1000 wichtigsten Begriffe des Forstwesens konzentriert. In den Erläuterungen des einleitenden Teils heißt es dazu:

Pour le choix des concepts de la première partie, on a, par principe, retenu les notions les plus importantes et les plus repandues. Comme en terminologie forestière aucun résultat de recherches portant sur l'analyse des fréquences d'utilisation n'était connu, ce choix a été effectué sur la base de critères subjectifs, tenant surtout compte des concepts usuels de la foresterie de l'Europe centrale. (Lexicon Silvestre I fr., VI)

Trotz dieser Einschränkungen ist gerade die aus der fachlichen Perspektive der Berufswelt getroffene Begriffsauswahl für meinen Zweck eine sehr gute Basis. Ein weiterer Vorteil des Lexicon Silvestre liegt in der Angabe einfach strukturierter und auf das Wesentliche des jeweiligen Begriffs konzentrierter Definitionen. Auch hierzu möchte ich noch einmal aus der Einleitung zitieren:

Le contenu d'un concept, ou dénotation, est donné par une définition. Dans le "Lexicon silvestre" ce ne sont donc pas des termes qui sont expliqués - comme c'est le cas dans la "Terminology" de FORD-ROBERTSON (1971) - mais au contraire, ce sont les termes qui sont subordonnés aux définitions.

Pour établir les définitions on a eu recours aux terminologies, normes et glossaires existants ainsi qu'à des conseillers spécialisés et des linguistes; [...]

(Lexicon Silvestre I fr., VI)

Um dem standardisierten Interview in der Untersuchung eine geeignete terminologische Basis geben zu können, habe ich zunächst alle 1000 Begriffe des Lexicon Silvestre I fr. mit ihren jeweiligen Definitionen aufgelistet und in verschiedene thematische Bereiche gruppiert. Innerhalb dieser Bereiche wurden dann Fragen formuliert, die sich auf zentrale Begriffe des jeweiligen Themengebiets beziehen. Dabei sind die Fragen unterschiedlich ausgerichtet, so dass z.T. einzelne Termini im Vordergrund der Antwort stehen, z.T. aber auch stärker auf die dahinter stehenden Begriffskonzepte Bezug genommen wird.

Da die Möglichkeit fachlicher Detailerklärungen im Rahmen dieser Arbeit limitiert ist, beschränke ich mich darauf, die relevanten termes-clés aus dem 
Lexicon Silvestre I fr. im Anschluss an die Formulierung einer jeden Frage zu zitieren. Die Auswertung nimmt gegebenenfalls auf die Verwendung dieser Begriffe in den Diskursen der Probanden Bezug. Allerdings hat sich herausgestellt, dass trotz der Reduktion auf einige wesentliche zentrale Fachbegriffe selbst diese in ihrer terminologisierten Form eher selten in den Diskursen Verwendung finden. Es erweist sich daher in der Tat als sinnvoll, zwischen concept und terme zu differenzieren ${ }^{183}$ und die Untersuchung eindeutig auf fachliche Begriffskonzepte auszurichten. Die in der alltäglichen und beruflichen Konversation verwendete mündliche Fachsprache ist nur ansatzweise terminologisch bestimmt. Ihre Normierung lässt sich nicht auf die Strukturen der fachlichen Kodifikation zurückführen. Dessen ungeachtet wird das Sprechen in Fachkontexten durch eine Verbindung von Sach- und Regionalnormen (in dem bereits definierten Sinn) charakterisiert, die der mündlichen Fachsprache die Gestaltungsform eines regionalen Sprachgebrauchs geben. Diese Normierung des Sprechens im thematischen Sektor des 'Waldbaus im Béarn' nachzuweisen ist das Anliegen der Analysen des folgenden Kapitels.

${ }^{183} \mathrm{Vgl}$. “concept - Unité de pensée constituée par les caractéristiques qui sont attribuées à un objet ou à une classe d'objets. Remarque: les concepts ne sont pas liés à une langue particulière. “ - ,terme - Désignation d'un concept par une expression linguistique. " (Lexicon Silvestre Ifr., IX) 
2.4.3. Die Befragung zum Thema Gestion de la forêt et sylviculture en Béarn-Detailauswertung von vier Gesprächen

Zunächst werde ich dem Leser in einer Legende zur Auswertung der französischen Interviews die im Folgenden benutzten Abkürzungen erläutern:

I $=$ Inhalt $($ Def $=$ Definition, Org $=$ Organisation, Antw. $=($ genaue $)$ Antwort, Komm $=$ Kommentar)

$\mathbf{S}=$ Sprache (lex $=$ lexikalisch)

D $=$ Diskurs $(\mathrm{BSP}=$ Beispielgebung, Biogr $=$ biographischer Bezug, Verh $=$ Verhalten)

$P=$ Position, d.h. Zeitpunkt, an dem der ausgewertete Gesprächsausschnitt beginnt (Angabe in Min. und Sek.)

$\mathbf{L}=$ Länge des ausgewerteten Gesprächsteils (Angabe in Min. und Sek.)

$\mathbf{Z}^{*}=$ Zitat (Angabe der genauen Position)

Partie A (données biographiques)

A.1. Vous vous appelez comment?

A.2. Vous avez quel âge?

Jean T. (EF1): [F1.mp3: 44:39, F2.mp3: 33:14]

$44 \mathrm{~J}$.

Paul A. (EF2): [F1.mp3: 44:52, F2.mp3: 7:02]

$62 \mathrm{~J}$.

Pierre de B. (LF1): [F1.mp3: 44:05, F2.mp3: 26:21]

$78 \mathrm{~J}$.

Paul D. (LF2): [F.mp3: 43:06]

$67 \mathrm{~J}$. 


\section{A.3. Vous êtes Béarnais? Vous êtes né ici?}

Jean T. (EF1):

ist Bearnese (Vater und Mutter sind beide bearnesisch)

Paul A. (EF2):

ist Bearnese, in dem Haus geboren, in dem auch das Interview stattfindet; hat Boden geerbt, den seine Vorfahren seit ca. 1400 besitzen

Pierre de B. (LF1):

ist gebürtiger Bearnese (sein Vater war auch Bearnese, seine Mutter nicht); ist in dem Bauernhaus (maison agriculteur) geboren, in dem das Gespräch stattfindet

Paul D. (LF2):

ist Bearnese, in der Region geboren

\section{A.4. Quelle est votre profession / quel est votre métier?}

Jean T. (EF1):

technicien auprès du Centre Régional de la Propriété Forestière (CRPF), Aufgabenbereich: Beratung und fachliche Aufklärung privater Waldbesitzer als conseiller forestier

Paul A. (EF2):

besuchte eine landwirtschaftliche Schule in Grenoble, arbeitete danach als Ingenieur in der Düngemittel-Industrie

Pierre de B. (LF1):

war sozusagen sein ganzes Leben lang Landwirt, eine Zeit lang auch Vertreter: "J'ai été représentant un certain temps." (Z* 00:36)

Paul D. (LF2):

war früher als chauffeur du personnel bei dem Erdgasunternehmen Elf Aquitaine Production tätig; seine Frau besitzt ein Waldstück in der Gegend, um das er sich kümmert 


\section{Partie B (rapport à la matière)}

\section{B.1. Vous êtes concerné par la gestion du bois? Vous avez une proprié- té. De combien d'hectares?}

Jean T. (EF1):

Besitz von ca. 10 ha Wald in den Hautes Pyrénées; betreibt dort seit ca. 15 Jahren Waldbau (natürliche Bestände, vorwiegend Buche)

\section{Paul A. (EF2):}

besitzt 33 ha Land, davon 13 ha Wald in der Gemeinde St.-Laurent-Bretagne und ein weiteres kleines Waldgebiet in den benachbarten Gemeinden Monassut und Audiraqc; zum Teil handelt es sich um natürlich gewachsenen Wald (des taillis), zum Teil um angepflanzten Wald, bei dessen Anpflanzung die modernsten Techniken verwendet wurden

\section{Pierre de B. (LF1):}

ist vom Waldbau betroffen, da er selbst mehr als 25 ha Wald besitzt; bewertet diese Tatsache: "ce qui est dans le département des Pyrénées-Atlantiques quelque chose qui est peu courant" ( $Z^{*}$ 01:00); die Besitzer größerer Waldflächen wurden als gens forestiers bezeichnet, waren aber nicht sehr zahlreich; Nachfrage zur Beschaffenheit des Waldes (bois naturel): Es handele sich um natürlichen Waldbestand, aber auch um Anpflanzungen: "J'ai fait les plantations." (Z* 01:38), "Oui, c'étaient des forêts qui étaient... particulièrement, autrefois, en châtaigniers." (Z* 01:40); erläutert die Verarbeitung des Kastanienholzes, geht besonders auf die Verwertung der déchets ein, die in großen Reisigbündeln (fagots) an die Salzfabrikation ausgeliefert wurden (integriert in die Erklärung des Bündelns die bearnesischen Wörter bencilh und barrolha); anschließend ausführliche Erläuterungen zur regionalen Salzherstellung; man bemerkt die Offenheit des Probanden und seine Bereitschaft, viele Erklärungen zu geben, die ihn schon zu Beginn des Gesprächs dazu führt, sich weit von der ursprünglichen Fragestellung zu entfernen.

\section{Paul D. (LF2):}

fühlt sich ein bisschen vom Waldbau betroffen; der Landbesitz seiner Frau erstreckt sich über 19 ha (scheinbar weitgehend ohne natürliche Bewaldung), von denen 15 ha landwirtschaftlich nutzbar sind; die restlichen 4-6 ha sind Hänge oder steiniger Boden. Für eine Forstkultur reicht es nicht, aber er legt Pflanzungen an. Es handelt sich eher um Brennholz (du chêne, du frêne). Der Besitz liegt in Lombia. 


\section{B.2. Vous vous sentez à l'aise dans le domaine de la sylviculture? Vous connaissez (un peu) le métier du forestier?}

\section{Jean T. (EF1):}

Kommentar zur professionellen Beratung der Waldeigentümer: "Très bien, parce que nous répondons à une demande, c'est-à-dire que les propriétaires qui nous téléphonent ou viennent nous voir ou participent aux réunions que nous organisons ou aux stages de formation, sont demandeurs d'un service. Ce service est extrêmement varié puisque [...] ça peut être des renseignements sur les cubages, les plantations [...]" (Z* 01:42); "[...] les relations sont toujours excellentes." ( $Z^{*}$ 02:06); definiert seine Rolle als conseiller und nicht als Aufsichtsperson: "Comme en plus, nous avons un rôle de conseiller forestier et non pas de surveillance de quoi que ce soit, [...], il y a absolument pas de rôle de gendarme [...]" (Z* 02:08); bewertet die Kontakte als sehr zufriedenstellend: "[...] les contacts sont toujours, je le souligne, toujours excellents." ( $\mathrm{Z}^{*}$ 02:19)

\section{Paul A. (EF2):}

fühlt sich vertraut mit dem Gebiet des Waldbaus; beschreibt zwei Typen von forestiers: a. die wenigen, die sehr viel Wald besitzen, b. die Mehrheit der Besitzer, die er als paysans forestiers bezeichnet und denen kleine Waldstücke gehören; erklärt den Unterschied zwischen der sylviculture in den PyrénéesAtlantiques, die auf die Produktion von Wertholz auf kleinen Flächen ausgerichtet ist und der Situation in den Landes: "C'est la grande différence, Monsieur, entre ce type de sylviculture dans les Pyrénées-Atlantiques où le bois du reste pousse très bien et où il y a des essences magnifiques par rapport au département voisin des Landes qui est un pays, disons, où des sylviculteurs forestiers sont de véritables industriels." ( $\left.Z^{*} 02: 56\right)$

\section{Pierre de B. (LF1):}

direkte Beurteilung des Berufs:"Oh, c'est un métier très difficile." ( $Z^{*}$ 04:46); "On ne sait jamais tout." (Z* 04:52); spricht von den Bodenproblemen in der Gegend: "On est sur une rupture, un point de rupture du sol." (Z* 05:07); Nachfrage nach der Bodenqualität: sehr unterschiedlich in der Gegend, aber es handelt sich eher um sauren Boden; erwähnt die canalisation d'eau, die dort angelegt wurde, um die unterschiedliche Bodenbeschaffenheit auf geringem Raum zu demonstrieren; Fazit: Die Reaktion des Probanden, seine spontane freiwillige Stellungnahme zu diesem Metier und zu Problemen, die mit dem Waldbau zusammenhängen, zeigen, wie sehr ihm dieser Bereich vertraut ist. 
Paul D. (LF2):

Seine Eltern waren Landwirte, so dass er die Materie ein bisschen kennt.

\section{B.3. Vous avez des contacts avec des professionnels forestiers?}

Jean T. (EF1):

ist durch seinen Beruf als technicien bedingt ständig in Kontakt mit anderen Leuten, die sich beruflich mit dem Waldbau beschäftigen

Paul A. (EF2):

hat regelmäßigen Kontakt zu Leuten, die sich beruflich mit dem Waldbau beschäftigen; ist Präsident des CETEF und Mitglied des Syndicat des Propriétaires Forestiers Sylviculteurs; gehört bis jetzt noch keiner Kooperative an

\section{Pierre de B. (LF1):}

Er selbst ist Mitglied einer Kooperative, d.h., dass er durchaus in Kontakt zu den professionnels steht; sieht die Leute der Kooperative als sehr kompetent an

Paul D. (LF2):

hat einige Kontakte beruflicher Art mit Herrn T. und Herrn V. vom CRPF; diese techniciens haben ihm geholfen, seine Pflanzung anzulegen. 


\section{Partie C (connaissance du béarnais)}

\section{C.1. Vous parlez béarnais?}

Jean T. (EF1):

Spontanantwort auf Bearnesisch: "un drin" (Z* 02:27), entspricht dem Französischen un peu (Anmerk.: normgemäß wäre nur drin)

Paul A. (EF2):

spricht ein bisschen Bearnesisch, aber nicht fließend; versteht es jedoch weitgehend

\section{Pierre de B. (LF1):}

versteht Bearnesisch, spricht es aber nicht, da seine Mutter die Sprache nicht beherrschte; sein Vater sprach gut Bearnesisch, was er aber mit Rücksicht auf seine Mutter nicht zu Hause anwendete.

Paul D. (LF2):

spricht Bearnesisch, zeigt sich in dieser Sprache teilweise sicherer als im Französischen

\section{C.2. Dans quelles situations est-ce que vous parlez béarnais? Pendant le travail ou à la maison?}

Jean T. (EF1):

In seinem Beruf ist es nicht notwendig, Bearnesisch zu sprechen, aber die Tatsache, dass er Bearnese ist und es versteht, vereinfacht die Beziehungen zu den Eigentümern, die so mehr Vertrauen zu ihm bekommen.

\section{Paul A. (EF2):}

entfällt, da er kaum Bearnesisch spricht

\section{Pierre de B. (LF1):}

bedauert, kein Bearnesisch gelernt zu haben, da sich vieles gut auf Bearnesisch und weniger gut auf Französisch ausdrücken lässt; empfindet das Bearnesische als reicher als das Französische

Paul D. (LF2):

spricht zu Hause mit seiner Frau Bearnesisch, nicht aber mit seinen Kindern, die es wohl verstehen, aber nicht sprechen 


\section{C.3. Vous parlez aussi du bois et des affaires forestières en béarnais?}

Jean T. (EF1):

Die Eigentümer sprechen häufig untereinander Bearnesisch, wenn sie sich kennen und sich zusammen im Wald befinden. In Versammlungen jedoch wird selten Bearnesisch gesprochen, da sich die Leute dort häufig nicht kennen. Wenn die Eigentümer in Gegenwart eines technicien Bearnesisch sprechen, fragen sie oft aus Höflichkeit, ob er sie versteht und es ihn nicht stört.

\section{Paul A. (EF2):}

Die Leute der Region sprechen ein bisschen Bearnesisch. Er kommentiert die Stellung von Dialekten im Allgemeinen (erwähnt das Baskische, das Okzitanische, das Bretonische, das Korsische), die vor allem zu Beginn des Jahrhunderts zurückgedrängt wurden; spricht von der jetzt auftauchenden Tendenz, diese Dialekte erneut zu lernen; bemerkt abschließend zur Rolle des Bearnesischen: "La possession de la langue béarnaise ou basque n'est pas quand même d'une importance capitale pour faire de la forêt ou faire quoi que ce soit dans l'agriculture ou d'autres domaines." (Z* 05:13)

Pierre de B. (LF1):

keine aktiven bearnesischen Sprachkenntnisse vorhanden (s. C.1. und C.2.)

Paul D. (LF2):

Frage auf Bearnesisch gestellt (02:44), kurze Antwort: "Que depènde la persona qu'ei en faça." 


\section{Partie D (Vocabulaire technique et compétences spéciales)}

\section{Peuplements forestiers et arbres}

\section{D.1.a. Ici, en Béarn, on a des peuplements mélangés dans les bois. Quelles sont les essences principales qu'on trouve?}

284: peuplement mélangé / mixte: Peuplement où sont présentes deux ou plusieurs essences. La part totale des essences mélangées est de $\geq 5(10) \%$ de la surface terrière du peuplement.

250: structure / composition / constitution d'un peuplement

Jean T. (EF1):

I-Aufzählung: le chêne, le châtaignier, le hêtre; ensuite: des feuillus divers: du merisier, du noyer, du frêne, de l'érable; parmi les résineux, seuls les sapins et le pin de montagne sont autochtones, le reste est exotique

I-Anzahl: $9(7+2)$

I-Anordnung: nach Wichtigkeitsgrad; eigene Unterteilung vorgenommen: 1., 2., 3. und feuillus divers

I-Komm: verweist, ohne zu präzisieren, auf 3-4 Eichenarten; dokumentiert Fachwissen; gibt Erklärungen für die Anordnung und die Wichtigkeit der einzelnen Hölzer: "Le châtaignier autrefois était très utilisé ici pour des [...] utilisations agricoles ou pastorales." (Z* 04:12); Zusatzinformationen zum Ursprung des châtaignier (" $n$ 'est pas autochtone" $Z^{*}$ 04:33)

D-Verh: zeigt z.T. Unsicherheit: "je crois que c'est le châtaignier" ( $Z^{*}$ 04:09); gibt ausführliche Erläuterungen; pädagogische, verständliche Erklärungen, sehr gegliedert

P: 03:47

Paul A. (EF2):

I-Aufzählung: 1. en montagne: le hêtre; 2 . dans le piémont et dans la région de coteau: le chêne pédonculé; 3. hier, im Béarn: le chêne, le frêne, le hêtre, des résineux (les Douglas de provenance américaine, etc.), die künstlich angepflanzt wurden, aber gut wachsen; le mélèze; les chênes rouges d'Amérique; les tulipiers de Virginie; des merisiers; auf Nachfrage hin: les châtaigniers

I-Anzahl: 12

I-Anordnung: ordnet die verschiedenen Baumarten entsprechend ihres geographischen Vorkommens an: "Ça, ça dépend, Monsieur, de la région dans la- 
quelle vous vous trouvez." ( $\mathrm{Z} *$ 05:36)

I-Komm: sehr systematische Antwort, die eine klare Gliederung aufweist; es wird dem Gesprächspartner leicht gemacht, dem Diskursverlauf zu folgen; erläutert außerdem die generellen klimatischen Bedingungen der Region (05:59); auf Nachfrage hin erläutert er die Wichtigkeit der châtaigniers D-Verh: sehr höflich; ist dazu bereit, viele Informationen zu geben P: 05:25

\section{Pierre de B. (LF1):}

I-Aufzählung: 1. le châtaignier; 2. les chênes (de bordure, wie er sagt)

I-Anzahl: 2

I-Anordnung: chronologische Anordnung der Baumarten: "Bon, ici, donc, c'étaient des châtaigniers, comme je vous ai dit, à l'origine, hein, donc, euh, après, je pense que les chênes sont venus, des chênes de bordure." ( $\mathrm{Z} * 08: 04)$; beurteilt die Qualität der Eichen: "des chênes qui sont, qui ne sont pas beaux" (Z* 08:21) und gibt die Gründe hierfür an: "La génétique n'a pas, n'est pas passée par là et... et c'est très malheureux, bon, en plus, sur ce coin-ci, on a un gros gros inconvénient, la gélivure." ( $Z^{*}$ 08:27)

I-Komm: nennt zwar nur zwei Baumarten, die er aber ausführlich kommentiert; kein quantitativ großer Beitrag, doch man erkennt das Interesse des Probanden und seine Fähigkeit, die Situation einzuschätzen und zu kommentieren P: 07:57

Paul D. (LF2):

I-Aufzählung: 1. le chêne; 2. le hêtre; 3. le frêne

I-Anzahl: 3

I-Anordnung: Der chêne ist für ihn eindeutig die wichtigste Baumart.

I-Kommentar: kommentiert Punkt 1 seiner Aufzählung: Die chênes kommen natürlich vor, ohne dass eine tatsächliche exploitation stattfinden würde, produzieren dann aber schlechtes Holz.

D-Verh: antwortet nicht sehr ausführlich, aber erläutert das für ihn Wesentliche

P: 03:00

\section{D.1.b. Qu'est-ce qu'on entend par 'peuplement dominant'?}

183: peuplement dominant / étage $\sim / \sim$ du peuplement / $\sim$ supérieur / ensemble des arbres dominants. Partie d'un peuplement, (comportant des arbres de même âge) qui est formée des arbres dominants et qui représente la partie la plus haute du couvert. 
277: peuplement principal: Strate du peuplement qui constitue l'essentiel de sa valeur économique et qui - le plus souvent - est représentée par les arbres de l'étage dominant.

\section{Jean T. (EF1):}

I-Def: definiert futaie, taillis, taillis-sous-futaie: "Vous avez la futaie, donc, des arbres issus de graines, de drageons, bon, ce sont des arbres qui ont leur propre souche. Un arbre, une souche. Le taillis, c'est quand quelqu'un avant vous a coupé un arbre de futaie. Et la souche, au lieu de mourir, a rejeté. Elle a fait deux, trois, quatre, parfois dix, douze ou quinze brins. On appelle ça des brins. Vous avez des petits arbres issus de la même souche. C'est comme ça qu'on faisait pour avoir des piquets, c'est comme ça qu'on faisait pour avoir des bûches pour faire du bois de chauffage. Et un système intermédiaire entre les deux consiste à avoir des arbres de futaie, donc des arbres issus de graines, de drageons, donc de gros, parfois de gros arbres, au milieu de taillis. On coupait autrefois des taillis pour avoir du bois de feu, des piquets, on laissait quelques arbres au milieu pour avoir des arbres dont on fait des meubles, du bois d'œuvre, pour la maison, pour la grange, pour, pour faire des planches ou des meubles. Ce système intermédiaire s'appelle taillis-sous-futaie." (Z* 05:22)

I-Org: 1. Definition des Begriffs; 2. Untergliederung in verschiedene Arten von peuplement: a. la futaie, b. le taillis, c. le taillis-sous-futaie; 3. zusammenfassende Definition

I-Def. Def. korrespondiert nur teilweise mit der im Lexicon Silvestre existierenden Def.: seine Def.: "la façon dont s'agencent les arbres entre eux, un peu leur origine" ( $Z^{*}$ 05:17), "Le peuplement dominant, c'est un peuplement dans un endroit donné, un département, une, une région, une commune, une propriété est le peuplement qui au niveau de la surface est le plus important." ( $\mathrm{Z}^{*}$ $06: 13)$

I-Komm: gibt fundierte Erklärungen der Fachbegriffe, jedoch mit anderer aspektueller Schwerpunktsetzung als im Lexicon Silvestre; klare, verständliche Diskursführung

S-lex: viele Fachbegriffe, (zu finden im Lexicon Silvestre - z.B. taillis-sousfutaie '239), die 'pädagogisch' eingesetzt werden; gute Erklärungen

D-Verh: große Sicherheit in der Erklärung

P: 05:10, L: 01:23

Paul A. (EF2):

Kenntn.d.Begr.: kennt den Begriff: "C'est un terme courant." ( $Z * 08: 05)$ 
I-Def: gibt Definition des peuplement dominant: "Un peuplement dominant, c'est qu'il soit naturel ou artificiel, disons que c'est l'essence qui est la plus que l'on trouve disons en nombre et en hectare, disons, dans la région." (Z* 08:08)

I-Org: antwortet nur mit einem Satz

I-Komm: kurzer, einfacher Beitrag

S: Satz ist grammatisch nicht ganz korrekt $-\mathrm{s}$. Zitat 08:08

P: 07:57, L: 02:32

\section{Pierre de B. (LF1):}

I-Def: "Ah, le peuplement dominant, c'est le peuplement de variété, la variété qui est dominante, [...]" (Z*08:51)

I-Org: 1. Definition, Präzisierung: in dieser Region zählen die Eichen zum peuplement dominant; 2. lenkt die Antwort auf seine persönlichen Erfahrungen D-Biogr: Verweis auf seine persönlichen Verfahrensweisen: "Et alors, après, moi, j'ai, mon père et moi, nous avons planté, euh, semé ou planté un peu de résineux, pour voir ce qu'il y a." (Z* 09:01); verweist auf die Allee der résineux, die nahe bei seinem Haus liegt, und die sein Großvater gepflanzt hat; direkter Bezug auf seine Biographie: Da sein Großvater früh gestorben ist und keine Dokumente hinterlassen hat, wusste man nicht, um welche Arten von résineux es sich handelt. (09:26)

D-Verh: Der Proband beweist seine persönliche Eingebundenheit in das Thema, z.B. ehrliches Bedauern darüber, dass keine Dokumente mehr vorliegen zu den Anpflanzungen seines Großvaters (s. D-Biogr 09:26). Man spürt den engen Bezug, den er zum Waldbau hat und der auch in seiner Familiengeschichte begründet liegt (s. Verweis auf seinen Großvater D-Biogr). Tiefergehendes Interesse, das sich auch auf den Ursprung der Anpflanzungen bezieht: "On sait ce que c'est, si vous voulez, mais on ne sait pas les origines." ( $\left.Z^{*} 09: 48\right)$

P: 08:46, L: 00:49

\section{Paul D. (LF2):}

I-Def: gibt keine Definition

I-Org: 1. in den Landes handelt es sich um die pins; hier sind es die chênes (03:42); (Verweis darauf, dass sie nicht gut genutzt werden)

I-Komm: keine Definition des Begriffs und kein konkretes Eingehen auf die Fragestellung

D-Verh: scheint das Gesagte mit seiner Gestik zu untermalen (Klopfen auf den Tisch): "c était tout comme ça, quoi" (Z* 03:47)

P: 03:30, L: 00:30 


\section{D.1.c. Vous connaissez la notion de 'sous-étage'?}

184: sous-étage / strate inférieure / étage $\sim / \sim$ dominé. Partie du peuplement constituée par les arbres dont les houppiers ne participent pas à la voûte foliaire des arbres dominants ni de l'étage intermédiaire.

185: sous-étage / peuplement secondaire. Partie d'un peuplement à deux ou plusieurs étages constituant la voûte foliaire inférieure.

187: sous-bois / sous-étage / brousse de sous-étage [+]. Jeunes arbres et/ou arbustes croissant sous le couvert d'un peuplement.

\section{Jean T. (EF1):}

I-Kenntn.d.Begr.: kennt den Begriff: "Bien entendu." (Z* 06:27)

I-Alternativ: kein Alternativvorschlag, da Kenntnis des Begriffs; Erwähnung des Terminus sous-bois: auf Nachfrage Def. des Begriffs: "C'est beaucoup plus vaste. Le sous-bois, c'est tout ce qu'on voit de l'étage zéro, donc de zéro centimètre à l'étage dominant." ( $\left.Z^{*} 08: 40\right)$, sous-étage im Terminus sous-bois eingeschlossen

I-Org: 1. Def. des Begriffs: "Le sous-étage, c'est un, c'est un ensemble de végétaux qui n'ont pas leur part de soleil au niveau dominant." ( $Z^{*}$ 06:29); 2. differenziert verschiedene étages: étage dominant-étage dominé-sous-étage I-Beurteilg: sous-étage als wichtig beurteilt (07:26); Leute kennen sous-bois, aber nicht sous-étage

I-Komm: Erklärungen der Fachtermini, aber auch Beurteilung; spricht ökologische Kriterien an: Erhaltung der die sous-étage konstituierenden Bäume ist wichtig, da sie die Stämme der großen Bäume schützen und im sous-bois das Wachstum der Schädlinge, wie der ronce, der fougère verhindern; außerdem sind die Bäume, meistens Obstbäume, von Bedeutung für die Fauna: Lebensraum für Vögel, die die Früchte fressen, aber auch für andere Tiere

S-lex: Einführung neuer Fachtermini mit Erklärung, z.B. strate ligneuse

D-Biogr: verweist auf seinen Berufsstand: "pour nous forestiers" ( $Z^{*}$ 07:30)

D-Verh: Sicherheit; direkte Beurteilung des Begriffs: "très importante" (Z* 06:28)

P: 06:24, L: 01:14

\section{Paul A. (EF2):}

I-Kenntn.d.Begr.: kennt den Begriff, ohne ihn genau beschreiben zu könnenvor allem in den Bergen benutzt

I-Alternativ: vom Fragesteller eingebrachter Begriff: sous-bois, der bekannt 
ist: "C'est la végétation, disons, qui est au pied des arbres. Alors, un sous-bois peut être composé de végétaux inutiles, nuisibles, comme des ronces ou des fougères. Mais un sous-bois peut être composé aussi de nouvelles petites tiges, qui est de la régénération naturelle. Tout ça, c'est le sous-bois." (Z* 08:59)

I-Komm: kennt zwar den eigentlich gefragten Terminus sous-étage nicht, gibt dafür aber auf Nachfrage hin eine einfache, verständliche Def. von sous-bois; Kenntnis anderer Schädlinge (fougère, ronce)

P: 08:30, L: 00:33

\section{Pierre de B. (LF1):}

I-Kennt.d.Begr.: kennt den Begriff sous-étage

I-Org: 1. spontane Antwort auf die Frage: stellt direkt den regionalen Bezug her: "Ici, il y en a trois, au minimum." (Z* 09:57); 2. erklärt diese Etagen auf Nachfrage hin: a. le chêne, b. les abrisseaux (le noisetier), c. la fougère, l'herbe, fügt noch la ronce hinzu; 3 . Nachfrage nach sous-bois: für ihn sind es la ronce und la fougère

I-Komm: keine allgemeine Definition des Begriffs, sondern direkter regionaler Bezug

D-Verh: Der Proband macht einen sehr entspannten Eindruck. (z.B. Lachen nach der Beantwortung der Frage s. 09:57); er scheint gerne zu antworten P: 09:52, L: 01:06

Paul D. (LF2):

I-Kenntn.d.Begr.: kennt den Terminus sous-étage nicht

I-Alternativ: Nachfrage nach sous-bois: Dieser Terminus ist bekannt.

I-Def: "C'est ni taillis, ni bois de futaie." (Z* 04:11)

P: 03:57, L: 00:27

\section{D.1.d. Vous pouvez commenter l'aspect de la densité d'un peuplement? C'est bon pour un arbre, la position en lisière?}

259: densité du peuplement. Qualité d'un peuplement caractérisée par le nombre d'arbres, la surface terrière, ou le volume du peuplement forestier rapportés dans chaque cas à l'ha.

227: position en lisière. Position des arbres sur la limite extérieure de la bande de régénération (dans le système des coupes progressives en bandes) avec lisière plus ou moins éclaircie.

298: lisière / du peuplement / bord de la forêt / bordure de bois. Bande au bord d'un peuplement d'âge mûr pouvant être utilisée pour les besoins de la sylviculture, de la protection ou pour faciliter la récolte. 


\section{Jean T. (EF1):}

I-Beurteilg: betrachtet diesen Aspekt als sehr wichtig und begründet: "La grosseur d'un arbre dépend de la densité." ( $Z *$ 09:13)

I-Org: 1. Beurteilung; 2. Erklärung der zwei Hauptprinzipien: "Donc, les deux principes que je dis fondamentaux de la sylviculture sont les suivants: la hauteur d'un arbre dépend de la fertilité de la station, donc de la richesse, plus un sol est fertile, plus l'arbre deviendra haut. Il suffit pour ça de voir un peuplier de la vallée de la Garonne et la hauteur qu'il a, comparé à un pin qu'on trouve à côté du [?] qui lui a, aura peut-être six cents ans, mais il fera deux, trois mètres de haut, donc, hauteur d'un arbre-fertilité de la station. Par contre, la grosseur dépend de la densité. S'il a des copains tout autour qui lui prennent la, le soleil, et qui empêchent sa photosynthèse, il va monter, cet arbre, parce qu'il aura la richesse du sol, mais il ne pourra pas grossir, parce qu'ils seront trop nombreux." (Z* 09:26)

D-Biogr: Verweis auf seinen Beruf "pour nous forestiers" (Z* 09:10)

D-Bsp: belegt das erste Hauptprinzip mit Beispielen (s. unter I-Org, 09:26)

D-Verh: gibt sich sehr sicher: "Ça, c'est très facile!" (Z* 09:08); schematisiertpädagogische Erklärung; spricht das Grundprinzip eines conseiller forestier aus: "Un conseiller forestier doit toujours adopter un langage simple pour être compris de l'interlocuteur qui souvent n'a aucune notion forestière." $(\mathrm{Z} * 09: 20)$

P: 09:04, L: 02:40

I-Beurteilg: position en lisière ist nicht gut für einen Baum!

I-Org: differenziert die Beurteilung: 1. für die Biologie des Baums; 2. für die biodiversité; 3. für den forestier

D-Verh: unterstreicht seine Rolle als forestier: "pour nous forestiers" (Z* 11:09)

P: 10:35, L: 01:31

\section{Paul A. (EF2):}

I-Antw: "Ça alors, la densité, c'est excessivement variable." (Z* 09:39)

I-Org: 1. kurze Antwort (s.o.); 2. nimmt Unterscheidung vor zwischen: a. peuplements artificiels (Erklärung) und b. parcelles plus naturelles (Erklärung), für die der Aspekt der densité eine unterschiedliche Bedeutung hat I-Komm: unter Punkt 2 gleichzeitige Definition eines peuplement, die übereinstimmt mit der im Lexicon Silvestre unter ' 175 angegebenen Def. des peuplement forestier; korrekte, ausführliche Antwort, bei der sein Fachwissen erkennbar ist

S-lex: Gebrauch von Fachtermini 
D-Bsp: gibt ein Beispiel an für die Eichen (10:50), um seine Erklärung zu konkretisieren

D-Verh: denkt sich hier wirklich in die Materie ein und scheint offener zu sein (im Vergleich zu den vorherigen Fragen)

P: 09:27, L: 00:57

Frage nach der position en lisière nicht gestellt

\section{Pierre de B. (LF1):}

I-Antw: "Non, non, ici justement, on a des bois qui sont, j'allais dire, de mauvaise venue." ( $\left.Z^{*} 10: 46\right)$

I-Org: 1. spontane Antwort; 2. Erklärung der Antwort: zu große Dichte; Grund dafür: "Et comme il y avait de la ... euh, du châtaignier autrefois, et les bois sont,... euh, sont venus naturels, et n'ont pas été resemés, replantés, alors on a souvent une densité un peu trop forte. Comme ce sont pas des bois de valeur, souvent, ils n'ont pas été éclaircis et il fallait, comme il fallait et c'est un inconvénient." ( $Z * 10: 55)$; durch den Verkauf wird nicht so viel eingenommen, wie nötig wäre, um eine neue Anpflanzung anlegen zu können; 3. Vorschlag zur Verbesserung der Qualität des Holzes: "Alors, pour bien faire, il faudrait couper... et et replanter, ce que peut faire l'administration, ce que peut faire difficilement un particulier." ( $\left.Z^{*} 11: 30\right)$

I-Komm: erklärt nicht nur neutral die Situation in seiner Gegend, sondern nimmt Stelllung (s. I-Org 10:46, 10:55), äußert Verbesserungsvorschläge und erklärt die Schwierigkeiten (s. I-Org 11:30)

D-Verh: scheint sich vom Waldbau tatsächlich betroffen zu fühlen; kennt innere Zusammenhänge, z.B. die Tatsache, dass nicht die Eigentümer radikale Maßnahmen vornehmen können, wie er sie unter I-Org 11:30 beschreibt P: 10:35, L: 00:43

I-Antw: "C'est bon pour l'esthétique." (Z* 11:51), "Au point de vue forestier, certainement pas, hein." ( $Z^{*}$ 11:57); Nachfrage zum Grund: "Parce qu'ils vont, ils vont fabriquer des branches sur les côtés,... ils vont aller vers la lumière." (Z* 12:02)

I-Komm: Obwohl es sich nicht um eine lange Antwort handelt, werden doch zwei wichtige Gesichtspunkte einander gegenübergestellt: l'esthétique, le point de vue forestier.

D-Verh: sehr entspannt, humorvoll; schafft eine gelöste Gesprächsatmosphäre P: 11:43, L: 01:08

Paul D. (LF2):

I-Beurteilg: Baumbestand ist zu dicht und nicht ausreichend dicht: "trop et pas 
$\operatorname{assez}^{\prime \prime}\left(\mathrm{Z}^{*}\right.$ 04:28)

I-Org: 1. Beurteilung; 2. Erklärung der Aspekte trop dense und pas assez dense: a. trop dense: "Ça monte pas, ça monte, mais ça reste, puis ça s'étouffe." (Z* 04:32), b. pas assez dense: "[...] Du bois d'œuvre, il y en a pas." (Z* $04: 40)$

I-Komm: erklärt zwei kontradiktorische Aspekte bezüglich der densité d'un peuplement, aus denen sich jeweils Probleme ergeben.

D-Bsp: gibt als Beispiel für mögliche Probleme eine große Kältewelle im Jahre '56 an, bei der fast alle Bäume erfroren sind (04:47); der Bezug zwischen der Antwort und dem Beispiel ist nicht ganz eindeutig (vermutlich die Tatsache, dass bei der Kältewelle zuviel Wertholz abgestorben ist).

P: 04:19, L: 00:22

I-Beurteilg: beurteilt die position en lisière als positiv, da der Baum mehr Licht erhält

I-Komm: Die Beurteilung des Probanden, der sich hauptsächlich privat mit dem Waldbau auseinandersetzt, setzt sich stark von der eines Fachmannes ab (s. Touyarou).

P: 04:57, L: 00:38

\section{D.1.e. Vous pouvez me dire comment on fait l'estimation d'un peuple- ment?}

76: estimation de peuplements / sur pied / inventaire d'un peuplement. Estimation en volume (et en valeur) du capital ligneux des peuplements forestiers.

Frage nicht gestellt, da die kommerzielle Beurteilung ganzer Bestände nicht im Erfahrungsbereich der privaten Waldbesitzer im Béarn liegt. Die zu erwartenden Antworten wären daher ein Vorgriff auf die Fragen D.1.g. und D.5.a. gewesen.

\section{D.1.f. Vous avez déjà entendu parler de la 'surface terrière'? (Est-il vrai que cette notion s'applique tant au peuplement qu'à l'arbre seul?) Qu'est-ce que c'est, la surface terrière d'un arbre?}

748: surface terrière du peuplement / unitaire du peuplement. La somme des surfaces terrières des individus d'un peuplement (exprimée en m5 par ha).

746: surface terrière / de l'arbre / de la section transversale / à 


\section{Jean T. (EF1):}

$1,30 \mathrm{~m}$. Surface de coupe transversale du fût à hauteur de poitrine.

I-Def: erklärt kurz den Terminus: "Pour moi, c'est, surface terrière, c'est la, c'est une, c'est un terme qui ehm, qui réunit la surface de tous les arbres si on les coupait à une certaine hauteur. D'accord, surface terrière, c'est la surface de, de ces arbres-là." (Z* 11:47)

I-Org: 1. Def.; 2. Beurteilung des Begriffs: unterscheidet zwischen a. Wichtigkeit des Begriffs für die techniciens und $\mathrm{b}$. Kompliziertheit des Begriffs für die propriétaires; Begriff wird wegen seiner Kompliziertheit nicht in den Versammlungen gebraucht, ebenso wie die facteurs d'espacement, die zu technisch sind und nur unter techniciens Verwendung finden

I-Komm: Schwerpunkt auf Erklärung des unterschiedlichen Gebrauchs der termes techniques je nach Gesprächspartner (techniciens-propriétaires)

D-Biogr: stellt sich wieder auf die Seite der techniciens; definiert genau die unterschiedlichen Rollen techniciens-propriétaires

P: 11:44, L: 01:09

\section{Paul A. (EF2):}

Kenntn.d.Begr.: Der Proband kennt den Begriff nicht, weshalb die Frage nicht weiter behandelt wird.

P: 11:01, L: 01:34

\section{Pierre de B. (LF1):}

I-Kenntn.d.Begr.: fragt zunächst nach, kennt den Terminus aber nicht I-Org: Nachdem der Fragesteller auf Nachfrage des Probanden hin die Definition gegeben hat, äußert sich dieser zum Gesagten, wobei aber schnell auf die nächste Frage übergelenkt wird: "Quand on mesure, on a décidé qu'un jour... qu'on mesurait des arbres à 1 m30 de diamètre." ( $\mathrm{Z} * 12: 55)$

D-Verh: zeigt Interesse an dem Begriff und fragt nach, um was es sich dabei handelt; diese Nachfrage zeigt sein grundsätzliches Interesse an dem Gebiet und seine Aufgeschlossenheit.

P: 12:10, L: 00:27

\section{Paul D. (LF2):}

I-Kenntn.d.Begr.: kennt den Begriff nicht, obwohl er trotzdem eine Antwort versucht

I-Komm: Versuch einer inhaltlichen Zuordnung: "C'est la nature du sol, ça?" (Z* 05:27), liegt jedoch mit seiner Antwort nicht richtig

D-Verh: erbittet eine Präzisierung der Frage: "Pour la plantation?" ( $Z^{*}$ 05:20)

- es geht um ein peuplement

P: 05:09, L: 00:12 


\section{D.1.g. Quels sont les critères pour la valorisation d'un arbre? Vous connaissez le système de calcul? Vous avez déjà entendu parler de la tolérance d'écorce / la défal- cation de l'écorce?}

751: classe de hauteur. Catégorie de classification selon hauteur totale d'un arbre, particulièrement pour les peuplements hétérogènes et inequiennes [sic!].

738: classe de grandeur / dimension / catégorie de grandeur / dimension. Unité de classement selon grandeur, p.ex. hauteur de l'arbre, diamètre à hauteur de poitrine.

742: classe de diamètre / de grosseur / catégorie $\sim$. Intervalle retenu pour la classification des diamètres des fûts et des grumes en réunissant des diamètres voisins dans une même classe.

755: coefficient de forme / biaisé / artificiel / de l'arbre / 1 ' total. Rapport entre le volume d'un arbre, par ex. le bois fort, le bois de fût, et le volume d'un cylindre calculé par la surface terrière et la hauteur de l'arbre.

734: mètre-cube / - réel / / réel / volume réel. Unité de volume correspondant à un mètre-cube de la substance bois.

735: mètre-cube récolté / réel / volume récolté / réel / abattu / stère / unité de volume apparent d'1 x 1 x $1 \mathrm{~m}$ de bois empilé / volume réel de récolte après façonnage. Unité de volume. Mesure de volume en mètre cube de la quantité de bois réellement récoltée.

736: mètre-cube sur pied / volume sur pied / mètre-cube de volume sur pied / $\sim \sim$ au tarif. Volume réel de capital ligneux, en général de bois fort.

763: barème de cubage pour arbres abattus / [FRA] / tarif $\sim \sim / \sim \sim \sim$ des bois abattus / table $\sim$ [CHE]. Tarif donnant le volume (en mètres cubes) des bois façonnés (grumes et billes) d'après le diamètre au milieu et la longueur.

753: défalcation de l'écorce / déduction en volume pour l'écorce / tolérance d'écorce / déduction d' . Défalcation de volume exprimée en pour-cent pour la conversion du volume de bois avec écorce en volume sans écorce.

Jean T. (EF1):

I-Org: 1. Nachfrage zum Terminus, Präzisierung; 2. Angabe verschiedener Kriterien zur valorisation (insgesamt 4: a. essence précieuse, b. bonne santé, c. bien conformé, d. situé dans un peuplement améliorable); 3. Beurteilung der 
valorisation: Hinweis auf die Komplexität und die daraus resultierenden Probleme für die forestiers: Feststellen des Problems / Diagnose, wenn die Eigentümer sich an sie wenden

I-Komm: zeigt präzises Fachwissen kombiniert mit übersichtlicher Diskursorganisation

P: 12:37, L: 00:53

I-Org: gibt die Kriterien an und erklärt sie: a. circonférence, b. hauteur, c. intérieur de cubage (14:14)

S-lex: Definition der Fachtermini; bearnesischer Ausdruck, der im Zusammenhang mit der valorisation d'un arbre benutzt wird: "a vista de nas, com disem a noste en biarnés" ( $\mathrm{Z} * 14: 30)$

P: 14:06, L: 01:31

I-Def: vereinfacht den Begriff: "c'est une certaine épaisseur d'écorce" (Z* 15:22)

I-Org: 1. Vergleich heute verwendete Methode - frühere Methode: a. le cubage au réel u. Erklärung, b. le cubage au quart ou au cinquième und Erklärung I-Komm: erklärt verschiedene Methoden und beurteilt sie: "Par rapport au cubage réel, le cubage au quart ou au cinquième étaient des cubages nettement inférieurs." ( $\mathrm{Z*}$ 15:57)

D-Bsp: "je pense au chêne notamment" ( $\left.Z^{*} 16: 09\right)$, "comme le hêtre" (Z* 16:13)

P: 15:14, L: 01:08

\section{Paul A. (EF2):}

I-Org: 1. Nennung der wichtigen Kriterien: a."la rapidité avec laquelle il va être à complet développement" (11:23), b."la qualité de son bois", c."la manière dont il crôtt"; 2. auf Nachfrage hin: Ergänzung der schon genannten Kriterien: a. le diamètre, b. le port de l'arbre

I-Komm: gut gegliederte Antwort, die viele Erläuterungen enthält

D-Bsp: 12:03: gibt zur Verdeutlichung des Gesagten Beispiele an für Punkt 2b

D-Verh: nimmt einleitend einen Teil der Frage wieder auf: "Les critères pour la valorisation d'un arbre" (Z* 11:15)

P: 11:10, L: 00:09

I-Antw: kannte das Verfahren, müsste sich jetzt allerdings neu einarbeiten; Verweis auf Handbücher als theoretische Grundlage und auf die techniciens: "Mais disons, pour être tout à fait honnête, qu'en général, le sylviculteur ne le connaît pas et fait venir un expert." (Z* 12:43)

I-Komm: keine Erklärung des Systems: gibt ehrlich die Grenzen seines Wissens zu und verweist auf Hilfsmittel, die man zu Rate ziehen kann 
D-Biogr: antwortet für sich persönlich: "Oui, je l'ai connu, mais je le, actuellement, il faudrait que je le retravaille." ( $\left.\mathrm{Z}^{*} 12: 28\right)$

D-Verh: steht zu dem Wissen, das er besitzt und schämt sich nicht seiner Grenzen

P: 12:24, L: 01:14

Frage nicht gestellt

\section{Pierre de B. (LF1):}

I-Aufzählung: la circonférence / le diamètre, la hauteur; danach erst: la qualité (apparente)

I-Org: 1. Aufzählung; 2. Nachfrage zur Maßeinheit (mètre-cube)-wird vom Probanden bestätigt

P: 13:31, L: 00:25

I-Antw: kennt das système de calcul: "A 1 m30 et puis alors, euh, après, on a des tables." (Z* 13:11), "On peut prendre la circonférence ou le diamètre,... suivant les tables que l'on a... qu'on se servait et et puis, on estime la hauteur,... ce qui est le plus difficile... à estimer." ( $\left.Z^{*} 13: 17\right)$

I-Komm: keine sehr technische Erklärung des système de calcul, aber man erkennt, dass sich der Proband damit in der Praxis auskennt

S: falscher relativischer Anschluss (s. I-Antw: "qu'on se servait" 13:17)

P: 13:06 (Frage zuerst gestellt, da sie sich aus dem Gesprächskontext ergab),

L: $00: 54$

I-Kenntn.d.Begr.: kennt den Begriff

I-Antw: "Ça, ça dépend des, des variétés. Il faut calculer l'écorce plus ou moins grosse." ( $Z *$ 14:01)

D-Bsp: verdeutlicht das Gesagte an einem Beispiel zweier Baumarten: séquoia und hêtre (14:05)

P: 13:57, L: 00:26

Paul D. (LF2):

I-Org: 1. Bitte um Präzisierung; 2. Beurteilung

I-Beurteilg: "Il n'est pas exploité. Alors, les arbres poussent mal." (Z* 06:06); es gibt keinen Wald mit sehr schönen Bäumen.

D-Verh: erkundigt sich erneut nach der Frage: "Comment ça, pour la vente?" (Z* 05:48)

P: 05:42, L: 00:31

I-Org: 1. gibt an, das système de calcul zu kennen, ohne jedoch konkret darauf 
einzugehen; 2. klagt erneut über die schlechte Qualität der Bäume; es gibt nur bois de charpente; 3. Hinweis auf die Konsequenzen der umfangreicheren déboisements, die zwischen ' 45 und '60/'70 stattgefunden haben: "Ils ont mis tout ça en culture. [...] Ce qui est resté, c'est des pentes comme ça, mais elles n'ont jamais été... bien travaillées, euh, il y a pas eu de coupes [...] ça monte comme ça." (Z*07:08)

I-Komm: geht nicht direkt auf die Frage ein, sondern nimmt sie zum Anlass, Kritik auszusprechen und auf Probleme hinzuweisen

D-Verh: umgeht eine präzise Antwort und erläutert die Probleme, die es bezüglich des Waldbaus in der Region gibt

P: 06:22, L: 00:40

Frage nach der défalcation de l'écorce nicht gestellt

\section{D.1.h. Qu'est-ce que c'est, la dendrométrie / qu'un dendromètre?}

739: dendrométrie. Science qui a pour des arbres sur pied ou abattus, des différentes parties de l'arbre et de peuplement forestiers. [sic!] Dt.: Lehre von den Messmethoden an stehenden und liegenden Bäumen bzw. Baumteilen sowie an Beständen

Jean T. (EF1):

I-Antw: erklärt Herkunft des Begriffs dendromètre: aus dem Griechischen dendros

I-Beurteilg: "les derniers sont très sophistiqués" ( $\mathrm{Z} * 16: 38)$

I-Def: erklärt die Funktion des Geräts: "permet à distance de mesurer la hauteur d'un arbre" (Z* 16:40)

I-Komm: wiederholt am Ende der Erklärungen nochmals wortgleich seine erste Definition: "C'est ce qui permet à distance de mesurer la hauteur d'un arbre." ( $Z^{*}$ 16:55); man spürt seine Bemühung um Deutlichkeit und seine pädagogische 'Ader'

S-lex: la hauteur totale d'un arbre, la hauteur marchande, la hauteur d'une bille, la hauteur d'une surbille, la hauteur d'une fourche

P: 16:28, L: 01:14

\section{Paul A. (EF2):}

I-Antw: hat dieses Instrument bereits gesehen, könnte es jedoch nicht beschreiben

I-Komm: Frage mit einem Satz beantwortet

D-Verh: zeigt ein sehr natürliches, lockeres Verhalten; antwortet sehr gelöst 
und spricht offen aus, dass er die Frage nicht beantworten kann P: 12:57, L: 00:33

\section{Pierre de B. (LF1):}

I-Antw: kennt diesen Gegenstand nicht; als er erklärt wird, sagt er: "Ah oui, mais je m'en suis jamais servi." (Z* 14:19).

I-Komm: Gegenstand ist dem Probanden nicht bekannt, was er indirekt damit begründet, dass er ihn nie benutzt hat - wegen fehlender Praxisbezogenheit kann der Terminus nicht erklärt werden

P: 14:12, L: 00:15

Paul D. (LF2):

I-Kenntn.d.Begr.: kennt den Terminus dendromètre nicht P: 07:30, L: 01:08

\section{Parties et structure de l'arbre}

\section{D.2.a. Parlons un peu des différentes parties de l'arbre. Chaque arbre a bien sûr un tronc. Vous pensez que 'fût' et 'tige' signifient la même chose que 'tronc'?}

84: fût / tige / tronc. Partie de l'arbre s'élevant au dessus du sol en forme de colonne jusqu'à la cime ou la fourche, c.-à-d. jusqu'à la hauteur où deux ou plusieurs branches, sensiblement de même grosseur, se sont formées.

Jean T. (EF1):

I-Def: "La tige, c'est ce qui supporte les branches. Le tronc, c'est la partie commercialisable. Le tronc s'arrêtera à une hauteur inférieure par rapport à la tige." (Z* 17:25); Nachfrage nach dem Begriff fût, Antwort: "La partie sans branches." ( $Z *$ 17:39)

I-Org: 1. Def. tige, Def. tronc, auf Nachfrage hin Def. fût; 2. nach Zögern Erklärung von bille und surbille im Gegensatz zu tronc

D-Verh: zu Beginn etwas zögerlich, unsicher, nicht ausführlich, vor allem im Vergleich zum restlichen Gesprächsverhalten, was er jedoch auch offen zugibt: "Honnêtement et entre nous, que ça soit pas reporté ailleurs, je n'en suis pas sûr." $\left(Z^{*} 17: 44\right)^{184}$

P: 17:12, L: 00:44

${ }^{184}$ Les doutes émis par Monsieur Touyarou étaient justifiés: ne l'ai-je pas 'trahi'? Mais que Monsieur Touyarou ne m'en tienne pas rigueur: la Science reste confidentielle... 
Paul A. (EF2):

I-Def: "Non, le tronc, je pense, c'est une donnée beaucoup plus générale. Tandis que fût et tige sont plus, c'est plus précis. C'est surtout du fût, je pense, qu'on tirera par exemple les, euh, les pièces nobles, la tige étant l'ensemble de, de l'arbre. Le tronc, c'est un peu général, c'est." (Z* 13:24)

I-Org: 1. Def. tronc; 2. zusammengefasste Definition von fût und tige; 3. abschließende Bemerkung zu tronc

D-Biogr: greift auf sein Wissen zurück und gliedert sich hier nicht in den Stand der sylviculteurs allgemein ein: "En fait, selon moi, je sais pas si c'est la bonne définition." (Z* 13:47)

D-Verh: keine absolute Sicherheit bezüglich der Begriffe, vor allem des Begriffs tronc

P: 13:11, L: 00:14

\section{Pierre de B. (LF1):}

I-Def: "La, la tige, c'est quand il est jeune, le tronc, c'est quand il est ancien, quoi, quoi, il est exploitable, quoi." (Z* 14:32)

I-Org: 1. Definition; 2. Nachfrage nach dem Unterschied zwischen fût und tronc: "Quand vous avez un arbre qui est gros, c'est une tige, mais on dirait un tronc... hein." ( $\left.Z^{*} 14: 48\right)$; "La tige, c'est un arbre qui est mince encore, qui qui est jeune, quoi." (Z* 14:54); 3. Nachfrage, ob fût und tronc synonym seien: "Le fût, oui,... c'est la même chose, c'est..." (Z* 14:59)

I-Komm: keine sehr konkreten Stellungnahmen, keine strukturierte Antwort P: 14:23, L: 00:11

Paul D. (LF2):

I-Def: "Il y a trois parties. Il y a la première jusqu'au premier noud." ( $Z^{*}$ 07:52), "Ça, c'est le premier tronc. Celui-là, c'est le meilleur." (Z* 07:58), "Après, c'est la charpente, le deuxième, et après, des traverses de chemin de fer et puis le bois de chauffage." ( $\left.\mathrm{Z}^{*} 08: 03\right)$

I-Org: 1. Differenzierung der drei Teile eines Baumstammes unter dem Gesichtspunkt der Verwertbarkeit des Holzes: a. le premier tronc-gibt eine Beurteilung: "Celui-là, c'est le meilleur." (Z* 08:01), b. la charpente, c. des traverses de chemin de fer; 2. Nachfrage nach la tige: Antwort: "C'est tout l'arbre." (Z* 08:37)

I-Komm: Fragesteller schwenkt am Ende der Diskussion dieser Frage auf das Bearnesische um, was der Proband sofort annimmt (08:45), antwortet spontan mit: "lo casso", bestätigt tronc und cama

D-Verh: etwas zögerlich, antwortet auf Nachfrage hin, z.B. Antwort (07:58) nur auf konkrete Nachfrage hin

P: 07:42, L: 00:12 


\section{D.2.b. Est-ce que la souche fait partie du fût ou des racines?}

78: souche. Souche d'arbre, y compris l'ensemble des racines.

\section{Jean T. (EF1):}

I-Antw: rechnet souche zu den Wurzeln

I-Komm: gibt Antwort, die er dann präzisiert für den Fall des noyer, wodurch er seiner zwischenzeitlichen Unsicherheit entkommt; er führt diesen Fall aus und umgeht sozusagen das Gebiet seiner eigenen Unsicherheit; gewinnt dann wieder die gewohnte Sicherheit zurück: Erklärung dafür, dass souche zu den Wurzeln gerechnet wird

D-Biogr: gibt persönliche Antwort, als er nicht mehr ganz sicher ist

D-Verh: gibt zu Beginn entschiedene Antwort: "La souche, c'est justement la partie intermédiaire." ( $Z^{*}$ 18:11), über die er dann im Nachhinein nachdenkt, sie im Endeffekt jedoch bestätigt-allerdings auf persönlicher Ebene (er nimmt sich etwas zurück): "Moi, je la mets toujours du côté des racines." (Z* 18:18)

P: 18:06, L: 00:54

Paul A. (EF2):

Frage versehentlich nicht gestellt

Pierre de B. (LF1):

I-Antw: "La souche fait surtout partie des racines." ( $Z * 15: 08)$

I-Komm: keine Diskussion, nur sehr kurze Antwort

P: 15:04, L: 00:41

Paul D. (LF2):

I-Antw: souche ist für ihn eher ein Bestandteil der Wurzeln

I-Komm: sehr kurze, keinen ganzen Satz umfassende Antwort

P: 09:02, L: 01:20

\section{D.2.c. Vous connaissez la différence entre 'racine pivotante' et 'plateau racinaire'? Vous savez que les arbres d'ici ont des racines diffé- rentes?}

79: racine pivotante / principale / pivot. Racine principale, comme celle formée par les Pinus sylvestris L. et les Quercus L. 
80: plateau racinaire / racines superficielles / souche-plateau. Ensemble des racines, en forme d'assiette, tel que le développe la majorité des essences sur les sols de faible profondeur.

309: surface de sol sous le houppier / plaque circulaire entourant le pied d'un arbre. Surface de sol sous le houppier d'un vieil arbre, offrant des conditions écologiques défavorables à l'installation de semis naturels.

\section{Jean T. (EF1):}

I-Org: 1. chêne: racine pivotante; 2. hêtre: enracinement traçant; 3 . geht sofort zur abstrakteren, allgemeinen Ebene über: Erklärung der essence pivotante und der essence à racinement traçant; 4 . Baumarten, die mehr oder weniger windanfällig sind - Erklärung auf Nachfrage hin; 5. andere Faktoren, die für die Windanfälligkeit eine Rolle spielen; Anführung anderer Baumarten in anderen Regionen

I-Beurteilg: beurteilt die verschiedenen Wurzelstämme und gleichzeitig die allgemein vorliegende Auffassung zu diesem Thema

I-Komm: wird sofort konkret, was eventuell jedoch durch die direkte präzise Nachfrage bedingt ist

S-lex: führt neue Fachtermini ein und erklärt sie

D-Bsp: fängt direkt mit Beispielen an; bei der Erklärung der Windanfälligkeit: Angabe von Beispielen: peuplier

P: 19:08, L: 00:58

\section{Paul A. (EF2):}

I-Frage: Frage etwas anders gestellt: direkte Nachfrage zu den Wurzeln der chênes

I-Org: 1. Einteilung der Wurzeln in racines pivotantes und racines adjacentes, die den verschiedenen Baumarten zuzuordnen sind; 2. Wurzelwuchs ist unterschiedlich je nach Bodenbeschaffenheit; 3. Beispiel einer Gegend, in der man dt. 'Orstein' (fr. alios) findet im Gegensatz zu einer, in der der Boden tiefer ist und die racines pivotantes sich so auch tiefer verwurzeln können

I-Komm: ausführliche Kommentierung der Begriffe mit Neueinführung anderer Termini

I-Zusatzfrage: Frage nach der Windanfälligkeit der verschiedenen Baumarten I-Org: 1. les mélèzes sind sehr windanfällig; 2. auf Nachfrage hin: les chênes sind ein bisschen weniger windanfällig; 3. les résineux: "Certains résineux, puisque j'ai fait une expérience malheureuse, les pins [?] en provenance d'Amérique, sont très sensibles au vent." ( $\left.Z^{*} 15: 17\right)$

S-lex: Einführung des Terminus racines adventices bzw. les adventis (14:54), den er parallel setzt mit dem Terminus racines de surface; beide Termini sind 
nicht im Lexicon Silvestre zu finden, dort lediglich: '75: racine aérienne, pneumatophore, '79: racine pivotante, principale, ' 80: plateau racinaire, racines superficielles, souche-plateau; Verwendung des Begriffs alios, das ein Wort gaskognischer Herkunft ist: s. Petit Robert: "Alios [aljos]. n. m. (1843; mot gascon, du rad. de lie, liais.). Grès organique et ferrugineux constituant un des horizons du podzol des Landes."; vgl. auch Dictionnaire Forestier Multilingue, Kennz. 4109

D-Biogr: bei der Beantwortung der Zusatzfrage (s. I-Org, 15:17) Erwähnung einer persönlichen Erfahrung, die der Proband beim Waldbau gemacht hat D-Bsp: gibt konkretes Beispiel zur Verdeutlichung und kündigt dieses auch an: "Prenons un exemple" (Z* 14:25); Beispiel bezieht sich auf den alios, der viel in den Landes zu finden ist

D-Verh: ist zu Beginn etwas unsicher und schränkt seine Antwort gleich ein: "Oui, non, avec précision, non." ( $Z^{*}$ 14:08); beantwortet nicht direkt die gestellte Frage, die Auskunft über die chênes verlangte, sondern liefert eine allgemeinere Antwort, die generelle Informationen zu den Wurzeln beinhaltet P: 13:51, L: 00:40

\section{Pierre de B. (LF1):}

I-Kenntn.d.Begr.: bestätigt sofort, beide Termini zu kennen und bezieht den letzten Begriff - plateau racinaire - direkt auf eine Baumart: "C'est le pin si vous voulez." $\left(Z^{*} 15: 18\right)$

I-Org: 1. Antwort des Probanden; 2. Nachfrage zu den Wurzeln des chêne: "a une racine pivotante, euh importante." ( $\left.Z^{*} 15: 22\right)$ und der sapin: "Le sapin a... une racine tressante." ( $\mathrm{Z} *$ 15:27)

I-Zusatzfrage: Frage nach der Windanfälligkeit der verschiedenen Baumarten: I-Antw: "En, en théorie, mais les... pivotants se tiennent mieux." ( $\left.Z^{*} 15: 38\right)$, "Ils cassent à ce moment-là." (Z* 15:45)

D-Verh: Lachen nach der Antwort 15:45, gelöste Atmosphäre, zeigt sich sehr bereitwillig zu antworten, Auskunft zu geben

P: 15:11, L: 00:07

\section{Paul D. (LF2):}

I-Antw: kennt den Unterschied zwischen racine pivotante und plateau racinaire nicht; kann jedoch einigen Baumarten die verschiedenen Wurzeltypen zuordnen

I-Org: 1. le chêne: "Il a un pivot qui est très profond." ( $\left.\mathrm{Z}^{*} 09: 40\right) ; 2$. le châtaignier: "Le châtaignier n'a pas de pivot." (Z* 09:50) - vergleichbar mit den sapins; 3. Nachfrage nach den frênes: "Ah, le frêne, ça a des racines, oui, ça." (Z* 10:03), 4. Frage nach der Entwurzelung von Bäumen: Es kommt vor, vor allem jedoch, wenn der Boden bereits sehr feucht ist. Es handelt sich meistens 
um ältere Bäume; kein Problem, das nur auf bestimmte Baumarten beschränkt ist - es kann bei allen möglichen Baumarten passieren; 5. spricht über die peupliers, die in der Mitte durchbrechen

D-Verh: zu Beginn gibt er an, die beiden erfragten Begriffe nicht zu kennen; bei anders formulierter Frage, die direkter auf die Wurzeln einzelner Baumarten abzielt, zögert er zwar, kann dann jedoch antworten

P: 09:12, L: 00:10

\section{D.2.d. Est-ce qu'il y a en sylviculture une expression pour 'I'ensemble des branches, rameaux et feuilles de tous les houppiers d'un peu- plement'? (' 'couvert forestier', etc.)}

261: voûte foliaire / couvert forestier / voûte foliacée / couverture des cou^ ronnes / cimes. Ensemble des branches, rameaux, feuilles (aiguilles) de tous les houppiers.

774: degré de fermeture du couvert / couverture [CHE] / couvert / fermeture / couvert des houppiers / densité des cimes / consistance du peuplement . Rapport entre la surface résultant de la projection horizontale de la voûte foliaire d'un peuplement forestier et la surface du peuplement. Rapport utilisé généralement pour exprimer la densité des houppiers.

\section{Jean T. (EF1):}

I-Antw: antwortet nicht auf die Frage

I-Alternativ: "toute la matière verte produite par un peuplement" ( $Z * 21: 42)$; geht über zu houppier

I-Org: 1. Zögern; 2. Def. von houppier: "La définition de un houppier, c'est de, c'est, euh, tout ce qui est branches, brindilles, bourgeons, euh, euh, feuilles etc., c'est, d'un arbre. Le houppier d'un arbre, c'est l'ensemble de tout ça." ( $Z^{*}$ 21:48); antwortet auf couvert forestier: "Ça, c'est une superficie." ( $\left.Z^{*} 22: 09\right)$; führt den Begriff couvert total und couvert forestier insuffisant inklusive Erklärung ein; 3. erläutert verschiedene Aspekte des couvert: "un couvert qui peut être plus ou moins dense" ( $Z * 22: 50)$; 4 . kennt nachgefragte Begriffe, die er nicht erklären soll: voûte foliaire, voûte foliacée, couverture des couronnes, couverture des cimes

S-lex: Einführung neuer Fachtermini

D-Bsp: gibt Beispiele für verschiedene Baumarten: 22:57, 23:02

D-Verh: weiß zu Anfang nicht so recht, wie er mit der Frage umgehen soll, zeigt sich unsicher; geht dann zu houppier über und erläutert diesen Begriff P: 21:18, L: 02:10 
Paul A. (EF2):

I-Antw: 1. kennt keinen Begriff für die gegebene Def.; 2. Nachfrage zur Kenntnis des Begriffs couvert forestier, voûte foliaire, voûte foliacée: Obwohl er diese Begriffe bereits gehört hat, zählt er sie nicht zu seinem Wortschatz-sie werden in Versammlungen verwendet.

S-lex: Ausgrenzung der Fachtermini couvert forestier, voûte foliaire und voûte foliacée aus seinem Wortschatz

D-Verh: zuerst Nachfrage zur Fragestellung: "Une définition? Un terme?" (Z* 15:44); langes Zögern als Reaktion auf die 2. Frage, keine Antwort, eventuell Verneinung durch Kopfschütteln oder ähnliches

P: 15:30, L: 01:39

\section{Pierre de B. (LF1):}

I-Antw: "Ah, si, je savais le nom, ça avant." (Z* 16:07)

I-Org: 1. spontane Antwort; 2. Vorgabe des Terminus couvert forestier: ist bekannt, sucht aber noch nach einem anderen Terminus: "Mais il y a un autre nom pour les... les forêts tropicales, euh, il y a un autre nom, je m'en... je,... que je... je ne sais pas. Mais maintenant, on fait des études sur les forêts tropicales." (Z* 16:21); 3. Vorgabe der Termini voûte foliaire, voûte foliacée, couverture des couronnes: Begriffe sind ihm bekannt

I-Komm: kann die vorgegebene Definition inhaltlich einordnen, ohne jedoch den treffenden Terminus zu finden; bei Vorgabe der Fachtermini kann er sich dazu äußern

S-lex: passive Beherrschung der Fachtermini, ohne sie aktiv verwenden zu können

P: 15:51, L: 00:40

\section{Paul D. (LF2):}

I-Kenntn.d.Begr.: nein, kennt weder einen Terminus für die gegebene Definition, noch den Terminus couvert forestier

D-Verh: erklärt seine Position und die Tatsache, dass er bestimmte Termini nicht kennt: "Ah, je suis pas très technicien." (Z* 11:25)

P: 10:57, L: 01:45

\section{D.2.e. Vous pensez qu'élaguer' signifie autre chose qu'ébrancher' ou 'émonder'?[Vous connaissez la différence entre 'élaguer en sec' et 'élaguer en vert'?]}

431: élaguer / ébrancher / émonder / ébrancher sur pied. Éliminer des branches de la partie inférieure d'un fût afin de récolter plus tard du bois d'œuvre de grande valeur. 
432: élaguer en sec. Eliminer des branches sèches d'un fût afin de récolter plus tard du bois d'œuvre de grande valeur.

433: élaguer en vert / ébrancher à l'état vert / émonder. Eliminer des branches vivantes d'un fût afin de récolter plus tard du bois d'œuvre de grande valeur.

\section{Jean T. (EF1):}

I-Def: kurze Definitionen siehe I-Org

I-Org: 1. Def. von élaguer: "Bon, ehm, normalement, élaguer, c'est couper les branches." ( $\left.Z^{*} 23: 47\right) ; 2$. Def. von ébrancher: "Ébrancher, c'est enlever des branches." ( $Z * 24: 00)$; 3. Unterscheidung des Begriffsverständnisses bei den propriétaires und bei den techniciens: "Mais dans le terme, dans la tête du propriétaire, c'est souvent pareil, couper des branches et élaguer. Élaguer pour nous, c'est enlever des branches en bas pour avoir une bille sans branches. Une bille, donc, pas un tronc. Une bille sans branches." ( $\left.\mathrm{Z}^{*} 24: 03\right) ; 4$. taille de formation, élagage: "On, on distinguera l'élagage de la taille de formation. En, à la taille de formation, on enlève des branches, mais qui sont pas forcément en bas. Elles peuvent déjà se situer plus haut, on enlève une fourche qui va devenir énorme dans quelques années. Donc, élagage et taille de formation sont de l'ébranchage. Mais l'ébranchage n'est pas forcément élagage. Vous comprenez ce que je veux dire. Élaguer, on enlève des branches en bas pour avoir une hauteur sans nœuds, et taille de formation, on enlève des branches en haut pour éviter que l'arbre, dans plusieurs années, n'ait une grosse fourche." (Z* 24:19); 5. Def. von émonder: "Émonder, un arbre d'émonde, c'est un arbre que l'on, euh, que l'on coupe tous les, euh, dix, quinze, vingt, vingt cinq ans suivant l'essence, parce qu'il gêne, pour faire du bois de feu, pour faire de... souvent pour faire du bois de feu. Ce sont des arbres qu'on coupe comme des bougies, régulièrement, en laissant peut-être un brin pour qu'il puisse tirer la sève encore, faire la photosynthèse [...]" (Z* 24:52)

I-Komm: distanziert sich erneut von den propriétaires: "Mais dans le terme, dans la tête du propriétaire, c'est souvent pareil, couper les branches et élaguer." (Z* 24:03); für die techniciens bedeutet élaguer: "enlever des branches en bas pour avoir une bille sans branches" ( $\left.Z^{*} 24: 09\right)$

S-lex: Einführung des Begriffs taille de formation, der dem Begriff élagage entgegengesetzt wird; Einführung des Begriffs un arbre d'émonde; benutzt für élaguer en sec eher taille hivernale

D-Biogr: bezieht sich zu Anfang auf seine persönlichen Kenntnisse: "pour moi, oui" (Z*23:45)

D-Bsp: vergleicht das Schneiden der Bäume mit dem Schneiden beim Friseur 
(25:16)

D-Verh: zögert zu Beginn; gibt an, den Begriff zu kennen, ohne ihn aber direkt zu erklären; die Erklärung erfolgt erst nach kurzer Bedenkzeit; Nachfragen zur konkreten Fragestellung, nachdem élaguer erklärt wurde

P: 23:36, L: 02:18

\section{Paul A. (EF2):}

I-Org: 1. Erläuterung zu élaguer; 2. Erläuterung zu ébrancher; 3. Def. von émonder

I-Def: élaguer ist der eigentliche Fachterminus; ébrancher gehört dem Dialekt an; beide Termini bedeuten im Grunde aber dasselbe; émonder wird zu den termes locaux gezählt, gehört dem langage béarnais an: Erklärung, wie man früher mit den chênes verfuhr, die man dieser Technik unterzog (17:07)

I-Komm: In seiner Erklärung verweist er auf die Herkunft der Fachtermini und ihre Zugehörigkeit zum langage béarnais.

D-Bsp: bezieht sich auf frühere Zeiten mit einer ausführlichen Erklärung (und Begründung) des regionalen Kopfholzbetriebs (émonder), um das Verfahren émonder zu begründen und zu erklären

P: 16:24, L: 00:54

\section{Pierre de B. (LF1):}

I-Antw: sieht einen klaren Unterschied zwischen den drei Begriffen élaguer, ébrancher und émonder

I-Def: 1. "Élaguer, c'est enlever les mauvaises branches... Oui, les branches qui peuvent être nuisibles... oui, ou qui peuvent être inutiles. Oui, vous élaguez, vous enlevez, diminuez là, large." ( $\left.Z^{*} 16: 59\right) ; 2$. fragt nochmals nach: "Après, vous m'aviez dit?" (Z* 17:12) - "Ébrancher... Vous allez ébrancher un arbre, vous allez couper une grosse branche qui est... bon, c'est ça, enfin [...], ébrancher, c'est enlever les branches. Et et émonder,... euh, je sais pas la définition d'émonder. Je savais au moins ce que c'est, mais je sais pas vous donner la définition." (Z* 17:17); 3. obwohl er nicht die exakte Definiton von émonder kennt, weiß er, dass émonder und élaguer keine Synonyme sind; versucht erneut, eine Definition zu geben: "Émonder, c'est enlever une partie inutile... euh, il me semble." (Z* 17:45)

I-Komm: bestätigt spontan, die vorgegebenen Begriffe zu kennen, fragt jedoch nochmals nach, als er um Präzisierung gebeten wird: "Entre?" (Z* 16:55)

D-Verh: Lachen zu Beginn der Antwort; bei der Definition von émonder leichtes Zögern, Unsicherheit, unterstrichen durch das Klopfen auf den Tisch (17:31) - er kennt die Definition nicht

P: 16:44, L: 00:53 
Paul D. (LF2):

I-Def: 1. "Élaguer, c'est arranger l'arbre pour qu'il fasse le maximum de rendement." (Z* 11:42); 2. ébrancher hat für ihn eine ähnliche Bedeutung wie élaguer; 3. émonder ist ihm nicht bekannt

I-Komm: Nachfrage zu den Entsprechungen von élaguer auf Bearnesisch: "eslagar, esbrancar (moins!)" (12:10)

P: 11:34, L: 00:37

\section{D.2.f. Vous pouvez décrire la forme de la feuille du chêne? \\ Est-ce que le chêne d'ici, c'est-à-dire le pédonculé, et le chêne rouge d'Amérique, qu'on trouve aussi dans la région, ont des feuilles tout à fait pareilles? \\ Vous connaissez d'autres différences entre ces deux espèces?}

Jean T. (EF1):

I-Beschr: beschreibt Blattform des chêne pédonculé direkt im Vergleich mit der Blattform des chêne sessile, beschreibt das Blatt wie ein Kind es zeichnen würde: "... bon, elle est simple par rapport aux feuilles composées, pennées, bon, elle est simple, elle a un pétiole qui est relativement eh... facile à trouver, encore que entre le chêne sessile et le chêne pédonculé, c'est pas le même, mais bon, disons on va prendre le chêne tel qu'un gamin la dessinerait: je mettrais un pétiole relativement court, et un limbe avec ehm... des, des auréoles, avec des ehm, de part et d'autre donc de la nervure centrale des ehm, des sortes de petits, de petits arrondis qui permettent aisément de la différencier de toutes les autres espèces puisque seul le chêne euh, du pays, puisque le chêne d'Amérique n'est pas pareil, donc des petits arrondis de part et d'autre, donc les limites du limbe facile à le distinguer de n'importe quelle autre essence. C'est l'essence la plus facile à repérer, même chez les enfants." (Z* 25:41)

I-Org: 1. Beschreibung der Blattform des chêne pédonculé; 2. Beschreibung der Unterschiede zwischen dem chêne d'ici und dem chêne d'Amérique; auf Nachfrage hin: gliedert Beschreibung nach verschiedenen Kriterien, wie taille etc.; 3. weitere Unterschiede, die er auf Nachfrage hin nennt; 4. geht über zu den chênes $d u$ pays, die sich auch durch diese Kriterien unterscheiden; merkt an, dass man in der Beschreibung der chênes viel genauer sein müsste-verweist auf Sprache der Botanisten; Aufzählung verschiedener Arten der chênes; nennt die vier chênes principaux

I-Komm: sehr anschauliche Beschreibung, pädagogisch; lässt in der Beschreibung seine Kenntnisse zu anderen Arten des chêne einfließen (chêne sessile, 
d'Amérique etc.)

S-lex: verwertet häufig biologische Fachbegriffe in der Beschreibung; unterscheidet zwischen genre und espèce für die Arten des chêne P: 25:37, L: 02:01

Antwort schon im Kontext der ersten Fragestellung behandelt

Antwort schon im Kontext der ersten Fragestellung behandelt

\section{Paul A. (EF2):}

I-Antw: "Oui, je sais, comment est une feuille de chêne, mais la décrire..." (Z* 17:55)

I-Beschr: Beschreibung der Blattform der chêne pédonculé: "Bon, elle a des, des bords arrondis, disons, euh, des nervures, euh,... pour la décrire, bon elle est, elle est évidemment, elle a, ce sont pas de véritables dents puisque c'est assez doux comme euh, comme feuillage, euh, elle en porte suivant la, la grandeur des feuilles de... six à huit ou à dix, euh, bon, c'est, c'est une feuille qui fait quoi, qui fait entre quatre centimètres et dix-huit centimètres." ( $\left.Z^{*} 18: 04\right)$ I-Komm: trotz des anfänglichen Zögerns eine detaillierte Beschreibung D-Verh: sehr zögerlich, nicht aus mangelndem Wissen, sondern aus der Schwierigkeit heraus, die wohlbekannte Blattform des chêne zu beschreiben; langsamer bedächtiger Sprachrhythmus; man spürt, dass er sich Mühe gibt, die Frage möglichst genau zu beantworten

P: 17:45, L: 01:21

I-Beschr: Vergleich der Blattform des chêne rouge d'Amérique mit der zuerst beschriebenen bezüglich der Größe, der Rundungen

I-Komm: nur sehr kurze Antwort

P: 18:42, L: 00:57

I-Beschr: Obwohl das Holz des chêne rouge d'Amérique qualitativ schlechter als das des chêne pédonculé ist, handelt es sich doch um eine Baumart, die den Vorteil hat, schnell zu wachsen.

I-Komm: sehr kurz, keine genaueren oder längeren Ausführungen

P: 19:25, L: 00:43

Pierre de B. (LF1):

I-Antw: Präzisierung der Fragestellung: "Ça dépend d'abord des chênes." (Z* 18:12)

I-Beschr: "C'est une, c'est une feuille qui est... qui est... ah [...] qui est hachurée, qui n'est pas, pas régulière sur les bords." (Z* 18:20); Nachfrage des 
Fragestellers: "On pourrait dire dentelé?" - zustimmende Reaktion des Probanden: "Dentellée, c'est ça, c'est le mot, oui." (Z* 18:34); "...qui est dentellée, qui est bien veinée et qui a un... un pédoncule plus ou moins long suivant les variétés. Puisque certains chênes sont pédonculés parce que ils ont un pédoncule particulier, donc qui marquent les... variétés. Elle est de couleur différente... eh... face euh au soleil et face à l'ombre." (Z* 18:35)

I-Org: 1. wiederholt die Fragestellung: "Décrire la forme de la feuille du chêne." ( $\left.Z^{*} 18: 03\right)$; 2. versucht eine Beschreibung, die der Fragesteller z.T. durch Zwischenfragen vervollständigt

I-Komm: Ab dem Moment, in dem der Proband seine Sicherheit wiederfindet, geht er auf viele verschiedene Kriterien ein und äußert sich sehr ausführlich.

D-Verh: scheint zunächst nicht genau zu wissen, wie er auf die Frage reagieren soll: langes Schweigen, Wiederholung der Frage; scheint wirklich verunsichert und sagt dies auch explizit: "Je trouve plus mes mots maintenant." ( $\left.\mathrm{Z}^{*} 18: 26\right)$, verstärktes Klopfen auf den Tisch; gegen Ende der Antwort findet er seine alte Sicherheit wieder und gibt eine ausführliche, zusammenhängende Erklärung $\mathrm{ab}$.

P: 17:56, L: 01:12

Antwort im Kontext der dritten Fragestellung behandelt

I-Antw: "Le chêne d'Amérique, euh, a euh une feuille beaucoup plus large, hein, euh qui est d'une couleur différente et qui rougit l'automne. Et puis, elle est beaucoup plus, plus importante la feuille, les, elle a une forme beaucoup plus, plus aplatie et elle est pas dentellée, elle. Elle est... comment on pourrait donc dire..." ( $Z *$ 19:14)

I-Org: Erklärung der Blattform des chêne d'Amérique; 2. Nachfrage zu weiteren Unterschieden zwischen den beiden Eichenarten: "Ah oui oui oui, c'est très différent." (Z* 19:51); 3. Nachfrage zur Qualität des Holzes: "La qualité du bois est différente." (Z* 19:56); 4. Nachfrage, welches der beiden Hölzer von besserer Qualität sei: "Ça dépend du service qu'on va lui demander." (Z* 20:08), trotzdem stuft er das Holz des chêne pédonculé als besser ein: es ist härter-schränkt ein: "Quand il pousse bien, je parle, en qualité, hein." (Z* 20:22); das Holz der chêne d'Amérique wird nicht häufig gebraucht; 5. Frage, warum man die chênes d'Amérique in der Region anpflanzt: Sie wachsen schneller

I-Komm: äußert seine Schwierigkeit, sich theoretisch zu dieser Frage zu erklären: "Je trouve pas les mots pour... pour décrire. Il faudrait être dessinateur pour savoir décrire les..." (Z* 19:41)

P: 19:08, L: 01:12 
Paul D. (LF2):

I-Antw: gibt zu bedenken, dass es verschiedene Varietäten des chêne gibtEingrenzung auf die chênes du pays

I-Beschr: Beginn der Beschreibung: "Elle est grande comme la main, à peu près, ah non, pas tant. Et avec des... elle est un peu dentellée." (12:36)

I-Org: 1. spontane Antwort; 2. beginnt, die Blattform der chênes du pays ein bisschen zu beschreiben

I-Komm: keine sehr kohärente Antwort; es werden einige Merkmale genannt, jedoch nicht in organisierter Form

P: 12:23, L: 00:49

I-Org: Nachfrage zu den chênes rouges d'Amérique: nicht exakt wie Platanen, aber doch etwas vergleichbar (Blätter sind größer und grün, ein bisschen rot)

P: 12:45, L: 00:22

I-Antw: "Oui, oui, il y en a d'autres." (Z* 13:16)

I-Org: 1. Antwort; 2. Angabe des tauzin (chêne tauzin); 3. Nachfrage zum tauzin: hier in der Gegend recht klein, bezeichnet ihn als bruchon [fr. buisson] (13:33); 4. erwähnt, dass es drei, vier Arten der Eiche mit größeren Blättern gebe

I-Komm: nennt keine tatsächlichen Unterschiede zwischen dem chêne pédonculé und dem chêne rouge d'Amérique, dafür gibt er aber verschiedene Varietäten des chêne an

D-Verh: antwortet auf die gestellte Frage, indem er sie bejaht, geht jedoch von sich aus nicht weiter darauf ein - erst auf konkrete Nachfrage hin

P: 13:13, L: 00:28

\section{D.2.g. Est-ce qu'il y a un mot pour 'l'ouverture des bourgeons à feuilles au début de la saison de végétation'? (' débourrement, etc.)}

167: feuillaison / foliation / débourrement. Ouverture des bourgeons à feuilles au début de la saison de végétation.

Jean T. (EF1):

I-Antw: "le débourrement" (Z* 29:39)

I-Org: Struktur der Antwort durch Nachfragen vorgegeben; 1. erklärt feuillaison; 2. erklärt débourrement

I-Komm: äußert sich zusätzlich zu Krankheiten und außergewöhnlichen Erscheinungen

S-lex: bevorzugt feuillaison, nicht foliation 
D-Biogr: verweist auf seine Funktion als technicien

P: 29:31, L: 03:54

\section{Paul A. (EF2):}

I-Antw: Spontan gibt er an, den Ausdruck nicht zu kennen, verweist dann aber auf die viticulture, wo der Begriff débourrement geläufig sei. Im Waldbau werde er jedoch selten benutzt.

I-Org: 1. Angabe des Terminus débourrement, den man in der viticulture benutzt; 2. Nachfrage zu feuillaison: Moment, der sich dem débourrement anschließt

D-Biogr: keine allgemeingültige Aussage-weist auf die Subjektivität der Erklärung hin: "selon moi" (Z* 20:24)

D-Verh: spontane Reaktion auf die Frage: "S'il y a un mot pour cela?" (Z* 20:01); daran anschließend langes Zögern

P: 19:53, L: 00:28

\section{Pierre de B. (LF1):}

I-Antw: spontane Antwort, die noch fast während der Frage geäußert wird: débourrage

I-Org: 1. spontane Antwort; 2. Nachfrage zum Terminus débourrement: antwortet nicht richtig (Das Gespräch wird unterbrochen. - Wiederaufnahme mit Punkt 3); 3. Frage nach der Definiton von débourrage: "C'est le, le commencement de la végétation, au moment de la végétation au printemps." ( $\mathrm{Z}^{*}$ 21:20); 4. Unterschied zwischen feuillaison und débourrage erfragt: "Le débourrage, c'est au moment où le, le bourgeon s'ouvre. La feuillaison, c'est au moment où les feuilles vont pousser." (Z*21:31)

I-Komm: genaue Unterscheidung zwischen den verschiedenen Fachtermini

S-lex: kennt die Fachtermini und kann sie auch recht spontan erklären

P: 20:51, L: 01:43

\section{Paul D. (LF2):}

I- Antw: langes Zögern, keine Antwort

I-Kenntn.d.Begr.: 1. auf konkrete Nachfrage nach débourrement hin antwortet der Proband: "Ah, oui, aussi." (Z* 14:19); 2. keine Kenntnis der Termini feuillaison, foliation

I-Komm: Nachfrage zu débourrement auf Bearnesisch, Antwort: "que brojo$n a^{\prime \prime}(14: 30)$

S-lex: Kenntnis des Fachbegriffs débourrement, nicht jedoch der Begriffe feuillaison und foliation

D-Verh: scheint sich nicht sehr für diese Frage zu begeistern, da er sich fast gar nicht dazu äußert 
P: 13:55, L: 00:42

\section{Régénération et plantation}

\section{D.3.a. Le reboisement des terres délaissées ou défrichées, est-ce que ça joue un rôle pour les propriétaires privés de la région?Quand on veut laisser faire la nature pour que les arbres repoussent. Com- ment faut-il s'y prendre? (' régénération naturelle)}

301: création d'un peuplement / de forêt / boisement / reboisement $[<] /$ reforestation $[<]$. Création d'un peuplement forestier par premier boisement ou régénération .

302: régénération [FRA] / de la forêt / reboisement / reconstitution des forêts / rajeunissement [CHE]. Renouvellement d'un peuplement forestier par voie naturelle et/ou artificielle.

304: régénération naturelle / rajeunissement naturel. Renouvellement d'un peuplement par semis naturel ou rejet de souche.

305: ensemencement naturel / semis / ensemencement. Etablissement d'un peuplement par des semis naturels.

\section{Jean T. (EF1):}

I-Org: 1. Verweis auf frühere Vorgehensweise, bei der dieses Verfahren oft angewendet wurde (reboiser des bois minables, reboiser la déprise, d.h. die ehemals landwirtschaftlich genutzten Flächen; beurteilt dieses Verfahren: kann eine wichtige Rolle spielen, wirft aber technische Probleme auf, da es sich bei diesen Feldern um die am wenigsten fruchtbaren handelt, die schlecht zugänglich sind; zusammenfassend sagt er: "Donc, ce sont des terres donc, souvent, qui sont difficiles à remettre en valeur." ( $\left.Z^{*} 31: 26\right) ; 2$. stellt dem reboisement der Felder, die er mit déprise beschrieben hat, den reboisement des terres agricoles gegenüber, bei dem die Eigentümer finanziell unterstützt und dazu angeregt werden, auf diesen Feldern Wald anzulegen; (Unterbrechung durch Telefonat)

I-Komm: beurteilt das Verfahren (reboisement); äußert sich kritisch

S-lex: Einführung des Begriffs la déprise ("ce que l'agriculture laisse derrière elle en se retirant", $Z *$ 31:09), dem er den Begriff le boisement gegenüberstellt $Z^{*}: 31: 09,31: 26$

P: 30:49, L: $01: 18$ 
I-Org: Erklärung der régénération naturelle: schematisiert, erklärt sie in verschiedenen Schritten, wobei er auf verschiedene Arten der coupe eingeht: a. die coupes progressives: nicht alle Bäume werden zur gleichen Zeit entfernt, sondern man entfernt sie nach und nach; b. la coupe d'ensemencement: dient dazu, den Boden zu lichten (enlever le sous-étage); c. la coupe secondaire: die Bäume untereinander werden gelichtet, da ihnen sonst Licht fehlen würde; d. la deuxième coupe secondaire: weitere überschüssige Bäume werden einige Jahre später entfernt; e. la coupe définitive: man entfernt definitiv alle übriggebliebenen Bäume

I-Komm: beurteilt die régénération naturelle als kompliziert und schwierig anzuwenden, gibt zusätzlich eine sehr genaue, logische Erklärung, wobei er die Arbeitsschritte nacheinander darlegt: resümiert, dass diese Methode nur ausgewählten verlässlichen und engagierten Waldbauern empfohlen werden könne

S-lex: Neueinführung des Begriffs régénération naturelle par coupes progressives-es handelt sich um einen Fachterminus, der eine bestimmte Arbeitsmethode beschreibt (weitere Informationen zu dieser Arbeitsmethode s. unter D.4.c.); benutzt Fachtermini, z.B. glandée, die er erklärt; beschreibt im Laufe seiner Erklärung verschiedene Arten der coupe (s. I-Org)

D-Biogr: eigene Erfahrungen als technicien fließen ein; bezieht sich auf Kontakte mit anderen techniciens (Exkursion mit A. Berton) und baut so eine persönliche Verbindung zum Gesprächspartner auf, bezieht ihn mit ein: "Vous avez vu" (Z*35:44)

D-Verh: scheint viel zu gestikulieren-verstärktes 'Händeklopfen auf den Tisch' P: 32:05, L: 01:16

\section{Paul A. (EF2):}

I-Antw: Das Phänomen reboisement spielt eine Rolle, hat sich zur Zeit jedoch noch nicht richtig durchgesetzt.

I-Org: 1. spontane Antwort; 2. Erklärung, warum sich immer mehr Leute dafür interessieren: "Parce que dans les dernières dispositions de l'APAC, on a mis beaucoup de terrains en jachère d'une part, d'autre part, la baisse du, du prix de vente du maïs amène les gens à reconsidérer euh les cultures qu'ils avaient faites dans des terrains difficiles, caillouteux, en pente etc. Donc, souvent, ils reconsidèrent disons leur, leur euh, façon de faire et euh commencent à boiser ces terrains-là." (Z*21:12)

D-Verh: Nachfrage zur Antwort-Frage wird wiederholt P: 20:41, L: 00:48

I-Org: 1. Erklärung der régénération naturelle: wird als geläufiger Terminus beurteilt; 2. Einteilung in zwei Methoden: a. en entretenant sa forêt, b. en 
laissant faire la nature; Nennung des nötigen Arbeitsschrittes für den entretien de la forêt: Unkraut und konkurrierende Vegetation beseitigen

P: 21:47, L: 01:06

\section{Pierre de B. (LF1):}

I-Beurteilg: glaubt, dass bedauerlicherweise zu wenig brachliegendes Land in Wald umgewandelt wird

I-Org: 1. persönliche Einschätzung und Beurteilung der Situation (I-Beurteilg); 2. Grund dafür, dass die Situation so ist: la présence des chevreuils: "L'excès des chevreuils, euh, fait que,eh, la plantation devant être protégée, revient trop chère. Puisque la protection coûte beaucoup plus chère que le plant... et que le travail." (Z* 22:14)

I-Komm: keine allgemeine Erklärung des Verfahrens, sondern direkter Bezug zur Anwendung des Verfahrens in der Region

D-Biogr: persönliche Einschätzung der Situation, bei der er sich nicht ganz sicher ist: "je crois que" (Z*21:55), "je pense, moi" ( $\left.\mathrm{Z}^{*} 22: 07\right)$

P: 21:45, L: 00:54

I-Org: 1. Erklärung der régénération naturelle: "Les arbres fabriquent des semences et c'est ces semences qui poussent d'une manière naturelle". (Z*22:51); 2. führt das Problem, dass sie zur Zeit weniger wachsen, auf die Tatsache zurück, dass das Vieh nicht mehr wie früher die Samen in den Boden stampft (Früher ließ man das Vieh auf Feldern weiden, die an Waldstücke angrenzten-die Tiere hielten sich auch im Wald auf.); 3. Nachfrage zu den verschiedenen Etappen einer régénération naturelle (23:22): "Alors, la régénération naturelle se fait au, au moment où il y a des coupes, quoi. C'est-à-dire, se fait avant, pour bien faire, il faudrait qu'elle se fasse avant, qu'elle existe avant, que au moment de la coupe, les, les... les jeunes plants, les jeunes semences puissent y pousser." ( $\left.Z^{*} 23: 31\right)$; 4 . Frage nach der ersten zu erledigenden Arbeit: "Ben, c'est surtout de laisser, de, de pouvoir donner la possibilité aux semences de, de créer des... de démarrer sans être étouffées par par les ronces ou les plants... ou qu'il y ait assez de lumière sans trop d'ailleurs, tout est là, toute la difficulté est là." (Z* 24:01)

D-Verh: stellt eine persönliche Beziehung zum Fragesteller her, der eine Veranstaltung besucht hat, wo die Frage der régénération naturelle behandelt wurde: "Ah, vous étiez l'autre jour à la ...[lacht]" (Z*22:42); gute Gesprächsatmosphäre

P: 22:33, L: 00:48

Paul D. (LF2):

I-Antw: verweist auf die Notwendigkeit, das Terrain zu säubern und die weite- 
re Arbeit, die mit einer Anpflanzung verbunden ist: "Bo c..., premièrement, c'est le nettoie parce que autrement c'est c'est... c'est de suite sale. Et alors c'est... et puis ça l'occupe et..." (Z* 14:55)

I-Org: 1. Antwort; 2. Frage nach anderen Leuten, die wie der Proband selbst Pflanzungen anlegen: Einige Leute fangen damit an, Pflanzungen so anzulegen wie er; 3. spricht von einer Versammlung, die am Ende des Monats stattfinden wird-geht in diesem Zusammenhang auf Subventionen ein (vom Fragenden hinzugefügt: seitens der $D D A$ ); 4."Et alors, euh, on va être... on va être sûrement assez même davantage et... et en même temps, il y a des communaux qu'ils vont aussi... il y a des communaux qui ne servent à rien où qu'il y a du très mauvais bois, alors ils comptent raser tout ça et puis le mettre en une... en... en... défoncer, enfin, travailler le sol pour... pour le mettre en exploitation." (Z* 15:45)

P: 14:46, L: 00:51

I-Org: Beurteilung der régénération naturelle: funktioniert nicht besonders gut-es ergibt kein gutes Holz; für die sapins ist es vorteilhaft

I-Komm: Verweis auf den verbreiteten Wildwuchs des Waldes in der Region (régénération naturelle im Sinne von laisser pousser): "Ici, ça l'est tout. Tout tout tout, tout ça l'est..." (Z* 16:27)

D-Biogr: spricht von seiner persönlichen Erfahrung: "Moi, j'ai essayé, il y a longtemps, $j$ 'ai essayé dans dans dans plusieurs eh... dans plusieurs euh parcelles... d'y semer des glands et tout ça, des arbres que je voyais à peu près bons. Bon, d... ça pousse ou ça pousse pas, et puis après il y a des chevreuils qui y sont et alors ça ça c'est une..." (Z* 16:59) - hat das grundlegende Problem in der Gegend (les chevreuils) erfasst

P: 16:16, L: 01:30

\section{D.3.b. Parlons des conditions naturelles qu'il faut respecter pour pouvoir faire pousser des arbres avec succès. Commençons par le sol / la terre. Vous savez quelque chose sur la qualité du sol d'ici / en gé- néral?}

Jean T. (EF1):

I-Antw: Die Qualität des Bodens ist der wichtigste Faktor, den man zuerst untersucht.

I-Org: 1. Erklärung (definierte diese Begriffe bereits unter D.3.a.) des Unterschieds von boiser-reboiser; 2. Nennung wichtiger Faktoren zur Auswahl der Baumart; 3. Eigenschaften der in der Gegend vorhandenen Böden; 4. Erklä- 
rung der Methode zur Bestimmung des pH-Wertes; 5. Eigenschaften des Bodens in der Gegend (auf Nachfrage hin)

I-Komm: gute Erklärung, sehr veranschaulichend dargestellt

D-Bsp: nennt verschiedene Regionen zur Veranschaulichung der Unterschiedlichkeit der Böden und der Abhängigkeit der Baumart vom Boden

D-Verh: sehr gelöst, humorvoll

P: 36:24, L: 04:19

Paul A. (EF2):

I-Antw: Bodenbeschaffenheit ist sehr unterschiedlich, je nachdem, ob man sich in hügeligem Gelände oder in einer Niederung befindet

I-Org: 1. Differenzierung der Bodenbeschaffenheit; 2. Erläuterung der generellen Bodenbeschaffenheit: "En général, on a des argileux-limoneux en général, des terrains acides, assez peu calcaires dans le département." ( $\left.Z^{*} 22: 47\right)$; 3. Verweis darauf, dass man die Auswahl der zu pflanzenden Baumarten auf den Boden abstimmen muss

D-Bsp: Anführung eines Beispiels unter Punkt 3: man soll keine peupliers auf saurem Boden pflanzen, sondern auf kalkhaltigem

P: 22:36, L: 00:49

Pierre de B. (LF1):

Frage nicht gestellt

Paul D. (LF2):

I-Org: 1. generelle Antwort zur Bodenqualität: le marécageux, la terre noire, l'argileux (17:36); 2. Nachfrage nach Bodenqualität auf seinem Landbesitz: Antwort dementsprechend auf die Qualität seines Bodens bezogen: "Ah, moi, où je le fais, c'est argile et cailloux." (Z* 17:43); 3. auf Nachfrage hin: die techniciens machen diese Bodenanalysen und empfehlen, was gut anzupflanzen ist

I-Komm: gibt Erklärungen ab, die nicht sehr ausführlich erläutert werden, jedoch das Grundsätzliche aussagen

S-lex: Anführung der für die Angabe der Bodenqualität typischen Begriffe: argileux, cailloux

D-Biogr: nennt auf Nachfrage des Fragestellers hin die Qualitäten seines eigenen Bodens (17:43)

P: 17:20, L: 01:04 


\section{D.3.c. Quels problèmes vous sont connus: sol encroûté (durci, tassé), sol engorgé, sol acide, sol contaminé?}

29: encroûtement du sol / durcissement $\sim$ / tassement. Tassement de la couche du sol, près de la surface.

18: engorgement / d'eau / engorgé. Augmentation excessive de la teneur en eau du sol ayant une influence négative sur la croissance des plantes.

16: acidification. Augmentation de la concentration en ions hydrogène.

341: décontamination du sol / désinfection du sol / stérilisation du sol. Mise en œuvre de procédés chimiques et/ou physiques en vue de supprimer dans le sol les organismes nuisibles aux plantes.

Jean T. (EF1):

I-Kenntn.d.Begr.: kennt nicht den Begriff sol encroûté, wohl aber sol engorgé I-Org: 1. Def. sol engorgé; 2. Unterscheidung: a. engorgement temporaire, b. engorgement total / permanent und Def.; 3. auf Nachfrage hin: drainage / fossé

I-Komm: fasst seine Kommentare zusammen in einem kurzen Resümee: "Donc, un engorgement permanent n'est pas un bon sol." (Z* 39:15)

S-lex: Präzisierung der Termini "drainage" und "fossé": im Bereich der Landwirtschaft arbeitet man mit dem System der drainage, im Bereich des Waldbaus legt man fossés an

P: 38:42, L: 02:18

\section{Paul A. (EF2):}

I-Kenntn.d.Begr.: ihm sind die Fachtermini bekannt

I-Org: 1. sehr unterschiedliche Bodenbeschaffenheit in den Pyrénées-Atlantiques: zones humides-zones sèches (23:33)

I-Komm: erläutert diese Frage sehr detailliert

S-lex: korrekte Ausdrucksweise, fachliches Vokabular zum Wortfeld ,Bodenbeschaffenheit': (zones humides / sèches, la climatologie, terrains riches / acides, pH, calcaire): "Bon, c'est un pays très divers, les Pyrénées-Atlantiques, donc, on a des zones très humides, et des zones euh, très sèches. Donc, euh, c'est, disons, dù à la climatologie et il est bien évident que c'est pour certaines essences plus difficile de euh, de faire pousser par exemple des peupliers dans une zone sèche que dans une zone assez humide." ( $\left.Z^{*} 23: 29\right)$

D-Biogr: Verweis auf eigene Erfahrungen, allerdings auf Nachfrage hin: "Mais j'ai eu des problèmes sur le plan de la qualité du sol, personnellement avec des peupliers dont j'ai parlé tout à l'heure." (Z* 24:02) 
D-Verh: zeigt bei der Beantwortung dieser Frage eine große Sicherheit P: 23:15, L: 00:39

Pierre de B. (LF1):

Frage nicht gestellt

Paul D. (LF2):

Frage nicht gestellt, da dem Fachniveau des Probanden nicht entsprechend

\section{D.3.d. Quelles espèces végétales / plantes peuvent être nuisibles à la cul- ture du bois?}

180: broussailles / buissons / fourré. Formation végétale épineuse dense et difficile à pénétrer.

720: plante nuisible en forêt / herbe / mauvaises herbes / herbes nuisibles / plantes adventices. Toute espèce végétale indésirable dans les peuplements forestiers.

721: mauvaise herbe / végétation adventice / plante indésirable. Toute espèce végétale non souhaitée qui s'installe dans des peuplements d'essences utiles.

\section{Jean T. (EF1):}

I-Aufzählung: 1. les graminées; 2. la fougère; 3. la ronce; 4. le liseron; 5. le chèvrefeuille

I-Anordnung: Die ersten zwei Schädlinge stellt er heraus, danach sagt er: "Il y a plein d'autres essences. Vous avez la ronce aussi qui peut être embêtante." (Z* 40:26)

I-Komm: gibt Schädling an mit Erklärung, Begründung und Folgen, die dieser Schädling hervorruft; bei Punkt 3 keine Erklärung von sich aus, ausführliche Beschreibung jedoch auf Nachfrage hin, wobei er recht weit ausholt: "Le principe qu'on peut adopter chez un arbre, c'est que, il faut la tête au soleil et le tronc à l'ombre. Quel que soit l'âge de l'arbre: la tête au soleil et le tronc à l'ombre. Donc, si le petit arbre a la tête au soleil, la ronce ne sera pas gênante, par contre, si l'arbre est dessous... Par contre, la ronce peut être embêtante pour l'ouvrier qui va avec des sécateurs passer pour faire de l'élagage. Donc, là, il faudra s'en débarrasser." (Z* 40:46); keine Erklärung zu Punkt 4jedoch erstaunliche Gedankenführung: nimmt den Faden eigenständig nach Unterbrechung wieder auf

S: korrigiert sich selbst: Der 'accord' bei "la ronce ne sera pas gênant...e" 
wird nachträglich vorgenommen. ( $Z * 40: 58)$

P: 39:34, L: 00:52

\section{Paul A. (EF2):}

I-Aufzählung: nennt nur les ronces

I-Org: 1. Nennung der typischen Dornensträucher; 2. auf Nachfrage hin Anführung der Bekämpfungsmittel: les traitements chimiques, le débroussaillage à la main; 3. kennt die Produkte nicht sehr gut und antwortet nicht sehr präzise, als danach gefragt wird; 4. gibt persönliche Erfahrungen preis, als er darauf angesprochen wird (s. I-Biogr); 5. nach Aufforderung Erklärung des Terminus débroussaillage

I-Komm: beschränkt sich auf eine Schädlingsart, keine Anführung weiterer Schädlinge

D-Biogr: auf Nachfrage hin gibt er eine persönliche Auskunft über seine Vorgehensweise bei der Schädlingsbekämpfung, in der er erklärt, dass er sich nicht auf dem Gebiet der chemischen Produkte auskennt: "Moi, j'ai eu une chance d'avoir une main d'ouvre assez bon marché venant du Portugal. J'avais fait le débroussaillage à la main." (Z*25:12)

D-Verh: Nachfrage, bevor die Antwort gegeben wird: "Les végétaux nuisibles à la culture du bois?" (Z* 24:39); nach anfänglichem Zögern dann aber sehr sichere und klare Antwort

P: 24:29, L: 01:14

\section{Pierre de B. (LF1):}

I-Aufzählung: gibt als Schädlinge nur certains champignons an

I-Org: 1. spricht über Pilze im Allgemeinen: Einige sind nützlich, andere sind sehr schädlich; 2. Frage danach, ob junge Bäume stärker betroffen sind-nennt eine bestimmte Pilzart: "Ah, les champignons, alors, le le l'oüdium, le, eh... l'oüdium surtout pour les chênes, est, eh... est très, très, très mauvais. Alors, eh... ici, je pense que, eh... une année sur trois... euh, l'oïdium, eh... euh tue les... jeunes chênes." ( $\left.Z^{*} 24: 46\right) ; 3$. Frage danach, ob dieser Pilz tödlich sein kann für die jungen Eichen: Kleine Eichen, die nur $20 \mathrm{~cm}$ hoch sind und vier Blätter haben, werden erstickt; 4. Nachfrage zur Schädlichkeit der ronces: haben sogar eine bestimmte Schutzfunktion, sind nicht völlig nutzlos; 5. Bitte um Stellungnahme zum Ratschlag, die ronces mit einem Mittel (produit) zu bekämpfen: weiß nicht recht, ob es ein guter Vorschlag ist - Bezugnahme auf die kurze Periode, in der man davon betroffen ist

I-Komm: Bitte um Wiederholung der Frage: "J'ai pas entendu." (Z* 24:28); gibt Auskunft über das Gebiet, in dem er sich auskennt und sagt explizit, wo seine Grenzen sind: "Je connais pas beaucoup les... sur les autres arbres, mais [...]." (Z* 25:13); äußert sich nicht spontan in Form eines längeren Diskurses 
zu dieser Frage, aber beantwortet bereitwillig alle gestellten Nachfragen S-gS: elliptischer Satz: " [...] et le moment où les ronces ne sont pas encore, eh... sont encore... où la sève continue à descendre." $\left(Z^{*} 26: 21\right)$

D-Verh: Lachen direkt nach der Antwort - gelöste Atmosphäre (24:40); scheint nicht sehr sicher zu sein, was die langen Sprechpausen vermuten lassen; äußert sich nicht spontan und nicht besonders ausführlich

P: 24:24, L: 01:41

Paul D. (LF2):

I-Antw: "Le saule peut-être." (18:21)

I-Org: 1. Hinweis auf den (regionaltypischen) Wildwuchs der Weiden; 2. Nachfrage nach den ronces: bestätigt ihre Gegenwart, ohne ihnen jedoch eine größere Bedeutung beizumessen; 3. betont, dass man die ronces mit einem Schädlingsbekämpfungsmittel (Gardon) vernichten kann, sieht aber keine großen Probleme, da das Wertholz (er zitiert beispielhaft die frênes) sich aus eigener Kraft durchzusetzen vermag: "de suite quelques... les feuilles... les fr... ĖCHES [hybride Bildung aus fr. frênes und b. rèches 'Eschen'] y touchent; les ronces, elles partent... elles s'étouffent." (Z* 18:39); 4. Nachfrage zu den mauvaises herbes: keine konkrete Antwort, allerdings weitere Stellungnahme zu den ronces: "Même ils préconisent les ronces là, de les laisser, à cause des chevreuils." (Z* 19:01)

I-Komm: sprachlich sehr karge (elliptische) Antworten auf die gestellten Fragen; Insgesamt wird der Eindruck vermittelt, dass es keine gravierenden Probleme mit Schädlingen bzw. der Schädlingsbekämpfung gebe.

D-Biogr: Der Themenbereich scheint ihn nicht besonders zu betreffen. Für sein eigenes Waldstück stellt sich hier offensichtlich kein Problem.

D-Verh: sehr langes Zögern als erste Reaktion auf die Frage, zu Beginn der Antwort

P: 18:03, L: 00:43

\section{D.3.e. Il y a des dégâts de gibier dans le bois? De quelle façon est-ce qu'il fait du mal?}

67: dégâts de gibier / causés par le gibier / dommages . Dommages causés aux plants utiles par le gibier.

68: dégâts d'abroutissement / de broutement. Dégâts de gibier causés aux plantes cultivées par broutement.

680: dégâts d'écorçage / dégât d' / frottis / frotture. Dégâts causés aux végétaux ligneux par enlèvement de l'écorce par le gibier ou le bétail. 


\section{Jean T. (EF1):}

I-Antw: spontane Antwort: "Oui, bien entendu, oui, oui. Énormément de dégâts de gibier, ça nous pose de gros problèmes." (Z* 41:32)

I-Org: 1. Beurteilung (s. I-Antw); 2. Begründung: a. Bei der régénération naturelle ist das Wachstum sehr eingeschränkt, da das Wild die Bäume abfrisst; b. Auch in allen anderen Anpflanzungen richtet das Wild erhebliche Schäden an-es ist nötig, Schutzvorkehrungen zu treffen, von denen er einige aufzählt: des tubes, des grillages, des clôtures; 3. Möglichkeiten, die Pflanzen zu schützen; 4. zwei Arten der Schäden: a. le frottis: "Et le frottis, c'est l'arbre qui est suffisamment résistant, suffisamment euh, raide, pour que le chevreuil ou le cerf se frottent dessus [...] L'arbre est pelé et il meurt parce que la sève ne circule plus. Ça, c'est le frottis." (Z* 42:08), b. l'abroutissement: "L'abroutissement, c'est un arbre qui est brouté par le, disons par le cervidé, que ce soit le chevreuil en plaine ou le cerf en montagne, donc, l'arbre brouté, c'est l'abroutissement." (Z* 41:59)

I-Komm: beurteilt: "Ça nous pose de gros problèmes." (Z* 41:36) P: 41:29, L: 01:55

Auf den Inhalt der Frage wird bereits im Kontext der vorangehenden Antwort Bezug genommen

Paul A. (EF2):

I-Antw: spontane Antwort: "Les dégâts causés par des gibiers sont importants, pour ne pas dire, très importants, parce que, et essentiellement par le chevreuil." (Z* 25:47)

I-Org: 1. Ursache für die größten verursachten Schäden ist das Wild (s. I-Antw); 2. Erklärung des Problems der chevreuils (sind in Gebiete eingeführt worden, in denen es sie vorher nicht gab; zur Zeit: Überbevölkerung der chevreuils, da der Jagdplan keinen durchschlagenden Erfolg hat; bedingt durch die Überbevölkerung werden bei neuen Anpflanzungen ausdrücklich Schutzmaßnahmen gefordert, die den Preis dieser Anpflanzungen fast verdoppeln); 3. auf Nachfrage hin Beschreibung der Schutzmaßnahmen: "des systèmes de tubes ou de filets le long de la tige" (26:33)

I-Komm: ausführliche und logisch strukturierte Problemdarlegung (bei Punkt 2); spricht ohne ausdrückliche Nachfrage die zwei verschiedenen Arten der Schäden an, die durch die chevreuils angerichtet werden (s. u. I-Org zur nächsten Frage)

P: 25:44, L: 01:15

I-Org: Frage wird nicht gestellt, sondern der Inhalt vom Probanden während der Beantwortung der vorhergehenden Frage mitbehandelt: 1. Einteilung in 
zwei Arten von Schäden: a. par frottis, b. par abroutissement (26:46); 2. auf Wunsch des Fragenden hin Präzisierung des frottis (betrifft die Rinde); wird als der schwerwiegendere Schaden eingestuft; Präzisierung des abroutissement (die Blätter werden gefressen)

S-lex: Def. des Probanden stimmt inhaltlich mit der im Lexicon Silvestre angegebenen Def. überein

D-Verh: Bei der Erklärung der Schäden scheint der Proband das Phänomen des abroutissement (Punkt b) durch seine Gestik zu veranschaulichen (Geräusch). P: 26:45, L: 00:59

\section{Pierre de B. (LF1):}

I-Antw: Einschätzung der Situation: stuft die Wildschäden als "considérable" (26:38) ein

I-Beurteilg: äußert sich persönlich zum Beispiel des Rentners (s. D-Bsp), das er abgibt: "Et eh... c'est du gaspillage. Et en plus, pour faire plaisir à qui? A des gens qui, qu'il connaît pas, hein." (Z* 27:39)

I-Org: 1. spontane Antwort; 2. unterscheidet zwischen a. dégâts réels und b. dégâts psychologiques: zu a.: "Vous avez un plan, il est esquinté par...le machin." (Z* 26:48), zu b.: "Et le dégât psychologique, c'est que les gens plantent pas." ( $\left.Z^{*} 26: 51\right)$; 3. Frage, auf welche Weise den jungen Bäumen geschadet wird: "Premièrement, il broute." ( $Z^{*}$ 28:09) und kurze Erklärung; 4. Frage nach dem frottis: "Le frottis, c'est, c'est les jeunes plants." (Z* 29:17); erklärt das Verhalten des Rehs, das entweder seine Hörner an den Bäumen abstößt oder sein Revier markiert: "Ça pèle l'écorce." (Z* 29:47); 5. Nachfrage zu den Schutzmaßnahmen für die jungen Bäume: tubes, die allerdings sehr teuer sind (der dreifache Preis der Pflanzen)

S-lex: mehrmalige Wiederholung von aberrant innerhalb der Ausführungen zu den Schutzvorkehrungen gegen Wildschaden: "Il y a, il y a une, bon euh, il y a une aberration là sur le le eh... sur la protection des chevreuils telle qu'il, elle est faite actuellement, qui est... aberrante. C'est, c'est quelque chose d'aberrant." (Z* 27:47) - verdeutlicht seine Erregung (s. auch D-Verh)

D-Biogr: spricht von seinen eigenen Erfahrungen, bei denen Bäume durch abroutissement schwer beschädigt wurden: "C'était spectaculaire. J'avais eh... fait l'éclaircie des chênes d'Amérique justement, dont on parlait tout à l'heure, [...] Ils ont monté très très bien, ils sont sortis à euh quatre-vingts centimètres la première année, et... au bout de quelque temps, ils sont redescendus à vingtcinq centimètres. Et actuellement, ils sont toujours à vingt-cinq centimètres trois ans après. [...] C'est brouté à,... au maximum." (Z*28:22)

D-Bsp: Zur Verdeutlichung der dégâts psychologiques geht er beispielhaft auf die Situation eines Rentners ein, der die ronces bekämpfen und Schutzvorkehrungen gegen das Wild anlegen müsste und für den der Wald somit finanziell 
nicht rentabel wäre.

D-Verh: Händeklopfen auf den Tisch: $(27: 51 ; 30: 09)$ - er ereifert sich im Gespräch, es scheint ihn tatsächlich persönlich zu betreffen (s. I-Beurteilg)

P: 26:31, L: 02:07

Auf den Inhalt der Frage wird bereits im Kontext der vorangehenden Antwort Bezug genommen.

Paul D. (LF2):

I-Antw: "Le chevreuil-c'est surtout le printemps. " (Z* 19:15), "Ah, ils, avec les cornes, ils euh, ils blessent toutes les... les pousses jeunes." ( $\left.Z^{*} 19: 20\right)$

I-Org: 1. Antwort; 2. Verweis auf persönliche Erfahrungen; 3. Nachfrage nach besonderen Schutzvorkehrungen: es hängt davon ab - bei sapins, pins z.B. ist das nicht so einfach, bei den chênes, hêtres, frênes etc. trifft man Schutzvorkehrungen; 4. trotz der Schutzvorkehrungen Probleme, da man zehn Jahre warten muss, bevor diese ihre Funktion richtig erfüllen können; 5. Nachfrage danach, ob die chevreuils die Pflanzen auch fressen: abhängig von den Baumarten, ob sie gefressen werden - wenn, dann ist vor allem die tige betroffen I-Komm: ausführlichere Beschreibung zum Punkt 3 - Aufzählung von Baumarten, bei denen Schutzvorkehrungen getroffen werden; selbständiger Verweis auf trotz der Schutzvorkehrungen entstehende Probleme

S-lex: keine Verwendung der erwarteten Fachbegriffe (le frottis, l'abroutissement), dennoch Beschreibung der Phänomene mit einfachem Vokabular

S-gS: häufig keine vollständigen Sätze; der Proband braucht oft lange, um etwas auszudrücken. Dabei handelt es sich nicht um Gesprächsteile, die viel Fachvokabular aufweisen, z.B. 19:15, 19:20.

D-Biogr: Verweis auf eigene Erfahrungen mit den chevreuils; zeigt Eingebundenheit in das Thema, persönliche Betroffenheit

P: 19:09, L: 00:54

Auf den Inhalt der Frage wird bereits im Kontext der vorangehenden Antwort Bezug genommen.

D.3.f. Est-ce qu'on connaît ici des maladies / fléaux causé(e)s par la vermine (des chenilles, des larves, des coléoptères ou d'autres insectes)?

724: attaque massive / pullulation. Attaque des nuisibles après une pullulation provoquant d'importants dégâts aux organismes de la biogéocénose forestière et à leurs produits. 
725: dénombrement d'insectes par sondage statistique. Comptage des insectes nuisibles (ou utiles) par sondage.

Jean T. (EF1):

I-Alternativ: gefragt ist: "maladies causées par la vermine"-Antwort: "La vermine n'existe pas." ( $\left.Z^{*} 42: 31\right)$, "On appelle vermine ici toute une série d'agents pathogènes-ça s'appelle des champignons[...]" (Z* 42:32); der Eigentümer kann ein Insekt etc. erkennen, ohne den exakten Namen zu wissen; I-Org: 1. Diskussion des Begriffs vermine; 2. Rolle des technicien; 3. Rolle der correspondants du DSF (Département de la Santé des forêts), die sich besser als die techniciens mit allem, was die Feinde des Waldes angeht, auskennen

I-Komm: definiert nochmals die Rolle der techniciens: im Gegensatz zum propriétaire, der die Namen der Insekten, Parasiten nicht kennen muss, muss der technicien sie kennen, sie diagnostizieren und möglichst ein Gegenmittel finden

D-Bsp: gibt Beispiele der attaques massives: "des chenilles" ( $Z * 44: 05)$

D-Verh: sehr sicher, interessiert; freier Redefluss; man erkennt sein persönliches Interesse

P: 42:25, L: 00:56

\section{Paul A. (EF2):}

I-Antw: Frage nach maladies causées par la vermine-Antwort: "Oui. Il y en a, mais là, je suis pas très compétent." (Z* 27:27)

I-Org: 1. Bestätigung der Existenz solcher Krankheiten mit Angabe der geographischen Ansiedlung: "Mais il y en a dans le département. Et il y en a notamment plus vers l'Océan, disons vers l'Atlantique." (Z* 27:35); 2. Bestätigung der Tatsache, dass es in diesem département keine fléaux gibt

D-Biogr: keine persönliche Betroffenheit durch dieses Problem: "Non, moi, j'ai pas eu de problèmes. " ( $\mathrm{Z} * 27: 33)$

P: 27:21, L: 00:36

\section{Pierre de B. (LF1):}

I-Antw: antwortet mit "Pas tellement." (Z*30:21) auf die Frage, ob man in der Region des maladies causées par la vermine kenne

I-Org: 1. Antwort; 2. gibt Schädlinge an: des larves, des insectes, des chenilles $(30: 28)$; 3. Frage, ob es fléaux gebe: bestätigt dies - bezieht sich erneut auf sein Beispiel: "Ah oui, il y a, il y en a, euh, il y a quelques-uns qui sont morts, qui sont, quelques chênes grands, hein, des chênes qui avaient quarante ans. Parce que ils ont été attaqués deux fois,... deux ans de suite." (Z* 30:44); 4. Frage nach einem Gegenmittel: "Oui, il faut traiter par, eh... hélicoptère." (Z* 31:03)-Diese Methode wird nicht angewendet, da sie zu kostspielig ist.

D-Bsp: präzisiert Punkt 2 (I-Org): "Des chenilles. Il y a des années. Il y a, il y 
a des époques, il y a eu, il y a cinq ou six ans, il y a eu une époque sur les chênes, euh, où ça, eh... ça frôlait la catastrophe." (Z* 30:31)

D-Verh: langes Zögern, bevor er antwortet - zeigt sich nicht sehr sicher; Verhalten wird durch die Antwort bestätigt: Er kennt sich auf diesem Gebiet nicht sehr gut aus.

P: 30:13, L: 03:42

Paul D. (LF2):

I-Antwort: "Oh, il y en a de plus en plus de maladies. Même chez les chênes là." (Z* 20:30)

I-Org: 1. Antwort; 2. Stellungnahme zu den Krankheiten: Es gibt immer mehr Krankheitsfälle, auch bei den Eichen; nennt eine spezielle Krankheit: den Mehltau (le mildiou); 3. Nachfrage zur persönlichen Situation; 4. Nachfrage zur konkreten Situation ("Quand il y a un arbre attaqué par la vermine...") Antwort: "Qu'est-ce que vous voulez y faire? On ne peut pas monter en haut pour la laisser tomber." (Z*21:09); 5. Anführung der chenilles

I-Komm: Diese Krankheiten scheinen ihn nicht sehr $\mathrm{zu}$ beunruhigen-keine Vorschläge zur Bekämpfung (s. 21:09)

D-Biogr: "Moi, non, comme je vous dis, ici, c'est du bois de chauffage." $\left(Z^{*} 20: 50\right)$

P: 20:26, L: 01:17

\section{D.3.g. Quand vous voyez une nouvelle plantation d'arbres, pouvez-vous juger de la qualité des plants et du système de plantation? / Vous voyez si c'est bien fait, comme il faut?}

Jean T. (EF1):

I-Antw: "Une nouvelle plantation? Non, la qualité du plant, pas forcément, parce qu'il y a le système racinaire qu'on ne voit pas." ( $\left.Z^{*} 00: 14\right)$

I-Org: 1. keine Beurteilung der Pflanzen möglich - mit Begründung: "Donc, on pourra voir si la partie aérienne est jolie, si les plants sont bien conformés, s'ils sont pas fourchus, si euh, on est, après, après le débourrement, on voit si on a une bonne reprise, si les arbres sont vivants. Par contre, la partie qui est enterrée, donc n'est pas visible, donc, ce sont peut-être des arbres qui n'ont pas un bon enracinement, qui n'ont pas de pivot, ou bien qui n'ont pas de chevelure." ( $Z * 00: 20) ; 2$. Beurteilung der plantation direkt, nachdem sie angelegt wurde, möglich; Aufzählung der Kriterien, die man beurteilen kann, z.B. l'alignement des plants

I-Komm: keine sehr ausführliche Antwort; beschränkt sich auf die wichtigsten 
Kriterien, ohne sie näher auszuführen

P: 00:08 (F2.mp3)

Paul A. (EF2):

I-Antw: ersichtlich, ob das Wachstum der Pflanzen normal ist und die Unterhaltung der Anpflanzung angemessen: "Oui, bon, il faut se rendre bien évidemment dans le peuplement. On voit assez rapidement si la croissance est normale, on voit assez rapidement si l'entretien a été convenable... eh..., oui, ça se voit disons à l'œil relativement facilement." ( $\left.Z^{*} 28: 04\right)$

I-Komm: sehr kurze Antwort, keine ausführlicheren Erläuterungen

P: 27:53, L: 00:32

\section{Pierre de B. (LF1):}

I-Antw: "Tout est relatif, ça, hein." (Z* 31:31)

I-Org: 1. spontane Antwort; 2. Man kann schon eine Beurteilung abgeben: "On aime, on n'aime pas." (Z* 31:36), kommt in diesem Zusammenhang auf die finanziellen Probleme zu sprechen: "C'est très difficile, ça peut pas... le, euh, le gars qui investit dans une, dans une plantation, euh, il mettra... il faut faire un choix, il y a... l'administration peut faire parfaitement... en général." (Z* 31:42); 3. Frage, ob die $D D A$ die Kontrolle übernehme: verneint dieses sei der Eigentümer, der verantwortlich ist, zahlt etc.; 4. Frage, ob es tatsächlich Leute gebe, die all das eigenverantwortlich übernehmen: verweist auf seine eigene Situation (s. D-Biogr); 5. Fortführung des Gesprächs auf einer persönlicheren Ebene, s. D-Biogr.

S-gS: elliptische Sätze, nicht ganz zu Ende geführte Gedankengänge (s. I-Org $31: 42)$

D-Biogr: "Sans subventions? Ah oui, oui, par exemple moi. J'ai jamais eu de subventions. J'ai jamais touché de subventions." ( $Z^{*}$ 32:25); erklärt seine eigene Situation: "J'ai planté... il y a deux ans... deux hectares et demi... eh... $i c i$, j'ai planté, euh,... euh, deux fois un hectare, trois fois un hectare." (Z* 32:34); spricht von seiner Erfahrung vor ca. 20/25 Jahren, als er mit Hilfe der administration 10 ha angepflanzt hat: "Ç'a été une catastrophe." (Z* 32:56), analysiert diesen Fehlschlag: "Et j'ai l'impression qu'ils se sont servis de désherbants... qui étaient pas adaptés ou... à l'époque." ( $\mathrm{Z*}$ 33:29) D-Verh: entspannte Atmosphäre; Der Proband zeigt Humor: "On a fait des bonsaïs merveilleux." (Z*33:35), lacht. (33:02)

P: 31:20, L: 01:07

Paul D. (LF2):

I-Antw: bejaht die Möglichkeit, bei einer neuen Anpflanzung sehen zu können, ob sie gut oder weniger gut angelegt ist 
I-Org: 1. Antwort; 2. auf Nachfrage nach den Kriterien hin antwortet er: "Ah, euh, les plantations sont faites quand même sous la direction de la DDAF qui nous régit tous." ( $\left.Z^{*} 21: 37\right)$; 3. "Et puis, après, ils viennent nous y aider quand même." ( $\left.Z^{*} 21: 51\right)$, "Ils vous conseillent." ( $\left.Z^{*} 22: 02\right)$

D-Verh: bejaht die Frage, ohne selbständig eine Begründung zu geben; erst auf Nachfrage hin liefert er eine Erklärung

P: 21:23, L: 00:57

\section{D.3.h. Vous avez une idée précise des différents soins de plantations? / Quand ça commence à pousser, que faut-il faire?}

408: soins des plantations / aux $\sim$ / dégagement de plantation / soins culturaux / jeunesse / désherbage $\approx$ / entretien des cultures. Ensemble de mesures à effectuer pendant les premiers stades de développement d'un peuplement pour améliorer les conditions de croissance des plants.

\section{Jean T. (EF1):}

I-Aufzählung: 1. auf andere Pflanzen achten, die in der Nähe wachsen-Einsatz von désherbants etc.; 2. auf das Problem der chevreuils achten; 3. Zusammenfassung der Punkte 1 und 2

I-Komm: strukturiert seine Antwort durch mehrmalige Wiederholung des Satzteils "Quand ça commence à pousser", der die jeweiligen Teilantworten einleitet; hier wiederzufinden: die für ihn typische Kurzzusammenfassung des Gesagten am Ende seiner Antwort

D-Verh: wiederholt häufig einen Teil der gestellten Frage, um dann zu antworten, z.B.: "Quand ça commence à pousser? Quand ça commence à pousser, il faut veiller à ce qu'il n'y ait rien d'autre qui pousse trop autour [...]" (Z* 01:03)

P: 00:56, L: 00:48

\section{Paul A. (EF2):}

I-Org: 1. Pflege während der ersten drei Jahre (die Pflanzen bekämpfen, die für das Wachstum der Bäume schädlich sind); Erklärung (in der Region viel Regen, reichhaltige Böden, was die gesamte Vegetation gut wachsen lässt) I-Anordnung: nach Wichtigkeitsgrad: "Ici, le plus important, c'est l'entretien pendant les trois premières années." ( $\left.Z^{*} 28: 31\right)$

I-Komm: beschränkt sich bei der Aufzählung der Maßnahmen lediglich auf die Pflege während der ersten drei Jahre, die ihm sehr wichtig zu sein scheint P: 28:23, L: 00:30 


\section{Pierre de B. (LF1):}

I-Org: 1. sehr schwierig, genau festzulegen, was man zu tun hat; gibt als Grund für diese Schwierigkeit das Rehwild an; 2. grundlegende Notwendigkeit: "S'il $y$ avait pas le chevreuil, euh, il faut nettoyer." (Z* 34:04); 3. "L'idéal, ça serait de broyer." (Z* 34:11); 4. geht erneut auf das Problem des Rehwildes ein, durch die man z.T. 10, 20, $30 \%$ der Anpflanzung verlieren kann, wenn sie ungeschützt ist; 5. Erläuterungen zu den Schutzmaßnahmen gegen die Rehe (Schutzvorkehrungen in Form von tubes oder grillages)

I-Komm: große Bereitschaft, sich mitzuteilen und auf Details einzugehen D-Biogr: war persönlich betroffen: "Moi, je m'en suis pas servi de grillages du tout. J'avais des tubes." (Z* 35:24)

D-Verh: zeigt große Sicherheit, scheint sich im Gespräch sehr wohlzufühlen P: 33:48, L: 02:28

\section{Paul D. (LF2):}

I-Antw: "Moi je crois que pour les planter, il faut les planter le mois de novembre." ( $Z * 22: 17)$

I-Org: 1. spricht den günstigsten Zeitpunkt für das Pflanzen an; 2. wird nach dem Grund für die Bestimmung dieses Zeitpunktes gefragt; 3. Frage, ob die Anpflanzung manchmal gesäubert werden muss: wird bejaht - zweimal jährlich; Erwähnung und auf Nachfrage hin Nennung eines Produktes (Velpar)

I-Komm: keine Angabe der wirklichen Kriterien der Pflege, außer, auf ausdrückliche Nachfrage hin, der Erwähnung eines Produktes

D-Verh: sehr lange Pausen innerhalb der Antwort; der Fragesteller gibt oft Hilfeleistung, damit der Proband die begonnenen Sätze beendet, z.B. 22:26; Proband: "Il a été..." (Z* 23:01) - Fragesteller "...pas fort quoi." (Z* 23:03); Der Proband äußert seine Schwierigkeiten, das auszudrücken, was er weiß: "Je sais pas comment dire." (Z* 23:07); elliptische Sätze: "Il n'a pas suffisamment de racines pour alimenter le..." $\left(\mathrm{Z}^{*} 23: 10\right)$

P: 22:07, L: 00:44

\section{D.3.i. 'Pincer' ( les branches gourmandes, les pousses latérales), ça veut dire quoi en sylviculture?}

430: pincer / les branches gourmandes / pousses latérales / couper les branches gourmandes. Supprimer les pousses latérales du fût avec un sécateur ou une pince coupante.

\section{Jean T. (EF1):}

I-Org: 1. erklärt die zwei Wachstumsphasen eines Baumes innerhalb des Jahres: a. période de l'élongation, b. période de la lignification; 2. erklärt auf 
diesem Hintergrund pincer: "Pincer un arbre c'est, c'est couper avec des ongles ou un petit sécateur dans certains cas un arbre qui n'a pas fini son élongation, c'est-à-dire qu'on coupe la partie qu'il est en train de se développer, de, de, de développer." (Z* 01:59); 3. auf Nachfrage hin: Erklärung von: "pincer les pousses latérales" ("Celles qui concurrencent." ( $Z^{*}$ 02:31)) und "pincer les branches gourmandes: Les branches gourmandes, ce sont des branches qui se développent le long du tronc et les pousses latérales... Quand un arbre, ce qu'on veut, c'est qu'il soit comme ça, on veut pas qu'il soit comme ça, arrondi. Donc, vous avez la pousse terminale et si vous avez des parties, d'autres, des pousses latérales qui commencent à devenir trop importantes et dépasser le bourgeon terminal,... tic." (Z* 02:36)

I-Komm: fragt nach (Missverständnis): "passer. "-Richtigstellung durch den Fragenden: "pincer - Ah, pincer, oui, pincer, oui, oui, bien entendu." (Z* 01:38); erklärt die zwei Phasen zweimal auf unterschiedliche Art: zuerst mit den Fachbegriffen, dann nochmals etwas einfacher; innerhalb der Antwort, rekapitulierend: "Voilà ce qui s'appelle 'pincer'." (Z* 02:20); zeigt etwas zur Veranschaulichung der Wuchsform des Baumes mit einem Gegenstand (Geräusch): "Ce qu'on veut, ce qu'il soit comme ça. On ne veut pas qu'il soit comme ça., arrondi." (Z* 02:42); auch am Ende veranschaulichende Beschreibung: Erklärung wird durch verstärktes Klopfen auf den Tisch untermauert $(02: 49)$

S-lex: gibt eine Alternative zu dem von ihm zuerst benutzten Begriff an: "La lignification, qu'on appelle l'aoûtement." ( $Z^{*}$ 01:51); "tic" ( $Z^{*}$ 02:53)Lautsprache zur Veranschaulichung des Schneidevorgangs; sehr große Begriffspräzision bezüglich der pousses latérales und der branches gourmandes (s. Def. unter I-Org)

D-Verh: ist sofort bereit, Zusatzinformationen zu geben; auf die Nachfrage zu den pousses latérales und branches gourmandes hin steigt er direkt in die Erklärung ein und gibt sich nicht nur damit zufrieden, anzugeben, ob er diese Begriffe kennt oder nicht.

P: 01:34, L: 00:38

\section{Paul A. (EF2):}

I-Org: 1. spontane Antwort: hat davon gehört; 2. Begriff, der eher im Bereich des jardinage benutzt wird, nicht im Bereich der arboriculture: "En arboriculture, moi, je n'ai pas fait cette chose-là." (Z* 29:27); es handelt sich für ihn um einen terme horticole

I-Komm: keine Kenntnis der Technik, die im Lexicon Silvestre unter ' 430 definiert wird

S-lex: keine Eingliederung des Begriffs in den Fachbereich, der ihm vertraut ist 
D-Verh: scheint sich in diesem Bereich nicht ganz so sicher zu fühlen und antwortet dementsprechend vage und ausweichend (s. I-Org: cette chose-là) P: 29:10, L: 00:47

$Z^{*}: 29: 27$

\section{Pierre de B. (LF1):}

I-Def: "Pincer, c'est, c'est enlever le, c'est quand un bois est très, très... friable, il n'est pas aoûté. Je sais pas,... Et euh, vous pincez ou vous recoupez avec les doigts le bout, le bout de eh... de la tige." ( $\mathrm{Z}^{*}$ 35:53)

I-Beurteilg: sieht dieses Verfahren im Waldbau nicht sehr häufig angewendet I-Komm: kurze Antwort, die aber inhaltlich mit der des Experten übereinstimmt (s. Touyarou, I-Org)

P: 35:46, L: 01:58

\section{Paul D. (LF2):}

I-Antw: Methode ist erst im 3. oder 4. Jahr anwendbar

S-lex: vom Fragesteller vorgeschlagene Alternative: "On dirait plutôt 'couper'" wird bestätigt

D-Verh: Nachfrage zur Fragestellung-der Begriff scheint nicht bekannt zu sein; keine Stellungnahme zum Begriff oder Definition, sondern direkter Bezug zur Praxis (weist auf seine praktischen Erfahrungen hin)

P: 24:25, L: 02:18

\section{Sylviculture et écologie de la forêt}

\section{D.4.a. Avez-vous déjà entendu parler de la 'production soutenue' ou du 'rendement soutenu' en foresterie. Vous pouvez expliquer ce que c'est?-La notion de 'gestion durable' vous dit quelque chose?}

802: production soutenue / rapport / rendement soutenu. Mode d'aménagement caractéristique des forêts qui vise à ce que tous les rôles qui lui sont assignés aux plans écologique, économique et social soient durablement remplis, et d'une manière optimale.

\section{Jean T. (EF1):}

I-Kenntn.d.Begr.: kennt den Begriff production soutenue / rendement soutenu, ohne ihn in den Versammlungen zu benutzen

I-Org: 1. Kommentar zur Anwendung des Begriffs; 2. Definition des Begriffs: "La production soutenue, c'est une production intensive, c'est-à-dire le maxi- 
mum de ce que peut faire, produire une forêt, c'est-à-dire une sylviculture intensive." ( $Z^{*}$ 03:08); 3. auf Nachfrage hin: Erklärung der gestion durable: "La gestion durable vient du congrès de Rio qui a décidé que tout produit devrait être issu d'une gestion durable, c'est-à-dire en d'autres termes, une sylviculture adaptée de façon à ne pas compromettre aussi l'avenir de la forêt." (Z* 03:55)

S-lex: Begriff, den er alternativ vorschlägt: production intensive

D-Verh: Zögern bei der Nachfrage nach der gestion durable: kurze Unsicherheit, die er aber sofort in den Griff bekommt; er erklärt sein Zögern: "Là, on est dans les termes qui sont plus nouveaux." ( $Z^{*}$ 03:51); Erklärung des Ursprungs des Begriffs; trotzdem noch leichtes Stottern (04:02); hat am Ende der Antwort seine alte Sicherheit wiedergefunden

P: 02:58, L: 01:24

\section{Paul A. (EF2):}

I-Kenntn.d.Begr.: gibt an, den Begriff zu kennen, wobei die Definition jedoch von der im Lexicon Silvestre unter ' 802 angegebenen abweicht: "Oui, une production ou un rendement soutenu, c'est le fait d'un peuplement qui crôt normalement par rapport à la moyenne locale et qui même, disons, va vers une excellente productivité, quoi, de l'accroissement annuel des arbres." $\left(Z^{*} 29: 53\right)$

I-Org: 1. Def. des Begriffs (s. I-Kenntn.d.Begr.); 2. Nachfrage nach dem Begriff gestion durable: a. Beurteilung des Begriffs: "La gestion durable est un mot à la mode maintenant." (Z* 20:23), b. Definition des Begriffs; 3. Nachfrage nach der Kenntnis des Begriffs foresterie: er wird benutzt, ist aber nicht geläufig; der Fragesteller deutet an, dass dieser Begriff aus einer anderen Gegend stammen könnte, wo er eventuell häufiger benutzt wird. Diese Möglichkeit unterstützt der Proband.

S-lex: Abgrenzung des Begriffs rendement soutenu / production soutenue vom Begriff gestion durable, den er folgendermaßen definiert: "Bon, la gestion durable est un mot à la mode euh, maintenant, euh, bon qui qui consiste euh à..., certainement à... à gérer euh dans de meilleures conditions et comme on l'indique eh... dans le temps, c'est-à-dire, pas, pas, pas à court terme, à moyen terme et à long terme." (Z* 30:22)

D-Verh: Bei Punkt 3 wirkt der Proband nicht sehr sicher und bejaht die ihm vom Fragesteller vorgeschlagene Möglichkeit (Gebrauch des Begriffs in einer anderen Gegend), ohne dass man weiß, ob er tatsächlich davon überzeugt ist. P: 29:45, L: 00:35

Pierre de B. (LF1):

I-Kenntn.d.Begr.: kann mit dem Begriff rendement soutenu nichts anfangen 
I-Org: 1. Diskussion über den Begriff foresterie, (s.u. S-lex); 2. Antwort zu dem Begriff rendement soutenu; 3. Nachfrage zu dem Begriff gestion durable: kennt den Terminus und definiert ihn folgendermaßen: "Ben, c'est, c'est de prévoir, euh, une gestion de la forêt, eh... puisque la forêt, c'est à très longue échéance, de prévoir euh ce qu'on va faire euh dans les cinq, dix euh vingt ans, hein." ( $\mathrm{Z} * 37: 32)$

S-lex: nimmt den in der Frage vorkommenden Terminus foresterie auf und hinterfragt seine Existenz: "En foresterie... Ça se dit, foresterie?" (Z* 36:33)Dieser Begriff ist dem Probanden demnach nicht geläufig. Alternativ schlägt er culture forestière vor.

D-Biogr: "Par exemple, moi, que si je plante maintenant, j'ai beaucoup planté de l'acacia. Ben, eh... je dis, voilà, dans vingt ans euh, ils seront coupés, euh, ça sera." (Z* 37:52)

D-Verh: hinterfragt den Begriff foresterie, (Anm.: Der Begriff stammt aus dem kanadischen Französischen und ist in Frankreich als terminus technicus wenig geläufig): "C'est la première fois que je l'entends." (Z* 36:45); Lachen nach der von ihm gestellten Frage (36:36)-amüsiert sich offensichtlich, humorvoll: "Vous êtes sûr que c'est français, foresterie?" (Z* 36:48)

P: 36:25, L: 00:39

Paul D. (LF2):

I-Antw: "Oui, mais ici, c'est pas le cas." (Z* 24:54)-keine genaue Auskunft darüber, welche Methode in seiner Region angewendet wird - "C'est du rendement." (Z* 25:06)

I-Kenntn.d.Begr.: Die Antwort des Probanden lässt darauf schließen, dass ihm der Terminus bekannt ist, obwohl er im Folgenden nicht weiter erläutert wird. D-Verh: keine Definition, lediglich Verweis darauf, dass dieses Phänomen für seine Region nicht von Bedeutung ist

P: 24:48, L: 00:23

\section{D.4.b. Le 'jardinage', qu'est-ce que ça veut dire en tant que terme fo- restier?}

235: exploitation par la méthode du jardinage / jardinage / traitement en futaie par bouquets $[\mathrm{CHE}]$ / régime de la coupe progressive / par groupes et bouquets / jardinage par bouquets / traitement par coupes progressives en bouquets / en futaie par parquets / mode de régénération $\sim \sim / \sim \sim \sim$ bouquets / système des coupes progressives [CAN]. Régime sylvicole particulier du traitement en futaie régulière par coupes (à caractère) jardinatoire faisant progresser lentement la régénération (naturelle ou artificielle) par bouquets. 
236: futaie jardinée / forêt $\sim$. Une des formes de futaie comprenant des arbres à tous les stades de développement répartis sur de petites surfaces.

237: jardinage / régime du jardinage / traitement en futaie jardinée . / par la méthode du jardinage $\approx$. Régime sylvicole appliquée aux futaies jardinées.

219: jardiner / traiter en jardinage / coupes jardinées / faire du jardinage. Exploiter des arbres choisis individuellement (ou par petits groupes) pour obtenir ou maintenir une futaie de type jardiné en assurant simultanément les soins nécessaires, la récolte et la régénération.

218: coupe jardinatoire / à caractère jardinatoire / progressive / par groupes / jardinage par bouquets / femel coupe / coupe de jardinage par bouquets / jardinatoire par bouquets / par trouées / bouquets . Coupe portant sur des petites surfaces (jusqu'à 0,5 ha) irrégulièrement distribuées dans le peuplement et ayant pour objectif soit une régénération naturelle (conduite lentement) soit une régénération artificielle.

\section{Jean T. (EF1):}

I-Org: 1. Definition des Begriffs jardinage: "Une forêt est dite jardinée quand on a sur une même parcelle des arbres d'âge différent. D'accord." ( $\mathrm{Z}^{*}$ 04:38); 2. setzt der forêt jardinée die forêt régulière begrifflich gegenüber: "Au contraire, c'est..., d'une futaie jardinée, c'est une forêt régulière. Dans les Landes, vous avez sur quarante hectares un arbre, le pin maritime, ils ont tous été semés, plantés en même, en même temps. Vous allez en montagne, vous avez des sapins qui ont cent-vingt ans, vous en avez des petits qui ont dix ans, des semis de un an, vous avez de ces arbres de 40 ans. C'est une forêt irrégulière." (Z* 04:43); 3. Beurteilung der beiden Methoden: a. Vorteile der forêt irrégulière: kontinuierlicher Erhalt des Waldzustands (Vegetation verschiedenen Alters); besonders wichtig im Gebirge; 4. auf Nachfrage nach anderen méthodes d'aménagement hin: Erklärung der forêt régulière: verweist auf die Alternativen: coupe rase und replantation oder régénération naturelle; 5. nochmalige Gegenüberstellung forêt régulière und jardinage unter dem Aspekt der notwendigen Arbeitsmethoden; 6. kritische Reflexion

S-lex: Einführung und Erklärung neuer Fachtermini (forêt jardinée ou irrégulière); benutzt die Synonyme parallel, um sie tatsächlich auch im Verständnis des Hörers gleichzusetzen

S-gS: beginnt Satz, den er nicht weiterführt (Ellipse): 04:34

D-Bsp: gibt konkrete Zahlen für die Region Landes (04:47) an, um die forêt régulière zu demonstrieren; Berge als Beispiel für den Begriff forêt irrégulière (04:53); zur Veranschaulichung: Beispiel aus dem Garten: (05:50)

P: 04:30, L: 01:32 
Paul A. (EF2):

I-Kenntn.d.Begr.: hat von diesem Begriff gehört, den er nicht zum Vokabular eines forestier rechnet

I-Org: 1. Antwort; 2. Versuch einer Def. des Begriffs: "Jardinage ne peut vouloir dire que, ne peut être qu'une allusion aux petites parcelles, aux microparcelles." (Z* 31:21)

P: 31:03, L: 01:18

\section{Pierre de B. (LF1):}

I-Kenntn.d.Begr.: kennt den Begriff

I-Def: "C'est une manière, manière de, euh travailler la, la forêt, et euh, à la différence, j'allais dire, de euh de quelqu'un qui va euh décider que sur toute une euh pièce, on va euh le couper, faire une coupe à plat, hein, et tandis que le jardinage vous enleverez les arbres, les arbres abîmés, euh, non productifs, eh." (Z* 38:16): gegenüber anderen Verfahren, die sich auf das gesamte Waldstück beziehen, werden bei dem jardinage nicht alle Bäume zum gleichen Zeitpunkt behandelt

I-Komm: gerät an einer Stelle der Antwort etwas ins Stocken, löst diese Situation auf, indem er sich auf eine konkrete Situation bezieht (s. D-Bsp)

D-Bsp: verdeutlicht das Gesagte unter Verweis auf die entsprechende Demonstration während einer tournée forestière: "Tenez, l'autre jour où nous étions, il nous disait euh, la, la première station euh, il fait un, un, en... [?] clairière et là-dedans, il va planter quelques arbres de sang. C'est du jardinage, ça." (Z* 38:50)

P: 38:03, L: 01:38

Paul D. (LF2):

I-Antw: Frage wird vom Probanden verneint

P: 26:00 (Frage im Anschluss an die darauffolgende Frage gestellt), L: 00:46

\section{D.4.c. Y a-t-il d'autres méthodes / des méthodes différentes de faire une coupe? (C'est-à-dire, on coupe tous les arbres d'un peuplement d'un seul coup ou seulement quelques-uns?)}

206: régime sylvicole / méthode d'aménagement / de traitement / régime / forestier / mode de traitement / régime $\sim \sim$ / mode d'exploitation / d' $\sim$ des forêts / genre de régime / traitement sylvicole / système [CAN]. Méthode de gestion d'une forêt au moyen des techniques sylvicoles, p.ex. régime de futaie. 
211: futaie à coupes réglées / régulière / forêt à coupe réglée / futaie traitée par coupes [CHE]. Mode d'aménagement d'une futaie où chaque peuplement est complètement régénéré, en une fois sur toute sa surface, pendant une période de régénération de durée limitée.

232: méthode de la coupe d'abri / mode de régénération par coupes progressives / régime de coupes d'abri / traitement en futaie régulière avec régénération par coupes d'abri / traitement par coupes progressives $\approx$. Régime sylvicole appliqué aux futaies à coupes réglées avec comme but de la régénération artificielle ou naturelle sous abri réduisant en déserrant et éliminant graduellement l'abri.

230: mode de régénération par coupes progressives uniformes / méthode $\sim \sim \sim \sim$ assises sur de grandes surfaces / coupe de futaie régulière / régime de la coupe d'abri par grandes surfaces. Méthode de la coupe d'abri appliquée (à peu près systématiquement) à toute la surface à régénérer en même temps.

231: structure d'abri / ouverture du couvert. Répartition des arbres d'un peuplement créée par une coupe d'abri ou un boisement transitoire.

233: mode de régénération par coupes progressives en bandes / méthode de coupe en lisière / système des coupes progressives en bandes / traitement par $\sim$ en lisière. Régime sylvicole caractérisé par régénération naturelle sur des lisières progressant graduellement.

423: traitement par éclaircies très fortes / méthode par coupes d'éclairement. Régime sylvicole caractérisé par des éclaircies fortes dans le couvert pour obtenir, pour les arbres de qualité élevée, un fort accroissement en diamètre dans une période relativement courte (et préparer la régénération).

\section{Jean T. (EF1):}

I-Def: konkrete Frage nach dem coupe d'abri; gibt kurze, verständliche Def. I-Org: 1. a. Definition, die vor der Unterbrechung gegeben wird: "Coupe d'abri, c'est euh, on fait une coupe d'abri quand on coupe certains arbres mais qu'on en conserve d'autres pour protéger les, notamment les plantations." (Z* 06:37), b. Definition, die nach der Unterbrechung gegeben wird: "Une coupe d'abri, c'est une coupe d'arbres mais dont on veut conserver le couvert de certains autres qui restent pour protéger des jeunes. Donc, on fera des plantations sous abri, on fera des coupes d'abri sur des jeunes semis qui existent déjà ou des jeunes plantations. On attend des arbres qui restent un abri contre le gel et contre le vent." (Z* 06:52); 2. Methode zu schwierig, daher kaum angewendet

I-Komm: Unterbrechung durch Telefonat; die vor dieser Unterbrechung gege- 
bene und die danach gegebene Def. ähneln sich sehr (s. I-Org): zeigt, dass das Wissen so präsent ist, dass es jederzeit abgerufen werden kann und immer auf ähnliche Weise wiedergegeben wird

P: 06:31, L: 02:01

\section{Paul A. (EF2):}

I-Aufzählung: 1. la coupe rase; 2. le balivage

I-Org: 1. Anführung der beiden verschiedenen Arbeitstechniken; 2. Verbindung verschiedener Baumarten mit der jeweiligen Technik (des résineux: coupe rase, des chênes pédonculés oder chênes rouges d'Amérique: coupe d'éclaircie); 3. Erklärung der unterschiedlichen Ziele der coupes d'éclaircie: a. die schönsten Bäume entnehmen, damit die anderen noch besser wachsen können, b. die Bäume der schlechtesten Qualität werden entnommen, damit die anderen wachsen: "Et une éclaircie, il peut y avoir deux sens. Il peut y avoir des arbres en haute futaie où on enlève les plus beaux pour garder les, ceux qui doivent encore pousser. Et éclaircie ou balivage peut être valable également dans des taillis où là, on fait l'inverse. On garde les plus beaux pour, et on coupe les plus, les sujets les plus mauvais disons pour que les autres poussent. Mais dans un cas, dans le premier cas, c'est qu'on coupe les plus beaux sujets pour faire du bois d'œuvre, tandis que dans le deuxième cas, on coupe les plus mauvais pour faire du bois de chauffage. C'est tout à fait différent." $\left(Z^{*} 32: 12\right)$

I-Komm: führt selbständig einen neuen Fachbegriff ein (coupe d'éclaircie), den er sehr ausführlich und umfassend darlegt; gute, verständliche Darstellung S-lex: Neueinführung des Begriffs coupe d'éclaircie

D-Verh: erscheint während dieser Antwort sehr sicher P: 31:27, L: 00:24

\section{Pierre de B. (LF1):}

I-Antw: "Les termes, je les connais peut-être, mais ça me vient pas maintenant à... l'idée." (Z*39:12)

I-Aufzählung: l'exploitation complète oder l'exploitation dirigée: Waldstück wird einheitlich auf eine Art und Weise bearbeitet - stellt dieser Methode die der jardinage gegenüber: "Le jardinage, c'est eh... euh, c'est plus soigné, si vous voulez." ( $\mathrm{Z} * 39: 50)$

S-lex: erläutert unbewusst sein fachsprachliches Wissen: er kennt die Inhalte, ohne immer die entsprechenden Fachtermini zuordnen zu können (s. I-Antw) P: 39:05, L: 01:02 
Paul D. (LF2):

I-Org: 1. bestätigt, dass es verschiedene Arten gibt, einen Baum zu schlagen; 2. Aussage zum Hieb: Man lässt immer die schönsten Bäume: "On fait,... on dit qu'ici, on laisse toujours les, les, les plus beaux." ( $\mathrm{Z}^{*}$ 25:28); 3. Einschränkung der unter Punkt 2 gemachten Aussage: man muss trotzdem den Platz zwischen den Bäumen berücksichtigen: "Et puis après, il faut un espace quand même. Je vois que le chêne, c'est euh adulte, c'est, c'est c'est quatrevingts, quatre-vingts hectares. Et encore, je sais pas." ( $\left.Z^{*} 25: 43\right)$

I-Komm: keine sehr vollständige Aussage; man erkennt nicht, wie weit das Wissen des Probanden in diesem Punkt reicht und ob er persönliche Erfahrungen auf diesem Gebiet zu verzeichnen hat oder nicht.

P: 25:14, L: 00:26

\section{D.4.d. Quand on veut profiter du bois, on doit faire des éclaircies de temps en temps. Vous pouvez dire pourquoi, quand et comment? [Vous faites la différence entre 'éclaircir par le haut' et 'éclaircir par le bas'?]}

419: rotation / des éclaircies / périodicité / des éclaircies / intervalle entre éclaircies / les éclaircies / des éclaircies / cycle d'éclaircies. Intervalle de temps (planifié) entre deux éclaircies effectuées sur une même parcelle.

418: éclaircir / faire une éclaircie / pratiquer / effectuer. Verbe désignant les soins à apporter à un peuplement ayant dépassé le stade du fourré. Enlever un certain nombre d'arbres, pour augmenter l'espace de croissance de ceux qui restent, sans interrompre le couvert d'une façon définitive, en ayant comme but d'améliorer la qualité et la stabilité du peuplement sur pied ainsi que celle des horizons supérieurs du sol et d'obtenir du bois brut.

422: éclaircie par le haut. Type d'éclaircie au cours de laquelle sont surtout enlevés des arbres dominants au bénéfice des autres arbres dominants - des arbres d'avenir - de meilleure qualité.

421: éclaircie par le bas. Type d'éclaircie au cours de laquelle sont surtout enlevés les arbres appartenant aux classes sociologiques inférieures, mais, suivant la force de cette intervention, également des arbres dominants malades et de mauvaise qualité. 
Jean T. (EF1):

I-Org: 1. erklärt, warum "de temps en temps"; 2. äußert sich zu dem Aspekt "comment" der Frage; 3. erläutert einige Arten von éclaircie; 4. Zusammenfassung: stellt der éclaircie sanitaire (bei Krankheit des Baumes) die éclaircie sylvicole (wenn die Bäume zu dicht stehen) gegenüber; 5. auf Nachfrage hin: Erklärung von rotation

I-Komm: achtet sehr genau auf die Fragestellung und reagiert auf alle dort angesprochenen Gesichtspunkte, indem er sie geordnet, der Reihe nach bearbeitet; gibt Schlagwörter, die er nicht alle erklärt, was er aber begründet: "Ça nous mènerait trop loin dans la description, mais on a des éclaircies sanitaires, on a des éclaircies sylvicoles, on a des coupes d'amélioration." (Z* 07:42); er erklärt lieber Allgemeines-die Grundtendenz: "[...] on a plusieurs types d'éclaircies. Mais généralement, on éclaircit un peuplement quand il est trop serré ou bien quand il présente des problèmes sanitaires importants $[\ldots]^{\prime \prime}\left(Z^{*} 07: 57\right)$

Typisches Vorgehen des Probanden: erklärt grundsätzlich wichtige Dinge, bei denen er Details erwähnt, in die er sich jedoch nicht verstrickt, wodurch sein Diskurs übersichtlich bleibt, ohne zu ungenau zu sein (erinnert an ein Lexikon, das Definitionen gibt mit entsprechenden Verweisen, die ersichtlich machen, dass mehr Wissen vorhanden ist, das aber zu weit führen würde)

S-lex: verschiedene Fachbegriffe zu den verschiedenen Arten von éclaircies, die erklärt werden

D-Bsp: 08:52: gibt immer Beispiele für seine Erklärung: große Praxisbezogenheit

D-Verh: verstärktes Händeklopfen, vor allem gegen Ende der Antwort P: 07:24, L: 00:53

\section{Paul A. (EF2):}

I-Antw: Antwort auf diese Frage zum größten Teil bereits bei der Beantwortung der vorhergehenden Frage behandelt

I-Frage: Frage nach der anzuwendenden Technik für die coupe d'éclaircie

I-Org: 1. Erklärung der Technik: Ziel ist eine gute Verteilung der Bäume auf dem Landstück, wobei nicht systematisch vorgegangen wird (man entfernt z.B. nicht jeden zweiten Baum); 2. Nachfrage nach dem Terminus rotation: a. bekannter Begriff, der in der Landwirtschaft verwendet wird, b. Erklärung des Terminus (allerdings nur auf ausdrückliche Nachfrage hin)

D-Verh: längeres Zögern nach dem Bejahen der Frage; man bekommt den Eindruck, als sähe der Proband die Frage damit als ausreichend beantwortet an. Auf Ermunterung seitens des Fragestellers hin wird die Antwort dann doch fortgesetzt.

P: 32:50, L: 01:23 
Pierre de B. (LF1):

I-Org: 1. "Premièrement, il y a des époques suivant la croissance, il y a des époques de croissance, et il faut éclaircir de manière euh à... à pouvoir avoir des arbres qui se développent correctement." (Z* 40:11); erklärt, dass jeder Baum ein bestimmtes Potential hat, aber genügend Raum braucht ("un espace vital" 40:33); 2. erläutert eine im Norden praktizierte Methode, die méthode française genannt wird: Es werden 10.000 Setzlinge pro Hektar gepflanzt. Danach wird durchforstet, so dass die Bäume, die bestehen bleiben, so viel Platz wie möglich haben. Nachteil: "Les arbres poussaient en massifs, très serrés." (Z* 41:19); 3. Nachfrage, ob für das Lichten bestimmte Perioden zu beachten seien: er bestätigt dies: "On sait qu'à certaines périodes là,... on aura besoin d'éclaircir, quoi." (Z* 41:31); 4. Frage nach der Existenz einer bestimmten Technik des Lichtens: a. la technique systématique, die er erklärt; b. le jardinage; 5. Frage, welche Methode in den natürlich gewachsenen Wäldern angewendet werde: die Methode des jardinage

I-Komm: kann die Perioden, während denen gelichtet wird, nicht genau angeben, verweist hier auf die Spezialisten: "Les spécialistes sont... assez compétents." ( $\left.Z^{*} 41: 36\right)$

P: 39:59, L: 00:54

Paul D. (LF2):

I-Org: 1. Antwort schon beim Stichwort éclaircies: "On le fait l'hiver, ça. Quand la feuille est tombée. Quand la sève est tombée, quoi." ( $Z^{*}$ 26:27); 2. Nachfrage zur Häufigkeit: Gegenüberstellung ,früher' - ,heute':"C'est-àdire, avant, on le faisait, ça se faisait plus que maintenant. Parce qu'il y avait le chauffage ici, c'était au bois." (Z* 26:41), "Et les éclaircies, c'était un peu pour ça aussi." (Z* 27:00); 3. Beurteilung der heutigen Situation als weniger vorteilhaft (Wälder entwickeln sich schlechter, wenn sie selten gelichtet werden)

D-Verh: äußert sich ausführlicher zu dieser Frage; setzt immer wieder neu zur Antwort an, selbst wenn der Fragesteller offensichtlich schon zur nächsten Frage übergehen möchte; Frage scheint ihn zu interessieren

P: 26:13, L: 00:13

D.4.e. Quelles sont les techniques (sylvicoles) que vous connaissez pour améliorer le bois? (coupe d'amélioration, coupe d'extraction des arbres de mauvaise qualité, soins des plantations, élaguer, amélioration hydrique)

205: technique sylvicole. Domaine partiel de la sylviculture comprenant les mesures sylvicoles pour atteindre les buts de culture et de régénération. 
424: coupe d'amélioration $/ \sim$ à caractère cultural / d'entretien $/ \sim$ d' $\sim$ des peuplements / $\sim$ d'éducation / d'éclaircie / éducative / éclaircie $\approx$. Enlèvement d'arbres dans un peuplement non arrivé à l'âge d'exploitabilité qui vise, en première ligne, à améliorer le peuplement restant sur pied et à régulariser l'espace vital dont dispose chaque arbre.

428: coupe d'extraction des arbres de mauvaise qualité / d'amélioration / extraction de mauvais bois / coupe de nettoiement. Enlèvement des arbres de peu de valeur d'un peuplement (pour favoriser la croissance de ceux de grande valeur).

408: soins des plantations / aux $\sim$ / dégagement de plantation / soins culturaux / jeunesse / désherbage $\approx$ / entretien des cultures. Ensemble de mesures à effectuer pendant les premiers stades de développement d'un peuplement pour améliorer les conditions de croissance des plants.

431: élaguer / ébrancher . / émonder / ébrancher sur pied. Eliminer des branches et la partie inférieure d'un fût afin de récolter plus tard du bois d'œuvre de grande valeur.

413: amélioration hydrique de la forêt / du sol forestier / des caractéristiques hydriques d'une forêt. Amélioration durable des propriétés de la station au moyen de l'irrigation et du drainage pour favoriser la production ligneuse.

\section{Jean T. (EF1):}

I-Aufzählung: 1. faire des tailles de formation-l'élagage; 2. les soins contre la végétation concurrente; 3 . l'extraction des arbres malades

I-Komm: bei der Nachfrage nach der amélioration hydrique: kennt den Begriff nicht unbedingt, zieht für sich eine Schlussfolgerung und versucht eine dennoch präzise Def: "enlever un excès d'eau" ( $Z^{*}$ 09:57)

D-Verh: typisches Nachfragen vor der Antwort: "En coupe? En matière de coupe." (Z* 09:21)

P: 09:06, L: 01:42

\section{Paul A. (EF2):}

I-Antw: "L'améliorer, c'est l'entretien. " (Z* 34:15)

I-Aufzählung: 1. l'élagage; 2. l'entretien de la forêt; 3 . débroussailler chez des jeunes plantations; 4 . dans des chênaies couper des lierres qui poussent le long des arbres; 5. auf Nachfrage hin: couper les arbres de mauvaise qualité I-Komm: fasst abschließend die Punkte 3 und 4 der Aufzählung unter l'entretien zusammen: "L'entretien, c'est tout cela." (Z*34:39)

P: 34:05, L: 01:15 


\section{Pierre de B. (LF1):}

I-Antw: "J'ai, j'en ai entendu beaucoup parler, mais je n'ai pas trouvé la bonne." ( $\left.Z^{*} 42: 35\right)$

I-Org: 1. Antwort; 2. Vorgabe von zwei Methoden durch den Fragesteller: a. la coupe d'extraction des arbres de mauvaise qualité, b. l'élagage: Der Proband präzisiert den Punkt élagage: "Oui, mais ça, c'est dans la plantation jeune." (Z* 42:51); 3. Nachfrage zu weiteren Methoden: es gebe sehr viele Möglichkeiten, aber es sei eine Frage der finanziellen Mittel; erklärt, dass in den bois médiocres, die in der Region vorliegen, sehr viel getan werden müsste, was aber aufgrund des fehlenden Gewinns nicht möglich ist; 4. Frage nach der amélioration hydrique: ist dem Probanden nicht bekannt, erst nach weiterer Erklärung weiß er, was gemeint ist-diese Methode werde in der Region nicht angewendet; 5. Frage nach dem drainage: in der Region sei dies unnötig D-Biogr: bei der Äußerung zu den Punkten 4 und 5 Verweis auf die Vorgehensweise in der Region

D-Verh: Lachen nach der Antwort (42:35)

P: 42:25, L: 02:26

Paul D. (LF2):

I-Org: 1. "Oui c'est-à-dire que maintenant, là, ils cherchent à le faire, ça, mais en plantant d'autres... la même variété, mais... d'autres, d'autres plants que les plants qu'il y a, qu'il y a ici." (Z* 27:48); 2. Nachfrage nach dem Schlagen schlechter Bäume, um den Wald zu verbessern: bejaht dies; 3. Nachfrage nach der amélioration hydrique / drainage: gibt es in der Landwirtschaft, aber nicht im Waldbau

S-gramm: elliptische Sätze; schwierig, den Gedankengang nachzuvollziehen D-Verh: passives Verhalten, reagiert auf Nachfragen, zeigt jedoch keine eigene Initiative

P: 27:33, L: 01:20

\section{D.4.f. Vous voyez une différence entre 'sylviculture' et 'arboriculture'?}

204: traitement sylvicole. Mise en œuvre des principes et règles de la sylviculture.

300: arboriculture / culture arboricole. Ensemble des sciences et techniques appliquées à la culture des arbres et arbustes. Cf. sylviculture.

429: soins culturaux aux arbres / arboriculture / soins arboricoles. Toute mesure visant à modeler la croissance et la forme d'un arbre, compte tenu des ob- 
jectifs, par exemple ou moyen de tailles.

Jean T. (EF1):

I-Def: definiert sylviculture: "La sylviculture, c'est une ehm, une ehm, un ensemble de techniques qui euh améliorent un peuplement, une plantation dans sa globalité [...] On appliquera certaines méthodes. Ce sont des termes généraux, donc de eh... un terme général qui s'applique à un ensemble de techniques propres à un peuplement, une éclaircie, une plantation, etc. L'arboriculture, c'est qu'on ne s'attarde plus à un peuplement dans sa totalité, mais au sujet, à l'arbre. L'arboriculture, c'est le propriétaire ou le technicien qui s'arrête au pied de un arbre [...] On le considère en tant que individu. Un soin particulier à un arbre." ( $Z * 10: 09)$

S-gramm: viele Parallelismen, die man oft in seinem Diskurs vorfindet und die zur Verstärkung des Gesagten dienen, z.B.: "Il a trop de branches. Il a une fourche. Il a ceci. Il est malade." (Z* 10:49)

P: 10:02, L: 00:56

Paul A. (EF2):

I-Antw: "La sylviculture s'adresse plus à la forêt, tandis que l'arboriculture s'adresse plutôt aux arbres fruitiers." (Z* 34:58)

I-Komm: kurze, präzise Antwort

P: 34:52, L: 00:47

Pierre de B. (LF1):

I-Def: 1. sylviculture: "Ah, sylviculture, c'est, c'est le euh travail du bois. " (Z*00:52); 2. arboriculture: "Et arboriculture,... euh, c'est, c'est plutôt la plantation... euh, il me semble, quoi." ( $\mathrm{Z}^{*}$ 00:55)

I-Komm: beginnt mit der Definition von sylviculture, bei der er sich ganz sicher zu sein scheint, zeigt bei der Erklärung von arboriculture Unsicherheit; nachdem der Fragesteller eine Erklärung von arboriculture vorgeschlagen hat, bestätigt der Proband das Gesagte (01:11).

D-Verh: zeigt sich bei der zweiten Definition unsicher und schließt direkt an seine Antwort die Frage an: "C'est ça ou pas ça?" (Z* 01:04); die Frage zeigt, dass er sich wirklich dafür interessiert und die ,richtige" Antwort gerne kennen möchte.

P: 00:47 (F2.mp3)

\section{Paul D. (LF2):}

I-Antw: sieht keinen Unterschied zwischen diesen beiden Begriffen; will sich aufgrund seiner Unkenntnis nicht genauer dazu äußern; bemerkt scherzhaft: "je vais passer loin" (Z* 28:48) (metaphorische Übertragung aus der Sprache des Jägers)

P: 28:42, L: 01:09 


\section{D.4.g. Le bois fait partie du paysage béarnais. Il vous donne plutôt l'idée d'un terrain à exploiter, d'un terrain de loisir (où l'on fait des promenades ou la chasse) ou d'un système écologique précieux et fragile? Pourriez-vous vous expliquer sur ces différents aspects?}

\section{Jean T. (EF1):}

I-spontane Antw: antwortet nicht direkt auf die gestellte Frage, sondern erläutert erneut die Rolle eines technicien, dessen Aufgabe die folgende ist: "Mais on doit présenter les trois possibilités au propriétaire qui doit être le seul à décider." ( $\left.Z^{*} 11: 52\right)$

I-Org: beschreibt die Aufgabe eines technicien, der nicht seine persönlichen Vorlieben darstellen darf, sondern dem propriétaire wertfrei über die verschiedenen Möglichkeiten Auskunft geben soll

S-gS: Umgangssprache: "[...]on dit: 'Tiens, cet arbre est chouette." (Z*11:35)

D-Biogr: spricht für sich persönlich, stellt seine persönliche Einstellung der des technicien gegenüber

D-Bsp: "On a une forêt de sapins magnifique en montagne [...]" (Z* 12:00): veranschaulicht vorher Gesagtes anhand dieses Beispiels

P: 11:07, L: 01:05

\section{Paul A. (EF2):}

I-Antw: In der Region kann man noch nicht von einem système écologique sprechen. Die Punkte 1 (terrain à exploiter) und 2 (terrain de loisir) der Frage sind zutreffender, wobei der Aspekt terrain de loisir überwiegt (la chasse, des champignons).

I-Org: 1. Antwort s. I-Antw; 2. Einschränkung der generell gegebenen Antwort, bei der er für die gesamte Bevölkerung gesprochen hat; Präzisierung: für die propriétaires tritt der Aspekt terrain à exploiter natürlich in den Vordergrund; 3. äußert sich in diesem Zusammenhang kritisch und erklärt gleichzeitig die Bedeutung des Waldes für viele propriétaires: "Mais les propriétaires, c'est plutôt à exploiter, mais c'est mal fait dans les Pyrénées-Atlantiques, parce que les propriétés sont petites et que en général, ces bois sont conservés de génération en génération. En cas d'avoir un pépin dans une famille, c'est le bas de laine. C'est les économies que l'on garde si jamais il y a un pépin. Mais le bois dans les Pyrénées-Atlantiques n'est pas du tout bien géré entre guillemets comme dans les Landes ou dans des pays industriels." ( $Z^{*}$ 36:01); 4. Gründe dafür, dass es Probleme im Waldbau gibt: a. kleine Waldstücke, b. mangelndes Interesse an der Verwaltung des Waldes (viele interessieren sich für den Wald als terrain de loisir) 
I-Komm: äußert sich sehr ausführlich zur Rolle des Waldes, zur Qualität des Waldbaus, indem er sich auch auf verschiedene Regionen bezieht

D-Verh: sehr aufgeschlossen, man spürt seine persönliche Erfahrung P: 35:06, L: 00:14

\section{Pierre de B. (LF1):}

I-Antw: bittet zunächst um Wiederholung der Frage

I-Org: 1. "C'est d'abord, un, un terrain, en France, c'est un terrain pour exploiter." ( $\left.Z^{*} 01: 58\right) ; 2$. "Après, il est évident que... euh, c'est ça... ça contribue à ... la, un bon équilibre de... du pays. Le loisir vient après." ( $Z^{*}$ 02:03); für ihn liegt der Hauptaspekt nicht im Freizeitbereich: "La vocation première de la forêt, c'est de fabriquer euh des... du bois de qualité si on peut et... et puis de... en fonction des poumons de la... terre, hein [...]" (Z*02:45); 2. Nachfrage nach dem ökologischen Aspekt: Terminus écologique stört ihn, da er oft missbraucht wird

D-Biogr: setzt sich von den Naturschützern (écologistes) ab: "Moi, je suis pas tout à fait écologiste, non, non. Dans ce sens, je le suis dans la réalité, mais je le suis pas dans les mots comme ça." (Z* 03:34); man erkennt seine persönliche Verbundenheit: "Mais l'arbre, c'est, ça me fait de la peine de le couper, hein." (Z* 03:42)

D-Verh: Lachen, nachdem er sich zum Aspekt écologie geäußert hat-entspannte Atmosphäre (03:12); äußert sehr frei seinen Standpunkt den Naturschützern gegenüber: "Oui, et puis un peu n'importe quoi, quoi. L'écologiste est... pour tout et pour rien, quoi." (Z* 03:22) - zeigt, dass er keine Hemmungen im Gespräch hat und sehr natürlich reagiert; man spürt, dass er auch emotional eingebunden ist (s. D-Biogr 03:42).

P: 01:31, L: 00:44

Paul D. (LF2):

I-Antw: "Les trois." (Z* 29:15)

I-Komm: Trotz mehrfacher Versuche seitens des Fragestellers, den Probanden zu einer ausführlicheren Stellungnahme zu ermutigen, beschränkt er sich auf diese kurze Antwort, ohne weitere Erläuterungen zu geben.

D-Biogr: Bezug zu seinen eigenen Interessen: "Moi, j'avais des plantations, j'aimais bien aller chasser." (Z* 29:25)

P: 28:53, L: 00:11 


\section{Exploitation du bois, techniques sylvicoles}

D.5.a. Parlons un peu de l'exploitation dans le sens de la récolte des arbres mûrs. D'après quels critères est-ce qu'on décide de la qualité d'un arbre? / Comment peut-on savoir qu'un arbre est arrivé à maturité, que c'est un arbre d'avenir?

Le terme de 'défilement' vous dit quelque chose?

208: peuplement exploitable / arrivé à maturité / mûr / adulte. Peuplement exploitable.

804: exploitabilité / maturité. Qualité d'un peuplement (ou d'un arbre) lorsqu'est atteint l'objectif de production en ce qui concerne l'âge, le diamètre du fût, la valeur ou autres considérations.

274: tige d'avenir / arbre d' $\sim / \sim$ de place / $\sim$ du peuplement final . Arbre sélectionné et marqué car appartenant à l'élite du peuplement en raison de sa position sociologique, de son état sanitaire et de ses qualités, ce qui justifie qu'il fasse partie du peuplement final.

320: arbre plus / sélectionné / d'avenir / tige sélectionnée. Arbre sélectionné - mais non testé - qui d'après son port est supérieur à la moyenne des arbres de même âge, en prenant en considération un ou plusieurs critères de qualité.

758: défilement / décroissance du diamètre / diminution / décroissance métrique / décroissement. Propriété d'un fût d'arbre (ou de grume) dont le diamètre va en diminuant vers l'extrémité.

\section{Jean T. (EF1):}

I-Aufzählung: 1. le diamètre d'exploitabilité; 2. l'âge de l'exploitabilité; 3. le reste

I-Org: 1. Erklärung des ersten Kriteriums: "Un diamètre d'exploitabilité, c'est qu'on décide à l'avance que tous les arbres qui font plus de telle, telle dimension de circonférence vont être coupés. Et tout arbre, quel que soit son âge, jeune ou assez vieux, qui dépasse ce diamètre-là est bon pour le bûcheron." (Z* 13:28); 2. Erklärung des zweiten Kriteriums: "Et ensuite, vous avez un âge d'exploitabilité. Telle parcelle qui a des arbres qui ont tel âge. [...] A partir du moment où il a cet âge-là, on le coupe. Ça c'est un critère d'âge d'exploitabilité." ( $Z^{*}$ 13:47); 3. "Le reste, en dehors de ces deux critères-là, c'est subjectif, arbitraire." (Z* 14:04)

I-Komm: antwortet sehr flüssig, ohne zu stocken 
D-Bsp: Bei der Erklärung des zweiten Kriteriums gibt er wieder Beispiele für die verschiedenen Baumarten an. (13:52)

D-Verh: sehr sicher, pädagogisch: fasst nach der Erklärung des ersten Kriteriums nochmal zusammen: "Un: on se fixe un diamètre." ( $\left.Z^{*} 13: 44\right)$

P: 13:04, L: 01:57

Paul A. (EF2):

I-Antw: relativ einfach zu bestimmen für die résineux oder Arten, die schnell wachsen, z.B. peuplier, chêne rouge d'Amérique, le tulipier de Virginie; schwieriger für die chênes und noyers (37:33)

I-Org: 1. Antwort; 2. Gründe für die bei den chênes auftauchenden Probleme (längere Wachstumsphase); 3. Einschätzung erfolgt à l'œil; 4. Nachfrage nach den zu beachtenden Kriterien: "Non, enfin, il y en a peut-être, mais pour ma part, je les connais pas avec rigueur." ( $\left.Z^{*} 37: 56\right)$; 5. Frage nach dem Erkennen eines arbre d'avenir: anhand von forme, hauteur, volume; 6. Nachfrage nach dem Terminus défilement (38:30), der nicht bekannt ist im Gegensatz zum Terminus décroissance, der geläufig ist

D-Biogr: gibt zu, die Kriterien nicht genau zu kennen (s. I-Org, 37:56)

D-Bsp: gibt konkretes Beispiel mit Zahlen, um Punkt 5 der Antwort zu verdeutlichen (38:16)

D-Verh: sehr langes Zögern im Anschluss an die Frage, dann aber eine klare Antwort

P: 37:02, L: 00:56

\section{Pierre de B. (LF1):}

I-Org: 1. versucht eine Definition der maturité d'un arbre: "La maturité d'un arbre, oui, euh, alors, bon, il y a des arbres qui sont euh, qui arrivent à maturité, c'est-à-dire que, ils montrent des... signes de dépérissement. Donc, donc, ils sont à... à maturité, hein." (Z* 04:09); 2. Präzisierung der Anzeichen des Verfalls: "Bon, vous avez certains signes qui indiquent que euh, que l'arbre ne... pousse mal, ne pousse plus, et, et n'est plus..., n'est plus en forme, en bonne santé, quoi. Bon, à ce moment-là, euh, il faut, il faut, il faut le couper, quoi." (Z* 04:28); verweist auf Wurmbefall von Bäumen, der ein Indikator für die schlechte Eigenabwehr dieser Bäume gegen Ungeziefer ist; 3. Zusammenfassende Antwort: "L'arbre est mûr quand il commence à dépérir. Voilà." (Z* 05:15); 4. Hinweis auf die finanzielle Ausbeutung eines Baums: "Après, il peut être mûr d'une manière, j'allais dire, financièrement parlant." ( $Z^{*}$ 05:21) "Financièrement parlant, vous avez des arbres qui sont beaux, qui ont un..., qui sont par hasard, très demandés à une époque donnée, bon euh, ou le propriétaire, lui, a besoin d'argent, bon euh, il déclare que... hein." ( $\mathrm{Z}^{*}$ 05:27); oftmals werden Bäume, die eigentlich stehen bleiben könnten, geschlagen, da 
sie profitabel sind; 4. Nachfrage zum Terminus défilement: Dieser Begriff ist dem Probanden nicht bekannt; 5. Nennung des Terminus décroissance: ist dem Probanden bekannt

I-Komm: Direkt nach der Fragestellung zögert der Proband. Es scheint für ihn nicht einfach zu sein, ganz spontan auf die Frage zu reagieren. Er äußert sich nicht konkret, sondern hält seine Aussagen eher allgemein, z.B. präzisiert er nicht, welche Anzeichen des Verfalls man finden kann. Er beschränkt sich lediglich auf die Ausführungen zum Wurmbefall.

S-lex: Kenntnis des Terminus décroissance, nicht aber des Terminus défilement

D-Bsp: erläutert die Phasen eines Baums am Beispiel der Eichen: "On vous dira qu'un chêne grandit, pousse pendant cent ans, se maintient pendant cent ans, et dépérit pendant cent ans." (05:03)

P: 03:53, L: 02:22

Paul D. (LF2):

I-Org: 1. Nachfrage zum Verständnis der Frage: "A la maturité, ça c'est-pour un arbre. " ( $Z * 29: 51) ; 2$."Il y a les branches du bout qui sèchent. " $\left(Z^{*} 29: 55\right)$ $\mathrm{Zu}$ dem Zeitpunkt muss man das Holz verkaufen, da es nutzlos wird; 3. Nachfrage zu défilement: Terminus nicht bekannt

P: 29:39, L: 00:46

\section{D.5.b. Quand c'est qu'on parle d'une 'coupe définitive'?}

207: coupe définitive / de réalisation / récolte d'arbres mûrs / coupe finale / exploitation de régénération / coupe . Exploitation d'un peuplement (arrivé à maturité) - ou d'arbres du peuplement, par ex. dans une futaie jardinée -, pour la régénération ou en vue d'une autre utilisation du sol.

220: coupe définitive / de régénération / secondaire. Enlèvement des vieux arbres restant de l'ancien peuplement au-dessus d'une régénération déjà existante. (Cet enlèvement se fait en une coupe ou plusieurs opérations).

221: coupe définitive / de réalisation / finale. Coupe des derniers arbres d'un peuplement (c'est la dernière coupe dans la méthode des coupes d'abri, pour favoriser la régénération obtenue.

Frage nicht gestellt, da sich eine zu enge inhaltliche Verbindung zu der vorangehenden Frage D.5.a. ergeben hätte. Wie sich zeigte, ist der Hieb größerer Bestände aus Sicht der bearnesischen Waldbauern eine seltene forstliche Maßnahme, deren Beurteilung nicht zu ihrer alltäglichen Lebensrealität gehört. 


\section{D.5.c. Parlons de l'abattage d'un seul arbre. Vous croyez que la coupe à la hache existe encore en Béarn? Connaissez-vous d'autres outils qu'on a utilisés d'autrefois?}

481: couper à la hache / abattre / trancher. Verbe désignant la Acoupe@.

\section{Jean T. (EF1):}

I-Antw: verneint sehr bestimmt

I-Komm: Antwort besteht nur aus einem Satz

P: 14:36, L: 01:32

I-Aufzählung: 1. la hache; 2. le passe-partout

I-Komm: gibt keine weitereren Werkzeuge an-bewertet ihre Wichtigkeit: "C'étaient surtout les deux les plus employés." (Z* 14:50)

D-Biogr: direkter Verweis auf seine Familie: "Mon grand-père coupait les arbres au passe-partout, avec un ami à lui." ( $\left.Z^{*} 14: 51\right)$

P: 14:43, L: 00:07

\section{Paul A. (EF2):}

I-Antw: coupe à la hache existiert nicht mehr

P: 38:54, L: 01:52

I-Aufzählung: 1. la hache; 2. le passe-partout

D-Biogr: direkter Bezug zu seiner eigenen Erfahrung: "Je connais le passepartout. Avant qu'il y n'ait les tronçonneuses, moi, je l'ai utilisé moi-même." (Z*39:10)

P: 39:04, L: 00:10

Pierre de B. (LF1):

I-Antw: "Eh,... je pense pas, non. Non. La hache sert toujours, oui." (Z* 06:40)

I-Komm: scheint sich bei dieser Antwort nicht ganz sicher zu sein-zögert ein bisschen und spricht in einem nicht sehr überzeugenden Tonfall P: 06:32, L: 02:39

I-Aufzählung: 1. la hache (die man auch la cognée nannte); 2. le passe-partout I-Anordnung: geht zuerst auf die Axt ein und erläutert die verschiedenen Formen, die eine Axt haben kann, je nachdem, wie der Baum beschaffen ist; geht danach kurz auf die Methode mit dem passe-partout ein I-Beurteilg: gibt seine eigene Einschätzung ab: "C'est tout un art, ça, d'abattre 
des arbres. “ $(\mathrm{Z} * 07: 37)$

I-Komm: kennt noch einige von den alten Werkzeugen, obwohl er selbst sagt: "Oui, mais peu tout de même, pour vous dire, eh..., j'étais pas bûcheron, alors." (Z* 07:17)

D-Biogr: verweist darauf, dass er selbst noch eine der älteren Methoden kennengelernt hat: "Autrefois, on a..., on abattait, moi, j'ai connu abattre au passe-partout." (Z* 07:25)

D-Verh: Man spürt, dass der Proband in dieses Fachgebiet eingebunden ist und sich dafür interessiert und begeistert, z.B. Kommentar s. I-Beurteilg (07:37)

P. 06:48, L: 00:16

\section{Paul D. (LF2):}

I-Antw: coupe à la hache existiert seiner Meinung nach nicht mehr im Béarn P: 30:24, L: 00:45

I-Aufzählung: 1. le passe-partout; 2. la hache; 3. les coins (33:17); 4. la masse (33:18); 5. une corde

I-Org: 1. Nennung der zwei Objekte; 2. Erklärung des passe-partout (Maße der Klinge, Beschreibung des Arbeitsvorgangs, an dem zwei Personen beteiligt waren); 3. Versuch einer Erklärung der Verwendung der hache; 4. kurze Erläuterung zur corde

I-Komm: Bei der Erklärung der hache (Punkt 3) hat der Proband Probleme, die Erläuterung $\mathrm{zu}$ vervollständigen, was er auch ausspricht: "Ah, comment on appelle? Moi, je sais pas." (Z* 31:19) - auf Aufforderung des Fragestellers hin Fortführung auf Bearnesisch: "Que cau espiar d'abòrd on... on lo har càier. Il $y$ a des fois qui... les branches, il faut regarder les branches. Et puis après, on fait l'espic ('la charnière) devant... là ou l'on veut le faire tomber, on lo vòu har càier. E après on y passe lo passa-pertot darrèr, je parle moi, ah, de l'ancien temps, hein, e un còp qui èra drin... lo passa-pertot que $i$ avè hicat la dent, on i hicava un cuenh, un cuenh en hèr, dab ua massa, e que serviva endà'u guidar. Si om vedè que'v anava partir d'un estrem o de l'aute, om que'u hicava de l'estrem o darrèr, que dependè, e après quan... quan èra quasi sarrat, om que'u herrava lavetz, com cau, shens de'u forçar tròp. Per'mor autement que l'averèn hèit càier e que's seré tot eschasclat. Lavetz que sarravan aquiu, e om que deishava drin de bués aci endà'u retiéner, endà'u har càier end'aquiu, o si om volè'u har càier endà delà deishant drin ad aqueth estrem. E har passar lo passa-pertot endà dehòra." (31:32)

S-lex: Unterstreichung der Beschreibung mit seiner Gestik (Geräusche 31:05)direkter Hinweis auf die Gestik: "On passait comme ça." (Z* 31:06)

D-Biogr: bei der Erklärung des passe-partout: Verweis darauf, dass er selbst so vorgegangen ist 
D-Verh: wechselt auf Aufforderung des Fragestellers hin zum Bearnesischen über, um dann aber recht schnell wieder zum Französischen zu wechseln (ab 31:46); erneuter, diesmal freiwilliger Übergang zum Bearnesischen (ab 31:59); außergewöhnlich ausführliche Antwort größtenteils auf Bearnesisch; man bekommt das Gefühl, dass der Proband durch den Wechsel zum Bearnesischen besonders animiert worden sei, frei und ungezwungen zu sprechen.

P: 30:33, L: 00:09

\section{D.5.d. Vous savez ce que c'est qu'une 'grume'?-L'expression 'entamer une grume' vous semble courante? Vous la comprenez (quand même)?}

476: commencer l'abattage / entamer / entamer une forêt / grume. Commencer à abattre (un arbre ou un peuplement).

521: bois brut / non façonné / non transformé / en grume / non travaillé . Arbres abattus, grumes, bois ronds, particules de bois, bois de fente, de souche et résidus d'exploitation qui, tous, sont destinés à la transformation ou à utilisation comme bois de chauffage.

526: tronce / bille / grume / surbille / rondin / tronche / billon $[<]$. Tronçon de bois obtenu à partir d'une grume ou de grosses branches et qui peut être utilisé comme bois d'œuvre ou de chauffage.

529: bille / billon / rondin / tronce / surbille / grume. Tronce d'une grume.

530: bois de fût / de tige / grume. Bois du fût de l'arbre (ne détermine pas une catégorie de bois).

534: grume / fût / tronc / grume tronc. Fût (ou section de fût) séparé de la souche, coupé au fin bout et ébranché.

\section{Jean T. (EF1):}

I-Org: 1. Frage nach Kenntnis des Begriffs la grume: kennt und erklärt den Begriff: "La grume, c'est le ehm, c'est le bois ehm, dont on a retiré, c'est un arbre dont on a retiré le houppier." ( $\left.Z^{*} 15: 10\right) ; 2$. Frage nach entamer une grume: kennt den Begriff nicht

S-lex: Einführung des Begriffs débarder 
D-Verh: zögert sehr lange, bevor er antwortet; zögerlicher, nicht so selbstsicherer Beginn der Erklärung; bei der zweiten Frage (entamer une grume): Wiederholung des Begriffs - wie oft bei anderen Fragen, dann negative Antwort

P: 15:00, L: 00:17

Paul A. (EF2):

I-Def: Frage nach dem Terminus la grume: "Disons, c'est quand il y a un arbre abattu, c'est l'ensemble du tronc, disons, et de l'arbre." ( $\left.Z^{*} 39: 49\right)$

I-Antw: Frage nach dem Ausdruck entamer une grume (40:07): kennt den Ausdruck nicht

I-Komm: ungenaue Def. des Terminus grume, wobei der Proband jedoch auch nicht sehr sicher erscheint

P: 39:40, L: 00:36

\section{Pierre de B. (LF1):}

I-Kenntn.d.Begr.: "Oui, alors, c'est une, j'allais dire une bille." ( $Z^{*}$ 09:43)

I-Def: "C'est, eh... c'est, c'est l'arbre, l'arbre est abattu et euh ébranché, eh. C'est, c'est le, bon, ce qu'on appelle aussi la bille ou ou la grume." (Z* 09:59) I-Komm: keine sehr ausführliche Antwort, die aber dennoch die wichtigsten Aspekte enthält (s. Lexicon Silvestre ' 534)

S-lex: für ihn scheint es keinen Unterschied zwischen bille und grume zu geben (s. I-Kenntn.d.Begr.)

D-Verh: Lachen nach der Antwort (09:46)

P: 09:41, L: 02:00

Paul D. (LF2):

I-Antw: auf Nachfrage zur Definition der grume: "Ah, c'est l'arbre abattu. " (Z* 33:42); auf Nachfrage zur bearnesischen Bezeichnung für grume: "La gruma tanben. " ( $\left.Z^{*} 33: 44\right)$, bestätigt auch bearnes. bilha

I-Komm: Das Wort la gruma stellt einen offensichtlichen Französismus dar.

P: 33:36, L: 03:03

\section{D.5.e La technique de la coupe à la tronçonneuse vous est familière? Vous pouvez l'expliquer un peu?}

576: scie à moteur à chaîne / tronçonneuse à chaîne / scie à moteur / à dents articulées / mécanique à dents articulées. Scie à moteur avec chaîne sans fin portant les dents. 
575: scie à moteur / tronçonneuse à moteur / scie mécanique. Scie entraînée par un moteur.

577: scie à moteur / à un homme / à un homme. Scie à moteur (à chaîne) manœuvrée par un seul homme.

574: passe-partout scie / scie à tronçonner / à deux mains / passe-partout / tronçonneuse à main. Scie à manier par deux hommes - avec les dents sur le côté convexe de la lame - utilisée pour l'abattage ou le tronçonnage des grumes.

\section{Jean T. (EF1):}

I-Kenntn.d.Begr.: spontane Antwort: "bien sûr" ( $\left.Z^{*} 15: 45\right)$, präzisiert allerdings nach Reflexion: "Enfin, pas véritablement familière, mais je connais le principe, oui." (Z* 15:46)

I-Org: 1. Antwort; 2. Erklärung des allgemeinen Prinzips, 3. Präzisierung / Hinweis auf andere Prinzipien, im Falle einer anderen Konstitution des Baumes ("si l'arbre est fragile" (Z* 16:58))

S-lex: kennt den Fachbegriff für coupe sous forme d'un triangle nicht, worauf er selbst hinweist; erklärt das Prinzip, ohne die genauen Fachbegriffe zu kennen und zu verwenden

D-Verh: steht zu seinen 'Lücken', was das Fachvokabular anbetrifft und erklärt das Prinzipielle-gibt dies am Ende seiner Antwort zu verstehen: "C'est grossièrement décrit, mais c'est les principes fondamentaux." ( $Z * 17: 15)$

P: 15:41, L: 00:41

\section{Paul A. (EF2):}

I-Kenntn.d.Begr.: kennt die Technik gut, obwohl er sie nicht mehr anwendet I-Org: 1. Beschreibung des Baumfällens in verschiedenen Schritten; 2. Nachfrage nach den Unterschieden zwischen der herkömmlichen Methode und der technique à la tronçonneuse: keine großen Unterschiede; das Grundprinzip bleibt gleich.

\section{I-Komm: einfache, klare Erklärung}

D-Verh: zeigt sich sicher; man spürt, dass er auf diesem Gebiet Erfahrung hat P: 40:48, L: 01:08

\section{Pierre de B. (LF1):}

I-Beschreibung: 1. "D'abord, il faut, il faut bien, bien regarder de quel côté l'arbre penche, puisque mettons que, mettons que vous ayez un arbre qui est normal, donc qui est droit, mais il penche toujours d'un côté plus au moins, bon. Alors, si vous pouvez l'envoyer du côté où il penche, c'est, c'est merveilleux, quoi." (Z* 07:55); genaue Erklärung der verschiedenen durchzufüh- 
renden Arbeitsschritte; 2. Nachfrage zum Risiko, beim Aufprall das Holz zu spalten: Bemerkung s. D-Verh (09:12)

I-Komm: sehr detaillierte Beschreibung, die davon zeugt, dass der Proband sich auf diesem Gebiet gut auskennt; auffällig, dass ihm die dazugehörigen Fachtermini fehlen (s. S-lex)

S-lex: Bei der Erklärung der Methode der coupe à la tronçonneuse stellt er fest, dass ihm ein spezieller Ausdruck fehlt: "Il y avait un nom pour ce machin-là. Je me rappelle plus le le le nom." (Z* 08:23), (es handelt sich um eine Art charnière, die im Regionalsprachgebrauch typischerweise mit b. espic bezeichnet wird, s. die entspr. Antw. von Dabancens); kann das Verfahren sehr detailliert erklären, jedoch nicht immer mit den entsprechenden Fachtermini belegen

D-Verh: zeigt Humor, lacht, geht mit einer scherzhaften Bemerkung auf eine Nachfrage ein: "Ah, non, ça, c'est un mauvais bûcheron, alors. Celui-là, il va pas l'employer." (Z*09:12)

P: 07:41, L: 00:53

Paul D. (LF2):

I-Antw: kennt die Technik der coupe à la tronçonneuse, ohne sie selbständig weiter zu erläutern

I-Org: 1. Antwort; 2. Stellungnahme zu dieser technique à la tronçonneuse: "On est pratiquement sûr de ne pas l'abîmer." (Z* 34:19); Erklärung der Technik in Grundzügen

P: 33:57, L: 00:21

\section{D.5.f. Y a-t-il des mesures à prendre pour nettoyer l'endroit après une coupe réalisée? Quand est-ce qu'il faut dessoucher le terrain?}

564: enlèvement des rémanents de coupe / nettoiement de coupe / nettoyage du parterre de coupe / enlèvement après exploitation / mise en état de la coupe / nettoiement du parterre de coupe. Enlèvement des rémanents de coupe (et d'autres obstacles à la sylviculture) du parterre de la coupe.

561: dessoucher / arracher les souches / défricher / essoucher. Extraire les souches du sol (avec leurs racines).

Jean T. (EF1):

I-Antw: differenziert seine Antwort direkt zu Beginn: "Ça dépend de ce qu'on veut faire." (Z* 17:26) 
I-Org: 1. führt die verschiedenen Maßnahmen nacheinander aus, gegliedert nach verschiedenen Kriterien: a. régénération naturelle, b. une plantation, c. un ruisseau; Diskursführung: unter den Umständen a. müßte man Folgendes tun, unter den Umständen b. etwas anderes; 2. auf Nachfrage hin: präzisiert die hier gängigen Vorgehensweisen, erläutert die von den techniciens bevorzugten Methoden

I-Komm: gute Gliederung, strukturierte Antwort

P: 17:20, L: 01:39

I-Antw: "Si on veut replanter après, c'est une technique, mais elle est pas forcément la meilleure." ( $Z *$ 18:35)

I-Beurteilg: 1. gibt positive Folgen für die Entnahme der Wurzeln bei einer coupe rase an; 2. nennt negative Begleiterscheinungen, die auftreten können, wenn man die Wurzeln entfernt; 3. Zusammenfassung 'pro' und 'contra': "Donc, vous avez ceux qui sont favorables au dessouchage et d'autres qui sont au contraire hostiles. Donc, ça, c'est à chacun de se prononcer. " (Z* 19:17); 4. auf Nachfrage hin: In der Gegend werden meistens die Wurzeln entnommen I-Komm: gibt nicht nur objektive Erklärungen, sondern auch Hintergrundwissen, persönliche Einschätzungen und Beurteilungen; allerdings verweist er von sich aus nicht häufig auf die Gewohnheiten in der Gegend-äußert sich dazu hingegen gern und spontan auf Nachfrage hin

P: 18:33, L:01:13

Paul A. (EF2):

I-Antw: "Après une coupe réalisée, tout dépend de ce que l'on veut faire." (Z*41:54)

I-Org: 1. Antwort; 2. Darstellung der Ziele, die man verfolgen kann und der entsprechend zu ergreifenden Maßnahmen: a. erklärt anhand eigener Erfahrungen, was zu tun ist, wenn man neu pflanzen möchte (s. D-Biogr); b. man kann zwischen den Wurzeln pflanzen, wenn man nicht die ausreichenden finanziellen Mittel zur Verfügung hat: dévitaliser les souches; 3. Nachfrage nach der dépouille: man gruppiert sie in einer Ecke und lässt sie dort verwesen, bzw. verbrennt sie, was etwas schwieriger ist, 4 . Nachfrage dazu, ob die dépouille als Brennholz benutzt werden kann: schwierig, da es sich vor allem um Wurzeln usw. handelt und die Arbeitskräfte teurer wären als das Holz selbst

D-Biogr: direkter Bezug zu seiner eigenen praktischen Erfahrung: "Moi actuellement, je vais replanter, donc, j'ai coupé. Maintenant, je vais faire passer un bulldozer pour dessoucher [...] pour pouvoir planter dans de meilleures conditions." (Z* 42:00)

D-Verh: spricht viel; man hat das Gefühl, dass er gern auf diese Frage antwortet und auch gern viel erklärt; sehr aufgeschlossen 
P: 41:47, L: 00:59

Auf den Inhalt der Frage wird bereits im Kontext der vorangehenden Antwort Bezug genommen.

\section{Pierre de B. (LF1):}

I-Antw: "En théorie, en théorie, oui. Il faut eh... enlever le,... tout le houppier." (Z*10:19)

I-Org: 1. Antwort; 2. Normalerweise werden die Abfälle, die beim Fällen eines Baums anfallen, entfernt. Viele marchands de bois holen diese Abfälle heutzutage jedoch nicht mehr ab.

P: 10:11, L: 00:30

$\mathrm{Z}^{*}: 10: 19$

I-Antw: Methode wichtig, wenn man danach neu anpflanzen möchte; für den Wald der Landes ist es unerlässlich. (Anm.: Die Aussage ist nach unseren Informationen allerdings nicht zutreffend.); in seiner Region wird diese Methode nur sehr selten angewendet, da es teuer ist.

I-Komm: kurze Antwort, die aber die wesentlichen Informationen enthält P: 11:07, L: 00:56

Paul D. (LF2):

I-Org: 1. Aufzählung der zu ergreifenden Maßnahmen: "Il faudrait, il faudrait d'abord, quand l'arbre est coupé, élaguer et nettoyer. Et ça ne se fait pas toujours. Après, on enlève le grumeau et on revient là pour faire l'autre." $\left(Z^{*} 35: 32\right)$

I-Komm: gegliederte Aufzählung der Maßnahmen, die zu ergreifen sind, ohne dass der Proband jedoch vertiefend darauf eingeht

P: 35:23, L: 01:26

I-Antw: Methode dessoucher le terrain ist nicht üblich P: 35:59, L: 00:36

D.5.g. Qu'est-ce qu'il faut faire avec un arbre abattu avant de faire débarder la grume? (' écimer, écorcer, équarrir)

504: écimer / étêter / couper au fin bout. Verbe désignant la Adécoupe au fin boute.

507: écorcer. Oter l'écorce d'un arbre (ou d'une partie de l'arbre). 
508: écorcer partiellement / forestièrement. Oter l'écorce par endroits ou par bandes.

509: écorcer à blanc / blanc-blanc / complètement. Enlever totalement l'écorce sur une pièce de bois.

448: écorcer l'écorce à tan / lever l' / écorcer en sève. Oter l'écorce avec le liber (en période de pleine sève) pour produire l'écorce à tan.

449: taillis à écorce $/ \sim$ de chêne à écorce. Taillis de chêne aménagé essentiellement pour la production d'écorce à tan.

450: écorcer superficiellement. Enlever le rhytidome sans mettre à nu le tissu vivant (sur environ deux tiers de la circonférence du tronc pour gemmer un pin).

512: façonner une grume / tailler à la hache / équarrir. Façonner une grume avec une hache de bûcheron ou un autre outil de coupe.

\section{Jean T. (EF1):}

I-Antw: le façonnage - erklärt den Begriff: "Le façonnage, c'est-à-dire qu'on enlève toutes les branches." ( $Z * 19: 51)$

I-Kenntn.d.Begr: 1. Nachfrage nach écimer: kennt den Begriff und fügt ébrancher hinzu; 2. es wird nach écorcer gefragt, das, wie er betont, eine andere Bedeutung hat - erklärt den Begriff; 3. Nachfrage zu équarrir - hat für ihn aber auch eine ganz andere Bedeutung, erklärt hingegen, wie man die souche schneidet

D-Bsp: verweist auf die Tannen in den Bergen, bei denen der Arbeitsschritt écorcer angewendet wird; bei der Erklärung der coupe de la souche: Vergleich mit einem Stift: "On l'aiguise un petit peu comme un crayon." (Z* 20:19); Vergleich mit einem Schlitten: " [...] pour que quand elle est tirée, débardée, l'arbre rebondisse comme une luge sur une souche, sur un obstacle, sur un caillou [...]" (Z* 20:26)

P: 19:48, L: 01:15

\section{Paul A. (EF2):}

I-Antw: 1. Entfernen der Äste; danach folgt der débardage; 2. Nachfrage nach écorcer: abhängig davon, was der marchand damit machen will; es kommt vor, ist aber selten; 3. Nachfrage nach équarrir: wird abgelehnt

I-Komm: Beantwortung der Frage seitens des Fragestellers immer wieder durch Nachfragen angeregt; kein sehr großes persönliches Interesse des Probanden feststellbar 
D-Verh: Die Frage scheint ihn nicht zum Sprechen zu animieren: "On enlève les branches. C'est tout." (Z* 43:06)

P: 42:55, L: 01:08

\section{Pierre de B. (LF1):}

I-Org: 1. Vorgabe durch den Fragesteller: ébrancher; 2. weitere Arbeitsschritte, die vorzunehmen sind: "L'ébrancher, le le le le... le tailler à la, à la longueur... marchande." (Z* 12:03); 3. Differenzierung: Erklärung der zwei Möglichkeiten: a. man entfernt den Baum als Ganzes (Kommentar s. D-Biogr $12: 22,12: 24)$ oder b. man nimmt den Baum vor Ort auseinander, was in der Gegend die Regel ist (s. I-Org 2.); 4. Nachfrage nach der Notwendigkeit, die Rinde zu entfernen: Für Tannen ist das notwendig, nicht aber für Eichen: "C'est les résineux, je crois, qu'il faut écorcer. “ ( $\left.Z^{*} 13: 07\right)$; 5. Nachfrage zur Methode équarrir: wird am Sägewerk gemacht, da die Maschine, die dazu benötigt wird, sehr gefährlich ist (13:11); Name der Maschine fällt ihm nicht mehr ein - "Comment ça s'appelle, là... c'est comme une pioche, là, une... " (Z* 13:16) - verweist darauf, dass er selbst diese Methode bereits gesehen hat (s. D-Biogr 13:34) und erklärt den Vorgang genauer

I-Komm: äußert sich vor allem ausführlich und begeistert zu den Punkten, bei denen er eigene Erfahrungen gemacht hat, z.B. das Verfahren selbst gesehen hat

S-lex: Kenntnis der Fachtermini, die ganz selbstverständlich und natürlich im Diskurs des Probanden vorkommen

S: Verdeutlichung des Gesagten (Beschreibung der Maschine, s. I-Org, 13:16) durch Geräusche und vermutlich auch durch die Gestik (13:28); nochmalige Untermalung des Gesagten (Sägegeräusche) durch Nachahmung des Vorgangs $(14: 06)$

D-Biogr: äußert sich persönlich zu der Methode des Baumabtransportes: "J'ai vu faire ça il y a pas longtemps." ( $\left.Z^{*} 12: 22\right)$; man spürt seine Begeisterung: "C'est spectaculaire." (Z* 12:24); weiterer Verweis darauf, dass er die Methode selbst gesehen hat: "J'ai vu faire. J'ai vu équarrir et j'ai vu scier de long [‥] sur place." $\left(\mathrm{Z}^{*} 13: 34\right)$

D-Verh: humorvoll - spielt auf sein Alter an, als er auf die Frage, ob es lange her sei, dass er das gesehen habe (im Anschluss an 13:34), antwortet: "Ben, malheureusement ça fait longtemps, hein. " ( $Z^{*}$ 14:14) - Untermalung durch Klopfen auf den Tisch

P: 11:53, L: 00:46

Paul D. (LF2):

I-Antw: "Une fois tombé, vous écimez, vous coupez toutes les branches. Et puis, vous gardez la... Il faut garder la première bille le plus long, le plus long 
possible. C'est pas toujours facile. " $\left(\mathrm{Z}^{*} 36: 27\right)$

I-Org: 1. Antwort; 2. Nachfrage zur Notwendigkeit des écorcer: sieht er nicht als notwendig an, nur bei den pins; 3. Nachfrage nach équarrir: "Ah oui, mais ça, équarrir, ça se fait en série ça. " $\left(Z^{*}\right.$ 37:08)

D-Verh: Nachfrage zur gestellten Frage: "Comment, qu'est-ce qu'il faut faire." (Z* 36:20); Unsicherheit ist zu bemerken - zweite Nachfrage, in abgewandelter Form: "Une fois tombé. " $(\mathrm{Z} * 36: 24)$

P: 36:13, L: 00:14

\section{D.5.h. Le débusquage ou le débardage, ça marche comment?}

606: débusquage [FRA] / débardage [CHE] / extraction / vidange / extraction $\mathrm{du}$ bois / traînage. Transport des bois sur petites distances, entre le carreau de la coupe et le lieu de façonnage ou le dépôt provisoire (en forêt), vidange de bois.

603: débardage / extraction / évacuation / transport / enlèvement (par charroi, camion). Transport des produits (ligneux) depuis les places de chargement accessibles aux camions ou aux moyens de transport à grande distance, jusqu'à un lieu de déchargement.

\section{Jean T. (EF1):}

I-Org: 1. antwortet direkt auf débusquage, ohne dies zu Beginn explizit zu sagen: "Ça se fait mécaniquement, par un tracteur qui va débusquer les souches [...]" (Z* 20:44); 2. erläutert den Begriff débardage: "Et le débardage se fait en le tirant par câble ou alors par porteur. Il ehm, il ehm, il le tire, il le charge et il le porte." (Z* 20:49)

I-Komm: sehr kurze Antwort; keine weiteren Ausführungen, nur die konkrete Definition gegeben

D-Verh: starkes Händeklopfen

P: 20:40, L: 00:52

Paul A. (EF2):

I-Kenntn.d.Begr.: 1. kennt den Terminus débusquage nicht; 2. Kenntnis des Terminus débardage

I-Org: 1. Antwort; 2. Erklärung des Verfahrens débardage: Abtransport des geschnittenen Holzes vom Waldstück zur Straße mit Hilfe eines Traktors; in einigen Regionen, vor allem im Gebirge, erfolgt der Abtransport mit Hilfe von Pferden, was aber ziemlich selten geworden ist

S-lex: Verwendung des Verbs débarder in Anlehnung an das Substantiv dé- 
bardage

P: 43:36, L: 00:41

Pierre de B. (LF1):

I-Org: 1. "Oui, on peut, on peut le tirer, le porter avec, le soulever avec un diable.[...] Vous savez ce que c'est? Je vous en montrerai, hein. Je vous montrerai tout à l'heure. " (Z* 14:43); 2. Beschreibung des Werkzeugs diable und seiner Funktionsweise; 3. Nachfrage zur Methode des débardage: wird durch große Maschinen bewerkstelligt, die den gesamten Abtransport übernehmen D-Verh: verstärktes Klopfen auf den Tisch, bereits beim Anhören der Frage; sehr offen dem Fragesteller gegenüber-bietet ihm bereitwillig an, ihm ein bestimmtes Werkzeug zu zeigen, das er offensichtlich für interessant hält: " $A$, oui, parce qu'il faut voir, quoi." (Z* 14:56)-persönliche, nette Gesprächsatmosphäre

P: 14:31, L: 02:38

Paul D. (LF2):

I-Antw: "Il y a pas d'exploitation ici." (Z* 37:25); Holz wird in der Gegend nicht sehr häufig verkauft; man benutzt Karren oder den Traktor, um das Holz abzutransportieren (38:20); erklärt, dass Bäume oftmals geschlagen werden, wenn man sie braucht

I-Komm: Der Proband stellt einen direkten Bezug zu den in seiner Gegend gegebenen Verhältnissen her. Daher gibt er keine konkrete Antwort auf die Frage, da diese Phänomene wenig geläufig sind."Ici et souvent quand on en a besoin d'une pièce, on va aller la couper. " (Z*37:39)

P: 37:13, L: 01:00

\section{Administration et loi forestières}

\section{D.6.a. Vous avez déjà vu une carte forestière? Vous sauriez la lire?}

706: carte forestière / plan forestier / carte forestière thématique / de la forêt $1 \sim$ des forêts. Toute carte topographique donnant des renseignements thématiques pour la foresterie.

797: carte forestière de base / plan de forêt. Carte de la surface forestière (à l'échelle de 1:5000) avec les origines de la propriété, les limites, les divisions de la forêt et la position des surfaces non boisées faisant partie de la forêt. Cette carte est la base de toutes les cartes forestières. 
Jean T. (EF1):

I-Antw: gestellte Frage: "Vous croyez que les propriétaires d'ici pouvaient lire ces cartes aussi." - Antwort: Nein, die Eigentümer können diese Karten nicht oder nur unvollständig lesen.

I-Org: 1. spontane Beantwortung der Frage; 2. Ausführung der zwei Kartentypen, die existieren: a. les cartes d'état major-des cartes d'IGN, Beurteilung ihres Zwecks; b. le plan cadastral-le plan d'une parcelle, Eigentümer können diese Pläne nur teilweise lesen: sie können erkennen, wo sich ihr Gebiet befindet, aber sie könnten nicht die Gesamtheit der anderen Zeichen interpretieren; 3. Erklärung einiger auf einem Plan vertretenen Zeichen

I-Komm: Das Wissen der propriétaires wird dem der techniciens gegenübergestellt und die Unterschiede werden erklärt.

D-Biogr: verweist auf seine Position als technicien: " [...] et que j'apprends moi. Dans la prochaine formation que je fais, il y a deux heures qui sont consacrées à la lecture d'une carte pour apprendre aux propriétaires justement la compréhension de tous ces petits signes-là." (Z* 22:08); begründet, warum er diesen Bereich in seine Seminare aufgenommen hat

P: 21:02, L: 00:22

\section{Paul A. (EF2):}

I-Antw: glaubt, dass so etwas existiert, besitzt sie aber nicht

I-Org: 1. Antwort; 2. Erklärung des plan cadastre-plan d'état major, wobei der erste Terminus vom Fragesteller vorgegeben wurde: offizielle Pläne; plans d'état major im Handel erhältlich, plans cadastraux bei der administration du cadastre erhältlich; man trägt dort Zeichnungen ein, die mit dem Waldstück übereinstimmen; 3. Nachfrage nach der Schwierigkeit, diese Pläne zu lesen: nicht schwierig

P: 00:00 (F2.mp3)

\section{Pierre de B. (LF1):}

I-Antw: kann eine solche Karte problemlos lesen

I-Komm: Redeanteil des Fragestellers dominiert; Proband gibt nur kurze Bestätigung

P: 16:18, L: 01:47

\section{Paul D. (LF2):}

I-Antw: hat bereits eine carte forestière gesehen; kann sie ein bisschen lesen: "Comme ça, oui. “ (Z* 39:02)

I-Org: 1. Antwort; 2. Nachfrage, ob die Karten kompliziert zu lesen seien: Proband empfindet die Karten als gute Darstellungen; 3. auf Nachfrage hin: besitzt selbst eine Karte von seinem Waldstück 
I-Komm: sehr kurze Antworten, die sich meistens auf ein "oui" oder "non" beschränken

P: 38:53, L: 01:40

D.6.b. Qui s'occupe de l'administration forestière des propriétés privées? Quels rôles différents jouent le CRPF (Centre Régional de la Propriété Forestière) et l'ONF (Office National des Forêts) pour la gestion du bois d'ici?

Jean T. (EF1):

I-Aufzählung: 1. la DDAF; 2. le Service Fiscal

I-Org: 1. Darstellung des Aufgabenbereichs der DDAF (Direction Départementale de l'Agriculture et de la Forêt); 2. Darstellung des Service des Impôts; 3. es wird nach der Rolle des $C R P F$ gefragt: Erklärung der Aufgaben; 4. Nachfrage zur Rolle des $O N F$ : Erläuterung der Aufgaben; 5. es wird gefragt, ob der ONF nichts mit den propriétés privées zu tun habe, Antwort: persönliche Meinung, keine objektive Auskunft, seine persönliche Wertung ist erkennbar: "malheureusement" ( $Z^{*}$ 24:02); 6. Gegenüberstellung (auch zahlenmäßige Gegenüberstellung) des $O N F$ und der techniciens, um die Position der beiden 'Institutionen' zu verdeutlichen

I-Komm: geht sehr ins Detail und präzisiert die Aufgabenbereiche einer jeden für den Wald zuständigen Stelle; bleibt bei den Ausführungen zu Punkt 5 und 6 nicht objektiv, sondern ereifert sich; man spürt sein persönliches Interesse, seine Betroffenheit; äußert Kritik am $O N F$

S-lex: verwendet in der Erklärung den Begriff le plan simple de gestion, der auch im Lexicon Silvestre ( '800) zu finden ist; Begriff forêt publique eingeführt neben den Begriffen: les forêts communales, les forêts domaniales; Def. der forêt domaniale: " [...] les forêts communales ou domaniales qui appartiennent à l'État. " $Z^{*}$ 23:48) - vgl. die im Lexicon Silvestre zu findenden Begriffe: forêt de l'État, domaniale (' 1009), forêt communale (' 1010), forêt publique 'forêt de l'État ( ' 1009)

S-gS: "les sous" (Z*25:17) - umgangssprachliche Wortwahl

D-Biogr: "À mon avis à moi" (Z* 23:57) - gibt seine persönliche Stellungnahme zur Verbindung des $O N F$ mit den propriétés privées

D-Verh: verlangt eine Präzisierung der Fragestellung: "C'est-à-dire? Qu'est-ce que vous entendez par administration forestière. " ( $Z * 22: 31)$; bei der Erläuterung des Punktes 4: direkte Einbeziehung des Fragenden auf einer persönlichen Ebene: "Vous connaissez Berton. “ ( $Z * 24: 14)$

P: 22:27, L: 01: 25 
Auf den Inhalt der Frage wird bereits im Kontext der vorangehenden Antwort Bezug genommen.

\section{Paul A. (EF2):}

I-Aufzählung: 1. Syndicat des propriétaires forestiers sylviculteurs; 2. technischer ausgerichtete Organisationen: le CETEF, le Groupement des Producteurs de Bois (' GPB 64), Navarrenx

P: 00:54, L: 00:54

I-Antw: 1. Frage nach der Rolle des $C R P F$ : kümmert sich um die propriétés privées und die Entwicklung in der Region; 2. Frage nach der Rolle des $O N F$ : öffentlicher Dienst des Staates, der sich vor allem für die propriétés domaniales und die proprietés des collectivités territoriales, d.h. der communes interessiert; 3. Frage danach, ob sich die propriétaires auch an den $O N F$ wenden: kommt selten vor, aber die propriétaires richten sich manchmal auch an die $D D A F$, um Rat und Subventionen zu erhalten

I-Komm: gute Kenntnis der verschiedenen Organisationen und ihrer ungefähren Aufgabenbereiche

S-lex: führt Fachtermini ein: propriétés domaniales und proprietés des collectivités territoriales

P: 01:44, L: 00:50

\section{Pierre de B. (LF1):}

I-Antw: spontane Antwort: "Votre collègue, là." (Z* 16:41), (gemeint ist Herr A. Berton vom $C R P F$ )

I-Org: 1. spontane Antwort; 2. Nachfrage zum CRPF: Antwort auf der persönlichen Ebene, s. D-Biogr

I-Komm: spontane Antwort direkt auf der persönlichen Ebene; eine allgemeinere Ebene wird hier nicht erreicht.

D-Biogr: spricht von seinen persönlichen Erfahrungen mit dem CRPF: "CRPF, oui. Avec qui je suis, eh..., qui me voit pas d'un bon oil, parce que je leur ai pas répondu." ( $\left.\mathrm{Z}^{*} 16: 47\right)$

D-Verh: Lachen vor der Antwort; sehr spontane, ungezwungene Antwortgelöste Gesprächsatmosphäre; erneutes Lachen, als er über seinen schlechten Kontakt mit dem CRPF spricht (16:47)

P. 16:35, L: 00:37

I-Antw: Der $O N F$ kümmere sich nicht um die forêt privée, sondern um die forêt communale.

I-Komm: Im Gegensatz zur Antwort auf die vorher gestellte Frage läuft das Gespräch hier auf einer allgemeineren Ebene ab; die Auskünfte sind aber nicht 
sehr ergiebig.

S-lex: unterscheidet zwischen forêt privée-forêt communale

P: 16:56, L: 00:21

Paul D. (LF2):

I-Antw: führt als zuständige Organisation die $D D A$ an, ohne weitere Erläuterungen zu geben

P: 39:26, L: 00:33

I-Org: 1. Frage nach der Rolle des CRPF: Proband fasst darunter die techniciens und erläutert kurz deren Aufgaben (sie kommen; organisieren Versammlungen; zeigen exploitations, die in dem Jahr oder vor 5, 10 Jahren gemacht wurden); 2. Frage nach der Rolle des $O N F$ : "C'est des gars qui travaillent ensemble, évidemment. " ( $\left.Z^{*} 40: 15\right) ; 3$. Nachfrage, ob der Proband Mitglied einer Kooperative ist: ist Mitglied; erläutert dieses Faktum aber nicht näher P: 39:36, L: 00:10

\section{D.6.c. Le code forestier officiel (c'est-à-dire la loi qui s'occupe du bois) vous concerne? De quelle façon?}

1015: loi forestière / législation $\sim$ / règlement forestier / droit $\sim$ / code $\sim$ / réglementation forestière / ordonnance $\sim$. Loi s'appliquant, dans tous les domaines, à la préservation, à l'entretien, à la protection et à l'utilisation de toutes les forêts d'un état (ou d'une province, d'un ALand@ ou d'une fédération).

1016: droit d'usage / $\sim$ d' $\sim$ forestier / servitude de forêt $/ \sim$ forestière. Droit réel que possède une personne de jouir des biens d'une forêt appartenant à une autre personne.

\section{Jean T. (EF1):}

I-Antw: 1. betrifft die techniciens; 2. hat eine noch größere Bedeutung für die propriétaires

I-Org: 1. erläutert, inwiefern der code wichtig für ihn ist; 2. Erklärung, warum der code besonders die propriétaires betrifft; 3. auf ausdrückliche Nachfrage hin gibt er Beispiele für die Bezugnahme auf den code bei der Beratung der propriétaires

D-Biogr: erwähnt nicht seine Position als technicien, sondern man gewinnt den Eindruck, als sei er wirklich persönlich betroffen: "Le code forestier me concerne, parce que les statuts du CRPF sont dans le code forestier. Par contre, 
tout ce qui est réglementation, qui concerne le propriétaire, est dans le code forestier et le concerne directement. Et là où il me concerne moi, c'est que moi, je suis censé le connaître et lui dire: 'Voilà, vous n'avez pas le droit de faire ceci, parce que c'est dans le code. Vous pouvez faire cela, parce que c'est pas dans le code.' " (Z* 25:42)

P: 25:31, L: 03:04

Paul A. (EF2):

I-Antw: Das Gesetz betrifft ihn; führt ein Beispiel an (Fall eines Autobahnbaus), bei dem man das Gesetz möglichst gut kennen sollte. Manchmal kann es Probleme geben bei der Einschätzung des Wertes eines Waldes.

D-Bsp: Anführung eines Beispiels (03:22), um zu verdeutlichen, wie wichtig es in einigen Fällen ist, das Gesetz zu kennen

P: 03:10, L: 01:26

\section{Pierre de B. (LF1):}

I-Antw: "Ça me concerne et je voudrais la supprimer tout de suite." (Z* 17:24); "Ça sert à rien, ce truc-là. Ça sert à embêter les propriétaires forestiers, c'est tout." (Z* 17:29)

I-Org: 1. spontane Antwort; 2. Nachfrage zur Rolle, die das Gesetz spielen kann: äußert sich nicht konkret, sondern bringt erneut seinen Unmut zum Ausdruck: "Administration avec un grand 'a' et avec tous les défauts que ça comporte. " (Z* 17:42); 3. erneute Nachfrage nach konkreten Situationen, in denen man vom Gesetz betroffen sein kann: Der Proband gibt keine Auskunft, sondern wiederholt erneut: "Ils embêtent les gens, c'est tout. " (Z* 18:01)

I-Komm: keine objektiven Auskünfte, ausschließlich persönliche wertende Aussagen-sehr negativ gefärbt

D-Biogr: Die Antwort befindet sich ausschließlich auf der persönlichen Ebene. Der Proband spricht offen über die Konflikte, die er mit den Organisationen austrägt.

D-Verh: Lachen und sehr inoffizielle Antwort-Vertrauensbasis zum Fragesteller wird sichtbar; er möchte offensichtlich nicht viel Auskunft zu dem Thema geben, da es ihn spürbar erregt (z.B. Seufzen bei der wiederholten Nachfrage nach Situationen, in denen man vom Gesetz betroffen sein kann, 18:00). Er lässt sich nicht auf die gestellten Fragen ein; verstärktes Klopfen auf den Tisch am Ende der Antwort (18:15). Trotz der Tatsache, dass ihm das Thema unangenehm scheint und er objektive Auskünfte umgeht, verliert er nicht seinen Humor-ironische Äußerungen, die ihn selbst zum Lachen bringen: "Qu'ils bouffent du papier, heureusement, il faut qu'ils en bouffent, comme ça, on va normal à la papeterie. “ $\left(\mathrm{Z}^{*} 18: 12\right)$

P: 17:19, L: 00:23 
Paul D. (LF2):

I-Antw: fühlt sich nicht vom code forestier betroffen und ist der Meinung, dass auch die Leute der Region nicht davon betroffen sind

P: 40:41, L: 01:05

\section{D.6.d. Est-ce qu'il y a, à votre connaissance, une loi qui restreint la ma- nipulation génétique des arbres qu'on plante? Avez-vous entendu parler du 'cloning'?}

\section{Jean T. (EF1):}

I-Org: 1. genetisch manipulierte Organismen sind nicht zulässig; 2. nennt als Beispiel für das Gesetz die peupliers D-Bsp: greift sehr schnell auf ein Beispiel zurück (s. Punkt 2)

D-Verh: kurzes Zögern vor der Antwort, nicht ganz sicheres Auftreten: "Je crois que les organismes génétiquement modifiés, les OGM, ne sont pas encore sur le marché." (Z* 26:54)

P: 26:41, L: 00:50

I-Org: 1. bestätigt die Existenz des cloning; 2. clonage gibt es für sehr viele verschiedene Baumarten - vor allem auch für den peuplier; 3. erklärt clonage und gibt Beispiele für Baumarten, bei denen clonage wirklich angewendet wird

I-Komm: Nachfrage, ob clonage auch für Eichen existiert, worauf er keine ganz sichere Antwort geben kann: "Je crois que" (Z* 29:12)

P: 27:38, L: 00:57

\section{Paul A. (EF2):}

I-Antw: weiß nicht, ob es ein solches Gesetz gibt

P: 03:57, L: 00:47

I-Antw: hat in Zeitschriften darüber gelesen, nicht aber im département davon gehört

I-Org: 1. Antwort; 2. Nachfrage zu den peupliers: er hat in der ,Region“ der Lot-et-Garonne davon gehört, nicht aber in dieser Region

P: 04:12, L: 00:15

Pierre de B. (LF1):

I-Antw: weiß nicht, ob ein solches Gesetz existiert und weiß nicht, wozu dieses Gesetz nützlich sein könnte, was er folgendermaßen begründet: "Je vois 
pas qu'est-ce qu'il,... qu'est-ce qu'il ferait, qu'est-ce qu'il pourrait faire. Comme ça se passe en laboratoire et que ça se passe dans le monde entier..., on fabrique des clones de ceci et cela." (Z* 18:31)

I-Komm: sieht die praktische Seite des Waldbaus, die für ihn sehr weit von der Theorie entfernt ist

P: 18:17, L: 00:58

I-Antw: bestätigt, davon gehört zu haben

I-Org: 1. bestätigt die Existenz eines solchen Gesetzes; 2. auf Nachfrage, ob es sich auch bei den peupliers um clones handle: "Ah, euh, tous les peupliers sont des clones." ( $\left.Z^{*} 18: 50\right)$; 3. auf Nachfrage nach anderen Baumarten, bei denen es sich um clones handelt, nennt er die ormeaux (junge Ulmen), äußert sein persönliches Erstaunen (s. D-Biogr), spricht über den Parasitenbefall dieser Baumart; ist erstaunt darüber, dass sie in Amerika überleben, nicht aber in Frankreich; 4. glaubt, dass man über die ormeaux viele Untersuchungen machen könne-schlägt dies dem Fragesteller sogar vor

I-Komm: Man spürt das Interesse des Probanden, der sich vor allem zum Punkt 3 (I-Org) sehr ausführlich äußert.

D-Biogr: zeigt sich verwundert: "J'ai été étonné que l'autre jour, le type, eh... l'ormeau, à ma, à... ma connaissance, c'est l'ormeau européen et c'est un clone." (Z* 19:02)

D-Verh: scheint für ihn selbstverständlich, dass man vom cloning gehört hat (leichtes Lachen auf die Frage hin); zeigt besonderes Interesse an dem Phänomen der ormeaux; betont immer wieder, wie erstaunt er selbst war und wie unverständlich ihm einige Dinge in diesem Zusammenhang erscheinen

P: 18:42, L: 00:25

\section{Paul D. (LF2):}

I-Antw: hat noch nichts von dem Gesetz zur restriction de la manipulation génétique des arbres cultivés gehört

P: 41:07, L: 00:26

I-Antw: gibt vor zu wissen, was clonage ist, kann jedoch auf die Nachfrage hin, ob es üblich sei, zunächst keine näheren Erläuterungen geben; stellt Gegenfrage: "Et qu'est-ce que c'est, maintenant, le clonage. " ( $\mathrm{Z}^{*}$ 41:26)

I-Org: 1. Antwort auf die erste Teilfrage nach der restriction de la manipulation génétique; 2. Antwort auf die zweite Teilfrage nach dem clonage; 3. Überlegungen zum Terminus clonage; 4. Hilfestellung seitens des Fragestellers zum Terminus clonage - daraufhin: "Non, je sais pas. J'ai entendu parler, mais... Non." (Z* 42:02); 5. Nachfrage, ob es in dem Gebiet, in dem er pflanzt, clones gebe: "C'est quoi, ça. " (Z* 42:18); 6. nach nochmaliger Erklärung von 
clone seitens des Fragestellers: "On les plante avec, dans des gobelets." $\left(Z^{*} 42: 29\right)$

I-Komm: bestätigt zwar zunächst, den Terminus clonage zu kennen, überlegt dann aber sehr lange, was die wirkliche Bedeutung ist: "Il y a pas longtemps que je le, que je le... du clonage. " ( $\mathrm{Z}^{*}$ 41:34); Verweis auf andere Hilfsmittel, da er selbst keine präzise Auskunft geben kann: "Ah, j'ai un prospectus sur le clonage, qu'est-ce que c'est, je... ah, maintenant, je sais... " (Z* 41:40); auffällig, dass der Proband den Begriff clone sogar nach Erklärung des Begriffs clonage seitens des Fragestellers (s. I-Org 4.) im Kontext der darauffolgenden Nachfrage (I-Org 5.) nicht einordnen kann (42:18)

P: 41:20, L: 00:13 


\subsubsection{Zusammenfassende Analyse der französischen Textcorpora: kommunikatives Verhalten, fachsprachliche Kompetenz, Konzep- tualisierung und Diskursgestaltung}

\subsubsection{Kommunikatives Verhalten}

Die Dauer des standardisierten Interviews liegt in einem flexiblen Zeitrahmen von grob 1 Stunde, was keinem der Probanden offensichtlich zu lang vorkam. Die Gespräche mit EF1 (78 Min.) und mit LF1 (71 Min.) fielen rund eine halbe Stunde länger aus als die mit EF2 (52 Min) und LF2 (43 Min.). Dies bestätigt den Eindruck, dass der Status des Probanden als Experte oder Laie nicht unbedingt auf die zu erwartende Länge des Interviews schließen lässt. Zumindest gibt es neben der professionellen Integration in den Sachbereich ('Waldbau als Beruf oder in ehrenamtlicher Funktion') noch andere Faktoren, die die Bereitschaft, über fachliche Inhalte zu sprechen, bedingen. Hervorzuheben sind insbesondere die Aspekte des persönlichen Interesses ('Waldbau als Hobby'), der Erfahrung ('Waldbau als (freiwilliges) Metier') und der faktischen Betroffenheit ('Waldbesitz, ggf. auch ohne aktiven Waldbau', vgl. EF4 u. LF4). In der Regel kommen mehrere dieser Faktoren biographisch zusammen und ermöglichen eine Art Kategorisierung des Gesprächspartners.

Die Probanden machten durchweg den Eindruck, bereitwillig und gern zu antworten, was für ihre grundsätzliche Vertrautheit mit dem Thema spricht. Im Verlaufe der einzelnen Gespräche zeigten sie eine gleichbleibende Auskunftsfreudigkeit. Allerdings schwankte die Ausführlichkeit der Antworten je nach inhaltlicher Komplexität der Fragestellung sowie auch nach Maßgabe der fachlichen Sicherheit und der faktischen Betroffenheit des Probanden in jedem einzelnen Fall. Die inhaltlichen Fragestrukturen des Interviews wurden sehr diszipliniert respektiert, wodurch sich eine gute Vergleichsmöglichkeit in der Auswertung ergibt. Nur in einem Fall war ein größeres Abschweifen vom Inhalt der Frage zu verzeichnen (LF1: B1), das jedoch noch vor dem Beginn des Sachfragenbereichs lag und nur Ausdruck der großen fachbezogenen Mitteilungsbereitschaft des Probanden war.

Der Charakter der einzelnen Konversationen wurde von den grundsätzlichen kommunikativen Verhaltensweisen der Probanden geprägt. Das Gespräch mit EF1 dokumentierte erwartungsgemäß die Ausrichtung seiner beruflichen Tätigkeit als conseiller forestier und gestaltete sich in einer sehr informativen und zugleich didaktischen Art und Weise. Die klar strukturierten Antworten von EF1 nahmen bisweilen enzyklopädische Züge an, ohne dabei jedoch belehrend zu wirken. Der Proband legte somit genau das kommunikative Verhalten an den Tag, das eine wesentliche Voraussetzung für den Erfolg seiner Arbeit 
darstellt und für den beruflichen Sektor des privat orientierten Forstwesens charakteristisch ist (so z.B. auch für EF3).

EF2, Präsident des CETEF, begegnete mir während des gesamten Gesprächs mit einer besonderen Höflichkeit, in der er auch auf Fragen detailliert einzugehen versuchte, die an der Grenze seiner fachlichen Kompetenz lagen (vgl. D4b). Er bewies dabei eine gewisse Gewandtheit im Umgang mit offensichtlichen Wissenslücken (D1c, D1f, D1h, D2c, D3i, etc.), die er auf der anderen Seite durch fundierte Kenntnisse zu anderen Fragen kompensierte (D1d, D1g, D3b, D3c, D4c, etc.). Auch dieses Gesprächsverhalten erscheint prototypisch für ein Fachgebiet, in dem es wenig Ausbildung und viele semi-professionelle Funktionen gibt.

LF1 gab ein sehr spontanes, freundliches und offenes Interview, das von einem besonders ungezwungenen kommunikativen Verhalten geprägt ist. Im Laufe des Gesprächs stellte sich dabei sogar eine gewisse Heiterkeit ein, die vor allem bei der Beantwortung der Fragen D6b und D6c deutlich wird. Der von LF1 bewiesene Humor ist sicherlich ein persönliches Charakteristikum und als solches nicht zu verallgemeinern. Jedoch zeigt die gelöste Gesprächsatmosphäre zusammen mit der interessierten Grundhaltung des Probanden auch eine typische Freude am Fach, die meiner Erfahrung nach in vielen Situationen fachkontextuellen Sprechens bestimmend ist.

Ganz anders geartet ist das Gesprächsverhalten von LF2. Auch er liebt den Wald und spricht gern über die mit ihm verbundenen Tätigkeiten (wie ich auf einer Führung durch seinen Besitz im Anschluss an das Gespräch feststellen konnte). Die fachspezifischen Fragen des Interviews waren jedoch für ihn ein offensichtliches Hemmnis der Kommunikation. Das analytische Bewusstsein des Probanden bewegte sich kontinuierlich im Rahmen normativer Grenzen, aus denen er aufgrund seiner sprachlichen Disposition nicht auszubrechen vermochte. Andererseits zeigt die genauere Analyse seines Antwortverhaltens die Stabilität fachspezifischer Grundeinsichten, mit denen sich LF2 durchaus angemessen und effektiv in der regionalen Realität des Faches bewegen kann. In diesem Sinne ist auch er ein typischer Vertreter des kommunikativen Verhaltens in regionalen Fachkontexten.

Die Antworten zu Frage B2 zeigen die unterschiedlichen persönlichen $\mathrm{Zu}$ gänge der Probanden zum Fachgebiet. EF1 antwortet ganz aus der beruflichen Perspektive, indem er seine Funktion als eine erfolgreiche Dienstleistung für die privaten Waldbesitzer definiert. EF2 lenkt in seiner Antwort über zu der Charakterisierung des typischen bearnesischen paysan forestier und seiner Abgrenzung gegenüber den Waldbauern der Landes. LF1 dokumentiert einen praktischen Bezug zum Fach, indem er unvermittelt auf das (für ihn beherrschende) Problem der Bodenqualität eingeht. LF2 schließlich beruft sich auf die Tradition einer Landwirtschaft, die stets in enger Verbindung zu Wald und 
Waldbau stand. In allen Fällen ist der besonders lebenspraktische Bezug zum Fach das für die Antwort entscheidende Kriterium.

Die Probanden gehen mit unterschiedlicher Genauigkeit die Beantwortung der jeweiligen Frage an. Insbesondere bei den allgemeineren Fragestellungen wird die normative Gebundenheit des Fachwissens offenbar. Dies verdeutlicht das Beispiel der Frage D4g, in der nach den verschiedenen Waldfunktionen gefragt wird. ${ }^{185} \mathrm{EF} 1$, der ansonsten fachlich präzise und genau strukturiert auf die ihm gestellten Fragen reagiert, bringt hier unvermittelt die Diskrepanz zwischen beruflicher und privater Perspektive ins Spiel und verzichtet auf eine analytische Darstellung der Thematik. Auch EF2 äußert sich nicht fachspezifisch, sondern hebt die normativen Besonderheiten der Region hervor. Er unterscheidet u.a. die Sichtweisen von Waldbesitzern und Nicht-Waldbesitzern, sowie den Konflikt zwischen den Anforderungen einer ökonomisch und ökologisch sinnvollen Nutzung des Waldes und dem traditionellen Bedürfnis nach existentieller Sicherheit ('Der Wald als Sparstrumpf'). LF1 hingegen betrachtet das Problem aus der Sicht des französischen Staates und hebt die Aspekte des ökonomischen Interesses sowie - als seinen Konterpart - eine 'ökologistische' Grundhaltung hervor. Wieder wird die These der regionalen Gebundenheit des Sprechens bestätigt, denn LF1 distanziert sich eindeutig von beiden Perspektiven:

Mais l'arbre, ça me fait de la peine de le couper, hein? -

Moi, je suis pas tout à fait écologiste, non, non. Dans ce sens, je le suis dans la réalité, mais je ne le suis pas dans les mots comme ça.

(LF1: D4g)

Auch LF2 dokumentiert eine Form der regionalen Verankerung im Sachbereich, die für ihn sogar zu einem Substitut jeglichen analytischen Bewusstseins wird. Er antwortet undifferenziert, alle genannten Funktionen seien wichtig, um sich hernach zu erklären:

Moi, j'avais des plantations, j'aimais bien aller chasser.

(LF2: D4g)

Die biographische Perspektive ist des Öfteren im Antwortverhalten der Probanden beherrschend. Dies gilt besonders bei Themen, deren fachliche Durchdringung im regionalen Leben eher unüblich ist. Ich möchte zur Illustration auf die Frage D3g eingehen, in der es um die Beurteilung der Güte einer Neuanpflanzung geht. Selbst EF1 äußert sich hier nicht fachanalytisch (was durchaus möglich gewesen wäre), sondern betont die praktische Irrelevanz der Fragestellung: Die Wurzeln, auf die es ankommt, seien in einer Anpflanzung nicht zu sehen. EF2 hebt den intuitiven Charakter der Sacheinschätzung hervor. LF2

${ }^{185}$ Zum fachlichen Hintergrund dieser Frage vgl. z.B. Das Kosmos Wald- und Forstlexikon, 1998, 780 f., wo zwischen Nutzfunktionen, Schutzfunktionen und Erholungsfunktionen des Waldes unterschieden wird. 
verweist auf die Kompetenz fachlicher Institutionen. All diese Antworten sind recht kurz und umgehen eine fachliche Stellungnahme, da die Kriterien rein theoretischer Natur wären. LF1 gestaltet nun seine Antwort ganz anders, indem er auf die Probleme seiner eigenen Anpflanzungen zu sprechen kommt. Dabei entwickelt sich spontan eine relativ komplexe Argumentation, die Investitionsbereitschaft, institutionelle Unterstützung, Subventionsannahme und wirtschaftlichen Erfolg miteinander in Verbindung bringt. Das Resultat wird in der dem Probanden eigenen humorvollen Weise resümiert:

On a fait des bonsaïs merveilleux.

(LF1: D3g)

Was den spezielleren Umgang mit der Kommunikationsform des (fachlichen) Erklärens anbelangt, die meine Befragung ja in hohem Maße herausfordert, so lassen sich einige grundsätzliche Beobachtungen anführen. Zunächst einmal ist hervorzuheben, dass es Grenzen der Bereitschaft, sich zu erklären, gibt. Diese Grenzen sind dann erreicht, wenn eine präzise Frage auf Unkenntnis stößt, ohne dass es einen kommunikativen Ausweg aus diesem Dilemma gibt. Ich habe solche Fälle bei allen Probanden registrieren können (EF1: D3c EF2: D1h, LF1: D1f, LF2: D2d). Allerdings kommt dies recht selten vor. In der Regel versuchen die Probanden stets, eine Antwort zu finden. Ihre Motivation liegt dabei weniger in der Dokumentation fachlichen Wissens, als vielmehr in der freundlichen Absicht, einem Außenstehenden (d.h. dem Befrager, der nicht in der Region lebt) normative Kenntnisse des Sachbereichs zu vermitteln. In diesem Sinne wird jede gestellte Frage als potentiell auf eine regionale Realität bezogen interpretiert und dementsprechend beantwortet.

Diese interpretative Grundhaltung, die bei allen Probanden nachweisbar ist, geht z.T. eine außergewöhnliche Verbindung mit der im Interview erforderlichen Angabe von Definitionen ein. Die Tatsache, dass diese Definitionen offensichtlich nicht zum Alltag des regionalen Sprachgebrauchs in Fachkontexten gehören, aber dennoch bereitwillig versucht werden, zeigt an, dass die Sprecher zwar von inhaltlichen Begriffskonzepten in der fachbezogenen Kommunikation ausgehen, diese jedoch in der Regel nicht in der präzisen Form einer Definition verbalisieren. Ich möchte das in den Interviews aufgedeckte Spannungsfeld von fachsprachlicher Präzision und gemeinsprachlich operabler Konzeptualisierung an einigen Beispielen verdeutlichen.

EF1 ist durch seine Ausbildung und seinen Beruf dazu in der Lage, die einzelnen Themen aus einer fachlichen Distanz analytisch darzustellen. Dieses Kommunikationsverhalten ist jedoch auch für ihn untypisch, was er mehrfach zum Ausdruck bringt (z.B. D1f). Besonders interessant ist die Tatsache, dass sein fachspezifisches Wissen im Hinblick auf die definitorisch exakte Abgrenzung einiger gebräuchlicher Begriffe Lücken aufweist. So kommt EF1 in Schwierigkeiten tige, fût und tronc begrifflich klar voneinander abzugrenzen 
(D2a) und zeigt auch Unsicherheiten in Bezug auf den Terminus grume (D5d). Der Grund hierfür liegt gerade in der Vertrautheit mit diesen Begriffen, die im (beruflichen) Alltag frequent und semantisch unpräzise benutzt werden. Die Definitionsfreudigkeit von EF1 hängt u.a. auch von der Abstraktheit der Begriffskonzepte $a b$. Je konkreter ein Begriff sich fachlich darstellen lässt, umso genauer ist auch seine sprachliche Erläuterung durch EF1. Dendromètre (D1h), pincer (D3i) und jardinage (D4b) sind Beispiele dafür. Die Definitionen haben hier einen tatsächlichen Erklärungswert und werden in einer natürlichen Form fachsprachlicher Kommunikation (mit Beispielgebungen und persönlichen Bezügen) geäußert.

EF2 kennt die fachsprachliche Terminologie nur aus der praktischen Erfahrung. Begriffe, die ihm unbekannt oder nicht geläufig sind, werden daher in diese Erfahrungswelt integriert oder aus ihr explizit ausgegrenzt. Auf die Frage nach der Bedeutung von jardinage antwortet EF2 zunächst, dass dieser Begriff nicht zum Vokabular eines forestier gehöre, ${ }^{186}$ versucht dann aber doch die folgende Definition:

Jardinage ne peut vouloir dire que, ne peut être qu'une allusion aux petites parcelles, aux microparcelles.

(EF2: D4b)

Die Unkenntnis des Probanden (und die aus ihr resultierende falsche Applikation von jardinage auf das Problem des morcellement parcellaire im Béarn) begründen sich aus der regionalen Gebundenheit seines Wissens. Die Antwort von EF1 macht deutlich, dass der jardinage als Betriebsform der forêt irrégulière vor allem im Gebirge angesiedelt ist, wo auf den dauerhaften Bestand einer natürlichen Waldlandschaft aus geographischen Gründen Wert gelegt wird. Die Forstinstitutionen favorisieren hingegen im nördlichen und mittleren Béarn die forêt régulière (in den Formen der plantation oder der régénération naturelle), die eine einfachere bzw. effektivere Form der waldbaulichen Produktion darstellt. Die Tatsache, dass EF2 in diesem für ihn relevanten Bereich über Kenntnisse verfügt, belegt seine Antwort auf die Frage $\mathrm{D} 4 \mathrm{c}$, in der er eine inhaltliche Ausdeutung des Terminus coupe d'éclaircie vornimmt, die in korrekter Weise auf die Prinzipien des regionalen Waldbaus rekurriert und dabei die im Béarn übliche Betriebsform des balivage ${ }^{187}$ beschreibt, die einer besonderen Stufe des taillis-sous-futaie ${ }^{188}$ entspricht und in der Gegend häufiger angewendet wird. Ich werde die komplizierten Zusam-

${ }^{186}$ Diese Aussage ist aus dem Mund eines Fachmanns überraschend. Allerdings stellt der Plenterwald im Béarn auch keine gängige Betriebsart dar. Ich werde auf die fachlichen Hintergründe dieses Wissens noch zu sprechen kommen.

${ }^{187} \mathrm{Zu}$ balivage vgl. den Dictionnaire Forestier Multilingue, Kennz. Fr. 78 und Fr. 42-77, unter dem Stichwort taillis-sous-futaie. Kritisch zu dieser Methode: Lanier 1994, 122 u. 137.

${ }^{188} \mathrm{Vgl}$. zu der Verbreitung und kritischen Einschätzung dieser Betriebsart in Frankreich das Kapitel 2.4.3.3 
menhänge, die sich aus den regionalen Normen des Waldbaus ergeben, in den folgenden Kapiteln noch genauer erläutern.

LF1 ist persönlich eng mit dem Waldbau verbunden und kennt sich in diesem Metier gut aus. Die Sprache des Forstwesens ist ihm jedoch eher ungeläufig. Sein Antwortverhalten spiegelt diese Diskrepanz deutlich wider. Auf die Frage nach dem peuplement dominant (D1b) z.B. versucht LF1 eine Definition zu geben, die kaum mehr als eine Paraphrase darstellt:

Ah le peuplement dominant, c'est le peuplement de variété, la variété qui est dominante, $[\ldots]$

(LF1: D1b)

Die gesamte Antwort des Probanden jedoch ist interessant, da sie biographisch gestaltet wird und sein Interesse an den Hintergründen waldbaulicher Maßnahmen dokumentiert. Der Verzicht auf Fachvokabular hindert LF1 nicht daran, präzise Vorstellungen von der Struktur und Bewirtschaftung des Waldes zu entwickeln. Auf die Frage nach dem sous-étage etwa betont er, dass es drei verschiedene étages des Waldes gebe. Er kann sie aber nicht fachlich korrekt bezeichnen (so wie EF1, der zwischen étage dominant, étage dominé und sousétage differenziert) und verweist daher auf die für das jeweilige Stratum in seiner Gegend typische Vegetationsart, konkret a. le chêne, b. les abrisseaux (le noisetier), c. la fougère, l'herbe, la ronce.

Die größten Schwierigkeiten mit der Angabe von Definitionen und theoretischen Erklärungen hat LF2. Seine Antworten gestalteten sich daher z.T. sehr wortkarg, obwohl er ansonsten (außerhalb des Interviews) durchaus mehr zu sprechen bereit war. An der Kürze seiner Antworten zeigt sich in der Regel eine starke Fixierung auf normative Gegebenheiten in der Region, die seine Bewertung der den Wald betreffenden Dinge prägen. Auf die Frage nach den verschiedenen soins de plantation (D3h) z.B. antwortet der Proband:

Moi, je crois que pour les planter, il faut les planter le mois de novembre.

(LF2: D3h)

Als er nach der Bedeutung von pincer gefragt wird (D3i), sagt LF2, die Methode (welche?) sei erst im dritten oder vierten Jahr anwendbar. Und als das Gespräch auf den Begriff des rendement soutenu kommt, ist seine Stellungnahme: 'Oui, mais ici c'est pas le cas.' Auch LF2 kennt sich im bearnesischen Wald und seiner Problematik grundlegend aus. Er ist jedoch an einer fachlichen Durchdringung dieses Sachbereichs uninteressiert. Seine persönlichen Gründe hierfür sind aus dem Interview nicht herauszuhören. Es ist jedoch ein Faktum, dass die negative und ablehnende Bewertung der sylviculture, die LF2 dokumentiert, im Béarn oft anzutreffen ist und eine lange Tradition hat: 'Il y a pas d'exploitation ici.' (D5h, vgl. auch D1g). 
Zum Abschluss der Darstellung des Kommunikationsverhaltens der Probanden möchte ich noch auf einige Aspekte der sprachlichen Ausdrucksfähigkeit $\mathrm{zu}$ sprechen kommen. Grundsätzlich ist anzumerken, dass die Gesprächssituation eines Interviews zum Thema 'Wald im Béarn' ohne praktischen Bezug als ungewöhnlich empfunden werden musste. Die meisten Gespräche über Aspekte und Probleme des Waldbaus finden nämlich vor Ort, d.h. im Wald selbst statt. Durch die Öffentlichkeitsarbeit der privatforstwirtschaftlichen Institutionen ergibt sich jedoch bei den Interessierteren und Betroffenen mehr und mehr auch eine gewisse Vertrautheit mit theoretischen Erklärungen. Allerdings sind in diesen Fällen (z.B. bei öffentlichen réunions oder während einer visite diagnostique) oft Monologe der ausgewiesenen Fachleute zu verzeichnen. In diesem Sinne war nur EF1 auf die Gesprächssituation des Interviews angemessen vorbereitet.

Es verwundert nicht, dass die sprachliche Komplexität in den Erklärungen von EF1 besonders hoch ist. EF2 und LF1 weisen natürlicherweise etwas weniger Gewandtheit in der (fach-)sprachlichen Darstellung auf. Ihre Diskurse sind oft durch die typischen Strukturmerkmale gesprochener Sprache geprägt. Ich gebe hierfür zwei Beispiele. EF2 etwa definiert peuplement dominant in folgender Weise:

Un peuplement dominant, c'est qu'il soit naturel ou artificiel, disons que c'est l'essence qui est la plus que l'on trouve disons en nombre et en hectare, disons, dans la région.

(EF2: D1b)

Und LF1 erklärt den Begriff jardinage mit den Worten:

C'est une manière, manière de, euh travailler la, la forêt, et euh, à la différence, j'allais dire, de euh de quelqu'un qui va euh décider que sur toute une euh pièce, on va euh le couper, faire une coupe à plat, hein, et tandis que le jardinage vous enlèverez les arbres, les arbres abîmés, euh, non productifs, eh.

(LF1: D4b)

Allerdings tauchen die sprachlichen Unsicherheiten bei beiden Probanden fast ausschließlich im Zusammenhang mit Definitionsangaben auf. Die Gründe hierfür habe ich bereits genannt.

Der sprachliche Ausdruck von LF2 erfordert einen besonderen Kommentar. Oft beschränkt der Proband seine Antworten auf eine sehr knappe Form, die kaum deutlich werden lässt, was er eigentlich sagen will (vgl. z.B. D4e, D6d). Der Fragesteller sieht sich z.T. sogar gezwungen, diese eingeschränkte Form der Kommunikation aktiv zu unterstützen (vgl. D3h, D6a). Ich bin auf die Hintergründe dieses sprachlichen Verhaltens bereits eingegangen. Allerdings kommt noch ein weiterer Aspekt hinzu. LF2 ist nämlich der einzige Proband, der das Bearnesische als Muttersprache gelernt hat und es offensichtlich immer noch mit größerer Leichtigkeit als das Französische verwendet. Seine Beantwortung der Frage D5c macht dies deutlich. Als es um die Technik des Baum- 
fällens geht, zeigt sich, dass der Proband hier ein besonders detailliertes Wissen hat, es aber nur mit Mühe im Französischen auszudrücken in der Lage ist. Das Signal des Fragestellers, die Erläuterung auf Bearnesisch zu geben, verändert das Kommunikationsverhalten von LF2 grundlegend: Es folgt ein erst noch mit französischen Phrasen durchsetzter, dann vollständig auf Bearnesisch formulierter Diskurs mit einer detaillierten Beschreibung der Fälltechnik. Diese plötzliche Mitteilungsfreudigkeit in Zusammenhang mit dem Sprachwechsel ist angesichts des technischen Inhalts der behandelten Frage und des ansonsten zurückhaltenden Antwortverhaltens von LF2 ein beachtenswertes Faktum.

Noch ein weiterer Aspekt der sprachlichen Analyse muss erwähnt werden: Der Gebrauch der Forstfachsprache ist in der Regel in praktische Kontexte eingebunden, in denen deiktische Kommunikationsformen eine wichtige Rolle spielen. Es ist daher bisweilen unnatürlich, dass die Probanden etwas erklären müssen, ohne es zeigen zu können. Besonders auffällig war dieser Verzicht bei Themen wie 'Beschreibung des Eichenblattes' oder 'Forstkarten'. Die Beschreibung des Eichenblattes (D2f) möchte ich kurz kommentieren.

Grundsätzlich haben alle Probanden außer EF1 die zu erwartenden Schwierigkeiten bei der exakten Beschreibung des Blattes gehabt. In der Fachliteratur wird das Blatt des chêne pédonculé folgendermaßen charakterisiert: 'lobée, avec deux oreillettes à la base, pétiole très court' (Becker / Picard / Timbal 1981Becker / Picard / Timbal 1981, 168). ${ }^{189}$ EF1 findet mit etwas anderen Ausdrücken zu einer ebenso genauen Deskription (limbes, aurioles, arrondis). Die übrigen Probanden unternehmen den sprachlich mehr oder weniger geglückten Versuch einer Beschreibung, die außerhalb ihrer kommunikativen Gewohnheiten liegt. Dabei assoziieren EF2, LF1 und LF2 dents bzw. dentelé als Charakteristikum mit dem Eichenblatt (EF2 allerdings nur in negativer Form). Die äußere 'Zahnung' ist aber gerade nicht für das gerundete Eichenblatt typisch, sondern eher für ein Blatt wie das der Buche, das ebenso bekannt sein dürfte. Vermutlich ist der Grund für die falsche sprachliche Assoziation in der normhaften Vorstellung typischer Blattformen zu finden (deren Rand entweder glatt oder gezahnt ist), wobei die spezifische Blattform der Eiche, die im Prinzip allen bekannt ist, nicht mit diesen Normen korrespondiert. ${ }^{190}$ Darüber hinaus ist das regionalspezifische Wissen der Probanden so differenziert, dass ihnen von vornherein die Vielfalt an Blattformen unterschiedlicher Eichenarten bewusst ist (EF1, LF1 und LF2 weisen von sich aus darauf hin). Diese Wissensdimension scheint mir für eine Region wie den Béarn typisch zu sein,

${ }^{189}$ Forey / Fitzsimons 1988, 70, geben die folgende Beschreibung: 'Feuilles avec de 3 à 6 paires de lobes, à bords ondulés, et une petite oreillette à la base.'

${ }^{190}$ Ich hätte allerdings eher vermutet, dass das Eichenblatt B besonders im Béarn - eine eigene Norm konstituiert und in seiner typischen Form von den Probanden mühelos beschrieben werden kann. 
in der die Eiche als Baumart dominant ist und in mehreren Varietäten auftritt. Sachnormen, Regionalnormen und Sprachnormen gehen hier genau die enge Verbindung ein, die eine wesentliche Grundannahme der gesamten Untersuchung ist.

\subsubsection{Fachsprachliche Kompetenz}

Das standardisierte Interview ist in mehrfacher Hinsicht auf die Eruierung terminologischen Wissens ausgerichtet: Es werden Begriffsdefinitionen erbeten, nach Termini für Inhaltskonzepte gefragt und Themenschwerpunkte behandelt, die indirekt eine Dokumentation des Umgangs mit dem Fachvokabular herausfordern. Die terminologischen Bezüge der jeweiligen Frage sind in der Auswertung durch die Voranstellung einiger zentraler Begriffe aus dem Lexicon Silvestre (vgl. Kap. 2.4.1) dokumentiert worden. Insgesamt zeigt die Analyse der Gespräche eine sehr geringe Frequenz dieses Fachwortschatzes im mündlichen Sprachgebrauch. Es fällt auf, dass nur die Ausführungen von EF1 durch ein hohes Maß an begrifflicher Präzision gekennzeichnet sind, während die drei anderen Probanden ihre Sacherklärungen, zum Großteil unter Verzicht auf die sog. termes techniques, in eine normale Form des alltäglichen Sprechens fassen. Unter dieser 'normalen Form des alltäglichen Sprechens' verstehe ich - im Sinne meiner theoretischen Darlegungen im ersten Teil der Arbeit - den Gebrauch des 'endogenen Standards' der Gemeinsprache, dessen Offenheit und Variabilität auch eine Eignung für die Versprachlichung fachkontextueller Themen impliziert. Dadurch werden die Grenzen zwischen Fachsprache und Gemeinsprache fließend. Diese Übergänge sind jedoch vornehmlich aus der Perspektive des Sprachgebrauchs und nicht aus derjenigen einer linguistischen Abgrenzung einzelsprachlicher Varietäten zu betrachten.

Das Kommunikationsbedürfnis im Fach wird durch die regionalen Gegebenheiten bestimmt. Unter Bezug auf den Waldbau im Béarn lassen sich vier Typen von Gesprächskonstellationen als Normalität im Alltag beobachten:

1) Das Gespräch von Fachleuten unter sich, das einen Sonderfall beruflicher Kommunikation darstellt.

2) Das Gespräch über administrative und politische Aspekte der gestion forestière, das insbesondere der institutionellen Ebene vorbehalten ist, durch Versammlungen und Informationsveranstaltungen jedoch auch an die Öffentlichkeit getragen wird.

3) Das Gespräch zwischen Fachmann und Laie, das insbesondere die Öffentlichkeitsarbeit der privatwirtschaftlich orientierten Forstinstitutionen $(C R P F, C E T E F, C P B$ 64 , etc.) prägt. 
4) Das Gespräch der Amateure und Laien untereinander, für die der Waldbau von einer marginalen Nebenbeschäftigung bis hin zu echter Passion reicht.

Die Feldforschungen vor Ort haben mir Einblick in die Realisation aller vier Konstellationstypen gewährt. Hinsichtlich der beiden ersten Typen ist anzumerken, dass sie sich als Form des aktiven Sprachgebrauchs im engeren beruflich und institutionell definierten Bereich des Fachs vollziehen. Fälle dieser Art wären etwa ein Gespräch zwischen EF1 und EF3 oder Redebeiträge von EF2 auf einer Mitgliederversammlung des CETEF. Die vorliegende Untersuchung erfasst diese Bereiche fachsprachlicher Kommunikation nicht, sondern widmet sich den Typen 3) und 4), deren soziale Reichweite und normale Verbreitung weitaus größer ist. Die lexikalischen Ressourcen und textuellen Gestaltungsformen des Sprachgebrauchs in Fachkontexten können in Gesprächen, die nicht professioneller oder institutioneller Natur sind, auf einer gemeinsprachlichen Basis analysiert werden und bieten sich zudem für die Analyse der regionalsprachlichen Ausgestaltung des Kommunikationssektors an. Hinsichtlich der konkreten Gesprächsführung in den Interviews ist darauf zu achten, dass der Fragesteller den Status eines interessierten Laien behalten muss und nicht aufgrund seines speziell angeeigneten Wissens in die Rolle eines 'Kenners der Materie' rücken darf.

Unsere Gespräche mit EF1 und EF2 erfüllen die Bedingungen des Konstellationstyps 3 (Fachmann in beruflicher/institutioneller Funktion-interessierter, aber fachfremder Laie), diejenigen mit LF1 und LF2 gehören zum Typ 4 (Amateur mit Erfahrung - Amateur mit Interesse). Die jeweilige Darlegung des Fachwissens in den Gesprächen hängt von dem Grundverständnis dieser Konstellationstypen ab. Dabei ergibt sich in der Probandengruppe eine Staffelung der Kombination von theoretischem und praktischem Wissen, die ich - unter Berücksichtigung des jeweiligen Wissensniveaus durch die Größe der Symbole - wie folgt schematisiere:

Theoretisches Fachwissen: $\quad$ Erfahrungswissen im Fach:

EF1:

घEF2: $\mathbf{\square}$ LF1:

LF2:

EF1 ist daran gewöhnt, seine fachsprachliche Kompetenz in den Gesprächen mit Nicht-Fachleuten zurückzunehmen und die Zusammenhänge sprachlich einfach, d.h. ohne allzu viel Fachterminologie, darzustellen (explizit formuliert in D1d). Dieser Habitus geht zum Teil durch die fachspezifischen Fragestellungen des Interviews verloren, so dass EF1 mehrfach im Hinblick auf den Fachsprachgebrauch zwischen nous forestiers und les propriétaires unterscheidet (vgl. D1c, D1f, D6a ). 
Eine gute Illustration dafür, wie EF1 mit fachlichen Erklärungen sprachlich umgeht, gibt die Frage D3i nach der Bedeutung des Begriffs pincer. EF1 geht die Frage zunächst auf dem Hintergrund einer theoretischen Erläuterung der Wachstumsphasen des Baums (élongation, lignification) an, woraufhin er eine präzise Definition des Terminus gibt und auch in der Lage ist, auf ergänzende Rückfragen noch genauer einzugehen (pincer les pousses latérales, $p$. les branches gourmandes). Interessanterweise wechselt EF1 daraufhin spontan in ein anderes Erklärungsregister, dessen sprachliche Form dem Konstellationstyp Fachmann - Laie angemessener ist. In syntaktischer Hinsicht wird die Erklärung dabei ungenauer, jedoch ergänzt EF1 sie durch sprachbegleitende Tätigkeiten (Zeigen mit den Händen, Geräuschimitation):

Quand un arbre, ce qu'on veut, c'est qu'il soit comme ça, on veut pas qu'il soit comme ça, arrondi. Donc, vous avez la pousse terminale et si vous avez des parties, d'autres, des pousses latérales qui commencent à devenir trop importantes et dépasser le bourgeon terminal,... tic.

(EF1: D3i)

Das Fachwissen von EF2 ist schwerpunktmäßig verteilt. Der Proband äußert sich daher nur zu bestimmten Fragen in einer fachlich anspruchsvollen Form. Dabei stellt EF2 eine andere Form der Konzeptualisierung seines Wissens unter Beweis als EF1. EF2 ist nämlich nicht nur in den praktischen Bezügen, sondern auch in seiner theoretischen Wissensstruktur stärker an den Besonderheiten der Region orientiert. Die Frage nach den im Béarn hauptsächlich vertretenen Baumarten beispielsweise (D1a) gliedert EF2 nicht, so wie EF1, nach den Kriterien der botanischen Klassifikation, sondern bezieht sich sofort auf die unterschiedliche regionale Verteilung der Dominanzen. Seine Vertrautheit mit diesem Gesichtspunkt unterstreicht er dabei durch Hinweise auf klimatische Unterschiede und die Erklärung der regionalspezifischen Bedeutung von Kastanienbeständen. ${ }^{191}$

Noch auffälliger ist die regionale Bezugnahme des Wissens bei LF1. Auf die Frage nach der Dichte von Beständen (D1d) reagiert der Proband nicht mit einer theoretischen Erklärung (so wie EF1 und EF2), sondern mit dem direkten Hinweis auf ein regionales Problem: Die bearnesischen Wälder sind in der Regel zu dicht, da verwildert und nicht waldbaulich gepflegt. LF1 begnügt sich aber nicht mit der bloßen Feststellung des Problems (so wie LF2: „Ça monte pas, ça monte, mais ça reste, puis ça s'étouffe. "), sondern verweist auch auf die regionalspezifischen Hintergründe:

${ }^{191}$ Selbstverständlich ist anzunehmen, dass auch EF1 dieses Wissen zur Verfügung steht. Es geht mir hier aber um die Hervorhebung von Feinheiten in der Unterscheidung einer fachinternen und einer regionalen Gebundenheit des sprachlich geäußerten Wissens. In diesem Zusammenhang ist auch die Antwort von LF1 interessant, dessen chronologisches Gliederungskriterium ebenfalls regionalgebunden ist (Wandel des vorherrschenden Bestands in der Mikroregion des Probanden). 
Et comme il y avait de la ... eh, du châtaignier autrefois, et les bois sont,... eh, sont venus naturels, et n'ont pas été resemés, replantés, alors on a souvent une densité un peu trop forte. Comme ce sont pas des bois de valeur, souvent, ils n'ont pas été éclaircis et il fallait, comme il fallait et c'est un inconvénient.

(LF1: D1d)

Die Antwort ist für jemanden, der mit der regionalen Geschichte und aktuellen Situation nicht vertraut ist, so verkürzt in ihrer Darstellung, dass sie kaum verständlich ist. Zwar hat der Proband schon zu Beginn des Interviews auf die frühere wirtschaftliche Bedeutung der Kastanienbestände in seinem Heimatgebiet hingewiesen, ohne jedoch das ungewöhnliche Faktum zu erwähnen, dass diese Bestände mit der Aufgabe ihrer Nutzung systematisch verschwunden sind. Der Grund hierfür lag in der Verbreitung der Kastanienkrankheit, die aus wirtschaftlichem Desinteresse heraus nicht wie anderorts durch die Maßnahme der Anpflanzung resistenter (gepfropfter) Arten kompensiert wurde (woraufhin in dem Gebiet vermehrt Eichen zu wachsen begannen). Die Tatsache, dass sich der Gesprächspartner diesen sehr speziellen Hintergrund 'zusammenreimen' muss (wenn er es denn überhaupt kann), verdeutlicht, in welchem hohen Maß die Fachwissensstrukturen konzeptionell und sprachlich auf das Leben in der Region bezogen sind. Wir finden hier also ein gutes Diskursbeispiel für die regionale Determination des Sprechens in Fachkontexten.

LF2 gibt in seinen Redebeiträgen insgesamt nur ein bescheidenes Fachwissensniveau zu erkennen. Er selbst äußert auch, dass er aus fachlicher Sicht nicht als kompetent gelten kann (D2d, „Ah, je suis pas très technicien. “; D4f, „Je vais passer loin."), fragt nach, wenn er die Frage aus terminologischen Gründen nicht richtig versteht (D1f, D1g) und gibt mehrfach unumwunden seine Begriffsunkenntnis zu. Vor dem Hintergrund der regionalen Gebundenheit der Wissensstrukturen ist diese fachliche Unkenntnis jedoch nicht mit einer Inkompetenz im Sachbereich gleichzusetzen. Es zeigt sich nämlich immer wieder, dass LF2 die wesentlichen Normen der fachlichen Realität - und hiermit sind sowohl Sachnormen als auch regionale Normen und biographische Erfahrungen gemeint - durchaus kennt und im Sinne seines persönlichen Zugangs zum Fach auch verbalisiert. Dabei gewinnt das Normative z. T. gegenüber einer aus fachlicher Sicht notwendigen differenzierteren Betrachtungsweise die Oberhand, so dass die Äußerungen von LF2 gedanklich einfach strukturiert und sehr kategorisch wirken. Eines der bei LF2 in mehreren Zusammenhängen wiederkehrenden Themen ist z.B. die Vernachlässigung und Ungepflegtheit der bearnesischen Wälder. Es handelt sich dabei um eine sachlich richtige Einschätzung, die jedoch aus der Sichtweise des Betätigungsfelds eines technicien forestier eine andere Bewertung erfährt als aus der Sicht eines Bearnesen, der in der Tradition des Umgangs mit dem Wald groß geworden ist und keine innovativen Impulse zur Änderung der gegebenen Verhältnisse verspürt. Die übereinstimmende normative Einschätzung der Realität bleibt 
aber dennoch eine wesentliche Gesprächsgrundlage zwischen dem Experten und dem Laien. Auch der Konflikt zwischen innovativem Engagement und konservativem Denken muss sprachlich ausgetragen werden.

Das Problem der regionalen Fachkommunikation ist in sprachlicher Hinsicht vielschichtiger als es zunächst scheint. Das innovative Denken und Handeln, das in jedem Fall fachlich begründet ist, setzt nämlich an Normen an, die oft einer fachlich unangemessenen Einschätzung entsprechen. Die Versprachlichung dieser Normen ist einfach und kategorisch (vgl. LF2: D1a, D1g, D5h). Ihre Veränderung bzw. Überwindung setzt jedoch kompliziertere Formen des fachkontextuellen Sprechens voraus, die aber dennoch für den NichtFachmann verständlich und sogar überzeugend sein müssen. Das eigentliche Problem besteht dabei nicht nur in der Rücknahme des fachsprachlichen Niveaus (so wie bei EF1 nachweisbar), sondern in der expliziten Anknüpfung an die normativen Wissensstrukturen, Bewertungen und Erwartungen der faktisch Betroffenen, in diesem Fall also der privaten Waldbesitzer. Es wäre völlig deplaziert, ein mangelndes Fachwissen von LF2 zu belächeln, ohne dabei zu bedenken, dass dieses Fachwissen zum einen im alltäglichen Lebensvollzug auch kommunikativ - nicht benötigt wird und dass zum anderen die fachliche Aufklärung nur dann Sinn macht, wenn sie an der regionalen Normalität des Fachs ansetzt und berücksichtigt, welches Bewusstsein die Betroffenen von der mit dem Fach verbundenen Lebensrealität internalisiert haben. Die Analyse dieses Problems ist wissenssoziologischer und psychologischer Natur, seine Lösung setzt kommunikative Strategien voraus, die prinzipiell in das Blickfeld fachinstitutioneller Aufklärungsarbeit zu rücken wären.

Kommen wir noch einmal auf das Spannungsfeld von Kompetenz und Inkompetenz im Falle von LF2 zurück. Die Ansätze zur Erlangung eines fachlichen Wissensniveaus hängen bei LF2 von dem vorhandenen Kontakt mit den forstwirtschaftlichen Institutionen ab. Allerdings bewertet der Proband diesen Kontakt ausschließlich aus der Perspektive einer ökonomischen Gewinnorientierung. Ich verweise hierzu kurz auf einige Antworten, die ein Gesamtbild konstituieren. ${ }^{192}$ LF2 kennt sich mit der Bodenqualität aus (D3b), weil eine offizielle Bodenanalyse auf seinem Terrain vorgenommen worden ist. Er hat eine Anpflanzung anlegen lassen, ohne sich mit den Zielsetzungen genauer auseinanderzusetzen (vgl. D3g, auch die ohne Hintergrundwissen unverständliche Reaktion bei D1f). ${ }^{193}$ Er besitzt eine Forstkarte seines Besitzes, ohne viel

${ }^{192}$ Ich ergänze dabei einige Tatsachen, die ich in Gesprächen mit LF2 außerhalb des Interviews erfahren habe. Die Interpretation der aufgezeichneten Diskurse setzt im Falle von LF2 nicht nur die Kenntnis regionaler Normen, sondern auch die biographischer Fakten voraus.

${ }^{193}$ Ich habe nach dem Interview diese Anpflanzung mit LF2 selbst begehen dürfen. Es handelt sich um ein Hochplateau, das von LF2 eingezäunt worden ist und in dem versuchsweise mehrere verschiedene Arten von pins Laricio gezogen werden. Der Einblick in die fachlichen Hintergründe dieser Anpflanzungsmaßnahme ist bei LF2 sehr gering (es existiert eine Auf- 
mit ihr anfangen zu können (D6a). Besonders wichtig ist ihm der Aspekt der Subventionierung waldbaulicher Tätigkeit (vgl. D6b, wo er von sich aus nur die DDA(F), also den Subventionsgeber, als Fachinstitution für den privaten Waldbau nennt). Seine Zusammenarbeit mit den forstwirtschaftlichen Institutionen begründet sich aus den Fehlschlägen eigener Initiativen einer Bewaldung ehemals ungenutzter Bodenflächen (vgl. D3a). Die Zusammenarbeit mit den Forstinstitutionen ist für ihn jedoch offensichtlich weder mit einer theoretischen Lernbereitschaft noch mit dem Einsatz eigener Arbeitsleistung verbunden.

Die Sachkenntnis und die fachsprachliche Kompetenz von LF2 werden durch seine Involvierung in moderne waldbauliche Maßnahmen nicht gefördert. Das, was er an fachbezogenem Wissen unter Beweis stellt, ist daher immer noch traditionell verankert und führt bisweilen sogar einen sprachlich nachvollziehbaren Kompetenzkonflikt vor Augen. Als sich LF2 beispielsweise zu der coupe d'éclaircie äußert (D4d), ist er über die traditionelle Sichtweise besser informiert als über die moderne:

C'est-à-dire, avant, on le faisait, ça se faisait plus que maintenant. Parce qu'il y avait le chauffage ici, c'était au bois. [...] Et les éclaircies, c'était un peu pour ça aussi.

(LF2: D4d)

Sein Antwortverhalten zeigt jedoch ein grundsätzliches Interesse an der Frage und die Vertrautheit mit dem Problem, zu dessen analytischer Einschätzung ihm jedoch die fachlichen (und fachsprachlichen) Grundlagen fehlen.

Die hier gegebenen Erläuterungen zu den Zusammenhängen zwischen fachinstitutioneller Arbeit und der Verbreitung von Fachkompetenz unter den privaten Waldbauern des Béarn sollen noch mit einem Hinweis auf LF1 ergänzt werden. Die Gesamtanalyse des Interviews zeigt, dass LF1 über ein erstaunlich hohes Maß an Sachkenntnis für einen Laien verfügt. Jedoch - offensichtlich aufgrund schlechter Erfahrungen und einer grundsätzlichen Abneigung gegen Bürokratie und Administration - lehnt LF1 eine Zusammenarbeit mit den Institutionen ab (vgl. D6b, D6c) und ist nicht einmal an dem Aspekt der Subventionierung interessiert (D3g). Dadurch koppelt LF1 Theorie und Praxis seiner waldbaulichen Tätigkeit (obwohl es sich um einen größeren Besitz handelt!) von der Arbeit des CRPF ab. Diese Abkoppelung und der Versuch, 'auf eigene Faust' Waldbau zu betreiben, der angesichts der bearnesischen Mentalität nicht unüblich zu sein scheint, hat aber einerseits den besonders intensiven Zugang zu den traditionellen Konzeptionen des Fachs zur Folge und bedingt

zeichnung der während der Begehung geführten Konversation). Die Erläuterungen von LF2 bezogen sich hauptsächlich auf die örtliche Abgrenzung der verschiedenen Varietäten und auf die Feststellung, dass eigentlich mehr Säuberung und Pflege des Terrains erfolgen müsste. 
andererseits eine oft hilflose Konfrontation mit den Aspekten der modernen sylviculture (vgl. z.B. D4a, D4c, D4d, D6d).

An den beiden exemplarisch analysierten Interviews aus der Gruppe der Nicht-Fachleute lässt sich also bereits eine Tendenz ablesen, die für den regionalen Sprachgebrauch in Fachkontexten ausschlaggebend ist: Trotz der staatlich geförderten Bemühungen um die Aufklärung und Modernisierung waldbaulicher Tätigkeit gibt es im Béarn (und sicherlich nicht nur dort) die Kontinuität einer im regionalen Lebensvollzug erworbenen Sachkenntnis, die durchaus auf Wandlung und Anpassung ausgerichtet ist, sich jedoch nur in dem Maße verändert und erweitert, wie ihre Fixierung auf Normen - und das heißt insbesondere auf die regional gültigen Normen - gewahrt bleiben kann. Diese Tatsache aber hat erhebliche sprachliche Konsequenzen, da die Kontinuität gerade in der Kommunikation im Sachbereich zum Ausdruck kommt. Der Waldbauer muss sich auf dem ihm eigenen fachsprachlichen Niveau und in seiner traditionellen Form des Sprechens über den Wald mit den neuen Einsichten und Perspektiven des Fachs auseinandersetzen und identifizieren können. Ich behaupte in dieser Hinsicht, dass die Möglichkeit, auch in der Regionalsprache über fachliche Inhalte zu sprechen, selbst wenn dies nicht mehr an der Tagesordnung ist, ein wesentliches Kriterium für diese Identifikationsmöglichkeit darstellt. Im Kapitel 2.5 werde ich einen solchen Fall vor Augen führen und näher analysieren. Dabei wird sich zeigen, dass sich die im Einzelfall positiv verlaufende Entwicklung einer Wandlung des Fachs in Verbindung mit einer Wandlung erlebter Normen auf der Grundlage einer gewissen sprachlichen Kontinuität vollzieht, die ich in theoretischer Anlehung an Schlieben-Lange und Stehl als Bewahrung von Diskurstraditionen interpretieren möchten. Zur Fundierung dieser These erläutere ich im Folgenden an einem weiteren Beispiel den typischen Mechanismus, mit dessen Hilfe fachliches Wissen eine normative Verankerung im regionalen Leben erfährt.

Auf die Frage nach den Techniken des Waldbaus, die zu einer qualitativen Verbesserung der Bestände führen (D4e), antwortet EF1 in einer sehr fachanalytischen Weise mit der Aufzählung von drei Maßnahmen: 1. faire des tailles de formation-l'élagage; 2 . les soins contre la végétation concurrente; 3. l'extraction des arbres malades. Dieses präzise analytische Konzept ist jedoch im Bewusstsein der Waldbauern noch längst nicht vorhanden. Die Antwort von EF2 gibt in diesem Sinne sehr prägnant die entsprechende Vorstufe zu erkennen: „L'améliorer, c'est l'entretien. “ Genau hier liegt nämlich das Problem auf regionaler Ebene, wo häufig die mangelnde Bereitschaft zu einem angemessenen entretien vorherrscht. So resümiert EF2 noch einmal nach der durch den Fragesteller herausgeforderten Analyse: „L'entretien, c'est tout cela. "Welche Konsequenz sich aus der simplen Konzeption améliorer 'entretien im Sachverstand des Laien ergibt, verdeutlicht die Antwort von LF1: 
J'ai, j'en ai entendu beaucoup parlé, mais je n'ai pas trouvé la bonne. (LF1: D4e)

Die geeignete méthode d'amélioration muss sich aus der praktischen Erfahrung ableiten lassen, sie wird als rein fachtheoretisches Konzept nicht akzeptiert. LF1 führt sogleich das eigentliche Problem vor Augen: die bois médiocres der Region, deren Bewirtschaftung nicht lohnenswert erscheint.

Auf eine andere und sprachlich drastische Weise wird der erforderliche Konnex von Fachwissen und Regionalnormen auch in der Antwort von LF2 deutlich:

Oui c'est-à-dire que maintenant, là, ils cherchent à le faire, ça, mais en plantant d'autres... la même variété, mais... d'autres, d'autres plants que les plants qu'il y a, qu'il y a ici. (LF2: D4e)

Das, was LF2 aus dem Bereich der fachinstitutionellen Arbeit als Faktum wahrnimmt, ist die Handlung der anderen ('là' als undifferenzierter Verweis auf die Fachinstitution), die im Waldbau etwas tun, was nicht in die Traditionen der Region hineinpasst: Sie pflanzen (um den Ertrag zu steigern) nicht einheimische Stecklinge von einheimischen Baumarten. Offensichtlich spielt der Proband hier auf den Einsatz resistenter oder schnell wachsender Varietäten bestimmter Baumarten an. ${ }^{194}$ Er findet aber in dieser Erfahrung keine Anknüpfung an eine - wenn auch noch so einfache - Konzeptualisierung seiner fachlichen Kompetenz. Der entsprechende Diskurs (ohne Andeutung von Kausalzusammenhängen) gestaltet sich daher in einer beinahe unverständlichen Form, die allenfalls eine Art Distanzierung zum Ausdruck bringt.

\subsubsection{Exkurs: Entwicklungstendenzen des Waldbaus im Béarn}

Im Anschluss an die Ausführungen über das fachsprachliche Niveau der Probanden möchte ich als Übergang zu der Betrachtung der Diskursebene einen Einblick in die landschaftsgeschichtliche, ökonomische und soziale Problematik geben, die sich aus der Anwendung der forstwirtschaftlichen Konzeptionen auf die regionale Wirklichkeit ergibt. Wenden wir uns zu diesem Zweck noch einmal dem Bereich der forstlichen Betriebsarten (fr. régimes, DFM, Kennz. 5383) zu. Im Französischen unterscheidet man zwischen régime de la futaie (dt. 'Hochwaldbetrieb'), régime du taillis (dt. 'Niederwaldbetrieb') und régime $d u$ taillis-sous-futaie (dt. 'Mittelwaldbetrieb'). Der wesentliche Unterschied zwischen den Betriebsarten futaie und taillis liegt in der Reproduktionsart des

${ }^{194}$ Die Anpflanzung auf seinem eigenen Grund und Boden stellt eine solche experimentelle Maßnahme dar. 
Bestandes. Der Hochwald ist die verbreitetste und wirtschaftlich sinnvollste Art der Gewinnung von Nutzholz. Die Erneuerung des Bestandes wird in dieser Betriebsart durch Saat (z.B. bei Eichen) oder Pflanzung (bei Nadelbäumen) erreicht. Demgegenüber ist der Niederwald eine Form der Bewirtschaftung, die den Stockausschlag einiger Laubbaumarten (im Béarn traditionell vor allem Kastanie und Eiche) für eine kurzfristigere Holzgewinnung (Brennholz, Pfähle, Rebstecken, Gerbrinde, etc.) nutzt. Der Mittelwald ist nun eine Mischform dieser beiden Betriebsarten, die aus der Sicht des effizienten Waldbaus nicht erwünscht ist, aber z.B. in Frankreich immer noch sehr verbreitet ist. Das Kosmos Wald- und Forstlexikon $(1998,496)$ vermerkt zu dieser Betriebsart:

Der Mittelwald ist eine heute kaum noch verbreitete forstliche Betriebsart. Zur Zeit beträgt sein Anteil am deutschen Wald etwa 1\% der Waldfläche. Entwickelt hat sich der Mittelwald schon im frühen Mittelalter und diente der Sicherung der Brennholzversorgung. Er war auch hervorragend für die Schweinemast (...) und die Viehweide (...) geeignet. [...]

Heutiges Produktionsziel des Mittelwalds ist die Gewinnung von Brennholz (Unterholz) und Nutzholz zur gleichen Zeit auf gleicher Fläche. Der Holzeinschlag erfolgt jährlich auf jeweils wechselnden Teilflächen [...]. Während das Oberholz stets einzelstammweise entnommen wird, erfolgt im Unterholz der Stockhieb auf der gesamten Fläche. Lediglich sog. Laßreitel bleiben im Unterholz zur Übernahme in das Oberholz stehen. Bleiben diese beim zweiten Umtrieb nochmals stehen, werden sie als Vorständer und nach dem dritten Umtrieb als angehender Baum bezeichnet.

Der Mittelwald ist Realität und Problematik der bearnesischen Wälder zugleich. Er verkörpert eine Norm, die den Bearnesen vertraut ist (bzw. auf vertrauten Techniken beruht und zu den landschaftlichen Gegebenheiten der Region passt) und die den traditionellen Nutzungsformen ihres Waldes entspricht. Demgegenüber nimmt die französische Forstpolitik eine sehr kritische Haltung zu dieser Betriebsart ein. Im Précis de Sylviculture von L. Lanier, dem bekannten Referenzwerk der École Nationale du Génie Rural, des Eaux et des Forêts $(E N G R E F)$ in Nancy beginnt das Kapitel über den taillis-sous-futaie mit den folgenden Worten:

Nous aurions souhaité pouvoir, dans un ouvrage de sylviculture écrit pour l'essentiel en 1984-1985, c'est-à-dire 160 ans après la création de l'École forestière de Nancy, supprimer le chapitre décrivant le régime du taillis-sous-futaie. Et pourtant, comme le lecteur pourra le noter, le volume de ce chapitre reste important, même si son objectif affirmé reste l'abandon de ce régime.

(Lanier 1994, 119)

Diesen einleitenden Sätzen folgt eine statistische Darlegung der Betriebsartenverteilung in den französischen Wäldern, an die sich die drastisch formulierte Forderung der vollkommenen Abschaffung des Mittelwaldes in Frankreich ('ce mort qui reste à tuer') anschließt. Das Fachbuch spricht von einem défi fo- 
restier und fragt, wie es überhaupt zu dem Phänomen des Erhalts dieser Betriebsart in Frankreich kommen kann. Des Weiteren heißt es:

Après avoir analysé les raisons du maintien de plus du tiers de la forêt de notre pays en taillis ou taillis-sous-futaie (alors que ce régime n'a jamais existé ou n'existe pratiquement plus dans aucun des autres pays forestiers du monde entier de conditions homologues), ${ }^{195}$ nous verrons plus en détail comment se présente la situation actuelle et comment surtout on peut y remédier dans les meilleures conditions possibles.

(Lanier 1994, 120)

Der absolut negativen und auf schnelle Umwandlung ausgerichteten Bewertung des Mittelwaldes steht heute zwar eine besondere ökologische Wertschätzung dieser Betriebsart entgegen, doch findet diese Sichtweise in Frankreich offiziell wenig Anerkennung. ${ }^{196}$ Die tatsächlichen Konflikte sind sehr vielschichtig, aber in einer verkürzten Interpretation lässt sich doch behaupten, dass der staatlich geförderte Waldbau in Frankreich seinen grundsätzlichen Interessen zufolge die regionalen Existenzformen des Waldes und seine Bewirtschaftung im Béarn nicht nur zu modernisieren versucht, sondern längerfristig auch in ihrer Kontinuität bedroht. In einer ersten Stufe hat sich heute im Béarn der Untergang des Niederwaldbetriebs schon fast vollzogen. Die aktuelle Phase ist durch Bemühungen gekennzeichnet, den Mittelwaldbetrieb so weit wie möglich abzuschaffen. Sollten diese Bemühungen mit staatlicher Lenkung zu den gewünschten Ergebnissen führen, so werden sie eine neue landschaftliche Realität im Béarn hinterlassen. Doch gibt es gerade in jüngerer Zeit auch von offizieller Seite Ansätze zu einer veränderten, ökologischeren Sichtweise des Problems.

Im folgenden Kapitel werde ich versuchen, anhand einiger Diskursanalysen in den zugrunde gelegten Interviews zu ermitteln, ob sich hinsichtlich der angedeuteten waldwirtschaftlichen Entwicklung ein Konfliktpotential in den fachbegrifflichen Vorstellungen und Assoziationen der Probanden abzeichnet.

\subsubsection{Fachliche Konzeptualisierung und Diskurs}

Für die Probanden war das Interview eine außergewöhnliche Form der Auseinandersetzung mit dem Fach. Ihr Antwortverhalten war insgesamt konstruktiv

\footnotetext{
${ }^{195}$ An dieser Stelle verweist eine Fußnote explizit auf die Situation in Deutschland, wo der Mittelwald sozusagen verschwunden ist. B Die Hervorhebungen entsprechen dem Original.

${ }^{196}$ In diesem Zusammenhang muss auf das europäisch eingebettete französische Naturschutzprojekt Natura 2000 aufmerksam gemacht werden, das in Frankreich (und gerade auch im Béarn) zur Zeit meiner Untersuchung große Besorgnis unter den Waldbauern ausgelöst hat. Das Projekt sieht die detaillierte Klassifizierung vieler privater französischer Waldbesitzungen als Naturschutzgebiete vor.
} 
und durch den Versuch geprägt, die ihnen geläufigen Konzepte des Fachs auf den Inhalt der Fragestellungen so zu applizieren, dass die spezifischen Probleme des Waldbaus im Béarn deutlich wurden. Oft zeigten sich bei diesem Bemühen Inkongruenzen oder auch besondere Gewichtungen in der theoretischen Interpretation und praktischen Bezugnahme, die zu interessanten sprachlichen Darstellungen führten. Ich möchte hierauf im Folgenden näher eingehen und das fachsprachliche Potential der Probanden unter dem Gesichtspunkt seiner kommunikativen Funktionalität betrachten.

Eine streng terminologisch orientierte Frage war die nach der Bedeutung von sous-étage (D1c), zu dessen Erläuterung die fachspezifische Kenntnis der Differenzierung von zwei oder mehr Baumschichten vonnöten ist. In der Forstfachsprache wird grob zwischen 'Oberstand' (fr. étage dominant, DFM 4147) und 'Unterstand' (fr. étage dominé bzw. sous-étage, DFM 6464-5) unterschieden, wobei das wesentliche Kriterium die Lichtverhältnisse sind, in denen sich die Baumkronen der jeweiligen Schicht befinden. Zusätzlich gibt es jedoch eine Bedeutungsüberschneidung von sous-étage und taillis (dt. 'Niederwald'), zu deren Klärung ich die entsprechende Definition des Dictionnaire Forestier Multilingue zitiere:

sous-étage-(2) Plus spécifiquement le taillis dans un taillis-sous-futaie.

(DFM 6466)

In dieser Bedeutung bezieht sich sous-étage auf eine sehr vertraute Erscheinungsform des Waldes im Béarn. Die begriffliche Konfusion wird aber dadurch noch größer, dass die meisten Sprecher sous-étage nicht kennen bzw. nicht verwenden und sich stattdessen des Begriffs sous-bois bedienen. Auch sous-bois (dt. 'Unterwuchs, Unterholz') gilt als Forstfachterminus, allerdings verweist der Dictionnaire Forestier Multilingue auf seine mangelnde Präzision:

sous-bois-Terme général imprécis désignant à la fois les plantes herbacées, les broussailles basses, et même les arbustes et les plus petits arbres, sous le couvert d'une forêt.

(DFM 719-6461)

Sous-bois entspricht in dieser undifferenzierten Bedeutung der Wahrnehmung des Waldinneren durch den Nicht-Fachmann in einer noch direkteren Weise als sous-étage. Der Terminus war allen Probanden bekannt und geläufig.

Gehen wir nun vor diesem fachterminologischen Hintergrund auf die Antworten in den ausgewerteten Interviews ein. EF1 unterscheidet zunächst in korrekter Form zwischen étage dominant und étage dominé. Interessanterweise differenziert er aber darüber hinaus zwischen étage dominé und sous-étage, wobei sich seine Erläuterungen zu sous-étage offensichtlich auf die oben zitierte Definition im Sinne von 'taillis dans un taillis-sous-futaie' beziehen: 
Et enfin vous avez dessous donc une, un sous-étage qui peuvent, que peut être constitué d'arbres dominés, mais souvent malingres, mais souvent d'arbres, de buissons ou de végétaux qui s'y trouvent très bien. Des arbres... ce sont souvent des fruitiers. Vous avez le noisetier, vous avez le néflier, vous avez eh d'autres, d'autres essences qui se... se plaisent dans le, dans le sous-bois et qui est intéressant de conserver pour, là aussi, plusieurs raisons. D'une part, pour nous forestiers, ça maintient une ombre et un couvert qui protège le tronc des grands arbres, donc du soleil, donc ce, ça maintient un tronc propre, ça évite ce qu'on appelle l'apparition du gourmand, ces petites branches que l'on voit le long d'un arbre qui est étiré. Ça maintient le sous-bois propre aussi, puisque ça fait de l'ombre dans le sous-bois, donc ça évite le développement de la fougère et de la ronce, des végétaux qui sont concurrents des arbres, et enfin un phénomène qui... dont on tient de plus en plus compte depuis 5 eh, depuis les 5 ou 6 dernières années. Comme je vous dis, ces arbres sont des fruitiers. Il est important de les conserver pour la vie faune, donc tout ce qui est maintien d'oiseaux ou maintien du biotope, maintien d'animaux dans le sous-bois. Vous avez des tas d'animaux qui sont des frugivores, de de, qui mangent des fruits, des des baies ou autres. Si on coupe ce sous-étage, on aura dans une futaie de chênes par exemple que des glands et bien on aura pas de petits oiseaux. On aura que des palombes, des geais, des corbeaux, mais on n'aura pas de petits oiseaux. Donc le maintien de ce sous-bois est un effort en raison de sylviculture, mais aussi donc de de biodiversité, pour maintenir donc des oiseaux en forêt, des oiseaux ou d'autres animaux, eh? Bien sûr tout... toute la chaîne. ${ }^{197}$

(EF1: D1c)

Dieses Diskursbeispiel von EF1 verdeutlicht die fachlichen und normativen Zusammenhänge sowie die soziale Relevanz des regionalen Sprachgebrauchs in Fachkontexten in hervorragender Weise. Gehen wir auf die wichtigsten Aspekte ein:

EF1 gibt die zitierten Erläuterungen auf die Frage nach der Bedeutung von sous-étage in der französischen Forstfachsprache. Das eigentliche Thema seiner Ausführungen ist aber nicht das analytische Konzept von étage dominant und sous-étage, sondern die Beschreibung der Realität des bearnesischen Waldes. Dementsprechend wechselt er, ohne es zu bemerken, im Laufe des Diskurses zu dem Begriff sous-bois über, der das von ihm dargelegte Konzept besser bezeichnet. Die Interpretation von sous-étage als sous-bois erlaubt es EF1 aber, auch im zweiten Teil seines Diskurses wieder sous-étage als Begriff $\mathrm{zu}$ verwenden. Die Frage ist nun, ob sous-étage und sous-bois für den Fachmann EF1 wirklich Synonyme sind. Dies wird auf einer reflexiven Ebene im

${ }^{197}$ Der insistierende Hinweis auf die petits oiseaux entspricht einem Aspekt des natürlichen Lebensraums der bearnesischen Wälder, der für die Bewohner des Béarn seit jeher zu einer wichtigen Erfahrung ihrer regionalen Umwelt gehört. Zur Dokumentation dieses traditionellen Verhältnisses der Gaskogner zu dem ornithologischen Reichtum ihrer Wälder verweise ich auf die interessante Publikation: Beigbeder, Francis, Ausèths. Les noms gascons des oiseaux sauvages. Denguin (Béarn) 1986. 
Rahmen der Beantwortung der Frage von EF1 selbst verneint. Auf Rückfrage gibt er die folgende Definition von sous-bois (ich zitiere hier nur die resümierenden Teile):

C'est beaucoup plus vaste. [...] Le sous-bois, c'est tout ce qu'on voit de l'étage zéro, donc de zéro centimètre à l'étage dominant.

(EF1: D1c)

Fachlich gesehen bezieht sich sous-bois demnach nicht nur auf die essences forestières unterhalb des étage dominant, sondern auch auf alle niedrigeren Vegetationsschichten des Waldes. ${ }^{198}$ Vor diesem Hintergrund ist der Diskurs von EF1 als ein Plädoyer für den Erhalt und die Pflege der unterständigen Waldbäume, Waldsträucher und Forstpflanzen zu werten, also als ein aufgrund seiner beruflichen Position sozial relevantes Bekenntnis zu dem Erhalt der natürlichen Waldvegetation im Béarn. Ob diese Einschätzung und Grundhaltung von EF1 institutionellen Rückhalt im CRPFA findet, konnte ich im Rahmen meiner Feldforschungen nicht ermitteln. In jedem Fall aber stellt sich die geäußerte Sichtweise gegen die langjährige offizielle Forstpolitik des französischen Staates. Auch diese Neuorientierung wird in dem zitierten Diskurs sprachlich geäußert.

EF1 verweist von sich aus sehr ausführlich auf die ökologische Bedeutung des sous-bois und nimmt damit einen modernen Standpunkt ein, dessen Rechtfertigungsdruck offensichtlich auch im Südwesten Frankreichs gegeben ist. Daher betont EF1, dass man erst seit 5 oder 6 Jahren den Aspekt des Naturschutzes ins Spiel bringe und insistiert nachdrücklich auf der entsprechenden Argumentation. Der sachliche Hintergrund dieses Redebeitrags wird erst durch einen Rückbezug auf den zuvor gegebenen Exkurs zu der seit vielen Jahren offiziell geplanten Umgestaltung der französischen Waldlandschaft hin zu der Ausdehnung des ökonomisch rentableren Hochwaldbetriebs verständlich. Man sieht an diesem Beispiel, dass es oft nicht leicht ist, den spontan formulierten regionalen Sprachgebrauch in Fachkontexten angemessen $\mathrm{zu}$ interpretieren. Die in den Diskursen erfolgten Argumentationen der Probanden spiegeln Sachbezüge und normative Vorstellungen wider, die nur mit einem profunden Wissen der regionalen Verhältnisse richtig verstanden werden können. Meine Absicht ist es aber nicht allein, auf diese Reflexionsebene hinzuweisen. Vielmehr vertrete ich die These, dass die normative Eingebundenheit der Sprecher in der fachbezogenen Alltagskommunikation in einem hohen Maße als Substitut für die reflexive Durchdringung des Gesagten (im produktiven wie im rezeptiven Sinn) fungiert. Was EF1 in dem Diskursbeispiel wirklich zum Ausdruck bringen will (ich beziehe mich hier auf die Sinn-Ebene des Textes nach

${ }^{198}$ Vgl. zur vegetativen Komposition des Waldes z.B. B. Boullard, Petite encyclopédie de la Forêt, Paris1992, 83 ff. oder auch Das Kosmos Wald- und Forstlexikon, 1998, 'Vegetationsschichten des Waldes', 749. 
Coseriu), ist für einen Außenstehenden nur nach mühevoller Interpretation zu begreifen. Der Sprecher mit regionalen Kenntnissen aber registriert die relevanten Bezüge weitaus schneller und direkter und wird kommunikativ in entsprechender Weise reagieren können. Im Rahmen der fachbezogenen Kommunikationen ergibt sich dadurch ein ganz besonders enger Bezug zwischen allgemeinsprachlicher und textueller Gestaltungsebene. Dieser Bezug aber ist in profunder Weise an regional gültigen Normen ausgerichtet.

Verfolgt man das gegebene Beispiel der Frage nach sous-étage noch ein wenig weiter, so kann man feststellen, dass auch die Antworten der übrigen Probanden wesentliche regionale Bezüge widerspiegeln. EF2 ordnet den Begriff sous-étage zunächst in den Bereich des Gebirgswaldes ein. Es handelt sich hierbei um eine Fehlinterpretation, der u.U. die Verwechslung mit der Unterscheidung verschiedener Waldschichten im Gebirge (étage du hêtre, étage de l'epicéa, etc., vgl. Boullard 1992, 71) zugrunde liegt. Wichtiger aber ist die Definition des dem Probanden bekannten sous-bois, die ebenfalls waldbaulich orientiert ist:

C'est la végétation, disons, qui est au pied des arbres. Alors, un sous-bois peut être composé de végétaux inutiles, nuisibles, comme des ronces ou des fougères. Mais un sous-bois peut être composé aussi de nouvelles petites tiges, qui est de la régénération naturelle. Tout ça, c'est le sous-bois.

(EF2: D1c)

Die definitorische Verbindung von sous-bois und régénération naturelle ist fachsprachlich nicht korrekt, wird aber nachvollziehbar, wenn man davon ausgeht, dass sous-bois im Sinne von sous-étage in der Vorstellung des Probanden die Bedeutung von taillis dans un taillis-sous-futaie umfasst bzw. unter Verzicht auf fachterminologische Zuordnungen ganz einfach einen Bezug zur Realität des forstwirtschaftlich genutzten Waldes im Béarn darstellt.

Vereinfacht lässt sich die unter den Fachleuten verbreitete Begriffskonzeption von sous-bois aus der Befragung wie folgt eruieren: 'Sous-bois ist unterhalb der obersten Baumschicht (étage dominant, futaie) angesiedelt und umfasst neben dem taillis(-sous-futaie) auch noch alle anderen Arten der tieferen Waldvegetation.' Die Antworten der befragten Laien setzen sich von diesem Begriffsverständnis allerdings ab, indem sie dem sous-bois nur das zuordnen, was weder den taillis noch die futaie konstituiert (vgl. LF2: 'C'est ni taillis, ni bois de futaie. '), also konkret die Schicht der Farne und Dornensträucher (vgl. LF1), deren Existenz in den bearnesischen Wäldern bestimmend ist.

Bereits an dem einfachen und gemeinsprachlich gängigen Wort sous-bois lässt sich also demonstrieren, dass die Kommunikation in Fachkontexten regional zum Scheitern verurteilt wäre, richtete sie sich nur nach den terminologischen Konzeptionen des Fachs aus. Die zahlreichen begrifflichen Inkongruenzen, die aus den unterschiedlichen Wissensniveaus der Sprecher resultieren, finden aber ihren gemeinsamen Maßstab in den sachbezogenen Normen 
der Region, die in der Regel allen an der Kommunikation Beteiligten bekannt sind. In diesem Sinne ist auch in dem hier näher untersuchten Fall nicht die terminologische Differenzierung wichtig, sondern das Wissen um die grundsätzliche Dreistufigkeit der bearnesischen Wälder, die (1) hohe Laubbäume, (2) niedrigeren Baumwuchs und Sträucher sowie (3) Farne und Dornensträucher umfassen. Für diese Dreistufigkeit aber gibt es im Französischen wie auch im Bearnesischen geeignete Bezeichnungen, die in den korrespondierenden sprachlichen Kontexten von den Sprechern problemlos zugeordnet werden.

Es würde im Rahmen dieser linguistischen Arbeit zu weit führen, die Gesamtheit der Fragen des Interviews unter dem Gesichtspunkt der in den Antworten nachweisbaren fachlichen Konzeptualisierungen detailliert zu analysieren. Das ausführlich kommentierte Beispiel des sous-bois macht jedoch das Grundprinzip der regionalen Kommunikation in Fachkontexten bereits deutlich. Dieses Grundprinzip lässt sich mit dem entsprechenden fachlichen Hintergrundwissen in den meisten der Antworten wiederfinden. Um dem Leser die Bewertung der analysierten Interviews in diesem Sinne zu erleichtern, verweise ich im Weiteren noch auf einige wesentliche Aspekte der normativen Gestaltung des Sachbereichs, insofern sie in den wiedergegebenen Gesprächen wirksam werden.

Die Probanden äußern sich dann besonders ausführlich zu einem Thema, wenn es eine regionale Problematik impliziert und/oder sie sich selbst in besonderer Weise betroffen fühlen. Oft hängen diese beiden Tatsachen ganz direkt miteinander zusammen. Es lassen sich somit in den geführten Interviews Themenfelder identifizieren, die für die Probanden von besonderer Relevanz sind, und andere, die sie nur aus einer distanzierten Sicht zu beurteilen in der Lage sind. Die Gestaltung der Diskurse passt sich der Art des persönlichen Zugangs zum Thema dabei deutlich an.

In einer Serie von Informationsbroschüren, die der Centre Régional de la Propriété Forestière d'Aquitaine mit Unterstützung des Conseil Régional d'Aquitaine für die Zielgruppe der privaten Waldbesitzer herausgegeben hat, lässt sich ein guter Überblick über die regionalen Themenschwerpunkte des Forstwesens gewinnen. Im Folgenden zitiere ich eine gezielte Auswahl an Titeln dieser Broschüren und ergänze sie durch knappe Hintergrundinformationen zu der jeweiligen Bedeutung des Themas für den Waldbau im Béarn. ${ }^{199}$

${ }^{199}$ Die Kommentare beziehen sich nicht direkt auf den Inhalt der Broschüren, die ebenso für private Waldbauern in der Dordogne oder in den Landes gemacht sind. Es soll vielmehr herausgestellt werden, wo aus einer spezifisch bearnesischen Sicht die Problematik des jeweiligen Themas liegt. Die Übertragbarkeit auf andere Regionen ist jedoch vielfach gegeben. 
La gestion forestière. Pour rentabiliser la sylviculture. Die Prinzipien einer forstwirtschaftlichen gestion forestière bzw. eines koordinierten aménagement de la forêt sind im Béarn wenig bekannt und werden dementsprechend kaum realisiert.

Le parcellaire, un élément essentiel de la gestion forestière. Die sinnvolle forstliche Erschließung der Parzellen gehört in theoretischer und praktischer Hinsicht zu den schwierigen Voraussetzungen des privaten Waldbaus. Im Béarn stellt sich in besonderem Maße das Problem des Kleingrundbesitzes (morcellement parcellaire).

Améliorer les boisements existants, pour produire du bois d'ouvre. Viele natürliche Waldbesitzungen im Béarn eignen sich-mit Hilfe entsprechender waldbaulicher Unterstützung-für die kurzfristigere Gewinnung von Bauholz.

Boiser les terres agricoles délaissées? Die Bewaldung und Wiederbewaldung verlassenen Agrarlands und brachliegender Flächen ist eine auf nationaler und europäischer Ebene geförderte Anstrengung zur Restrukturierung der Land- und Forstwirtschaft. Die Verlockungen von Subventionen müssen hier mit einer durchdachten Planung und Investionsbereitschaft an eigener Arbeitsleistung in Übereinstimmung gebracht werden.

D'autres pins, pour reboiser. L'alternative au Pin maritime landais sur les terrains fertiles. Die maritime Pinie ist ein schnellwachsendes Nutzholz, dessen Anbau in den Landes monokulturell betrieben wird. Im Béarn ist die Fruchbarkeit des Bodens für diese Baumart zu groß. Es werden daher angepasstere Arten für die Wiederbewaldung empfohlen. ${ }^{200}$

La plantation, un engagement à long terme. Die langen Produktionszeiten des Waldbaus sind häufig ein Hindernis für das Engagement der privaten Waldbesitzer. Das unfachmännische Anlegen von Pflanzungen ohne finanzielle Investionsbereitschaft ist die verbreitete Konsequenz einer oft nicht einmal mehr zu Lebzeiten zu erwartenden Amortisation.

La protection et l'entretien des plantations, des compléments d'investissement indispensables. Der Wildschaden in jungen Anpflanzungen ist speziell im Béarn ein Problem fatalen Ausmaßes, das viele Landbesitzer grundsätzlich vor einer waldbaulichen Tätigkeit zurückschrecken lässt.

Le travail en forêt. Arbeiten im Wald werden von den bearnesischen Waldbesitzern in der Regel je nach den individuellen Möglichkeiten privat mit eigener Ausrüstung und ohne fachspezifische Kenntnisse oder Erfahrungen vorgenommen.

Les outils du sylviculteur. Das Spektrum der für den Waldbau grundsätzlich notwendigen materiellen Ausrüstung ist im Béarn kaum bekannt. Fast jeder Betroffene verfügt jedoch über die Motorkettensäge als wichtigstes Arbeitsgerät.

${ }^{200}$ Dabei stellt sich allerdings das Problem einer massiveren Einführung von Nadelbäumen im Béarn, das der traditionellen Landschaftsgestaltung dieser Region nicht entspricht. Die Anstrengungen des CRPF gehen dennoch sehr stark in diese Richtung (vgl. in diesem Sinne die Veröffentlichung eines der Probanden: Berton / Liarcou 1991) 
Tailles de formation et élagages, un investissement nécessaire pour obtenir du bois de qualité. Die spezielle forstliche Technik der Wertästung ist im Béarn als Region ohne Traditionen in der Wertholzgewinnung fast gänzlich unbekannt. Es besteht daher die Neigung, nach eigenen Prinzipien (d.h. oft unfachmännisch) wertzuästen.

Les éclaircies, principes et modalités. Kleinere Lichtungshiebe sind im Béarn eine gängige Praxis, jedoch liegt ihr Schwergewicht traditionell auf der Gewinnung von Brennholz. Lichtungshiebe als Teil einer forstwirtschaftlich geplanten Produktion von Bau- und Wertholz sind hingegen regional unbekannt.

Produire du bois de qualité. L'œuvre du sylviculteur. Die Identifikation von Zukunftsbäumen, ihre angemessene Pflege und die Bewertung des Stammholzes gehören nur selten zum Erfahrungsbereich des bearnesischen Waldbauern.

La vente des bois, une affaire importante à suivre de près. Der Holzverkauf ist im Béarn traditionell okkasioneller Natur. Seine Optimierung nach den Gesichtspunkten von Produktivität und Gewinn ist ein Desiderat, das institutioneller Unterstützung bedarf. Die Arbeit der Forstkooperative ist in diesem Bereich sehr wesentlich.

Die Antworten der Probanden und ihr gesamtes Gesprächsverhalten während (sowie auch außerhalb) der Interviews zeigen deutlich, dass ihr fachliches Wissen auf Konzeptualisierungen beruht, die an den angesprochenen Problembereichen ausgerichtet sind. Es ist notwendig, diese Tatsache hinreichend zu dokumentieren, um die Gestaltungsprinzipien und die kommunikative Funktionalität des regionalen Sprachgebrauchs in Fachkontexten angemessen einschätzen zu können. Der Bezug der Antworten auf die sterile Folie einer fachlichen Nomenklatur oder eines analytischen Fachbuchwissens schafft hier keine Klärung.

In Frage D3a habe ich versuchsweise zwei aus fachlicher Sicht unterschiedliche Konzepte in einen Zusammenhang miteinander gebracht: die (Wieder-) Bewaldung (reboisement des terres délaissées ou défrichées) und die Naturverjüngung (régénération naturelle). Die Zusammenführung in einer Frage ist interessant, da es sich hier um zwei alternative Formen der Waldnutzung handelt, die im Béarn beide realisiert und gefördert werden. Sie implizieren jeweils zwei langfristige waldbauliche Maßnahmen, die - vereinfacht dargestellt - im ersten Fall in der Anlage einer Anpflanzung und ihrer weiteren Pflege, im zweiten Fall in der Durchführung eines systematischen Verjüngungsverfahrens im Naturwald, dem sog. 'Schirmschlag' liegt.

Der Schirmschlag ist das Verfahren der Naturverjüngung (régénération naturelle), um dessen Anwendung im Béarn sich der CRPF in ausgewählten Fällen bemüht. EF1 war als technicien dieses Zentrums in der Lage, mir die für dieses aufwendige und kostspielige Verfahren notwendige Abfolge von Hieben genau darzulegen. Er unterschied dabei (1) eine erste Phase, die in der französischen Fachliteratur mit den Begriffen fructification und coupe du taillis ('Vorbereitungshieb') bezeichnet wird, die er selbst aber ohne Benutzung 
dieser Fachbegriffe umschrieb (,,...ensuite on attend qu'il y ait une glandée ou une faînée, c'est-à-dire que les arbres aient des fruits... " etc.), (2) die sog. coupe d'ensemencement ('Besamungshieb'), (3) zwei aufeinanderfolgende coupes secondaires ('Lichtungshiebe') und (4) die coupe définitive ('Räumungshieb'), deren Resultat EF1 wie folgt charakterisiert:

Et on a une jeune futaie de sept ans, dix ans, quinze ans qui est impénétrable parce très serrée avec des milliers d'arbres, mais c'est une futaie en puissance. (EF1: D3a)

Das vollständige Konzept der régénération naturelle ist bei den landschaftlichen Voraussetzungen im Béarn und bei der mangelnden Erfahrung der Bearnesen mit der Produktion von Wertholz nur schwer in die Praxis umzusetzen. Gleichwohl wird es vom CRPF in jüngerer Zeit massiv propagiert. ${ }^{201} \mathrm{Die}$ Ergebnisse der Untersuchung zeigen aber die Grenzen der institutionellen Aufklärungsarbeit auf. Selbst EF2 stellt in seiner Beantwortung der Frage kein umfassendes Wissen von dieser Methode unter Beweis. Für ihn ist die régénération naturelle ein terme courant, der zwei Möglichkeiten des Umgangs mit dem Jungwuchs im Wald impliziert: alles einfach wachsen zu lassen oder es waldbaulich zu pflegen (entretenir). Das Vorhandensein oder Fehlen des entretien ist für EF2 der grob vereinfachende Maßstab der fachlichen Konzeptualisierung. Inhaltlich verbindet er mit dem entretien im konkreten Fall nur die Säuberung des Bodens von der störenden niederwüchsigen Vegetation, die wesentlich durch die ronces bestimmt wird. Damit reduziert sich das Konzept der régénération naturelle im fachlichen Sinn auf seine erste Stufe, den sog. 'Vorbereitungshieb'.

Interessanterweise sind die Kenntnisse von LF1 zu diesem Thema sogar ein wenig differenzierter als die von EF2, da ihm der Zusammenhang dieser Methode mit der Durchführung verschiedener Hiebe bewusst ist. Allerdings ist die Konzeptualisierung so konfus, dass es dem Probanden schwerfällt, sie in einen klaren sprachlichen Ausdruck zu fassen:

Alors, la régénération naturelle se fait au, au moment où il y a des coupes, quoi. C'est-à-dire, se fait avant, pour bien faire, il faudrait qu'elle se fasse avant, qu'elle existe avant, que au moment de la coupe, les, les... les jeunes plants, les jeunes semences puissent y pousser.

(LF1: D3a)

${ }^{201}$ Ich habe mich davon persönlich durch die Teilnahme an zwei Informationsveranstaltungen in Coarraze (CETEF, 4.3.1997) und Bosdarros (GPB 64, 5.9.1997) überzeugen können. Von der Tournée forestière in Bosdarros existiert eine Tonbandaufzeichnung. 
LF2 hat überhaupt keinen Zugang zu der fachspezifischen Bedeutung des Terminus. Dieses Faktum ist jedoch weder mit der Begriffsunkenntnis noch mit einer mangelnden Konzeptualisierung gleichzusetzen. Auch in diesem Fall ist die normative Referentialisierung des Begriffsinhalts und die eigene Erfahrung wieder ein Substitut für fachliche Kenntnisse. Der Diskurs von LF2 gestaltet sich daher folgendermaßen: ${ }^{202}$

(La... la régénération naturelle, ça vous dit quelque chose?) Oui, mais ça marche pas tant que ça. (Non?) Ça eh.... c'est très long et ça donne pas du bon bois (Ah bon... ah oui, ah oui.) Ici ça l'est tout. Tout tout tout, tout ça l'est, enfin eh partout, il y a pas eu de plantations, alors eh... (Ça repousse tout seul.) ....il n'y a... ça repousse tout seul. Alors il faut voir ce qu'il y a, il y a rien. Mais les pins c'est, les sapins c'est c'est c'est bon parce que ça ça monte tandis que ceci non. (Hm, et pour faire, pour laisser faire la nature, quoi, il f... comment faut-il s'y prendre en tant que sylviculteur, quoi, en tant que quelqu'un qui qui...) Bon, ici, on s'en occupe pas. (Non, on s'en occupe pas. Il faudrait peut-être des éclaircies ou des des... pour nettoyer) Non, non, moi j'ai essayé, il y a longtemps, j'ai essayé dans dans dans plusieurs eh... dans plusieurs eh parcelles... d'y semer des glands et tout ça, des arbres que je voyais à peu près bons. Bon, $\mathrm{d}$... ça pousse ou ça pousse pas, et puis après il y a des chevreuils qui y sont (ah oui, ça) et alors ça ça c'est une... (Oui, oui, on parlera de ça donc, oui.)

(LF2: D3a)

Die hier von LF2 geäußerte Vorstellung und seine Bewertung der régénération naturelle sind im Béarn typischerweise so anzutreffen. Die Konsequenz dieser Sichtweise lässt sich wie folgt resümieren: 'Der Waldbau im Béarn lohnt in Bezug auf die bestehenden Wälder nicht, da er keine günstigen natürlichen Voraussetzungen hat. Er ist langwierig, mühevoll und aufwendig. Seine Produktivität ist gering, die Bereitschaft zu investieren entsprechend nicht vorhanden. Die konkurrierende Vegetation (ronces) und der Wildschaden (chevreuil) sind große Hemmnisse.'

Es lässt sich beobachten, dass die Beantwortung vieler Fragen auf dieses Grundthema zurückführt oder zumindest Aspekte der implizierten Problematik zur Sprache bringt. Die Etablierung des Waldbaus im Béarn hängt demnach allein von der massiven Anlage von Neuanpflanzungen ab. Selbst unter den Besitzern solcher plantations ist aber das notwendige fachliche Verständnis nicht genügend verbreitet. Die Konzeptualisierung läuft hier in vielen Fällen allein über den Aspekt der Subventionierung und Fremdbearbeitung. Ich gebe hierzu noch einmal die Antwort von LF2 als Beispiel. Sie zeigt gleichzeitig in sprachlicher Hinsicht, wie weit fachkontextuelles Sprechen und Fachsprachengebrauch oft voneinander entfernt sind:

${ }^{202}$ Die Hervorhebungen dienen zur Verdeutlichung der Argumentationsstruktur. 
(Bon, le reboisement des terres délaissées ou défrichées, est-ce que ça joue un rôle pour le propriétaire privé de la région? C'est un peu votre cas, je crois, hein?) Bo c..., premièrement, c'est le nettoie $^{203}$ (ouais) parce que autrement c'est c'est... c'est de suite sale. (Oui.) Et alors c'est... et puis ça l'occupe et... Celui qui plante il n'emploie jamais là... ils y [unverständl.] et c'est c'est... c'est ceux qui arrivent qui aiment [unverständl.] ici, mais enfin...

(Et il y en a plusieurs qui font comme vous, des des plantations nouvelles) Bé, ils s'y mettent un petit peu à présent. Il va y avoir une réunion là cette fin du mois là pour pour faire un peu de reboisement aussi. (Où, à...) à Lombia, c'est Monsieur Touyarou qui va la faire. (Ah bon, ah bon.) Ah oui, je vais lui demander parce que... il y a des subventions là à partir de 10 hectares (Ah oui, oui, de la DDA, c'est ça?) Oui, oui, de la DDA, oui. Et alors, eh, on va être... on va être sûrement assez même davantage et... et en même temps, il y a des communaux qui vont aussi... il y a des communaux qui ne servent à rien ou qu'il y a du très mauvais bois, alors ils comptent raser tout ça et puis le mettre en une... en... en... défoncer, enfin, travailler le sol pour... (oui) pour le mettre en exploitation.

(LF2: D3a)

Die Subventionierung von Neuanpflanzungen fungiert im Béarn allgemein als Anreiz für waldbauliche Maßnahmen. Die Arbeitsschritte 'Rodung, Bodenaufbereitung, Pflege (Säuberung und spätere Beschneidung)' sind als grundsätzlicher 'Input' in die Waldarbeit akzeptiert. Die Protektion gegen Wildschäden hingegen wird vordergründig als (ungelöstes) Problem wahrgenommen. Die Gesamtkonzeption des Waldbaus im Béarn befindet sich somit in einer latenten Spannung zwischen äußeren Einwirkungen, Gewinnorientierung und der Bereitschaft zu eigener Arbeit. Auch dieser Aspekt ist für die Konzeptualisierung vieler Themenbereiche maßgeblich. Beispielhaft sei auf die Antworten zur Frage D3h nach den soins de plantations hingewiesen. Ein schönes Diskursbeispiel, das die Dominanz der dargestellten Gesamtkonzeption des Waldbaus im Béarn verdeutlicht und zugleich die wesentliche Problematik dokumentiert, findet sich in der Antwort von LF1 auf die Frage nach der Bedeutung der Wildschäden. LF1 personalisiert seine Ausführungen durch eine Beispielgebung, die letztlich nichts weiter ist als der Hinweis auf eine normative Erfahrung, zu der er sich selbst-so wie es sicherlich viele bearnesische Waldbauern tun-indirekt in einen kritischen Bezug setzt: ${ }^{204}$

${ }^{203}$ LF2 verwendet an dieser Stelle eindeutig diese im Französischen unübliche Wortbildung (Null-Ableitung). Der korrekte Fachterminus ist nettoiement (DFM, Kennz. Fr 584) und gehört in den Bereich der Jungwuchspflege. Es wurde bereits darauf hingewiesen, dass LF2 bearnesischer Muttersprachler ist und sich in dieser Sprache teilweise sicherer fühlt als im Französischen. Vermutlich geht der Gebrauch von fr. *le nettoie daher auf den Einfluss von b. lou netéy 'nettoyage' zurück. Vgl. in diesem Zusammenhang das von S. Palay gegebene Beispiel: Ço qui n'an tiràt qu'a hèyt bet netéy. 'Ce qu'on a ôté a bien nettoyé la place.'

${ }^{204}$ Die psychosoziale Implikation der gängigen Wissensdimensionen, Meinungen und Ängste im Bereich des Fachs wären ein interessantes Untersuchungsfeld, das die Kommunikation im Sachbereich als Ausdruck von Konflikten unter den Aspekten des ökonomischen Wandels, 
Mettez le, eh... le retraité eh... agricole qui avait des terres. Il peut louer les terres qui sont à peu près plates, mais dans une région comme dans la nôtre où il y avait des pentes qui servaient de pacage eh... au bétail. Bon, ces pentes, là, il y a plus de bétail, ces pentes-là sont, sont perdues. Actuellement, justement il met... il mettra des désherbants contre les ronces. Bon, il va tenir les ronces, mais... Et il planterait des arbres là. Mettez, mettez un retraité qui n'a pas de suite, pourquoi voulez-vous qu'il plante des arbres, quand il va être obligé de mettre une protection qui va lui coûter trois fois le prix de la plante.

(LF1: D3e)

der demographischen Entwicklung, der materiellen Existenzsicherung, des Werteerhalts, usw. zu erklären hätte und dabei einen wichtigen Beitrag zur Ökolinguistik liefern würde. 


\subsection{Fachbezogene Kommunikation auf Bearnesisch im Sachbereich 'Waldbau im Béarn'}

\subsubsection{Zielsetzung, methodisches Vorgehen und Probandenauswahl}

Die Analyse der auf Französisch geführten Interviews zum Thema 'Waldbau im Béarn' hat gezeigt, dass die typischen Strukturen der Fachsprache für die alltägliche Kommunikation im Sachbereich nur von einer marginalen Bedeutung sind. Diese Feststellung gilt sowohl in Bezug auf die verschwindend geringe Frequenz an spezifischem Fachvokabular als auch hinsichtlich der syntaktischen Planung der Diskurse, die in der typischen Form gesprochener Sprache gestaltet sind und daher nicht mit den Erfordernissen eines präzisen Satzbaus in der geschriebenen Fachsprache korrespondieren. Unter dem sprachstrukturellen Gesichtspunkt ist also keine Verwendung einer eigenen Sprachvarietät (d.h. einer 'Fachsprache' im strengen Sinne) feststellbar, so dass das Sprechen in den üblichen Fachkontexten problemlos von dem flexiblen Standard der verwendeten Sprache übernommen werden kann. Die Kommunikation im Sachbereich 'Waldbau' lässt sich daher von ihren einzelsprachlichen Voraussetzungen her ebenso gut im Bearnesischen wie im Französischen verwirklichen. Dies gilt umso mehr, als die bislang gegebenen Sprachdokumentationen den Nachweis erbracht haben, dass die bearnesische Sprache die nomenklatorischen und fachterminologischen Wortschatzbereiche im speziellen Fall sehr gut abdeckt und sich bestens für die Darstellung der relevanten Themenbereiche des Fachs eignet. Hinzu kommt, dass das Bearnesische wie jede lebendige Sprache, solange es noch aktiv verwendet wird, genügend Anpassungs- und Wandlungsfähigkeit für die Bewältigung der sich verändernden Kommunikationsbedürfnisse bereithält.

Stellt man die Frage, warum dennoch heute auch im Béarn der Gebrauch des Französischen im Sachbereich 'Waldbau' dominiert, so lassen sich hierfür auf der Basis der bereits angesprochenen sprach- und sozialgeschichlichen $\mathrm{Zu}$ sammenhänge die folgenden drei Argumente anführen:

1) Das Bearnesische ist im Sprachgebrauch der forstlichen Fachinstitutionen vollkommen inexistent. Es ist aus diesem Bereich des öffentlichen Lebens nicht verdrängt worden, sondern hat hier nie eine Rolle gespielt. Um dies besser zu verstehen, muss daran erinnert werden, dass die Forstpolitik und Forstadministration in Frankreich zentralstaatlichen Ursprungs ist und sich erst in jüngerer Zeit im Zuge einer Regionalisierungspolitik, die vor allem in den Händen der offiziellen französischen Regionen liegt, dezentralisiert. Diese Dezentralisierung führt $\mathrm{zu}$ einem massiven Eindringen fachinstitutioneller 
Aktivitäten auf regionaler Ebene, wodurch im Falle des Béarn die Sprachtraditionen des Sachbereichs grundlegend umgestaltet werden.

2) Das Bearnesische ist eine Sprache, in der jahrhundertelang auch über den Wald und seine Nutzung gesprochen wurde. Die entsprechenden sprachlichen Traditionen haben wesentliche Veränderungen des Sachbereichs kommunikativ begleitet und sind dementsprechend selbst modifiziert worden. Die soziale Dichte dieser kommunikativen Funktionalität befindet sich jedoch seit Jahrzehnten in einem kontinuierlichen Auflösungsprozess. Dieser Auflösungsprozess ist faktisch durch die immer stärkere Abnahme an Sprechern bedingt. Dies führt zu einer Veränderung der sprachnormativen Erwartungshaltung von Muttersprachlern, die immer weniger davon ausgehen können, dass ihr Gegenüber auch Bearnesisch beherrscht.

3) Das Bearnesische wird heute faktisch nicht mehr als Familiensprache, d.h. nicht mehr zwischen Eltern und Kindern, benutzt. Dieser Aspekt, der den freiwillig gewählten Sprachuntergang impliziert, ist grundsätzlich von dem zuvor genannten Phänomen der abnehmenden Sprecherzahl zu unterscheiden. Im Gegensatz zu dem typischen Verhalten vieler Sprachminderheiten, die sich gegen die quantitative Bedrohung ihrer Sprache zur Wehr setzen, unternimmt die große Mehrheit der bearnesischsprachigen Bevölkerung nicht einmal mehr den Versuch, das Bearnesische als Muttersprache weiterzugeben. Dieses ethnologisch auffällige Verhalten lässt sich nach wie vor am besten mit dem diglossischen Interpretationsmodell erklären, das auf das enge Zusammenwirken sprachpolitischer, sprachsoziologischer und sprachpsychologischer Fakten hinweist.

In Bezug auf den einzelnen Sprecher haben die drei genannten Phänomene jeweils eine spezifische Auswirkung auf das Sprachverhalten, die sich sehr kurz resümieren lässt:

- Man spricht auf institutioneller Ebene kein Bearnesisch.

- Man spricht unter Freunden und bei der Arbeit nur noch mit denen Bearnesisch, die als Bearnesischsprecher bekannt sind.

- Man spricht mit den Kindern (und der jüngeren Generation allgemein) kein Bearnesisch mehr.

Das spezifische Interesse der Untersuchung, nämlich die Gestaltung und kommunikative Funktionalität des regionalen Sprachgebrauchs in Fachkontexten, ist sowohl in theoretischer als auch in empirischer Hinsicht unabhängig von den beschriebenen Fakten der diglossischen Realität. ${ }^{205}$ De facto habe ich mich

${ }^{205}$ Diese Aussage darf nicht missverstanden werden. Sie gilt deshalb, weil die sprachsoziologische Realität auf mikrodiglossischer Ebene wesentlich komplexer ist, als es eine grobe Sicht der Dinge (high-variety vs. low-variety) vermuten lässt. Den Erfahrungen unserer Untersuchung entspricht dabei die folgende Beobachtung: Je klarer die makrodiglossischen Verhältnisse, umso entspannter (konfliktfreier) gestalten sich die Nischen bewahrter Sprachfunk- 
bei der Untersuchung auf die nicht-institutionelle Ebene konzentriert und nur Muttersprachler $^{206}$ interviewt. Allein diese Beschränkung, die sich schon aus der thematischen Schwerpunktsetzung der Arbeit ergibt, reicht aber aus, um auch den bearnesischen Sprachgebrauch zur empirischen Grundlage der erweiterten Untersuchung machen zu können. Dies geschieht nicht, um die kommunikative Funktionalität von Französisch und Bearnesisch im Sachbereich gleichzusetzen, denn das hieße in der Tat, an den Fakten der Sprachrealität vorbeizuschauen. Gleichwohl aber macht es Sinn zu demonstrieren, wie das Bearnesische noch heute - kurze Zeit vor seinem scheinbar unabwendbaren Untergang - den kommunikativen Anforderungen des modernen Lebens, konkret den modernen Strukturen eines gesellschaftlich höchst relevanten Sachbereichs, mühelos begegnet und sich sogar als fähig erweist, die Regionalnormen des Fachs in besonderer Weise zu repräsentieren.

Im Rahmen meiner Untersuchung ist mit dieser Demonstration der kommunikativen Kapazität des Bearnesischen ein grundlegendes theoretisches Anliegen verbunden. Es soll nämlich gezeigt werden, dass Sprach- und Diskurstraditionen auf den drei von Coseriu unterschiedenen Ebenen der sprachlichen Realität ineinandergreifen, das heißt auf den Ebenen der sachbezogenen Referentialisierung, der einzelsprachlichen Bedeutung und des textgebundenen Sinns, wobei die Ebene des Sinns nicht nur mit der situativen Pragmatik des Sprechens, sondern auch - im Rahmen einer kognitiven Interpretation - mit der umfassenderen Konzeptualisierung des mitgeteilten Sprachinhalts in $\mathrm{Zu}$ sammenhang steht. Die Einzelsprache erfüllt eine wesentliche Funktion im Hinblick auf diese Konzeptualisierung, die andererseits in einem engen Bezug $\mathrm{zu}$ den Sach- und Regionalnormen der besprochenen Wirklichkeit steht. In dieser komplexen gegenseitigen Bezugnahme kann es gelingen, in bestimmten kommunikativen Bereichen einen gesellschaftlichen Sprachenwechsel vorzunehmen, der mit dem Erhalt von übereinzelsprachlichen Sprach- und Diskurstraditionen einhergeht.

Am konkreten Beispiel bestimmter Fachkontexte lässt sich zeigen, dass die Bezugnahme auf Sach- und Regionalnormen einerseits und auf fachspezifische Konzeptualisierungen andererseits dem erforderlichen Sprachenwechsel einen kommunikativen Rückhalt gibt, der es den Sprechern erlaubt, sich in einer kontinuierlichen Sprachtradition zu bewegen. Allerdings lässt sich nicht leugnen, dass relativ abrupte Sprachsubstitutionen, wie sie sich aus unglücklich

tionen in Bereichen, die keine Konkurrenz der Kontaktsprachen (mehr) implizieren. Ob es eine Rückwirkung solcher Nischen auf die diglossischen Verhältnisse gibt oder geben kann, ist eine Frage, die in den Interessenbereich der soziolinguistischen Forschung fällt.

${ }^{206}$ Der Begriff 'Muttersprache' ist in Bezug auf das Französische bei manchen der Probanden heikel. Ich verwende ihn hier der Einfachheit halber so, wie ihn jeder französische Zensus interpretieren würde, also auch für den Fall, dass der Proband bis zum Schulalter und darüber hinaus in seiner Familie auf Bearnesisch sozialisiert wurde. 
verlaufenden diglossischen Konfliktlösungen ergeben, auch Bruchstellen einer übereinzelsprachlichen Kontinuität des gesellschaftlichen Kommunikationsverhaltens darstellen und - zumindest solange es den Sprachkontakt beider Sprachen noch gibt - von den Sprechern immer wieder als konfliktär empfunden werden.

Die analytische Zielsetzung der Ausweitung meiner Untersuchung auf das Bearnesische ist in dem angedeuteten theoretischen Hintergrund zu suchen. Im Rahmen einer weiteren kompletten Interviewauswertung soll exemplarisch dargestellt werden, wo die Übereinstimmungen und Grenzen der kommunikativen Leistungsfähigkeit von Französisch und Bearnesisch im Sachbereich liegen. Dabei wird auch der Frage nachzugehen sein, ob der Gebrauch der Regionalsprache eine besondere Ausrichtung der fachsprachlichen Kompetenz oder ein spezielles kommunikatives Verhalten impliziert. Die empirische Basis für diese Beobachtungen ist größer als das der Auswertung zugrunde gelegte Textcorpus von nur einem Interview. Sie soll im Folgenden kurz erläutert werden.

Die folgenden fünf Probanden waren so freundlich, sich im September 1997 für ein auf Bearnesisch geführtes Interview zum Thema Los ahars deu bòsc $e$ la silvicultura dens lo Biarn zur Verfügung zu stellen: ${ }^{207}$

EB1: Roger H., Lasseube (C. Lasseube) [' P6]

69 J., ehem. Landwirt und Fischzüchter, Waldbesitz ca. 70 ha, widmet sich intensiv dem Waldbau, bewirtschaftet mehr als 100 ha, größtenteils Anpflanzungen. Fachmann mit leitenden Funktionen in forstwirtschaftlichen Institutionen

Gesprächsdauer: ca. 44 Min (B.mp3: 43:55)

EB2: Joseph B., Coslédaà-Lube-Boast (C. Lembeye) [“ P3]

63 J., ehem. Landwirt und Schweinezüchter, Waldbesitz ca. 50 ha, davon 25 ha umgewandeltes Agrarland (Anpflanzungen), betreibt Waldbau mit staatlicher Förderung, verrichtet leichtere Waldpflegemaßnahmen selbst.

Gesprächsdauer: ca. 45 Min (B.mp3: 45:01)

LB1: Hubert S.-B., Monein (C. Monein) [' P7]

$70 \mathrm{~J}$., ehem. Bankangestellter (anfänglich Landwirt), Waldbesitz ca. 15 ha (Naturwald, teilweise auch landes), betreibt keinen Waldbau (verkauft gelegentlich einzelne Bäume und gewinnt selbst Brennholz), Interesse an der bearnesischen Sprache.

Gesprächsdauer: ca. 40 Min. (B.mp3: 39:12)

${ }^{207}$ Ich verwende die Bezeichnungen EB für 'Experte, Bearnesisch' und LB für 'Laie, Bearnesisch'. EB1, EB2 und LB1 waren bereits im März 1997 unter den Informanten der Befragung zum bearnesischen Wortschatz im Bereich 'Wald und Nutzung des Waldes'. 
LB2: Jean C., Lucq-de-Béarn (C. Monein)

62 J., noch aktiver Landwirt, stammt aus Bidache, Waldbesitz ca. 5,5 ha (eine ca. 25 Jahre alte Anpflanzung: Pinien, 4 ha; eine jüngere Anpflanzung: amerik. Eiche, 1,5 ha) auf landwirtschaftl. nicht nutzbaren Flächen, unternimmt keine Waldpflegemaßnahmen.

Gesprächsdauer: ca. 35 Min. (B.mp3: 34:53)

LB3: Alain B., Lucq-de-Béarn (C. Monein)

47 J., Mathematiklehrer, stammt aus Lons (C. Lescar), Waldbesitz ca. 6 ha (eine Anpflanzung, 3 ha, Naturwald, 3 ha) betreibt keinen aktiven Waldbau, nutzt seinen Naturwald für die Gewinnung von Brennholz. Interesse an der bearnesischen Sprache.

Gesprächsdauer: ca. 48 Min. (B.mp3: 47:56)

Die Einteilung nach Experten und Laien ist hier nach dem Gesichtspunkt der praktischen Erfahrung im Waldbau erfolgt. EB1 nimmt aber innerhalb der gesamten Probandengruppe als institutionell angesehener Fachmann und passionierter Waldbauer eine exponierte Stellung ein.

Die Gesprächsdauer war tendenziell etwas kürzer als bei den auf Französisch geführten Interviews. Diese Tatsache lässt jedoch keine weiteren Rückschlüsse $\mathrm{zu}$, da auf die technischen Aspekte des Waldbaus z. T. in verkürzter Form eingegangen wurde und einige speziellere Fragen aus dem bearnesischen Interview völlig herausfielen. Der Grund hierfür liegt in der Absicht, die Gespräche so natürlich wie möglich zu halten. Die Diskussion forstlicher Betriebsarten wäre in diesem Sinne ein zu artifizielles Kommunikationsthema im Bearnesischen gewesen.

Im Prinzip wurde die Struktur des französischen Fragebogens unverändert übernommen. In manchen Fällen jedoch musste die Formulierung der Frage in diaphasischer Hinsicht dem Gebrauch der Regionalsprache angepasst werden. ${ }^{208}$

Das Antwortverhalten der Probanden zeigte oberflächlich betrachtet kaum Unterschiede zu den auf Französisch geführten Interviews. Interesse oder sogar Freude am Gespräch, Ungezwungenheit und Natürlichkeit in der sprachlichen Darstellung waren die bestimmenden Merkmale. Die Formulierung des fachlichen Wissens und die persönliche Stellungnahme zu bestimmten Themen gestalteten sich auf Bearnesisch ebenso mühelos wie auf Französisch.

Die Probanden fielen während der Dauer des gesamten Gesprächs nicht in das Französische zurück. Leichtes Code-Switching war nur bei EB1 zu verzeichnen, worauf ich in der Analyse dieses Gesprächs noch eingehen werde. In syntaktischer Hinsicht waren die Formulierungen im Allgemeinen gut struktu-

${ }^{208}$ Ich danke an dieser Stelle Herrn Albert Peyroutet aus Aubertin für die hilfreiche Unterstützung bei der sprachlichen Umsetzung meines Questionnaire in die bearnesische Sprache. 
riert und wurden flüssig vorgebracht. Die typischen Merkmale der gesprochenen Sprache zeigten sich ähnlich wie im Französischen. Die Übernahme von Französismen in das Bearnesische hielt sich in den Grenzen des heute üblichen Sprachgebrauchs, war also aufgrund der fachlichen Thematik nicht besonders frequent.

Die vergleichende Auswertung der fünf Interviews würde in Bezug auf das Thema der Untersuchung zu ähnlichen Ergebnisse führen wie die schon geleistete Analyse der französischen Gespräche. Ich ziehe es daher vor, nur das Interview mit EB1 exemplarisch zu dokumentieren, um auf einige besondere Aspekte des Gebrauchs der Regionalsprache in fachlichen Kontexten hinweisen zu können. ${ }^{209}$ Als Neuheit ergibt sich die kontinuierliche Darstellung des gesamten Gesprächsverlaufs, die einen Einblick in die Differenzierung des kommunikativen Verhaltens zu den einzelnen Fragen bietet. Die abschließende Interpretation nimmt einige ergänzende Betrachtungen zu den bisherigen Untersuchungsergebnissen vor, um auf den spezifischen Charakter des bearnesischen Sprachgebrauchs im Kommunikationsbereich des Waldbaus aufmerksam zu machen. Hieraus werden sich schließlich einige allgemeine Schlussfolgerungen hinsichtlich der Identifikation und Bewertung sprachlicher Traditionen und ihrer Normabhängigkeit ergeben.

${ }^{209}$ Die detaillierte einzelsprachliche Analyse der Gespräche (als Sprachdokumente des Gaskognischen) liegt nicht im Bereich des Themas und der Möglichkeiten dieser Arbeit. Bei besonderem Interesse an dem vorhandenen sprachlichen Dokumentationsmaterial bin ich gern bereit, eine Kopie der Gespräche auf jeweils einer Audio-CD zur Verfügung zu stellen. 


\subsubsection{Die Befragung zum Thema Los ahars deu bòsc e la silvicultura dens lo Biarn-Detailauswertung eines Gesprächs}

\section{QUESTIONARI: LOS AHARS DEU BÒSC E LA SILVICULTURA DENS LO BIARN}

\section{Partida A (la persona entervistada)}

\section{A.1. Quin v'aperatz?}

Roger H., Lasseube

\section{A.2. Quin atge avetz?}

„Suassanta-nau an“: 69 Jahre [September 1997]

\section{A.3. Ètz biarnés? Ètz vadut ací?}

bezeichnet sich als Bearnese ,cap-e-tot" [entspricht in etwa dem dt. 'voll und ganz'], in Lasseube geboren. Lebensgeschichte: Vollwaise mit 9 Jahren, bis zum Alter von 13 Jahren Waisenhaus und Schulheim, danach als vailet de paisan [fr. domestique] (00:56) in der Nachbargemeinde, ,, après que $i$ avè un bordèr [fr. métayer] ací, que... $i$ avè la gran-mair, qu'èi près la proprietat a l'atge de 14 ans, qu'èri chèf d'expluatacion a 14 ans, dab un hrair mei joen que jo, e la gran-mair que's morí l'an après. E qu'em demorats tot sols dinc a que'm soi maridat a 21 ans."

\section{A.4. Quau ei lo vòste mestièr?}

betont, dass er im Rentenalter sei, auf die Frage nach der Zeit davor, bietet er spontan eine Kurzfassung seiner außergewöhnlichen Lebensgeschichte an (00:35, s.o.), endet mit: ,,Voilà, tà har lo paisan, unicament. “, berichtet davon, dass sie im Krieg ihr Geld mit dem Betrieb von Kornmühlen verdient haben. 


\section{Partida B (rapòrt a la matièra)}

\section{B.1. E v'aucupatz de har vàler lo buès? Avetz ua proprietat? De quants d'ectaras?}

P: 02:02; holt zu einer weiten biographischen Erklärung aus: Nach der frühen Heirat bekam er schon bald drei Kinder, für die große Familie war der Landbesitz zu klein, daher Gründung eines Forellenzuchtbetriebs, der später noch erweitert wurde. Der Waldanbau wurde zur einfachsten und sinnvollsten Nutzung der Ländereien: „,Alavetz qu'èi abandonat la proprietat, e qu'èi rebuasat, a partir de 80 qu'èi rebuasat tota la proprietat a part tres o quate ectaras. " Tätigkeit durch Ankauf von Ländereien und durch Betreuung familiären Besitzes erweitert: „Qu'en gèri quand-mème mei de 100 ectaras. "Verweist des Weiteren auf seine Funktion als president de l'Agropament de Buès de las Pirenèus Atlanticas (03:18), präzisiert auf Französisch: „,DU GROUPEMENT DES PRODUCTEURS DE BOIS DES PYRÉNÉES-ATLANTIQUES (GPB 64) “ und ergänzt: „ET VICE-PRÉSIDENT DE LA COOPÉRATIVE FORESTIÈRE DES PYRÉNÉESATLANTIQUES “, verweist auf die Sitzung am darauf folgenden Tag.

\section{B.2. E'v troubatz ad aisa dens las causas de la silvicultura? Coneishetz lo mestièr forestièr?}

P: 03:50; fragt nach, was mit dem Begriff ad aisa gemeint sei, bestätigt dann: „Oui, que coneishi lo tribalh deu bòsc, oui. ", betont sein Bemühen, den Waldbestand so gut es geht zu pflegen: „que l'entertiéni au maximúm“, um die selbst gepflanzten Bestände eines Tages ertragreich werden zu lassen, für seine Enkel oder Urenkel.

\section{B.3. Avetz contacts dab los professionels forestièrs?}

P: 04:27; fragt nach, was mit professionels forestièrs gemeint sei; bestätigt die Frage in Bezug auf tecniciens, die u.a. in der Kooperative arbeiten; pflegt auch Kontakt zum Zentrum der privaten Waldeigentümer (CRPF), hat allerdings keine arbeitstechnische Verbindung mit dem verantwortlichen Ministerium, schon eher mit dem Syndicat Forestier des Departements. 


\section{Partida C (coneishença deu biarnés)}

\section{C.1. E parlatz tostemps biarnés?}

Frage nicht gestellt; Beurteilung:

spricht sehr gut, flüssig und schnell Bearnesisch; verändert während des Sprechens häufiger den Satzbauplan, so dass abgebrochene Satzteile entstehen; wechselt gelegentlich zwischen Bearnesisch und Französisch (CodeSwitching)

\section{C.2. En quina aucasion e parlatz biarnés? Au tribalh o a casa?}

P: 05:19; spricht Bearnesisch „a casa e dab los vesins “ und bei der Arbeit mit denen, die noch Bearnesisch sprechen; bedauert, dass dies immer weniger werden: , qu'ei domatge“

\section{C.3. Tà parlar deu buès e deus ahars deu buès, e parlatz tanben en biarnés?}

P: 05:33; hängt allein von der Bereitschaft und Sprachkenntnis des Gesprächspartners ab: , que depen de la persona qu'avetz devant “ Diejenigen, die noch Bearnesisch sprechen, verwenden es „,mei ad aisa... mei ad aisa... qu'ei l'abituda, què?" 


\section{Partida D (Vocabulari tecnic e competenças especialas)}

\section{Puplaments forestièrs e arbes}

\section{D.1.a. Ací en Biarn, los arbes que son mesclats. Quins ordis d'arbes se tròban en partida?}

P: 05:54; rückversichert sich „quinas espèças“, zählt dann auf lo casso, lo hrèischo, lo hau (Eiche, Esche, Buche) als natürliche Bestände, wiederholt dies später noch einmal zusammenfassend (de l'ordi de grandor), ergänzt dabei castanhèr(s), die aber vom Holz her wertlos seien, sowie auch einige cerisèrs (fr. merisiers). Verweist darauf, dass alles Weitere in der Regel saloperia sei. In eigenen Anpflanzungen noguèrs (fr. noyers) als Besonderheit: noguèrs negres d'America.

\section{D.1.b. Qu'ei çò qui entenetz per 'puplament dominant'?}

P: 07:00; gibt Definition: ,lo mei gran nombre d'arbres en ua parcela de la mèma essença", wobei essença offensichtlich ein Französismus ist.

\section{D.1.c. E sabetz çò qui vòu díser 'sous-étage' en francés?}

P: 07:19; gibt Def.: „lo petit buès qui possa devath los arbres“, präzisiert dann: „Qu'ei aquò que'v disí: IF, NOISETIER, SUREAU, SAULE“ und ergänzt RONCES. Schlägt als b. Begriff lo talhís vor, besser aber noch: saloperia

\section{D.1.d. E podetz parlar de la densitat d'un puplament? Qu'ei bon entà un arbe de's trobar en bordura deu bòsc?}

P: 08:00; erklärt, warum die Dichte eines Bestands in den ersten Jahren wichtig, danach schädlich ist: „La densitat, au depart que s'i planta hèra sarrat, o que leishan sarrats. Perquè? Per'mor l'arbre qu'a la tendença a cercar la lutz que puja cap-sus, e que s'alaga [fr. il s'étire] mei plan naturalament si ei sarrat, mes après que cau hà'u plaça entà que grossesca. Si n'ei pas gròs un arbre n'a pas jamei de valor. Mème si ei hèra beròi. “

P: 08:29; verweist darauf, dass der Baum zwar schneller wächst, dafür aber auch mehr Äste ausbildet: „Que vaden sovent mei bèths que los autes, mes qu'an mei d'arramas tanben. " 


\section{D.1.e. [estimacion d'un puplament]}

$<$ Frage nicht gestellt ‘

D.1.f. Avetz dejà entenut parlar de la surfaça terrièra d'un bòsc / d'un arbe?

P: 08:50; zögert; bemerkt dann in Bezug auf den einzelnen Baum: „Que n'i a qui cobreishen mei de cent mètres quarrats quand-mème. "

D.1.g. Quin cau har entà estimar la valor d'un arbe? E coneishetz lo sistèma de calcul? [defalcament de la pèt]

P: 09:15; beschreibt das Verfahren, einen Baum zu messen: Umfang in 1m30 Höhe und die (geschätzte) Größe sind die Parameter für den barèma. Betont, dass es noch einfacher sei, die Messungen an einem schon gefällten Baum durchzuführen.

$<$ siehe vorangehende Frage ‘

$<$ Frage nicht gestellt ‘

\section{D.1.h. Qu'ei çò qui ei un dendromètre?}

P: 09:50; Def. des dendromètre: „,qu'ei un aparelh tà calcular la hautor de l'arbre"

\section{Partidas e estructura de l'arbe}

D.2.a. Parlem drin de las diferentas partidas de l'arbe. Cada arbe qu'a ben segur un tronc. $E$ coneishetz d'autes mots entà díser 'lo tronc de l'arbe'? (' la cama, etc.)

P: 10:08; gibt als alternativen Begriff zu tronc 'bilha' an, bestätigt auf Nachfrage la cama und fügt lo pè hinzu. Wohl ausgehend von diesem Wort ergänzt er zu dem vorherigen Thema: „D'alhurs, [...] dens un arbre actualament 80 per cent de la soa valor qu'ei dens los cinq purmèrs mètres deu pè enlà, la soa valor, mème si a hèra de buès au dessús. " Schließt eine Erklärung zur Wohlgeformtheit des Stammes und zur Verwertbarkeit des Holzes an. 


\section{D.2.b. La soca que hè partida deu tronc de l'arbe o de las arradits?}

P: 11:08; geschickte Umgehung einer Zuordnung: „La soca qu'ei çò qui demora enter los arradits e l'arbre qu'an hèit càder. "; Stumpf bleibt als wertlos in der Erde

\section{D.2.c. Los arbes d'ací qu'an diferentas fòrmas d'arradits. E coneishetz los mots tà díser aqueras diferentas fòrmas?}

P: 11:30; antwortet spontan, dass manche Bäume eine Pfahlwurzel, eine clau [fr. pivot], haben; so z.B. die Eiche, wenn sie jung ist, vermutet aber, dass dies später nicht mehr der Fall sei: „, mes vielh ne crei pas que n'aja“; alternative Verwurzelung z.B. bei der Esche: „Lo hrèischo per exemple qu'a las arradits superficielas, que [...] van luenh e hèra nombrosas en surfaça. Qu'an las...en patuès que disen qu'an las arradits per dessús. “

\section{D.2.d. I a ua expression tà díser 'l'ensemble de las arramas, las granas e las petitas, i las huelhas deu bòsc?}

P: 12:46; Nachfrage, ob Bezug auf Baum oder Wald gegeben sei; in Bezug auf den Wald: Hinweis auf mehrere mögliche Bezeichnungen; nach Vorgabe des frz. couvert forestier: "Que disen parelh: lo cobèrt", danach Hinweis auf übliche Ausdrucksweise: Aque hèn ombra e, verbunden mit dem Problem ,que leishan pas passar la lutz" wie z.B. die Esche oder die Buche; wiederholt auf Frz. „LE HETRE C'EST UN ARBRE QUI COUVRE TOUT, PLUS QUE LE CHENE. “ und ergänzt: ,IL N'Y A PAS DE MOT PARTICULIER. “

Zusätzliche Nachfrage, ob die Krone eines Baums als som bezeichnet werden kann: bestätigt dies, fügt dann aber lo chapèu an, findet schließlich das Wort hopièr und erklärt: „,que disen un casso qu'a fòrça quan a un gran hopier, qu'ei bèth de tronc, que possa viste per'mor qu'a un gran hopièr, qu'a un gran pomon tà respirar, qu'a un gran huelhatge, donc que possa..."

\section{D.2.e. Quan copatz las arramas d'un arbe, quin at disetz aquò en biar- nés: esbrancar, eisharramar, eslagar, o quin disetz?}

P: 14:12; eslagar, definiert auf Nachfrage eisharramar als ,,copar shens nada precaucion"; umgeht genauere Definition von eslagar durch die Floskel ", 'eslagar' qu'ei çò qui ei ", gibt esbrancar als Synonym an; kommentiert: „qu'ei un nom naveth dens lo patuès, eslagar, lo monde n'at hasèn pas quauque còp. Qu'esbrancavan, qu'esbrancavan mème entà har fagòts, mème 
tà... dens certènas regions tà norrir lo bestiar, dab lo 'frène' (!) per exemple, mes eslagar que crei qu'ei un nom naveth dens lo patuès. Enfin crei hèra per'mor que n'at hasèn pas hèra quauque còp. Çò qui hasèn qu'era 'acotar', 'acotar' LES TETARDS DES FOIS, ILS FAISAIENT DES TETARDS, aquò qu'aperavan 'copar un tarèr' o 'eslagar un tarèr' [offensichtlicher Versprecher, bessert sich aus:] 'acotar', 'acotar lo tarèr'"“

\section{D.2.f. E podetz descríver la fòrma de la huelha deu casso. \\ I a per ací los cassos deu pèis e tanben cassos d'America. An las huelhas parièras? \\ Sabetz d'autas diferenças enter las duas espèças?}

P: 15:47; antwortet spontan, dass jede Eiche(nart) ihre spezifische Blattform habe: ,que'v vau amuishar dètz cassos, n'i a pas nat qui a exactament la mèma fòrma. "; womit er offensichtlich auf verschiedene Varietäten der einheimischen Eiche anspielt. Versucht dann dennoch, etwas zur Blattform zu sagen, wobei ihm jedoch die Worte fehlen: „La fòrma, quin cau aperar la fòrma? Eh, qu'a ua fòrma, jà, qu'ei dentelada, pas dentelada, qu'ei... qu'a tres o quate... eh... sèi pas, quin cau aperar, quate... sèi pas. “

P: 16:21; betont den Unterschied: Die amerikanische Eiche habe größere Blätter, die sich im Herbst rot färben.

P: 16:53; mit Bezug auf die Frucht: kennt den grundsätzlichen Formunterschied der Eicheln, findet ihn aber in der Realität nicht recht bestätigt: „Non, per'mor que $i$ a glands de 'pédonculés' qui an lo mème gland que l'ameriquén. Per contre, l'ameriquén-ne n'èi pas vist pros enqüèra-qu'an lo gland mei gròs e cort. En general, en general. "Verweist schließlich darauf, dass er beim Baumschneiden die verschiedensten Formen der Eichel auf der Erde sieht.

\section{D.2.g. E sabetz un mot que vòu díser com en francés 'débourrement'? E sabetz un mot biarnés, quan s'aubreishen los broncs?}

P: 17:52; Spontandefinition: „, 'Débourrement' qu'ei quan lo borronc s'aubreish "; bietet als bearnesische Begriffe que desborra und que sòrten an. 


\section{Regeneracion e plantacion}

\section{D.3.a. De tornar plantar bòsc sus terras deishadas, ei important aquò taus proprietaris deu bòsc d'ací? (' reboscatje) \\ Tà tornar plantar, que se pòt deishar har la natura. Los arbes que tornan possar tots sols. Mes que cau entertiéner / netejar? (' rege- neracion naturala)}

P: 18:24; gibt Hinweis auf den möglichen Profit: „Ah que van meilèu plantar bòsc que de leishar possar sègas. ", führt sich selbst als Beispiel an. Betont dann, dass der Wildschaden ein großes Hindernis für den Waldbau sei: „, Que $i$ a un gran problèma, que n'i... que planterén lhèu lo monde si n'i èran pas la... las bèstis qui destrueishen aqueths arbres. Principalament lo 'chevreuil'. “ Der Wildschaden zerstöre z.T. 50\% der Anpflanzung und sei auch im Naturwald erheblich. Die Situation sei früher nicht so schlimm gewesen; heute müsse man die Anpflanzungen schützen. Erklärt die Art des Schadens auf Nachfrage: „Quin hè mau? Que descòrça los arbres e los arbustes, que'us hè càder." „Que minja las possas, mes aquò n'ei pas grave, ne tua pas l'arbre, tandis que quan se pèla a quaranta centimètres de tèrra que'u tua hèra sovent. " Gibt des Weiteren die interessante Prognose einer Entwicklung, in der nur die resistenten Baumarten, vor allem die Esche, in der Region überleben wird: „Ne destrueish pas tot, mes a long terme que's coneisherà, i averà hèra mei chic de bòsc que bitara. N'i a pas que certens arbres qui van aver ua resistenci mei grana que... tà s'at virar lhèu, que los... los arbres qui an possat en las sègas. E sustot lo hrèischo. Lo hrèischo qui sòrt de l'ombra tot sol, qui sòrt de... lo hau tanben, mes n'i a pas hèras per ací. Mes lo hrèischo qui sòrt de l'ombra hèra viste, que grosseish viste quan ei petit e qui's vi... que's sap at virar per'mor qui i a hèra densitat, que's sap at virar, que i averà pas qu... un dia lhèu que hrèischos per aci. "

P: 20:27; erwähnt zunächst, dass jeder Wald natürlich gewachsen sei, auf die gezielte Frage: ,, que cau entertiéner o non? “ gibt er die lapidare Antwort: „,Si se vòu quauqu'arren de beròi, òc. "; antwortet schließlich auf die Frage nach einer tecnica silvicola mit dem Vergleich des Pinienanbaus in den Landes: Ein solches monokulturelles Verfahren sei auch für die Eichen im Bearn möglich, „, a condicions d'en tirar la vegetacion autorn tà'us leishar. Qu'at èi hèit... sus certenas parcelas. “ 


\section{D.3.b. E la tèrra, sabetz quina tèrra avetz ací au pèis? En partida?}

P: 21:14; kurze Antwort: argela, ergänzt auf Fr.: ARGILE, CALCAIRE; bestätigt, dass die Bäume in der Gegend in der Regel gut wachsen, als Einschränkung: „sauf quauqua parcela qui ei mei prima de tèrra e tot sèca, possan mei doçament, mes sinon que possan pertot."

\section{D.3.c. E vòlen har los arbes per ací? (' problemas quant a la tèrra)}

$<$ Frage schon unter D.3.b beantwortet "

\section{D.3.d. E quinas plantas e pòden har mau a la cultura deu bòsc?}

P: 21:40; verneint auf Nachfrage die Schädlichkeit der sègas (fr. ronces), solange sie den Baum nicht völlig bedecken. Führt stattdessen an: l'èrba für den jungen Baum, la CLÉMATITE und lo CHÈVREFEUILLE für den älteren Baum, erklärt: ,' 'clématite' qu'ei çò qui hè com la 'liane' ET LE CHÈVREFEUILLE QUI S'ENROULE, QUI FAIT DES DÉGÂTS... qui arriva a destruir un arbre mème pro gran, que'us carca, que'us estofa. Que cau préner la precaucion de'u copar quan ei petit..."

\section{D.3.e. E lo gibièr, e hè domau au buès? Quin hè domau?}

$<$ auf die Frage wurde schon unter D.3.a. eingegangen '

\section{D.3.f. I a malaudias portadas per la vermina?}

P: 22:22; verweist vor allem auf verschiedene Arten der chenilha (frz. chenille), die je nach Region unterschiedlich vorkommen und nicht ganz auszurotten sind, d.h. nach einigen Jahren immer mal wieder massiv auftreten; gibt keine weiteren Präzisierungen; erwähnt auch die Gattung Pilz als Schädling, wobei er als Beispiel das oïdium anführt: ,, Que $i$ a malaudias criptogamicas, lo... lo... champinhons, qui atacan. L'ö̈dium per exemple, qui a hèit hèra desgats en quate-vint-nau" - Typisches Beispiel für französisiertes Bearnesisch! 


\section{D.3.g. E v'i coneishetz tà díser si ua plantacion ei plan hèita, qu'ei com cau?}

P: 23:09; ironisiert zunächst die Frage: „Si m'i coneishi jo? Oui, drin, òc. Qu'em sembla que m'i coneishi!", verweist dann später auf seine lange Erfahrung ,"lo temps que soi dehéns!" Zur Sache selbst führt er aus, dass es allein auf die regelmäßige Pflege ankommt: „Suvant la creishença deus arbres, quin son tienguts. Qu'ei com un camp de milhòc o un casau. SI LES PLANTS SONT ENTRETENUS..."

D.3.h. E quan comença de vàder la plantacion, sabetz çò qui cau har, quin la cau suenhar, la cau netejar, desherbar, entertiéner?

P: 23:45; gibt eine sehr einfache Erklärung des Sachverhalts: „Que caleré copar tot çò qui possa autorn, tot çò qui la gèna, com a totas las plantas, dirèi [korrekt: diserí]. “

\section{D.3.i. Sabetz que se talhan los arbres. I a un mot qui ei esprès tà díser aquò: 'talhar los arbres'? (' podar, etc.)}

P: 24:05; nennt die Termini talhar und eslagar als Synonyme.

\section{Silvicultura e ecologia deu bòsc}

\section{D.4.a. Los qui esplèitan un bòsc, e credetz que cau que pensen tanben a la beutat deu pèis. Pr'amor qui los bòscs qu'ei beròi.}

P: 24:22; hakt bei dem Begriff espleitar ein, der ungebräuchlich sei: unterscheidet zwischen den möglichen Bedeutungen ,,los qui hèn càder " ('fällen') und ,, los qui venen “ ('verkaufen'); als Reaktion auf die Frage demonstriert er die Schönheit eines wirtschaftlich nutzlosen Waldstückes vor seinem Haus: „Escotatz, escotatz, escotatz! [um die Fragestellung des Interviewers zu unterbrechen] Tè, qu'avetz un bòsc ací! [Geht mit dem Interviewer zum Fenster, wo sich das sehr schöne Panorama einer Waldlandschaft auftut] Aqueth! Beròi, lo bòsc, tot aqueth! N’i a pas cinquanta arbres de valor aquiu dens. Alavetz qu'aciu sus ua mieia ectara que n'i a mei de dus cents. Aquiu n'an pas nada valor. Per tant qu'ei beròi, [...] vist atau. Jo que l'espii de vath enlà. " [dt. von unten her; gemeint ist: aus dem Tal heraus]. Er ergänzt dies mit der Bemerkung, dass ein nicht profitabler Baum (Kriterium ist der Stamm) ein umso schöneres Laubwerk habe: „LA BEAUTÉ DU PAYSAGE, qu'ei ua causa, mes la beutat deu bòsc, jo que la cal... 
qu'ei... qu'ei la... lo FEUILLatge [korrekt: huelhatge] qui hè la beutat deu peisatge. Puish qu'ei tanben la... lo... lo... la valor de... de l'arbre qui possa. Si avetz un... 'saule' o un... un arbre qui n'a pas nada valor d'aviéner qu'a un huelhatge tant beròi, jà, mei com un arbre de valor. "

P: 25:58; auf die Nachfrage nach der europäischen Gesetzgebung zum Wald betont er, dass die entsprechenden Gesetze wenig bekannt seien, gleichwohl aber Angst verbreiteten, ohne dass man genau wisse wovor; mit konkretem Bezug auf das Programm Natura 2000: „Actualament que parlan hèra de Natura 2000, ne... que va ser ua contrenta certenament, mes n'i a pas nat qui sap çò qui... quinas contrentas $i$ va aver, çò qui van empachar, çò qui van preservar, çò qui van empachar de har dehéns... “

\section{D.4.b. ['jardinage’ (fr.)]}

$<$ Frage nicht gestellt ‘

\section{D.4.c. Quan copan lo buès, i a metòdas diferentas. E vòu díser: o que copan los arbres tots d'un còp o que copan sonque quauques arbres? En esclarint / en hant esclaridas?}

P: 26:45; spontane Antwort: „Aquiu que i a a minjar e a béver. “ (bearnesische Umsetzung der französischen Wendung là, il y a à boire et à manger). Begründet dann seine Ablehnung der Technik der régénération naturelle aufgrund persönlicher Erfahrung: „Certens tecniciens que van díser que cau leishar arbres tà rehar un ensemençament naturel, mes jo, personalament, que prefereri har ua petita parcela en copa rasa e rebuasar que de har atau. Perquè? Per'mor qu'arribatz pendent trenta o quaranta ans a non pas aver sus ua parcla que quaranta o cinquanta arbres tot sols qui n'aumentan pas de valor, qui son tròp clars, e l'ensemençament qui possa ne pòt pas possar per'mor qu'ei tròp a l'ombra. O que caleré leishar de grans clarièras. “ Betont abschließend noch einmal, dass er hier einen anderen Standpunkt als die Waldtechniker einnimmt.

\section{D.4.d. I a ua tecnica de l'esclarida?}

P: 27:49; bestätigt „Ben solide [frz. bien sûr] “ und erklärt zunächst sehr einfach: „Que cau leishar los arbres los mei beròis, que'n cau leishar pros e pas tròp”, präzisiert dann für die Eichen: ,,dens los cassos que caleré leishar quate-vints, cents, cent-vints arbres a l'ectara, pas mei, mes plan repartits!" Auf Nachfrage nach der Häufigkeit erklärt er, dass in einer neuen Anpflanzung erst 
nach 14, 15 Jahren gelichtet werden muss. In der Folgezeit müsse dann regelmäßig Kleinholz geschlagen werden, um den größeren Bäumen (lo bòsc d'aviéner) Raum zur Entfaltung zu geben.

D.4.e. I a manièra d'amilhorar lo buès? Copar los arbes qui son pas bons, qui son de maishanta qualitat. Que cau tanben suenhar un bòsc? Que cau esbrancar, cau tirar l'aiga à còps?

P: 28:42; reagiert erst abwartend, nach der Beispielgebung ,tirar los troncs de maishanta qualitat“ erklärt er: „Hèra còps que valeré mei de'us copar tà'us leishar poirir que de'us leishar sus plaça per'mor qui contunhan d'aucupar de còps mei de cent mètres quarrats e... e après arren que pòt possar devath. Ne valen pas arren e n'aumentan pas de valor; o de vielhs castanhèrs o de vielhs tòhos, tanben 'tòhos '['fr. arbrot, arbre étêté] qu'aperam. "; Sinn der Darlegung ist vor allem der Hinweis darauf, dass die wirtschaftlich nicht wertvollen Bäume häufig den profitablen zuviel Platz und Licht wegnehmen.

P: 29:20; betont auf Nachfrage, dass Entwässerungsmaßnahmen (drenatges) in dem Gebiet nicht nötig seien.

\section{D.4.f. [diferença enter silvicultura e arboricultura]}

$<$ Frage nicht gestellt ‘

\section{D.4.g. Lo bòsc que hè partida deu paisatge biarnés. Un bòsc que pòt estar un terrin de rapòrt, un terrin de plaser (tà se passejar, tà caçar) o tanben quauqu'arren tà sauvar, cò qui a valor, qui ei fra- gile (com hèn los ecologistas). Què pensatz d'aquestes tres punts?}

P: 29:54; erkennt alle 3 Aspekte als wichtig an: „Tà jo, qu'ei tot en un còp! Qu'ei un terrin de... de gran tribalh quan se hica en plaça, qu'ei un terrin de plaser quan ve promenatz [korrekt: ve passejatz] e quan vedetz possar los arbres, e... e après qu'arriva un dia que... que vaden grans, que s'i pòt, que... que... que... que'us vedetz a possar, qu'ei un plaser de'us véder a possar, e lo rapòrt qui's hè, qu'ei suassanta-dètz o quate-vints ans après, mes pas tau qui a plantat, qu'ei tau... tà... tà duas o tres generacions après. " 


\section{Espleitada deu bòsc, tecnica silvicola}

\section{D.5.a. Quin podetz conéisher qu'un arbe qu'ei pro hèit, qu'a arribat a la maturitat? \\ Si voletz un arbre d'aviéner, quina fòrma e dèu aver / e quinas fòrmas que caleré qu'avossa?}

P: 30:55; „, tà aver ua valor optimúm que cau qu'aja ua certena grossor. Si ei gròs, si cont... si l'arbre possa normalament que deu continuar de grossir. Mes que $i$ a terrins on per rasons d'estar tròp sarrat o autas ne grosseish pas mei. Alavetz vau miélher lo har càder que de... que de'u leishar sus plaça ací. Si(non) meilèu que de... mes sinon ua copa que's pòt har a vint o trent'ans près, un arbre pòt pas deperir. Qu'ei a suassanta o suassanta-dètz ans que sia gròs, si'u voletz leishar vint ans de mei que continua a grossir, mes ne pèrd pas la... los sòus ['frz. les sous]. Si après e copan las arramas, quan a... qu'arriva un moment que vad senile com tot, com nosauts quan vadem vielhs."

P: 32:00; „Un arbre d'aviéner que deu aver cinc o sheis mètres shens nada arrama au pè, que cau que sia dret, autant que possible, nada arrama dinc a cinc o sheis mètres, e qu'ei tot, eh?"

\section{D.5.b. [copa definitiva]}

$<$ Frage nicht gestellt ‘

\section{D.5.c. E credetz que s'i hè tostemps càier cassos a còp de destrau / piòlas?}

E coneishetz d'autes utís d'autes còps tà har càier un arbre?

P: 32:26; verneint

P: 32:35; er nennt den passa-pertot, berichtet dann von seiner eigenen Erfahrung: ,Q Que n'èi hèit càder jo tà l'entertien. En cinquanta, l'an que'm maridèi, qu'estó grelada la proprietat, que'm gahèi a har càder cassos tà un marchand de buès, tota la sason, dab un vailet que avi que partim tots dus tà anar har càder cassos. "Als einzig für das Fällen nötige Werkzeuge benennt er destrau und passa-pertot, auf Nachfrage auch cuenh und massa ,tà dirijar".

\section{D.5.d. Quin disen en biarnés lo mot francés 'une grume'?}

P: 33:07; nennt als b. Begriffe: tronc und bilha 


\section{D.5.e Que coneishetz la tronçonusa. Alavetz, e podetz díser quin hètz entà har càier un casso dab la tronçonusa?}

P: 33:25; betont zunächst, dass es auf die Fallrichtung des Baums ankommt: „Que i a tecnicas si's vòu dirijar. “, bestätigt dann, dass er (sich) seine eigene Technik (angeeignet) habe, weist aber darauf hin, dass dies eine Besonderheit sei: „Ne n'an pas tots“. Ist der Meinung, dass die Technik, die Fallrichtung zu bestimmen, früher im Prinzip dieselbe war wie heute (mit der Kettensäge); stellt aber fest, dass heutzutage vielfach nicht mehr auf die Fallrichtung geachtet wird: „Adara ne hèn pas atencion. Boh! Non, non, los... los amaturs adara ne hèn pas mei aten(cion)... que'us leishen càder tà l'on vòlen anar. Sauf si i a quauqu'arren a preservar. " Er wisse noch, wie es geht, und erklärt auf Nachfrage: „Quin cau har?... que cau vueitar l'arbre deu costat qui's vòu har càder, e après copar de darrèr enlà tà... dab cuenhs e possà 'u... tà har lo... JE SAIS PAS COMMENT ON APPELLE ÇA!" Bestätigt des Weiteren, dass man heute auch mit Seilen und einer Seilwinde den Baum ziehe: ,Tanben, adara que i a 'treuils', que tiran dab lo 'treuil' [dt. Haspel], qu'ei mei solide. " und dabei oft einen Traktor zu Hilfe nehme.

\section{D.5.f. Un còp hèita la copa, que cau netejar. E cau tanben tirar las socas?}

P: 34:49; die Antwort zeigt, dass der Säuberung nach einem Schlag keine Bedeutung zugemessen wird: „...netejar lo què? “ Die despolha [frz. dépouille] wird liegen gelassen, bis sie verfault, oder man nutzt sie für Brennholz.

P: 35:06; die socas [frz. souches] werden nie aus der Erde entfernt: „Non, non, non, ne tiran pas jamei,... pas per ací au mens,... pas tau casso,... nà n'i hà 'n què? ['dt. um was damit zu machen?]"

\section{D.5.g. Quan ei caiut un arbre, abans de'u tirar d'aquiu què cau har? Que'u cau esbrancar, que cau har sautar la pèt, esquarrì'u?}

P: 35:20; kurze Antwort: nur Entastung ist notwendig; hingegen weder die Entrindung noch die Zerstückelung des Stammes vor Ort:"Brut, que parteish brut atau, que'u tiran las arramas, qu'ei tot, e qu'u haràn partir tot sancer en general. “ 


\section{D.5.h. Tà desemboscar, quin hèn, tà tirar los troncs deu bòsc?}

P: 35:38; verweist in der kurzen Antwort auf den Unterschied zwischen heute und früher: „Tracturs et 'treuils' adara. Quauque còp qu'at hasèn dab mulas. “

\section{Administracion e lei forestièras}

\section{D.6.a. Avetz dejà vist ua carta forestièra? La podetz léger?}

P: 35:53; erkundigt sich genau, welcher Typ von Karte gemeint ist; macht den Unterschied zwischen den offiziellen Karten für ausgedehntere Gebiete und den Karten zur Dokumentation von privatem Einzelbesitz deutlich, die die Grundlage für eine Anbauplanung abgeben: „Que $i$ a cartas forestièras, mes que n'i a de privadas tanben. Los qui an hèit un plan de gestion, qu'an ua carta privada." Geht vom Tisch und holt seine eigene, selbst erstellte Waldbaukarte: „Mes ei ua carta forestièra, qu'ei jo qui l'èi hèita, n'ei pas lo... VOILA, VOILA UNE CARTE FORESTIERE D'UNE PROPRIETE DE 70 HA. “ Nach einer (weiter auf Bearnesisch gestellten) Frage zur Karte schließt er eine Erklärung zum dargestellten Waldgebiet an, aus der sein Stolz auf die selbst bewerkstelligte Erschließung des Gebiets spricht: „A l'origina, lo... aquera proprietat, que $i$ avè suassanta parcelas cadastralas. Qu'èran... qu'èran...-que $i$ son per aquiu enqüèra los trets-... qu'èra... aquò qu'èra ua parcèla... aquò tanben, dab numerós. Jo qu'èi hèit pistas, e qu'èi las pi... que'm soi servit de las pistas tà har las naveras parcelas. E qu'an totas un numerò. E aquò qu'ei... aquò qu'ei... tot çò qui ei negre qu'ei las pistas. (Alav)etz qu'èi l'accès pertot a cent mètres près en tots los cuenhs de la proprietat. "Danach gibt er weitere Erklärungen zu dem im Anhang beschriebenen plan de gestion auf Französisch.

\section{D.6.b. Qui s'aucupa de l'administracion forestièra de las proprietats privadas? \\ Qu'ei çò qui hèn lo CRPF (Centre Regionau de la Proprietat Fo- restièra) e l'ONF (Office Nationale des Forêts)?}

P: 38:38; Frage wird zunächst kurz und provokant mit „Arrés “ [frz. personne] beantwortet

P: 38:45; nach Hinweis auf den Centre Régional de la Propriété Forestière (CRPF) folgt als Erläuterung: „Lo CRPF que s'aucupa de... de las proprietats quan hèn apèl [korrekt 'aperet'] ad eth, pas autadement. Sauf si i a un plan de 
gestion.Per'mor qu'ei agreat per lo CRPF justament, e la DDA [Direction Départementale de l'Agriculture] tanben, i a organismes qui s'aucupan deu bòsc, mes que voi díser per aquiu que..., si i avè un defrichament qui se hasè en ua parcela, nat que i a qui intervien. N'an pas lo dret de... de debuasar, de... o mème si..., las comunas-que $i$ a un P.O.S. ['plan d'occupation du sol] tanben-que pòden reclamar que non... que ua tèrra... que ua colina ne sia pas desbuasada... tà... l'environament, ... “

P: 39:31; verweist auf eine Versteigerungsaktion der Kooperative am 27. des Monats, in der 7.000 Kubikmeter verkauft werden sollen; betont aber, dass gleichzeitig ca. 50.000 Kubikmeter direkt an die Händler verkauft würden: „Passan pas tots per nosauts. “- Erklärt auf Nachfrage kurz die Funktion des ONF und das Vergabesystem von Subventionen über die DDA.

\section{D.6.c. Entà parlar deu code forestièr, qui ei la lei qui s'aucupa deu bòsc. Que'v toca aquera lei? De quina manièra?}

P: 40:26; zunächst kritische Nachfragen: „, Quau lei? [...] Mes què voletz díser: si'm tòca? "; antwortet dann mit der Gegenfrage, ob der Code Forestier dem Fragesteller wirklich bekannt sei: es gebe dort mehr als 7.000 Artikel: „,qu'ei articles pratiques taus notaris, tà las successions, tà çò qui s'i..., suvant las fòrmas de... de gestion que s'i hè. Mes autament lo 'code forestier' qu'ei quauqu'arren qui... disem que... que soi solide que dens lo departament que i a chic de proprietaris qui l'an, eh!" Verweist darüber hinaus auf weitere Gesetzgebungen im Code Civil und im Code Rural. Holt sowohl den Code Forestier als auch den Code Civil, um sie dem Interviewer zu zeigen. Blättert schließlich im Code Forestier und verweist auf die große Anzahl an Paragraphen und Artikeln: „E vedetz si n'i a articles. Sabetz, tà piochar aquiu dehéns, que cau... quan vedetz ua lei, jo que'm... quan vei ua lei, qu'an hèit dab article untel, que... que'u me cerqui tà véder çò qui ei, mes autadement... "Wendet sich abschließend gegen den Einwand, dass die Gesetzgebung schwer zu verstehen sei: „Que's compren quan s'i lei l'article... com va... que vedetz ua lei per exemple, l'article...-DANS LA PRESSE OU DANS UNE ENTRE...UNE REVUE QUELCONQUE-ARTICLE 150 DU CODE CIVIL, COMME LE CODE... OUI, ALORS ON CHER... ON CHERCHE CE NUMÉRO-LA ET ON VOIT CE QUE C'EST. Autadement... “ Sprachlich interessante Wiederholung der Erklärung auf Französisch! 


\section{D.6.d. E sabetz si i a ua lei qui restrenh la manipulacion genetica deus arbes que plantatz? Avetz entenut parlar deu 'clonatge'?}

P: 42:48; „N'en sèi pas tròp arren, si i a ua lei qui la restrenh. ... D[ã] los arbres, ne crei pas que i aja nada lei qui... sauf la... maintenant avec la... que hèn milhòc transgenic, que hèn... que modifian los gènes dens las personas, que van har... que van har aulhas dab òmis..., que van har..., enfin... “

P: 43:14, bestätigt, dass es clonatge (wiederholt auf Fr. des clônes) bei Bäumen gibt, nennt als Beispiel eine Hybridbildung von noguèrs, die aus einer Kreuzung von einheimischen und nordamerikanischen Nussbäumen stammt, wendet dann aber selbst ein, dass es sich dabei eher um eine Art (künstliche) 'Befruchtung' handle: „C'EST... qu'ei ua fecondacion meilèu, oui, sus las flors, sus lo...", weiß aus eigener Erfahrung, dass es dieses Verfahren schon seit längerem gibt. 


\subsubsection{Analyse des bearnesischen Textcorpus: Normative Gestaltungs- ebenen des fachkontextuellen Sprechens}

Das dargestellte bearnesische Interview ist im Rahmen der Untersuchung von besonderem Wert und Interesse. Dies liegt vor allem daran, dass EB1 als Person die Normierung des fachkontextuellen Sprechens auf allen unterscheidbaren Normierungsebenen in einer sehr prägnanten Weise repräsentiert. Er ist zum einen ein Fachmann im Bereich des Waldbaus mit einer langjährigen reichen Erfahrung ('Sachnormen'). Zudem hat er einen ausgesprochen regionalspezifischen Zugang zum Fach, was - wie ich noch herausstellen werde im Interview sehr deutlich wird ('Regionalnormen'). Darüber hinaus ist er nicht nur in persönlicher Hinsicht ein leidenschaftlicher Waldbauer, sondern mit dieser Tätigkeit auch existentiell seit vielen Jahren verbunden ('biographische Normen'). Schließlich gehört er zu den 'ur-typischsten' Bearnesischsprechern, die ich in der Gegend getroffen habe, und verkörpert somit auch eine besondere Affinität zur Regionalsprache ('Sprachnormen'). Es soll versucht werden, diese Aspekte im Folgenden unter Bezug auf das Interview zu verdeutlichen.

EB1 war ein halbes Jahr vor der Durchführung des Interviews einer der Informanten in der Befragung zum bearnesischen Fachwortschatz zu 'Wald und Nutzung des Waldes' (als P6). Im Anschluss an diese auf Bearnesisch durchgeführte Befragung begleitete ich ihn auf einem Rundgang durch seine Anpflanzungen und Wälder. Während des mehrstündigen Gesprächs gab EB1 alle Erklärungen auf Französisch und war nur selten zu einem Wechsel in das Bearnesische zu bewegen. Dies zeigt deutlich, dass dem Probanden der Gebrauch der Regionalsprache im Sachbereich des Forstwesens Fremden gegenüber nicht vertraut ist. In Gesprächen mit seiner Frau, den Nachbarn und vielen Freunden und Bekannten verwendet EB1 jedoch - selbst außerhalb seines engeren Heimatgebietes - regelmäßig Bearnesisch. Hingegen ist seine fachspezifische Tätigkeit in Zusammenarbeit mit den forstlichen Institutionen (als Präsident des Groupement des Producteurs de Bois 64 und als Vizepräsident der Kooperative von Navarrenx) durch den ausschließlichen Gebrauch des Französischen geprägt.

Der Bitte, das fachlich orientierte Interview vollständig auf Bearnesisch zu führen, konnte EB1 - ebenso wie die anderen genannten Probanden - aufgrund seiner Sprachkompetenz ohne weiteres nachkommen. Allerdings war seinem Kommunikationsverhalten anzumerken, dass für ihn die Art der inhaltlichen Darstellung des Fachlichen zu einem erheblichen Teil an die Verwendung der Einzelsprache gebunden ist. Die technischen Erklärungen zum Waldbau, die 
EB1 auf Französisch zu geben gewohnt ist, gestalten sich im Interview daher kurz und knapp. Es ist jedoch interessant zu beobachten, dass nicht eine mangelnde Ausdrucksfähigkeit für diese Knappheit verantwortlich ist. Aufgrund seiner fachlichen und sprachlichen Kompetenz ist EB1 nämlich dazu in der Lage, sehr prägnante Definitionen zu geben, denen er jedoch die zu erwartenden weiteren Erklärungen nicht folgen lässt. Beispiele dieser Art sind die meisten Antworten zum Thema puplaments forestièrs e arbes (D1b, D1c, D1d(2), D1f, D1h) sowie die Beantwortung einer Reihe fachspezifischer Fragen in den anderen Teilen des Interviews (z.B. D3a(2), D3b,D3h, D5f, D5g, D5h). Auf die sprachlich konzise Art der Darstellung zu diesen Fragen werde ich noch eingehen.

Während bei den Themen mit reinem Sachbezug das Gespräch nicht richtig in Gang kommt, erweist sich die Mitteilungsfreudigkeit des Probanden bei anders gearteten Fragen als recht groß. Hier sind mehrere Verhaltensweisen zu unterscheiden. EB1 setzt oft an fachlichen Fragestellungen an, um weitere Erklärungen zu geben, wenn es sich um Aspekte des Fachs handelt, die er aufgrund seiner spezifischen Erfahrung in besonderer Weise zu beurteilen in der Lage ist. Ich sehe dies als einen Einfluss von Regionalnormen an, da es sich in diesen Fällen oft um die typischen Probleme des Waldbaus im Béarn handelt. Ein Beispiel hierfür ist die Antwort auf Frage D3a, in der nicht nur die typische Konzeptualisierung von 'Bewaldung-Anpflanzung-Wildschaden' auftaucht, sondern darüber hinaus noch ein weiterer origineller Gedankengang angeführt wird: ${ }^{210}$

Ne destrueish pas tot, mes a long terme que's coneisherà, i averà hèra mei chic de bòsc que bitara. N'i a pas que certens arbres qui van aver ua resistenci mei grana que... - tà s'at virar lhèu - que los... los arbres qui an possat en las sègas. E sustot lo hrèischo. Lo hrèischo qui sòrt de l'ombra tot sol, qui sòrt de... lo hau tanben, mes n'i a pas hèras per ací. Mes lo hrèischo que sòrt de l'ombra hèra viste, que grosseish viste quan ei petit e que's vi... que's sap at virar per'mor qui $i$ a hèra densitat, que's sap at virar, que i averà pas qu... un dia lhèu que hrèischos per ací.

(EB1: D3a)

Die Durchsetzungskraft der Esche gegenüber dem konkurrierenden Niedrigwuchs und die dadurch bedingte Zunahme an Eschenbeständen im Béarn entsprechen einer regionalen 'Insider'-Erfahrung, die selten so deutlich verbali-

${ }^{210}$ „Il ('le chevreuil) ne détruit pas tout, mais à long terme, on verra, il y aura beaucoup moins de forêt que maintenant. Il n'y a que certains arbres qui vont avoir une résistence plus grande que... - pour se débrouiller peut-être - que les... les arbres qui ont poussé dans les ronces. Et surtout le frêne. Le frêne sort de l'ombre tout seul, il sort de... le hêtre aussi, mais il n'y en a pas beaucoup ici. Mais le frêne sort de l'ombre très vite, il grossit vite quand il est petit et se debr... il sait se débrouiller parce qu'il y a beaucoup de densité, il sait se débrouiller, il n'y aura que... un jour peut-être que des frênes ici.“ 
siert wird. ${ }^{211}$ Sie geht mit einer forstlichen Wertschätzung des relativ schnell wachsenden Eschenholzes einher und ist auch für die Arbeit der regionalen Forstinstitutionen von Bedeutung.

Das Interview gibt noch an mehreren Stellen zu erkennen, dass EB1 über regionalspezifische Kenntnisse verfügt. So zeigt sich in der Beantwortung der Fragen D1a, D2c, D2f, D3f, D4d sein differenziertes Wissen über die Landeseiche in der Erläuterung verschiedenster Aspekte. Besonders hervorzuheben ist dabei die Äußerung zu der Pfahlwurzel (b. clau), von der EB1 vermutet, dass sie für die ältere Eiche nicht mehr charakteristisch sei (mes vielh ne crei pas que n'aja, D2c), was zutrifft, aber selbst unter Fachleuten ein nur wenig bekanntes Detailwissen ist. ${ }^{212}$

Auf die Tatsache, dass EB1 sich grundsätzlich nur in sehr knapper Form zu technischen Fragen des Waldbaus auf Bearnesisch äußert, dabei aber sprachlich präzise formulierte Definitionen gibt, habe ich schon hingewiesen. Beispiele hierfür sind die Antworten in D1b und D1h:

puplament dominant: „lo mei gran nombre d'arbres en ua parcela de la mèma essença“"

dendromètre: „un aparelh tà calcular la hautor de l'arbre“

Ausführlicher wird seine Darstellung jedoch, wenn es darum geht, Hintergründe und besondere Sichtweisen des Fachs zu erläutern. Beachtenswert ist in diesen Fällen die sprachlich oft sehr gelungene Form einer konzisen Erläuterung. Führen wir D1d (Bestandsdichte) und D4e (Bestandspflege) als Beispiele für dieses beachtliche Maß an fachbezogener Sprachkompetenz an: ${ }^{213}$

La densitat, au depart que s'i planta hèra sarrat, o que leishan sarrats. Perquè? Per'mor l'arbre qu'a la tendença a cercar la lutz que puja cap-sus, e que s'alaga mei plan naturalament si ei sarrat, mes après que cau hà'u plaça entà que grossesca. Si n'ei pas gròs un arbre n'a pas jamei de valor. Mème si ei hèra beròi.

Hèra còps que valeré mei de'us copar tà'us leishar poirir que de'us leishar sus plaça per'mor qui contunhan d'aucupar de còps mei de cent mètres quarrats e... e après arren que pòt possar devath. Ne valen pas arren e n'aumentan pas de valor; o de vielhs castanhèrs o de vielhs tòhos, tanben 'tòhos' qu'aperam.

${ }^{211} \mathrm{Vgl}$ in diesem Zusammenhang Track 11 der beiliegenden Audio-CD (Transkription in Kap. 2.3) sowie die Antwort D3d von LF2 in Kap. 2.4.3

${ }^{212}$ Vgl. Das Kosmos Wald- und Forstlexikon 1998, 181: „Die Stieleiche hat anfangs eine starke Pfahlwurzel, später kräftige Herzwurzeln, im Alter häufig mit starkem Wurzelanlauf.“

${ }^{213}$ sarrat 'serré', leishar 'laisser', lutz 'lumière', pujar 'monter', cap-sus PALAY: puyà toustém mey cap-sus 'monter toujours plus haut', alagar PALAY: alacà-se 's'étendre', beròi 'joli, beau'; poirir 'pourrir', arren 'rien', tanben 'aussi', tòho 'arbrot, arbre étêté', aperar 'appeler' 
Die Umsetzung fachlichen Wissens auf die regionalen Bedingungen des Waldbaus ist ein Aspekt, zu dem sich EB1 besonders gern äußert. Dabei ist es nicht nur in seinem persönlichen Fall - ein gängiger Topos, sich gegen die vom CRPF oder anderen Institutionen offiziell vertretenen Empfehlungen und Techniken zu stellen. ${ }^{214}$ Es zeigt sich hier bisweilen ein Konflikt zwischen nicht akzeptierten Sachnormen und persönlicher Erfahrung (die regionalspezifischer oder individueller Natur sein kann). EB1' negative Bewertung der régénération naturelle gibt hierfür ein Beispiel (vgl. D4c).

Das Antwortverhalten von EB1 weist im Verlauf des Interviews einen auffälligen Wandel zwischen dem zweiten Teil von D5 (D5f-D5h) und D6 ( $A d-$ ministracion e lei forestièras) auf. Die Fragen zur Forstkarte, zu den Forstinstitutionen und zur Forstgesetzgebung werden von dem Probanden mit sehr viel persönlichem Einsatz beantwortet. Grund hierfür ist die Möglichkeit, seine persönliche Betroffenheit zum Ausdruck zu bringen. So erklärt EB1 die kartographische Erfassung seines eigenen Waldbesitzes anhand einer carta privada, die er stolz präsentiert und kommentiert. Er bezieht sich dabei auf die Konzeptualisierung eines wichtigen Problems des Waldbaus im Béarn, nämlich den sog. parcellaire. ${ }^{215}$ Ebenso wie hier sind auch die Antworten $\mathrm{zu}$ den beiden nächsten Fragen durch den Aspekt seines persönlichen Engagements im Waldbau entscheidend geprägt.

Die persönliche Betroffenheit ist auch für die besondere Form der Beantwortung von Frage D4a ausschlaggebend. Ebenso wie bei D6a und D6c nutzt der Proband hier wieder die Möglichkeit, seine Erklärungen mit einer Demonstration zu verbinden. ${ }^{216}$ Der Inhalt dieses Diskurses ist aus dem Mund eines langjährigen Waldbauern überraschend: ${ }^{217}$

Escotatz, escotatz, escotatz! [um die Fragestellung des Interviewers zu unterbrechen] Tè, qu'avetz un bòsc ací! [Geht mit dem Interviewer zum Fenster, wo sich das sehr schöne Panorama einer Waldlandschaft auftut] Aqueth! Beròi, lo bòsc, tot aqueth! N'i a pas cinquanta arbres de valor aquiu dens. Alavetz qu'aciu sus ua mieia ectara que n'i a mei de dus

${ }^{214}$ Vgl. zu dieser Haltung auch die Äußerungen von EB2 (' P3) in den Tracks 5 u. 6 der beiliegenden CD (Transkription von Track 6 in Kap. 2.3) sowie die Grundhaltung von LF1 in Kap. 2.4.3.

${ }^{215} \mathrm{Vgl}$. hierzu die Ausführungen in Kap. 2.4.4.4.

${ }^{216}$ EB1 ist kein Theoretiker. Die interessantesten Erklärungen zum Waldbau gab er mir auf der Führung durch seine Anpflanzungen im März 97 jeweils vor Ort: „, Que podem tanben tribalhar sus plaça... “

${ }^{217}$ „Écoutez, écoutez, écoutez [um die Fragestellung des Interviewers zu unterbrechen] Tenez! Vous avez là un bois. [Geht mit dem Interviewer zum Fenster seines Wohnzimmers, vor dem sich das schöne Panorama einer Waldlandschaft auftut] Ce bois, il est beau, celui-là! Il n'y a pas cinquante arbres de valeur là-dedans. Tandis que celui-ci, sur un demi-hectare, il n'y en a plus de deux cents. Là, ils n'ont pas du tout de valeur. Pourtant il est beau, vu comme ça. Moi je le regarde de bas en haut." 
cents. Aquiu n'an pas nada valor. Per tant qu'ei beròi, [...] vist atau. Jo que l'espii de vath enlà.

(EB1: D4a)

Dieses Zitat ist ein Beleg für die psychologische Dimension fachkontextuellen Sprechens, die häufig vollkommen übersehen wird. Die alltägliche Kommunikation im Sachbereich dient aber vielfach gerade dazu, in einer nicht pragmatisch zweckgebundenen Weise den persönlichen Standort im Fach zu finden und zu definieren. Die Erholungsfunktion des Waldes, die schon mit dem Empfinden seiner Ästhetik beginnt, muss in diesem Sinne zu der innersten fachlichen Erfahrung gerechnet werden. Es ist selbstverständlich, dass diese Erfahrung einen eminent regionalen Bezug hat und durch ihre sprachliche Äußerung zu einer sozialen Wirklichkeit wird. Die Verwendung der Regionalsprache zum Ausdruck dieser sehr persönlichen Zugänge zum Fach ist in dieser Hinsicht ein typisches Phänomen. Man kann - im Falle des Probanden EB1 sowie vieler Bearnesischsprecher - vermuten, dass das Bearnesische und das Französische hier nicht dieselbe kommunikative Funktionalität ausfüllen.

Betrachtet man das Ergebnis der rein fachlich ausgerichteten Befragung unter dem Gesichtspunkt des z.T. sehr persönlich geprägten Charakters der Diskurse, so fallen noch einige weitere Besonderheiten auf. Zunächst einmal ist es erstaunlich, dass EB1 gleich zu Beginn des Interviews bereitwillig über seinen außergewöhnlichen Lebenslauf Auskunft gibt. Der entsprechende Bericht erfolgt zunächst als Antwort auf die Frage A4 nach dem Beruf (lo mestièr), den der Proband früher ausgeübt hat. Er ist aber zugleich auch eine rückbezügliche Antwort auf die Frage A3 nach der Herkunft, zu der EB1 in Form einer kleinen Lebensskizze Stellung nimmt. Die Offenheit und Detailfülle, mit der diese biographischen Erklärungen gleich zu Anfang des Gesprächs gegeben werden, sind erstaunlich. EB1 ist in dieser inhaltlichen Diskursführung so engagiert, dass er auch auf die Frage B1, die sich auf sein Verhältnis zum Waldbau bezieht, in einer Weise reagiert, die es ihm erlaubt, weiter über seinen Lebensweg zu sprechen. In einer Antwortlänge von genau 1:40 Min. gelingt EB1 dabei ein argumentativ gut nachvollziehbarer Brückenschlag von seiner Heirat und familiären Situation bis hin zu seiner Präsidentschaft in zwei Forstinstitutionen.

Der in sich kohärente Diskurs zu A3, A4 und B1 lässt im doppelten Sinne 'tief blicken'. Er dokumentiert zum einen den engen Bezug von Leben und Fach und die konstitutive Rolle, die biographische und regionale Normen in dieser Bezugnahme für das fachliche Selbstverständnis spielen. Er zeigt aber auch, dass die Regionalsprache ein wichtiges Ausdrucksmittel für dieses Selbstverständnis darstellt. Auf der Basis des vorhandenen Datenmaterials lässt sich natürlich nicht behaupten oder gar nachweisen, dass die Tatsache der Verwendung des Bearnesischen den persönlich gefärbten Diskurs des Probanden herausgefordert habe. Dennoch ist das kommunikative Verhalten hier 
nicht unabhängig von der Wahl der Sprache zu sehen. EB1 ist ein typischer Vertreter der im ruralen Milieu anzutreffenden Mentalität. Er ist Fremden gegenüber freundlich, aber durchaus auch zurückhaltend. Seine Tätigkeit als forestier bringt ihn oft mit noch unbekannten Personen zusammen. Bei diesen Treffen ist er es gewohnt, ausführliche fachliche Erklärungen zu geben, bedient sich aber - wie ich es selbst erlebt habe - in diesen Situationen ausschließlich des Französischen. Im Interview nun zeigt sich, dass die (forcierte) Wahl des Bearnesischen sein Gesprächsverhalten zum Teil umkehrt: Die fachlichen Erläuterungen werden tendenziell recht knapp gegeben, während die persönlichen Bezüge des Diskurses ein teilweise ungewöhnlich großes Gewicht bekommen.

Als ich EB1 ein halbes Jahr vor der Durchführung des Interviews kennenlernte, erlebte ich eine ähnliche Situation, in der mir der Proband von seinem Leben erzählte. Dies ergab sich während meines ersten Gesprächs mit ihm über den bearnesischen Wortschatz zu 'Wald und Nutzung des Waldes', das grundsätzlich auf Bearnesisch geführt wurde, in dem EB1 (damals P6) aber häufiger in das Französische zurückfiel. ${ }^{218}$ Besonders interessant ist der Teil des Gesprächs, der mit meiner Frage nach der Übersetzung von fr. noyer (b. noguèr oder esquilhotèr) beginnt. P6 wird hier durch eine Reihe von Assoziationen von der Kommentierung dieser Baumart über die Darstellung seiner eigenen Biographie zu der grundsätzlichen Beurteilung seines Engagements im Waldbau geführt. Den entsprechenden Abschnitt habe ich auf die beiliegende Audio-CD als Track 15 (7:26 Min.) gebrannt. Er stellt in meinen Augen sowohl in inhaltlicher als auch in formaler Hinsicht ein wichtiges Dokument für die psychologische Dimension des Sprechens in der Regionalsprache dar. Ich verzichte hier auf die Transkription dieses längeren Textes und fasse nur kurz seinen Verlauf und die inhaltliche Gedankenführung zusammen, damit es der Leser bzw. Hörer einfacher hat, dem Diskurs des Probanden zu folgen:

- Frage nach den noguèrs (bzw. esquilhotèrs). P6 sagt, es gebe traditionell nur einige Walnussbäume um die Häuser herum, er selbst aber habe eine Anpflanzung von Nussbäumen zur Wertholzproduktion, bei der es sich jedoch um eine hybride Nussbaumart handele (Kreuzung zwischen der einheimischen und einer amerikanischen Varietät). ${ }^{219}$

${ }^{218}$ Dieses Verhalten lag zu einem erheblichen Teil an der für den Probanden ungewöhnlichen Situation, mit einem bis dato unbekannten Deutschen Bearnesisch zu sprechen.

${ }^{219}$ Der Diskurs ist an dieser Stelle inhaltlich etwas obskur. P6 spricht von den hybriden noguèrs, erklärt sie aber in dem darauf folgenden Satz als eine Kreuzung von Eichen. Seine weiteren Ausführungen beziehen sich dann nur noch auf die Eiche. Zieht man zur Erklärung dieser Passage die Antworten von EB1 auf die Fragen D1a und D6d (clonatge) zu Rate, so wird deutlich, dass der Proband tatsächlich hybride Nussbäume gepflanzt hat (die er mir im Übrigen später auch zeigte). Allerdings assoziiert er mit dieser Tatsache in dem Gespräch von März 1997 unvermittelt die ebenfalls auf seinen Ländereien erfolgte Anpflanzung hybrider 
- Der Diskurs geht nahtlos zu der Erklärung entsprechender Kreuzungen von Eichen über. P6 betont, er habe solche hybriden Eichen bzw. auch eine rein amerikanische Varietät (cassos negres) gepflanzt, da sie leichter in eine gute Wuchsform zu bringen seien.

- Ich bringe das Gespräch auf das Thema der erforderlichen waldbaulichen Maßnahmen. P6 stellt in Aussicht, mir eine Führung zu geben. Plötzlicher Wechsel zum Französischen: P6 erläutert, dass oft fachlich interessierte Personengruppen zu ihm kommen (bezieht sich auf den letzten Besuch dieser Art), begründet dies damit, dass er als aktiver privater Waldbauer einen Sonderfall im Departement darstelle.

- $\quad$ Erklärt auf Rückfrage, dass er sich alle technischen Kenntnisse und Fähigkeiten selbst angeeignet habe (währenddessen verabschiedet sich seine Frau).

- Teilt auf Nachfrage mit, dass ihn niemand fachlich beraten habe. Spontaner Wechsel zum Bearnesischen: „Per arrés [fr. 'par personne']. Vau racontar la mia vita! ..." Skizziert seine Lebensgeschichte (vgl. A3-B1), spricht einige Sätze Bearnesisch, wobei er zwei Wörter (vailet fr. 'domestique', bordèr fr. 'métayer') auf Französisch erklärt. Wohl aus Unsicherheit darüber, richtig verstanden zu werden, erfolgt kurz darauf ein spontaner Wechsel zum Französischen. Es schließt sich eine Reflexion zur Arbeitshaltung und Lebenseinstellung der jüngeren Generation an (ohne dass das Thema des Waldbaus dabei verlassen würde).

- $\quad$ Erneuter Wechsel zum Bearnesischen, ausgelöst durch meine Fragen, mit denen ich das Gespräch wieder auf das Thema des Waldbaus lenke. P6 betont, es sei eine harte Arbeit und beginnt eine geschichtliche Erklärung zum regionalen Umgang mit dem Wald. Rückversichert sich nach einigen Sätzen noch einmal, ob er auf Bearnesisch fortfahren kann: „Tot lo bòsc qui exist... qu'ei lo bòsc qui existe actualament qui a poussat tot sol. Eh... qui a de vielhs bòscs plantats lo segle.. DANS LES ANNEES... DE... que vau parlar patuès, comprenetz quandmème... dens las annadas... après la guerra de suassanta-detz o mèma abans, despuish Colbèrt d'alhurs, qu'avèn hèit plantar bòsc, que i a monde qu'avèn plantat bòsc. [...]“ P6 erläutert, dass die Vernachlässigung der eigenen Wälder mit der Einfuhr exotischen Holzes begonnen habe.

- Gibt auf Nachfrage Erklärungen zur Wiederbewaldung verlassener Ländereien, bezieht sich dabei auf die Situation der Kommune Lasseube, in der viele Landwirtschaftsflächen einfach brach liegen gelassen werden. Stellt sein Engagement für den Waldbau als Sonderfall hin (die Nachbarn sagen ihm, er sei verrückt: „Tu qu'ès hòu.“) Erläutert den Aspekt der allenfalls langfristigen Rentabilität des Waldbaus (mit Hinweis auf seinen Enkel).

Die Tatsache, dass es hier wieder eine enge Verbindung von Fach, regionalen Normen und Biographie gibt, ist unverkennbar. Noch während der Bezüge auf sein Leben fiel P6 (EB1) in dem Gespräch ins Französische zurück. In der

und ausländischer Eichen. (Anmerk.: Es ist nicht unbedingt erstaunlich, dass während der sukzessiven Befragung nach verschiedenen Baumarten der Proband kurzfristig den Bezug zu der gerade thematisierten Baumart verliert.) 
Folge aber zeigte sich, dass 'das Eis gebrochen' war und P6 mit mir weiter auf Bearnesisch redete, wobei er nur noch selten kurzzeitig zum Französischen wechselte. Dass aus der sprachlichen Darstellung solcher Zusammenhänge die Bereitschaft des Gesprächspartners erwächst, auch einem Fremden gegenüber (es war mein erster Besuch bei P6) das Bearnesische zu verwenden, halte ich für einen essentiellen Aspekt im Umgang mit dieser Sprache. Das Sprachdokument bezeugt zugleich auch, dass der Wechsel zwischen Französisch und Bearnesisch innerhalb eines Diskurses maßgeblich von der Einschätzung der Kommunikationssituation abhängt (Gesprächspartner, Thema), keineswegs jedoch durch ein Mehr oder Weniger an sprachlicher Kompetenz ausgelöst wird. Nach meiner Einschätzung ist daher in den meisten Fällen eine psycholinguistische Erklärung des Code-Switching angebracht. Unter diesem Aspekt ist auch die Feststellung interessant, dass die jeweilige Wahl der Sprache immer über einen längeren Zeitraum (normalerweise während des gesamten Gesprächs) durchgehalten wurde.

Dieser Feststellung widerspricht auch nicht die Tatsache, dass EB1 im Laufe des Interviews - als Einziger der Probanden - immer wieder Sätze auf Französisch gesagt hat. Es lässt sich nämlich deutlich nachweisen, welche Funktion diese französischen Einwürfe in seiner sprachlichen Darstellung haben. Ich verweise hierzu auf die Antworten D2d, D2e, D3g und D6c, in denen EB1 das Französische verwendet, um genau das zu wiederholen, was er zuvor bereits auf Bearnesisch geäußert hat. So antwortet er etwa auf die Frage, woran man erkennen kann, dass eine Pflanzung gut angelegt sei: ${ }^{220}$

Suvant la creishença deus arbres, quin son tienguts. Qu'ei com un camp de milhòc o un casau. Si LES PLANTS SONT ENTRETENUS...

(EB1: D3g)

Betrachtet man das Interview unter sprachstilistischem Aspekt, so fällt auf, dass EB1 seine Art zu sprechen dem Inhalt anpasst. Dies spricht für eine innersprachliche diaphasische Varietät des Bearnesischen, die von der modernen Linguistik in Bezug auf den mündlichen Sprachgebrauch kaum noch beachtet wird. Ich habe bereits auf die Kürze und Präzision hingewiesen, mit der der Proband fachliche Definitionen gibt. Der Gebrauch eines fachsprachlichen Stils im engeren Sinne wird durch das Interview kaum herausgefordert. Die Antwort auf Frage D3f gehört zu den seltenen Beispielen für die typische Gestaltung eines fachsprachlichen Diskurses:

Que i a malaudias criptogamicas, ...champinhons, qui atacan. L'oïdium per exemple, qui a hèit hèra desgats en quate-vint-nau.

(EB1: D3f)

${ }^{220}$ milhòc fr. 'maïs', casau fr. 'jardin potager' 
Es fällt auf, dass es sich bei dieser Äußerung um ein stark vom Französischen infiltriertes Bearnesisch handelt. Dies liegt zum einen an der Übernahme von Fremdwörtern (criptogamic, ö̈dium), zum anderen an der Verwendung von Französismen, die es erlauben, den fachsprachlichen Diskurs, der im Prinzip nur aus der dominanten Sprache bekannt ist, auf die Regionalsprache zu übertragen. Aus diesem Grund verwendet EB1 champinhon und desgat statt der im Bearnesischen üblichen Lexeme cèth und domau. ${ }^{221}$ Es zeigt sich also, dass nicht die mangelnde Sprachkompetenz des einzelnen Sprechers, sondern diglossische Funktionsverteilungen für ein diaphasisch bedingtes höheres Aufkommen an Interferenzen verantwortlich ist. In diesem Sinne lässt sich das wiedergegebene Zitat z.B. mit dem Sprachstil kontrastieren, den EB1 beim Thema des früher üblichen Baumfällens mit Säge und Axt verwendet. Abgesehen davon, dass es aufgrund der Diskurstraditionen den älteren Bearnesischsprechern keine Schwierigkeit bereitet, sich zu diesem Thema fachsprachlich zu äußern, ${ }^{222}$ fordert die entsprechende Frage auch einen Rückblick auf frühere Zeiten heraus, wobei die Darstellung dann oft einen narrativen Charakter bekommt. Ein solches Diskursbeispiel liefert auch EB1, und zwar in einem so schönen Stil, dass man sich die im Folgenden zitierte spontane mündliche Äußerung des Probanden auch als den Beginn eines autobiographischen Romans mit literarischem Anspruch vorstellen könnte: ${ }^{223}$

En cinquanta, l'an que'm maridèi, qu'estó grelada la proprietat, que'm gahèi a har càder cassos tà un marchand de buès, tota la sason, dab un vailet que aví que partim tots dus tà anar har càder cassos.

(EB1: D5c)

EB1 ist kein Sprachpurist. Er hat mir gegenüber nicht einmal ein besonders reflektiertes Verhältnis zum patois bekundet. Seine tiefe Verwurzelung in der bearnesischen Sprache steht aber außer Frage. Typischerweise führt auch bei EB1 der beständige Umgang mit beiden Sprachen zu einem gewissen Maß an Interferenzen. Im Rahmen seiner Antwort auf Frage D4a beispielsweise macht der Proband die folgende Äußerung:

LA BEAUTE DU PAYSAGE, qu'ei ua causa, mes la beutat deu bòsc, jo que la cal... qu'ei... qu'ei la... lo FeUILLatge qui hè la beutat deu peisatge. [...]

(EB1: D4a)

Bereits zwei Sätze später verwendet EB1 die korrekte bearnesische Form huelhatge für fr. feuillage, wodurch deutlich wird, dass der Gebrauch des hyb-

${ }^{221}$ Im Bearnesischen wird das Wort für fr. cèpe 'Steinpilz', einer im Béarn häufig vorkommenden und als Speisepilz geschätzten Varietät, verallgemeinernd für 'Pilz' benutzt. B. domau (fr. wörtlich 'du mal') entspricht fr. dommage und wird auch im Sinne von dégât verwendet. Palay führt als Beispiel an: la grêle qu'a hèyt gran doumàu 'la grêle a ravagé (les récoltes)'.

${ }^{222} \mathrm{Vgl}$. die Beantwortung der Frage D5c durch LF2 in Kapitel 2.4.3.

${ }^{223}$ gahà-s fr. 'se prendre', vailet fr. 'domestique' 
riden Lexems als Folge des Code-Switching anzusehen ist. Es ist darüber hinaus auffällig, dass der Proband von Zeit zu Zeit Französismen verwendet, die bei einer sprachpuristischen Haltung durchaus vermeidbar wären, aber für den heute üblichen Sprachgebrauch typisch sind. Beispiele hierfür sind etwa dirèi 'je dirais' statt diserí (vgl. D3h), promenà's 'se promener' statt passejà 's (vgl. D4g) und apèl 'appel' statt aperet (vgl. D6b). Im nomenklatorischen Bereich macht sich EB1 häufig nicht einmal mehr die Mühe einer Übertragung der Begriffe in das Bearnesische. So verwendet er z.B. in Frage D1c zur Charakterisierung des Unterholzes die französischen Lexeme if, noisetier, sureau und saule, obwohl ihm mit Sicherheit zumindest ein Teil der bearnesischen Entsprechungen (tash/tèsh, averanhèr/averoèr, saüc/saüquèr, saus/saliga) noch bekannt ist (was ich aus der Wortschatzbefragung sicher weiß). Ebenso verwendet er in Frage D3d die französischen Lexeme clématite und chèvrefeuille, deren bearnesische Übersetzungen heute allerdings meinem Eindruck nach kaum noch geläufig sind (vitauba/vitaubèra, seuvamair/crabahust).

Die Beobachtung der schwindenden Kenntnis oder des zurückgehenden Gebrauchs von botanischer Nomenklatur oder ganz allgemein von fachspezifischer Terminologie in der Regionalsprache ist weder verwunderlich noch neu. Sie darf aber nicht mit einer Gleichgültigkeit der Sprecher gegenüber den Besonderheiten des bearnesischen Sprachgebrauchs gleichgesetzt werden. Die Antworten von EB1 zeigen im Gegenteil recht deutlich, dass ein entsprechendes Normbewusstsein noch vorhanden ist und auch verbalisiert werden kann. Ich verweise zur Illustration dieser Tatsache ganz besonders auf die Antworten, die der Proband im Befragungsteil D2 Partidas e estructura de l'arbe gibt. Hier zeigt sich nicht nur die reine Lexemkenntnis, sondern auch der sprachpraktische Erfahrungsbereich als Maßstab der Beurteilung. Immer wieder gibt EB1 Hinweise darauf 'wie man im Bearnesischen sagt':

Lo hrèischo per exemple qu'a las arradits superficielas, que [...] van luenh e hèra nombrosas en surfaça. En patuès que disen qu'a las arradits per dessús. (D2c)

'Couvert forestier': Que disen parelh: lo cobèrt. (D2d)

[...] que disen un casso qu'a fòrça quan a un gran hopièr, [...] (D2d)

'eslagar' [...] qu'ei un nom naveth dens lo patuès [...] (D2e)

Çò qui hasèn qu'èra 'acotar' $[\ldots]$ 'acotar lo tarèr' (D2e)

Interessant ist der ausführliche Hinweis des Probanden auf den 'Neologismus' eslagar im Bearnesischen. EB1 macht deutlich, dass dieses Wort nicht einfach als Französismus empfunden wird und gibt eine Erläuterung für seine Aufnahme in die Regionalsprache: Der Grund liegt seiner Meinung nach in der Tatsache, dass die Leute früher die Tätigkeit selbst (das Wertästen) gar nicht kannten, heute aber im Waldbau mit dieser Praxis vertraut werden. In demsel- 
ben Maße wie eslagar in das Bearnesische Eingang findet, scheint aber acotar (als Verb des traditionellen, aber nicht mehr üblichen Kopfholzbetriebs) aus dem Sprachgebrauch zu verschwinden. Auch EB1 muss sich an dieses Wort erst wieder erinnern.

Der Beginn der Antwort zu D4a beweist, dass nicht jeder Begriff, den das Bearnesische aus der französischen Fachsprache übernehmen oder nachahmen könnte, auch von den Sprechern akzeptiert wird. In den Wörterbüchern - so auch bei Palay - findet sich das bearnesische Lexem espleitar als klare Entsprechung zu fr. exploiter. Ich habe es daraufhin zur Formulierung der Frage D4a verwendet, aber nie aus dem Munde eines Bearnesischsprechers gehört. ${ }^{224}$ EB1 nun macht mich von sich aus auf zwei alternative Bedeutungen des Begriffs und ihre Wiedergabe im Bearnesischen aufmerksam: har càder (fällen) und véner (verkaufen). Er dokumentiert damit ein differenziertes semantisches Bewusstsein, dessen Begründung selbstverständlich in der Kenntnis des Sachbereichs zu suchen ist.

Die lexikalisch-semantische Differenziertheit des Sprachgebrauchs zeigt sich auch in der Beantwortung der Frage D2b nach der Zuordnung des Baumstumpfs ('Wurzelstocks') zu Stamm oder Wurzeln. Während die meisten Probanden als Reaktion zunächst eine leichte Unsicherheit zeigten, dann aber in der Regel die souche den Wurzeln zuordneten, ${ }^{225}$ gibt EB1 die klarste Antwort, die ich auf diese Frage in allen Interviews, ganz gleich in welcher Sprache, überhaupt bekommen habe:

La soca qu'ei çò qui demora enter los arradits e l'arbre qu'an hèit càder. (EB1: D2a)

Das genaue Begriffsverständnis des Probanden hängt mit den im Bearnesischen zur Verfügung stehenden Lexemen und ihrer semantischen Differenzierung zusammen. Zur Illustration habe ich die entsprechende Erklärung, die mir P6 ('EB1) ein halbes Jahr zuvor gegeben hatte, als Track 16 auf die beiliegende CD gebrannt. Dort unterscheidet der Proband zwischen den Bezeichnungen la soca (bzw. la sosha) für den zum Stockausschlag bestimmten Wurzelstock des Kastanienniederwalds und la tronga für den Baumstumpf der Eiche oder anderer Werthölzer (vgl. Kap. 2.2.2.3.2). Die besondere Wertschätzung des Wurzelstocks (soca) als Basis des Ausschlagholzes, die im Béarn lange Zeit hindurch gegeben war und auch P6 noch präsent und vertraut ist, verhindert die simple semantische Zuordnung der souche zu den Wurzeln. Solche Be-

${ }^{224}$ Der Französismus expluatar wird hingegen hin und wieder verwendet. Allerdings wird der Begriff als nicht bearnesisch empfunden und von den meisten Sprechern im Bearnesischen auch vermieden.

${ }^{225}$ Vgl. zu dieser Zuordnung die Definition des 'Wurzelstocks' im Kosmos Wald- und Forstlexikon, 1998, 853: „der unterste Teil des Baumschaftes, der mit dem Wurzelholz bei der Fällung als Stock (Stubben) zurückbleibt.“ 
obachtungen gehören sicherlich zu einer subtilen Beurteilung der einzelsprachlich repräsentierten Begriffskonzeptionen. Sie zeigen aber auch -sowohl im Falle von espleitar als auch hinsichtlich des Lexems souche -, dass die von der französischen Sprache vorgegebenen Konzeptualisierungen im fachlichen Bereich nicht immer mit den Sprachtraditionen der regressiven Regionalsprache übereinstimmen. Auch wenn die Sprecher unter solchen Inkongruenzen im Einzelfall nicht leiden, so summieren sich doch eine Fülle von Unangepasstheiten des Französischen an den regionalen Sprachgebrauch (in Fachkontexten) zu einer Form des unvertrauten Umgangs mit der Sprache und damit zu Konflikten, die oft von den älteren Sprechern auf der semantischen Ebene zu Gunsten der Bewahrung von Sprachtraditionen und zu Ungunsten der französischen Norm entschieden werden.

Die Auswertung und Kommentierung des auf Bearnesisch geführten Interviews hat gezeigt, ein wie hohes Maß an Sprachkompetenz noch heute von den Muttersprachlern mühelos unter Beweis gestellt wird. Diese Sprachkompetenz ermöglicht nicht nur die kommunikative Bewältigung von Fachkontexten; sie findet darüber hinaus im Falle der traditionellen Bindung des Faches an die Region sogar ihre Begründung in dieser kommunikativen Leistungsfähigkeit. Es ist selbstverständlich, dass Sprecher des Bearnesischen, die ihre Muttersprache in der Familie aufgegeben haben und nur noch Französisch mit ihren Kindern reden, diesen Kindern dennoch Sprachtraditionen vermitteln, die sie zuvor im Bearnesischen internalisiert haben. Diese Sprachtraditionen sind dabei an vielfältige Normen geknüpft, deren Existenz und Wirkung auf den Sprachgebrauch am Beispiel des Sachbereichs 'Waldbau im Béarn' ausführlich dokumentiert und zu erläutern versucht wurde. Die Anknüpfung an ein umfassendes sprachtheoretisches Modell, das die Erklärung des Sprechens nicht allein auf die Einzelsprache fixiert, kann dabei Klarheit darüber verschaffen, ob es möglich - oder in gewissen Fällen auch nicht möglich - ist, mit den Normen, die das Leben in der Region (und auch das ganz persönliche eigene Leben) betreffen, weiterzuleben, obwohl der Bruch mit der eigenen Sprachtradition zu einem unausweichlichen Faktum geworden ist. Ich hoffe, auf der Basis dieses Modells aus einer sprachnormativen Sicht einige neue Einblicke in die Zusammenhänge von Sprachdynamik, Sprachtradition und Sprachsubstitution gegeben zu haben. Das Thema meiner Untersuchung ist damit aber noch nicht erschöpft. Es muss nämlich noch geklärt werden, wie denn die Funktionalität der Regionalsprache in Fachkontexten beschaffen ist, wenn der Untergang der dominierten Sprache nicht kurz bevorsteht, ja wenn es sogar noch Hoffnung auf ihre stetige Funktionserweiterung im offiziellen und inoffziellen Sprachgebrauch gibt. Ich möchte daher im zweiten Teil meiner empirischen Untersuchung genau dieser Fragestellung im Hinblick auf den valenzianischen 
und spanischen Sprachgebrauch im Sachbereich des Zitrusfruchtanbaus in der Comunitat Valenciana nachgehen. 


\section{Die sprachlichen Untersuchungen zum Sachbereich 'Zitrusfruchtanbau' in der Comunitat Valenciana (Spanien)}

\subsection{Das Untersuchungsgebiet}

\subsubsection{Die Comunitat Valenciana}

Das in den verschiedenen Landesteilen Spaniens verbreitete Regionalbewusstsein entspricht weitgehend der aktuellen Einteilung des Staates in 17 politische Autonomien, die sich in einem mehrjährigen Prozess nach dem Tode Francos und der Einsetzung der heutigen spanischen Verfassung herausgebildet haben. Spaniens politische Neustrukturierung erfolgte unter der Respektierung historisch gewachsener Regionen und deren Anspruch auf Selbstbestimmung. Die Dezentralisierung der Monarchie war von Beginn an demokratisch geprägt und wird von den politischen Kräften des In- und Auslands allgemein als eine positive Entwicklung anerkannt. Die meistens wirtschaftlich begründeten Spannungen und Konflikte, die sich auch in Spanien in der Auseinandersetzung der autonomen Regierungen mit der zentralstaatlichen Macht ergeben, gehören zum politischen Alltag und sind ein notwendiges Regulativ der föderativen Staatsführung.

Die Comunitat Valenciana ist eine der Regionen, deren Einbindung in den spanischen Staat sich weitgehend konfliktfrei darstellt. Die politischen, wirtschaftlichen und kulturellen Beziehungen zwischen Valencia und Madrid sind traditionell eng und haben schon lange vor der Demokratisierung Spaniens bestanden. ${ }^{226}$ Auf ihrer Grundlage hat sich eine geistige Affinität des valenzianischen Bürgertums mit Kastilien (und seiner Sprache) entwickelt, die heute immer noch deutlich spürbar ist. Die Comunitat Valenciana gerät damit in ein Spannungsfeld zwischen zwei Machtzentren: demjenigen Madrids und demjenigen Barcelonas als 'Metropole' der 'Katalanischen Länder'. Dieses Spannungsfeld gibt seit der politischen Liberalisierung immer wieder Anlass zu internen sozialen Konflikten, im Rahmen derer die Sprachenfrage zu einem Symbol der Auseinandersetzung wird. Es handelt sich dabei aber um eine Auseinandersetzung, die weiten Teilen der Bevölkerung durch den Einfluss verschiedener Institutionen nur aufoktroyiert ist und die selten einer prinzipiellen Ablehnung des Katalanischen (oder sogar der Katalanen) und einer bedingungslosen Befürwortung alles Kastilischen (oder gar Nationalen) entspricht.

${ }^{226}$ Im Spanischen Bürgerkrieg war Valencia von November 1936 bis Oktober 1937 Sitz der republikanischen Regierung. 
Über den 'valenzianischen Konflikt', der mehr als nur ein Sprachkonflikt ist, wird bis heute viel diskutiert und geschrieben. Dabei ist nicht alles gut Gemeinte auch in der Wirkung gut. Denn die Verwirrung, die durch institutionellen Aktivismus von innen und außen in der Comunitat Valenciana gestiftet worden ist, wird sich voraussichtlich nur in einer Phase stabilisierender Ruhe wieder legen. Damit plädiere ich nicht für Inaktivismus. Aber die Strategie zu einer dauerhaften Konfliktlösung und vor allem ihr Fundament muss sich in der Comunitat selbst entwickeln und konsolidieren. Warum, so wird man fragen, argumentiere ich hier so offensichtlich sprachpolitisch? Die Antwort ist einfach: weil das wissenschaftliche Diskusssionfeld selbst durch und durch sprachpolitisch ist und der Sprachwissenschaftler, will er objektiv bleiben, nicht die Augen verschließen darf, sondern sich nur bemühen sollte, aus der Schusslinie zu bleiben. Was ich unter dieser Haltung verstehe, wird sich im Laufe meiner weiteren Ausführungen noch ergeben.

Die Belastung des regionalen Bewusstseins ist für den einzelnen Valenzianer immens. Selbst die Benennungen der Region, in der er lebt, und der Sprache, die er spricht, werden zu einem Politikum. Miquel Strubell schreibt: ${ }^{227}$

A final symbolic question was the name of the region. The right favoured 'Regne de València' (a constitutional doubtful proposal), having used the empty concept 'Levante' quite frequently for years. The democratic opposition defended 'País Valencià', a word introduced not long before, to stress that Valencia is one of the 'Països Catalans'. However, the name of the region finally chosen was not País Valencià, but Comunitat Autònoma Valenciana.

(Strubell 1994, 246)

Der Vorzug des Begriffs Comunitat Valenciana liegt in der Tat in seiner Neutralität und positiven Konnotierung, die zu einer hohen Gebrauchsfrequenz dieser Bezeichnung führen. Eine historische oder geographische Benennung der Region, die auf die Qualifikation als 'Gemeinschaft', 'Königreich' oder 'Land' verzichten könnte (so wie Catalunya, Islas Baleares, Galicia oder Euskadi) ist im Falle Valencias nicht gegeben. Dies ist mit zu berücksichtigen,

${ }^{227}$ Strubell stellt die Ausdrücke 'Règne de València' und 'Levante' als Symbole eines (undemokratischen) rechten Regionalbewusstseins hin. Dies entspricht einer Bewertung der politischen Konfrontation, der ich grundsätzlich zustimme. Doch ist eine solche Form der Terminologisierung politischer Haltungen (für die Strubell nicht verantwortlich ist, sondern die er hier nur resümiert) aus dem Blickwinkel der valenzianischen Bevölkerung, die dem politischen Konflikt neutral gegenübersteht, eher unsensibel. Das 'Königreich Valencia' existiert nach wie vor im kollektiven Bewusstsein der Valenzianer als Ausdruck der historischen Dimension ihrer Region (noch heute trägt der spanische König offiziell auch den Titel 'König von Valencia'!) und nicht als Gegenpol zu dem sozial nie etablierten Begriff 'Valenzianisches Land'. Des Weiteren ist auch 'Levante' immer noch ein identifikationsstiftender Terminus für viele Valenzianer, ohne unbedingt mit einem politischen Bekenntnis verbunden zu sein (Die meist gelesene Tageszeitung Valencias heißt 'El Levante'). 
wenn man sich über die Annahme oder Nicht-Annahme der Bezeichnung 'País Valencià' Gedanken macht.

Die in der Comunitat neben dem Kastilischen gesprochene Sprache wird in der Verfassung wie auch von den Bewohnern selbst bis auf vereinzelte Ausnahmen (meist aus dem universitären Bereich) Valenzianisch und nicht Katalanisch genannt. Auch dies erklärt sich aus der politischen und sozialen Geschichte des Landes. Meiner Erfahrung nach ist dieser Wortgebrauch in der breiten Bevölkerung kein Ausdruck eines separatistischen Sprachverständnisses, sondern beruht auf der verständlichen Reaktion, dem von außen gesteuerten Identifikationsdruck durch die Konzentration auf ein unabhängiges Selbstverständnis $\mathrm{zu}$ begegnen. Bei nachlassendem Identifikationsdruck scheint mir die Bereitschaft sehr hoch zu sein, ein integratives Sprachbewusstsein zu entwickeln und auch ein Gemeinschaftsgefühl mit den anderen 'katalanischen Ländern' - ganz gleich, ob man sie nun so nennen mag oder nicht aufzubauen. Ich werde noch Belege für diese Grundhaltung aus dem Fundus meiner Befragungen anführen. Unter meinen Probanden befand sich niemand, der die Einheit des Valenzianischen mit dem Katalanischen geleugnet hätte oder der nicht wie selbstverständlich in Barcelona 'seine' Sprache verwendete. Dies sind m.E., bei allen institutionell geführten Diskussionen, die wesentlichen Anknüpfungspunkte für eine befriedigende Beilegung des Sprachkonflikts.

Auch aus historischer Perspektive ist die Entwicklung eines Regionalbewusstseins in der Comunitat Valenciana nicht unproblematisch. Sagunt, $30 \mathrm{~km}$ nördlich von Valencia, war im 3. Jh. vor Christus die Pforte für die Herrschaft der Karthager auf spanischem Boden. Es war aber, nach der Niederlage Hannibals, auch der Ausgangspunkt der frühen Romanisierung des Landes. Im Zuge der Besetzung durch die Westgoten assimilierte sich die Bevölkerung im 5. Jh. recht schnell an die neue Herrschaft. Doch schon bald darauf sollte Valencia mit dem Einfall der Mauren zu einem wichtigen Zentrum der arabischen Macht werden. Früher und intensiver als andere Regionen wurde es schließlich $\mathrm{zu}$ einem Streitobjekt zwischen den arabischen taifas und der kastilischen Krone. Die Rolle des Cid ist nicht leicht zu definieren. Er wird als spanischer (und nicht als valenzianischer) Nationalheld vereinnahmt, als jemand, der Valencia vor dem Einfluss der Almoraviden bewahrt hat. Aber er hat ebenso auch gegen die romanischen Westgoten auf arabischer Seite gekämpft und zweimal den Grafen von Barcelona, Ramon Berenguer II., besiegt (1088, 1090). Letztlich ging es dem Cid nur um das Ziel der individuellen Machtausübung in der Region Valencia. Der 'Kämpe' ist daher keine Identifikationsfigur für die Valenzianer, ebenso wenig wie die nach seinem Tod (1099) genauer: nach dem Tod seiner Frau Ximena (1102) - folgenden schwachen Herrscher der Almoraviden. 
Unter den Almoraviden und vor allem den Almohaden, die um die Mitte des 12. Jhs von Nordafrika aus Besitz von Valencia ergriffen, kam es zu einer intoleranten und zunehmend auch despotischen Machtausübung gegenüber den Andersgläubigen. Auf diese Weise wurden die meisten christlichen Mozaraber schließlich aus Valencia vertrieben oder gezwungen, sich vollständig zu arabisieren. Als nach der Schlacht von Las Navas de Tolosa (1212) die beherrschende Stellung der Araber auf der Halbinsel gebrochen war, erlangte das Königreich Aragón zunehmenden Einfluss in Valencia. Jaume I eroberte schließlich in der Zeit von 1232 bis 1245 das ganze Küstengebiet bis südlich von Alicante (Alacant). Diese Phase markiert den Beginn des neu konsolidierten Königreichs Valencia, dem jedoch nach der Vertreibung der Araber die autochthone Bevölkerung weitgehend fehlte: ein problematischer Neuanfang für das regionale Selbstverständnis der Valenzianer.

Es ist eine geschichtlich bekannte Tatsache, dass die Besiedlung des neu eroberten regne de València durch Aragonesen (vorwiegend im Landesinneren) und durch Katalanen (vorwiegend im Küstenbereich) erfolgte. Jens Lüdtke (1991, 233) weist jedoch darauf hin, dass nicht nur Aragonesisch und Katalanisch, sondern auch Kastilisch und Arabisch im Königreich gesprochen wurden und dass es im Laufe der Zeit einige Sprachgrenzverschiebungen gab. Wesentliche Faktoren der weiteren Entwicklung waren die schnelle Abnahme der Morisken und der dadurch bedingte Rückgang des Arabischen sowie die Assimilation der verbliebenen Mozaraber, die ihren romanischen Dialekt schon vor der Eroberung des Königreichs aufgegeben hatten. Den komplizierten und noch nicht vollständig geklärten Prozess der Ausbildung des Valenzianischen als einer Varietät des Westkatalanischen habe ich in einer früheren Studie wie folgt kommentiert:

Malauradament, tenim molt poca coneixença, fins ara, del diferent paper que jugaren els catalans (orientals i occidentals), els aragonesos, els àrabs parcialment romanitzats i els mossàrabs en aquella fusió lingüística. En base a alguns estudis recents podem suposar tanmateix que els mossàrabs de la Catalunya Nova no mantingueren l'ús de llur llengua fins al període de la reconquesta de Jaume I, és a dir, fins al segle XIII. En aquella època, el País Valencià probablement ja no era bilingüe sinó completament arabitzat. La re-romanització d'aquesta zona constituí, des del punt de vista lingüístic, un procés bastant llarg, durant el qual hi havia una influència constant de nous pobladors. La varietat del català que es formà al País Valencià s'explica doncs, amb molta probabilitat, per la procedència dels primers repobladors i dels immigrants subsegüents que, en el curs de la normalització lingüística, imposaren una variant del català occidental, modificada un xic pels substrat àrab i mossàrab de la població anterior i caracteritzada sobretot per una dinàmica dialectalització posterior.

(Hoinkes 1993, 470f.) 
Namhafte Linguisten wie Germà Colón und Antoni Ferrando haben sich hinter diese Reconquista-These der Entstehung des Valenzianischen gestellt. Ihre Anerkennung kostet jedoch außerhalb des rein wissenschaftlichen Bereichs in der Comunitat Valenciana oft ideologische Überwindung. Der unsensible Umgang mit diesem Problem gab und gibt den z.T. gewagtesten Theorien und Spekulationen über ein unabhängig formiertes Valenzianisch Nahrung. Doch geht es bei dieser ganzen Thematik hauptsächlich um eine politisch-institutionelle Konfrontation, die für viele Valenzianer mit dem alltäglichen Sprachgebrauch und seiner Bewertung in keinem so engen Zusammenhang steht, wie es manchen Linguisten, Soziologen und Politikern vorkommt.

Die Debatte um das Valenzianische und das Selbstverständnis der Valenzianer wird m.E. inzwischen zu einseitig aus einer sprachpolitischen Perspektive geführt. Die Region als identifikationsstiftender Lebensraum umfasst mehr als nur die Sprache. Valenzianisch ist für die Betroffenen, d.h. die Mehrzahl der Sprecher, nicht primär eine zu kodifizierende oder zu normalisierende Sprache, sondern die Sprache ihrer alltäglichen vertrauten Lebensrealität, auf die sie großen, ja teilweise den größten Wert legen. Das Potential einer 'Normalisierung von unten', wenn ich es einmal so nennen darf, sollte in der Comunitat Valenciana nicht unterschätzt werden. Aber es handelt sich eben um einen extrem regionalen Sprachgebrauch, der nicht deshalb regional ist, weil er sich von dem Katalanischen absetzen will, sondern weil die Sprache in einer diglossischen Funktionsteilung mit dem Kastilischen steht, die aus Barceloniner Sicht oft nicht angemessen nachvollzogen wird. ${ }^{228}$

Der Themenschwerpunkt dieser Arbeit öffnet den Blick für eine nicht zu übersehende Realität: Die Valenzianer 'hängen' an ihrer Sprache, weil sie ihnen vertraut ist, und sie ist ihnen vertraut, weil sie sie als regionale Sprache in ihrer unmittelbaren Lebensrealität verwenden. Diese Beobachtung trifft bekannterweise nicht auf die Stadt Valencia selbst zu, da ihre Einwohner mehrheitlich einem seit Generationen kastilianisierten Bürgertum angehören. Aber schon jenseits der engeren Stadtgrenzen wandelt sich das Bild völlig mit

\footnotetext{
${ }^{228}$ Die katalanische Soziolinguistik hat die bekannte These vom 'Selbsthass' (auto-odi) insbesondere in Bezug auf das Valenzianische entwickelt. Das Phänomen mag als psychosoziales Verhaltensmuster richtig erkannt sein. Es sollte aber nicht zu der Grundlage eines monokausalen Erklärungsansatzes werden. Die große Herausforderung des Normalisierungsprozesses ist sicherlich nach wie vor die Eroberung offizieller Kommunikationsräume im öffentlichen Leben und die Verankerung des Valenzianischen im Bildungssystem. Doch ist es heute nicht mehr angemessen, solche erforderlichen Normalisierungsmaßnahmen soziolinguistisch als Befreiungsschläge gegen eine institutionalisierte Sprachunterdrückung zu werten. Die Mehrzahl der Valenzianer hat sich mit der diglossischen Situation im Alltag besser arrangiert, als dies Vertreter grober Konflikttheorien wahrhaben wollen. Man wird darüber nachdenken müssen, welche Konsequenzen daraus für den Normalisierungsprozess zu ziehen sind und wie die Sprecher selbst zu einem größeren Engagement für die valenzianische / katalanische Sprache zu bewegen sind.
} 
der primären agrarwirtschaftlichen Orientierung der Küstenregion. Meine Untersuchung zielt auf den Sprachgebrauch in diesem ländlichen Lebensbereich ab. Es wäre jedoch eine falsche Vorstellung, zu glauben, in der Region Valencia träfe man ein zurückgebliebenes rurales Milieu an. Im Gegenteil zeigt sich der Anbau von Obst und Gemüse in der Küstenregion in einer dynamischen Variante, die vorwiegend auf den Export ausgerichtet ist und modernste Techniken der Produktion nutzt. Ich werde mein Untersuchungsgebiet im engeren Sinne unter den relevanten geographischen und sozioökonomischen Aspekten im Folgenden kurz darstellen.

\subsubsection{Die Region Valencia (L'Horta)}

Die Comunitat Valenciana hat auf einer Fläche von $23.291 \mathrm{~km}^{2}$ eine Einwohnerzahl von 3.722.000. Sie umfasst drei Provinzen: Castelló de la Plana im Norden, Valencia in der Mitte und Alacant im Süden. Der Großteil der Bevölkerung lebt in der Küstenregion, wo auch die blühendsten Wirtschaftsstrukturen des Landes zu finden sind. Neben der Bewässerungsagrarwirtschaft-dem Anbau von Obst, Gemüse und Reis an der Küste - spielt aber auch die Trokkenkultur-Mandeln (almendras), Johannisbrot (algarrobas), Oliven (aceitunas) u.a. - im Landesinneren eine wichtige Rolle. An der Küste gibt es ferner mehrere Industriezweige und den Tourismus. In Valencia selbst findet sich zudem ein gut ausgebauter Dienstleistungssektor.

Die klimatischen Verhältnisse sind innerhalb der Comunitat recht unterschiedlich. Im Landesinneren des Nordens ist es im Winterhalbjahr rauh und kalt, während die Gegend um Elx (Elche) mit ihren ausgedehnten Palmenbeständen und Oriola (Orihuela) im Süden durch ein sehr warmes und auch im Winter noch mildes Klima gekennzeichnet sind. Insgesamt fehlt es bei einer Jahresniederschlagsmenge von nur $430 \mathrm{~mm}$ in den Monaten September bis November der Landwirtschaft an natürlicher Bodenfeuchte. Aufgrund dieser Tatsache gibt es im Hinterland eine zwar ausgedehnte, aber nur wenig intensive Form der Trockenkultur (secano interior), zu der der Anbau von Mandeln und Oliven gehört. Die Landwirtschaft an der Küste hingegen ist sehr ertragreich, da sie sich auf ein gut funktionierendes Bewässerungssystem stützen kann, das im Wesentlichen die vorhandenen Wasservorräte aus den talwärts fließenden Gebirgsflüssen und z.T. auch unterirdische Wasserreservoirs nutzt. Die Intensivierung dieses regadio litoral fand in den letzten Jahrzehnten statt, aber das Bewässerungssystem selbst geht auf eine jahrhundertealte Tradition zurück, deren Ursprünge in römischer Zeit liegen, deren hohe Kultivierung jedoch eine Leistung der Araber war. 
Im ausgehenden 19. Jh. gab es in der Comunitat Valenciana ein Bewässerungsgebiet von ca. 145.000 ha (1879), auf dem vor allem Getreide und Gemüse (legumbres) angebaut wurden $(65 \%)$. Auch Reis wurde damals schon unter ökonomischen Gesichtspunkten, d.h. nicht nur für den Eigenbedarf, kultiviert $(15 \%)$. Der Kleingemüseanbau (hortalizas) machte $11 \%$, derjenige von Wein $7 \%$ und die bewässerten Olivenkulturen 5\% aus. Das 'Schlusslicht' bildete zu dieser Zeit noch der Zitrusfruchtanbau mit nur $1 \%$ Anteil an der gesamten bewässerten Agrarfläche. Im Laufe der nachfolgenden Jahrzehnte bewirkte der kontinuierliche Aufschwung der Bewässerungskultur einen erheblichen agrarstrukturellen Wandel. Während der Anbau von Getreide lange Zeit stagnierte und im Laufe des 20. Jahrhunderts fast vollkommen aufgegeben wurde, nahm die Bedeutung der citricultura in Riesenschritten zu. Die Fläche des regadio hat sich bis heute um mehr als $150 \%$ gegenüber 1879 vergrößert und liegt bei über 365.000 ha. Der Zitrusfruchtanbau erreichte eine Größenordnung von 214.000 ha im Jahre 1982 und ist seitdem noch weiter angewachsen. Er dürfte heute einen Anteil von mehr als $65 \%$ der Bewässerungskulturen ausmachen. Daneben behauptete sich der Anbau von hortalizas mit ca. $20 \%$ und derjenige von Tafelwein mit ca. $4 \%$. Auch die Reiskulturen stellen immer noch einen Wirtschaftsfaktor der Region dar. ${ }^{229}$

Neben dem Agrarsektor ist auch die Industrie ein Fundament der valenzianischen Wirtschaft. Es lassen sich grundsätzlich traditionellere und jüngere Industriebereiche unterscheiden. Traditionell ist beispielsweise die Herstellung von Textilien und Schuhen, aber auch die Keramikmanufaktur sowie Zweige der metallverarbeitenden Industrie. Daneben spielt schon seit dem vergangenen Jahrhundert die Holzverarbeitung und Möbelproduktion ein wichtige Rolle. Erst nach dem Krieg hinzugekommen sind einige Branchen der Lebensmittelindustrie. Hierzu gehört vor allem die Weiterverarbeitung von Wein, Gemüse und Obst. Im Bereich der citricultura spielt zum einen die Konfektion der für den Export bestimmten Orangen in sog. almacenes eine wichtige Rolle. Zum anderen gibt es eine Saft- und Konservenindustrie, insbesondere als Weiterverarbeitung von Orangen und Mandarinen. Die enge Verbindung des primären und sekundären Wirtschaftssektors im Bereich der citricultura ist ausschlaggebend für die Tatsache einer wirtschaftlichen Omnipräsenz der Orangen und Mandarinen. Darüber hinaus ist auch die Außendarstellung der Comunitat Valenciana durch den Export der Orangen geprägt. Die citricultura stellt daher einen Wirtschaftsbereich dar, der in hohem Grad mit der Region und ihren sozio-ökonomischen Lebensverhältnissen assoziiert wird.

Das Untersuchungsgebiet im engeren Sinne liegt in der Horta de València. Die Horta ist eine comarca der Provinz Valencia, die nördlich der Hauptstadt

${ }^{229}$ Angaben nach Piqueras Haba 1992, 74 ff.

230 'Horta' ist eine Ableitung von 'hort'. Vgl. die Bedeutungserklärungen im Diccionari General de la Llengua Catalana von Pompeu Fabra: HORT 'tros de terra en què es conreen verdures i 


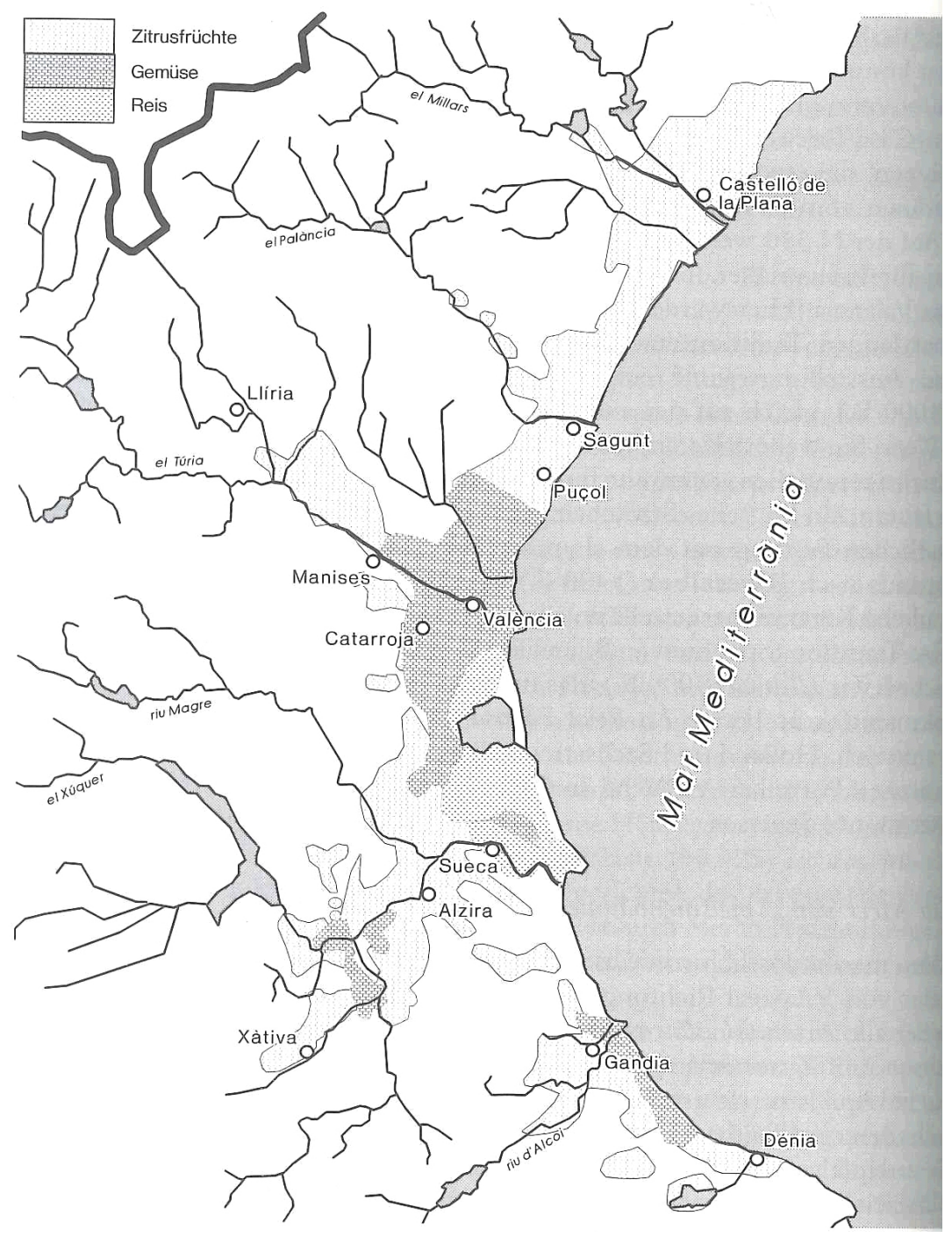

Die Anbaugebiete von Zitrusfrüchten, Gemüse und Reis im mittleren País Valencià

Die Karte ist entnommen aus: Stegmann 1992, 368. 
liegt, aber nur in einem schmalen Küstenstreifen die Stadtgrenze erreicht. Westlich der Horta schließt sich das Gebiet des Pla de Quart an, der Teil der comarca El camp de Túria ist und sich bis zu der katalanischen Sprachgrenze im Landesinneren erstreckt. Südlich des Pla de Quart befinden sich die subcomarcas Torrent und Catarroja. Die Landwirtschaftsflächen der Horta und des Pla de Quart werden aus Abzweigungen des Flusses Túria bewässert. Nördlich des Túria gibt es vier große Bewässerungskanäle, die sog. séquies majors, die die Grundlage für die Fruchtbarkeit des Gebietes darstellen. Sie erreichen ein intensiv bewirtschaftetes und dicht bevölkertes Gebiet um die Städte Montcada, Tormos, Rascanya und Mestella. In der Nähe von Montcada, das ca. $6 \mathrm{~km}$ nordwestlich von Valencia liegt, haben meine Befragungen stattgefunden. Der Befragungsort lag damit in einer Mikroregion, die durch und durch vom Orangenanbau geprägt ist (vgl. die Beschreibung des Gebiets in Sanchis Guarner 1968, 12 f. und 33 ff.).

Die Bewässerungswirtschaft der Horta erfasst eine Gesamtfläche von 29.000 ha. Obwohl heute nur ein kleinerer Teil dieser Fläche, ca. 6.000 ha, zum Anbau von Gemüse genutzt wird, hat dieses Spezifikum zur Namensgebung der 'Horta' beigetragen. ${ }^{230}$ Auch Reisanbau findet sich noch heute in konzentrierter Form in einigen Bereichen der Horta. Seine Größenordnung liegt bei über 3.000 ha. Insgesamt aber wird die agricultura de regadio vom Orangenanbau beherrscht, der auf über 20.000 ha in der comarca betrieben wird und auch den traditionellen Gemüseanbau, der arbeitsintensiver und weniger ertragreich ist, nach und nach in Richtung Hauptstadt verdrängt. ${ }^{231}$ Viele Gemeinden leben fast ausschließlich von der citricultura. Zu ihnen gehört auch Montcada (1.000 ha). Die Intensivnutzung der Ländereien für den Orangenbau lässt das traditionelle Kanalbewässerungssystem schon seit längerem nicht mehr ausreichen. Inzwischen kommen $50 \%$ des Wassers nicht mehr aus Kanälen, sondern aus elektrisch betriebenen Brunnenanlagen, die das Grundwasser hochpumpen. Im Zuge dieses Strukturwandels jüngerer Zeit wird auch die Einführung einer neuen wassersparenderen Bewässerungsart (Tropfentechnik) verbreitet und gefördert. Ich werde auf diesen Aspekt noch an späterer Stelle zurückkommen.

Betrachtet man die Region Valencia als Ganzes, also inklusive der Hauptstadt, so fällt auf, dass zwar sehr viel Orangenanbau betrieben wird, aber nur ca. $10 \%$ der Bevölkerung überhaupt in der citricultura tätig sind. Der Grund

\footnotetext{
230 'Horta' ist eine Ableitung von 'hort'. Vgl. die Bedeutungserklärungen im Diccionari General de la Llengua Catalana von Pompeu Fabra: HORT 'tros de terra en què es conreen verdures i llegums'. HORTA 'terreny de regar destinat al conreu de verdures, llegums, arbres fruiters'.

${ }^{231}$ Angaben nach Piqueras Haba 1992, 224.
} 
hierfür liegt in der vielfältigen Wirtschaftsstruktur der Comunitat, die sich insbesondere im Raum Valencia in verschiedene Industriezweige und Dienstleistungssektoren gruppiert. Viele Menschen leben in der Umgebung Valencias und arbeiten in der Stadt. Aber ebenso gibt es nach wie vor viele, die Ländereien besitzen und diese für den Orangenanbau nutzen. Es handelt sich dabei meist um kleinere Grundstücke, für deren Bearbeitung der berufstätige Besitzer nicht viel Zeit aufbringen kann. Der Orangenanbau bietet sich hier an, da der Eigentümer die Bäume mehrjährig nutzen kann, ihre Bewässerung oft per Telefon in Auftrag gibt und auch mit der Ernte selbst, die in der Regel von Saisonarbeitern erledigt wird, nichts zu tun hat. Unter diesen Bedingungen hat sich in der Region der sog. minifundisme herausgebildet, also die Bewirtschaftung kleiner Ländereien in Teilzeitarbeit, die meist nach Dienstschluss oder am Wochenende stattfindet. Mehr als die Hälfte des Anbaugebiets in der Region Valencia besteht aus Feldern, die kleiner als 1 ha sind (im Durchschnitt sogar nur $0,1 \mathrm{ha}$ ), und weniger als $6 \%$ der Anbauflächen erreichen eine Größenordnung von 10 ha und mehr. Demgegenüber liegt der Durchschnitt in Spanien insgesamt bei 18,8 ha pro Feld. ${ }^{232}$

Wir haben es also in dem Untersuchungsgebiet in gewisser Hinsicht mit einer ähnlichen Situation zu tun wie im Béarn: Viele private Landbesitzer aktivieren sich neben ihrer beruflichen Haupttätigkeit in dem zu untersuchenden Sach- bzw. Wirtschaftsbereich, ohne allzu große finanzielle Erwartungen an diese Aktivität zu knüpfen. Die 'Diffusion' des Fachlichen in die Lebensrealität des Alltags ist auf diese Weise besonders groß, und Themen der citricultura sind in vieler Munde. Wenn auch die Fachterminologie nur bis zu einem bestimmten Grad bekannt ist, so spricht man doch gern und oft über das alltägliche Geschäft der Orangenproduktion, zu dem die meisten Bewohner der Region einen persönlichen Bezug haben. ${ }^{233}$ Wir werden sehen, dass diese Produktionsbedingungen sich sowohl auf die Wahl der bevorzugten Sprache, nämlich des Valenzianischen, als auch auf die Art und Weise des fachkontextuellen Sprechens auswirken.

\subsubsection{Der Gebrauch des Valenzianischen in der Region Valencia}

Auf den Sprachkonflikt in der Comunitat Valenciana und seine sprachpolitischen Hintergründe bin ich bereits in Kapitel 3.1.1 eingegangen. Die viel diskutierte Thematik soll im Rahmen der vorliegenden Untersuchung nicht ausführlicher erörtert werden, da sie für das analytische Interesse der Arbeit von

${ }^{232}$ Angaben nach Ahuir i Cardells, Vicent [u.a.] 1993, 22.

${ }^{233}$ Sánchez Münninghoff (1998) ist in einem ihrer Interviews zur citricultura sogar bei einem älteren Orangenbauern mit langjähriger Erfahrung auf die Unkenntnis des Begriffs gestoßen. 
keiner zentralen Bedeutung ist. Ich möchte hier nur einige Bemerkungen zum alltäglichen Gebrauch des Valenzianischen machen, die mir als Hinführung auf die empirische Untersuchung wichtig erscheinen. Im Rahmen der Untersuchung selbst werde ich dann noch einmal ausführlich auf das Verhältnis meiner Probanden zu ihrer Sprache (alle Probanden sind valenzianische Muttersprachler) eingehen.

Das Valenzianische ist, nach der Art und Weise seiner sozialen Verwendung zu schließen, eine vom Kastilischen dominierte Regionalsprache in einer typischen Diglossiesituation. Man spricht Valenzianisch auf dem Land und nicht in der Stadt (Valencia), man benutzt es in der Familie, unter Freunden und Bekannten, aber kaum in offiziellen Situationen. Ein Unbekannter wird fast nie auf Valenzianisch angesprochen, bei Ausländern und Touristen geht man grundsätzlich von der Unkenntnis der Landessprache aus. Das Sprachbewusstsein ist durch eine pejorative Einschätzung des Sprachgebrauchs geprägt. Die meisten Valenzianer sagen, sie sprächen 'schlecht' Valenzianisch ('parlem mal parlat') und begründen dies in der Regel mit dem immensen Einfluss des Kastilischen, dessen Wortschatz in die Regionalsprache interferiere. Oft ist auch eine negative Einschätzung der Zukunft des Valenzianischen zu hören, die sich offensichtlich sogar statistisch belegen lässt. Zur Zeit ist die Tendenz eindeutig so, dass das Valenzianische als eine regressive Sprache eingestuft werden muss, die von der Bevölkerung der Comunitat insgesamt immer weniger gesprochen wird. Prognosen für die weitere Entwicklung lassen sich daraus jedoch noch nicht ableiten.

Miquel Siguán trägt in seiner ausführlichen Studie über die Situation der Minderheitensprachen in Spanien auch Zahlenmaterial zur Comunitat Valenciana zusammen. Die Statistik bezieht sich dabei zum Großteil auf eine Auswertung der Ergebnisse einer offiziellen Volksbefragung in ganz Spanien im Jahre 1986. Das Problem statistischer Angaben zum Sprachgebrauch in der Comunitat liegt aber grundsätzlich darin, dass sich die Situation mikroregional sehr unterschiedlich darstellt. Zum einen gibt es einen katalanischsprachigen und einen kastilischsprachigen Teil der Autonomie. Zum anderen ist das Sprachverwendungsverhalten in der Stadt und auf dem Land sehr unterschiedlich. Hinzu kommt, dass es große Unterschiede hinsichtlich des Bildungsniveaus und der Berufsfelder gibt. Auch die schwankende Bevölkerungsdichte und der Grad an Immigration spielen eine Rolle. Aufgrund dieser Heterogenität sind statistische Angaben nicht sehr aussagekräftig, zumal wenn sie schon einige Jahre alt sind. Ich beschränke mich daher darauf, Siguáns Zahlenmaterial nur grob zu resümiern. Nach den Umfrageergebnissen von 1986 sprechen $48 \%$ der Bevölkerung in der gesamten Comunitat Valenzianisch, $74 \%$ verstehen es, und für $40 \%$ ist es die Erstsprache. Die Vergleichszahlen in Katalonien sind $65 \%$ (sprechen), $92 \%$ (verstehen) und $50 \%$ (Erstsprache). Mit 
genauerem Bezug auf den katalanisch-sprachigen Teil der valenzianischen Autonomie ergeben sich aber schon höhere Zahlen: ${ }^{234}$

\begin{tabular}{|c|c|c|c|}
\hline & Verstehen & Sprechen & Schreiben \\
\hline $\begin{array}{l}\text { Valenzianisch-sprachiges Gebiet } \\
\text { (3.290.000 Einwohner) }\end{array}$ & $84,1 \%$ & $55,2 \%$ & $7,8 \%$ \\
\hline $\begin{array}{l}\text { Kastilisch-sprachiges Gebiet } \\
\text { (410.000 Einwohner) }\end{array}$ & $22,6 \%$ & $4,4 \%$ & $0,8 \%$ \\
\hline
\end{tabular}

Auch innerhalb des valenzianischen Sprachgebiets sind die Unterschiede sehr deutlich zu spüren, wobei die Sprachkompetenz tendenziell von Norden nach Süden abnimmt. Die Fähigkeit zum aktiven Sprachgebrauch liegt in der Provinz Valencia (ohne die Hauptstadt) bei 53,4 \%, also im guten Durchschnitt. Für das Stadtgebiet selbst werden immerhin noch 39,7 \% angegeben, wobei zu berücksichtigen ist, dass es sich vielfach um Menschen handelt, die im öffentlichen Leben der Stadt die Regionalsprache nicht verwenden.

Ein wesentlicher Aspekt ist der Zusammenhang von Sprachkenntnissen und Bildungsniveau. Zwar belegt die Statistik, dass die Beherrschung der Sprache mit ansteigendem Bildungsgrad leicht zunimmt, doch muss das Problem vor dem Hintergrund der Ausbildungssituation und des tatsächlichen Sprachverhaltens gesehen werden. Die junge Generation hat bis heute in den Bildungsinstitutionen keinen oder nur einen sehr beschränkten Zugang zum Valenzianischen. Die obige Tabelle zeigt, dass nur wenige die Sprache schreiben können. Will man in der Region Valencia eine Zeitung kaufen oder betritt man einen Buchladen, so wird man der erdrückenden Übermacht des Kastilischen gewahr: Kastilisch ist eindeutig die gängige und normale Schriftsprache in der Comunitat. Dies hat Auswirkungen auf den Sprachgebrauch in Wissenschaft und Administration, wo das Katalanische / Valenzianische kaum verwendet wird. Auch der Publikumsverkehr mit nicht bekannten Personen (insbesondere in den Städten) vollzieht sich in der Regel auf Kastilisch.

In einer soziolinguistischen Untersuchung repräsentativen Charakters aus dem Jahr 1990 geben noch ca. ein Drittel der Valenzianer an, ihre Sprache mehr als das Kastilische zu verwenden, also auch im Beruf oder am Ausbildungsort. In Bezug auf den familiären Sprachgebrauch steigt der prozentuale Anteil der vorwiegend Valenzianisch Sprechenden auf 44 \% (Angaben nach Siguán 1993, 187).

${ }^{234}$ Dt. übers. Tabelle aus: Siguán 1993, 185. 
Wenn man diese Darstellungen zum Sprachgebrauchsumfang des Valenzianischen mit den in meiner Untersuchung erzielten Eindrücken vergleicht, so muss betont werden, dass das 'Milieu' des Orangenanbaus grundsätzlich sehr autochthon geprägt ist . Die von mir interviewten Probanden waren alle Valenzianer, die nicht nur Valenzianisch sprachen, sondern die sich auch mit dieser Sprache identifizierten oder sie zumindest als ihre normale Gebrauchssprache bezeichneten. Es gab in diesem Bekenntnis zur Sprache auch keine Unterschiede, die durch eine berufliche (d.h. soziale) Hierarchie bedingt gewesen wären. Meine Probanden gehören zu einem sozialen Umfeld, in dem die Regionalsprache sozusagen zu $100 \%$ gesprochen wird, aber eben nur gesprochen und auch nur in Verwendungsbereichen, die die Bekanntschaft und sogar eine gewisse Vertrautheit der Personen untereinander voraussetzt. Meiner Beobachtung nach nimmt vor allem in der jüngeren Generation die Bereitschaft zum Gebrauch des Kastilischen zu, allerdings oft unter dem Aspekt einer bewusst aufrecht erhaltenen persönlichen Zweisprachigkeit.

Der Sachbereich, in dem meine Untersuchung angesiedelt ist, wird offiziell vom Kastilischen dominiert. Das valenzianische Agrarforschungsinstitut, über das ich die ersten Kontakte geknüpft habe, präsentiert sich nach außen und auch in der internen Verwaltungsstruktur eindeutig kastilisch. Lehrgänge und Ausbildungskurse z.B. werden grundsätzlich in der Staatssprache abgehalten. Sobald jedoch eine Orientierung auf die praktische Arbeit des Orangenanbaus gegeben ist, wechselt das Sprachverhalten zu einer Dominanz des Valenzianischen. Grundsätzlich ist auf allen Ebenen der institutionellen Verbindung die Akzeptanz für den Gebrauch beider Sprachen gegeben. Der berufliche Alltag gestaltet sich daher eher unkompliziert und konfliktfrei, was die Valenzianer häufig auch als eine selbstverständliche und notwendige Form der Toleranz gegenüber dem Gesprächspartner ansehen. Die Kommunikation auf den Feldern und in den Bars vollzieht sich unter Einheimischen fast ausschließlich auf Valenzianisch. Man kann also dahingehend zusammenfassen, dass die Normalität des valenzianischen Sprachgebrauchs mit dem inoffziellen Charakter der Kommunikationssituation sprunghaft ansteigt. Dies war für mich auch ein entscheidendes Kriterium hinsichtlich der Art und Weise, in der ich die Interviews geführt habe. ${ }^{235}$

${ }^{235}$ Die spontanen Kontakte sind meiner Erfahrung nach in Spanien auch auf institutioneller Ebene durch weniger Formalitäten gekennzeichnet als in Frankreich oder Deutschland. Der Chef einer ministeriellen Agrarinstitution bietet mir sofort das 'Du' an, der Techniker fährt mit mir aufs Feld, weil man da besser reden kann, ein Angestellter gibt das Interview in der überfüllten U-Bahn, man trifft sich in der Bar oder wird gleich für abends nach Hause eingeladen. Diese 'Randerscheinungen' gehören vielleicht nicht unbedingt in eine wissenschaftliche Darstellung. Sie sind aber in Bezug auf die Bewertung meiner Untersuchung sehr wichtig. Der Sprachgebrauch der dominierten Sprache in einer Diglossiesituation lässt sich nämlich nur erleben, wenn es tendenziell gelingt, sich in den weniger formalen Bereich des 
In meinen Interviews habe ich auch die Frage gestellt, ob das Valenzianische in Bezug auf Themen der citricultura verwendet wird. Die Antworten stimmten alle dahingehend überein, dass das Valenzianische die gängige Gebrauchssprache sei, aber eben nicht im Forschungs- und Ausbildungsbereich, also auch nicht in der Fachliteratur verwendet würde. Die Frage nach der verfügbaren Terminologie wurde wiederum je nach Wissenschafts- oder Praxisbezug unterschiedlich bewertet. Dabei wurde immer wieder herausgestellt, dass in technischen Fachgesprächskontexten der Grad der Kastilisierung der Sprache sehr hoch sei. Diese Tatsache konnte ich in meinen Untersuchungen auch bestätigt finden. Ein Wort wie porta-injerto 'Pfropfunterlage' ist jedem, der damit zu tun hat, vertraut. Der entsprechende katalanische Begriff hingegen porta-empelt ist als Fachterminus unbekannt und wird durch das einfache Wort peu 'Fuß' ersetzt.

\subsubsection{Die citricultura in der Horta de València}

Unter Bezug auf die Kultivierungsgeschichte der Orangen muss zwischen Bitter- und Süßorangen unterschieden werden. Man nimmt an, dass die schon früh bekannte Bitterorange (Citrus aurantium L.) aus dem südwestlichen Raum Asiens, wahrscheinlich aus Indien, stammt, von wo aus sie in China kulturelle Verbreitung fand. Auch die Römer kannten, wenn vielleicht noch nicht die Orangenbäume selbst, so doch zumindest ihre Früchte. Wahrscheinlich haben arabische Händler, die in Indien ansässig waren, die Orangen im 10. Jh. in den Vorderen Orient gebracht. Sie wurden zuerst im Oman eingeführt, von wo sie im Irak, in Syrien, in Palästina und in Ägypten bekannt wurden. Die Einführung der Bitterorangen durch die Araber geschah mit der Absicht, die Bäume als Schmuck und die Früchte als Heilmittel zu nutzen. Vom Norden Afrikas aus fanden die Orangen im 11. Jh. n. Chr. ihren Weg über Sizilien und Sardinien nach Spanien. Zeugnisse von Orangenvorkommen in Spanien finden sich schon in der mittelalterlichen Literatur. In einem Bericht von 1494 macht Hieronymus Münzer auf die schönen Orangenbäume aufmerksam, die er auf einer Reise in Spanien entdeckte: ${ }^{236}$

Alltagslebens einzugliedern. Die Probanden haben mir dies leicht gemacht, was sicherlich auch an dem Sprachgebrauch des Valenzianischen lag. Innerhalb meiner Probandengruppe war damit eine diglossische Erfahrung gegeben, die die Theorie vom Selbsthass und der kulturellen Entfremdung relativiert erscheinen lässt. Als prädominant habe ich eine unkomplizierte Offenheit für die Wahl der Sprache empfunden, die mich während meines Feldforschungsaufenthalts kaum ein Wort Kastilisch reden ließ.

${ }^{236}$ Siehe Münzer, Hieronymus, „Itinerarium Hispanicum Hieronymi Monetarii (1444-1495)“, in: Revue Hispanique 48 (1920), 110. Für den freundlichen Hinweis auf diese Quelle danke ich Herrn Prof. Dietrich Briesemeister. 
Ingressi fueramus duos ortulos magnos ad redicem montis sitos pulcerrimos, in quibus canalia aque, que rigabant citros, arancios, mirtum, limones, oleas et alia. Maturi enim citraguli et inter folia viridia pulcrum spectaculum prebebant.

Die Süßorange (Citrus sinensis L.), von der die meisten kommerziellen Orangensorten in der Welt abstammen, hat vermutlich ihren Ursprung in einigen südwestlichen Regionen Chinas oder im Norden von Birma. Sie wurde erst wesentlich später bekannt als die Bitterorange. Ihre Präsenz in Italien, insbesondere in Ligurien, wird im 15. Jh. erstmalig bezeugt. Es wird vermutet, dass die Orangenbäume aus dem Orient als Geschenke genuesischer Seefahrer nach Italien gekommen sind. Möglicherweise gelangten sie Mitte des 15. Jhs. auch aufgrund des in Europa verbreiteten Handels über Italien nach Spanien. Auch die Portugiesen brachten im 16. Jh. Süßorangen von ihren Entdeckungsreisen mit in die Heimat, wo sie schon früher als in Spanien angebaut wurden. Der spanische Orangenanbau entstand im 18. Jh. sowohl in Andalusien (Sevilla) als auch im Königreich Valencia. Von Beginn an gab es frühe Formen des Handels nicht nur innerhalb der Iberischen Halbinsel, sondern auch mit anderen europäischen Ländern, unter ihnen Frankreich und Deutschland. Die Expansion der Anbaugebiete entwickelte sich seit Ende des 18. Jh. zunächst im Zentrum, dann im Süden und Norden. Als Chronologie der ersten Anpflanzungen lassen sich nennen: Carcaixent und Alcira 1781, Oriola ca. 1790, VilaReal 1790, Almassora 1800 und Borriana 1826. Das überregionale kommerzielle Interesse am Orangenanbau war von Anfang an vorhanden. Man achtete auf die Produktion wohlschmeckender und rentabler Orangensorten und vergrößerte die Anbauflächen durch eine immer effizientere Bewässerungskultur. Im 19. Jh. baute man Orangen in drei verschiedenen Zentren des Valenzianischen Landes an: in der Provinz Castelló (Borriana und Villa-Real), in der Horta de València, zunächst südlich, dann auch nördlich der Hauptstadt, und ganz im Süden des Königreichs (Oriola). Diese Gebiete haben sich im Laufe der Zeit zu prosperierenden Intensivkulturen entwickelt. Die beliebteste Orangensorte war in der ersten Hälfte des 19. Jh. die sog. blanca comuna. Erst in jüngerer Zeit hat sich der valenzianische Orangenanbau vor allem auf den Anbau von Navel-Orangen und Mandarinen spezialisiert (vgl. Zaragoza Adriaensens 1993, 21f.).

Der Zitrusfruchtanbau ist heute ein Hauptsektor der valenzianischen ExportWirtschaft. Es handelt sich um eine spezialisierte intensive Bewässerungskultur modernen Charakters, die ausschließlich in der Küstenregion zu finden ist. In der Provinz Valencia werden vorwiegend Navel-Orangen produziert, in der Provinz Castelló Mandarinen, wobei die Produktion verschiedener Sorten beständig den Marktbedürfnissen angepasst wird. Weiter südlich, in der Gegend von Alacant und Murcia, gibt es auch Zitronenkulturen. Die Produktion von Zitrusfrüchten ist seit Beginn der 60er Jahren sprunghaft angestiegen. Sie 
erreichte in der Erntesaison 1991-92 in ganz Spanien ein Volumen von 4,88 Mio. Tonnen auf einer Anbaufläche von über 250.000 ha, von der ca. $80 \%$ in der Comunitat Valenciana liegen. Die Intensivierung der Anbaumethoden und die Schwankungen der Konsumgewohnheiten haben in den vergangenen Jahrzehnten große Veränderungen bewirkt. Die prozentualen Verhältnisse im Anbau von Orangen, Mandarinen und anderen Zitrusfrüchten haben sich stark zugunsten der Mandarinen verschoben. Heute leben in der Comunitat mehr als 15.000 Familien ganz oder teilweise von der citricultura. Ihr Anteil an der landwirtschaftlichen Endproduktion liegt bei $30 \%,{ }^{237}$ auf nationaler Ebene bei $5 \%$. An der gesamten Güterausfuhr der Comunitat sind die Zitrusfrüchte mit $70 \%$ beteiligt, in Bezug auf ganz Spanien mit $35 \%{ }^{238}$ Diese Zahlen bestätigen die große wirtschaftliche Bedeutung, die dem Zitrusfruchtanbau regional und auch auf gesamtstaatlicher Ebene (zusammen mit den Anbauflächen in Andalusien) zukommt.

Der valenzianische Orangenanbau prägt nicht nur die Wirtschaftsstrukturen, sondern auch die Landschaft und ist sogar ein Faktor der touristischen Anziehungskraft des Landes. In dem Reiseführer 'Katalonien und die Katalanischen Länder' von Til und Inge Stegmann heißt es:

Die valencianische Apfelsine ist groß, dickschalig, von herrlich süßem Geschmack und außerdem gut haltbar. Meist handelt es sich um die kernlosen sogenannten 'Navelapfelsinen', die eine kleine Nebenfrucht am unteren Ende bilden. Die Blütezeit der Apfelsinen reicht von März bis Mai, und während dieser Zeit liegt ein betäubender Duft über der Landschaft. Die Haupternte erfolgt im darauffolgenden Dezember bis März. Viele Plantagenbesitzer lassen ihre Früchte aber noch länger am Baum hängen (während sie den nächsten Preisanstieg abwarten). Ausnahmsweise sind dann Früchte und Blüten am selben Baum zu sehen. Apfelsinenbäume brauchen viel Wasser (also künstliche Bewässerung) und vertragen keinen Frost. Mehrere Frostnächte (vielleicht noch zusammen mit kaltem Wind) sind für die Plantagen eine Katastrophe.

(Stegmann 1992, 367/370)

Die Bodenverhältnisse und die klimatischen Gegebenheiten sind in der Horta für den Anbau von Orangen bestens geeignet. Im Sommer ist es durchschnittlich $26^{\circ} \mathrm{C}$ warm und im Winter fallen die Temperaturen selten unter $8^{\circ} \mathrm{C}$. Hin und wieder kommt es dennoch zu Frost, der für den Orangenanbau, so wie es auch in dem Zitat zum Ausdruck kommt, bedrohlich ist. Die Orangenbäume

${ }^{237}$ Vgl hierzu Piqueras Haba 1992, 72: „Según datos oficiales, en 1986 la agricultura valenciana dedicaba un total de 933.000 ha a cultivos, de las que 662.000 corresponden a cultivos leñosos (150.000 de viñedos y el resto de árboles: cítricos, almendros, olivos, algarrobos y otros frutales).“

${ }^{238}$ Die Angaben beruhen auf Informationen, die ich im März 1998 bei einem Besuch des Museu de la Taronja in Borriana (Castelló) erhielt. 
sind sehr kälteempfindlich und infolge von extrem niedrigen Temperaturen kann es zu Schädigungen der Pflanzen und Früchte kommen. Aus diesem Grunde ist der Frost sehr gefürchtet, zumal kaum Schutzmaßnahmen möglich sind. Die für den Orangenanbau geeigneten fruchtbaren Böden der Region sind in der Regel rötlich gefärbt. Ihre typische Zusammensetzung besteht aus Tonerde, Morast, feinem Sand, grobem Sand und Kies, wobei die Fähigkeit erwünscht ist, die Bodenfeuchte möglichst lange zu halten. Bevor es zum Anbau der Orangen kommt, wird eine Bodenprobe entnommen und zur Analyse eingeschickt. Weist die Bodenbeschaffenheit Mängel auf, so wird sie mit Hilfe von Düngemitteln optimiert. Die Anbausorten werden auf die Boden- und Klimaverhältnisse abgestimmt.

Die große Variantenvielfalt der Orangen, die sich grundsätzlich in verschiedene Gruppen einteilen lassen, bildet zusammen mit den Veredelungsverfahren und dem Bewässerungssystem ein Charakteristikum der regionalen citricultur$a$. Die kultivierten Orangensorten werden laufend weiterentwickelt, zum einen weil durch spontane Mutationen neue Typen entstehen, zum anderen weil der Markt sich den Veränderungen des Konsumverhaltens anpasst. Die Entwicklung ist schnelllebig: Orangensorten, die im letzten Jahrhundert noch verstärkt angebaut wurden, sind heute fast völlig verschwunden. Die zur Zeit verbreitetsten Varietäten können in drei Gruppen unterteilt werden (vgl. Villalba Buendía 1996, 7 ff.):

(1) Gruppe 'Navel'. Die in der Horta am häufigsten anzutreffende Art. Sie zeichnet sich durch das Merkmal aus, dass die Blüten eine zweite Frucht bilden, die in die Hauptfrucht eingegliedert ist und deren Anblick an einen 'Nabel' (engl. navel) erinnert. Die wichtigsten Vertreter dieser Gruppe sind: Washington Navel (1910), Navelina, Navelate (1948 in Viñaroz als spontane Mutation der Washington Navel), Newhal (1966 aus Amerika importiert), Navel Lane Late (ab 1987 in Spanien, stammt aus Australien), Navel Ricalate (1977 spontane Mutation in Cabanes).

(2) Gruppe 'Blancas'. Diese Gruppe von Orangen ist weltweit die wichtigste und von großem kommerziellen Interesse. In Spanien hatte sie jahrzehntelang durch die große Nachfrage an Frischobst, aber auch durch die Möglichkeit ihrer industriellen Verarbeitung, große Bedeutung. Die Erntezeit für diese Art liegt etwas anders als die der Navel-Orangen. Es gibt eine Vielzahl von Sorten, so z.B. die Berna, Cadenera, Comuna, Castellana und Valencia Late.

(3) Gruppe 'Sangre'. Ein Rückgang dieser Orangengruppe ist schon seit langem zu verzeichnen. Heute sind die Blutorangen als Konsumartikel nicht mehr sehr beliebt. Das Hauptmerkmal dieser Art ist, dass sie im Fruchtfleisch 
und in der Schale ein rotes Pigment haben, das wasserlöslich ist. Die Intensität der Pigmentierung hängt von verschiedenen Faktoren ab (Sorte, Bodenart, Klima und meteorologische Verhältnisse). Bei dieser Gruppe können drei Hauptvarietäten unterschieden werden: neben der Doble Fina (in verschiedenen Subarten) gibt es die Sanguinelli, abstammend von der Doble Fina durch eine spontane Mutation im Jahr 1929 in Castellón. Diese Varietät wurde früher besonders viel angebaut. Auch die Entrefina ist durch spontane Mutation aus der Doble Fina entstanden.

Es wurde bereits mehrfach erwähnt, dass die citricultura im Valenzianischen Land von künstlicher Bewässerung abhängig ist. Der Agrarsektor konnte nur entstehen, weil schon die Araber ein sehr durchdachtes und technisch hochentwickeltes Bewässerungskanalsystem in der Region angelegt haben. Es gilt $\mathrm{zu}$ Recht als eine beachtliche Kulturleistung. Traditionell wurden die Plantagen ausschließlich mit Hilfe dieses (teilweise ergänzten und modernisierten) Kanalsystems bewässert. Diese Art der Bewässerung nennt sich a manta oder kat. a pla und geschieht durch das Öffnen kleiner Schleusentore in den verzweigten Wasserleitungen, was zu einem regelrechten Überfluten der Felder führt. Auch heute ist diese Bewässerungstechnik noch sehr beliebt, da sie lang vertraut ist und dem einzelnen Plantagenbesitzer wenig Mühe bereitet. Ihr prozentualer Anteil unterliegt lokalen Schwankungen, aber im Durchschnitt werden noch mehr als die Hälfte der Felder so mit Wasser versorgt. Das System hat eine alte Tradition, die die valenzianische Agrar- und Sozialstruktur entscheidend geprägt hat und zu einer besonderen Form des Wasserrechts in der Region geführt hat. Sanchis Guarner beschreibt dies in der folgenden Weise:

Els romans, que foren els primers dominadors que recolzaren l'economia del País damunt l'agricultura, iniciaren les obres de canalització de les aigües del Túria, que, potser, els íbers havien començat ja a aprofitar, servint-se de les vallades naturals. Els àrabs milloraren, però, considerablement el cultiu de la terra valenciana, en perfeccionaren i incrementaren els regs, $i$ van introduir-hi el taronger i altres espècies asiàtiques. Jaume I respectà pertot els usos i costums agrícoles dels sarraïns, els quals continuaren durant quatre segles essent-hi els principals conreadors de la terra. Aquell gran rei féu donació de les séquies del Túria als regants, i així quedà consagrat el principi de dret agrari valencià, segons el qual la proprietat de l'aigua és inseparable de la de la terra. Es conserva com un tresor el règim democràtic tradicional de les comunitats de regants, i té justa anomenada el Tribunal de les Aigües, que es reuneix cada dijous a la porta dels Apòstols de la Seu de València per jutjar i fallar inapel.lablement, només amb un breu procés verbal en la llengua del poble, tots els litigis que origina la distribució de l'aigua, la qual mai no es suficient.

(Sanchis Guarner 1968, 33)

Das valenzianische Wassertribunal ist heute eine Touristenattraktion, hat aber de facto nur noch eine minimale agrarrechtliche Bedeutung. Das System der 
Wasserverteilung und -bezahlung ist administrativ perfekt geregelt und führt daher kaum noch zu Konflikten. Die Verwaltung der Bewässerungsrechte ist immer noch in den sog. Sociedades de Regantes organisiert, die für die Kontingentierung und Zuteilung der Wasservorräte zuständig sind. Allerdings gerät das traditionelle Bewässerungssystem heute aus moderner Sicht zunehmend in Kritik. Bei der Überflutungstechnik handelt es sich in gewisser Hinsicht nämlich um eine Verschwendung des kostbaren Wassers, das von den Baumbeständen nicht optimal genutzt werden kann. Außerdem ist das Ideal einer kontinuierlichen Befeuchtung so nicht zu erreichen. Die Bemühungen gehen daher in die Richtung, eine neue, effektivere Bewässerungstechnik in der Region zu etablieren. Es handelt sich dabei um den sog. riego a goteo (rec a goteig), d.h. die Bewässerung mit Hilfe von Schläuchen und Wassertropfenspendern, die in der Nähe jedes Orangenbaums installiert werden. Diese Technik ist geeignet, sogar den individuellen Wasserbedarf eines jeden Baumes zu berücksichtigen und ihm optimale Bedingungen zu gewähren. Gleichzeitig kann der Wasserverbrauch selbst verringert und die Wasserzufuhr kontinuierlich geregelt werden. Die privaten Orangenbauern stehen dem riego a goteo dennoch teilweise skeptisch gegenüber. Zum einen trennt man sich nicht gern von den alteingesessenen Traditionen, zum anderen ist die Installation einer solchen Bewässerungsanlage recht kostspielig und von den Kleingrundbesitzern nicht zu finanzieren (vgl. Loussert 1990, 193-220 und González Sicilia de Juan 1960, 433-457). Der riego a manta wird sich daher voraussichtlich noch längere Zeit als altbewährtes System erhalten, auch wenn das Interesse an der neuen Technik durchaus zunimmt. Ein weiteres Bewässerungssystem muss der Vollständigkeit halber erwähnt werden: Es ist der riego por aspersión, bei dem das Wasser durch einen Sprenkler verteilt wird. Im Orangenanbau hat sich diese Bewässerungsart allerdings nicht bewährt, da die unvermeidliche Befeuchtung der Stämme leicht zu Erkrankungen führt. Für den Gemüseanbau in der Horta wird der riego por aspersión hingegen häufig genutzt.

Neben der Bewässerung, dem Düngen und der Pflege der Orangenplantagen ist das Beschneiden der Bäume eine wichtige Arbeit, die starke Auswirkungen auf das Gedeihen und die Produktion des Baumes hat. Normalerweise werden die Bäume einmal im Jahr gestutzt. ${ }^{239}$ Bei jungen Bäumen spielt der Zeitpunkt keine Rolle, solange nicht die Gefahr von Frost besteht. Bei älteren früchtetragenden Bäumen empfiehlt es sich, sie so bald wie möglich nach der Kälteperiode zu schneiden. Zu spätes Eingreifen in den Zyklus des Baumes kann zu Nachteilen bei der Produktion führen. Das Baumbeschneiden wird meist jähr-

${ }^{239}$ Es gibt Plantagenbesitzer, die ihre Bäume nur alle zwei oder drei Jahre schneiden lassen, um die Kosten so gering wie möglich zu halten. Dies wird aber von den Schulungen nicht empfohlen, weil dann die Verletzungen der Bäume größer sind und diese sich nicht mehr so leicht erholen können. 
lich praktiziert, um ein gesundes Wachstum der Bäume und eine gute Ernte zu garantieren. Die Orangenbauern schneiden zum Teil selbst, überlassen die Arbeit aber bei größeren Plantagen den spezialisierten podadores, die traditionell eine eigenständige Berufsgruppe in der Region bilden. Es gibt verschiedene Klassen der poda, die ihre eigenen Funktionen und Richtlinien haben. Es sind dies im einzelnen:

(1) Die poda de formación. Der Zweck dieses 'Pflanz- und Erziehungsschnitts' ist es, dem Baum eine optimale Form zu geben, um reichhaltige und ausgewogene Produktionen zu erlangen. Es wird darauf geachtet, dass der Baum eine klare Wuchsform ohne störende Astkreuzungen bekommt und dass die Früchte leicht zu ernten sind. Bedingt durch den ganzjährigen Blätterwuchs wird empfohlen, die poda de formación nicht vor dem 3. Jahr der Pflanzung zu beginnen, d.h. erst wenn sich das Wurzelsystem der Setzlinge (plantones) gefestigt hat.

(2) Die poda de fructificación y mantenimiento. Das Ziel dieses Schnitttyps ist es, die gute Verteilung des Baumsaftes zu sichern, d.h. das Wachstum der schwachen Triebe zu stärken und zu verhindern, dass einzelne große, oft wenig produktive Äste zuviel Baumsaft beanspruchen. Der 'Instandhaltungsschnitt' ist darauf spezialisiert, die Äste aufzulockern und ihr Ineinanderwachsen zu verhindern. Ein Lichten dieser Art ist notwendig, da Zitrusbäume die Tendenz zu starker Verzweigung haben. Das Ausdünnen des Baumes fördert und erhält somit die Fruchtbildung im Inneren des Baumes. Vertrocknete, zu kurze, sich überkreuzende und nicht mehr produktive Äste, die nur noch Saft ziehen (span. tirasavias, chupones, kat. mamóns), werden entfernt (vgl. Loussert 1990, 229f., Ribera de los Valles 1969, 129-142).

(3) Die poda de restauración y reparación. Der 'Wiederherstellungsschnitt' ist eine Form der grundsätzlichen Aufarbeitung des Baumes und wird bei ungepflegten, schlecht entwickelten oder durch Frost und Wind geschädigten Bäumen vorgenommen. Bei Bäumen mit unproduktiver Wuchsform ist die Anzahl der vorhandenen Leitäste häufig zu hoch. Einige dieser Äste kreuzen oder biegen sich, da sie ständig in Konkurrenz stehen. Im Inneren der Krone gibt es keine fruchttragenden Äste. Der hier anzuwendende Schnitt muss drastisch alle fehlentwickelten Äste eliminieren. Bei Bäumen mit Schäden ist es sinnvoll, zuerst die Schadstellen zu beschneiden, wobei die unproduktiv gewordenen Äste entfernt werden, damit neue Triebe wachsen können (vgl. Loussert 1990: $231 \mathrm{f}$.). 
Neben der poda ist das Veredelungsverfahren ein wesentlicher Bestandteil des Orangenanbaus, da man erst auf ihrer Grundlage die jeweils gewünschten Orangensorten erhält. Es lassen sich zwei Arten von Veredelungsverfahren unterscheiden, die beide im Frühling vorgenommen werden. Einerseits gibt es eine Technik des schnellen Wechsels der Orangensorte, bei der der Baum zunächst stark gestutzt und dann neu gepfropft wird. Eine andere, sanftere Form ist das teilweise Ausdünnen mit anschließender Veredelung der fruchttragenden Äste (vgl. Amorós Castañer 1995, 124 f.). Die Grundlage der Veredelung bildet der Zitrusbaum, auf den die gewünschte Varietät gepfropft wird (pie borde, kat. peu bort). In der Comunitat Valenciana wurde bis zum katastrophalen Auftauchen einer epidemischen Viruskrankheit, der sog. tristeza, Ende der 50er Jahre (vgl. Loussert 1990, 64 f.) fast ausschließlich die 'Bitterorange', der naranjo amargo, kat. taronger amarg, als ,Fuß' zum Veredeln verwendet. Die Bitterorange wies die besten Anpassungsfähigkeiten an Klimaund Bodenverhältnisse auf. Ebenso war sie sehr resistent gegenüber Krankheiten. Durch die tristeza wurden ca. 95\% des Orangenbaumbestandes im Valenzianischen Land (8 Mio. Bäume) vernichtet. Seit jener Zeit ist die Wissenschaft bemüht, neue optimale patrones für den Zitrusfruchtanbau zu finden. Unter anderem sind heute folgende Sorten im Einsatz: citranje Troyer, citranje Carrizo, mandarino Cleopatra, citrulemo $C P B$, Citrus volcameriana und $C i$ trus macrophyla. Von all diesen ist der citranje Carrizo der meist verwendete, da er gegenüber den Krankheiten wie Tristeza, Psoriasis, Xyloporosis etc. besonders resistent ist. Er reagiert allerdings sensibel auf Kalk und Salz (vgl. Villalba Buendía 1996: 29-32).

Für den Vorgang des Pfropfens (injertar, kat. empeltar) gibt es mehrere Techniken. Je nach Durchmesser des zu veredelnden Astes wird der Typ des Pfropfens ermittelt. Einerseits kann der escudo oder escudete 'Schild' verwendet werden, der auf Äste mit geringem Durchmesser aufgepfropft wird, vor allem bei stark gestutzten Bäumen. Andererseits gibt es die Pfropfen de chapa oder de plancha 'Plättchen', wobei nur ein kleiner Rindenteil aufgesetzt wird. Diese Art des Pfropfens ist besonders stark verbreitet. Um die Pfropfen zu fixieren, benutzt man Plastikstreifen, die um den Ast gewickelt werden. Einige podadores bedecken den ganzen gepfropften Ast, andere hingegen lassen einige Knospen unbedeckt. Nach 25 Tagen kann das Plastikband entfernt werden und am 40. Tag wird noch ein kleiner Einschnitt oberhalb der Pfropfstelle angebracht.

Die Agrarforschung ist heute ganz besonders an der Verbreitung und weiteren Entwicklung der microinjertos interessiert. Hierbei handelt es sich um ein Verfahren, bei dem kleine Keimlinge unter absolut sterilen Laborbedingungen unter dem Mikroskop mit Hilfe einer maschinellen Feinmechanik veredelt werden. Dieses Verfahren hat den Vorteil, dass die Viruserkrankungsgefahr, 
die stets mit dem Pfropfen verbunden ist, umgangen wird und dass sich sehr viele Pflanzen in kurzer Zeit präparieren lassen. Die Technik ist revolutionär und zöge bei konsequenter Anwendung eine wesentliche Neustrukturierung des Anbaubetriebs nach sich. Schon heute greifen die technologischen Entwicklungen so weit in das bestehende Agrarsystem ein, dass der Berufsstand des podador und die traditionellen Spezialisierungen des Fachs nicht mehr gefragt sind. Wenn man die Bestrebungen zur Renovierung des Bewässerungssystems mitbedenkt und den immer stärkeren Anpassungs- und Konkurrenzdruck des Marktes berücksichtigt, so bietet sich das Bild einer citricultura im Wandel oder doch zumindest im Aufbruch zu einem Wandel. Der zunehmende Einfluss von Wissenschaft und Technisierung sowie die internationale Verflechtung der Märkte und auch Reformen eines weltweit kooperierenden Ausund Weiterbildungssystems lassen den Schluss zu, dass die Traditionen des Orangenanbaus, obwohl sie als eine Form der Intensivkultur im Valenzianischen Land noch gar nicht alt sind, schon bald massiv umgestaltet werden. Die Frage ist, wie die Betroffenen mit dieser Situation fertig werden. Auch die Frage des Sprachgebrauchs und der kommunikativen Funktion des Valenzianischen werden in dem Prozess der Veränderung eine Rolle spielen. Der regionale Sprachgebrauch in Fachkontexten steht heute unter dem Druck einer Dynamik der Lebensverhältnisse, die notwendige sozio-ökonomische Veränderungen mit der Kontinuität vertrauter Erfahrungen in Einklang bringen muss. 


\subsection{Fachbezogene Kommunikation auf Katalanisch und Kastilisch im Sachbereich 'Zitrusfruchtanbau in der Horta de València'}

\subsubsection{Zielsetzung, methodisches Vorgehen und Probandenauswahl}

In der nachfolgenden Darstellung und Dokumentation meiner empirischen Untersuchungen zum Sprachgebrauch in Fachkontexten der valenzianischen citricultura möchte ich eine vergleichende Perspektive eröffnen. Dabei lege ich das Schwergewicht auf Aspekte, die in den bisherigen Analysen noch keine Beachtung gefunden haben, und auf Phänomene, die für das Untersuchungsgebiet spezifisch sind. Die Präsentation der Region und ihrer sprachlichen Situation sowie auch die des Sachbereichs haben gezeigt, dass im Vergleich zum Béarn manches ähnlich und manches grundsätzlich anders ist. Ebenso wie es erforderlich ist, jede diglossische Situation differenziert zu betrachten, erweisen sich auch die Produktionsbedingungen des Wirtschaftssektors als regional sehr unterschiedlich. Das Thema meiner Untersuchung hat damit zumindest zwei grundsätzliche Variablen, die es zu spezifizieren gilt, um zu angemessenen Ergebnissen zu gelangen.

Schaut man auf die Internet-Seite des Instituto Valenciano de Investigación Agraria (I.V.I.A.) in Montcada und informiert sich über die Qualifikation des Master en Citricultura, der ein jährliches internationales Ausbildungsangebot auf hohem fachwissenschaftlichen Standard darstellt, so fällt zumindest dem Linguisten der folgende Satz in die Augen: ${ }^{240}$

El idioma del trabajo del Curso será en todo momento castellano. Parte del material didáctico y los textos básicos estarán escritos en este idioma; no obstante, conocimientos básicos del inglés escrito son esenciales ya que buena parte del material de apoyo está en este idioma.

Diese sprachlichen Bedingungen erscheinen auch den valenzianischen Teilnehmern vollkommen normal und entsprechen dem internationalen Flair, das in dieser Ausbildungssituation vorherrscht. Doch ist dies nur die Spitze eines Eisbergs, der einem vor Ort schnell deutlich macht, dass der wissenschaftliche und technologische Bereich der citricultura heute vollkommen vom Sprachgebrauch des Katalanischen abgekoppelt ist. Angesichts dieser Situation habe ich mir die Frage gestellt, ein wie hoher Grad an Fachlichkeit in den alltäglichen sachbezogenen Gesprächen innerhalb und außerhalb des Berufssektors zu verzeichnen ist und ob diesem Grad an konstatierbarem Fachwissen auch eine besondere Form des Fachsprachengebrauchs entspricht. Sandra Sánchez Mün-

${ }^{240}$ Zitiert nach der gedruckten Form des offiziellen Kursangebots für Oktober 1998, das in der Hauptverantwortung der Universidad Politécnica de Valencia stand. 
ninghoff hat sich im Rahmen ihrer Magisterarbeit dieser Frage gewidmet und im Sommer 1997 eine Serie von Interviews geführt, deren fachspezifische Ausrichtung ähnlich gelagert war wie die meiner Interviews zum Thema 'Waldbau im Béarn'. Mit ihrer schriftlichen Arbeit liegt nun eine detaillierte Untersuchung zum Thema der 'regionalen Ausbildung fachsprachlicher Kompetenz in der spanischen Gemeinsprache, am Beispiel des Sachbereichs 'Zitrusfruchtanbau' ('citricultura') im Valenzianischen Land' vor. Die Analysen von Sánchez-Münninghoff basieren auf einer detaillierten Auswertung von 10 strukturierten Interviews, die jeweils ausschließlich auf Spanisch mit fünf Experten und fünf Laien geführt wurden. ${ }^{241}$

Die Ergebnisse von Sánchez-Münninghoff bestätigen im Wesentlichen die Interpretationen des Fachsprachengebrauchs in der dominanten Sprache, die ich im Rahmen der Analyse der französisch geführten Interviews zum Thema 'Waldbau' in dieser Arbeit vorgelegt habe. Als Besonderheit lässt sich jedoch hinzufügen, dass es im Falle des Sachbereichs der citricultura möglich war, deutlicher zwischen einer Gruppe von Experten und einer Gruppe von Laien zu unterscheiden. Wie nicht anders zu erwarten, differenzierte sich das feststellbare Fachniveau zwischen den Gruppen sehr deutlich. Allerdings ließ die sprachliche Umsetzung dies nur aus dem Blickwinkel des kritischen Sachverstands deutlich erkennen. Die Probanden benutzten nämlich kaum ein unterschiedliches Vokabular, da absolute termini technici auch von den Experten in den Interviews weitgehend vermieden wurden. Die Vermutung, dass es sich dabei um eine Form der Rücksichtnahme auf die Fragestellerin gehandelt hätte, ist nicht zu bestätigen, da das Interview fachlich gut durchstrukturiert war und immer wieder zu fachspezifischen Detailerklärungen herausforderte. Auch Sánchez Münninghoff kommt daher zu dem Ergebnis, dass ein grundlegendes fachsprachliches Niveau zwar in den fachkontextuellen Gesprächssituationen unabdingbar ist, darüber hinaus jedoch der Einsatz spezifischer Fachtermini in der beruflichen und außerberuflichen Alltagskommunikation nicht erforderlich und auch nicht verbreitet ist.

Gerade dann, wenn ein Sachbereich in einer Region einen hohen kommunikativen Stellenwert zuerkannt bekommt, wird über seine Gegenstände in einer Form gesprochen, an der sich Experten, Semi-Experten und interessierte Laien in gleicher oder zumindest ähnlicher Weise beteiligen können. Die Differenzierungen des Fachwissens schlagen dabei objektiv gesehen zu Buche und sind in Form unterschiedlicher Konzeptualisierungen der verwendeten Fachbegriffe zu erkennen. Sie behindern aber nicht das fachexterne Gespräch, insofern es auf Erklärungen, Bewertungen oder Kommentierungen des Fachlichen ausgerichtet ist, da der terminologische Gebrauch sich auf einen sozial weit diffun-

${ }^{241}$ Die empirische Basis der Arbeit ist mit insgesamt 26 vollständig durchgeführten Interviews noch wesentlich breiter. 
dierten Level beschränkt und konzeptuelle Abweichungen in fachlichen Darstellungen oder Assoziationen durch das Regulativ regionaler Normen, die allen Gesprächspartnern bekannt sind, ausgeglichen werden. Dadurch wird die Hemmschwelle zur Thematisierung des Fachlichen heruntergesetzt, und kommunikative Barrieren, die auf unterschiedlichen Fachniveaus beruhen, bauen sich erst gar nicht auf. Dieses Fakum markiert m.E. einen großen Unterschied zwischen den fachkontextuellen Gesprächen, deren Motivation hauptsächlich in der Betroffenheit der Gesprächspartner liegt, und den reinen Fachgesprächen, die mit spezialisierten Arbeitstechniken korrespondieren und in der Form einer terminologisierten Berufsgruppensprache keine soziale Verbreitung finden. Die zuletzt genannte Form der Fachsprache im engeren Sinne kann aber nicht gemeint sein, wenn es um die kommunikative Realität des Fachlichen in der Sprachgemeinschaft geht, die sich als solche zu einer regionalen Identität bekennt, zu der auch das Fach hinzugehört.

Wir müssen also unterscheiden, in welchem Rahmen Themen der citricultu$\mathrm{ra}$ besprochen werden. Wenn es sich um fachliche Ausbildungssituationen oder um berufliche Tätigkeiten eines hohen Spezialisierungsgrades handelt, so ist der Sprachgebrauch grundsätzlich anders zu bewerten als in den regional sehr häufig anzutreffenden Kommunikationssituationen fachkontextuellen Charakters, die ein soziales Phänomen darstellen, das zur Identitätsfindung der Gesellschaft und des Individuums in der Gesellschaft beiträgt. Im ersten der genannten Fälle wird auf Kastilisch und nur auf Kastilisch (oder gegebenenfalls auch auf Englisch) über die citricultura gesprochen. Im zweiten Fall ist Valenzianisch die gängige und bis in die institutionelle Ebene hinein anerkannte Gebrauchssprache der von der citricultura betroffenen Valenzianer, sofern sie untereinander über fachliche Themen sprechen. Dies zu unterscheiden, fällt dem Beobachter nicht immer leicht. Das Sprachwechselverhalten entspricht hier aber einer Form der fachspezifischen diglossischen Realität, die methodisch differenziert zu analysieren ist und bislang-wohl hauptsächlich wegen des Erfordernisses einer interdisziplinären Untersuchungsausrichtung-noch nicht das Interesse der Soziolinguisten gefunden hat. Ich bemühe mich, hier neue Akzente zu setzen.

Sandra Sánchez Münninghoff hat ihre empirischen Untersuchungen, die sich in das von mir initiierte Projekt zum 'Sprachgebrauch in Fachkontexten' eingliedern, im Juni/Juli 1997 durchgeführt. Den Fragebogen habe ich mit ihr gemeinsam erarbeitet und das Material anschließend den Erfordernissen des Projekts entsprechend technisch aufgearbeitet (Konvertierung in mp3Dateien). Ein halbes Jahr nach ihrer Feldforschungsreise bin ich selbst in das Untersuchungsgebiet gefahren und habe eine ähnliche Serie von Befragungen durchgeführt. Der wesentliche Unterschied bestand darin, dass die von Sandra Sánchez Münninghoff verwendete Sprache ausschließlich Kastilisch war, 
während ich mich nur des Katalanischen (in einer so gut wie möglich valenzianisierten Form) bedient habe. Diese methodische Konzeption erschien mir besonders interessant, um anhand konkreter Diskurse zu überprüfen, in welcher Art und Weise die Probanden in den jeweiligen Sprachen dieselben fachlichen Gegenstände kommunikativ erfassen und darstellen. Die Vergleichsbasis der Untersuchung war also (teilweise) durch die Auswahl derselben Probanden gegeben, mit denen ähnlich strukturierte fachbezogene Interviews in einem Abstand von acht Monaten durchgeführt wurden. Es steht außer Frage, dass dieses Verfahren nicht von ein und demselben Fragesteller in einer als natürlich empfundenen Weise hätte durchgeführt werden können, weshalb ich Frau Sánchez Münninghoff für ihre Mithilfe besonders dankbar bin.

Der Kontakt zu den Gesprächspartnern wurde uns über das schon genannte I.V.I.A. in Montcada vermittelt. ${ }^{242}$ Unser Ansprechpartner und Betreuer war während der Aufenthalte Herr Victor Real Boronat, dem ich zu großem Dank verpflichtet bin. Herr Real ist Leiter der Sección de Capacitación Agraria, die eine Institution der Conselleria de Agricultura y Pesca darstellt, deren Aufgabe es ist, Aufklärungsarbeit verschiedener Art zugunsten der in der Landwirtschaft tätigen Bevölkerung zu leisten, d.h. insbesondere Schulungen durchzuführen, schriftliche Informationen zu verteilen und konkrete Hilfen zu geben. Damit repräsentiert Herr Real genau die Verbindungslinie von fachlicher Institutionalisierung und Lebensalltag im Fach, denen das besondere Interesse meiner Untersuchung gilt.

Dank der Unterstützung durch die Capacitación Agraria habe ich während meines Aufenthalts im März 1998 insgesamt 18 Interviews führen können, die sich relativ gleichmäßig auf Experten, Semi-Experten und Laien verteilten. 8 meiner Gesprächspartner waren bereits zuvor auch Probanden von Sandra Sánchez Münninghoff gewesen. Als Grundlage für die Auswertung in dieser Arbeit habe ich 6 Probanden ausgewählt, von denen jeweils zwei den unterschiedlichen Fachniveau-Gruppen zuzuordnen sind. Vier dieser Probanden sind zuvor von Frau Sánchez Münninghoff interviewt worden, so dass der Auswertung insgesamt 10 Interviews zugrunde liegen. Im einzelnen danke ich den folgenden Gesprächspartnern für ihre Unterstützung: ${ }^{243}$

EV1: $\quad$ Angel B. P., Benifaraig (P. València)

44J., Landwirt, Baumschneider und Laborassistent im I.V.I.A., besitzt Orangenplantagen und Gemüsefelder, die er selbst bewirtschaftet, betreibt ökologischen Anbau, hat einen Master en citricultura erworben; mit der Arbeit ver-

${ }^{242}$ Ich möchte in diesem Zusammenhang dem Leiter des I.V.I.A., Herrn Salvador Zaragoza Adriaensens, für seine freundliche Unterstützung danken.

${ }^{243}$ Ich benutze als Kennung der Probanden die Abkürzungen EV (' Experte, Valenzianisch), SV (' Semi-Experte, Valenzianisch) und LV (' Laie, Valenzianisch). Zur Unterscheidung von Experten, Semi-Experten und Laien siehe die weiteren Erläuterungen. 
bundener Auslandsaufenthalt von drei Jahren in Kolumbien, Besuch von Spezialisierungskursen, Muttersprache: Valenzianisch, zeigt großes Interesse am Valenzianischen (Besuch von Universitätskursen)

Gesprächsdauer (val.): ca. 1 Std. 26 Min. (V1.mp3: 42:03, V2.mp3: 43:43)

Gesprächsdauer (kastil.): ca. 1 Std. 23 Min. (C1.mp3: 45:45, C2.mp3: 37:09)

EV2: José A. F., Bonrepós i Mirambell (P. València)

63 J., verwandt mit P1, Landwirt und Orangeneinkäufer, besitzt Orangenplantagen, die er selbst bewirtschaftet, hat Spezialisierungskurse besucht, Muttersprache: Valenzianisch

Gesprächsdauer (val.): ca. 1 Std. 06 Min. (V1.mp3: 46:00, V2.mp3: 19:37)

Gesprächsdauer (kastil.): ca. 51 Min. (C1.mp3: 34:55, C2.mp3: 15:37)

SV1: $\quad$ Rafel R. B., Benifaraig (P. València)

47 J., Landwirt und Bodenanalytiker, Orangenplantagen in Familienbesitz, die er selbst bewirtschaftet, Muttersprache: Valenzianisch

Gesprächsdauer (val.): ca. 1 Std. 21 Min. (V1.mp3: 45:54, V2.mp3: 35:06)

SV2: Juan Bautista H. P., Nules (P. Castelló)

36 J., Hilfsarbeiter (peó del camp) am I.V.I.A., besitzt eine kleine Orangenplantage in Nules, die er selbst bewirtschaftet; hat Spezialisierungskurse besucht, Muttersprache Valenzianisch

Gesprächsdauer (val.): ca. 43 Min. (V1.mp3: 37:43, V2.mp3: 05:23)

Gesprächsdauer (kastil.): ca. 36 Min. (C.mp3: 35:14)

LV1 Maria Teresa M. M., Alfara del Patriarca (P. València)

33 J., Verwaltungsangestellte in der Capacitación Agraria, kein Landbesitz, Vater war podador, verrichtet selbst keine Tätigkeiten im Orangenanbau, Muttersprache Valenzianisch

Gesprächsdauer (val.): ca. 45 Min. (V.mp3: 44:06)

LV2 María José A. L., Bonrepós i Mirambell (P. València)

30 J., Rechtsanwältin, kein Landbesitz, verrichtet selbst keine Tätigkeiten im Orangenanbau, zeigt großes Interesse am Orangenanbau; Tochter von EV2, Muttersprache Valenzianisch

Gesprächsdauer (val.): ca. 33 Min. (V.mp3: 32:46)

Gesprächsdauer (kastil.): ca. 33 Min. (C.mp3: 32:43)

Wie bereits erwähnt wurden die Interviews auf Spanisch im Juni/Juli 1997, die auf Katalanisch im März 1998 geführt. Die Dauer der Gespräche in den beiden Sprachen ist jeweils ähnlich, obwohl die Detailstrukturen der Interviews zum Teil recht verschieden waren. Keiner der Probanden wich während eines der Interviews von der zugrunde gelegten Sprache ab. Code-Switching oder ähnliche Phänomene waren nicht zu verzeichnen. 
Die Einteilung in die Fachniveaugruppen richtet sich nach der Ausbildung und dem Tätigkeitsbereich der Probanden. Die beiden Repräsentantinnen bzw. Repräsentanten einer jeden Gruppe gehören allerdings jeweils unterschiedlichen sozialen Gruppen an. EV1 besitzt das höchste fachtheoretische Ausbildungsniveau unter allen Probanden. Demgegenüber ist EV2 vor allem durch die Praxis seiner Berufsausübung als Experte zu qualifizieren. SV1 hat den Status eines gelernten Facharbeiters, während SV2 zur Gruppe der ungelernten Hilfsarbeiter gehört. LV1 ist Verwaltungsangestellte auf niedrigem Bildungsniveau, während LV2 über eine akademische Fachausbildung verfügt und im Bereich der Rechtspflege tätig ist. Die beiden Laien haben durch ihre Familien (Väter) einen direkten Bezug zum Orangenanbau. Die Experten und SemiExperten besitzen selbst eigene Plantagen und sind in das Tätigkeitsfeld der citricultura auch beruflich eingebunden.

Meine Analysen der angegebenen Gespräche werden sich hauptsächlich auf die Diskursgestaltungsebene beziehen. Dazu ist es notwendig, längere Transkriptionen vorzulegen. Um den Umfang der Untersuchung jedoch im Rahmen zu halten, werde ich mich nur auf einen Teil der Interviewinhalte konzentrieren. Insbesondere unterlasse ich es, eine genauere Auswertung des fachsprachlichen Niveaus der einzelnen Probanden vorzunehmen. Entsprechende Beispielanalysen und Interpretationen sind in der Arbeit von Sánchez Münninghoff hinreichend dokumentiert. Ein fachsprachlicher Niveauunterschied je nach Gebrauch des Kastilischen oder Katalanischen ist nicht zu erwarten, was auch in den längeren Textauszügen, die ich in beiden Sprachen zitieren werde, deutlich zum Ausdruck kommt. Meine Ergebnisse aus der Analyse des fachsprachlichen Niveaus in den französischen Interviews, die ich in dieser Arbeit ausführlich behandelt habe, lassen sich prinzipiell auch auf die spanischen und katalanischen Interviews übertragen. Der Leser wird hier manches Phänomen wiederentdecken, das ich bei dem gebotenen Gesamtumfang einer solchen Arbeit nicht eigens explizieren kann.

\subsubsection{Das standardisierte Interview zum Thema 'Zitrusfruchtanbau in der Horta de València' und seine Auswertung}

Die Grundlage der fachbezogenen Gespräche bildete ein strukturiertes Interview, das die wesentlichen Aspekte des Fachs abdeckt. Es besteht zum einen aus Fragen, die den Interviewten zu der selbständigen Darstellung ganzer Themenbereiche auffordern, geht zum anderen aber auch auf spezielleres Wissen und Fachtermini ein. 
Die ersten vier Teile des Interviews erfragten (1) die biographischen Daten, (2) das persönliche Verhältnis zum Fach, (3) den Zugang zur valenzianischen Sprache und (4) eine grundsätzliche Beurteilung der Bedeutung des Zitrusfruchtanbaus für die Region. Teil (5) schließlich setzt sich ausführlich mit den fachspezifischen Themen der citricultura auseinander. Im Einzelnen werden folgende Schwerpunkte behandelt: ${ }^{244}$

I. Orangen- und Mandarinensorten (varietats de cítrics)

II. Baum und Frucht (constitució de l'arbre i del fruit)

III. Bodenbeschaffenheit (sòl / terra)

IV. Klima / Frost (clima / glaçades)

V. Veredelung (empelts / peus)

VI. Plantagenarbeit / Baumschnitt (tractament entre les collites / poda)

VII. Bewässerung (regadiu)

VIII. Krankheiten und Plagen (malalties i plagues)

IX. Ernte (collita)

X. Verkauf und Bearbeitung der Frucht (venda i confecció)

XI. Export und Handel (exportació i indústria)

Eine besondere Schwierigkeit bei der Vorbereitung des Fragebogens lag darin, dass es kaum schriftliche Quellen auf Katalanisch / Valenzianisch gibt, die das Fachvokabular der citricultura beinhalten oder sogar lexikographisch erfassen. Allerdings hatte ich das Glück, im Vorfeld meiner Reise in den Besitz einer kleinen einschlägigen Veröffentlichung zu gelangen, die von der Federació del Camp, der Oficina de Promoció $i$ Ús del Valencià (Generalitat Valenciana), der Confederació Sindical de Comissions Obreres del País Valencià und dem Ajuntament d'Alzira gemeinsam herausgegeben worden ist. Die Broschüre (36 S.), die wahrscheinlich Mitte der 90er Jahre erstellt wurde, trägt den Titel Vocabulari del Camp i els Cítrics und beinhaltet ein nach Themenbereichen zusammengestelltes Fachvokabular inklusive Definitionen. Die thematischen Gruppierungen, die Termini selbst und die definitorischen Erläuterungen waren mir eine große Hilfe bei der Vorbereitung des Fragebogens.

Die analytische Darlegung des fachterminologischen Wissens, das in den Interviews zum Ausdruck kommt, würde keine neuen und interessanten Ergebnisse liefern, sondern nur zeigen, dass ein katalanisches Grundvokabular fast allen mit der Materie mehr oder minder vertrauten Sprechern bekannt ist, jedoch darüber hinaus die vermeintlichen Fachtermini nur noch von älteren Probanden oder Sprachliebhabern gekannt werden, aber in der fachbezogenen Alltagskommunikation keine Rolle spielen. Wenn es im Verlauf eines Gesprächs zu der Darstellung fachspezifischer technischer Inhalte kommt, so ist heute die Verwendung einer kastilischen Terminologie (meist sogar der kasti-

\footnotetext{
${ }^{244}$ Im Anhang der Arbeit gebe ich die Fragestruktur des Interviews vollständig wieder.
} 
lischen Sprache selbst) eine Selbstverständlichkeit. Dieses Phänomen wird bei der strukturellen Nähe der Sprachen zueinander auch kaum als 'Interferenz' konstatiert oder bewertet.

Die terminologische Ausrichtung der Analyse des Sprachgebrauchs in Fachkontexten verfolgt einen linguistischen Aspekt, der nur zu einem sehr geringen Teil erkennen lässt, 'was ein Sprecher wirklich tut' (Coseriu), wenn er im Alltag über fachliche Gegenstände spricht, die ihn beruflich und / oder persönlich betreffen. Ich möchte daher die Auswertung des Interviews im Folgenden auf die Diskursebene lenken und zeigen, wie eng der Sprachgebrauch und der fachliche Gegenstand der Kommunikation auf allen unterscheidbaren Ebenen des Sprechens miteinander in Zusammenhang stehen und wie groß die regionale Bindung des Sprechens in diesem Fall ist. Die Interviews bieten für diese methodische Zielsetzung eine hervorragende Grundlage, da in ihnen in vergleichbarer Weise regional relevante Themenbereiche des Fachs von verschiedenen Probanden zum Teil auf Valenzianisch und Spanisch spontan versprachlicht werden. Als Beispiele für die Dokumentation und Analyse wähle ich fünf relevante Themengebiete des Fachs aus, die mir die verschiedenen Aspekte des sektorgebundenen Sprechens in der Region besonders deutlich zu machen scheinen. Es sind dies (1) die Orangensorten, (2) das Klima, (3) die Veredelung, (4) die Baumbeschneidung und (5) die Bewässerung. 


\subsection{Die Befragung zum Thema 'Zitrusfruchtanbau in der Horta de València'-Teiltranskription von zwei Gesprächen (kastilisch / ka- talanisch)}

Um einen angemessenen Eindruck von der sprachlichen Form zu vermitteln, in der die fachlichen Inhalte in den Interviews behandelt werden, werde ich im Folgenden das komplette Antwortverhalten eines der Probanden zu der getroffenen Themenauswahl zunächst auf Kastilisch, dann auf Katalanisch wiedergeben. Die Transkriptionen erfolgen auf der Grundlage der orthographischen Regelungen in den beiden Sprachen, wobei ich jedoch elliptische Formen und klare Abweichungen von der Norm in der Verschriftung deutlich mache. ${ }^{245}$ Die Grammatik- und Wortformen in den katalanischen Diskursen werde ich so wiedergeben, wie sie der gesprochenen Norm (und nicht der schriftsprachlichen) entsprechen.

Die Autoren des Curs de gramàtica normativa. Per a ús dels valencians stellen im zweiten Band (Grau mitjà) die particularitats fonètiques dialectals (S. 29-34) dar. Das entsprechende Kapitel ist ähnlich wie die den Romanisten gut bekannte Appendix Probi aufgebaut und verweist darauf, welche Anpassungen der Schriftsprache an die regionalen Aussprachegewohnheiten die Valenzianer aus normativer Sicht unterlassen sollten. Hier einige Beispiele:

$\begin{array}{lll}\text { eixugar } & \text { i no } & \text { aixugar } \\ \text { seixanta } & \text { i no } & \text { sixanta } \\ \text { obrir } & \text { i no } & \text { aubrir } \\ \text { trencada } & \text { i no } & \text { trencà } \\ \text { altre } & \text { i no } & \text { atre } \\ \text { aigua } & \text { i no } & \text { aiua (i menys encara auia) } \\ \text { caure } & \text { i no } & \text { càurer } \\ \text { canvi } & \text { i no } & \text { càmbit } \\ \text { capaci } & \text { i no } & \text { pacaci } \\ \text { darrere } & \text { i no } & \text { raere (< radere) }\end{array}$

${ }^{245}$ Hierfür gibt es keine Regeln. Ich habe daher das Prinzip angewendet, auffällige Varianzen, die die regionalen Aussprachegewohnheiten erkennen lassen, in die schriftliche Form hineinzunehmen. Nur auf diese Weise war es möglich, den Charakter der gesprochenen Texte nicht durch eine übertriebene normative Anpassung zu verfälschen. Hinsichtlich der Phonetik ist zu berücksichtigen, dass die typischen Erscheinungen des español regional in der Comunitat Valenciana und der katalanischen Dialekte des valencià apitxat bzw. des valencià septentrional in den Interviews dokumentiert sind, in der Transkription aber leider nicht zum Ausdruck kommen. Ich verweise als grundsätzliche Darstellungen zu den valenzianischen Dialekten des Katalanischen auf: Veny i Clar 1991, 257 f. und auf den Curs de gramàtica normativa. Per a ús dels valencians, I, 1980, $26 \mathrm{f}$. 
Die angegebenen Beispiele sind nur eine Auswahl der phonetischen Besonderheiten des Valenzianischen, die dieser dialektalen Form des Katalanischen einen besonderen Charakter verleihen. Für den Zweck meiner Darstellung habe ich die deutlichen Fälle solcher Normabweichungen graphisch repräsentiert, um den regionalen Sprachgebrauch auch als eine Form des català regional auszuweisen. Mit diesem Repräsentationsverfahren soll jedoch keine grundsätzliche Stellungnahme zu den Normalisierungsbestrebungen der katalanischen Sprachpflegeinstitutionen Valencias verbunden sein.

Ich gebe im Folgenden - jeweils mit einem kurzen Kommentar im Anschluss - die Antworten des Probanden Juan Bautista Hueso Planellés (' SV2) wieder. SV2 ist ein typischer Vertreter des citricultura-Milieus, obwohl seine berufliche Tätigkeit ca. ein Jahr vor den Interviews in den Bereich der horticultura gewechselt hat. Er bezeichnet sich selbst als peó del camp und implizit auch als podador. Mit dem Orangenanbau ist er seit seiner Kindheit verbunden, hat jedoch keine Form der agrartechnischen oder agrarwirtschaftlichen Ausbildung genossen. Seine Verwurzelung in der katalanischen Sprache ist tief, jedoch nicht ideologisch geprägt. Die regionale Bindung des Probanden stellt einen Sonderfall dar: SV2 ist in der Provinz Castelló aufgewachsen, wo er noch heute lebt und eigene Felder besitzt. Seine Arbeitsstätte ist das I.V.I.A. in Montcada. Es wird sich zeigen, dass der Proband in den Fachbezügen deutlich zwischen seinem Heimatgebiet und der Horta unterscheidet. Das inhaltliche Verständnis der nachfolgend wiedergegebenen Erläuterungen des Probanden wird dem Leser nach der Lektüre des Kapitels 3.1.4 leicht fallen: ${ }^{246}$

\section{¿Qué sabes de la citricultura Valenciana? (C.mp3, 4:11 - 4:32)}

Bueno, en Castellón abunda más, digamos la Clementina. [Sí.] Y aquí abunda más tipo Nável. [Sí.] Tipo naranja Nável, y allí en Castellón, pues abunda más la... tipo... tipo clementina... [Mh] ...tipo mandarina. [Sí.] Clementina, Clemenules y tal, ¿no?. Clemen... Clemenules, Oroval y... Clemenules, Oroval y alguna, poca de Satsuma.

\section{Variedades de naranjas, I (C.mp3, 6:45)}

¿Cuales son las variedades que aquí en Valencia son las más importantes en este momento? (7:00 - 7:31)

${ }^{246}$ Die Redeanteile der Interviewerin bzw. später des Interviewers (in den katalanischen Transkriptionen) gebe ich in eckigen Klammern wieder. 
Aquí en Valencia, creo que es la Nável. Ha existido siempre la Nável... [Sí.] ...como digamos la más importante, creo, ¿eh? [Mh] Y ahora pues poco a poco van... van saliendo otras variedades que se van introduciendo poco a poco. Yo creo que es la /unverständl./, creo. [Sí. Y... y la Nável cómo, cómo... no sé cuales hay en Nável: la Navelina, creo, ¿no? ] Sí. Navelina, Návelwa... Washington Nável, eh... la Nável Lane Late... [Mh] ...está introduciéndose ahora.

\section{Clima, V(C.mp3, 13:32)}

¿Qué consecuencias pueden tener heladas para los naranjos? (13:36 - 14:00)

Pues, hiela: hiela la flor, hiela las ramas y hiela la naranja y muere. Muere digamos la... la... parte de ramas y el fruto muere... [Sí.] ...y la flor puede morir también de frío. [¡Ah! Y la naranja, o sea, a dentro qué pasa, se seca o... o... o...] Se seca la piel... [Bueno, sí.] ....se seca la piel y dentro. [iAha! Y para el comercio entonces ya no...] Ya no... [...no vale.] ...no vale para comer. [Bueno. $\mathrm{Y}$ hasta cuantos grados bajo cero no se efectúan daño graves en, en los naranjos; o sea, no sé, uno, dos grados, tres grados, cinco grados... cuándo se... o sea, si hay una helada, ¿cuándo puede seguir adelante el árbol y la fruta?] Bueno no, no interesa demasiado el que baje por un grado bajo cero. [Aha] Pero también depende del tiempo que esté este grado bajo cero. [Ah, sí.] No es lo mismo un grado bajo cero... [Aha] ...por ejemplo una hora, que diez horas, por ejemplo. [Sí. Entonces depende de eso...] Depende de, de la temperatura y depende del tiempo que esté esa temperatura sobre el árbol.

¿Hay otros peligros climáticos para un naranjo? (14:41 - 14:49)

La piedra. [La piedra. ¿Cómo qué la piedra?] El gra... el granizo... [Sí.] ...el viento.

\section{Injertos, VI (C.mp3, 14:50)}

¿Qué es un portainjerto? (14:56 - 15:20)

Portainjerto es lo que lleva el... digamos que es el... el patrón... [Sí.] Un árbol que no es bueno de... un árbol que no es bu... no... es bueno de... b... que produce una naranja que no es buena de comida, ¿no? Esa naranja, pues eh... de esa semilla se saca del plantón. Se saca los plantones... [Sí.] ...de esa semilla que no es buena de comida y luego se injerta una var, de una variedad que es buena de comida. 
¿Hay otros nombres para un portainjerto? (15:24 - 15:27)

Pie. [El pie, también.] Pie. 'Peu' en valencià.

¿Para qué se efectúa un injerto? (15:38 - 15:54)

Pues como ese... como el pie no puede... como la naranja que produce el pie no se puede comer, no es comestible, se injerta una variedad buena de comida, dulce y tal sobre ese pie... [iAha!] ...se injerta. Y entonces ya producimos un árbol que la naranja se puede comer.

¿Cómo se llaman los patrones utilizados para los naranjos? (16:05 - 16:35)

Aquí el que más fama tiene es el Carrizo. [El Carrizo.] Eh... Citrange Troyer también hay. [Sí.] Citrange Troyer. Algunos ponen Cleopatra, mandarina Cleopatra. [Aha. Pero antes había otro, ¿no? o sea...] Antes, antes estaba el amargo. [iAh, el amargo!] O sea que el amargo es sensible a la tristeza y la gente ya no lo pone. [Sí.] Ya no lo planta. [Mh] Y pone esos: el Carrizo... y tal. Y alguno que hay más también: el Volkameriana y Macrifila, sí.

¿Qué tipos de injertos conoces? (16:46 - 17:34)

Conozco el de plancha. [Que es más, más grande, ) no?] Cuadrado, sí. [Sí.] escudo, el escudo, y hay otro por ahí que he visto alguna vez que es el de... el de púa. [¿El de púa?] Sí. [Y eso... no sé, no...] El de púa, pues se corta digamos el árbol así, se corta... [Sí.] ...un palmo... [Sí.] ...se corta un palmo y se pone unas púas... [iAah!] ...de... unas varitas así de... de unos tres centímetros... [Sí, sí...] ...o cuatro... [...sí.] ...se pone, se ata y luego se pone la bolsa. [ (Aaah, ja! Y después ahí...] Y después... [...de ahí crecen...] ...y de ahí cre, crece un... un árbol, sí, crecen... [¡Ah, eso no lo sabía, mh!] Sí. Bueno, pero eso no, no... está muy, muy poco extendido, ¿eh? [Ah, vale.] Eso a penas se usa. [Bueno, bueno.] Porque es muy complicao, complicado. [sí, o sea dura más, también es, es más...] Costoso. [..más costoso.] Sí.

\section{Poda, VII (C.mp3, 18:18)}

¿Qué sabes de la poda? (18:26 - 19:39)

La poda es para que... para que el árbol, pues produzca la naranja de más calidad. [Sí.] Para eliminar las ramas que no producen... para digamos, para airear 
el árbol para que los productos fitosanitarios pues entren mejor en el árbol; sino no entrarían. [Sí. Y, y cuantas veces...] Y renovar, y renovar la leña. O sea renovar, las ramas, renovarlas. [O sea cuando son viejas, cortas...] Exacto. [...o secas, ¡zac! se cortan y después crece por otro brote una nueva que...] Nueva, sí. [¡Aah!] Que será el futuro, digamos. [Sí. ¿Y una vez al año, dos veces o... o...?] generalmente una vez al año. [Una vez al año.] En pri, en primavera. [En primavera. O sea, pero ¿antes de la floración o después de la floración?] A veces no importa. [iAh, eso no importa! Yo pensaba lo... después de la floración que hay algunos problemas o algo.] Lo ideal sería el mes de Abril. [¡Aah!] Lo ideal sería, pero como... [Sí.] ...falta mano de obra... [Sí.] ...en ese tiempo. A veces se prolonga hasta el Junio, la poda. [Mh] Que es después de la floración. Ya ha florecido y tal. O sea que desde Marzo hasta Junio hay gente que poda... [Sí.] ...por falta de mano de obra. [O sea que, que, que... Pero, o sea no todos pueden podar. Es un, uno en fin lo tiene que, que aprender también.] Claro, claro.

¿Existen varias clases de poda? (19:54 -20:26)

Sí, sí. Poda de formación, poda de p.. de producción, la poda para reinjertar. [iAha!] Poda para reinjertar, o sea para... [ ¿Y reinjerto, eh... es otra vez un injerto?] O sea, un injerto equivale a otro injerto, exacto. [iAaah! Sí, sí.] Dentro de un injerto muy antiguo, o sea de un árbol injertado de hace muchos años... [Sí] ...pues se vuelve a reinjertar para cambiar de variedad. [Aha. ¿Y entonces se cortan todas las ramas?] Se corta... no, todas no. Se cortan las que no... las que le sobran. [Ah, vale. Y después se echa ahí...] Las que le sobran al árbol. [...en la rama principal...] En las ramas principales se ponen unos injertos... [Bueno.] ...de la variedad que quieres cambiar.

\section{Riego, IX (C.mp3, 23:24)}

¿Qué importancia tiene el riego en la citricultura? (23:29 - 23:44)

Fatal. Eeeh... el riego es importante porque mmm, el árbol claro se moriría de sed, si no se regase. [Sí.] Y a parte pues que la naranja se quedarí, se quedaría pequeña. [Mh] Y en fin, es necesario el riego, claro. [Sí.] Sí.

¿Qué tipos de riego conoce Vd.? (23:54 - 24:29)

Sí, ahora... bueno, está... antiguamente estaba... bueno, está aún, está aún por esta zona se utiliza más que nada el... el riego 'a manta'. [Mh] El riego 'a man- 
ta'. [Sí.] Y, y alguno en algunas zonas, de Betxí o por ahí, pues ya están poniendo 'goteo'. [Mh. ¿Y hace otra cosa? O sea...] Y a zonas muy grandes... [...a manta es abrir la, la sequia, eso...] Es... [...y echarle...] Sí... [...al campo.] ...sí es así. Y el goteo, pues es unos tubos que va el agua por allí... [Sí.] ...y va saliendo la gota, gota a gota, y... y la riega, riega así el árbol, sí. [Sí. ¿Y aquí se utiliza eh, el riego por aspersión o no se utiliza...?] Yo he visto...poco, poco, poco. Goteo, más que nada.

Kommentar: Die Antworten zu allen fünf Themen sind relativ knapp, aber in sich ausgeglichen. Die fachlichen Konzeptualisierungen konzentrieren sich selektiv auf einige wesentliche Grundcharakteristika. Der Satzbau ist einfach strukturiert. Im Gebrauch des Kastilischen zeigen sich Unsicherheiten (una variedad que es buena de comida). Einige Erklärungen beschränken sich auf die Angabe von Schlüsselwörtern (la piedra, el granizo, el viento), was für die Hemmung spricht, längere fachliche Erläuterungen auf Kastilisch zu geben. Die Antwort zur poda zeigt deutlich, dass die Aspekte des theoretischeren Fachwissens auf Kastilisch erlernt worden sind:

Para eliminar las ramas que no producen... para digamos, para airear el árbol para que los productos fitosanitarios pues entren mejor en el árbol; sino no entrarían. [Sí. Y, y cuantas veces...] Y renovar, y renovar la leña. O sea renovar, las ramas, renovarlas.

Teilweise endet der Versuch theoretischer Erklärungen jedoch auch in relativ banalen Äußerungen:

Fatal. Eeeh... el riego es importante porque mmm, el árbol claro se moriría de sed, si no se regase.

Die meisten fachlichen Darstellungen wirken wie auswendig gelernt und geben ein falsches Bild von dem soliden Praxiswissen des Probanden. Eine gewisse Ausnahme machen die Darstellungen zum injerto de púa, einer seltenen Pfropfentechnik mit Hilfe von Stäbchen. Dabei ist es m.E. typisch, dass ein Vorgang beschrieben wird, der regional gerade nicht vertraut ist, da das Kastilische für SV2 letztlich die 'Sprache der Distanz' ist. Ebenfalls typisch ist, dass der Proband am Ende dieses Diskursteils seine valenzianische Aussprache des Kastilischen selbst 'zensiert': complicao, complicado.

Im Vergleich gebe ich nun die entsprechenden Teile des valenzianischen Interviews mit SV2 wieder: 


\section{Varietats de cítrics, I (V1.mp3, 9:07)}

\section{Grups de taronges que es poden distingir (9:07 - 11:05)}

Algunes, algunes. [¿Quins són els grups principals?] Bueno, EN LA MEUA ZONA és és més que tot la Clementina, Clemenules, EN EL MEU POBLE. [Sí.] N'hi ha també algo de tomatera i prou també n'hi ha un montó també Clementina fina, EN EL MEU POBLE. I EN BORRIANA MATEIXA que està a $7 \mathrm{~km}$ n'hi ha molta Nàvel... i n'hi ha algo més, o sea i alguna... i n'hi ha algo de Clemenules també... també. I... algo també de Clementina fina. [Mm... mm.] Pero EN EL MEU POBLE és, és tot, casi tot, el 90\%, el 99\% és... [La Clemenules.] ...Clementina. [Clementina, sí. I eh... ¿tu fas la diferència entre el grup Nàvel i el grup de Blanques i el grup de la Sang, etcètera ? ¿Fas la diferència o...?] No FAIG DIFERÈNCIA PERQUĖ AIXÒ NO N'HI HA. De Blanques n'hi ha molt poqueta, o sea... [València Late o Berna, SalAlustiana...] Això sí, això sí, això sí. [¿Fan part del grup de les Blanques?] Sí, sí. SE DIU... és un salAlustià, és un navelí, és un nàvel, és un... és un comú. Se sol, LA GENT SOL PARLAR EIXINA. [¡Ah ja! El comú vol dir...] El comú és una Blanca. [Una Blanca, ah.] Sí. [I la Berna, ¿què és?] La Berna és possible que siga una Blanca també. [Però és més aviat rar.] ¿Eh? [És, és rar...] Rar... [...com a varietat.] ...sí. N'hi ha, n’hi ha molt poqueta, actualment. Antes n'hi hava, però ara n'hi ha molt poqueta de Berna. [Sí. ¿Tu coneixes la paraula 'naronja', també?] ¿Com? [La naronja.] ¿Naronja? [Sí. No, no coneixes.] Naronja no. [L'he trobat en el diccionari per... per dir una taronja amarga, em sembla.] No, això... això... [a la taronja] ...a l'amarga en diem 'taronja borda'. [Borda, sí.]

\section{Varietats a la Comunitat Valenciana (11:06 - 11:42)}

[Frage wird z.T. schon in I.1 beantwortet]

[Em pots dir... ah bueno, ja m'has dit quines són les més conreades a la Comunitat. ¿Per resumir les més conreades...?] Ah, bueno. EN EL MEU, EN LA MEU, EN CASTEllo abunda més la Clementina. [La Clementina...] Tipo Clementina. [Sí, sí...] I ACÍ abunda més tipo Nàvel... [Sí.] ...tipo navelina, Nàvel... [Sí.] O sea, taronges... [Molt bé.] ...ACI taronges lo que diem 'naranja' en... en castellà, hi ha pues eh... 'mandarines'... [Sí, clar...] ...en castellà. 'Mandarines' i 'naranjas'.

\section{Diferències entre una Nàvel Late i una Berna (11:43-12:28 )}

Diferències de... [De... de l'aspecte, de l'interior, com...] Sí. La Berna és més agra, té la pell més forta... [Sí.] ...molt forta, és algo més tardana, ve més tard... 
[Sí.] ... que la Nàvel... [Sí.] Eh... en els anys quaranta, quan se va acabar la guerra, n'hi hava molta de Berna... [Sí.] ...se pagava caríssima... molt cara. [Sí.] Però com eren de més, de molt, de més bon sabor la Nàvel... [Sí.] ...vas començar a augmentar la Nàvel... la Nàvel la Nàvel. I els Bernos van desaparèixer. [Ah, és això.] Pràcticament ja no n'hi, no n'hi han. Se han empeltat tots o bé de Nàvel o bé de... de algun tipo de Clementina. [Sí.] Se han empeltat.

\section{Varietats de la mandarina}

[Frage nicht gestellt]

\section{Clima, IV (V1.mp3, 20:20)}

\section{Fred (20:20 - 20:58)}

EN EN LA MEUA ZONA, EN EL MEU POBLe, fa un montó de mal el fred. Perquè és una... és un clima pel taronger algo gelat. I de quan en quan gela i la taronja la... la... la congela... [Sí.] ...ja no és bona, ja. Ixa taronja ...fa dany el fred... [¿Fa dany al fruit?] Al frut. [Al frut.] Al frut. I... i algunes voltes, cada set o vuit anys, a la floració. [Sí. Mm...mm.] I si la gelà és molt forta la llenya també, pues li afecta a $1 \ldots$ a la fulla i a la llenya de l'arbre.

\section{2. 'Glaçada negra'o 'rosada negra' (21:00 - 22:11)}

¿Aranya? [... (de la 'gelada negra'!] Ah, ¡sí! ¿'Rosà negra’? Sí. [) Què vol dir?] Bueno ALLÀ diem 'rosà negra'... [Rosa negra] ...'rosà negra' [Ah, de la rosa negra...] No, 'rosà̀'; 'rosà negra'. ¡No rosa, eh! [Rosà negra.] Rosà. Rosa és una flor. [Ja, sí clar.] Es és, ALLÀ diem 'rosà negra' o 'rosà blanca'. [Mm... ¿i què vol dir?] La 'rosà negra' és quan en hivern... fa molt de fred... [Mm] ... i ..eh... la rosà a pen... a penes se veu. $\mathrm{O}$ sea, veus el arbre i dius 'este arbre té res', però te arrimes més a prop i veus que efectivament està fent-li molt de mal el gel. Es un gel que no se veu, casi transparent, que està apegat el gel a la fulla i no lo veus casi. Se diu 'rosà negra'. Perquè no es veu, no se veu casi. I la 'rosà blanca' fa menos mal a la fulla i a l'arbre, però se veu de més lluny. Es com si fora més neu. [Ah, ja. Ja entenc.] Entonces la 'rosà negra' és molt més mala que la 'rosà blanca'. Fa més mal. 
3. Mesures preventives contra els efectes de les glaçades (22:13 - 22:24)

No. [No.] Molt poquet. Algú fica algun ventilaor, però molt poquets ventilaors n'he vist jo, EN EL MEU POBLE.

\section{Altres perills climàtics $(22: 26-23: 13)$}

La pedra, eh... la pedra, eh... el el aire, també... pedra i eh... l'auia, sobretot l'auia, l'auia també. Com, quan hi ha, quan plou ix 'el pixat'. La taronja li diuen 'el pixat'. [Sí.] També la la podrix, també. [També. ¿I el vent?] ¿El vent? El vent DE LA MEUA ZONA poc perquè com és Clementina... [Sí.] ...la Clementina suporta millor el vent que la Nàvel. [¡A $\mathrm{A}$ ! Ja entenc.] ACI tenen... ACI tenen més problemes... ACI EN VALENCIA. Perquè com tot és Nàvel, la Nàvel el vent enseguida, ¡bum!, a terra. [Ah, aquesta és la fruita que cau.] Cauen a terra.

\section{Empelts, V(V1.mp3, 23:15)}

\section{Importància per al cultiu de citrics a la Comunitat Valenciana}

[Frage nicht gestellt]

\section{Altres mots en valencià $(23: 15-24: 00)$}

Bueno, diem 'empelt', 'empeltar'... [Sí. ) Eixart?] ¿Com? [Eixart. ¿Coneixes?] ¿Eixat? [Eixart. Ho he trobat al diccionari.] No, açò no, no ho he sentit mai en la vida. [Es pot parlar de 'portaempelts' com en castellà...] ¡Ah! [¿...'portainjerto'?] ) 'Portaempelts'? Eh ho sent molt poquet això. [¿O com es diu en valencià?... ¿Com es diuen?] Allí diem 'peu'. [Peu.] Sobretot 'peu'. Un arbre xicotet és un peu i damunt del peu li fiquem una... un empelt.

\section{Tipus de peu base (24:02 - 24:49)}

¿Peus? Pues eh... ah... an... antes estava el amarg... [Sí.] ...peu amarg. [Sí.] I actualment pues abunda molt el Citrange Troyer, Citrange Carrizo... [Sí.] ...i alguns més que volen traure ací en el guia. [Cleòpatra, ¿coneixes?] Cleopatra, però n'hi ha molt poquet de Cleopatra. [¿Volcameriana?] Volcameriana, Citrumelo, Macrofila... eh... [¿I per què es prefereixen ara aquestes varietats de 'peu'?] pues perquè la gent creu que són millors. Que el amarg, perquè el amarg agarra la 'tristesa'. I estos pues diu no la agarren... no la agarren la 'tri- 
stesa'. [No l'agarren. Són resistents...] Tolerants. [¿...o tolerants?] Tolerants. [Tolerants] Sí.

\section{4. 'Taronger bort' / 'taronger ver' (24:51 - 25:43)}

[Per fer oposició al 'taronger bort' ¿hi ha un altre mot?] ¡Ah! I...[¿Hi ha un altre mot?] Bueno el bort, bueno 'bort', 'bort' són tots els peus. 'Bort'. Lo que passa que el amarg, el bort amarg, agarra la Tristesa. [Sí.] I els borts, que ALLÀ DIEM 'borts', al Citrange Troyer també, al Carriz... això també són borts. [Sí.] Lo que passa que són borts tolerants. [¿I coneixes el terme de 'taronger ver'?] Ver [... ver.] Ver(a). El taronger ver és un... el taronger ver és un bort d'ixos, un bort que ha sigut empeltat. [Ah... que ha sigut empeltat.] Ja és ver(a). [Ah, ja entenc.] Vol dir 'bo'. [Molt bé.] Això és una tonteria d'aquest...jbo i apa!

\section{Tractament del taronger / poda, VI (V1.mp3, 25:44)}

\section{Tractament del taronger entre collites (25:44 - 27:23)}

¿Trataments? Pues el poll, el pulgó o sea, NATROS ALLÀ LI DIEM 'poll', ACí DIUEN 'un pulgó' pa matar ese bichet, pa matar-lo. Después allà fem també pel 'cuaje ${ }^{247}$... quan fem el 'cuaje', QUE LI DIM el 'cuaje', ja fiquem pel poll, pa matar-lo. I a la segon del 'cuaje'-hi ha una, una del 'cuaje' i una segon-a la segon del 'cuaje' ja són quinze dies después... [Sí.] ...fiquem pel 'cuaje' nutrients i tot això... [Sí.] ...i a part fiquem pa l'aranya, producte pa l'aranya, pa matar l'aranya... [Sí.] ...pa previndre. [Sí.] I eh, después, més avant, ve la mosca blanca... [Ah..] ...atra volta. I... ah... la mosca blanca. [Sí.] Allà... juliol o això la mosca blanca. Juny, juliol, juliol sobretot la mosca blanca. [Sí.] ¡He!... después de la mosca blanca te ve ja, pues a lo millor ja, alguna volta aranya també, sol repetir l'aranya, pues pa l'aranya. I ja al setembre que fem la última polvorizà, en setembre. Fem la última polvorizà... que ja... fiquem productes pa l'aranya i pa les... i productes pels insectes de serpetes i cotxinilles... pa matar la l'aranya i les cotxinilles que poguen digam marcar la pell de la... [Sí.] ...de la taronja. [Sí.] Sí. Això és en setembre.

2. ¿Quan i com s'efectua la poda? (27:24 - 28:56)

La poda sol fer-se en març... [Març.] ...març i abril. [Març i abril.] Març, abril, maig també. [ ¿ I és una poda de fructificació, de... de que prepara la fructifica-

${ }^{247}$ cuaje ist ein Kastilianismus für kat. quall $(<$ quallar) und bezeichnet fachsprachlich den Übergang von der Blüte zur Frucht. 
ció o?] Sí, és una poda pa... pa que la taronja siga gorda... [Sí.] ...pa eliminar les rames que no valen... [¿Coneixes la tècnica una mica de...de la poda?] Sí, en en la pràctica sí. [Com es fa, com es pot...] Pues... [i... explicar en dues frases?] Guant, és un guant de pell ahí, un guant... [Sí.] ... un serrutx atra mà... [Sí.] ...ivas llevant, vas llevant rames que creus tu que tenen que anar fora. [Sí.] Els xupons, o sea els... els mamons ${ }^{248} \ldots$ [Sí.] ...els mamons, les branques. [Sí.] Que llavors n'hi ha un arbre que té una branca cur... que no produix casi, ixa brancota, se arranca, se lleva. Si n'hi ha alguna rama que toca terra, se lleva també. [Està bé.] Evitar que el el arbre se vaja molt alt. [Sí.] Perquè el arbre té que ser ample. [Clar.] Més ample que alt. [Mm, mm, mm... és la tècnica, sí.] Sí. Per damunt damunt, pues és això. I EN FI, ES DIFICIL D'EXPLICAR PERQUE JO... JO PORTE VINT-I-CINC JA EN LA PODA. [Ah, ho coneixes...] /unverständl./ [...molt bé, sí.] Jo vaig ja començar ja als catorze anys o quinze en la poda, sí. [Mm... és una especialització per ací, ¿no?] Sí. [...que la gent...] No ACI, ACI NO, sinó en... [Ja.] LA GASTE PA LES MEUES FINQUES... [Ja, clar.] ...EN NULES.

\section{Eines per a la poda}

[Frage in VI.2 schon beantwortet]

\section{Regadiu, VII (V1.mp3, 29:15)}

\section{Importància per al cultiu de citrics a la Comunitat Valenciana}

[Frage nicht gestellt]

\section{Modalitats de rec (29:15 - 29:58)}

Sí, bueno, EN EL MEU POBLE se rega casi tot a pla. [A pla.] Tot a pla, sí. A manta, a manta que diem, també. Però ALLÀ DIEM 'a pla', 'regar a pla'. I eh... n'hi ha algo de goteo també. De goteo també n'hi ha alguna finca, molt poca. Però n'hi ha alguna...[Sí.] ...que se rega amb el sistema de goteo. Amb els tobets $i$ tal... [¿I és més eficaç que el sistema tradicional o...?] Jo pen... pense que sí. Pense que sí. [¿O resulta més car... la gent l'adopten o...?] No, la gent no l'adopta, alguns, alguns, pero poquets.

${ }^{248}$ mamó ist ein valenzianischer Ausdruck für kastil. chupón, das einen unproduktiven, saftziehenden Ast bezeichnet. 


\section{Funcionament del sistema de sèquies en la zona (29:59 - 31:27)}

[¿I el antic sistema de les sèquies en...encara funciona bé?] Es que allí, bueno les sèquies, EN EL MEU POBLE són sèquies, casi totes, són sèquies de obra, fetes de hormigó. I reguen de motor. O sea la majoria de finques se reguen de motor. Llevant de algunes poquetes finques... [Sí.] ...o algunes poques fanecaes que se reguen de dret de riu, de regadiu, de riu. [Sí.] Però és molt, molt poc. [Molt poc.] Molt poquet. [I eh... com es pot descriure... hi ha una sèquia...] Sí. [...i després la ramificació...] Sí. [Hi ha paraules per...per a...] Sí, o sea, està el motor. Motor pues trau l'auia de... de cent metros o de cinquanta metros. El motor ese, pues trau l'auia, la alça amunt... [Sí.] ...i per un reguer, per un reguer la distribuix. Ixe reguer pues té molts braços... [Sí .] ...que va re... redistribuint ixa auia per els horts. Después n'hi ha un encarregat, li diem el 'regaor'. Ixe regaor pues alça les portilles de la boquera, rega esta finca, torna a baixar la... la boquera a l'atra finca... [Sí.] ...torna a pujar la boquera... [Sí.] ...pa que entra l'auia. I eixina pues va regant les finques que li han ordenat. [iAh! està bé, hm.] ¿Eh?! I en el 'rec de riu', en el 'rec de riu' pues, casi tot en el meu poble, va també en reguers de hormigó també, casi tot. Es pot dir que casi tot, el 'rec de riu' també va tot per hormigó. Pa que no se perga auia.

\section{Funció del braçal (31:28 - 32:08)}

¿Braçal? Braçal ven a ser un...un... un reguer molt ample. Un reguer que.. [La paraula nor...] ...que porta molta auia. [La paraula més normal és braç, un braç, un...] Es que això ho... això ah...HO TINC JO POC GASTAT. No, eh, ho... dic poques vegades, jo això. AIXO A ON MES SE GASTARA ES EN... EN BORRIANA. Sinó pues allí fíca 'brazao', 'brazao número ocho', 'brazao número siete'... . [Ah... ja, ja, ja entenc...molt bé.] EN BORRIANA SOL. EN EL MEU POBLE 'brazao', 'braçal', 'braçal' NO SE GASTA. DIEM 'reguera, o sèquia o reguera'. [Reguera.] Reguera o sèquia... reguera.

Kommentar: Es fällt sofort auf, dass das Interview durch den Gebrauch des Valenzianischen einen völlig anderen Charakter bekommt. Die Auskunftsfreudigkeit des Probanden ist wesentlich größer, er spricht schneller und drückt sich differenzierter aus. Die typischen Merkmale der gesprochenen Sprache bleiben für die Sprechweise bestimmend. Sie beruhen jedoch in diesem Fall auf dem alltäglichen vertrauten Umgang mit dem Valenzianischen, insbesondere auch in den Fachkontexten, um die es hier geht. SV2 ist es nicht gewohnt, theoretische Erklärungen (auf Valenzianisch) zu seinem Fachgebiet zu geben. Aber er kompensiert diesen Mangel - der de facto im Berufsalltag gar keiner 
ist - durch eine Fülle von Hinweisen auf vertraute Details. Dabei reagiert SV2 auf die Befragungssituation des Interviews, indem er bereit ist, viele Informationen zu geben (im Gegensatz zum kastilischen Interview). Diese Informationen sind sowohl sachbezogen (unter Einbeziehung der regionalen Normen des Sachbereichs) als auch immer wieder sprachbezogen. Darüber hinaus kommt SV2 kontinuierlich auf den mikroregionalen Vergleich zwischen der Anbauregion Nules (in der Provinz Castelló) und der Horta zurück. Vermutlich hängt dieses Faktum damit zusammen, dass der Proband das Sprechen über die citricultura auf Valenzianisch in besonderer Weise mit seinem Heimatort verbindet (zumal er sich im I.V.I.A. der horticultura widmet). Die (mikro-)regionale Referenz des fachkontextuellen Sprechens ist somit in extremer Weise gegeben.

Meine Frage nach den verschiedenen Orangensorten wird von SV2 nicht (wie von anderen Probanden) durch die Nennung vieler verschiedener Arten beantwortet. Statt dessen konzentriert sich die Erklärung auf die Gegenüberstellung lokaler Anbau-Realitäten. Interessant ist in diesem Zusammenhang der Umgang mit der Frage nach der Differenzierung der wichtigsten Orangengruppen: „No faig diferència perquè això no n'hi ha. " Terminologien haben für den Probanden nur einen praktischen instrumentellen Charakter und lassen sich dadurch wesentlich reduzieren. Allerdings geht SV2 auf meine Frage freundlich ein und erklärt 'wie die Leute sagen'. Dieses Erklärungsmuster prägt sich zu Anfang ein und taucht im Laufe des Interviews mehrfach auf, so auch bei der Frage nach den tractaments:

¿Trataments? Pues el poll, el pulgó o sea, natros allà li diem 'poll', ací diuen 'un pulgó' pa matar ese bichet, pa matar-lo. Después allà fem també pel 'cuaje'... quan fem el 'cuaje', que li dim el 'cuaje', ja fiquem pel poll, pa matar-lo. I a la segon del 'cuaje'-hi ha una, una del 'cuaje' i una segon-a la segon del 'cuaje' ja són quinze dies después... [Sí.] ...fiquem pel 'cuaje' nutrients i tot això... [Sí.] ...i a part fiquem pa l'aranya, producte pa l'aranya, pa matar l'aranya... [Sí.] ...pa previndre.

Das Zitat zeigt sehr schön die fachsprachliche Erklärungsstruktur des Probanden: Es ist wichtig, das richtige Vokabular zu kennen, um 'mitreden' zu können, und 'mitreden können' bedeutet, in den Fachkontext eingebunden zu sein. Diese Logik fachkontextuellen Sprechens kann nur aus einem Interview herausgelesen werden, das - wie im vorliegenden Fall - nicht metasprachlich ausgerichtet ist, da ansonsten die direkt sachbezogene Diskursebene verdeckt wird. Sie erscheint mir aber für das Verständnis des Untersuchungsgegenstands sehr wesentlich. Der fachkontextuelle Sprachgebrauch in actu ist losgelöst von normativen Empfindungen oder Wertungen. Auf engstem Raum werden Kastilianisierungen (trataments [statt: tractaments], bichet [mit katal. Diminutiv], cuaje [statt: quall]) und typische Ausprägungen des regionalen Katalanisch (natros, que li dim, poll) mit Sprechweisen des Substandards (Be- 
tonung des unbetonten Personalpronomens, i a part fiquem pa l'aranya, etc.) verbunden. Erst dieses 'Konglomerat' sprachlicher Freiheit schafft die Realität eines 'endogenen Standards', der ein heimisches Sprechen (über vertraute Gegenstände) ist und in der nicht-regionalen Sprache erst in einem langsamen Prozess erreicht werden kann. Das valenzianische Sprachgebiet ist - zumindest in fachkontextuellen Kommunikationssituationen regionaler Prägung - weit davon entfernt, der kastilischen Sprache diese Funktionalität zukommen zu lassen. Sie wird daher von den meisten valenzianischen citricultors auch nur in offiziellen Situationen benutzt.

Nachdem nun die unterschiedliche Funktionalität von Kastilisch und Valenzianisch im Sachbereich exemplarisch deutlich gemacht werden konnte, werde ich im folgenden Kapitel einige Hinweise zu der Sprachbewusstseinsebene meiner Probanden und zu der konkreten Verwendung des Valenzianischen geben. Auf dieser Grundlage sollen dann die Diskurse in beiden Sprachen jeweils zu den einzelnen Themengebieten kommentiert werden. Dabei werden sich Rückbezüge auf die in diesem Kapitel wiedergegebenen Texte ergeben. 


\subsection{Hinweise zur Ebene des Sprachbewusstseins und zum Gebrauchs- umfang des Valenzianischen}

Der Teil 3 des strukturierten Interviews bezieht sich auf den Gebrauch der katalanischen Sprache im Untersuchungsgebiet und speziell im Sachbereich der citricultura. Die Antworten der Probanden sind angesichts der diglossischen Verhältnisse und der schon beschriebenen Sprachkonfliktsituation von großer Aussagekraft und sollen als Vorbereitung auf die fachsprachlichen Analysen in diesem Kapitel kommentiert werden. Ich zitiere zunächst wieder die Äußerungen des Probanden SV2 (V1.mp3) in voller Länge:

\section{Valencià, llengua materna (02.56)}

SI. [eh, ¿pots parlar o parles valencià amb facilitat en totes les ocasions?] Sí.

\section{¿Parla més el valencià que el castellà? El perquè (03.06)}

M'és, M'ES MES FACIL PARLAR EN VALENCIA que en castellà. [Sí] Castellà m'és, m'és un poc $\mathrm{m}$, el parle igual, ¿no?, parle igual, però me costa algo més. [Prefereixes el valencià perquè és la teva llengua.] Sí, m’és més fàcil.

\section{Caracterització de la parla que utilitza (03.27)}

M'agrada més el castellà. [¡Hmmh!] EL CASTELLÀ M’AGRADA MÉS. El veig, el valencià el veig molt, un acento que no m'agrada. Té una..., no m'agrada el valencià. Osea no m'agrada tant com el castellà. M'agrada més el... no sé perquè el castellà m'agrada més. A pesar d'això, a pesar d'això preferixc parlar el, el valencià. $[\mathrm{Hm}, \mathrm{hm}, \mathrm{hh}]$ Però el timbre ixe, el timbre del castellà m'agrada més. [iÉs veritat!] M'AGRADA MÉS EL TIMBRE IXE DEL CASTELLÀ. El veig una miqueta igual, una cosa eixina com el francès, una cosa que, que, el francès també té una, una cosa eixina que... [Ah ja, ja entenc.] ...que, que, que farta , ¿no? (lacht) el acento personalment el veig igual cosa que...

[Hm. ¿Quan parles amb una persona en valencià eh, i eh... i aquesta persona és d'una altra comarca, pots localitzar-la?] Sí. [Sí. ¿I saps les diferències entre...?] Sí, sí. Diferències, bé. [¿Són diferències de pronunciació o de, de vocabulari o...?] Vocabulari i, i acento... [Ja] ...i pronunciació. 
¿Són considerables les diferències entre valencià i català? (04.49)

No. [No, no n'hi ha...] No N'HI HA MOLTA... [..cap problema de comprensió...] ...Catorze o quinze paraules, catorze-quinze paraules hi ha hagut i set o buit... [Sí] ...quatre o cinc frases... [Sí, sí] ...fetes i avant. Sol és, sol és això. [¿A Barcelona tu parlaries sempre en valencià també?] Sí, igual.

\section{Ús del valencià tant en la feina com en la família i entre amics (05.16)}

¿Me canvia la, la faena? [Si... si et serveix la llengua a la feina tant com entre amics.] No te comprenc. [Utilitzes el, el valencià aquí a la feina al I.V.I.A. tan freqüentment com...] Sí, sí... [...entre amics?] ....sí, sí. ACI casi tots, CASI TOTS PARLEN VALENCIA. [Hm] Casi tots.

\section{Ús del valencià entre els citricultors (05.45)}

Sí. [Donat el cas que t'adrecis a un, a un altre emplegat del I.V.I.A., etc., ¿ho faries en, en valencià?] DINS DE, DINS DEL PAIS VALENCIA SI. [I amb els conreadors, llauradors en els camps sempre no?] SI. CASI TOTS SON VALENCIANS.

\section{Existència en valencià d'una terminologia tècnica del conreu de cítrics}

Eh, LES CASES COMERCIALS van, VAN APROXIMANT-SE A ALGUNES PARAULES I ALGUNES FRASES EN... en, EN VALENCIA. [Sí] S'hi van, van arrimant-se... $[\mathrm{Hmh}, \mathrm{hmh}]$....al valencià.

\section{Literatura tècnica en valencià per a la formació professional (06.32)}

La literatura pa, la literatura tècnica m'agrada més en castellà. [Hm] Perquè com en l'escola [¿Hi ha esforços de fer...] ...mos ensenyaven castellà... [...traduccions ara o...?] ¿Com? [¿Hi ha, hi ha un esforç de fer traduccions ara?] No. No, però AL LLEGIR LLIXC AMB MÉS FACILITAT EN CASTELLÀ. [Ah] Perquè com tota la vida els mestres en l'escola ensenyaven castellà... [Clar] ...i els llibres tots venen, o casi tots venien en castellà... [Ja, ja...] ...en castellà. $[\ldots . . j a, j a$. PERQUE ESTAVA PROHIBIT. ESTAVA PROHIBIT EL VALENCIA EN L'ESCOLA, m'és més fàcil eh, llegir en castellà.

SV2 hat ein ambivalentes Verhältnis zum Katalanischen. Es ist für ihn eine Gebrauchssprache, genauer: seine Familien-, Alltags- und Berufssprache, von 
der er weiß, dass er sie am besten beherrscht und am meisten verwendet. Seine Bewunderung gilt hingegen dem Kastilischen, das schöner klinge, ihm aber nicht so vertraut sei. Dies gilt mit Ausnahme des schriftsprachlichen Bereichs, da er in der Schule auf Kastilisch ausgebildet worden ist. In der Bewertung des Diskurses fällt die Leidenschaftslosigkeit auf, mit der SV2 der Sprachenfrage sowohl in Bezug auf das Kastilische als auch in Bezug auf das Katalanische begegnet. Es wird der Eindruck einer Normalität des Sprachgebrauchs erweckt. Berührungsängste zum Norm-Katalanischen sind nicht vorhanden, und das Kastilische wird zwar hoch bewertet, aber nicht um jeden Preis verwendet. Wo Valenzianer sind, spricht man Valenzianisch, und selbst der kommerzielle Bereich beginnt, sich danach zu richten.

Offensichtlich ist das zweisprachige Leben in der Comunitat Valenciana nicht ganz so konfliktfrei, wie es in der Darstellung des Probanden erscheint. Aus soziolinguistischer Sicht muss aber die Frage gestellt werden, ob es gerechtfertigt ist, die Äußerung ,m'agrada més el castellà “ bereits als Indikator eines Sprachkonflikts zu werten, oder ob es nicht vielleicht innerhalb gewisser sozialer Gruppen doch zu einer Form der sprachlichen Normalität kommt. Es wäre dies dann eine Form der 'Alltags-Normalität', in der wie selbstverständlich akzeptiert wird, dass die Schriftsprache (also auch die Presse), Ausbildung, Wissenschaft und Technik, offizielle Kommunikationssituationen (in hohem Maße) und jede Form der internationalen Beziehungspflege (inklusive Tourismus) Domänen des kastilischen Sprachgebrauchs sind und bleiben. Eine Normalität also, die davon ausgeht, dass das private und berufliche Leben sich $\mathrm{zu}$ einem überwiegenden Teil außerhalb dieser Bereiche vollzieht, und dann durch und durch Katalanisch gestaltet wird. Wir haben es hier mit einem Blickwinkel sozialer Existenz zu tun, der für den Agrarsektor typisch zu sein scheint. Er lässt sich aber nur bestätigen, wenn nachgewiesen werden kann, dass die berufliche Domäne und der mit ihr verbundene Sachbereich auch de facto durch den Gebrauch der Regionalsprache geprägt sind. Einige Stellungnahmen der übrigen Probanden sollen zeigen, wo die Grenzen der beschriebenen Normalität zu finden sind und wo die Konflikte beginnen.

Auch für EV1 (44 J.) ist das Valenzianische zunächst einmal eine Gebrauchssprache, die llengua quotidiana. Das Dorf, in dem er wohnt, $4 \mathrm{~km}$ von Valencia Stadt entfernt, ist 'català-parlant'. Doch geht EV1 sogleich auf den 'physischen Druck' ein, der von der Nähe der kastilisch-sprachigen Hauptstadt ausgeht und verweist auf die kastilische Ausbildungssituation, die er dort in seiner Jugend erfahren habe. Die Kenntnisse des Valenzianischen seien daher theoretisch nicht fundiert:

Entonces la base també, la problemàtica que ha dut això és que tota la meua generació i generacions anteriors no tenen una base teòrica. Jo ara estic fent un curs de va- 
lencià per, per anar assentant la teòrica, de... dominar la ortografia... [] ...dominar, donar-li una base per a poder escriure i per a poder parlar més científicament, ¿no?

EV1 erklärt, dass er versuche, seine privaten Notizen zu biologischen Anbauplänen auf Valenzianisch zu schreiben, aber immer wieder auf orthographische Unsicherheiten stoße. Sein Diskurs führt im Anschluss noch weiter zu der Darstellung innerer Sprachkonflikte, die aus seiner ausschließlich kastilischsprachigen Ausbildung resultieren:

Jo parle valencià perquè naturalment m'ix el valencià. És la, és la llengua... [Sí, sí.] ...natural. Jo tinc més recursos lingüístics en castellà. [...]

Els meus sentiments jo els expresse molt fàcil en castellà. [...] En valencià no tinc paraules tan aproximades. Tant que, que, que perfilen tant els meus sentiments. Entonces jo la poesia, les cartes als amics, tot és en, en castellà.

Das intellektuelle und öffentliche Leben ist hinsichtlich des Sprachgebrauchs stark konfliktbeladen. Dies steht in einem schroffen Gegensatz zu den Erfahrungen im landwirtschaftlichen Bereich. Auf meine Frage, ob es normal sei, über die Angelegenheiten der citricultura auf Valenzianisch zu sprechen, antwortet EV1:

Pues lo, lo, lo, lo raro és lo atre. Este matí jo he estat amb un llauraor, que hem estat en la seua finca, mirant-li unes vestrilleres. I el home s'ha dirigit a nosaltres en, en, en valencià. [Sí] I ha parlat de, de, totes les sues problemes del camp en valencià. [Sí] Supose que si l'haverem dit en castellà, la, l'haverem deixat... [] ....sí, fet pols. Perquè sa..., i al damunt l'haguerem fet mal a ell. Perquè a lo millor l'haguerem d..., l'haguerem ficat damunt de la taula que ell no sap, no domina el castellà, ¿no? I entonces és el problema dels majors ací. Ma mare no parla castellà. Parla castellà molt mal, fatal. No sap expressar-se en castellà.

Die beschriebenen Kontraste sind für den einzelnen Valenzianer nicht immer leicht in eine Lebenswelt zu integrieren. Sie treten besonders für die jüngere Generation mit einem gehobenen Ausbildungsniveau zu Tage. Demgegenüber verharren die älteren llauradors in einer Wahrnehmungswelt, die fast zu hundert Prozent Valenzianisch ist. Auf die Frage, warum er das Valenzianische dem Kastilischen vorziehe, antwortet EV2 (63 J.):

Pues perquè, si vol que li digui la veritat, com som valencians-valencians, mos agrada molt parlar el valencià i, i la zona que jo me belluge, ¿eh?, en tota esta zona pues tots són valencians. [Sí] I sempre parlem tots el valencià. [És natural, sí.] És natural, el valencià.

Interessanterweise führt das Thema des Valenzianischen im Gespräch mit EV2 $\mathrm{zu}$ einem Diskurs, dessen Inhalt ich nicht durch die Fragestellung angeregt hatte, der aber zeigt, dass es auch für die alteingesessenen Orangenbauern einen sozialen Konflikt im fachkontextuellen Bereich gibt. Es handelt sich 
dabei um die Einflussnahme von Neureichen, die mit viel Geld fincas aufkaufen und citricultura betreiben, ohne selbst Ahnung von den Anbaumethoden zu haben. Sie umgeben sich mit Ingenieuren und Agrarberatern, die neue Techniken und Kultivierungsformen in den Zitrusfruchtanbau einführen und dabei einen Traditionsbruch mit dem Fach und mit der in ihm verwendeten Sprache herbeiführen. Die Logik, dass der Zitrusfruchtanbau deshalb so stark valenzianisch geprägt ist, weil er traditionell von keiner akademischen Ausbildung abhängt, kommt in dem folgenden Diskurs von EV2 deutlich zum Ausdruck:

Jo també ho sé quan un taronger, digam té poll o té coses que tinc que polvoritzar-lo o quan tinc que abonar-lo. Osea que tot això, no necessite que $m$ 'ho diguen perquè ho sé ja de memòria de tota la vida. [Sí, clar.] Però hi ha per ixes persones, que és lo que te deia jo, de que com compren finques. [Sí] I se, se... no han sigut mai llauraors, claro si no tenen un home que sap de lo que va, pues ixos homes estarien penjats, perquè no sa, no saben per on van. $[\mathrm{Hm}]$ Les cuiden molt perquè tenen persones que els diuen això se té que fer eixina, se té que fer eixana.

Die Tochter von EV2 bekennt offen, dass sie durch ihre Elten von klein auf an den Gebrauch des Valenzianischen gewöhnt sei. Das Milieu der citricultura spielt auch für sie eine wesentliche Rolle:

Jo la veritat és que en la citricultura me resulta més, més familiar. Perquè com que sempre he escoltat a mon pare, i mon pare pa, parla sempre valencià, pues me resulta més, més cómodo.

Auf die Frage, warum sie selbst das Valenzianische bevorzuge, antwortet LV2:

Perquè és la meua llengua materna. Perquè des de menuda l'he parlat en casa i, i perquè si no la parlarem, es perdria. I si la gent que la sabem i que des de que nasquerem-i més en els pobles, ¿no?, que sempre s'ha parlat-si no la siguerem parlant se perdria. Ací se perdria.

Vergleicht man diese Antwort mit derjenigen ihres Vaters, so zeigt sich ein hohes Maß an Unsicherheit hinsichtlich der Zukunft des Valenzianischen. Das kollektive 'Wir' wird benutzt, um den moralischen Imperativ der weiteren Sprachverwendung zu formulieren. LV2, 30 Jahre alt, arbeitet selbst als Juristin in Valencia und erlebt dort einen ausschließlich kastilischen Berufsalltag. Das Valenzianische ist für sie die Sprache des Dorfes und ihrer Familie, aber nur noch in einem erheblich reduzierten Umfang die Sprache, in der sie Gelegenheit hat, sich auszudrücken.

Das Sprachbewusstsein von LV1 beruht auf teilweise ähnlichen, teilweise anderen Voraussetzungen. LV1 ist ebenfalls noch jung (33 J.) und auch Tochter eines Orangenbauern. In ihrer Arbeitsstätte in Moncada hat sie reichlich Gelegenheit, Katalanisch zu sprechen. Doch zeigen sich auch in ihren Äuße- 
rungen zur Sprache deutlich Konflikte. So stellt die Probandin unter mehreren Aspekten einen problematischen Zugang zum vermeintlich korrekten und angemessenen Gebrauch ihrer Muttersprache unter Beweis. Die Auseinandersetzung mit der Norm des Katalanischen spielt dabei für sie, wie für viele junge Valenzianer, eine entscheidende Rolle:

Lo que passa que jo parle el valencià pues que en ma casa s'ha, s'ha après. I entonces hui en dia s'està pues, osea, fent ensenyar un valencià com més perfecte, el que se supon que és el correcte. Entonces ixe sí que me costa un poquet. Perquè jo parle el meu, però a lo millor després no estic acostumbrat a dir-ho, jo dic después, i entonces... [Sí, clar.] ...Però vamos, el meu valencià, no tinc faci..., no tinc problema perquè és el que parle sempre, habitualment.

Die Distanz zum Norm-Katalanischen wird von LV1 offensichtlich überbewertet. Die entsprechende Äußerung zeigt, dass sprachpsychologische Barrieren auch dann eine Rolle spielen können, wenn keine ideologischen Konflikte impliziert sind:

Perquè jo per exemple intente ficar la emissora de, catalana que n'hi ha en la tele, en la televisión, que se agarra aquí a València, jo no m'entere de lo que diuen. Entonces pa mi sí que són diferències. [Hi ha problemes d'aquesta mena, ¿sí?, que...] Sí, sí. Jo no l'entenc. [iAh ja!] De fet no la fique mai. I n'hi ha gent que sí que s'aclarix. Jo no. No, no, no per res, sinó que no l'entenc. M'agradaria entrendre perquè a vegaes fan pelAlícules interessants i no puc veure-les.

Die Konsequenz eines solchen mikroregional orientierten Sprachverständnisses wird von der Probandin ebenfalls verbalisiert. Es handelt sich um das Problem, das Valenzianische als Kommunikationsmedium allem Neuen und Fremden gegenüber nicht mehr als selbstverständlich anzusehen und daher in nicht vertrauten Situationen tendenziell zum Kastilischen zu wechseln. Ein solches Verhalten aber ist der erste Schritt zu einer diglossischen Funktionsverteilung, die letztlich immer mit der Regression der dominierten Sprache verbunden ist. Auf meine Frage, ob es Gründe dafür gibt, dass sie lieber Valenzianisch als Kastilisch spricht, antwortet LV1 aus einer sehr persönlichen Perspektive, die das Problem als generationsspezifisch bewertet:

No, és que mon pare, per exemple, era una persona valenciana. I si li preguntava algú en castellà, no sabia parlar el castellà i contestava en valencià. [...clar.] Osea, entonces és... [Hm] ...una, una costum, però lògicament jo, si per exemple tu me parles en castellà i sé que parles castellà, pues me costaria a mi parlar-te en valencià. Vull dir que... [Hm] ...és una cosa psicològica, no sé.

Die Selbstverständlichkeit des katalanischen Sprachgebrauchs ist auch im Bereich der citricultura heute nicht mehr so wie früher gegeben. Allerdings scheint dies insbesondere ein Problem der jüngeren Generation und veränder- 
ter Produktionsbedingungen zu sein. Die das Berufsfeld zur Zeit beherrschende Sozialstruktur ist demgegenüber immer noch eng mit dem Gebrauch des Katalanischen verbunden. Ich möchte dies zum Abschluss dieses Kapitels durch Zitate von zwei weiteren Probanden aus meinem Untersuchungskorpus belegen. Im ersten Fall handelt es sich um eine Verwaltungsangestellte in der Agrarkooperative von Bétera, wo die Orangenernten von vielen privaten citricultors abgeliefert und weiter konfektioniert werden. Die sprachliche Situation in der Kooperative beschreibt die Probandin wie folgt:

Lo normal és que jo per exemple una persona que no conec me dirigix en valencià; si la persona no sap valencià, pues ja, pasaré al castellà. I en casa tinc, en casa valencià. Ací en la feina també en valencià - menys amb un parell de persones que se les pot, que la, l'entenen, però sempre he parlat amb elles en castellà i com parlen en castellà, pues... parlen ells en castellà. [Però a la feina ací molt en valencià.] En valencià, sobretot valencià. [Sobretot valencià.] Sí, sí, la gent que ve de fora, sobretot valencià.

Einen etwas anderen Blickwinkel auf das Sprachenproblem hat der Leiter des Servicio Desarrollo Tecnológico Agrario der Generalitat Valenciana, der ebenfalls zu meinen Probanden gehörte. Auf meine Frage, ob er auch einen Mitarbeiter des Agrarforschungsinstituts I.V.I.A auf Valenzianisch ansprechen würde, antwortet er:

Sí, jo sí. Però no sóc normal en ixe sentit. És a dir, jo ja sóc a voltes..., a mi me diuen 'Sí, u que parla sempre en valencià.' [Hm] Entonces quan..., això vol dir que eres atípic, anormal. Es a dir, quan la referència és que parles en valencià, això vol dir que eres atípic. Això vol dir que en el I.V.I.A. casi mai parlen en valencià. Inclús persones que parlen, que saben el valencià. Jo sé que parlen el valencià perquè jo parle a tot cristo valencià. És cert que si me diu algú que no el coneix, però allí no és normal. Ara, a nivell de llauraor, sempre.

Das engagierte Verhalten des Probanden ist sicherlich aufgrund seines hohen beruflichen Status von einer gewissen Wirkung. Insgesamt wird aber auch durch ihn das Faktum der sprachlichen Funktionsverteilung im Sachbereich der citricultura bestätigt. Die Verbindungen, die zwischen der technischen Entwicklung auf institutioneller Ebene und der Arbeit auf den Feldern beständig etabliert und intensiviert werden müssen, bringen in diesem Sinne auch sprachliche Konflikte mit sich. Es sind Konflikte, die aus dem Strukturwandel des Sachbereichs entstehen und zumindest für die jüngere Generation von Orangenbauern auf die Dauer unausweichlich sind. Die Frage des Erhalts, der Übertragung und der Veränderung von Diskurstraditionen spielt daher auch im valenzianischen Zitrusfruchtanbau eine zentrale Rolle. Ich werde versuchen, im folgenden Kapitel die kommunikationsstrukturellen Bedingungen dieser Sprachdynamik anhand einiger Beispielanalysen zu erläutern. 


\subsection{Vergleichende Analyse der katalanischen und kastilischen Text- corpora: Spezifika des fachkontextuellen Sprechens in seiner Ab- hängigkeit von Sprache, Sprecher und Sachbezug}

Die Gestaltung der alltäglichen Kommunikation in Fachkontexten ist sowohl innerhalb als auch außerhalb des beruflichen Sektors von der individuellen Person des Sprechers abhängig. Diese Erkenntnis, die in den bisherigen Analysen der Arbeit bereits belegt werden konnte, schafft besondere Bedingungen für die fachsprachenlinguistische Interpretation: Der enge Sachbezug, durch den sich die Fachsprache im Allgemeinen definiert, ist im Fall der Alltagskommunikation stets über die Person des Sprechers vermittelt, der der vermeintlichen Objektivität fachlichen Sprechens durch beständige Konnotationen und Wertungen einen durchaus subjektiven Charakter verleiht. Zudem ist die Wahl der Sprache ein ausschlaggebendes Kriterium der individuellen Kommunikationsgestaltung, wobei sprachpsychologische und diglossische Faktoren mit ins Spiel kommen. Die Determinationen fachkontextuellen Sprechens sind jedoch noch komplexer, da auch die Ebene der extern begründeten Sprachnormen mit zu berücksichtigen ist. Diese Sprachnormen werden nur zu einem geringen Teil als terminologische Fixierungen wirksam. Sie stellen in der Hauptsache regulative Bedingungen des Sprechens in der Gemeinschaft dar, die diese Normen aus gemeinsam erlebten Sachbezügen der regionalen Wirklichkeit aufbaut und zu ihrer kommunikativen Basis macht. Wer diese Normen nicht kennt, weicht von dem Standard des regionalen Sprachgebrauchs ab und wird als nicht zur Sprachgemeinschaft gehörig identifiziert.

Die Beispiele fachlicher Diskursgestaltungen in diesem Kapitel werden belegen, dass Fachsprache und regionaler Sprachgebrauch eine so enge Verbindung eingehen, dass es gerechtfertigt ist, von einer Normierung des sprachlichen Verhaltens auszugehen. Diese Normierung ist allerdings nicht auf die Sachebene beschränkt, sondern wandelt die Apperzeption des Fachs in eine Form der regionalen Erfahrung vermittels der Sprache um. Dieser dynamische Prozess, in dem Normen beständig neu konzipiert und wieder verworfen werden, bestimmt die innere Logik von Sprach- und Diskurstraditionen, insofern sie sich innerhalb der Kommunikation in einem Sachbereich konstituieren. Die sprachlichen Traditionen sind daher nicht statisch und erst recht kein retardierendes Moment des Sprachwandels, sondern im Gegenteil Ausdruck der engen Verbindung von historischer Sprache, individuellem Sprecher und besprochener Welt.

Die Spannungen, denen diese sprachlichen Traditionen in zweisprachigen Gebieten ausgesetzt sind, ergeben sich vornehmlich aus diglossischen Funktionsweisen, da der neutrale Parallelgebrauch zweier sozial gleichwertiger 
Sprachen in einem Sprachkontaktgebiet keine Unterschiede auf der Diskursgestaltungsebene erwarten ließe. Ein solches Konstrukt widerspricht jedoch jeglicher Erfahrung sprachlicher Wirklichkeit und wird empirisch kaum nachweisbar sein. Demgegenüber ist die Konfrontation der Gebrauchsformen von zwei oder mehr Sprachen aufgrund ihrer unterschiedlichen Normbindungen an den Sachbereich der Kommunikation eine ganz normale Erscheinung. Auf diese Weise lassen sich aber - unter sprachpolitischem Aspekt - die Sprachund Diskurstraditionen über die Einflussnahme auf die Normen des Sachbereichs von außen lenken und verändern. Solche konfliktären Erfahrungen machen viele Sprecher gerade in fachkontextuellen Kommunikationen, wenn sie sich mit den teilweise enormen Strukturveränderungen ganzer Sachbereiche auseinandersetzen. Ihre typische Reaktion in zweisprachigen Gebieten ist es, die Regionalsprache zur Aufrechterhaltung bestehender Diskurstraditionen zu nutzen und die übergeordnete Sprache in einer distanzierten Kommunikationshaltung zu verwenden, die es erlaubt, Innovationen in einer sprachlich vermittelten (und nicht in einer unmittelbaren) Form zu verarbeiten. Dieses 'Verfahren' einer diglossischen Funktionstrennung im Sachbereich geht aber nur so lange gut, wie der Gebrauchswert der dominierten Sprache in diesem Sachbereich uneingeschränkt gilt und bewahrt werden kann. Im Fall des Valenzianischen scheint sich hier ein generationsspezifischer Wandel zu vollziehen, der den Status der Regionalsprache in Bezug auf die Kommunikation im Sachbereich der citricultura zu unterminieren droht. Dieser Wandel lässt sich aktuell noch nicht verifizieren, da die Sozialstrukturen des Sachbereichs immer noch stark an die Verwendung des Valenzianischen gebunden sind. Gleichwohl zeigen sich auch heute schon dynamische Prozesse, die den Wandel erahnen lassen und seine sprachlichen Bedingungen deutlich machen. Ich möchte versuchen, dies in den nachfolgenden Beispielanalysen zu veranschaulichen.

Unter den beschriebenen Voraussetzungen verwundert es nicht, dass die Gespräche über Aspekte der citricultura, die zu meinen Textcorpora gehören, in formaler Hinsicht kaum als fachsprachlich gekennzeichnet sind. Betrachtet man 'fachsprachlich' als eine diaphasische Präzision des Sprechens, so ist es durchaus gerechtfertigt zu behaupten, dass die typische Stilebene dieses funktionell eingeschränkten Gebrauchs der Sprache in den Interviews über weite Strecken durch eine kolloquiale Form der Sprachverwendung relativiert wird, die bis zu der klaren Anwendung von Substandard-Registern reicht. Insbesondere aber stehen die syntaktisch ungeplanten und oft elliptischen Äußerungen der Probanden in einem schroffen Gegensatz zu den immer wieder hervorgehobenen Charakteristika des typischen Fachsprachengebrauchs. Diese beobachtbare Grundkonstante des spontanen Sprechens in Fachkontexten darf jedoch nicht zu der einzigen Grundlage der Bewertung des Sprachgebrauchs 
werden. Erkenntnisse darüber, durch welche Charakteristika der Sprachkompetenz die kommunikativen Absichten zu typischen Formen des regionalen Sprechens werden, lassen sich nicht gewinnen, solange das Hauptaugenmerk auf formalen und nicht auf inhaltlichen Strukturelementen der Sprachverwendung liegt. Ich halte es daher für wichtig, die Sinnebene der Texte nicht aus den Augen zu verlieren und ihr einen grundsätzlichen Erklärungswert hinsichtlich der Formalisierung des Sprechens in Fachkontexten zuzuerkennen.

Es gibt Zusammenhänge von fachlicher und sprachlicher Darstellung, die für den regionalen Sprachgebrauch charakteristisch sind. Die Antworten zur Gefahr des Windes für die Orangenkulturen sind ein Beispiel dafür. LV2 erklärt auf Kastilisch:

Y también, pues el viento. Cuando la naranja está madura... [Mm] ...se cae con más facilidad. [Mh] Y si viene un... si hace viento, pues se caen muchísimas naranjas a tierra. Eso también es... [Y entonces cuando se cae ya no se pueden...] No. [... exportar y tal.] No se pueden coger las naranjas del suelo, ;ts! [Ah, eso no lo sabía.] No se pueden coger.

Die Darstellung der Probandin ist sprachlich korrekt, gibt aber inhaltlich nur grundsätzliche Fakten wieder, deren regionale Relevanz auf der Ebene der Diskursgestaltung nicht deutlich wird. Demgegenüber ist der Diskurs ihres Vaters weniger fachsprachlich, aber wesentlich symptomatischer für den regionalen Sprachgebrauch:

Pero a veces piedras así... [Sí, sí, sí.] ...jMadre mía!, pero horrores de mal hace, y el viento también, que tira mucha naranja al suelo. [Ah, sí.] De normal la gente la suele asegurar la naranja, ¿me comprendes? [Sí.] Los seguros agrarios lo aseguran.

Auf Valenzianisch nun verlieren die Äußerungen noch mehr an fachsprachlichem Niveau, gewinnen aber an Aussagekraft hinsichtlich der regionalen Bedingungen der fachlichen Wirklichkeit. SV1 formuliert in einer auffällig elliptischen Weise:

El Vent? El vent de la meua zona poc perquè com és Clementina... [Sí.] ...la Clementina suporta millor el vent que la Nàvel. [Ah! Ja entenc.] ACI tenen... ACI tenen més problemes... ací en València. Perquè com tot és Nàvel, la Nàvel el vent enseguida, bum!, a terra. [Ah, aquesta és la fruita que cau.] Cauen a terra.

Die sehr einfach strukturierte Form des Sprechens, die in den Interviews überwiegend anzutreffen ist, eignet sich auch für die Darstellung fachspezifischer Aspekte. In dem Interview mit SV2 meldet sich beim Thema 'Wind' auch ein dem Gespräch beiwohnender Feldarbeiter zu Wort (sein Redebeitrag steht in Klammern): 
Sí, home, el vent. El vent també fa molt de mal i ve. Normalment per estes èpoques ve... ve el... el vent del nord. Comença a bufar i hi ha un des... un despren... un desprendiment de taronges prou fort, si no estan passades. [Hm, hm, hm.] (I en estiu un vent de Ponent, si te pilla la...) Sí. (...el sòl eixut). I a l'estiu també... (Que...) ...a l'estiu... (...te pilla pa regar, a lo millor que fa falta dos o tres dies pa regar, fa molt de mal. Desfo... desfolia tot el arbre). [Sí.] (vent a ponentà, eixina forta. Fa molt de mal).

Die sprachliche Darstellung des Fachlichen schwankt in der Regionalsprache zwischen affektiver Bewertung und technischer Bezugnahme auf Realitäten, die im Grunde als bekannt vorausgesetzt werden. Die Frage nach den Orangensorten, genauer: nach den Gruppierungen der Orangensorten, wurde in diesem Sinne in einer auffällig technischen Weise beantwortet. EV2 beispielsweise beginnt unvermittelt mit der Aufzählung der verschiedensten Sorten in einer Ausführlichkeit, die seinen Diskurs (auf Valenzianisch) erst nach $4 \mathrm{Mi}$ nuten und 20 Sekunden enden lässt. Dabei erwähnt er insgesamt 10 verschiedene Sorten. Die Darstellung ist aber nicht als theoretische Erklärung für einen Nicht-Eingeweihten konzipiert, sondern folgt dem einfachen Schema der Chronologie der Erntefähigkeit, die für den Orangenbauern von zentraler Bedeutung ist. Dabei ergibt sich ein nahtloser Übergang von den taronges menudes, die früh geerntet werden, zu den taronges grosses, die erst später reifen. ${ }^{249}$ Die Beantwortung der Frage ist vor allem aus der beruflichen Sicht des citricultors von Interesse. Allerdings lassen sich in einer Region wie der Horta kaum Probanden finden, die nicht mehrere Sorten zumindest vom Namen her kennen. Auch das ist ein Faktum, das es zu berücksichtigen gilt. Der durch die vielen, oft aus dem Englischen stammenden Namen stark terminologisch wirkende Bereich ist in der Region gerade durch seine Nomenklatur vertraut, auch wenn nur wenige (oft nicht einmal die Experten selbst) eine abgrenzende Beschreibung der verschiedenen Sorten geben können.

In den Antworten zum Thema 'Orangensorten' lässt sich eine Grunderfahrung hinsichtlich der verschiedenen Funktionen von Kastilisch und Valenzianisch im Sachbereich nachweisen. Es handelt sich dabei um die Tatsache, dass die Erklärungen auf Kastilisch in der Regel reflektierter (und damit auch distanzierter) ausfallen als im Valenzianischen. Dieses Phänomen lässt sich auch in den Antworten ein und desselben Probanden zeigen. Ich gebe im folgenden das Beispiel von EV1:

No, no, pero por lo que sea, aquí en la Comunidad Valenciana... [Sí.] ...eh, salen muchísimas mutaciones. [Hmh] Muchísimas. Ultimamente, el, antiguamente el agricultor iba seleccionando pues, sin tanta, sin tanto afán como ahora. [Hmm] Porque eh, en las variedades pasa como en toda la vida: estamos en una sociedad de consumo

${ }^{249}$ Das Wort taronga bedeutet im Valenzianischen zugleich 'Apfelsine', 'Mandarine' und 'Clementine'. Die Unterscheidungen werden oft durch den Rückgriff auf die kastilische Lexik deutlich gemacht. 
y se consume todo. [Hmh] Incluso las variedades: la gente se cansa de una variedad, no es porque no sea bueno, sino porque ha salido otra y cambia, y hay que... se consume, no sólo, no se consume comiendo, sino que se consume variedades que se agotan, pasan de moda... [Sí.] ...y entra otra. [Sí.] Y así, ¿no? Entonces de, de antigua, de antiguo pues había tres, cuatro variedades, no había más, de antiguo, en la citricultura clásica valenciana había tres, cuatro variedades, cinco. Pero ahora... ahora hay muchísimas variedades. Y no paran de salir porque el agricultor ahora está pendiente de esa demanda de mercado que quiere novedades... [Sí.] ...y está a la caza de la, de la mutación ¿no?

Der Proband reflektiert hier über die Gesetze des Marktes, die einen immer schnelleren Wechsel der Orangensorten erzwingen. Seine Erläuterungen sind argumentativ klar aufgebaut und nehmen auch Bezug auf die Geschichte des Orangenanbaus in der Comunitat. Ein solches Diskursverhalten ist in den katalanischen Texten kaum zu finden. Die Antwort von EV1 auf dieselbe Frage in dem späteren Interview ist dementsprechend völlig anders konzipiert:

Pues predominant... n'hi han dos grups: lo que són les mandarines... [Hm.] ... i les taronges... [Hm.] Mandarina és lo que vindríem a dir 'taronja xicoteta'... [Hm.] ...i... i, i la taronja en sí, que és pues les taronges de.. gran... grosses, que són del grupo Nàvel... [Hm.] ...Ixa és la diferència, osea. Ací el llauraor diu: 'taronja grossa' o...'taronja menuda', ¿no? [Sí.] Estan les mandarines i... i, i les taronges... [Sí...] ...no? Que en sí... [...i dintre de les taronges grosses eh...] ...Pues dins de les... [...hi ha...] ...dins de les... [...el grup Nàvel...] ...síii, dins les taronges grosses el, el, el que predomina és el gru... grup Nàvel. [¿Amb Navel Late...?] Sí, na...està eh... Washinton Nàvel, Navel Late, la SalAlustiana, que és una Blanca. [Sí.] Després està la València... [Sí.] ...¿¿saps? Ixes estan dins del grup de les taronges. Dins del grup de les mandarines, pues mamprenim ${ }^{250}$ en les...en les Satsumes, que és un subgrup... [Hm.] ...que està dins de les mandarines, que són les més precoces... [Hm.] ...les més primerenques, que venen a... a finals de setembre ja, que està allí, pués la Okitsu, la Satsuma Okitsu, la...la Jasimoto. Després venen ja lo que és la mandarina... en lo que diuen els llauraors 'mandarina en sí'. Que està la...la Orobal, la... la Marisol... [Hm.] ....la... la Clement-Pons... la Lauretina. Eh... són varietats que van escalonaes en el temps. I després ve la Clementina de Nules, que és la.... la clementina reina per excelAlència... [Sí.] ...¿¿eh? I... quan acaba la Clementina de Nules, ja ve pues la Navelina, que és també... és una varietat del grup Nàvel. [Hmh... ¿a part del grup Nàvel hi ha eh... el grup Blanques de...?] Sí, està eh, dins de... dins de... estan les Blanques. Que està, dins de les Blanques està la... la SalAlustiana, és la més important... [Sí. ¿La Berna?] La Berna, però la Bern... el cultiu de la Berna ja ve...ja... és... se, se dóna en... en uns llocs molt xicotets. És un cultiu ja... que tendix a desaparèixer. $[\ldots]$

EV1 dokumentiert hier ein fundiertes Fachwissen, das er auch zu strukturieren in der Lage ist. Die regionalen Bezüge sind dabei wiederum vorherrschend und

${ }^{250}$ Valenz. mamprendre 'començar' 
die typischen Erklärungsformen tauchen auf (Erklärung der regionalen Begrifflichkeit, chronologische Einteilung der Sorten). Der Diskurs hat mit 4 Min. 18 Sek. nicht nur fast dieselbe Länge wie der bereits erwähnte von EV2, er ist auch streckenweise ähnlich strukturiert. Die theoretische Reflexion, die das Antwortverhalten im Kastilischen prägt, taucht nur noch 'nebenbei' und in einer sprachlich kolloquialeren Form auf. Sie zeigt aber auch deutlicher den Aspekt der regionalen Betroffenheit:

Cal que hui en dia això ja....abans sí que estava molt... molt centralizat. Es... les diferències està... les fronteres de cada...de cada varietat estaven més delimitaes que ara. Ara ja... tots van buscant la màxima rentabilitat, i no miren ja la climatologia i més planifiquen de tot. [Clar...] És una fuga... [..clar.] ...és... eh... cap...cap al davant, ¿no? [Clar.] ...però... abans sí que estava més delimitat.

Solche Diskursteile sind in den valenzianischen Interviews in längere Darstellungen integriert und repräsentieren eine kritische Haltung zum Fach. Auch SV2, der ebenfalls sehr lang auf die Frage nach den Orangensorten (4:35 Min.) antwortet, kommt u.a. auf einen Kritikpunkt zu sprechen, der den regionalen Grundbezug zum Fach verdeutlicht: das massive Eindringen 'hybrider' Sorten, die den autochthonen Charakter des Anbaus verderben und aufgrund ihrer übereilten Einführung zu Problemen führen. Der Terminus polAlinització creuada ist dabei als Ausdruck einer fachspezifischen Sicht der Dinge zu werten:

[...] vull dir jo, dins... dins de les varietats de Clementina estan todas estes que te vai dir, que són autòctones ací. [Sí.] Són... són replegades varietats d'ací, i estan els híbrids també. Que està la Clemenbilla, que és... que és... que és la nova. [Hm.] Eh... (la Hortinique) ...però... però això ja són més tardanes. Bueno, també està la... a... la Clemenbilla, la Hortinique, la Fortune, la Wilkins, la... bueno, un sin fin. Pero han... han... però el problema que tenen estes és això de la... de la polAlinització creuada $\mathrm{i}$ coses d'estes. [¿De la...?] PolAlinització creuada. [Hm, hm.] Que trauen molt... molta... molt de pinyol. [Hm.] Aleshores ha sigut un problema bastant fort ací, ¿no? Perquè ací si se haguera estudiat bé, verament no feia falta ixos híbridos... ixos.... ixos híbrids que han portat de fora. [Sí, sí.] Que se haguera pogut suplir, pense jo, ¿eh?... $[\mathrm{Hm}, \mathrm{hm}$.] ...amb variedades autòctones sense ixe problema de... anyadir, de... de pinyolada.

Auch das Thema der Frostschäden ist geeignet, auf die Unterschiede im kastilischen und katalanischen Sprachgebrauch der Probanden hinzuweisen. EV2 gibt ein gutes Beispiel. Er beginnt seinen Diskurs auf Kastilisch mit einer grundsätzlichen Stellungnahme. Die regionale Bedeutung des Themas wird durch eine expressive Wortwahl und durch Wiederholungen hervorgehoben:

¡Fatales! [Fatales.] Ciertas... [O sea] ...ciertas variedades, por no decirte, casi todas padecen mucho las heladas. [Sí.] Claro, hay zonas que no hiela nunca. Aquí donde 
estamos es muy difícil que hiele; pero vamos, hay zonas, muy malas, muy malas, muy malas.

Im Anschluss daran geht EV2 auf eine Tatsache ein, die ihn grundsätzlich stört, von der er aber nicht selbst betroffen ist. Es handelt sich um die nach dem Abbau von Kontrollmaßnahmen verbreitete Praxis, geschädigte Orangen aus Profitgier schnell zu exportieren, bevor der Schaden offensichtlich wird. Signifikanterweise taucht die reflektierte Argumentation in der valenzianischen Antwort nicht auf. Stattdessen konzentriert sich EV2 auf die Darstellung fachspezifischen Wissens und erklärt, dass eine Orange, wenn sie reifer ist, aufgrund ihres höheren Zuckergehalts nicht mehr so stark unter dem Frost leidet. Das Thema wird auch am Ende der kastilischen Antwort noch behandelt, aber in eine sprachlich unbeholfenere Form gekleidet. Man vergleiche zunächst die kastilische, dann die katalanische Version:

[¿Y usted sabe hasta cuantos grados bajo cero no se efectúan daños graves en los naranjos?] Cuando llega... [O sea...] ... tres... [...a tres ya...] ...pues hiela. [Mh. Bueno...] /unverständl./ no hiela. [¿Y hay otros peligros climáticos...] También te voy a decir: a tres, a veces si tiene mucho azúcar que está madura la naranja... [Sí.] ...la toca, pero no tanto. La naranja la hiela cuando está verde, que no tiene azúcar. [Ah... sí.] Si tiene azúcar, tiene más calorías allá dentro. [O sea, por ejemplo las tardías cuando...] Las tardías padecen más. [Ya, mm...] Claro.

El taronger quan està la taronja maüra, quan està la taronja maüra, que té el sucre, pa gelar-la té que arribar al tres baix zero... ¿Eh? Pero quan tenen el sucre, ¿eh?, si ve en el dos també li fa barbaritats de mal... Pero vamos, quan té el sucre té que arribar al tres, eh?... Sí està gelant... i també marca molt les hores que estiga... [iAh!] ...¿M'has comprès? [Sí.] Si a lo millor ,;Eh! pues si he estat al tres, he estat al tres i mig“ pero ha estat un' hora, pues no ha hagut molts problemes... eh... s'han salvat... [Molt bé.] ...Pero claro, si són hores, hores, hores, entonces això lo que... la mareja. El sucre l'aguanta molt, perquè el sucre clar li dóna calories a... la fruta, a la taronja. Entonces el sucre aguanta molt el fred. I quan estan maüres taronges és més difícil gelar-les... Pero moltes les ha gelat algunes vegaes, en zones. Les zones ja de Moncà que coneixes $i$ això, $i$ on estan els investigaors... [Sí.] ...ixa zona és molt bona. Ixa zona les gela poques vegaes. Pero sí que n'hi han zones que les gela molt.

Die Erläuterungen im valenzianischen Diskursteil sind nicht nur differenzierter, sondern werden auch in einem lebhafteren Stil zum Ausdruck gebracht und vermitteln die regional erfahrbaren Zusammenhänge in einer sehr anschaulichen Weise. Die Ausführungen enden mit Hinweisen auf konkrete Anbauzonen. Demgegenüber wirkt der kastilische Diskurs 'blass' und wenig informativ. Diese Beobachtung lässt sich sicherlich auch darauf zurückführen, dass der Proband mit dem Kastilischen weniger vertraut ist. Worauf es im Zusammenhang der Untersuchung jedoch ankommt, ist die Tatsache, dass der Grad der Sprachkompetenz nicht nur ein Mehr oder Weniger an Ausdrucksfähigkeit 
impliziert, sondern darüber hinaus auch die Verwendung normativ geprägter Sprechweisen in der Region ermöglicht oder einschränkt. Funktionsverluste der Regionalsprache in der jüngeren Generation sind unter diesem Gesichtspunkt differenziert zu analysieren. Das Kastilische muss sich in jedem Fall an die Diskurstraditionen des Valenzianischen annähern, wenn es eine ähnliche Funktionalität im domänenspezifischen Sprachgebrauch erfüllen will.

Meine Frage nach der rosada negra verdeutlicht die Formen des konzeptionellen Verständnisses von Fachterminologien in der Regionalsprache. Grundsätzlich lässt sich ein analytischer und ein sensitiver Umgang mit fachlichen Erscheinungen unterscheiden. Beide Formen der Konzeptualisierung finden in der Regionalsprache einen definitorischen Rückhalt, auch wenn die entsprechenden Definitionen meist weit von fachsprachlicher Präzision entfernt sind. SV2 bringt zumindest ansatzweise ein analytisches Verständnis der rosada negra zum Ausdruck. In seiner Erklärung stellt der letzte Satz einen 'charmanten' Stilbruch dar:

La 'rosà negra' és quan no és... no és.... no és gelada de... de immersió. [Hm.] Que és un assentament de... de... que ve és de fred, digam. [Hm.] No és... no és de sentada de ros. [Hm, hm.] Vull dir jo, que... que és gelà, gelà. En vez de ser gelà de immersió, és gelà de... fa el fred polar... [Hm.] ...i va... va... va... va molt de fred. [I el... i el efecte que fa, ¿què és?] ¿El efecte que fa? Pues és casi més fotut que el de immersió.

Die Erläuterungen von SV1 sind hingegen vornehmlich auf die visuelle Wahrnehmung ausgerichtet, was für den Praktiker durchaus typisch ist. Der Bezug zum Fach ist hier stark normativ fixiert. Dies gilt zum einen hinsichtlich der Konzentration auf das Wahrnehmbare (bzw. im konkreten Fall auf das Paradoxon des Nicht-Wahrnehmbaren), zum anderen auch in Bezug auf die sprachliche Form des Terminus, von dessen valenzianischer Aussprache (mit phonetisch verkürzter Endung) der Proband auch in einem metalinguistischen Diskurs nicht abstrahieren kann:

Ah, ¡sí! ¿'Rosà negra’? Sí. [¿Què vol dir?] Bueno ALLÀ diem 'rosà negra’... [Rosa negra] ...'rosà negra' [Ah, de la rosa negra...] No, 'rosà̀'; 'rosà negra'. ¡No rósa, eh! [Rosà negra.] Rosà. Rosa és una flor. [Ja, sí clar.] Es és, ALLÀ diem 'rosà negra' o 'rosà blanca'. [Mm... ¿i què vol dir?] La 'rosà negra' és quan en hivern... fa molt de fred... $[\mathrm{Mm}]$... i ...eh... la rosà a pen... a penes se veu. $\mathrm{O}$ sea, veus el arbre i dius 'este arbre té res', però te arrimes més a prop i veus que efectivament està fent-li molt de mal el gel. Es un gel que no se veu, casi transparent, que està apegat el gel a la fulla i no lo veus casi. Se diu 'rosà negra'. Perquè no es veu, no se veu casi. I la 'rosà blanca' fa menos mal a la fulla i a l'arbre, però se veu de més lluny. Es com si fora més neu. [Ah, ja. Ja entenc.] Entonces la 'rosà negra' és molt més mala que la 'rosà blanca'. Fa més mal.

Die klimatischen Verhältnisse sind ein Thema, das von Experten und Laien zum Teil recht unterschiedlich behandelt wird. Ein Fachbegriff wie rosada 
negra ist kaum einem Laien bekannt. Hingegen finden die spektakulären Ventilatoren, die in der kalten Jahreszeit an einigen wenigen Feldern als Präventivmaßnahme gegen den Frost zu sehen sind, immer wieder Erwähnung. Das Thema der Schutzvorrichtungen gegen Wind und Kälte verleitet LV2 sogar zu einem Exkurs, der aus einer analytischen Sicht des regionalen Sprachgebrauchs in Fachkontexten eine typische Form der Diskursgestaltung darstellt. Obwohl ein thematisches 'Abschweifen' in kommunikativen Fachkontexten grundsätzlich nicht angemessen erscheint, ist dieses Phänomen im regionalen Sprachgebrauch immer wieder zu verzeichnen. Der Grund hierfür liegt in der engen Verbindung von Fach und sozialer (bzw. individueller) Betroffenheit, die in regional relevanten Berufssektoren oft auch eine Form der Existenzangst beinhaltet. Diese Logik bringt der Diskurs von LV2 sehr deutlich zum Ausdruck:

Mesures preventives? ... Jo crec que... que sí. Que n'hi hauran llauraors que fiquen com... com talles eixina, com malles negres... eh... digam... He vist que n'hi han... fiquen en palos unes malles negres o platificaes o com... de manera que eviten un poc. O si per exemple és una zona de molt de aire, pues a lo millor, lo fiquen de manera que... evite el aire. Si fa fred, pues fiquen... pues dalt... pues evitar... Pues en fin, jo crec que si que n'hi han maneres de... de intentar previndre, aunque claro, molt costoses. [Sí, clar.] Molt costoses i... en fin. Sí que n'hi han, però de moltes conseqüències cara $a . .$. al amo, digam. De diners i de...[Clar.] ...i de molta faena. Molta preocupació i no sé. [Vols dir que no val la pena...] Sí. [...fer-ho sempre, ¿no?] Pues a vegaes convé arriesgar-se i... La veritat és que la faena del taronger és molt problemàtica. Perquè... eh... después d'estar eh... una persona que se preocupa realment per les seues collites i per tindre-ho tot, pues molt bé i molt cuidat i... i sempre que arriba la època de tindre que guanyar ixos diners que estàs tot el any treballant-te, pues per pagar-te els abonos, eh... les podaes, en fin, totes les faenes. I arriba un moment $i$ tots els anys n'hi ha problemes cara a vendre les taronges. Sempre n'hi han conflictes i històries. I entonces n'hi ha pa vendre es camps i enviar-ho tot a ma ma$\mathrm{re}^{251}$. Entonces... vull dir que a vegades no val la pena si mires... ixes conseqüències. No, a l'hora de la verità no... la gent no trau lo que ha treballat tot el any. A vegaes... pues al millor n'hi haurà gent que hauran treballat la mitat i guanyen molt. Osea, és que no podem parlar de casos específics sinó que és una cosa molt generalizà. I... i sempre n'hi haurà que se beneficiarà molt en poques faenes o poques esforços $\mathrm{i} a$ millor la gent que realment se mereix guanyar un poquet per... per a... perquè subsistixen en això. Pues a lo millor esta gent pues pues són... són uns desgraciats i no... i no tenen sort. Vull dir que és que... [Hm.] ...són les coses molt complicaes pa uns i molt fàcils pa atres. Però vamos, relacionat en la pregunta ixa, pues sí, n'hi ha mitjos, però vamos... [Sí.] ...caldria estudiar un poc si val la pena o no el... [Sí, clar.] ...el ferho.

${ }^{251}$ Feststehender Ausdruck, etwa im Sinne von 'alles hinschmeißen'. 
Kommen wir nun wieder auf ein fachspezifischeres Thema zurück: die Veredelung der Bäume. Die grundlegenden Fakten dieses thematischen Bereichs sind klar strukturiert und werden durch zentrale Begriffe sprachlich repräsentiert. Den meisten Sprechern ist aus einem regionalen Grundverständnis heraus bekannt, dass die Kultivierung von Orangen von einer variantenreichen Form der Veredelung abhängt und dass diese Veredelung auf verschiedenen Techniken des Pfropfens beruht. Die zugehörige Grund-Begrifflichkeit ist sowohl fach- als auch regionalsprachlich gängig und kennt verschiedene Synonyme. Die fachsprachliche Ausdrucksweise wird im Kastilischen durch die Termini patrón, injerto und variedad repräsentiert. Auch im Valenzianischen finden sich diese Begriffe wieder (patró, empelt, varietat). Die gängige Bezeichnung für den patró ist aber peu 'Fuß', was im Kastilischen bisweilen mit 'pie' wiedergegeben wird, aber in dieser Sprache offensichtlich keiner (fach-)sprachlichen Tradition entspricht. Umgekehrt hat die technische Bezeichnung portainjerto kein Äquivalent in der möglichen katalanischen Bildung portaempelt. Auf meine Nachfrage zeigt LV2 folgende Reaktion:

Portaempelts... jés un empelt damunt d'un atre o algo eixina serà? [No és és el peu... el peu... el peu més aviat. Coneixes la paraula 'peu' en el sentit de... ] Peu, sí. Peu de l'arbre, digam. [Sí, el peu de l'arbre, que... que...] Sí, entonces, ¿què vol dir un empelt en el peu de l'arbre, digam? [...al peu hi ha un sinònim que diu 'porta... portaempelts'] ¡Ah...! [El peu, portaempels.] Ja, ja. No havia sentit mai el... [Portaempelts] Portaempelts. Pues igual sí. És que... [En castellà 'portainjertos'] Portainjertos. Sí, sí, sí, claro, sí, sí. En valencià no ho associava però en castellà sí, sí que és de veres. [Ah...] 'Portainjertos' sí, sí. Sí, que ho he sentit. Però en valencià menos. [¿’Però què vol dir 'portainjerto' es... es..., en valencià?] ¿Què què vol dir pa mi? No conec molt bé el significat de portar... [És el peu, o és el patrón de l'arbre, ¿no?] ¡Ah! ¡El Patrón! Sí, sí me sona com a patró de l'arbre, sí...sí.

Die Begriffsverwendungen sind hier also sprachspezifisch und können nicht ohne weiteres übersetzt werden. Das gilt insbesondere auch für das Begriffspaar (peu) bort und (peu) ver, das typisch valenzianisch ist und den Gegensatz von wildem und veredeltem Orangenbaum charakterisiert. Unter fachlichem Gesichtspunkt ist die Bedeutung von bort dabei heute unklar geworden, da der Terminus traditionell zwar den sog. peu amarg, die Bitterorange, als Grundlage aller veredelten Varietäten bezeichnet, nach dem massiven Befall des peu bort / amarg durch die Krankheit tristesa heute aber eine Vielzahl von peus in der Kultur Verwendung finden. EV1 stellt dies unter explizitem Bezug auf die Terminologie dar:

'Taronger bort'... 'taronger bort' diguem al patró. [Hm.] Abans el bort era el bort, el... el taronger amarg. [Hm.] No havia altre. Pero entonces, ara als patrons tolerants a 'tristesa' diguem també 'bort', quan està el patró per a empeltar... [Hm.] ...i quan 
està empeltat ja diguem 'ver'. ،Ver' sempre és, se referix a la varietat, a... a... a... a la part ja que tu has injertat... [Ja... ja.] ...el 'ver'.

Dieser terminologischen Aussage widerspricht die Darstellung des Probanden SV2, der eine wesentlich differenziertere Vorstellung von der Begrifflichkeit entwickelt, dabei allerdings primär von der Unterscheidung der Pflanzen selbst ausgeht:

Home, se poden distinguir entre el bort, entre el bort i... [Sí.] ...entre el bort i el... i el Volcamerianes o el Mandarí, es pot distinguir també, ixos... ixos tres. [¿El bort és el... el taronger amarg o...?] Sí, el bort és taronger amarg. [¿I els altres?] I el Mandarí comú, ixe és molt d'antic també. [¿Com es diu?] Mandarí. [Ah, Mandarí.] Mandarí comú. [Hm, hmh.] Eh... i el... i el Volcameriana o coses d'estes. I després estan el Carrizo i el Troyer. [Hm.] I ixos...no se poden distinguir entre ells perquè són trifolians. Però... i després n'hi han tres o quatre més... [Hm.] ...que ixos sí que se distinguixen, però que ixos són més tard ja.

Dieses Zitat macht bereits deutlich, dass es neben der beschriebenen terminologischen Grundstruktur eine reiche Nomenklatur gibt, die - ähnlich wie im Falle der Orangensorten - hauptsächlich dem Fachmann bekannt ist. In der Gruppe der Laien sind hingegen oft nur vage Vorstellungen des begrifflich Gemeinten zu finden. Die kastilische Antwort von LV1 dokumentiert dieses Phänomen:

¿Conoces algunos sinónimos para esos pies o portainjertos?

Yo lo que te he dicho. [Sí.] Siempre he oído que, que... suelen decir 'peu bort' o 'peu tolerant" que sé que es una... variedades distintas de... para plantar los, los árboles de pequeñitos. [Sí.] Y sé que los que... los que después se injertan... [Sí.] ...que no tienen una variedad concreta, son más fuertes. Es lo que... [Sí.] ...lo que siempre he oído; no exactamente como... si se llama de otra manera, no...

¿Sabes cómo se llaman los patrones?

[...algún nombre...] Sí... [...) ¿que se utiliza?] ...lo que te he dicho. El 'peu bort'... [Sí.] ...peu, 'peu tolerant'... [Sí.] ...que... borde, ‘bort' es que es más... [Sí.]... borde. [Sí.] ¿Sabes lo que quiero decir?, más así... y 'tolerant' es más tolerante... [Sí.] ... o sea que eso es lo que yo conozco. [iAha!] Lo que siempre he oído de esos, se llaman así, los que yo conozco. A lo mejor habrán más, seguro. [Sí.] Pero yo, que de eso...

Die speziellen Fachkenntnisse zu den Veredlungsverfahren sind unter Laien im Allgemeinen gering. Dies gilt insbesondere auch für die Pfropftechniken, die ein technisches Fachgebiet im engeren Sinne konstituieren und außerhalb des beruflichen Sektors kaum bekannt sind. Dennoch lösen solche fachspezifischen Themen auch unter Laien Assoziationen aus, die auf die regionale Relevanz des Fachs hinweisen. Dabei kommen spontanerweise immer wieder sozioökonomische Erklärungsmuster ins Spiel: 
Home, el empelt crec que és... se fa per a canviar la varietat de un arbre, crec. Entonces, si per exemple la varietat que té el arbre en particular eh... pues està en perill de que no se pot vendre bé i... és una varietat que no interessa pel comerç, pues entonces s'empelten pues pa... de la varietat que se... s'està més comercializant. Perquè, claro, la definitiva de tindre tarongers és vendre. Entonces, pués té molta importància, claro.

Ein Sachgebiet der citricultura, das auch außerhalb der Berufsfachwelt regional wahrgenommen wird, ist das des Baumbeschneidens. Der podador kennzeichnet traditionell eine ganze Berufsgruppe in der Comunitat Valenciana, die im Zuge der Strukturentwicklung des Fachs heute um ihre Existenz bangen muss. Dies hat vielfältige Gründe, liegt aber vor allem an einer beginnenden Neuorientierung der Produktionsbedingungen und hängt nicht mit der Mechanisierung dieses Arbeitsbereichs zusammen. EV1 reflektiert - typischerweise wieder auf Kastilisch - über die Tätigkeit selbst in einer philosophisch anmutenden Art und Weise. Er bringt dabei ein Verständnis der Berufsgruppe zum Ausdruck, das sich in einer langen Tradition entwickelt hat und die poda nicht nur als eine Technik, sondern als eine Kulturleistung charakterisiert:

Eh, la poda es... es un arte. [Vale.] Porque... ¿no? [iSí!] Eh, la poda es un arte. [Sí.] Estás manejando un ser vivo. [Sí.] ¿Entiendes? [Nnn] Entonces tú te has de plantear lo que quieres. [Aha] Y en función de lo que quieres, tienes que utilizar un tipo de poda o de otra, o sea. ¡Nt!... ¡Es que es verdad! El, la...Hoy hay mucha gente, o muy... o casi todos, pueden cortar madera. Cortar madera lo que hace cualquiera con una sierra; pero podar... [Es otra cosa.] ...es otra cosa. Es lo mismo que, que pintar: una cosa es pintar paredes y otra cosa es pintar cuadros, ¿no? [Hhm] Es, es eh, eh... eh, es un símil muy bueno para esto... [Sí.] ¿eh? Tú puedes coger un serrucho y salir ahí fuera y cortar una rama de un naranjo. Tú has cortado una rama, tú no has podado. [Mmh] Porque podar es buscar resultados en función a un manejo, ¿entiendes? Tú tienes que... tú buscas o rejuvenecer el árbol... [Mh] ...o aumentar la producción. En función de los objetivos que tú te marques, tienes que utilizar un tipo de poda o de otro.

Den podador umgibt im regionalen Bewusstsein immer noch das Geheimnis des Fachmanns, der seine Kunst nicht versprachlicht, sondern von Generation zu Generation durch die praktische Arbeit weiterträgt. Dieses Berufsethos wird heute durch die Existenz einer umfangreichen thematischen Literatur und durch das häufige Angebot an technischen Ausbildungskursen untergraben. Dadurch entsteht ein kommunikativer Sektor, der bislang beinahe traditionslos ist und vollständig vom Kastilischen beherrscht wird. Ihm steht eine Form der verbalen Ohnmacht des klassischen podador gegenüber, die z.B. in der Antwort des Probanden SV1 zum Ausdruck kommt: 
[¿Coneixes la tècnica una mica de...de la poda?] Sí, en en la pràctica sí. [Com es fa, com es pot...] Pues... [i... explicar en dues frases?] Guant, és un guant de pell ahí, un guant... [Sí.] ... un serrutx atra mà... [Sí.] ...i vas llevant, vas llevant rames que creus tu que tenen que anar fora. [Sí.] Els xupons, o sea els... els mamons... [Sí.] ...els mamons, les branques. [Sí.] Que llavors n'hi ha un arbre que té una branca cur... que no produix casi, ixa brancota, se arranca, se lleva. Si n'hi ha alguna rama que toca terra, se lleva també. [Està bé.] Evitar que el el arbre se vaja molt alt. [Sí.] Perquè el arbre té que ser ample. [Clar.] Més ample que alt. ( $\mathrm{Mm}, \mathrm{mm}, \mathrm{mm} . .$. és la tècnica, sí.] Sí. Per damunt damunt pues és això. I en fi, és difícil d'explicar perquè jo... jo porte vint-i-cinc ja en la poda.

Die hier hervorgehobene Schwierigkeit, eine seit 25 Jahren aus der praktischen Arbeit bekannte Tätigkeit verbal zu beschreiben, ist für einen fachlichen Sektor, der (bislang) weitgehend ohne theoretische Ausbildung ausgekommen ist, symptomatisch. Er prägt selbstverständlich auch die Diskurstraditionen in diesem Bereich, die dadurch weniger stark auf die typische Funktionalität der Fachsprache ausgerichtet sind. Die konkrete Nachfrage in den Interviews hat z.T. dennoch Erklärungsansätze zur poda herausgefordert. Es handelt sich dabei um Formen der sprachlichen Mitteilung, die für die Probanden losgelöst von der Arbeit vor Ort offensichtlich ungewohnt sind. Ein Vergleich der beiden Sprachen ist unter diesen Bedingungen besonders interessant. EV2 gibt zwei unterschiedliche Antworten, die es zu vergleichen lohnt:

¿Qué sabe Vd. de la poda?

No... pero la poda, la poda lo sé todo porque sé podar, ¿no? La poda... Tú ves el árbol... [Sí.] ...Es lo que te he dicho yo, pues esto mismo es un naranjo, ¿no? [Sí.] Si tú ves que una rama, una rama de estas... vamos, esto es el árbol... La poda es una rama que atraviesa aquí... [Sí.] ...esa va a molestar a esa, esa hay que cortarla. [Sí.] Los que sa... eh... seguí... se salen al medio, esos también hay que cortarlos. Pa que el naranjo pare redondo... [Sí.] ...bonito, ¿me comprendes? [Sí.] Tú ves alguna rama amarillenta, que ves tú que se ha hecho vieja y eso, esa hay que cortarla... [También.] y que, y ya sale, que brote de nuevo. [Sí.] ¿Eh?, eso es la poda que se hace aquí.

EV2s Beschreibung der Technik setzt die Evokation eines Baums vor dem geistigen Auge des Zuhörers voraus. Auf diese Weise ergibt sich eine Annäherung an die als natürlich empfundene Kommunikationssituation. Die tatsächlichen Erklärungen des Probanden reichen aber de facto nicht sehr weit: Der podador müsse darauf achten, dass die Äste des Baums sich nicht gegenseitig behindern, und alte, abgestorbene Äste entfernen, damit neue nachwachsen können. Die Darstellung und Begründung der Techniken fällt im Gegensatz zu dieser sehr grundsätzlichen Darstellung im Valenzianischen wesentlich präziser und fachlich fundierter aus:

¿Quan i com s'efectua la poda? 
La poda ara se m'ampren. Ara està podant-se ja sense parar... [Sí.] ...la poda ara, d'ara en avant. La poda quan fa fred no se deu de tocar el taronger perquè fas una ferida i de ahí encà li entra més prompt' el fred... [Hm, hm.] ...Pero ara com estava fent molt bon foratge estan podant ja tall a tall tots. [Hi ha diferentes formes de poda... ] Home... [¿...poda de formació i...?] ...la poda, la poda lo lo més això que té, digam açò és el taronger, veus açò. Pues la poda més ideal és eh... les bragaes, o siga les bragaes és lo de baix del taronger, això és on més taronja fa... Taronger on més taronja fa és baix. Dalt de les puntes poques perquè entre el aire i doncs això ahí n'hi fa poca taronja. Pero el taronger sempre se poda pa que una rama ixa mateixa, ixa rama travessa pac a allà i està allí perjudicant-la. I ixa rama que travessa se talla... pa que el arbre pare tot digam aguardeixina. I del mig sempre li se dixa una miqueta de hueco pa que, pa que li pegue el sol digam, que li entre el sol dins el el al centro del taronger. [¡Ah..! Mm, mm.] M'escol... ja m’ has comprès, ¿no? [Sí, sí. És la tècnica. Sí, sí la...] Que no estigui tota eixina [unverständlich] eixina, no, doncs eixina no. Que estiga una cosa més repartida eixina, veus... [Sí.] ...com està més neta eixina, una cosa eixina. [Mm, mm] Això és la poda del taronger... [La tècnica, ah...] I les bragaes se ha anat deixant-les perquè ja te dic, on més taronja fa sempre el taronger és de meitat taronger cap avall. És on més taronja fa.

Die Antwort wird durch die gleichzeitige Verbindung mehrerer Erklärungsebenen charakterisiert. Es wird die Technik selbst dargestellt, ihre genauere Begründung angeführt und ihre Realisierung (auch in deiktischer Form) verdeutlicht. Auf diese Weise ergibt sich eine große Informationsfülle, die der Äußerung einen typisch fachsprachlichen Charakter verleiht. Dabei ist hervorzuheben, dass dieser Typ von Fachsprache in einem engen Zusammenhang mit dem Gebrauch des Valenzianischen steht. Die Konstitution des fachsprachlichen Diskurses hängt dabei nicht zuletzt auch von der persönlichen Bindung des Sprechers an den Sachbereich ab. Seine Fachkompetenz ist in diesem Sinne eng mit seiner Sprachkompetenz verbunden. Diese Verbindung beruht auf der Wirkung regionaler Normen, die durch Erfahrungen im Fach vermittelt werden.

Als Kommunikationsfeld ist die poda heute sehr konfliktbeladen. Sie steht in Konkurrenz zu der labortechnischen Entwicklung von Varietäten, die zum Teil bereits veredelt auf die Felder gelangen und dort zunächst mehrere Jahre ohne einen Schnitt zur Produktion herangezogen werden sollen. Dieses innovative Verfahren macht die regelmäßige Arbeit des podador und damit letztlich auch seinen Beruf überflüssig. In dem Interview mit SV2 wird der Aspekt der no-poda in einer längeren Diskussion zwischen SV2 und einem Feldarbeiter auf Valenzianisch behandelt. Der von den Sprechern verwendete Stil ist dabei zum Teil weit von einem fachsprachlichen Niveau entfernt. Es zeigt sich aber am Beispiel dieser Diskussion, dass der regionale Sprachgebrauch in Fachkontexten auch eine Streitkultur mit einschließt. Im konkreten Fall lief das Gespräch sehr freundschaftlich ab. Ich gebe im Folgenden zwei kurze Aus- 
schnitte wieder. Die Gesprächsanteile des Feldarbeiters stehen in runden Klammern:

Està la poda de... de producció... [Hm.] ...i està la no-poda, perquè ara... eh... ara la no-poda també existix. ¡He! ¡He!... [Hm, hm, hm.] Sí, sobretot en varietats, en varietats... noves de ara $i$ en patrons nous molta gent eh... està podant $i$ fent els equi... $i$ fent els equilibris. Si està podant-los, lo únic que fan és endurir-los. [Hm, hm.] No sé, ací n'hi ha un esporgaor que no està molt d'acord, però és igual, és un burro! Ha! Ha! $\mathrm{Ha}$ !... [¡Ha! ¡Ha! ¡Ha!...] ( ¡Ha! ¡Ha! ¡Ha!... ¡Primer el otro!) [...]

... és un tema molt greu, això. (¡No, no...! no és un tema greu.) El te... el tema... hombre... bueno... si tu vas ahí, i portes un home a tallar-li los culetes, te costa mil pessetes l'hora... [Sí.] ...i fa mitja tira... [Sí.] ...i el amo diu: „Pues, hòstia per fer-li mitja tira llevant-li jo quatre o cinc anys... [Sí.] ...o cinc anys, vaig, me gaste... ha! ....una tercera part de lo que me costa..." (¡Nooo! És que la producció és casi... és la mateixa.) No és la mateixa. ( $i U i !)$ Home està... està provat, ¡home! ( ( $i$ Què va a estar provat! (¡Ese, así sí que sap esporgar!). ¡Ha! ¡Ha! ¡Ha!... (Ahí... ahí només és que saben llevar branques.) ¡Ha! ¡Ha!... (Jo lo ho demostre, jo lo ho demostre en tarongers de fer doble producció esporgant que no esporgant al cap de deu anys.)

Wenden wir uns zum Abschluss noch dem Bereich der Bewässerung zu. Wir haben es hierbei mit einem Fachgebiet zu tun, das in die Produktionsbedingungen des Alltags fest eingebunden ist und die regionalen und mikro-regionalen Besonderheiten des Zitrusfruchtanbaus repräsentiert. Das Wissen um die Herkunft und um die Funktionsweise der Kanalbewässerung ist in der Region insgesamt stark verbreitet. Keiner der Probanden zeigte hier grundsätzliche Wissenslücken. Allerdings ist die traditionelle Versorgung mit Wasser, zumindest solange die Spenderflüsse nicht ausgetrocknet sind, auch kein großes Diskussionsthema unter den betroffenen Plantagenbesitzern. Im Gegensatz dazu weckt die neue Technik der Tropfenbewässerung mittels Schläuchen ein immer größeres Interesse. Sie wird in der Regel positiv bewertet, obwohl die Einführung dieses Systems für viele noch zu kostspielig ist, um kurzfristig realisiert werden zu können. Immer mehr Orangenbauern schließen sich daher mit der Unterstützung durch eine Kooperative auf der Basis von Subventionen zusammen. Sie geben damit ihrem Willen zu einer Strukturveränderung Ausdruck, deren Vorteile sie erkennen und zur Verbesserung der Produktionsbedingungen nutzen wollen. Der Druck des internationalen Marktes spielt dabei eine wesentliche Rolle.

Das System der künstlichen Bewässerung wird in der Comunitat Valenciana aus einer theoretischen Sicht immer als Faktor der regionalen Besonderheit des Zitrusfruchtanbaus ins Gespräch gebracht. Das Bewusstsein der Abhängigkeit vom Wasser ist in diesem Sinne sehr groß. Als abstraktere Reflexion kommt dieser Aspekt vor allem wieder in den kastilischen Interviews zum Tragen. So beantwortet z.B. EV1 die Frage nach der Bedeutung des riego für die Orangenkultur ganz bewusst aus einer überregionalen Perspektive: 
Bueno, el árbol... la citricultura nuestra, a diferencia de la citr... citricultura de los países tropicales... [Sí.] ...por ejemplo en Chile, en Uruguay, en Colombia, en zonas de Argentina no riegan. Los cítricos allí se cultivan sin regar. Porque llueve, hay un ciclo de lluvias suficientemente amplio que permite cultivarlos ah, espontáneamente. [Sí.] Eh... es sin depender de la lluvia, ¿no? [Mh] Aquí como esto es un ... es un ... tenemos un clima mediterráneo con dos picos muy pronunciados de lluvia. No podemos plantearnos un cultivo de naranjo sin riego. Enton... y... y entonces el naranjo depende del riego.

Der distanzierte Betrachtungsstil des Probanden findet sich in der katalanischen Antwort typischerweise nicht wieder. Stattdessen führt der Diskurs in einer konzentrierten Form von den allgemeineren Betrachtungen zu der Darstellung der regionalen Besonderheiten und darüber hinaus sogleich zu einer Erläuterung der aktuellen Problematik, die mit einer Zukunftsvision verbunden wird. Der spontane Diskurs ist länger, gestaltet sich im Valenzianischen intensiver als auf Kastilisch und bringt-unter Bezug auf die regionalen Normen des Fachs-einen höheren Informationsgehalt zum Ausdruck:

Pues lo que...lo que ha facilitat el que se implantara la citricultura en la Comunitat ha sigut que la Comunitat en la zona cos...costanera tenia un sistema de regadius ja... que venen dels àrabs, eh?, implantats. [Sí.] El taronger és un arbre que té unes necessitats cítriques prou acusaes. Té fulla tot el any. [Sí.] Entonces això fa que...que les necessitats de ai...de aigua siguin elevaes. [Sí.] Eh... antigament el...el...els...els tarongers s'implantaren en les zones de regadiu que... perquè el taronger mensual, cada vint, vint-i-un dia, trenta dies - depèn de la època - es...es té que regar. Entonces s'implantà en les zones de regadiu.

I ui en dia el...el...les noves plantacions se fan totes en...en plan...en instalAlacions de degoteig. [Hm.] I a...i fa que el...el rega... el cultiu se haci estès a zones impensables abans. [Hm.] O sea, el taronger abans estava molt delimitat per la zona tradicional de regadiu, i hui en dia per la millo... per la millora - entre cometes, ¿no? - de la climatologia i de... i les... i les noves tècniques de... de instal-lació de rec per degoteig, ha fet que el...el...el àrea geogràfica del taronger s'escampara molt. [¿És més freqüent ara el... el regadiu per degoteig?] Pues encà no, encà no, però les polítiques... les polítiques de la Conselleria de Agricultura... [Sí...] ...en quant a subvencions... [...sí] ...i en quant a ajudes...eh... bé a mi me...me'n sembla que de ací uns anys la majoria estarà per degoteig. [Hm ,hm... ¿que resulta més eficaç també?] Sí, sí. Rea... sí. Home! És que aumenta la productivitat.

Die Antworten zum Themenbereich der Bewässerung fallen auch bei EV2 je nach Sprache sehr unterschiedlich aus. Hervorzuheben ist wiederum - als inzwischen nun schon gut bekanntes Phänomen -, dass die thematische Gestaltung auf Kastilisch reflektiert und analytisch ist. Der Proband bringt zunächst im Vergleich der Bewässerungssysteme a manta und a goteo eine kritische Sichtweise zum Ausdruck: die Tropfentechnik sei ideal für junge An- 
pflanzungen, aber nicht für die alten Bestände, da die Bäume auf diese Weise zu viele Wurzeln ausbilden würden, um von der zwar beständigen, aber geringen Wasserversorgung maximal zu profitieren. Die sich anschließenden Bemerkungen über die geographische Ausweitung des Orangenanbaus bis in die Gebirgsregionen hinein, die nur dank der Tropfentechnik möglich wird, machen deutlich, dass der begonnene Strukturwandel innerhalb der Region als gravierend empfunden wird:

Esto de... esto del goteo, eso lo sacaron los israelitas. [¡Aah!] ¿Sabes? [Sí.] Y esos jodieron también mucho la naranja. [Sí.] Porque al no haber visto tú fincas, que son montañas y tiran las gomas, y han plantao naranjos. Eso no podrían ver... no lo hubieran hecho nunca en la vida. [Sí, sí.] ¿Cómo un labrador en una montaña iba a plantar un campo de naranjos pa regar a manta, si no hubiera podido? [Sí.] Porque había de estar llano como esta mesa. [Sí, sí.] ¿Me comprendes? Tú habrás visto por ahí montañas plantadas. [Sí, sí.] Pues es porque está el goteo. [¡Aaah, ya!] Sino no se podrían plantarlas.

In der katalanischen Antwort des Probanden (3:56 Min., im Vergleich dazu kastil.: 1:39 Min.) ist die kommunikative Haltung weniger reflexiv und weitaus stärker fachsprachlich. Der regionale Fachsprachengebrauch geht dabei wiederum eine enge Verbindung mit der erfahrbaren Faktizität des Faches ein. Zur Demonstration zitiere ich den abschließenden Teil der Antwort, in dem das System der Bewässerung in der Gegend von Montcada kommentiert wird:

Bueno això és una sèquia principal i después de ahí, de ahí va agarrant varios ramals. Això és la sèquia Moncà, ¿eh?... [Mm..] ...això és la sèquia de ací de l'horta. És una sèquia grandíssima que se n'han tre... ¿Tu no has anat per aquí Moncà, no has vist una sèquia molt gran de auia? ¿L'has vista o no? [N...no...] No? Bueno, pues era una sèquia que ahí se, obrint varios pobles... digam. Com que nosaltros digam, estem regant... mamprèn des de Paterna. Ixa sèquia mamprèn de Paterna a regar. ¿Quan estan regant de Paterna, reguen de Paterna a... Moncà no saps on està? [Sí...] Moncà saps on està, ¿no? [Sí, sí.] Pues solen regar des de Paterna hasta Moncà. Quan fan un qua... ahí fan un quadrat. Ahí digam paren la sèquia i de ahí reguen hasta Paterna. Quan ja... allà van soltant-ne, van soltant el 'quadrat' que diuen. 'Quadrat' és una parà que fan. [Sí, clar.] Van soltant-la, van tirant-la avall. Entonces ja va obrint... raera Moncà, al Fara, al Patriarca que està al costat, a Oribinalesa, un poblet que n'hi ha ahí dalt, a obrir este poble, a Bonrepòs, a obrir ja les Cases de Albarsa... de Albàrsena $\mathrm{a}$ obrir a Meliana, a tots estos pobles $\mathrm{i}$ ja obrint varios forats. Perquè esta sèquia porta una burrà de auia... Entonces ja reguem molts pobles alhora. I totes les setmanes pega la volta hasta Puçol... ¿saps? Va hasta Puçol. I reguem hasta Puçol... [Sí, Puçol.] ...i reguem hasta Puçol. I totes les setmanes va pegar la volta la auia ixa eixina. Saps què vol dir? Eixina rega entrant pels forats, a cada terme té les seues sèquies, els seus braços pa regar... I ací tenim... en este poble mateixa n'hi han tres braços... eh.... el braç de Bonrepòs, que diuen, el braç de la Marchal i el braç de Mirambell, que se diu ací. Entonces primer rega el braç de la Marchal, después rega el braç de Bonrepòs... 
[Sí.] ...i después re... rega el braç de Mirambell. Va per braços. E... els llauraors pues estan regant-te ahí, quan d'això la giren i reguen atro i eixina. ... Se rega tot. Ben organitzat tot, sí.

Der zitierte Diskursteil ist ein typisches Beispiel des regionalen Fachsprachengebrauchs und der mit ihm verbundenen Kenntnis objektiver Gegebenheiten, die sich oft auf die mikroregionale oder sogar lokale Ebene konzentrieren. Die Einbindung des Probanden in die Faktizität des Sachbereichs und in seine Normen ist so stark, dass sie die kommunikative Haltung über das in der Gesprächssituation angemessene Maß hinaus bestimmt. Im Verlauf des Diskurses wird deutlich, dass die vermuteten geographischen Unkenntnisse des Interviewers in gewisser Weise als störend empfunden werden. Der ideale Gesprächspartner ist mit den regionalen Grundbedingungen der fachlichen Realität vertraut und an Detailwissen interessiert. Die Erklärungen zum Fach sind in diesem Sinne prinzipiell als ein soziales Integrationsangebot zu verstehen. Diese kommunikative Funktion der Fachsprache ist aber eindeutig auf den Gebrauch der Regionalsprache, d.h. des Valenzianischen, beschränkt. Die kastilischen Interviews haben daher einen vollkommen anderen Charakter.

Die ausführliche Dokumentation der unterschiedlichen Antworten der einzelnen Probanden, aber auch ihrer teilweisen Gemeinsamkeiten, hat die Charakteristika des regionalen Fachsprachengebrauchs in seiner Abhängigkeit von der verwendeten Einzelsprache aufgezeigt. Ein grundsätzliches Fazit kann dahingehend gezogen werden, dass die fachbezogenen Diskurse im Kastilischen tendenziell einen theoretischeren, analytischeren und distanzierteren Charakter annehmen als die ihnen entsprechenden Antworten auf Valenzianisch. In der Sozialstruktur des engeren Sachbereichs der citricultura sind die Sprach- und Diskurstraditionen, die das Sprechen über fachliche Gegenstände bestimmen, sehr eng mit der Sprachkompetenz im Katalanischen verbunden. Diese Sprachkompetenz erweist sich auf den verschiedenen Ebenen der Sprachbetrachtung - dem fachlichen Referenzbereich, der dialektalen Einzelsprache und dem individuellen Diskurs - als regional gebunden und von Normen bestimmt. Der regionale Sprachgebrauch in Fachkontexten stabilisiert sich auf diese Weise, so wie es im theoretischen Teil der Arbeit vermutet wurde, durch die Ausrichtung auf einen endogenen Standard, dessen Grundlage die normative Erfahrung der sozialen Wirklichkeit ist. Die einzelsprachlichen Funktionen (so etwa die Stilebene des Sprechens und das $\mathrm{Ma}$ an verwendetem Fachvokabular), aber auch die in der Regel sich innerhalb sozialer Sprechergruppen konstituierenden Diskurstraditionen richten sich an den normativen Bedingungen der Kommunikation im Fach aus. Auf diese Weise wird das Sprechen in Fachkontexten zu einer Form der Identifikation mit den Lebensbedingungen in der Region. 
Die beschriebene kommunikative Funktionalität wird vom Kastilischen in dem untersuchten Sachbereich der citricultura nicht erreicht. Dennoch hat auch das Kastilische seinen Platz in der fachlichen Kommunikation. Es dringt insbesondere über den institutionellen Bereich in die Alltagswelt des Faches ein. Seine Domäne sind die durch den wissenschaftlichen und technischen Fortschritt erreichten Innovationen, die zum Teil erhebliche Strukturveränderungen des Sachbereichs bewirken. Ihre soziale Durchsetzung wird notwendigerweise mit einem Sprachkonflikt größeren Ausmaßes verbunden sein, der in der Comunitat Valenciana auf Grund der prekären diglossischen Situation umso gravierender auszufallen droht. Es wird darauf ankommen, welchen Grad der Anpassung an die regionalen Sprachtraditionen das Kastilische im fachlichen Sektor erreicht und ob das katalanische Sprachbewusstsein der Valenzianer sich so weit festigt, dass es auch Veränderungen dieser Sprachtraditionen aktiv mitgestaltet. Es ist zu früh, hierzu Prognosen zu geben. Ich möchte daher meine Ausführungen mit einem Zitat beschließen, das in der Lage ist, Hoffnungen zu wecken. Es stammt von einem meiner Probanden, der als Angestellter im Agrarforschungsinstitut I.V.I.A. arbeitet:

Valencià, llengua materna. ¿La parla en totes les ocasions?

Sí, sí, sí. El parle... home, amb facilitat. No quizás per a expressar coses més eh... més abstractes, conceptes més abstractes eh, recorrixc al castellà. [Hmh] Perquè digam que és a través del castellà eh, ah, és, és a través del castellà la llengua la que... a través de la qual he accedit mitjançant eh, lectures, mitjançant eh... mmm, informacions en els mitjos eh... en els mitjos informatius... [Clar.] ...en castellà, ¿no? Eh... hi ha que dir també queee últimament, pues m'estic interessant més per, per a la expressió en valencià a tots els nivells. [Sí.] I m'està resultant efectiu i tinc un poquet més de soltura per a parlar de qualsevol concepte, de qualsevol cosa en valencià... [Ja entenc.] ...que abans. Abans recorria, molt sovint al castellà... [Hmh] ...per a parlar de certes coses de tota manera. I hui en dia m'atrevixc més... hui en dia m'atrevixc més a par..., a parlar de qualsevol cosa en valencià. 


\section{Schlussbetrachtung}

Für die Beschreibung der Sprachkompetenz in einem umfassenden Sinn gibt es bislang noch keine Methodik, wohl aber ein weites Feld sprachtheoretischer Diskussion, in der versucht wird, sich dem Phänomen analytisch zu nähern. Innerhalb dieser Diskussion habe ich mich für eine Konzeption entschieden, deren Mittelpunkt der Sprecher ist und die ihr Untersuchungsobjekt als die menschliche Tätigkeit des Sprechens definiert. Diese Konzeption wird von einem dynamischen Verständnis der Sprache geleitet, das die Ebenen der Psyche und des sozialen Eingebundenseins der Sprecher berücksichtigt. Auf diese Weise wird das Sprechen als Aktivität und als Inter-Aktivität zugleich begriffen. Seine Dynamik hängt von der Wechselwirkung zwischen Individuum und Gesellschaft ab.

Diese Gedanken sind nicht neu. Sie werden aber in der Arbeit zu dem theoretischen Ansatzpunkt eines Untersuchungsgegenstandes, den ich als regionalen Sprachgebrauch in Fachkontexten definiert habe und der bislang in der Forschung noch keine explizite Beachtung gefunden hat. Der Realitätsbezug dieses Interessensschwerpunkts steht außer Frage: 'Region, Sprache, Usus, Fach und Kontext' sind die Komponenten einer Verbindung, die jeder Sprecher tagtäglich erlebt und in seinem sprachlichen Verhalten verarbeitet. Wenn die Sprachwissenschaft sich diesem Analysebereich bislang noch nicht gewidmet hat, so gibt es Gründe dafür. Sie sind zum einem in dem schwierigen methodologischen Zugang zu finden, zum anderen in der nicht minder schwierigen Aufgabe, sich auf eine interdisziplinäre Analysehaltung einzulassen und einen Funktionsbereich der Sprache zu untersuchen, dessen Interpretation nicht ohne einen Zusatz an nicht-linguistischem Fachwissen auskommt.

Im Verlauf der theoretischen Situierung des Themas habe ich verschiedene Aspekte angesprochen, ohne sie im Rahmen dieser Arbeit abschließend behandeln zu können. Die Frage, wohin das Thema nun genau gehört, ist dementsprechend nicht leicht zu beantworten. Es hat sicherlich mit Fachsprache, mit Regionalsprache, mit Normen und Standard und nicht zuletzt auch mit Sprachkontakt zu tun. Die gemeinsame Basis all dessen kann auf einen varietätenlinguistischen Ansatz zurückgeführt werden, dessen Fundament die Betrachtung der Sprachkompetenz des einzelnen Sprechers ist und der die Grundlage einer Erklärung sprachlicher Standardisierung darstellt. Allerdings bleibt die Formalisierung des zu Erkennenden oder bereits Erkannten problematisch. Einerseits muss der Realitätsbegriff in Bezug auf die Sprache - als Teil einer zugleich individuellen und sozialen Wirklichkeit - grundsätzlich weiter gefasst 
werden, als es den gängigen formalistischen Erklärungsmodellen entspricht. Andererseits ist es notwendig, methodische Konzeptionen zu entwickeln, die helfen, diese Realität auch in ihren komplexeren Bezügen zu beschreiben. Was die Linguistik bislang erklären konnte, muss im Großen und Ganzen bescheidener eingeschätzt werden.

Der Untersuchungsgegenstand dieser Arbeit entspricht einer beständigen Erfahrung des Alltags. Unsere Lebensumwelt ist in eine Vielzahl von Fächern aufgeteilt, die wir nicht nur wahrnehmen, sondern von denen wir auch betroffen sind und in denen wir uns bewegen. Die Bezüge sind theoretischer Art durch Ausbildung, praktischer Art durch Beruf oder Hobby und sozialer Art durch Familie, Freunde oder Bekannte. In all diesen Bereichen wird über die (uns) betreffenden Fächer gesprochen, ohne dass in diesen Gesprächen in den meisten Fällen ein Expertentum impliziert oder relevant wäre. Die soziale Funktion des Fachs ist im Alltag - ganz gleich ob Ausbildungsalltag, beruflicher Alltag oder familiärer Alltag gemeint ist - unter den Gesichtspunkten von Kommunikation und Sprachgebrauch prädominant. Selbst Gespräche unter Experten, die man im Alltag gern als 'fachsimpeln' bezeichnet, entsprechen dieser kommunikativen Wirklichkeit: Sie sind Formen der oft entterminologisierten und auf einfachen Grundkonzeptualisierungen aufbauenden Konversation über fachspezifische Erfahrungen, die in sprachlichen Interaktionen aufgearbeitet werden müssen. Genau hier liegt aber auch der Grundansatz meines Interesses. Das Fach wird als thematischer Ort gemeinsamer Erfahrungen situiert, deren Versprachlichung mehrere Ebenen der Identifikation beinhaltet: Identifikationen mit den sachgebundenen Normen, mit den durch das Fach betroffenen Menschen und mit den Tätigkeitsbereichen, die das Fach hervorbringt und sozial stabilisiert.

Die soziale Funktionalität des Fachlichen, die in den jeweils besonderen Formen des fachkontextuellen Sprechens zum Ausdruck kommt, lässt sich im Falle ihrer eindeutig regionalen Bezugnahme auf eine faktische Basis zurückführen. Dies ist ein guter Ansatzpunkt für die linguistische Forschung, die auf Formalisierungen nicht völlig verzichten will. Ich habe mich bemüht, diesen Formalisierungsansatz als regionalen Sprachgebrauch in Fachkontexten zu kennzeichnen, wobei es erforderlich ist, 'regional' in einem anderen als dem in der Linguistik sonst üblichen Sinne zu verstehen. Auf der Ebene der Einzelsprache ergibt sich auf diese Weise die Unterscheidung von diatopischer und regionaler Variation. Die diatopische Variation gehört zu der Architektur der Einzelsprache, die in einer Form der Abstraktion verschiedener struktureller Variationsdimensionen beschrieben werden kann. Die regionale Variation hingegen ist ein Faktum, das durch eine Methodik des Strukturvergleichs innerhalb der Sprache nicht erkannt wird. Paradoxerweise lässt sich die regionale Variation des Sprechens nur in der Konzentration auf ihre Invarianzen inner- 
halb der Region erkennen und beurteilen. In normentheoretischer Hinsicht impliziert dies die Notwendigkeit, den regionalen Sprachgebrauch als eine Form der sprachlichen Standardisierung über den 'Umweg' seiner Bindung an regionale Normen zu beschreiben. Die Theorie sozialer Normen als 'Institutionen im Reich der Gedanken' hilft, diesen Umweg zu verstehen und methodologisch nachzuvollziehen.

Ein Hauptanliegen der Arbeit betrifft die Dokumentation sprachlicher Realitäten in einem empirischen Bezug auf konkrete Situationen des Sprechens. Die methodische Einschränkung des zu beobachtenden Sprachgebrauchs unter den Gesichtspunkten der Region und des Fachs erlaubt es dabei, ein Eruierungsverfahren zu entwickeln, das authentische Formen des Sprechens in einer vergleichbaren Weise bei verschiedenen Sprechern dokumentiert. Der Aufwand für dieses Verfahren ist erheblich, da einerseits mehrere lange Gespräche aufgezeichnet werden müssen und andererseits die genaue Strukturauswertung des gewonnen Sprachmaterials unverzichtbar ist. Aus diesem Grund wurde das Verfahren der Digitalisierung von Tonaufzeichnungen gewählt, das die Möglichkeiten des analytischen Umgangs mit konservierten gesprochenen Texten erheblich erweitert. Eine methodische Basis für die Datengewinnung wurde in der Gesprächsform des strukturierten Interviews gefunden, das sich in der Praxis als ein geeignetes Instrumentarium zur systematischen Erlangung primären Sprachmaterials erweist.

Die Untersuchung ist zu einem erheblichen Teil auf dem Gebiet der Sprachkontaktforschung angesiedelt. Sie setzt in diesem Bereich in erster Linie auf ein Verfahren des Sprachvergleichs, dessen tertium comparationis dieselben oder zumindest ähnliche sprachliche Produktionsbedingungen sind. Die Vergleichbarkeit des Sprechens ist durch das Fach als Kommunikationsgegenstand und durch die normierende Wirkung der Region innerhalb des Fachs gegeben. Auf der anderen Seite treten jedoch in mehrsprachigen Gebieten diglossische Funktionsverteilungen auf den Plan, die die Voraussetzung gleicher Kommunikationsbedingungen wieder einschränken und in jedem Fall angemessen zu berücksichtigen sind. Im Laufe der Auswertungen und Analysen wurde deutlich, dass die diglossischen Funktionen innerhalb von Fachkontexten in einem engen Zusammenhang mit dem Aufbau und Erhalt von Sprach- und Diskurstraditionen stehen, die jeweils in einem mehr oder minder starken Maße an den Gebrauch der Einzelsprache gebunden sind. Die Konfrontation dieser sprachlichen Traditionen mit den Strukturveränderungen der Lebensrealität (im konkreten Fall des Fachs) einerseits und mit den eingeschränkten sozialen Funktionen der beteiligten Sprachen andererseits führt unweigerlich zu Konflikten, deren Interpretation komplex ist und nicht mehr ausschließlich aus dem Blickwinkel der Normalisierung der weniger gebräuchlichen Sprache erfolgen kann. 
Die methodischen Erklärungsansätze sind hier noch nicht hinreichend konstituiert.

Ein Fazit oder Ergebnis der Untersuchungen lässt sich in globaler Form nur vorläufig formulieren. Es handelt sich dabei um die Entdeckung der gestaltenden Wirkung von Sprachnormen, deren Begründung in einer sozialen Realität außerhalb der Sprache selbst liegt. Diese externen Normen, die in meinen Untersuchungen als regionale Normen bestimmt werden konnten, werden von den Sprechern beständig wahrgenommen und in Formen des interindividuell gültigen Sprachgebrauchs umgesetzt. Aus formaler Sicht lässt sich dieser Prozess als Konstitution eines 'Sprachgebrauchsstandards' erklären und ansatzweise auch beschreiben. Dieser 'Sprachgebrauchsstandard', den ich unter dem Aspekt seiner Dynamik lieber als 'sprachliche Standardisierung' terminologisiere, hängt eng mit dem Aufbau, dem Erhalt und der Veränderung von Sprach- und Diskurstraditionen zusammen. Auf diese Weise werden in der Methodologie meiner Untersuchungen Erkenntnisse aus verschiedenen Bereichen der sprachwissenschaftlichen Forschung miteinander in Verbindung gebracht.

Vor allem die konzeptionelle Zusammenführung von Standardisierung und Sprachkontakt scheint mir ein geeignetes methodologisches Prinzip zu sein, um die formalisierende Wirkung eines Aspekts der sprachlichen Wirklichkeit zu erklären, der bislang unter den Gesichtspunkten des Fachsprachlichen, des Regionalsprachlichen und des Normsprachlichen immer nur ausschnittsweise behandelt wurde. Die isolierte Übertragung dieser disziplinär getrennten Analyseansätze auf die weniger gebräuchlichen Sprachen in Sprachkontaktsituationen hat sich als wenig fruchtbar erwiesen. Sie zeigt nur, dass auch Minderheitensprachen intern variieren, Fachterminologien ausbilden und im Spannungsfeld einer mehr oder weniger konstituierten Sprachnorm stehen. Erst die Zusammenschau dieser Aspekte schafft jedoch ein vollständiges Bild von den kommunikativen Funktionen, die diese Sprachen erfüllen und die sie gegenüber den dominanten Sprachen zu behaupten haben, um nicht in einem unaufhaltsamen Prozess substituiert zu werden.

Diese theoretischen Überlegungen am Ende einer langen empirischen Arbeit lassen erkennen, dass viele Fragen aufgeworfen wurden, die eine Herausforderung an weitere wissenschaftliche Forschungen darstellen. Dabei ist es m.E. wünschenswert, dass möglichst viele sich Gedanken machen und empirische Arbeiten vorlegen, die weitere Erkenntnisse zu den Querverbindungen zwischen regionalem Sprachgebrauch, fachsprachlicher Kompetenz, Sprachnormen und Sprachkontakt hervorbringen. Auch die Einbeziehung weiterer Aspekte wird sich als sinnvoll und notwendig erweisen. Ich freue mich daher, dass das vorgeschlagene Projekt schon vor dem Abschluss dieser Untersuchungen zu der Inangriffnahme von vier wissenschaftlichen Arbeiten geführt 
hat, von denen zwei bereits fertig gestellt werden konnten (Riehm 1997, Sánchez Münninghoff 1998) und zwei-zur Weidenkorbflechterei in der Touraine und zum Olivenanbau in Andalusien-sich noch in der Ausarbeitungsphase befinden. Die spontane Begeisterung der Studierenden für interdisziplinäre Aufgabenstellungen innerhalb der Sprachwissenschaft ist eine ermutigende Erfahrung, die die Grundlagen für das Beschreiten neuer Wege schafft.

Schließlich möchte ich noch einen weiteren Gedanken ergänzen. In den Untersuchungen dieser Arbeit konnte dokumentiert werden, welche zum Teil kaum noch $\mathrm{zu}$ vermutende kommunikative Funktionalität den aktiven Gebrauch sozial benachteiligter Sprachen auszeichnet. Im konkreten Fall wurde dies für das Bearnesische und das Valenzianische jeweils in den Verwendungsdomänen regionalspezifischer Fachkontexte nachgewiesen. Diesem Ergebnis steht das Faktum gegenüber, dass beide Sprachen in den jeweils untersuchten Sachbereichen von den Funktionen des öffentlichen und überregionalen Sprachgebrauchs völlig ausgeschlossen sind. Angesichts dieser Situation mag die abschließende Frage erlaubt sein, ob sich die Politiker, Wirtschaftsfachleute und Naturschützer der sprachlichen Realitäten in ihrem Betätigungsfeld hinreichend bewusst sind. Diese Arbeit wird kaum außerhalb des sprachwissenschaftlichen Bereichs wahrgenommen werden. Ich wünsche mir aber, dass das mit den vorliegenden Untersuchungen und weiteren linguistischen Arbeiten begonnene Projekt auf Dauer eine Wirkung zeigen wird, die den argumentativen Beitrag sprachwissenschaftlicher Forschung in der Diskussion um die Gestaltung moderner Lebensformen auch Nicht-Linguisten vor Augen führt. 


\section{Literaturverzeichnis}

\section{Auswahlbibliographie zum Thema der Arbeit}

50 ANS EN AQUiTAINE. Bilans et prospective, sous la direction d'Hubert Bonin, Bordeaux: L'Horizon chimérique 1995.

ABAD NeBot, Francisco, 1987, ASpanisch: Varietätenlinguistik des Spanischen“, Lexikon der Romanistischen Linguistik VI, 1, Tübingen: Niemeyer, 607-616.

ABAD NeBot, Francisco (HG.), 1977, Lecturas de Sociolingüistica, Madrid: Edaf.

AlBRECHT, JÖRN, 1986 / 1990,“'Substandard' und 'Subnorm'. Die nicht-exemplarischen Ausprägungen der 'Historischen Sprache' aus varietätenlinguistischer Sicht“", G. Holtus; E. Radtke (Hgg.), Sprachlicher Substandard I u. III, Tübingen: Niemeyer, 65-88 (Teil 1) u. 44-127 (Teil 2).

AlBRECHT, JÖRN, 1997, “Position und Status der 'Norm' im Varietätengefüge des Deutschen und des Französischen. Mit Ausblicken auf weitere europäische Sprachen“, K. J. Mattheier, Norm und Variation, Frankfurt a. Main, 11-25.

Alemany, R. (HG.), 1989, Els procesos de normalització lingüística a l'Estat espanyol actual, Alacant: Universitat d'Alacant / Ajuntament de Benidorm.

Alvar, Manuel, 1975, Teoría lingüistica de las regiones, Barcelona: Planeta.

Alvar, MANuel, 1976, Lengua y sociedad, Barcelona: Planeta.

Alvar, MANuel, 1977,“Actitud del hablante y sociolingüística“, R. Lapesa (Hg.), Comunicación y lenguaje, Madrid: Karpos, 87-105.

AMMON, UlRich, 1986, "Explikation der Begriffe 'Standardvarietät' und 'Standardsprache' auf normtheoretischer Grundlage“, G. Holtus; E. Radtke (Hgg.), Sprachlicher Substandard I, Tübingen: Niemeyer, 1-63.

Ammon, UlRich, 1987,"Funktionale Typen / Statustypen von Sprachsystemen“, Soziolinguistik ' HSK 3.1, Berlin / New York: de Gruyter, 230-263.

AMmON, UlRICH, 1987a,"Language-Variety / Standard Variety-Dialect", Soziolinguistik 'HSK 3.1, Berlin / New York: de Gruyter, 316-335.

AmMON, UlRich, 1987b, “Zu den Begriffen 'standardsprachliches Sprachzeichen', 'Standardvarietät' und 'Standardsprache'“, Zeitschrift für Phonetik, Sprachwissenschaft und Kommunikationskunde 40, 305-316.

AMMON, UlRICH, 1989, "Sociologie et didactique du dialecte et de la langue standard“, La Sociolinguistique en Pays de Langue Allemande, Lille: P.U.L., 65-88.

Ammon, UlRich, 1989a,"Towards a Descriptive Framework for the Status / Function (Social Position) of a Language within a Country“, U. Ammon (Hg.), Status and Function of Languages and Language Varieties, Berlin / New York: de Gruyter, 21-106.

Ammon, Ulrich (Hg.), 1989, Status and Function of Languages and Language Varieties, Berlin / New York: de Gruyter.

Ammon, Ulrich / Dittmar, N. / Mattheier, K. J. (HGG.), 1987/1988, Soziolinguistik. Ein internationales Handbuch zur Wissenschaft von Sprache und Gesellschaft, 2 Halbbde., Berlin / New York: de Gruyter (' Handbücher zur Sprach- und Kommunikationswissenschaft 3.1). 
Ammon, Ulrich / Mattheier, K. J. / Nelde, P. H. (HgG.) , 1988, Sociolinguistica 2, Schwerpunkt: "Standardisierungsentwicklungen in europäischen Nationalsprachen: Romania, Germania“, Tübingen: Niemeyer.

Ammon, Ulrich / Mattheier, K. J. / Nelde, P. H. (HgG.), 1991, Sociolinguistica 5, Schwerpunkt: "Status und Funktion der Sprachen in den Institutionen der Europäischen Gemeinschaft", Tübingen: Niemeyer.

ARNiCHES, Francisco, 1950, Diccionario de voces, locuciones y conceptos de economía, Madrid.

Auer, Peter, 1989,"Réflexions et études préparatoires pour une linguistique reconstructrice de la variation", La Sociolinguistique en Pays de Langue Allemande, Lille: P.U.L., 164-190.

BADÍA MARGARIT, ANTONIO MARIA, 1976,"Nivelación lingüística y lenguas en contacto“, REspL 6,2, 269-300.

BAdía MARGARIT, ANTONIO MARIA, 1977,"Lenguas en contacto: bilingüismo, diglosía, lenguas en convivencia“, R. Lapesa (Hg.), Comunicación y lenguaje, Madrid: Karpos, 107-133.

BADIA I MARGARIT, ANTONI MARIA, 1978,"Notes sobre el castellà parlat per catalans“, Llengua i Cultura al països catalans, Barcelona: Edicions 62.

BADiA I MARGARIT, ANTONI MARIA, 1981, “Entorn dels concepts de 'Llengua' i 'Dialecte' aplicats sobretot al català“, H. Geckeler [u.a.] (Hgg.), Logos Semantikos. Studia in honorem Eugenio Coseriu, Berlin / New York / Madrid, 19-25.

Baetens Beardsmore, Hugo, 1989, Principis bàsics del bilingüisme (Bilingualism: Basic Principles), Barcelona: Edicions de la Magrana.

BALDINGER, KURT, 1958,"La position du gascon entre la Galloromania et l'Ibéroromania“, Revue de Linguistique Romane 22, 241-292.

BALDINGER, KURT, 1971, La formación de los dominios lingüísticos en la Península Ibérica, 2. Aufl., Madrid: Gredos.

BANDhAuer, WolfGAng / TANZMEISTER, RoBerT, 1990,"Sprachnorm und Sprachvarietäten im Spannungsfeld von Sprachgebrauch und Sprachbewußtsein“, W. Settekorn (Hg.), Sprachnorm und Sprachnormierung. Deskription-Praxis-Theorie, Wilhelmsfeld: Egert, 117-138.

BARRERA I VidAL, AlBERT, 1991,"Le catalan, une langue d'Europe“, Sociolinguistica 5, 99-110.

Bartsch, Renate, 1985, Sprachnormen: Theorie und Praxis, Tübingen: Niemeyer, engl. Übers.: Norms of Language. Theoretical and Practical Aspects, London / New York: Longman 1987.

BARTSCH, RENATE, 1985a,"Normtheoretical notions in the analysis of multilingual conflicts“, P. H. Nelde (Hg.), Methoden der Kontaktlinguistik, Bonn: Dümmler, 193-203.

BARTSCH, RENATE, 1989,“A Normtheoretical Approach to Functional and Status Types of Language“, U. Ammon (Hg.), Status and Function of Language Varieties, Berlin / New York: de Gruyter, 197-215.

Bastian, SABINE, 1989, "Aspekte der Beschreibung der gesprochenen französischen Gegenwartssprache“, Fachsprache-Fremdsprache-Muttersprache 13 / 14, Dresden, 5-12. 
BAUM, RichARD, 1976,“Zum Problem der Norm im Französischen“, F. J. Hausmann (Hg.), Die französische Sprache von heute, 1983, Darmstadt, 366-410.

BAUM, RICHARD, 1987, Hochsprache, Literatursprache, Schriftsprache. Materialien zur Charakteristik von Kultursprachen, Darmstadt.

BAUSCH, KARL-HEINZ, 1976,"Fach- und Gemeinsprache als kommunikationssoziologisches Problem“, K.-H. Bausch; W. Schewe; H. R. Spiegel (Hgg.), Fachsprache. Terminologie-Struktur-Normung, Berlin / Köln: Beuth, 124-136.

BeC, PIERre, 1978, La langue occitane, 4. Aufl., Paris: PUF.

Bec, Pierre / Alibert, Louis, 1952, L'application de la réforme linguistique occitane au gascon, Toulouse: IEO.

Bechert, Johannes / Wildgen, WolfGang, 1991, Einführung in die Sprachkontaktforschung. Unter Mitarbeit von Christoph Schröder, Darmstadt: Wissenschaftliche Buchgesellschaft.

Bedard, Edith / Maurais, JaCQues (HgG.), 1983, La Norme Linguistique, Québec / Paris: Gouvernement du Québec / Conseil de la langue française / Le Robert.

BeIGBEDER, Francis, 1986, Ausèths. Les noms gascons des oiseaux sauvages, Denguin / Pau: Per Noste / Nosauts de Bigòrra.

BeInHAUer, Werner, 1958, Spanische Umgangssprache, 2. Aufl., Bonn, Span. Übers.: El español coloquial, 3. Aufl., Madrid: Gredos, 1978.

BENEŠ, EduARD, 1971,"Fachtext, Fachstil und Fachsprache“, Sprache und Gesellschaft. Beiträge zur soziolinguistischen Beschreibung der deutschen Gegenwartssprache, Düsseldorf: Schwann, 118-132.

Beneš, EduARD (HG.), 1971, Stilistik und Soziolinguistik. Beiträge der Prager Schule zur strukturellen Sprachbetrachtung und Spracherziehung, München: List, tschech. Erstausg.: 1969.

BERRETTA, MONICA, 1988, "Italienisch: Varietätenlinguistik des Italienischen“, Lexikon der Romanistischen Linguistik IV, 762-774.

Berruto, GAETANO, 1974, La sociolinguistica, Bologna: Zanichelli.

BerRuto, GAETANo, 1978, Le varietà dell'italiano, Bellizona.

Berruto, GAetano, 1980, La variabilità sociale della lingua, Torino: Loescher.

Berruto, Gaetano, 1987, Sociolinguistica dell'italiano contemporaneo, Roma: La

Nuova Italia Scientifica.

Berruto, Gaetano, 1987a,"Varietät“, U. Ammon; N. Dittmar; K. J. Mattheier (Hgg.),

Soziolinguistik. Ein internationales Handbuch zur Wissenschaft von Sprache und Ge-

sellschaft. Band1, Berlin / New York: de Gruyter, 263-267.

Berruto, Gaetano, 1989,“Tra italiano e dialetto“, G. Holtus; M. Metzeltin; M. Pfister

(Hgg.), La dialettologia italiana oggi. Studi offerti a Manlio Cortelazzo, Tübingen:

Narr, 107-122.

Berschin, Helmut, 1989,"Wie beschreibt man eine Fachsprache?“', W. Dahmen (Hg.),

Technische Sprache und Technolekte in der Romania. Romanistisches Kolloquium

II, Tübingen: Narr, 52-64.

Bidot-Germa, Dominique / Grosclaude M. / Duchon, J.-P., 1986, Histoire de Béarn, Pau: Per Noste.

Bochmann, KLAUS, 1989, Regional- und Nationalitätensprachen in Frankreich, Italien und Spanien, Leipzig: Verlag Enzyklopädie. 
Borrego Nieto, Julio, 1981, Sociolingüistica rural. Investigación en Villadepera de Sayago, Salamanca: Ed. Universitarias.

Bossong, GeOrG, 1996,"Normes et conflits normatifs“, P. Nelde (Hg.), Kontaktlinguistik' HSK 12.1, Berlin / New York: de Gruyter, 609-624.

BOUVIER, JEAN-ClAude, 1987,"Les langues régionales aujourd'hui“, Qui vive international 5, no. spécial Parlez-vous français?.

Cabrejas, Mara / Garcia, ERnest, 1997, València, L'Albufera, L'Horta: medi ambient $i$ conflicte social, Valencia.

CAMENisch, Claudio / KRISTOL, ANDRES, 1989, “L'intercompréhension entre le gascon, le languedocien et le catalan“, B. Moreux (Hg.), Langues en Béarn, Toulouse: Presses Universitaires du Mirail, 71-86.

Castellanos i Llorenç, CARles / Pazos i Noguera, Maria-Lluïsa, 1995, Curs de sociolingüistica per a BUP, COU i Reforma, Barcelona / Vilassar de Mar: oikostau.

Chateaureynaud, Marie AnNA, 1998,"Lectura de 1'enquesta“Practicas e representacions de l'occitan dens los Pirenèus Atlantics", Lengas 43, 117-142.

Christmann, Hans Helmut, 1978, "Gesprochene Sprache von heute oder alte Sprachstufen als 'wahrer' Gegenstand der Linguistik? Zur historischen Sprachwissenschaft des 19. Jahrhunderts und ihrer 'Überwindung'", Zeitschrift für Romanische Philologie 94, 549-562.

Christmann, Hans Helmut, 1983,“Das Französische der Gegenwart: Zu seiner Norm und seiner Défense“, F. J. Hausmann (Hg.), Die französische Sprache von heute, Darmstadt, 411-440.

Cichon, Peter, 1988, Spracherziehung in der Diglossiesituation: Zum Sprachbewußtsein von Okzitanischlehrern, Wien: VWGÖ.

COLÓN, GERMÁN, 1989, Español y catalán, juntos y en contraste, Barcelona: Editorial Ariel.

COMisión de LAS COMUNidAdes EuROPEAS (HG.), 1990, Las minorías lingüisticas en la Comunidad Económica Europea: España, Portugal, Grecia, Luxemburgo.

Cortelazzo, Manlio, 1982,"Italiano regionale e dialetto“, N. Dittmar; B. SchliebenLange (Hgg.), Die Soziolinguistik in romanischsprachigen Ländern. La sociolinguistique dans les pays de langue romane, Tübingen: Narr, 179-183.

Cortelazzo, Michele A., 1988,"Italienisch: Fachsprachen“, Lexikon der Romanistischen Linguistik IV, Tübingen: Niemeyer, 246-255.

Coseriu, Eugenio, 1974, Synchronie, Diachronie und Geschichte. Das Problem des Sprachwandels, München: Fink.

Coseriu, Eugenio, 1975, "Determinierung und Umfeld. Zwei Probleme einer Linguistik des Sprechens", E. Coseriu, Sprachtheorie und allgemeine Sprachwissenschaft. 5 Studien, München: Fink, 253-290.

COSERIU, EugENIO, 1987,"El gallego y sus problemas“, LEA 9.

COSERIU, EUGENIO, 1988, Schriften (1965-1987), eingeleitet und herausgegeben von Jörn Albrecht; J. Lüdtke; H. Thun (Hgg.), Energeia und Ergon. Studia in honorem Eugenio Coseriu, Bd. 1, Tübingen: Narr.

Coseriu, Eugenio, 1988a, Sprachkompetenz. Grundzüge der Theorie des Sprechens (Hg. H. Weber), Tübingen: Francke. 
Coseriu, Eugenio, 1988b, Einführung in die Allgemeine Sprachwissenschaft, Tübingen: Francke.

Coseriu, Eugenio, 2007, Textlinguistik, Hg. von J. Albrecht, 3. überarb. u. erw. Aufl., Tübingen / Basel: Francke.

COUderc, Yves, 1976,“A propos du francitan“, Cahier du Groupe de Recherche sur la Diglossie (Montpellier) 3, 1-17.

Coulmas, Florian, 1991, A Language Policy for the European Community. Prospects and Quandaries, Berlin / New York: Mouton de Gruyter.

CRIADO DE VAL, MANUEL, 1980, Estructura general del coloquio, Madrid: SGEL.

CURS DE GRAMÀTICA NORMATIVA. PER A ÚS DELS VALENCIANS, 1980 / 1983, Grau elemental (1980), grau mitjà (1983), grau superior (1980). Unter Mitarbeit von J. Barberà u.a., Univ. de València: Institut de Ciències de l'Educació.

Dahmen, Wolfgang [U.A.], 1989, Technische Sprache und Technolekte in der Romania. Romanistisches Kolloquium II., Tübingen: Narr.

Dahmen, Wolfgang [U.A.] (HGG.), 1991, Zum Stand der Kodifizierung romanischer Kleinsprachen. Romanistisches Kolloquium V, Tübingen: Narr.

Dahmen, Wolfgang [U.A.] (HgG.), 1995, Konvergenz und Divergenz in den romanischen Sprachen. Romanistisches Kolloquium VIII, Tübingen: Narr.

DANEŠ, FRANTIŠEK, 1988,"Herausbildung und Reform von Standardsprachen“, Soziolinguistik 3.1, Berlin / New York: de Gruyter, 1506-1516.

DARRIGRAND, RoBerT, 1971, Initiation au gascon, Pau: Per Noste.

DARrigrand, Robert, 1985, Comment écrire le gascon, Denguin: Per Noste.

Desplat, Christian, 1989, Pau, des origines à la révolution française (Texte imprimé), Pau: J. \& D.

Di Cesare, Donatella, 1988, "Die aristotelische Herkunft der Begriffe ěp

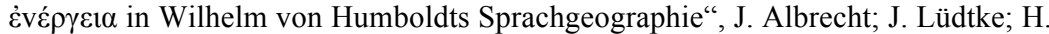
Thun (Hgg.), Energeia und Ergon. Studia in honorem Eugenio Coseriu, Bd. 2, Tübingen: Narr, 29-46.

Di LuZIO, ALDO, 1982,“La sociolinguistique en Italie“, N. Dittmar; B. Schlieben-Lange (Hgg.), Die Soziolinguistik in romanischsprachigen Ländern, Tübingen: Narr, 3352.

Dressler, Wolfgang / WodAK, Ruth, 1989, Fachsprache und Kommunikation. Experten im sprachlichen Umgang mit Laien, Wien: Bundesverlag.

DuARTE I MONTSERRAT, CARlos, 1991,"Katalanisch: Fachsprachen und Sondersprachen (Tecnolectos y jergas)“, Lexikon der Romanistischen Linguistik V, 2, 182-191.

EICHINGER, LudWIG M., 1992,"Konflikte und Minderheiten“, Germanistische Mitteilungen $35,45-53$.

EICHINGER, LudwiG M., 1999,“Objekte in wechselnder Bedeutung. Regional- und Minderheiten in West- und Mitteleuropa“, P. J. Weber (Hg.), Plurilingua XXI: Contact + Confli $(c) t$, Bonn: Dümmler, 13-27.

ERFURT, JÜRGEN, 1993, "Standard, Nonstandard, Substandard“, Zeitschrift für Romanische Philologie 109, 339-348. 
ERNST, GERHARD, 1983,"Was passiert, wenn eine Sprache vereinfacht wird? Gedanken zu den Termini 'einfach' und 'Vereinfachung' in der Sprachwissenschaft", G. Holtus; E. Radtke, (Hgg.), Varietätenlinguistik des Italienischen, Tübingen: Narr, 107-116.

EstalenX, JeAn-François D', 1993, Dictionnaire français-gascon. Des notions aux mots, 2 tomes, Toulouse: Ed. Univ. du Sud.

Esterbauer, FRIED (Hg.), 1979, Regionalismus. Phänomen-Planungsmittel-Herausforderung für Europa. Eine Einführung, Wien.

Euromosaic, 1996, Euromosaic. The Production and Reproduction of the Minority Language Groups of the EU, Brüssel / Luxemburg: European Commission.

FAUlSEIT, DiETER, 1975, Das Fachwort in unserem Sprachalltag, Leipzig: VEB Bibliographisches Institut.

Felber, Helmut / LANG, F. / Wersing, G., 1979, Terminologie als angewandte Sprachwissenschaft. Gedenkschrift für Univ.-Prof. Dr. Eugen Wüster, München et al.: Saur.

Fenie, Benedicte / Fenie, Jean-Jacques, 1992, Toponymie gasconne, Bordeaux: Sud Ouest.

Ferguson, Charles A., 1959,"Diglossia“, Word 15, 325-340.

FILL, AlwIN, 1993, Ökolinguistik, Tübingen: Narr.

Fishman, JoshuA A., 1965,"Who speaks what language to whom and when?", La Linguistique 2, 67-88.

FLUCK, HANS-RÜDIGER, 1985, Fachsprachen. Einführung und Bibliographie, München: Francke, 3. aktualisierte und erweiterte Auflage.

FrÖHLICH, HARALD, 1989,"Dreisprachiges Luxemburg: Sprachkontakt ohne Sprachkonflikt?", Germanistische Mitteilungen 30, 105-116.

GALli DE' PARATESI, NORA, 1985, Lingua toscana in bocca ambrosiana. Tendenze verso l'italiano standard: un'inchiesta sociolinguistica, Bologna: Il Mulino.

Generalitat de Catalunya, Departament de Cultura, Direcció General de PolítiCA LingüístiCA (HG.), 1987, Le catalan en Europe, Barcelone.

Gimeno, Francisco / Montoya, Brauli, 1989, Sociolingüistica, Univ. de València.

Gloy, Klaus, 1975, Sprachnormen I. Linguistische und soziolinguistische Analysen, Stuttgart / Bad Cannstadt.

Gloy, Klaus, 1987,"Norm“, Soziolinguistik 3.1, Berlin / New York: de Gruyter, 119124.

GloY, Klaus, 1995,"Zur Methodologie der Sprachnormenforschung“, Rostocker Beiträge zur Sprachwissenschaft I, 73-93.

GloY, KLAUS, 1997,“Sprachnormen als 'Institutionen im Reich der Gedanken’ und die Rolle des Individuums in Sprachnormierungsprozessen“, K. J. Mattheier, Norm und Variation, Frankfurt a. Main, 27-36.

Gnutzmann, Claus / Turner, John (HGG.), 1980, Fachsprachen und ihre Anwendung, Tübingen: Narr.

GOEBL, HANS, 1989,“Quelques remarques relatives aux concepts Abstand et Ausbau de Heinz Kloss“, U. Ammon (Hg.), Status and Function of Languages and Language Varieties, Berlin / New York: de Gruyter, 278-290. 
GOEBL, HANS, 1989a,“Spracheinheit-unité de la langue-unità della lingua-unidad de la lengua. Bemerkungen zum Problem des Sprachunitarismus“, F. H. Riedl / T. Veiter (Hgg.), Fédéralisme, régionalisme et droit des groupes éthniques en EuropeFöderalismus, Regionalismus und Volksgruppenrecht in Europa. Hommage à G. Héraud-Festschrift G. Héraud, Wien, 162-171.

Goebl, Hans / Nelde, P. H. / Starý, Z. / WÖlck, W. (HgG.), 1996, Kontaktlinguistik. Ein internationales Handbuch zeitgenössischer Forschung, 2 Halbbde., Berlin / New York: de Gruyter ('Handbücher zur Sprach- und Kommunikationswissenschaft 12.1).

Göschel, JoAChim / NAIL, N. / VAn DER Elst, G. (HGG.), 1976, Zur Theorie des Dialekts. Aufsätze aus 100 Jahren Forschung mit biographischen Anmerkungen zu den Autoren, Wiesbaden: F. Steiner.

Gogolin, Ingrid / Kroon, S. / KrÜger-Potratz, M. / Neumann, U. / Vallen, T. (HGG.), 1991, Kultur- und Sprachenvielfalt in Europa, Münster / New York: Waxmann.

GRASSI, CORRADO, 1985,“Ortssprachenanalyse in Italien und der Romania“, W. Besch; K. J. Mattheier (Hgg.), Ortssprachenforschung. Beiträge zu einem Bonner Kolloquium, Berlin: E. Schmidt, 49-61.

Gregory, Michael / CARroll, SuSAnNe, 1978, Language and Situation. Language Varieties and their Social Contexts, London: Routledge \& Kegan Paul.

Grosclaude, Michel, 1977, Lo Gascon lèu e plan, Paris: Omnivox.

Grosclaude, Michel, 1979, Le Béarn: témoignages sur mille ans d'histoire, Pau: Marrimpouey Jeune.

Grosclaude, Michel, 1986, La Gascogne. Témoignages sur deux mille ans d'histoire, Denguin: Deus Gaves.

Grosclaude, Michel, 1991, Dictionnaire toponymique des communes du Béarn, Pau: Escòla Gaston Febus.

Grosclaude, Michel, 1992, La langue béarnaise et son histoire. Étude sur l'évolution de l'occitan du Béarn, Orthez: Per Noste.

GUESPIN, LOUIS / LAROUSSI, FOUED, 1989,"Glottopolitique et standardisation terminologique“, La Banque des Mots numéro Spécial, Paris: C.I.L.F., 5-21.

Gumperz, John J. (Hg.), 1972, Directions in Sociolinguistics. The Ethnography of Communication, New York: Holt, Rinehart \& Winston, Nachdruck: Oxford [u.a.]: Blackwell 1986.

GuMPERZ, JOHN J., 1989,"Linguistics and Social Characteristics of Minorization / Majorization in Verbal Interaction“, B. Py; R. Jeanneret (Hgg.), Minorisation linguistique et interaction, Neuchâtel / Genève: Faculté des Lettres / Droz, 21-38.

HAARMAnN, HARALD, 1979, Elemente einer Soziologie der kleinen Sprachen Europas, Bd. 2: Studien zur Multilingualismusforschung und Ausbaukomparatistik, Hamburg: Buske.

HaArmann, Harald, 1980, Multilingualismus, Bd. 1: Probleme de Systematik und Typologie, Bd. 2: Elemente einer Sprachökologie, Tübingen: Narr.

HAARMAnN, HARAlD, 1983, Elemente einer Soziologie der kleinen Sprachen Europas, Bd. 1: Materialien zur Sprachökologie, 3., völlig veränd. u. neu konzipierte Fassung (1. u. 2. Aufl. unter dem Titel: Soziologie der kleinen Sprachen Europas), Hamburg: Buske. 
HaArmann, Harald, 1986, Language in Ethnicity. A View of Basic Ecological Relations, Berlin / New York / Amsterdam.

HAARMANN, HARALD, 1988,“Allgemeine Strukturen europäischer Standardsprachenentwicklung“, K. J. Mattheier (Hg.), Standardisierungsentwicklungen in europäischen Nationalsprachen: Romania, Germania, Tübingen, 10-51.

HAARMANN, HARALD, 1989,"Functional Aspects of Language Varieties-A TheoreticalMetodological Approach“, U. Ammon (Hg.), Status and Function of Languages and Language Varieties, Berlin / New York, 153-193.

HaARmann, Harald, 1993, Die Sprachenwelt Europas. Geschichte und Zukunft der Sprachnationen zwischen Atlantik und Ural, Frankfurt/Main / New York: Campus.

HAARMANN, HARALD; MULJAčIć, ŽARKO, 1996, “Distance interlinguistique, élaboration linguistique et 'coiffure linguistique"“, Kontaktlinguistik' HSK 12.1, Berlin / New York: de Gruyter, 634-642.

HAHN, WALTER VON, 1983, Fachkommunikation. Entwicklung-linguistische Konzeptebetriebliche Beispiele, Berlin / New York: de Gruyter.

HALlig, RUdOLF / WARTBURG, WALTHER Von, 1952, Begriffssystem als Grundlage für die Lexikographie. Versuch eines Ordnungssystems, Berlin: Akademischer Verlag.

Halliday, Michael Alexander KIRKwood, 1978, Language as Social Semiotic: the Social Interpretation of Language and Meaning, London: Arnold.

HAMmARSTRÖM, GÖRAN, 1976, “Towards More Exhaustive Descriptions of Languages“, Linguistics 177, 23-43.

Hanisch, Wilhelm, 1931, Stierkampf und Sprache (ein Problem nationalsprachlicher Sonderart), Marburg: R. Friederich's Universitätsdruckerei.

HARTUNG, WolfDIETRICH, 1985, “Divergierende Bewertungen sprachlicher Differenzierungen“, P. H. Nelde (Hg.), Methoden der Kontaktlinguistik, Bonn: Dümmler, 183192.

HARTUNG, WOLFDIETRICH, 1987,"Sprachnormen-ihr sozialer Charakter und die linguistische Begrifflichkeit“, Zeitschrift für Phonetik, Sprachwissenschaft und Kommunikationskunde 40, 3, 317-335.

Haugen, Einar, 1976,"Dialekt, Sprache, Nation“, J. Göschel [u.a.] (Hgg.), Dialekt und Dialektologie, Wiesbaden: Steiner, 152-169.

HAVRÁNEK, BohUSLAV (Hg.), 1932, Spisovná cestina a jazyková kultura [dt. Tschechische Schriftsprache und Sprachkultur], Prag: Melantrich.

Heger, Klaus, 1969,“'Sprache' und 'Dialekt' als linguistisches und soziolinguistisches Problem", Folia Linguistica 3, 46-67.

HEgER, KLAUS, 1989,"Zur plurizentrischen Sprachkultur“, Zeitschrift für Germanistische Linguistik 17, 226-228.

Helfrich, Uta; Riehl, Claudia Maria (HGg.), 1994, Mehrsprachigkeit in EuropaHindernis oder Chance?, Wilhelmsfeld: Egert.

HofFmann, LothaR, 1985, Kommunikationsmittel Fachsprache. Eine Einführung, Tübingen: Narr, 2. Aufl..

HOFFMANN, LOTHAR, 1986,"Ein textlinguistischer Ansatz in der Fachsprachenforschung“, M. Sprissler (Hg.), Standpunkte der Fachsprachenforschung, Tübingen: Narr, 91-105. 
HOINKES, UlRICH, 1993,"Nous aspectes del debat sobre la fragmentació dialectal del català“, Actes du XXe Congrès International de Linguistique et Philologie Romanes, Université de Zurich (6-11 avril 1992), publiés par Gerold Hilty en collaboration avec les présidents de section, tome II, Tübingen / Basel: Francke, 461-473.

HOINKES, UlRICH, 1995,"Distància i grau d'elaboració: nous paràmetres per a una lingüística de varietats?", Estudis de lingüística i filologia oferts a Antoni M. Badia i Margarit, Bd. 1, Barcelona: Publicacions de 1'Abadia de Montserrat, 379-394.

HoINKES, UlRICH, 1995a,"Das Spannungsfeld von linguistischer und sprachsoziologischer Funktion des innerromanischen Sprachvergleichs“, Chr. Schmitt; W. Schweickard (Hgg.), Die romanischen Sprachen im Vergleich. Akten der gleichnamigen Sektion des Potsdamer Romanistentages (27.-30.9.1993), Bonn, 150-166.

HoINKES, UlRiCH, 1997,"Varietät und Standard im Sprachkontakt. Überlegungen zu einem neuen Konzept sprachlicher Standardisierung“, K. J. Mattheier, Norm und Variation, Frankfurt a. Main, 37-52.

HoINKES, UlRICH, 1997a,"Norme et variation de la langue parlée“, Beitrag zum XVIe Congrès International des Linguistes, Paris, 20-25 juillet 1997, Amsterdam: Pergamon / Elsevier [erscheint ausschließlich auf CD-ROM, angekündigt für Dez. 1998].

HOINKES, UlRICH, 1997b,"Kommunikation in Sachbereichen und Fachsprachengebrauch. Versuch einer normentheoretischen Präzisierung", Beitrag zur Sektion Normen und Subnormen in Geschichte und Gegenwart-Methoden ihrer Rekonstruktion und Beschreibung des XXV. Deutschen Romanistentags 1997 (Romania I), Jena, 28.9-2.10.1997, [Veröffentlichung in Vorbereitung].

HOLTUS, GÜNTER, 1978,“Zu einigen Beschreibungsversuchen der Varietäten und Strukturen der französischen Gegenwartssprache“, Französisch heute 9, 161-169.

Holtus, GÜNTER / RADTKE, EdgAR (HGG.), 1984, Umgangssprache in der Iberoromania. Festschrift für Heinz Kröll, Tübingen: Narr.

Holtus, Günter / RAdTKe, Edgar (HGg.), 1986-1989, Sprachlicher Substandard, 3 Bde., Tübingen: Niemeyer.

Hourcade, ANDRE, 1986, Grammaire béarnaise, Pau: Los Caminaires.

HourCADE, ANDRE, 1990, Dictionnaire bilingue des expressions gasconnes, Pau: Los Caminaires.

Humboldt, Wilhelm von, 1972, Werke in fünf Bänden, Darmstadt: Wissenschaftliche Buchgesellschaft.

Insee / AQuitaine, 1995, Les Pyrénées-Atlantiques. Aspects socio-économiques, Dossier 15 .

ISCHREYT, HEINZ, 1965, Studien zum Verhältnis von Sprache und Technik. Institutionelle Sprachlenkung in der Terminologie der Technik, Düsseldorf: Schwann.

KABATEK, JoHANNES, 1996, Die Sprecher als Linguisten. Interferenz und Sprachwandelphänomene dargestellt am Galicischen der Gegenwart, Tübingen: Niemeyer.

KALVERKÄMPER, HARTWIG, 1988, Fachsprachen in der Romania, Tübingen: Narr.

Keller, Judith (1985): Histoire de la langue française en Béarn. In: Kristol, A. M. / Wüest, J. Th., 1985, 63-74. 
KeRn, RudOLF, 1991,"Das schwierige Projekt einer Europäischen Charta der Regionaloder Minderheitssprachen“, K. J. Mattheier (Hg.), Ein Europa-Viele Sprachen, Frankfurt u.a.: Peter Lang, 175-177, Kurzfassung (Vollfassung in Germanistische Mitteilungen 35 (1991).

KISSENBECK, ANNE, 1997, Fachsprache und Regionalisierung. Empirische Untersuchungen zum Wortschatz des Bergbaus, Frankfurt a. Main: P. Lang.

Klein, Wolfgang, 1974, Variation in der Sprache. Ein Verfahren zu ihrer Beschreibung, Kronberg: Scriptor.

KLoss, HeINZ, 1967,““Abstand languages' and 'Ausbau languages'“, Anthropological Linguistics 9, 29-41.

Kloss, HeInZ, 1976,“Abstandsprachen und Ausbausprachen“, J. Göschel; N. Nail; G. Van der Elst (Hgg.), Zur Theorie des Dialekts, Wiesbaden, 301-322.

KLoss, HeInZ, 1976a,"Über 'Diglossie'“, Deutsche Sprache 4, 313-323.

KLOSS, HeINZ, 1978, Die Entwicklung neuer germanischer Kultursprachen seit 1800, 2., erweiterte Aufl. (1. Aufl. 1952), Düsseldorf: Schwann.

Kloss, HeInZ, 1987,"Abstandsprache und Ausbausprache“, Soziolinguistik 'HSK 3.1, Berlin / New York: de Gruyter, 302-308.

КосH, Peter, 1985,"Gesprochenes Italienisch und sprechsprachliche Universalien“, G. Holtus; E. Radtke (Hgg.), Gesprochenes Italienisch in Geschichte und Gegenwart, Tübingen: Narr, 42-76.

Koch, Peter, 1986,"Sprechsprache im Französischen und kommunikative Nähe“, Zeitschrift für französische Sprache und Literatur 96, 2, 113-154.

KосH, Peter, 1988,"Norm und Sprache“, J. Albrecht; J. Lüdtke; H. Thun (Hgg.), Energeia und Ergon. Studia in honorem Eugenio Coseriu, Bd. 2, Tübingen: Narr, 327-354.

Koch, Peter / Oesterreicher, Wulf, 1985,"Sprache der Nähe-Sprache der Distanz. Mündlichkeit und Schriftlichkeit im Spannungsfeld von Sprachtheorie und Sprachgeschichte“, Romanistisches Jahrbuch 36, 15-43.

Koch, Peter / Oesterreicher, Wulf, 1990, Gesprochene Sprache in der Romania: Französisch, Italienisch, Spanisch, Tübingen: Niemeyer.

KOMMUNIKATION UND SPRACHVARIATION, 1981, mit Beiträgen von W. Hartung, H. Schönfeld u.a., Berlin: Akademie-Verlag.

Koppelberg, StePhan, 1991,"Galegisch, Euskara und Katalanisch. Sprachen und Sprachpolitik im spanischen Staat", W. L. Bernecker; J. Oehrlein (Hgg.), Spanien heute, Frankfurt a. Main: Vervuert, 387-426.

Krefeld, ThOmas, 1988, “Italienisch: Periodisierung“, Lexikon der Romanistischen Linguistik IV, Tübingen: Niemeyer, 748-762.

KREMNITZ, GEORG, 1974, Versuche zur Kodifizierung des Okzitanischen seit dem 19. Jahrhundert und ihre Annahme durch die Sprecher, Tübingen: Narr.

Kremnitz, GeOrG, 1981, Das Okzitanische. Sprachgeschichte und Soziologie, Tübingen: Niemeyer.

KREMNITZ, GEORG, 1982,"La sociolinguistique dans les Etats français et espagnol", N. Dittmar; B. Schlieben-Lange (Hgg.), Die Soziolinguistik in romanischsprachigen Ländern. La sociolinguistique dans les pays de langue romane, Tübingen: Narr, 13-28. 
Kremnitz, GeOrg, 1987,"Diglossie / Polyglossie“, Soziolinguistik 'HSK 3.1, Berlin / New York: de Gruyter, 208-218.

Kremnitz, GeOrG, 1989,"Zur Situation des Okzitanischen im Val D’Aran“, P. Anreiter (Hg.), Investigationes Romanicae I, Innsbruck, 18-25.

KremnitZ, GeORG, 1989a,"Die Rolle der Sprache bei der Konstitution des kollektiven Bewußtseins in den Katalanischen Ländern“, Semiotische Berichte 13, 349-371.

KREMNITZ, GEORG, 1990, Gesellschaftliche Mehrsprachigkeit, Wien: Braumüller.

Kremnitz, GeORG, 1990a,"Okzitanisch: Soziolinguistik“, Lexikon der Romanistischen Linguistik V, 2, Tübingen: Niemeyer, 33-45.

KremnitZ, GeORG, 1995,"Sprache und Gesellschaft in den Katalanischen Ländern“, Sprachen in Gesellschaften. Annäherung an eine dialektische Sprachwissenschaft, Wien: Braumüller, 94-129.

KremnitZ, GeORG, 1995a,"Zum Sprachkonflikt im Bearn und in der Gaskogne im 16. Jahrhundert", Sprachen in Gesellschaften. Annäherung an eine dialektische Sprachwissenschaft, Wien: Braumüller, 55-61.

Kremnitz, GeORG, 1996,"Diglossie“, Kontaktlinguistik 'HSK 12.1, Berlin / New York: de Gruyter, 245-257.

KremnitZ, GeORG, 1997, Die Durchsetzung der Nationalsprachen in Europa, Münster / New York / München / Berlin: Waxmann.

Kremnitz, Georg (Hg.), 1979, Sprachen im Konflikt. Theorie und Praxis der katalanischen Soziolinguisten. Eine Textauswahl, Tübingen: Narr.

Kremnitz, GeOrg (Hg.), 1982, Entfremdung, Selbstbefreiung und Norm. Texte aus der okzitanischen Soziolinguistik, Tübingen: Narr.

LAFONT, ROBERT, 1979,"La diglossie en pays occitan, ou le réel occulté“, Kloepfer, Rolf (Hg.), Bildung und Ausbildung in der Romania, Akten des Romanistentages in Gießen 1977, vol. 2, München: Fink, 504-512.

LAFONT, ROBERT, 1989,“Trente ans de sociolinguistique occitane (sauvage ou institutionnelle)“, Lengas 25, 13-25.

Lamuela, Xavier, 1994, Estandardització i establiment de les llengües, Barcelona: Edicions 62.

LANGUES EN BEARN, 1989, Cahiers de l'Université de Pau et des Pays de l'Adour 15, Toulouse-Le Mirail: Presses Universitaires du Mirail.

LAPESA, RAFAEL (HG.), 1977, Comunicación y lenguaje, Madrid: Karpos.

LARA, Luis Fernando, 1974, El concepto de norma en lingüística, México: Fondo de Cultura Económica.

LARA, LuIS FERNANDO, 1983,"Le concept de norme dans la théorie d'Eugenio Coseriu“, E. Bédard; J. Maurais (Hgg.), La norme linguistique, Québec, 153-177.

LARA, LUIS FERNANDO, 1986,"Wissenschaftlich-technische Fachsprachen in Lateinamerika und der Entwicklungsstand des Spanischen. Das Beispiel Mexiko.“, T. Bungarten (Hg.), Wissenschaftssprache und Gesellschaft. Aspekte der wissenschaftichen Kommunikation und des Wissenstransfers in der heutigen Zeit, Hamburg: Akademion, 180-198.

LENGERT, JOACHIM, 1994, Regionalfranzösisch in der Literatur. Studien zu lexikalischen und grammatischen Regionalismen des Französischen in der Westschweiz, Basel / Tübingen: Francke. 
LePinetTe, BrigitTe, 1989,“L'essai sur les vices du langage de B. Sajus (Pau, 1821): Un lexique à viseé corrective“, Université de Pau et des pays de l'Adour, Langues en Béarn, 184-201.

LóPEZ DE CASTILlo, Lluís, 1976, Llengua standard i nivells de llenguatge, Barcelona: Ed. Laia.

LÓPEZ Morales, Humberto, 1989, Sociolingüística, Madrid: Gredos.

LÜDI, GEORGES, 1989, “Situations diglossiques en Catalogne“, G. Holtus; G. Lüdi; M. Metzeltin (Hgg.), La corona de Aragón y las lenguas románicas, Tübingen: Narr, 237-265.

LÜDI, GeORGES, 1990,"Französisch: Diglossie und Polyglossie“, Lexikon der Romanistischen Linguistik V, 1, Tübingen: Niemeyer, 307-334.

LÜdI, Georges (HG.), 1994, Sprachstandardisierung. Standardisation des langues. Standardizzazione delle lingue. Standardisation of languages, Fribourg: Univ.Verlag.

LÜdtKe, Helmut, 1980,“Auf dem Wege zu einer Theorie des Sprachwandels“, H. Lüdtke (Hg.), Kommunikationstheoretische Grundlagen des Sprachwandels, Berlin / New York: de Gruyter, 182-252.

LÜDTKE, JENS, 1988, "Situations diglossiques, variétés et conscience linguistique“, Actes $d u$ XVIIIe Congrès International de Linguistique et de Philologie Romanes, vol. 5, Tübingen: Niemeyer, 121-128.

LÜDTKE, JENS, 1991,“Katalanisch: Externe Sprachgeschichte“, Lexikon der Romanistischen Linguistik V, 2, 232-242.

Mattheier, Klaus J. (HG.), 1988, Standardisierungsentwicklungen in europäischen Nationalsprachen: Romania, Germania, Tübingen: Niemeyer.

Mattheier, Klaus J. (HG.), 1991, Ein Europa-viele Sprachen. Kongreßbeiträge zur 21. Jahrestagung der Gesellschaft für Angewandte Linguistik GAL e.V., Frankfurt u.a.: Peter Lang.

Mattheier, Klaus J. (Hg.), 1997, Norm und Variation, Frankfurt a. Main: P. Lang.

MAZEL, JEAN, 1975, "Français standard et français d'oc", Cahiers du Groupe de Recherche sur la Diglossie Franco-Occitane 2.

MAZEL, JEAN, 1980,"Francitan et français d'oc. Problèmes de terminologie“, Lengas 7, 133-141.

Meisenburg, Trudel, 1985, Die soziale Rolle des Okzitanischen in einer kleinen Gemeinde im Languedoc (Lacuane/Tarn), Tübingen: Niemeyer.

MöHn, Dieter / Pelka, Roland, 1984, Fachsprachen. Eine Einführung, Tübingen: Niemeyer.

Moreno Fernández, Francisco (HG.), 1990, Estudios sobre variación lingüistica, Alcalá de Henares Univ. de Alcalá de Henares.

Moreux, Bernard, 1989, “L'Essai de B. Sajus: français régional et idéologie à Pau en 1821", Université de Pau et des pays de l'Adour, Langues en Béarn, 203-234.

Moreux, Bernard / MoreuX, ColetTe, 1989,"La transmission du béarnais en milieu rural aujourd'hui“،, Université de Pau et des pays de l'Adour, Langues en Béarn, 235-256.

Moya, GonZalo / Lago, Jesus, 1977, Bilingüismo y trastornos del lenguaje en España, Madrid: Saltés. 
Müller, Bodo, 1975, Das Französische der Gegenwart: Varietäten, Strukturen und Tendenzen, Heidelberg, frz. Übers.: Le français d'aujourd'hui, Paris: Klincksieck 1985.

MüLLER, Bodo, 1977,"Soziale Sprachvarietäten und heutiges Französisch“, Imago Linguae. Beiträge zu Sprache, Deutung und Übersetzen. Festschrift zum 60. Geburtstag von F. Paepcke, München, 411-424.

MüLlER, BODO, 1990, “Gesprochene und geschriebene Sprache (Langue parlée et langue écrite)“, Lexikon der Romanistischen Linguistik V, 1, Tübingen, 195-211.

MünZER, Hieronymus, 1920, Itinerarium Hispanicum Hieronymi Monetarii (14441495), nach der Handschrift in der Bayrischen Staatsbibliothek aus dem Besitz des Hartmann Schedel, Revue Hispanique 48.

MuHr, Rudolf, 1981, Sprachwandel als soziales Phänomen. Eine empirische Studie zu soziolinguistischen und soziopsychologischen Faktoren des Sprachwandels im südlichen Burgenland, Wien: Braumüller.

MulJAčIć, ŽARKO, 1983, “Für ein neues Modell der 'Architektur' des Italienischen', G. Holtus; E. Radtke (Hgg.), Varietätenlinguistik des Italienischen, Tübingen, 142150.

MulJAčIć, ŽARKO, 1983a, "Italienischfundierte 'Ausbausprachen' und (andere) romanische 'Ausbausprachen' Italiens“, Italienisch 5, Heft 9, 10-25.

MulJAčIć, ŽARKO, 1986, “L'enseignement de Heinz Kloss (modifications, implications, perspectives)", Languages 83, 53-63.

MuLJAčIć, ŽARKO, 1988, “Italienisch: Sprachnormierung und Standardsprache. Norma e standard“, Lexikon der Romanistischen Linguistik IV, 286-305.

MuljačIć, ŽARKO, 1989,"Über den Begriff 'Dachsprache”“, U. Ammon (Hg.), Status and Function of Languages and Language Varieties, Berlin / New York: de Gruyter, 256-277.

MulJAčIć, ŽARKO, 1991,"L'Approccio relativistico“, Rivista Italiana di Dialettologia $15,183-191$.

Munsberg, Klaus, 1994, Mündliche Fachkommunikation. Das Beispiel Chemie, Tübingen: Narr.

MuÑoz CORTÉs, MANUEL, 1958, El español vulgar, Madrid.

MuÑoz CORTÉs, MANuEL, 1973,"El habla de la Huerta“, El libro de la Huerta, Murcia: Nogués, 97-111.

NABRINGS, KIRSTEN, 1981, Sprachliche Varietäten, Tübingen: Narr.

Nelde, Peter Hans, 1984,"Sprachkontakt als Kulturkonflikt", W. Kühlwein (Hg.), Sprache, Kultur, Gesellschaft, Tübingen: Narr, 31-40.

Nelde, Peter Hans, 1988,"Sprachkonfliktforschung“, Folia Linguistica 22, 1-2, 73 84.

Nelde, Peter Hans , 1989,"Le contact des langues en tant que conflit linguistique“, T. Veiter (Hg.), Fédéralisme, Régionalisme et Droit des Groupes Ethniques en Europe-Hommage à Guy Héraud, Wien: Braunmüller, 277-287.

Nelde, Peter Hans, 1989a,"Langues en contact et en conflit-quatres réflexions", K. R. Güttler; E. Mornin (Hgg.), Interrelations and interactions. Symposium 1987. 6. Symposium Deutschkanadische Studien, 72-85. 
Nelde, Peter Hans, 1991,"Language Conflicts in Multilingual Europe-Prospects for 1993", F. Coulmas (Hg.), A Language Policy for the European Community. Prospects and Quandaries, Berlin / New York, 59-73.

Nelde, Peter Hans, 1994,"Sind Sprachkonflikte vermeidbar?", U. Helfrich; C. M. Riehl (Hgg.); Mehrsprachigkeit in Europa-Hindernis oder Chance?, Wilhelmsfeld: Egert, 115-125.

NiCKel, AlEXANDRA, 1992, Einsprachige Mehrsprachigkeit. Eine empirische Studie zu Sprachwissen und Sprachvariation einer Sprecherfamilie in Ste. Gauburge-Ste. Colombe (Normandie), unveröffentl. Magisterarbeit, Paderborn.

Ninyoles, RAFAel Lluís, 1969, Conflicte lingüistic valencià, Valéncia: Ed. Tres i Quatre.

Ninyoles, Rafael Lluís, 1989, Estructura social i política lingüística, Alzira: Ed. Bromera, (Übersetzung von Ninyoles 1975).

OESTERREICHER, Wulf, 1979, Sprachtheorie und Theorie der Sprachwissenschaft, Heidelberg.

OESTERREICHER, WuLF, 1988,"Sprechtätigkeit, Einzelsprache, Diskurs und vier Dimensionen der Sprachvarietät“, J. Albrecht; J. Lüdtke; H. Thun (Hgg.), Energeia und Ergon. Studia in honorem Eugenio Coseriu, Bd. 2, Tübingen, 355-386.

OesterReICHER, Wulf, 1995,“Die Architektur romanischer Sprachen im Vergleich. Eine Programm-Skizze“, W. Dahmen [et al.] (Hgg.), Konvergenz und Divergenz in den romanischen Sprachen. Romanistisches Kolloquium VIII, Tübingen: Narr, 321.

OfFORD, Malcolm, 1990, Varieties of Contemporary French, Houndmills / London: Macmillan.

OKSAAR, ELS, 1987, Fachsprachliche Dimensionen, Tübingen: Narr.

PAlay, Simin, 1991, Dictionnaire du béarnais et du gascon modernes (Bassin Aquitain), 3. Aufl., Paris: CNRS.

PAyrató, Lluís, 1985, La interferència lingüística. Comentaris i exemples catalàcastellà, Barcelona: Curial Ed. Catalanes.

PAYRATO, Lluis, 1990, Català col.loquial: aspectes de l'us corrent de la llengua catalana, 2. Aufl., Valencia: Universitat de València.

PETIT DiCTIONNAIRE FRANÇAIS-OCCITAN (BEARN), Pau: La Civada / Per Noste 1984.

PiQueras HabA, Juan, 1992,“Comunidad Valenciana“, J. Bosque Maurel; J. Vilá Valentí (Hgg.), Geografía de España, Bd. 10, Barcelona: Planeta, 9-335.

PöCKL, WolfGANG, 1990,"Französisch: Fachsprachen“, Lexikon der Romanistischen Linguistik V, 1, Tübingen: Niemeyer, 267-282.

PÖLl, BERNHARD, 1994, Fachsprache-kontrastiv. Beiträge der gleichnamigen Sektion des 21. Österreichischen Linguistentages Salzburg, 23.-26. Oktober 1993, Bonn: Romanistischer Verlag.

Puig Moreno, GenTIL, 1993,"Les processus de standardisation dans les pays catalans. Standards et para-standards en catalan moderne, considérés dans une perspective sociolinguistique“, S. Guillorel (Hg.), Langues, dialectes et écritures. Les langues romanes de France. Actes du Colloque de Nanterre du 16, 17 et 18 avril 1992, Paris / Nanterre: I.E.O., 202-212. 
Pusch, Claus Dieter, 1998, Präverbale Marker im gesprochenen Gaskognisch. Zur Distribution, Genese und Pragmatik des Enunziativs. Mit einem Korpus mündlicher Texte zwischen konzeptioneller Nähe und Distanz, Freiburg: unveröffentl. Dissertation.

Py, Bernard / JEANNEREt, Rene (HGG.), 1989, Minorisation Linguistique et Interaction. Actes du symposium AILA/CILA (16-18sept. 1987), Neuchâtel / Genève: Faculté des Lettres / Droz.

QuAsthoff, U.M., 1980, Erzählen in Gesprächen. Linguistische Untersuchungen zu Strukturen und Funktionen am Beispiel einer Kommunikationsform des Alltags, Tübingen.

RADTKE, EDGAR, 1981,“Gesprochenes Gegenwartsitalienisch zwischen Dialektalität und Standardisierung“, Italienisch 3, 33-50.

RADTKE, EDGAR, 1982,"Die Rolle des Argot in der Diastratik des Französischen“, Romanische Forschungen 94, 151-166.

RADTKE, EDGAR, 1983,“Gesprochenes Italienisch zwischen Varietätenlinguistik und Gesprächsanalyse“, G. Holtus; E. Radtke (Hgg.), Varietätenlinguistik des Italienischen, Tübingen, 170-194.

RADTKE, EDGAR, 1986,“Abtönungen im gesprochenen Französisch“, Neuphilologische Mitteilungen 87, 45-58.

REyes, Román, 1988, Terminología científico-social. Aproximación crítica, Barcelona: Anthropos.

RICKHEIT, GERT / HANS STROHNER, 1993, Grundlagen der kognitiven Sprachverarbeitung: Modelle, Methoden, Ergebnisse, Tübingen / Basel: Francke Verlag.

RiEHM, HANNE, 1997, Untersuchungen zur regionalen Ausbildung fachsprachlicher Kompetenz in der französischen Gemeinsprache, am Beispiel des Sachbereichs 'Austern- und Muschelzucht' ('ostréiculture et mytiliculture') in der Region von Sète (Languedoc), Münster: unveröffentl. Staatsarbeit.

RINDLER SCHJERVE, RositA, 1990,“Zur Konfliktsituation des Sprachenwechsels in der Minderheitenfamilie“, P. H. Nelde (Hg.), Plurilingua X: Language Conflicts and Minorities, Bonn: Dümmler, 223-235.

RINDLER SCHJERVE, RositA, 1996,"Domänenuntersuchungen“, Kontaktlinguistik 'HSK 12.1, Berlin / New York: de Gruyter, 796-804.

RINDler SCHJERVE, Rosita, 1999, "There is no contact without conflict", P. J. Weber (Hg.), Plurilingua XXI: Contact + Confli(c)t, Bonn: Dümmler, 1-11.

Rodrígez Richart / José; Thome Gisela; Wilss, Wolfram (HgG.), 1982, Fachsprachenforschung und-lehre, Schwerpunkt Spanisch. Internationales Kolloquium an der Universität des Saarlandes (Saarbrücken, 6.- 8. November 1980), Tübingen: Narr.

Rogge, Waltraud / Beinke, Christiane, 1991,"Katalanisch: Sprachnormierung und Standardsprache", Lexikon der Romanistischen Linguistik V, 2, 192-218.

ROHLFs, Gerhard, 1977, Le gascon, études de philologie pyrénéenne, 3. Aufl., Tübingen / Pau: Niemeyer, Marrimpouey.

RusCH, P., 1989,"National versus regional models of language variation: The case of Austrian German", Language, Culture and Curriculum 2, 1-16. 
SABATINI, FrANCESCO, 1985,"L'"italiano dell'uso medio": una realtà tra le varietà linguistiche italiane“, G. Holtus; E. Radtke (Hgg.), Gesprochenes Italienisch in Geschichte und Gegenwart, Tübingen: Narr, 154-184.

SÁNCHEZ MüNNINGHOFF, SANDRA, 1998, Untersuchungen zur regionalen Ausbildung fachsprachlicher Kompetenz in der spanischen Gemeinsprache, am Beispiel des Sachbereichs 'Zitrusfruchtanbau' ('citricultura') im Valenzianischen Land, Münster: unveröffentl. Magisterarbeit.

SANCHIS GUARNER, MANUEL, 1968, Els pobles valencians parlen els uns dels altres. III. Sector central litoral, Valencia: L'Estel.

SANDIG, B., 1976,"Schriftsprachliche Norm und die Beschreibung und Beurteilung spontan gesprochener Sprache“, G. Presch; K. Gloy (Hgg.), Sprachnormen II. Theoretische Begründungen-außerschulische Sprachnormenpraxis, Stuttgart / Bad Cannstadt, 93-105.

SCHERER, HANS SIEGFRIED, 1984, Sprechen im situativen Kontext. Theorie und Praxis der Analyse spontanen Sprachgebrauchs, Tübingen: Stauffenburg.

SChlieben-LANGE, BRIGITTE, 1973, Okzitanisch und Katalanisch. Ein Beitrag zur Soziolinguistik zweier romanischer Sprachen, 2. Aufl., Tübingen: Narr.

SChlieben-LAnge, BRIGITTE, 1983, Traditionen des Sprechens. Elemente einer pragmatischen Sprachgeschichtsschreibung, Stuttgart / Berlin / Köln / Mainz: Kohlhammer.

SchmitT, CHRistian, 1987,"Zur Ausbildung der Sprachnorm des Neuspanischen", C. Strosetzki; M. Tietz (Hgg.), Einheit und Vielfalt der Iberoromania. Akten des Deutschen Hispanistentages, Passau, Hamburg: Buske, 125-146.

SCHMitT, Christian, 1988, “Typen der Ausbildung und Durchsetzung von Nationalsprachen in der Romania“, Sociolinguistica 2, 73-116.

SCHMitT, CHRISTIAN, 1990,"Zur Entstehung fachsprachlicher Defizite in Minderheitensprachen. Beobachtungen zur Ausbildung der Fachsprache des Skilanglaufs im Engadinischen“, P. H. Nelde (Hg.), Plurilingua X. Language Conflicts and Minorities, Bonn: Dümmler, 53-63.

SchmitT, Christian, 1992,"Spanisch: Fachsprachen", Lexikon der Romanistischen Linguistik VI, 1, Tübingen: Niemeyer, 295-327.

SCHÖNFELD, HELMUT, 1985,"Varianten, Varietäten und Sprachvariation", Zeitschrift für Phonetik, Sprachwissenschaft und Kommunikationskunde 38, Berlin, 206-267.

SCHRÄDER, AlFONS, 1991, Fach- und Gemeinsprache in der Kraftfahrzeugtechnik. Studien zum Wortschatz, Frankfurt a. M. / Berlin / New York / Paris: Peter Lang.

Seco, Manuel, 1977, *El léxico de hoy+, R. Lapesa (Hg.), Comunicación y lenguaje, Madrid: Karpos, 183-201.

Seguy, J., 1978, Le français parlé à Toulouse, 2. Aufl., Toulouse.

SEIBICKE, Wilfried, 1981,"Fachsprache und Gemeinsprache“, W. Hahn (Hg.), Fachsprachen, Darmstadt: Wiss. Buchgesellschaft, 40-66.

SETtEKorn, WolfGang, 1988, Sprachnorm und Sprachnormierung in Frankreich: Einführung in die begrifflichen, historischen und materiellen Grundlagen, Tübingen: Niemeyer.

SETteKorn, WolfGang (HG.), 1990, Sprachnorm und Sprachnormierung. DeskriptionPraxis-Theorie, Wilhelmsfeld: Egert. 
SiguAn, MiQuel, 1989,"Languages and Dialects in the Educational System of Spain“, Sociolinguistica. Internationales Jahrbuch für Europäische Soziolinguistik 3, Tübingen: Niemeyer, 128-142.

Siguan, MiQuel, 1993, Multilingual Spain, Amsterdam / Lisse / Berwyn: Swets \& Zeitlinger.

Silva-Corvalan, CARmen, 1989, Sociolingüística. Teoría y análisis, Madrid: Alhambra.

Sobrero, Alberto A., 1989,"La variation linguistique dans les domaines romans: approches méthodologiques et problèmes théoriques“, D. Kremer (Hg.), Actes du XVIII Congrès International de Linguistique et de Philologie Romanes, tome V, Tübingen: Niemeyer, 41-49.

Söll, Ludwig / Hausmann, Franz Josef, 1985, Gesprochenes und geschriebenes Französisch, 3. Aufl.; Berlin: Schmidt.

SPEnCER, John (Hg.), 1964, Linguistics and Style, London: Oxford Univ. Press, dt. Übers.: Linguistik und Stil, Heidelberg: Quelle \& Meyer 1972.

SPRISSLER, MANFRED, 1986, Standpunkte der Fachsprachenforschung, Tübingen: Narr.

Steger, HugO, 1979,“Gesprochene Sprache. Zu ihrer Typik und Terminologie“, P. Braun (Hg.), Deutsche Gegenwartssprache, München, 172-205, Original: 1969.

Steger, Hugo, 1982, Über die Würde der alltäglichen Sprache und die Notwendigkeit von Kultursprachen, Mannheim.

STEGER, HugO, 1987,“Bilden 'gesprochene Sprache' und 'geschriebene Sprache' eigene Sprachvarietäten?“, H. Aust (Hg.), Wörter. Schätze. Fugen und Fächer des Wissens. Festgabe für Theodor Lewandowski zum 60. Geburtstag, Tübingen, 35-58.

Steger, Hugo, 1988, "Erscheinungsformen der deutschen Sprache“, Deutsche Sprache, 289-319.

STEGER, Hugo, 1991,“Alltagssprache. Zur Frage nach ihrem besonderen Status in medialer und semantischer Hinsicht", W. Raible (Hg.), Symbolische Formen, Medien, Identität, Tübingen: Narr, 55-112.

Stegmann, Till / Stegmann, Inge (HgG.), 1992, Katalonien und die katalanischen Länder. Kunst- und Reiseführer, Stuttgart / Berlin / Köln: Kohlhammer.

STEHL, ThOmas, 1988, 'Les concepts de 'continuum' et de 'gradatum' dans la linguistique variationnelle“, D. Kremer (Hg.), Actes du 18 e Congrès Inernational de Linguistique et de Philologie romanes (Trèves, 19-24 mai 1986), Bd. 5: Linguistique pragmatique et sociolinguistique, Tübingen: Niemeyer, 28-40, 51-54.

STEHL, THOMAS, 1990,“Ansätze einer strukturalistischen Beschreibung der Variation im Französischen und Italienischen“, G. Holtus; E. Radtke (Hgg.), Sprachlicher Substandard III. Standard, Substandard und Varietätenlinguistik, Tübingen: Niemeyer, $172-210$.

Stehl, Thomas, 1991, Funktionale Analyse der sprachlichen Variation. Untersuchungen zur Dynamik von Sprachkontakten in der Galloromania und Italoromania, Univ. GH Paderborn: unveröffentl. Habilitationsschrift.

STEHL, THOMAS, 1991a,"Il concetto di italiano regionale e la dinamica dell'italiano nelle regioni“, J. Kramer (Hg.), Siue Padi ripis Athesim seu propter amoenum. Festschrift für Giovan Battista Pellegrini, Hamburg: Buske, 385-402. 
STEHL, ThOMAS, 1994,"Français régional, italiano regionale, neue Dialekte des Standards: Minderheiten und ihre Identität im Zeitwandel und im Sprachenwechsel“", U. Helfrich; C. M. Riehl (Hgg.), Mehrsprachigkeit in Europa-Hindernis oder Chance?, Wilhelmsfeld: Egert, 127-147.

STEPHENS, MeIC, 1976, Linguistic Minorities in Western Europe, Llandysul.

Strubell i Trueta, Miquel, 1994,"Catalan in Valencia. The story of an attempted secession“, G. Lüdi, Sprachstandardisierung, Freiburg, Schweiz: Universitätsverlag, 229-254.

TANZMEISTER, ROBERT, 1994,"Sprachwissen, Sprachbewußtsein, Sprachideologie, Sprachgefühl: Konzepte zur Repräsentation von Sprachnormen“, B. Neumer (Hg.), Zeichen, Sprache, Bewußtsein. Österreichisch-Ungarische Dokumente zur Semiotik und Philosophie 2, Wien / Budapest: ÖGS/ISSS, 359-400.

TANZMEISTER, ROBERT, 1995,"Normalisierung und Standard: eine Begriffsdifferenzierung", P. Cichon; K. Ille; R. Tanzmeister (Hgg.), Lo gai saber. Zum Umgang mit sprachlicher Vielfalt. Georg Kremnitz zum 50. Geburtstag, Wien: Braumüller, 199-229.

TAUPIAC, JACQUES, 1963, La prononciation normalisée du gascon, Toulouse: IEO.

TERgan, Sigmar-Olaf, 1986, Modelle der Wissensrepräsentation als Grundlage qualitativer Wissensdiagnostik, Opladen: Westdeutscher Verlag, 104-139.

Tergan, Sigmar-OlaF, 1989,"Psychologische Grundlagen der Erfassung individueller Wissensrepräsentation. Teil II: Methodologische Aspekte", Sprache und Kognition 8, Heft 4, 193-202.

Terglane-Fuhrer, AnNe, 1996, Die Sprache der Speisezubereitung. Empirische Untersuchungen zur vertikalen Variation, Frankfurt a. Main / Berlin / New York.

Thun, Harald, 1988,"Abgrenzung durch Sprache, Abgrenzung in der Sprache“, J. Albrecht; J. Lüdtke; H. Thun (Hgg.), Energeia und Ergon. Studia in honorem Eugenio Coseriu, Bd. 2, Tübingen: Narr, 467-485.

Thun, HARAlD, 1994, "Normprobleme bei der Übersetzung der Bibel in eine romanische Kleinsprache. R. Canton: Lous Ebanyèlis en lengue biarnese“, Rostocker Beiträge zur Sprachwissenschaft I, 227-244.

Tucoo-Chala, Pierre, 1970, Histoire du Béarn, 2. Aufl., Paris: PUF (' Que sais-je? 992).

Ureland, Per Sture (Hg.), 1985, Entstehung von Sprachen und Völkern. Glotto- und ethnogenetische Aspekte europäischer Sprachen. Akten des 6. Symposions über Sprachkontakt in Europa, Mannheim 1984, Tübingen: Niemeyer.

VAllVerdú, FrANCESC, 1979, La normalització lingüística a Catalunya, Barcelona: Editorial Laia.

VALLVERDÚ, FRANCESC, 1989,"El català estàndard: problemes i realitat", Homenatge a Lluis Guarner (1902-1986), València: Generalitat Valenciana.

VALlVERDÚ, FrANCESC, 1990, L'ús del català: un futur controvertit, Barcelona: Edicions 62.

VALlVERDU, FRANCESC, 1990a,"El concepte de 'normalització lingüística' en els estudios sociolingüístics catalans", Per Robèrt Lafont. Estudis ofèrts a Robèrt Lafont per sos collègas e amics, Montpelhièr / Nimes: Centre d'Estudis Occitans, Vila de Nimes, 275-284. 
VERDOODT, A., 1989, Les langues régionales et minoritaires des pays membres du Conseil de L'Europe, Québec: Les Presses de L'Université Laval.

Vermes, GeneVieVe (HG.), 1988, Vingt-cinq communautés linguistiques de la France. Tome 1: Langues régionales et langues non territorialisées. Publié avec le concours du Centre National des Lettres, Paris: L'Harmattan.

Viaut, Alain, 1987, L'occitan gascon en Catalogne espagnole: le Val d'Aran, Bordaux: Maison de Sciences de l'Homme d'Aquitaine.

Viaut, Alain, 1997,"L’Aquitaine et ses langues régionales: quelles pratiques institutionnelles?", Quo vadis Romania? 10, 36-49.

WARNANT, LOUIS, 1973, "Dialectes du français et français régionaux", Langue Française $18,100-125$.

Weber, Peter J. (Hg.), 1999, Plurilingua XXI: Contact + Confli(c)t, Bonn: Dümmler.

WeGNER, IMMO, 1985, Frame-Theorie in der Lexikographie. Untersuchungen zur theoretischen Fundierung und computergestüzzten Anwendung kontextueller Rahmenstrukturen für die lexikographische Repräsentation von Substantiven, Tübingen: Narr.

WEINRICH, HARALD, 1980,"Über Sprachnormen nachdenken“, Der öffentliche Sprachgebrauch 1, 9-24.

WEISGERBER, BERNHARD, 1990,“Das Verhältnis von Dialekt und Standardsprache als Problem sprachlicher Minderheiten“, P. H. Nelde (Hg.), Plurilingua X. Language Conflicts and Minorities, Bonn: Dümmler, 23-32.

Weisgerber, Bernhard, 1996,"Mundart, Umgangssprache, Standard“, Kontaktlinguistik 'HSK 12.1, Berlin /New York: de Gruyter, 258-271.

WEISGERBER, BERNHARD, 1999,"Sprachliche Varietäten und sprachliche Minderheiten“, P. J. Weber (Hg.), Plurilingua XXI: Contact + Confli(c)t, Bonn: Dümmler, 71-81.

Wesch, ANDrEAs, 1992,“Grammatische und lexikalische Aspekte des Spanischen von Barcelona“, Iberoromania 35, 1-14.

Wesch, ANDREAS, 1994, "Elemente des gesprochenen Katalanisch“, A. Schönberger; K. Zimmermann (Hgg.), De orbis Hispani linguis litteris historia moribus. Festschrift für Dietrich Briesemeister zum 60. Geburtstag, Frankfurt a. Main: Domus Editoria Europaea, 309-332.

WESCH, ANDREAS, 1994a,"El castellano hablado de Barcelona y el influjo del catalánesbozo de un programa de investigación“, Verba. Anuario Galego de Filoloxía 24.

WEYDT, HARALD / SCHLIEBEN-LANGE, BRIGITTE, 1981,"Wie realistisch sind Variationsgrammatiken?“, H. Geckeler [u.a.] (Hgg.), Logos Semantikos. Studia in honorem Eugenio Coseriu, Bd. 5, Berlin / New York / Madrid: de Gruyter / Gredos, 117 145.

WiChTER, Sigurd, 1985,"Methodologische Prinzipien der Bedeutungsermittlung und Bedeutungsbeschreibung" G. Stötzel (Hg.), Germanistik-Forschungsstand und Perspektiven. Vorträge des Deutschen Germanistentages 1984, I, Berlin / New York, 55-62.

WiCHTER, SIGURD, 1994, Experten- und Laienwortschätze. Umriß einer Lexikologie der Vertikalität, Tübingen: Niemeyer.

WICHTER, SIGURD, 1995,"Vertikalität von Wissen“, Zeitschrift für germanistische Linguistik 23, 284-313. 
Willemyns, R. / Bister, H., 1989,“The language continuum as a pluridimensional concept", U. Ammon (Hg.), Status and Function of Languages and Language Varieties, Berlin / New York: de Gruyter, 541-551.

WinkelmanN, Otто, 1989, Untersuchungen zur Sprachvariation des Gaskognischen im Val d'Aran, Tübingen: Niemeyer.

WinkelmanN, OTtO, 1990,"Französisch: Sprachnormierung und Standardsprache“, Lexikon der Romanistischen Linguistik V, 1, 334-353.

WÜEST, JАKOB, 1989,“L'analyse des langues parlées en Occitanie. Aspects linguistiques et aspects discursifs“, Lengas 25, 135-156.

WÜESt, JAKoB Th. / Kristol, Andres M. (HgG.), 1985, Drin de tot. Travaux de sociolinguistique et de dialectologie béarnaises, Bern / Frankfurt a.M. / New York: Peter Lang.

WÜESt, JAKOB Th. / Kristol, Andres M. (HgG.), 1993, Aqueras montanhas. Etudes de linguistique occitane: Le Couserans (Gascogne pyrénéenne), Tübingen / Basel: Francke.

Zamora Vicente, Alonso, 1982,"Regiones con una lengua al fondo“, Revista de Occidente 10 / 11, 23-32.

\section{Auswahlbibliographie zum Fachgebiet 'Waldbau' (im Bé- arn / in Frankreich)}

Bazire, Pierre / Gadant, Jean, 1991, La forêt en France, Paris: Documentation Française.

Becker, Michel / PiCARD, J.-F. / Timbal, J., 1981, La forêt: le milieu vivant; l'homme et la forêt; les grandes forêts de France; les arbres de la forêt, Paris: Mason.

Berton, Alain / LiARCOU, JEAN-RAYMOND, 1991, Le pin radiata en Sud Aquitaine (pin de Monterey, pin insignis): introduction et possibilités de développement, Bordeaux: C.R.P.F. d'Aquitaine.

Berton, Alain, 1993, La Forêt du Nord-Est du Béarn: Cantons de Garlin, Lembeye et Montaner, Bordeaux: C.R.P.F. d'Aquitaine.

LE BOIS EN BEARN \& SON EXPLOITATION, Musée Béarnais-Château de Pau, 1979.

Boullard, Bernard, 1992, Petite encyclopédie de la forêt, Paris: Ellipses Marketing.

LA FORET LANDAISE. Une aventure de l'homme et de son milieu, sous la dir. de Jean Montané, Toulouse 1994.

LA FORET PYRENEENNE. Textes, documents, diapositives, Coproduction FIEP-CDDP, 2e éd., Pau 1986.

Forey, PAmela / Fitzsimons, Cecilia, 1988, Arbres. Un guide pratique pour identifier facilement 190 arbres, Paris: Librairie Gründ.

GADANT, JEAN (sous la direction de), 1991, L'atlas des forêts de France, Paris: de Monza.

HuSSON, JEAN-PIERRE, 1995, Les forêts françaises, Nancy: Presses Universitaires.

DAS KOSMOS WALD- UND FORSTLEXIKON, hg. von R. Erlbeck, I. E. Haseder, G. K. F. Stinglwagner, Stuttgart: Franckh-Kosmos 1998.

LANIER, LouIs, 1994, Précis de sylviculture, 2 éd., Nancy: E.N.G.R.E.F., 1re éd. 1986.

LEFIEVRE, JoËL, 1991, Généralités sur la forêt, Bordeaux: C.R.P.F. d'Aquitaine. 
Leroy, PhilipPe, 1991, Des forêts et des hommes, Paris: Presses Pocket.

Leveque, François / Peguret, Agnes, 1988, Forêts et industrie du bois: structures et performances, Paris: Economica.

LORETTE, DiDIER, 1996, La forêt française et son bois au seuil de l'an 2000, Bordeaux: CRDP.

METRO, ANDRE, 1990, Terminologie forestière: sciences forestières, technologie, pratiques et produits forestiers: version française, Association Française des Eaux et Forêts, Paris: Conseil International de la langue française ("Collection de terminologie forestière multilingue, 2), [titre de couverture: Dictionnaire forestier multilingue], 1re éd. 1976.

Montane, Jean (Hg.), 1994, La Forêt Landaise. Une aventure de l'homme et de son milieu, Toulouse.

PINEDE, JoËL, 1994, Guide culturel de la forêt d'Aquitaine: réseaux, pédagogie et culture, Creil (16, rue des Pierres C 35, F-60100): J. Pinède.

Simon, Karl-Hermann, 1996, Lexicon Silvestre. Prima Pars. Dictionnaire de foresterie. Partie française (I fr) avec des définitions, 2 me éd rev. et corr., Eberswalde: Förderverein"Lexicon silvestre"e.V.

\section{Auswahlbibliographie zum Fachgebiet 'Zitrusfrucht- anbau' (in der Comunitat Valenciana)}

ABAD GARCÍA, ViCENTE, 1989, Historia de la naranja, Valencia.

ABAD GARCÍA, Vicente / PÉREZ RoJAs, FRANCISCO JAVIER / ZANÓN RODRIGO, F., 1996, La fruta dorada: la industria española del citrico, 1781-1995, Valencia: Generalitat Valenciana.

Abellá, Lllorenç, 1993, Política de estructura agraria en la Comunidad Valenciana, Valencia: Generalitat Valenciana.

Ahuir Cardells, Vicent / Ponce GonzÁlez, marta / SAlom i Salom, FRAncesc, 1993, La agricultura, la pesca y ganadería en la Comunidad Valenciana, Valencia: Generalitat Valenciana.

AliÑo, B., 1900, El naranjo, Madrid: La agricultura española.

Arnalte Alegre, Eladio vicente, 1980, Agricultura a tiempo parcial en el País

Valenciano, Madrid: Servicio de Publicaciones Agrarias.

Amorós CASTAÑER, MANUel, 1995, Producción de agrios, Madrid: Mundi Prensa.

Citricultura, 1991, Fundación "La Caixa", Barcelona: AEDOS.

LA FRUTA DAURADA. 750 ANYS AMB TARONGES, 1989, Valencia: Generalitat Valenciana.

GOGORCENA AOIZ, MARÍA YOLANDA, 1990, Caracterización e indentificación varietal de citricos, Valencia: Universidad de Valencia.

GONZÁlez SiciliA DE JuAN, EuSEBIO, 1960, El cultivo de los agrios, Madrid: I.N.I.A.

LOPEZ FERNANDEZ, Jose, 1995, La naranja, composición y cualidades de sus zumos y esencias, Valencia: Generalitat Valenciana.

Loussert, RAYMOND, 1990, Los agrios, Madrid: Mundi Prensa.

Llueca Úbeda, Emilio [U.A.], 1995, Presente y futuro de la citricultura valenciana, Valencia: Ayunt. Quartell.

NACHER, Francisco, 1962, Tus naranjos... Tu riqueza. Manual de citricultura, 4. 
Aufl., Valencia.

Maroto Borrego, J. V., 1987, Aproximación a la evolución histórica de técnicas agricolas, Valencia: Generalitat Valenciana.

PIQUERAS HABA, JUAN, 1985, La agricultura valenciana de exportación y su formación histórica, Madrid: Instituto de Estudios Agrarios, Pesqueros y Alimentarios.

Ribera de los VAlles, JAime, 1969, Poda del naranjo, Valencia: Editorial Bello.

Rivero ACAÑIZ, Jose MARIA DEL, 1993, Efecto de factores naturales y de origen mixto sobre los citricos, Valencia: Universidad Politécnica de Valencia.

Rebour, Henry, 1969, Los Agrios. Manual práctico de citricultura, Mundi-Prensa.

SChirarend, CARsten / HeIlmeyer, Marina, 1996, Die goldenen Äpfel. Wissenswertes rund um die Zitrusfrüchte, Berlin: GH Verlag.

LA TARONJA, 1990, Valencia: Generalitat Valenciana.

Villalba Buendía, DAVID, 1995, Plagas de los cítricos más importantes en la Comunidad Valenciana, Valencia: Generalitat Valenciana.

Villalba Buendía, DAVID, 1996, Apuntes del Servicio Tecnológico Agrario, Valencia: Generalitat Valenciana.

Zaragoza Adriaensens, SAlvador, 1984, Notas sobre la citricultura española, Madrid: INIA.

Zaragoza Adriaensens, SAlvador, 1993, Pasado y presente de la citricultura española, 2. Aufl., Valencia: Generalitat Valenciana. 


\section{Questionnaire: Gestion de la forêt et sylviculture en Béarn}

\section{Partie A (données biographiques)}

A.1. Vous vous appelez comment?

A.2. Vous avez quel âge?

A.3. Vous êtes Béarnais? Vous êtes né ici?

A.4. Quelle est votre profession / quel est votre métier?

\section{Partie B (rapport à la matière)}

B.1. Vous êtres concerné par la gestion du bois? Vous avez une propriété. De combien d'hectares?

B.2. Vous vous sentez à l'aise dans le domaine de la sylviculture? Vous connaissez (un peu) le métier du forestier?

B.3. Vous avez des contacts avec des professionnels forestiers?

\section{Partie C (connaissance du béarnais)}

C.1. Vous parlez bérnais?

C.2. Dans quelles situations est-ce que vous parlez béarnais? Pendant le travail ou à la maison?

C.3. Vous parlez aussi du bois et des affaires forestières en béarnais?

\section{Partie D (Vocabulaire technique et compétences spéciales)}

\section{Peuplements forestiers et arbres}

D.1.a. Ici, en Béarn, on a des peuplements mélangés dans les bois. Quelles sont les essences principales qu'on trouve?

D.1.b. Qu'est-ce qu'on entend par, peuplement dominat'?

D.1.c. Vous connaissez la notion de, sous-étage"? 
D.1.d. Vous pouvez commenter l'aspect de la densité d'un peuplement? C'est bon pour un arbre, la position en lisière?

D.1.e. Vous pouvez me dire comment on fait l'estimation d'un peuplement?

D.1.f. Vous avez déjà entendu parler de la ,surface terrière"? (Est-il vrai que cette notion s'applique tant au peuplement qu'à l'arbre seul?) Qu'estce que c'est la surface terrière d'un arbre?'

D.1.g. Quels sont les critères por la valorisation d'un arbre?

Vous connaissez le système de calcul?

Vous avez déjà entendu parler de la tolérance d'écorce / la défalcation de l'écorce?

D.1.h. Qu'est-ce que c'est, la dendrométrie / qu'un dendromètre?

D.2.a. Parlons un peu des différentes parties de l'arbre. Chaque arbre a bien sûr un tronc. Vous pensez que ,fût' et ,tige' signifient la même chose que ,tronc'?

D.2.b. Est-ce que la souche fait partie du fût ou des racines?

D.2.c. Vous connaissez la différence entre ,racine pivotante' et ,plateau racinaire'? Vous savez que les arbres d'ici ont des racines différentes?

D.2.d. Est-ce qu'il y a en sylviculture une expression pour ,l'ensemble des branches, rameaux et feuilles de tous les houppiers d'un peuplement'? ( $>$, couvert forestier', etc.)

D.2.e. Vous pensez qu',élaguer' signifie autre chose qu',ébrancher' ou ,émonder"?

[Vous connaissez la différence entre ,élaguer en $\sec ^{6}$ et ,élaguer en vert'?]

D.2.f. Vous pouvez décrire la forme de la feuille du chêne?

Est-ce que le chêne d'ici, c'est-à-dire le pédonculé, et le chêne rouge d'Amérique, qu'on trouve aussi dans la région, ont des feuilles tout à fait pareilles?

Vous connaissez d'autres différences entre ces deux espèces?

D.2.g. Est-ce qu'il y a un mot pour ,l'ouverture des bourgeons à feuilles au début de la saison de végétation'? ( $>$ débourrement, etc.) 


\section{Régénération et plantation}

D.3.a. Le reboisement des terres délaissées ou défrichées, est-ce que ça joue un rôle pour les propriétaires privés de la région?

Quand on veut laisser faire la nature pour que que les arbres repoussent.

Comment faut-il s'y prendre? ( $>$ régénération naturelle)

D.3.b. Parlons des conditions naturelles qu'il faut respecter pour pouvoir faire pousser des arbres avec succès. Commençons par le sol / la terre. Vous savez quelque chose sur la qualité du sol d'ici / en général?

D.3.c. Quels problèmes vous sont connus: sol encroûté (durci, tassé), sol engorgé, sol acide, sol contaminé?

D.3.d. Quelles espèces végétales / plantes peuvent être nuisibles à la culture du bois?

D.3.e. Il y des dégâts de gibier dans le bois? De quelle façon est-ce qu'il fait du mal?

D.3.f. Est-ce qu'on connaît ici des maladies / fléaux causées par la vermine (des chenilles, des larves, des coléoptères ou d'autres insectes?

D.3.g. Quand vous voyez une nouvelle plantation d'arbres, pouvez-vous juger de la qualité des plants et du système de plantation? / Vous voyez si c'est bien fait, comme il faut?

D.3.h. Vous avez une idée précise des différents soins de plantations? / Quand ça commence à pousser, que faut-il faire?

D.3.i. ,Pincer' $(\sim$ les branches gourmandes, $\sim$ les pousses latérales $)$, ça veut dire quoi en sylviculture?

\section{Sylviculture et écologie de la fôret}

D.4.a. Avez-vous déjà entendu parler de la ,production soutenue ${ }^{\text {‘ }}$ ou du ,rendement soutenu' en foresterie. Vous pouvez expliquer ce que c'est? - La notion de ,gestion durable“ vous dit quelque chose?

D.4.b. Le ,jardinage', qu'est-ce que ça veut dire en tant que terme forestier?

D.4.c. Y a-t-il d'autres méthodes / des méthodes différentes de faire une coupe? (C'est-à-dire, on coupe tous les arbres d'un peuplement d'un seul coup ou seulement quelques-uns?) 
D.4.d. Quand on veut profiter du bois, on doit faire des éclaircies de temps en temps. Vous pouvez dire pourquoi, quand et comment?

[Vous faites la différence entre ,éclaircir par le haut ${ }^{`}$ et ,éclaircir par le bas'?]

D.4.e. Quelles sont les techniques (sylvicoles) que vous connaissez pour améliorer le bois? (coupe d'amélioration, coupe d'extraction des arbres de mauvaise qualité, soins des plantations, élaguer, amélioration hydrique)

D.4.f. Vous voyez une différence entre 'sylviculture' et , arboriculture'?

D.4.g. Le bois fait partie du paysage béarnais. Il vous donne plutôt l'idée d'un terrain à exploiter, d'un terrain de loisir (où l'on fait des promenades ou la chasse) ou d'un système écologique précieux et fragile? Pourriez-vous vous expliquer sur ces différents aspects?

\section{Exploitation du bois, techniques sylvicoles}

D.5.a. Parlons un peu de l'exploitation dans le sens de la récolte des arbres mûrs. D'après quels critères est-ce qu'on décide de la qualité d'un arbre? / Comment peut-on savoir qu'un arbre est arrivé à maturité, que c'est un arbre d'avenir?

Le terme de ,défilement' vous dit quelque chose?

D.5.b. Quand c'est qu'on parle d'une ,coupe définitive'?

D.5.c. Parlons de l'abattage d'un seul arbre. Vous croyez que la coupe à la hache existe encore en Béarn?

Connaissez-vous d'autres outils qu'on a utilisés d'autrefois?

D.5.d. Vous savez ce que c'est qu'une, grume‘? - L'expression, entamer une grume' vous semble courante? Vous la comprenez (quand même)?

D.5.e. La technique de la coupe à la tronçonneuse vous est familière? Vous pouvez l'expliquer un peu?

D.5.f. Y a-t-il des mesures à prendre pour nettoyer l'endroit après une coupe réalisée?

Quand est-ce qu'il faut dessoucher le terrain?

D.5.g. Qu'est-ce qu'il faut faire avec un arbre abattu avant de faire débarder la grume? (> écimer, écorcer, équarrir) 


\section{Administration et loi forestiéres}

D.6.a. Vous avez déjà vu une carte forestière? Vous sauriez la lire?

D.6.b. Qui s'occupe de l'administration forestière des propriétés privées? Quels rôles différents jouent le CRPF (Centre Régional de la Propriété Forestière) et l'ONF (Office National des Forêts) pour la gestion du bois d'ici?

D.6.c. Le code forestièr officiel (c'est-à-dire la loi qui s'occupe du bois) vous concerne? De quelle façon?

D.6.d. Est-ce qu'il y a, à votre connaissance, une loi qui restreint la manipulation génétique des arbres qu'on plante? Avez-vous entendu parler du ,cloning'? 


\section{Qüestionari: Citricultura valenciana}

\section{Part primera}

1. Nom i cognom

2. Any i lloc de naixença

3. ¿Ets originari de quina regió?

4. ¿Des de quan resideixes a la Comunitat Valenciana?

5. ¿Et vas quedar un període més llarg fora de la Comunitat?

6. ¿Qual és la teva formació profesional?

7. ¿I qué van fer tos pares com a profesió?

\section{Part segona}

1. ¿Com pots explicarla significació que tenen els tarongers en ta vida?

2. ¿Diries que el treball del cultiu de tarongers t'és familiar?

3. ¿Tens coneixements teòrics de la citricultura?

4. ¿Coneixes un citricultor o una persona que treballa en este sector?

\section{Part tercera}

1. ¿El valencià és la teua llengua materna? Parles valencià amb facilitat en totes les ocasions?

2. ¿Tot plegat, parles més el valencià que el castellà? Per quina raó prefereixes el valencià / el castellà?

3. ¿Com es pot caracterizar el parlar que utilitzes. És el parlar d'una regió determinada?

4. ¿Per a tu, les diferencies entre el valencià i el català són considerables?

5. ¿Parles el valencià tant a la feina com a la vida familiar o entre amics?

6. ¿Diries que és normal parlar sobre assumptes de la citricultura en valencià? Donat cas que (suposant que)

(a) ...s'adrecis a un emplegat del IVIA (parlant d'algun aspecte teòric).

(b) ...vulgues parlar amb un conreador en el camp. 
7. ¿Penses que tota la terminologia tècnica del conreu de cítrics existeix en valencià?

8. ¿Es pot trobar literatura tècnica en valencià per a la formació profesional?

\section{Part quarta}

1. ¿El cultiu de tarongers tè una llarga tradició a València. Saps quan va començar? Era molt diferent quan eres xicot?

2. ¿Em pots explicar la importància actual dels tarongers per a l'economia de la regió?

3. ¿I ha moltes persones que treballen en este sector?

4. ¿Quina és la posició de la citricultura dins de l'agricultura valenciana? ¿I ha d'altres conreus?

\section{Part cinquena}

\section{Varietats de cítrics}

1. ¿Quins grups de taronges es poden distinguir? (grup Navel [Navel-lane, Navel-late, Navelina, Newhall, Thomson, W. Neval] / grup blanques [Berna, Sal.lusitana, València Late] / grup de la sang [Doble fina, Entre fina, Sanguinelli] )

¿Què és una naronja?

2. ¿Em pots dir quines són les varietats de cítrics més conreades a la Comunitat Valenciana?

3. ¿Saps les differències entre per exemple una Navel-late i una Berna?

4. ¿Coneixes també varietats de la mandarina?

\section{Constitució de l'arbre i del fruit}

1. ¿Què és un melic? (segon fruit de les taronges del grup navel situada a la part oposada al peduncle. Tambè: Arrel central i més llarga d'un arbre.) 
2. ¿De quina manera un tarronger fa arrels? ¿Quines classes d'arrels existixen? (barbareta, clau)

3. ¿Com es diu una branqueta (un brot) que consumeix molta saba? (mamó, xupló, tany). S'utilitza el terme de ,desmam(on)ar"? (=llevar els mamons)

4. ¿Pots d'escriure la flor d'un taronger? ¿Hi a un nom particular? (Tarongina)

\section{Sòl / terra}

1. ¿Pots indicar les proprietats característiques del sòl d'un camp de taronges?

2. ¿Què tipus de terreny es troba arreu d'aquesta zona? ¿I ha zones a la Comunitat Valenciana on la terra és diferenta?

3. ¿Què és un ,alterò'? (Petita elevació del terreny, pujolet) ¿I un ,tarús‘? (Inclinació d'unnterreny, rampa; caient inclinat del costat d'una muntanya escarcatada per les runes, erosió, etc.)

4. ¿Hi per ací el problema de terrenys amb una baixa capacitat de retindre l'auia?

\section{Clima / glaçades}

1. ¿De quina manera el fred pot fer dany als tarongers?

2. ¿Ja has sentit parlar de la ,glaçada (gelada) negra' (,la rosada negra')? (Glaçada a conseqüència de la qual les parts tendres dels vegetals es moren i es tornen d'un color fosc.)

3. ¿Es prenen mesures preventives contra els efectes de les glaçades?

4. ¿Hi ha d'altres perills climàtics per als tarongers? (la pedra, el vent)

\section{Empelts / peus}

1. ¿Quina importància tenen els empelts per al cultiu de tarongers?

2. ¿S'utilitzen d'altres mots en valencià per a parlar dels empelts? (eixart) Es pot parlar de ,portaempelts' com en castellà (portainjertos)? 
3. ¿Quins tipus de peu base es poden disting(u)ir? (taronger amarg, t. dolç, Mandarí Cleòpatra, Citrange Troyer / C. Carrizo, Citrus Volkamericana; Macrofila)

4. ¿Has sentit parlar de ,taronger bort" i de ,taronger ver"? (bort: salvatge, no produeix fruita comestible, ver: empeltat per producir un tipus determinat de fruit)

\section{Tractament del taronger entre les collites / poda}

1. ¿Quines formes de tractament hi ha en el cultiu de tarongers?

2. Quan i com s'efectua la poda de frutificació?

3. ¿Saps quines eines (quins instruments) s'empleguen en la poda?

4. ¿Què vol dir ,quallar' o el ,quallat"? (Coagular, aglevar. Dit generalment de l'acció de quall en la llet. Referit a la flor fa referència al procés de conversió de la flor en fruit. Def. gleva)

\section{Regadiu}

1. ¿Quina importància té el regadiu per al cultiu de cítrics a la Comunitat Valènciana?

2. ¿Coneixes les modalitats de rec que es poden efectuar? (regar a manta / regar a degoteig [goteo])

3. ¿Com funciona el sistema de séquies que s'aplica en esta zona?

4. ¿A què serveix un ,braçal'? (Braç de riu o de sèquia, ramal de segla. renc, ramal. Ramificació a partir de les filloles. S'encarreguen de regar directament el camp i donar eixida a l'auia a dreta i esquerra)

\section{Malalties i plagues}

1. ¿Es pot dir en valencià que un arbre fruiter està ,malurat‘? ¿S'utilitza la paraula de ,malura'?

2. ¿Em pots explicar un poc la malaltia del tarongers que s'anomena ,tristesa"? (Síntomes, peus resistents) 
3. ¿Com es pot reconéixer la gomosi? (Nom de les diverses malures de les plantes, i especialment dels arbres fruiters, caracteritzades per la presència de nòduls gomosos a l'escorça $\mathrm{i}$ als fruits. Goma $=$ exsudació dels arbres).

¿Què es fa per a combatre la gomosi?

4. ¿De quines plagues sofreixen els tarongers per ací? (cotxinilla [caparreta blanca], minador)

\section{Collita}

1. ¿Coneixes el terme de ,alfarrassar'? (Ajustar a un tant alçat (cast. ajustar por un tanto alzado, alfarrazar [ant.]); mesurar a ull la quantitat de fruita que hi ha en un camp o un bancal. - Avaluar a ull la quantitat de collita d'una extensió de terreny determinada)

2. ¿Quan i com es realitza la collita de les tarongers? ¿Què vol dir ,espigolar'? (Collir les tarronges que han quedat després de la collita). Es practica encara hui en dia l'espigolada?

3. Què cal fer amb les taronges recentment recol·lectades? ¿Com són transportades?

4. ¿Saps el que és un ,repom‘? (Magenques. De segon flor. Taronges, pomes, peres, etc., de flor endarrerida, que es cullen després de la recol·lecció normal. Solen presentar un aspecte més flàcid i un sabor de vell.) - Magenc, -a, adj, relatiu o pertanyent al mes de maig.

\section{Venda i confecció}

1. ¿A on es venen les taronges. Em pots explicar un pòc com funciona la venda?

2. ¿Quines tècniques o quins mecanismes s'apliquen per a ajudar a madurar els fruits? (estufa, humificador). Com s'aconsegueix la desverdització de les taronges?

3. ¿Quins altres tractaments (manipulacions) de la taronja coneixes? (abrillantament, amb cera, per a donar lluentor al fruit) 
4. ¿Segons quins criteris s'efectua la classificació de les taronges? (calibre [tamany/diàmetre, fruit gros], característiques de la varietat [aroma, dolçor, gust/sabor/tast amarg, de molt/poc suc, amb molts/pocs pinyols, pinyolenc [con mucho hueso])

\section{Exportació i indústria}

1. ¿Diries que es parla sovint publicament per ací dels problems de la comercialització de les taronges (als diaris, en els bars)? ¿En saps alguna cosa? (per que fa a l'exportació, la indústria de begudes [suc de taronges])

2. ¿Com funciona el mercat interior en aquest sector?

3. ¿Quina és la teua opinió respecte al futur de la citricultura a València? 